\title{
In Pursuit of a Light Bulb and a Smokeless Kitchen
}

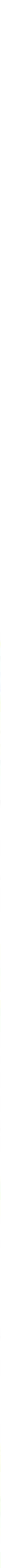




\title{
IN PURSUIT OF A LIGHT BULB AND A SMOKELESS KITCHEN
}

\section{LONGITUDINAL ANALYSIS OF THE ROLE OF ENERGY SECTOR POLICIES TO ALLEVIATE RURAL ENERGY POVERTY IN INDIA}

\section{DISSERTATION}

\author{
to obtain \\ the degree of doctor at the University of Twente, \\ on the authority of the rector magnificus, \\ prof.dr. H. Brinksma, \\ on account of the decision of the graduation committee, \\ to be publicly defended \\ on Wednesday 19th of December 2012 at 16.45 hours
}

by

Shirish Sinha

Born on the 27th of June 1973, in Guwahati, Assam, India 
This thesis has been approved by:

Promoter: prof. dr. H. Th. A. Bressers

Assistant Promoter: dr. Joy S Clancy 


\section{Committee}

\begin{tabular}{|c|c|c|}
\hline Chair & prof.dr. R.A. Wessel & University of Twente \\
\hline Secretary & prof.dr. R.A. Wessel & University of Twente \\
\hline Promoter & prof.dr. J.Th.A. Bressers & University of Twente \\
\hline Assistant Promoter & dr. J.S. Clancy & University of Twente \\
\hline Member & prof.dr. N.G. Schulte Nordholt & University of Twente \\
\hline Member & dr. M.J. Arentsen & University of Twente \\
\hline Member & prof.dr.ir. T.H. van der Meer & University of Twente \\
\hline Member & prof.dr. M.P. van Dijk & Erasmus University, Rotterdam \\
\hline Member & dr. Konrad Blum & $\begin{array}{l}\text { Carl von Ossietzky Universität } \\
\text { Oldenburg, Germany }\end{array}$ \\
\hline Member & dr. Venkata Ramana Putti & The World Bank \\
\hline
\end{tabular}

The doctoral research was supported by: the Joint Japan World Bank Graduate Fellowship (JJWBGSP) of the World Bank Institute and by the WOTRO Developing Country Fellowship provided by the Netherlands Foundation for the Advancement of Tropical Research (WOTRO) - Netherlands Organisation for Scientific Research (NWO).

(C) Sinha, Shirish. 2012

In Pursuit of a Light Bulb and a Smokeless Kitchen

No part of this publication may be reproduced, stored in a retrieval system, or transmitted, in any form or by any means, electronic, mechanical, photocopying, recording or otherwise, without prior written permission of the author.

ISBN: 9789036534826

\section{UNIVERSITY OF TWENTE.}

School of Management and Governance

Twente Centre for Studies in Technology and Sustainable Development (CSTM)

Enschede, The Netherlands

E-mail (for correspondence): shirish.sinha@gmail.com 



\section{IN PURSUIT OF A LIGHT BULB AND A SMOKELESS \\ KITCHEN}

Longitudinal Analysis of the Role of Energy Sector Policies to Alleviate

RURAL ENERGY POVERTY IN INDIA

Dedicated to

My Father Vijoy Narain Sinha 



\section{Table of contents}

List of Tables $\quad$ ix

List of Maps and Figures $\quad$ X

List of Boxes $\quad$ xi

Abbreviations, Indian Administrative/Hindi terms, Units of Measurements xii

Acknowledgements xvii

Prologue xxi

1. Introduction 1

1.1 Context 1

1.2 Problem Statement 5

$\begin{array}{ll}1.3 \text { Structure of the Dissertation } & 10\end{array}$

2. Applied Concepts on Energy-Development and Policy Reforms 13

2.1 Introduction 13

2.2 The Broader Context: Energy and Development 14

2.2.1 Energy and Development 15

$\begin{array}{ll}\text { 2.2.2 Energy Poverty } & 17\end{array}$

$\begin{array}{ll}\text { 2.2.3 Energy Poverty and Policy Reforms } & 27\end{array}$

2.3 Institutional Aspects of Public Sector Reforms 28

2.3.1 Economic Efficiency as a Motive for Reforms $\quad 29$

2.3.2 Government Delivery of Energy Carriers 33

2.3.3 Policy Instruments: Entitlements and Subsidies 35

2.3.4 Government versus Market: Arguments for Reforming the Energy Sector 38

2.4 Characteristics, Capabilities and Culture $\quad 40$

2.5 Analytical Framework $\quad 43$

2.5.1 Delivery Pathways 43

2.5.2 Enabling Factors $\quad 44$

2.5.3 Contextual Influences 46

2.5.4 Main Research Questions $\quad 48$

3. Research Methodology 51

3.1 Introduction 51

3.2 Case Study Regions

3.2.1 Selection of the States: West Bengal, Chhattisgarh and Orissa 53

3.2.2 Selected Case Study Regions: Gosaba, Bastar and Kalahandi Blocks $\quad 56$

3.2.3 Village Selection and Field Surveys $\quad 61$

3.2.4 Sampling Households $\quad 64$

3.3 Research Techniques 66

3.3.1 Research Techniques for Village Clusters 66 
3.3.2 Research Techniques for Policy Analysis $\quad 68$

3.4 Validity and Reliability 70

4. Rural Energy Policy in India: The Meek Shall Inherit 73

4.1 Introduction 73

4.2 Organisational Setting for Rural Energy $\quad 75$

$\begin{array}{ll}\text { 4.2.1 Constitutional Provisions } & 75\end{array}$

$\begin{array}{ll}\text { 4.2.2 Central and State Organisations } & 77\end{array}$

4.2.3 Local Organisations $\quad 83$

4.2.4 Implications of the Organisational Setting 84

4.3 Political Economy of Rural Energy Policy: Transition from State Monopoly to Inclusive Reforms $\quad 85$

4.3.1 Phase I: Centralised Planning (1950-69) 86

4.3.2 Phase II: Political Populism (1969-91) 87

4.3.3 Phase III: Reform (1991-2004) 90

4.3.4 Phase IV: Inclusive Reform (2004-2010) 93

4.4 Policies and Programmes for Rural Energy Access 96

4.4.1 Phases I and II (1950-1991) 96

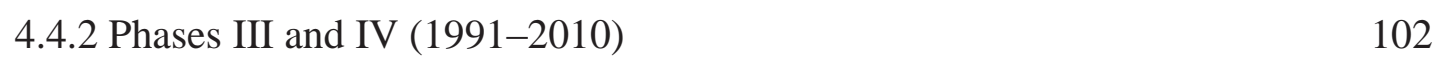

4.5 Conclusions: Answer to Main Research Question $1 \quad 116$

5. Understanding Energy Access: Gosaba, Bastar and Kalahandi 127

$\begin{array}{ll}5.1 \text { Introduction } & 127\end{array}$

$\begin{array}{ll}5.2 \text { Gosaba Case Study } & 129\end{array}$

5.2.1 Delivery Pathways - Before and After $2004 \quad 133$

5.2.2 Access to Modern Energy Carriers: Who Has Access? 143

5.2.3 Contextual Influences Affecting Energy Access 148

5.2.4 Policy Design in relation to Implementation 157

$\begin{array}{ll}5.3 \text { Bastar Case Study } & 160\end{array}$

5.3.1 Energy Availability in Bastar: Delivery Pathways 162

5.3.2 Access to Modern Energy Carriers: Who Has Access? 172

5.3.3 Contextual Influences that Affect Energy Access 175

5.3.4 Policy Design in relation to Implementation 182

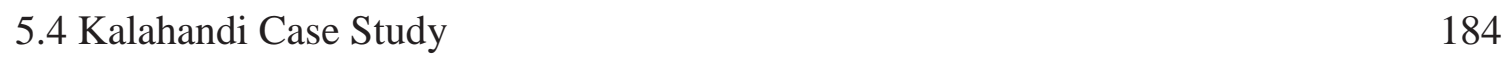

5.4.1 Energy Availability in Kalahandi: Delivery Pathways 188

5.4.2 Access to Modern Energy Carriers: Who Has Access? 198

5.4.3 Contextual Influences that Affect Energy Access 201

5.4.4 Policy Design in relation to Implementation 206

5.5 Conclusions: Answering Main Research Question 208

6. Conclusions and Recommendations: Will Rural India Shine? 227

6.1 Introduction $\quad 227$

6.2 Changes Required in Enabling Factors: Answer to Main Research Question 3230 viii 
6.2.1 Changes Required in Organisations $\quad 231$

6.2.2 Changes Required in Policies and Policy Instruments 233

6.3 Policy Recommendations 236

6.3.1 Enabling Regulatory Framework 238

$\begin{array}{ll}\text { 6.3.2 Local Organisations as Intermediaries } & 240\end{array}$

6.3.3 Making Subsidies and Entitlements Work Better - Need for Targeting 243

6.4 Contributions of this dissertation 245

$\begin{array}{ll}\text { 6.4.1 Contribution to Academic Knowledge } & 245\end{array}$

6.4.2 Contribution to India's Energy Policy Discussion 247

6.4.3 Suggested Areas for Future Research in India 248

6.5 Concluding Remarks 249

$\begin{array}{ll}\text { References } & 251\end{array}$

$\begin{array}{lr}\text { Summary } & 269\end{array}$

$\begin{array}{ll}\text { Samenvatting } & 277\end{array}$

Annex I: Profile of Case Study Regions $\quad 287$

Annex II: Rural Energy Scenario in India $\quad 297$

Annex III: Survey Instruments 299

Annex IV: Rural Electrification Programmes in India (1950-2010) 306

About the Author 309

\section{List of Tables}

Table 3.1: Access to Modern Energy Carriers and Rural Poverty Rate 56

Table 3.2: Access to Energy Carriers for Cooking and Lighting 59

Table 3.3: Research Techniques $\quad 69$

Table 4.1: Electricity Subsidies 1996 -2002 92

Table 4.2: Plan Budget for Rural Electrification in India (1951-90) 98

Table 4.3: Plan Budget for Rural Electrification in India (1992-2012) 106

Table 4.4a: Central Government Subsidies on PDS Kerosene oil and LPG 109

Table 4.4b: Central Government Subsidies on PDS Kerosene oil and LPG 109

Table 5.1: Delivery Pathways and Policy Instruments (2001-02 and 2008-09) 133

Table 5.2: Phases and Functions of Electricity Distribution 135

Table 5.3: Phases and Functions in LPG and Kerosene oil distribution 139

Table 5.4: Energy Carriers used in Gosaba 144

Table 5.5: Low-Capacity End-Users in Gosaba Island 145

Table 5.6: Mapping Energy Access by Economic Status and Occupation 146 
Table 5.7: Energy Access and Women in Income/Non-Income Earning Activities

Table 5.8: Delivery Pathway and Policy Instruments (2001-02 and 2008-09)

Table 5.9: Phases and Functions of Electricity Distribution

Table 5.10: Phases and Functions of LPG and Kerosene Distribution

Table 5.11: Energy status in case-study villages of Bastar

Table 5.12: Low-Capacity End-users in Bastar

Table 5.13: Mapping Energy Access to Economic Status and Occupation

Table 5.14: Energy Access and Women in Income/Non-income Earning Activities

Table 5.15: Delivery Pathway and Policy Instruments (2001-02 and 2008-09)

Table 5.16: Phases and Functions of Electricity distribution 190

Table 5.17: Problems Related to Grid Electricity Privatisation

Table 5.18: Phases and Functions of LPG and Kerosene oil distribution 194

Table 5.19: Energy status in village clusters of Kalahandi 198

Table 5.20: Low-Capacity End-Users in Kalahandi 199

Table 5.21: Mapping Energy Access by Economic Status and Occupation 200

Table 5.22: Energy Access and Women in Income/Non-income Earning Activities 200

Table 5.23: Delivery Pathways and Enabling Factors - Comparative Analysis 212

Table 5.24: Factors influencing Energy Access - Comparative Analysis 218

Table 5.25: Contextual Influences affecting Access - Comparative Analysis 226

\section{List of Maps and Figures}

Figure 1.1: Structure of the thesis 12

Figure 2.1: Energy Poverty - the vicious circle 22

Figure 2.2: Analytical Framework 44

Figure 3.1: Status of rural electrification 54

Map 3.1: Location of Case Study Regions in India 58

Figure 4.1: Organisational Setting for Rural Energy in India (2010) 78

Figure 4.2: India's Energy Development Policy - 1950 to 2010

Figure 4.3: Rural Electrification Programme in India (1950-1990) 97

Figure 4.4: Petroleum Energy Programme in India (1950-1990) 100

Figure 4.5: Rural Electrification Programme in India (1990-2010) 106

Figure 4.6: Subsidy for Rural Electrification under RGGVY (2004/05 -2009/10) 108

Figure 4.7: Petroleum Sector Reforms and Rural Access (1990-2010) 111

Figure 4.8: Politics of petroleum pricing 113

Map 5.1: Map of Gosaba case-study villages $\quad 131$

Figure 5.1: The interplay between Contextual Influences - Gosaba 149

Map 5.2: Map of Bastar Case Study Villages 164 
Figure 5.2: The Interplay between Contextual Influences - Bastar 176

Map 5.3: Map of Kalahandi Case-Study Villages 187

Figure 5.3: The interplay between Contextual Influences - Kalahandi 202

\section{List of Boxes}

Box 1.1: Energy Carriers and Energy Services $\quad 2$

Box 1.2: Low-Capacity End-Users 4

Box 2.1: Theoretical Underpinnings of Public Sector Reforms 30

Box 2.2: Policy Instruments 35

Box 2.3: Phases and Functions $\quad 41$

Box 3.1: Approach, Method and Focus in the two field surveys 52

Box 4.1: Constitutional Provisions $\quad 76$

Box 4.2: Economic Reforms Measures of $1991 \quad 91$

Box 4.3: Administered Pricing Mechanism and Oil Pool Account 99

Box 4.4: Reform Measures in Electricity and Petroleum Sectors 102

Box 4.5: Policy and Regulatory Framework for Rural Electrification - After $2004 \quad 105$

Box 4.6: Policy Reform in Petroleum Sector - Before and After 2004

Box 4.7: Renewable Energy Obligation - After $2004 \quad 116$

Box 5.1: Binoy Bhushan Jana - A Combination of Modern Energy Carriers 151

Box 5.2: Ashwani Kumar Paul - Choice of LPG for Cooking 151

Box 5.3: Mangali Biswas - Reducing Energy Poverty 152

Box 5.4: Amiyon Mandal and Anita Shikari - Reasons for not using LPG 152

Box 5.5: Sojit Das - Continuing with Biomass and LPG for Cooking 154

Box 5.6: Shanti Pal and Subhash Mandal - Opposite Faces of Willingness to Pay 156

Box 5.7: Policy Design and Implementation in Gosaba 159

Box 5.8: B S Thakur - A Combination of Modern Energy Carriers 177

Box 5.9: Rita Baghel - Shifting back from LPG to Biomass for Cooking 178

Box 5.10: Mandhar - Inability to Pay the Electricity Connection Cost 179

Box 5.11: Mahesh Ram and Phulmati - Inability to Buy Modern Energy Carriers 179

Box 5.12: Policy Design and Implementation in Bastar 183

Box 5.13: Functions of the Village Bidyut Sangha 191

Box 5.14: Darshan Chachang: Forfeiting Kerosene Oil Entitlement 196

Box 5.15: Bal Majhi - A battery to run a Television 203

Box 5.16: Loknath Mishra - A Combination of Modern Energy Carriers 204

Box 5.17: Bhibuti Deo - Choice of LPG for Cooking 204

Box 5.18: P N Behera - Biomass for Cooking 204

Box 5.19: B Mishra and S Mund - Backward and Forward Shifts in Cooking 205

Box 5.20: Policy Design and Implementation in Kalahandi 207 


\section{Abbreviations, Indian Administrative/Hindi terms, Units of Measurements}

\begin{tabular}{|c|c|}
\hline $\mathrm{ADB}$ & Asian Development Bank \\
\hline APDRP & Accelerated Power Development and Reforms Programme \\
\hline APL & Above Poverty Line \\
\hline APM & Administered Pricing Mechanism \\
\hline BJP & Bhartiya Janata Party \\
\hline BPCL & Bharat Petroleum Corporation Limited \\
\hline BPL & Below Poverty Line \\
\hline BSES & Bombay Sub-urban Electricity Supply Company Limited \\
\hline CEA & Central Electricity Authority \\
\hline CERC & Central Electricity Regulatory Commission \\
\hline CoI & Census of India \\
\hline CREDA & Chattisgarh Renewable Energy Development Agency \\
\hline CSD & Commission on Sustainable Development \\
\hline CSEB & Chattisgarh State Electricity Board \\
\hline DfID & Department for International Development (UK) \\
\hline DNES & Department of Non-Conventional Energy Sources \\
\hline FPS & Fair Price Shops \\
\hline FYP & Five Year Plan (of Planning Commission) \\
\hline GDP & Gross Domestic Product \\
\hline GoI & Government of India \\
\hline GRIDCO & Grid Corporation of Orissa \\
\hline HPCL & Hindustan Petroleum Corporation Limited \\
\hline IOC & Indian Oil Corporation Limited \\
\hline IPP & Independent Power Producers \\
\hline IREDA & Indian Renewable Energy Development Agency \\
\hline IREP & Integrated Rural Energy Planning \\
\hline KBK & Kalahandi Bolangir Koraput \\
\hline KJP & Kutir Jyoti Programme \\
\hline LAMPS & Large Area Multi-Purpose Cooperative Societies Limited \\
\hline LI & Lift Irrigation \\
\hline LPG & Liquefied Petroleum Gas \\
\hline
\end{tabular}




\begin{tabular}{|c|c|}
\hline MFP & Minor Forest Produce \\
\hline MLA LAD & Member of Legislative Assembly Local Area Development \\
\hline MNES & Ministry of Non-Conventional Energy Sources \\
\hline $\mathrm{MoP}$ & Ministry of Power \\
\hline MoPNG & Ministry of Petroleum and Natural Gas \\
\hline MP LAD & Member of Parliament Local Area Development \\
\hline NABARD & National Bank for Agriculture and Rural Development \\
\hline NCAER & National Council for Applied Economic Research \\
\hline NDA & National Democratic Alliance \\
\hline NGO & Non-governmental Organisation \\
\hline NHPC & National Hydro Power Corporation Limited \\
\hline NOGC & National Oil and Gas Companies \\
\hline NPBD & National Programme on Biogas Development \\
\hline NPIC & National Programme on Improved Cookstoves \\
\hline NSSO & National Sample Survey Organisation \\
\hline NTPC & National Thermal Power Corporation Limited \\
\hline $\mathrm{OBC}$ & Other Backward Classes \\
\hline OCC & Oil Coordination Committee \\
\hline OHPC & Orissa Hydel Power Corporation \\
\hline OPA & Oil Pool Account \\
\hline OPGC & Orissa Power Generating Company \\
\hline OREDA & Orissa Renewable Energy Development Agency \\
\hline OSEB & Orissa State Electricity Board \\
\hline PC & Planning Commission \\
\hline PDS & Public Distribution System \\
\hline PHC & Primary Health Centre \\
\hline PMGY & Pradhan Mantri Gramodaya Yojana \\
\hline PMS & Parallel Marketing Scheme \\
\hline PPP & Purchase Power Parity \\
\hline PRI & Panchayati Raj Institutions \\
\hline PSU & Public Sector Undertaking \\
\hline REC & Rural Electrification Corporation \\
\hline REDA & Renewable Energy Development Agency \\
\hline REDC & West Bengal Rural Energy Distribution Corporation \\
\hline REST Mission & Rural Electricity Supply Technology Mission \\
\hline
\end{tabular}




\begin{tabular}{|c|c|}
\hline RET & Renewable Energy Technologies \\
\hline RGGVY & Rajiv Gandhi Grameen Vidyutikaran Yojana \\
\hline RGLVP & Rajiv Gandhi LPG Vitrak Pariyojana \\
\hline RVEP & Remote Village Electrification Programme \\
\hline SC & Scheduled Caste \\
\hline SEB & State Electricity Board \\
\hline SERC & State Electricity Regulatory Commission \\
\hline $\mathrm{SPV} / \mathrm{PV}$ & Solar Photovoltaic/Photovoltaic \\
\hline ST & Scheduled Tribe \\
\hline TERI & $\begin{array}{l}\text { The Energy and Resources Institute (earlier called Tata Energy Research } \\
\text { Institute) }\end{array}$ \\
\hline UNDP & Untied Nations Development Programme \\
\hline UPA & United Progressive Alliance \\
\hline VBS & Village Bidyut Sangha \\
\hline WB & World Bank \\
\hline WBREDA & West Bengal Renewable Energy Development Agency \\
\hline WCED & World Commission on Environment and Development \\
\hline WDR & World Development Report \\
\hline WESCO & Western Orissa Electricity Supply Company Limited \\
\hline WBSEB & West Bengal State Electricity Board \\
\hline XIMB & Xavier Institute of Management, Bhubaneshwar \\
\hline
\end{tabular}

\begin{tabular}{|l|l|}
\hline Aam Aadmi & $\begin{array}{l}\text { Common man referring to people of India, used since 2004 as political agenda } \\
\text { of the coalition government lead by the Indian National Congress }\end{array}$ \\
\hline Antyodaya & $\begin{array}{l}\text { This means 'rise of the last' or in other words, upliftment of a woman/man who } \\
\text { is at the lowest stratum of social and economic structure. }\end{array}$ \\
\hline Baghdha & Tiger Prawn (collection of seeds a source of livelihood in Sundarbans) \\
\hline Bhadralok & Middle income class community as referred in West Bengal \\
\hline Bharat & $\begin{array}{l}\text { Hindi translation of 'Bhärata', the official Sanskrit name of Republic of India, } \\
\text { as derived from ancient texts }\end{array}$ \\
\hline Bharat Gas & Brand name of LPG marketed by BPCL \\
\hline Bijli/Bidyut/Vidyut & Electricity as used in different Indian dialects \\
\hline Block & $\begin{array}{l}\text { Administrative unit of the State that is at a level higher than the Gram } \\
\text { Panchayat and at a level below the district. Group of blocks constitute a } \\
\text { district, and a block has numbers of Gram Panchayats. }\end{array}$ \\
\hline Gonthiyas & Landlords in Kalahandi, Orissa \\
\hline Gram Panchayat & Gram Panchayats (GP), village level people's institutions, responsible for \\
\hline xiv
\end{tabular}




\begin{tabular}{|l|l|}
\hline & social and economic planning and development \\
\hline Grameen & Rural \\
\hline HP Gas & Brand name of LPG marketed by HPCL \\
\hline Indane & Brand name of LPG marketed by IOC \\
\hline Pada/Basti & Hamlet (in a village) \\
\hline Pani & Water \\
\hline Pratinidhi & Representative \\
\hline Sadak & Road \\
\hline Super Gas & Brand name of LPG marketed by SHV Energy \\
\hline Vitaran & Distribution \\
\hline Yojana & Plan or Planning \\
\hline
\end{tabular}

\begin{tabular}{|l|l|}
\hline Crore & $10,000,000=10$ million \\
\hline Kg & Kilogram \\
\hline $\mathrm{kW}$ & Kilo Watt \\
\hline Lakh & Kilo Watt Hour \\
\hline MMt & $100,000=0.1$ million \\
\hline Mt & Million metric tonnes \\
\hline Mtoe & Metric tonnes \\
\hline $\begin{array}{l}\text { Private sector LPG } \\
\text { cylinder size }\end{array}$ & Million tonnes of oil equivalent \\
\hline $\begin{array}{l}\text { PSU LPG cylinder } \\
\text { size }\end{array}$ & 14.2 Kg (domestic) \\
\hline Rs & Indian Rupee (INR) \\
\hline $\begin{array}{l}\text { Rupee - US Dollar } \\
\text { conversion }\end{array}$ & $\begin{array}{l}\text { Rs 45 }=1 \text { US Dollar (average conversion rate, Rupee fluctuated between Rs } 44 \\
-46 \text { for one US Dollar, between 2001 and 2003 and between Rs 45 and Rs 50 } \\
\text { in 2008-09) }\end{array}$ \\
\hline Wh & Watt hour \\
\hline Wp & Watt peak \\
\hline
\end{tabular}




\section{Acknowledgements}

This dissertation would not have been possible without the support, guidance and inputs of many people. Through the years, I have managed to learn and gather lessons from my supervisors, the experiences of my colleagues, as well as from the villagers and people I spent time with understanding the various dimensions of energy access and energy policy. This academic journey has helped me to understand the real lessons in appreciating energy policies and their implementation.

I have had the privilege of having the best combination of promoters and co-promoters a student could ask for - Hans Bressers, Nico Schulte Nordholt and Joy Clancy. Hans in particular was kind enough to help me in the final stages of this thesis. I would not have reached this stage without the guidance of Nico and Joy, who have helped me throughout this journey and guided me in bridging the knowledge gap between the field realities and political economy of public policy reforms. I am very grateful for their trust, support and most importantly patience. They have not only shaped this research study and helped it towards its logical conclusion, they have also inculcated a systematic and logical approach in my thinking as an individual, allowing me to gain new insights and knowledge. Nico and Joy offered some very sensible suggestions on streamlining the dissertation. So, thank you very much for all that you have done for me. The Upanishads says 'acharya devo bhava', which means 'revere the teacher' and I hold both of you in the highest regard. I also want to thank Nico for translating the English summary into Dutch and Cara Ella for proofreading Nico's translation.

During my two fieldwork periods, I benefited from the kindness and support of the villagers and households in my three case-study regions - Gosaba Island, Bastar and Kalahandi. My field assistants, Ardhendu Mandal and Chiranjib Chakraborty (Gosaba), Vijay Shukla and Dinesh Singh (Bastar) and Srinivas Rao and Akshya Kumar Das (Kalahandi), guided me and introduced me to different aspects of energy poverty and development challenges faced by the communities and their coping mechanisms in enabling energy access. I will always value their assistance. My fieldwork in Gosaba, Bastar and Kalahandi would not have been completed without the support and cooperation that I received from the following organisations: Ramakrishna Mission, Narendrapur and its Rupayan centre in Gosaba; Panchayati Raj Department, Bastar and the Office of the District Collector, Bastar in Jagdalpur; and the Xavier Institute of Management, Bhubaneshwar and its project office in Bhawanipatna and Brundaban Sanskrutik Anusthan in Kalahandi. Thank you Ruchi Pant and Prabhjot Sodhi for help in identifying field assistants during my second fieldwork period.

This thesis would not have been possible without the cooperation of the households that I surveyed, some twice, and who provided and shared their experiences of accessing energy for meeting their daily needs and answered my questions with a great degree of patience. I benefited from interacting with several individuals and experts in my three case-study regions and I am indebted to them for sharing their knowledge of local context. In particular, M A Iqbal, who showed me with great enthusiasm the life and culture of Bastar and introduced me 
to the dynamic women's Self Help Group in the village of Puriras and their story of Tare Tare Kiss.

Acknowledgements are also due to the funding agencies that supported the dissertation research at different times. I extend my thanks to The World Bank Institute for awarding me the Joint Japan World Bank Graduate Scholarship for two years, which laid the foundation stone of this research. I am grateful to the Netherlands Foundation for the Advancement of Tropical Research (WOTRO) - Netherlands Organisation for Scientific Research (NWO) for granting me a WOTRO Developing Country Fellowship, which allowed me to complete my fieldwork and thesis writing.

I owe many thanks to Giles Stacey. Giles, through his comments and editing of this thesis, saved me from a number of pitfalls and deconstructed my rambling sentences into sensible reading. He persevered through the entire thesis and made comments and improvements in both substance and form. Giles and Joy also ensured that I had a comfortable stay in their home and I am grateful for their hospitality. From Giles, I have learnt some new vegetarian cooking and I hope that in return he has learnt from my tomato recipes!

The organisations and individuals that I have worked with have helped shape my understanding and knowledge of energy access in rural areas from different perspectives. I would also like to put in a word of gratitude here to The Energy and Resources Institute (TERI), the place where I started working, learnt considerably and enhanced my understanding of rural energy and development by working on some challenging projects in various remote parts of rural India. I gained tremendously by working with Ajay Mathur, C S Sinha, Nandita, Sameer, Soma, Venkata Ramana and many other colleagues in TERI. Thanks to Chris Scott and Tushar Shah for opening up the field of electricity sector policy and ground water management in India at the International Water Management Institute (IWMI) and allowing me to understand a new dimension of rural electrification in India's agriculture sector.

I am grateful for the friendship and opportunity of working with Shubhranshu Patnaik and Chandrashekar Iyer at PricewaterhouseCoopers (PwC), for with them I could learn new aspects of policies and regulations in the Indian energy sector and specifically at the State level. Thanks to Sejal and my climate and energy team at World Wide Fund for Nature (WWF) in India and to Stephan Singer, Raf Senga and Tasneem Essop (in WWF International) from whom I could broaden the horizon of my knowledge to include the wider aspects of climate change, sustainability and conservation, and understanding the politics of policymaking. In the last two years, my colleagues at Swiss Agency for Development and Cooperation (SDC), especially Veena Joshi, K R Viswanathan and Yuka Greiler, have been kind enough to hold the fort and keep an eye on my programmes during my absences to write this thesis and I am extremely grateful to them for their understanding and support.

I am indebted to the Technology and Development Group (TDG) and now to the CSTM of the University of Twente for hosting me, and to all the colleagues and friends there. Working in this multicultural international environment has provided many good opportunities to learn through interacting with the vast and diverse experiences of staff and students. Thank you Ada, Annemiek, Barbera and Monique for all your help and support over these years, you xviii 
have been a great help in addressing all the administrative and logistical requirements and provided wonderful support. I will also like to thank Hans Opdam for providing help with my theoretical chapter, and Prof. Bert Steenge at the University for his comments and suggestions.

I am grateful to Joyeeta Gupta at IVM for her constructive comments and suggestions on my policy chapter and to Andrew Barnett for his detailed comments on my initial research findings, which were very helpful in later analysis and in writing my thesis. I would especially like to thank Margaret Skutsch, for she has been a wonderful support with her inputs and comments on this thesis.

Thank you Anurag, Annemarije, Irna, Jetske, Martin, Subhro and Rob van Waarde for your friendship and support. I am also thankful to Eashwar for helping with copy-editing an earlier draft of this thesis. I am grateful to Manoj for his support in designing the cover page. In the last two years, I had the support of three young people who have rallied around in various ways when I have bullied them to produce information, data and reports whenever it was needed: thank you Divya, Ronnie and Tirthankar for your help, because without your support this thesis would not have been possible.

Throughout this phase, my family have been there to support me. My parents, Vijoy Narain Sinha and Veena Sinha, raised me with a sense of direction and a freedom to chart my own path that has always helped me in finding my way. My sister Swapna and my brothers Saurabh and Sharad, and their families, have been pillars of great strength and support. In 2008, just a few weeks before he passed away, my father inspired me to finish what I had started. I have dedicated this dissertation to my father, who though no longer with us is always in our hearts and our guiding star. I thank my in-laws for their constant motivation and unwavering support. My mother in-law, Adarsh Soni, has constantly encouraged and taken care of many things in our daily lives so that I could concentrate on writing this thesis. Thank you Twinkle and Sidharth for letting me work from your Kasauli home, which allowed me to complete a substantial part of the case-study chapter. Many thanks to Sujata for her constant encouragement and to Amardeep for being his usual best! A special thanks to Ashok Uncle who painstakingly improved the maps of the case-study regions into a presentable format.

Above all, I want to thank Preeti Soni, my best friend and wife. She has been a wonderful life partner, a great support through the difficult times and constant in encouraging and supporting my efforts. She has been a source of strength and inspiration, and has often pulled me out of despair and enabled me to finish this dissertation. Since we both work in the same field, we have had many discussions on the issues covered by this thesis and I have gained from her experience and above all her patience in dealing with any situation. Thank you for standing with me, being there and taking on multiple responsibilities in the last few years during my long absences. Finally, Mannat, this is for you. I have finally finished. I have missed being part of your growing up, but I hope we can spend a lot of time together enjoying every little small thing in life. Six years back, you walked into our life like morning dew; let us now enjoy the sun, the moon, and the stories of our noni jungle!

New Delhi, November 2012 


\section{Prologue}

My journey to this $\mathrm{PhD}$ on energy poverty in the context of policy reforms in the energy sector has been long and enriching. I can trace the origin of my interest in this topic way back to 1994 when I was in the final year of my Masters in Rural Management. I decided to undertake a project with Tata Energy Research Institute (now called The Energy and Resources Institute, or TERI) on preparing a district-level energy plan for Changlang district, Arunachal Pradesh in North-Eastern India. This two-month research project, which involved understanding household energy use, energy resource assessment and the potential for renewable energy interventions, gave me a new direction and rural energy became a major field in my professional development and career.

In 1998, I attended a short course on decentralised rural electrification conducted by the Technology and Development Group at the University of Twente. Since then, this Group and the University have become a part of my life. During the course, I had detailed interactions with Dr Joy S Clancy and the discussions sowed the seeds for this doctoral research study, with a focus on the commercialisation of renewable energy technologies in India.

Two weeks before I reached the Netherlands to start my doctoral research in late 1999, I was part of a discussion organised to create a policy space for renewable energy so that remote villages could gain access to electricity in India. The discussion involved the participation of members of the Planning Commission, officials of the Ministries of Power and NonConventional Energy Sources, Non-Governmental Organisations (NGOs) and research institutions. During the course of the discussion, I raised a question regarding implementation of rural electrification programmes, especially Kutir Jyoti, a targeted programme for the population below the poverty line (BPL), in the state of Orissa. Orissa was the first state in India to initiate electricity sector reforms and privatise its electricity distribution. There was silence in the room. It emerged from the meeting that there was little information available on the impacts of policy reforms on rural electrification and if the perceived benefits of policy reforms, including economic reforms, were reaching the rural areas. The 'sound of silence in the room' eventually became the topic of my doctoral research.

After starting at the University of Twente, I discussed the idea of research looking at energy policy reforms in developing countries with Prof. Nico G Schulte Nordholt and Dr Joy S Clancy. Within the following few months, guided by them, I formulated a detailed research proposal focusing on access to modern energy carriers and addressing the problems of energy poverty in rural areas of India in the context of public sector policy reforms. The research proposal considered public policy reforms in the broader context of energy and development. The research study received funding in the form of a Joint Japan-World Bank Scholarship (1999-2000) and subsequently a WOTRO Developing Country Fellowship (2001-03).

In 2001 and 2002, I conducted my fieldwork in three different regions of India and in the period between 2002 and 2003, I started analysing the data from the case studies. It increasingly became clear that the information I had acquired was on two different levels one related to household-level energy access and factors influencing this; and the second on 
policy reforms in the energy sector that were rapidly evolving on the level of central government, but failing to be translated to the state level. The ability to link these two different levels of information became a major challenge in finalising the thesis. This eventually resulted in spiralling delays. While the desire to finalise the thesis remained ever present, personal reasons and supporting my family in India delayed its completion. In retrospect, 2003 and 2004 were some of the most difficult years for me personally, and provided opportunities to learn new lessons in life, albeit in a hard way.

In the period from 2004 onwards, through various assignments, I became more involved in rural electrification management projects. I looked at the water - energy nexus in agriculture, addressing issues of policy reforms in energy, irrigation and agriculture sectors. Between 2005 and 2007, I was part of an assignment that involved working with state governments and distribution utilities to establish franchisees to manage rural electricity distribution, as mandated under the national Rajiv Gandhi Grameen Vidyutikaran Yojana (RGGVY) rural electrification programme. Besides this, I was involved in assisting two state governments in preparing their power policies including a rural electrification policy and policies for mainstreaming renewable energy. In this period, I was also engaged as a subject expert on the sub-committee for Rural Electrification, established by the Rural Electrification Corporation. This involved providing inputs on the experiences and lessons related to franchising of rural electricity distribution and reviewing the RGGVY as part of preparing India's Eleventh FiveYear Plan (2007-2011). From 2007 onwards, I became more actively involved in national and international policy debates on energy and climate change. This involvement in energy and climate policy provided an opportunity to draft policy position papers on the critical issues of energy access and inter-linkages in the context of climate change vulnerabilities for national and international policy stakeholders.

This cumulative experience provided significant practical insights and perspectives on the issues of energy access in the context of energy reforms and of the changing policy context in India. The disconnect between policy formulation and on-the-ground realities became sharper and, despite all the measures taken to close the implementation gaps, there were serious lapses in programme implementation. Therefore, in 2008, I decided to reassemble the pieces of my PhD research puzzle once again. In 2008-09, in consultation with my supervisors and with their encouragement, I went back to my surveyed villages to see if and how energy access had changed in these villages since the initiation of new policies and programmes at the national/state level in 2004. Revisiting the case study regions provided new insights on the issues and reasons that boost or restrict modern energy access in rural India.

This dissertation, covering energy policies before and after 2004 by looking at energy access at two different points in time (2001-02 and 2008-09), therefore provides an in-depth insight into the kinds of constraints and opportunities that occur when attempting to enable access to modern energy carriers. The use of longitudinal primary data from the case studies gives this dissertation great relevancy. The analysis focuses on issues of energy access and the dynamics of energy policy alongside issues of social and economic development in India. 


\title{
1. Introduction
}

\begin{abstract}
"The most important demand-side initiative we have to take is related to the pricing of energy. I also believe that we must adopt an economically rational pricing policy that has the built-in incentive for consumers to voluntarily try and conserve energy through its optimal and rational utilisation. This multi-faceted approach should be adopted in the pricing of all forms of energy including petroleum, LPG, kerosene, water, and electricity". (Manmohan Singh, 2004) ${ }^{1}$
\end{abstract}

\subsection{Context}

The above statement by Manmohan Singh, the Indian Prime Minister, emphasises the need for a rational energy policy framework. In order to implement such a framework, it is being argued here that changes are needed in policy instruments relating to those who already have access to modern energy. The statement, however, fails to reflect on the lack of modern energy access by the majority of India's population, especially those living in villages, who continue to wait for access to energy forms that enable them to switch on an electric light bulb and cook food on a clean stove. As citizens, these people also need to be considered as part of any rational energy policy framework.

How does one achieve the objective of providing rural people in India with access to the socalled modern energy forms of electricity and petroleum products and moving them out of energy poverty ${ }^{2}$ ? Perhaps, by putting a market value on energy, and selling energy at an "economically rational" price? However, there is more to valuing energy than merely putting a market value on energy. Nobody values energy more than the women who walk long distances to fetch firewood or other forms of biomass to cook for their families. Nobody values energy more than the women in a remote tribal village in Chhattisgarh or the men and women on some remote islands in the Sundarbans, who walk five to six kilometres to the nearest market to buy a few litres of government-subsidised kerosene oil - only to then be denied even that despite being legally entitled. At the other end of the spectrum, there are the dishonest traders and retailers illegally siphoning off the subsidised kerosene oil from the public distribution system (PDS) and selling it to the people at a premium. Nobody values energy less than those who live in India's rapidly growing cities, who nevertheless complain that they are being robbed of their savings if the government reduces the subsidy ${ }^{3}$ on liquefied petroleum gas (LPG) for domestic use.

\footnotetext{
${ }^{1}$ Dr Manmohan Singh, India's Prime Minister since 2004, is a noted economist. As India's Finance Minister from 1991 to 1996, he initiated a series of reforms to liberalise the Indian economy and is regarded as the architect of economic reforms in India.

${ }^{2}$ Energy poverty will be further discussed in detail in Chapter 2, Section 2.2.2. There is no universally agreed definition of energy poverty although an often cited one is "the absence of sufficient choice in accessing adequate, affordable, reliable, high quality, safe and environmentally benign energy services to support economic and human development" (Reddy, 2000a).

${ }^{3}$ The politics of pricing petroleum fuels are further discussed in Chapter 4.
} 


\section{Box 1.1: Energy Carriers and Energy Services ${ }^{4}$}

\section{Energy carriers can be divided into two categories:}

(a) Traditional energy carriers, including fuelwood and other forms of biomass such as crop residues and dung-cakes, which are used in low-efficiency traditional stoves and generally produce high levels of smoke linked to respiratory illnesses; and

(b) Modern energy carriers, including electricity, liquefied petroleum gas (LPG) and kerosene oil for household end-uses, such as cooking and lighting, and for productive end-uses.

In this study, the focus is on access to modern energy carriers as defined above. Modern energy carriers are superior to the traditional energy carriers in the sense of being cleaner, more efficient, and more convenient to use.

Energy services, as defined in this study, refer to energy for consumptive end-uses (including lighting and heating and in the provision of social benefits such as healthcare and education) and productive end-uses (such as agriculture and other enterprises based on economic activities) that rely on modern energy carriers.

Nobody values electricity more than the remote rural households in India who do not have access to electricity even after more than six decades of economic and social development programmes targeted at benefiting the "poorest of the poor" or rural households. Rural households, if they are lucky, may be connected to the grid but still get no electricity supply when they need it most. Nobody values electricity more than farmers, who have to be constantly prepared to pump water to irrigate their crops because electricity is supplied to them only at odd hours when the overall demand for electricity from the grid is low. Nobody values electricity less than the politicians across India, who offer free electricity ${ }^{5}$ to farmers as a populist measure to ensure that they are voted back to power.

The reality of India's rural population is one of limited access to modern energy carriers (see Box 1.1) which, despite the country's steady economic growth, belies the 'India Shining' claims $^{6}$. India's economy, which in the early part of this century had been growing at between $8-9 \%$ annually, was initially largely unaffected by the economic downturn and global financial crisis of 2008. However, since 2010, the economy has slowed, there is high inflation (around 10\%) and the Gross Domestic Product (GDP) growth rate is less than 7\%

\footnotetext{
${ }^{4}$ In this dissertation, the terms 'energy carriers' and 'energy services' are used rather than 'energy sources' or 'fuels'. From the point of view of the end-user, what matters is the 'energy service' not the energy source or the fuel. Primary forms of energy are converted into various energy carriers, and these are the energy forms delivered to end-users. Energy carriers are used by end-users to derive energy services in practical and affordable ways to support their social and economic development and their wellbeing.

${ }^{5}$ Free electricity and subsidies, and the politics thereof, are discussed in Chapter 4.

${ }^{6}$ 'India Shining' was the campaign slogan of the National Democratic Alliance (NDA) led by the Bhartiya Janata Party (BJP) in the 2004 national elections. 'India Shining' was used to show that India, including its rural areas, was progressing rapidly along a path of economic prosperity. The BJP was trying to cash-in on the feel-good factor (engendered in part by a GDP growth rate of $8.9 \%$ and foreign exchange reserves passing $\$ 100$ billion in 2004) (Mahendra Dev, 2004). However, the NDA was defeated in the elections, reflecting an emerging consensus that while India may be shining at the macro-level, Indians who live in villages see a completely different and somewhat dismal picture. 
(GoI, 2012). India's growth story, which started with the economic reforms of 1991, has started to show signs of weakening, and this has been attributed to the rising fiscal deficit and the reduction in Foreign Direct Investment (FDI) inflows (Ahluwalia and Little, 2012).

India is a country of extreme economic and social contrasts, a situation that poses sustainability and development problems of varying magnitude linked to its scale and geographical diversity. The rapidly growing economy, while bringing economic prosperity at the aggregate level has also created social imbalances and inequities including in access to, and use of, resources. India is endowed with vast natural and human resources but the demand for economic growth and development, together with unmet human needs, continues to exert pressure on its natural resources. One of the outcomes of, and indeed a contributor to, economic growth has been an unprecedented increase in demand for energy (Planning Commission, 2006). Two critical aspects of India's future energy demand are part of this economic growth - energy demand nexus. The first aspect is the energy security ${ }^{7}$ necessary to meet the national aspirations for economic growth. The second aspect pertains to lack of access to modern energy carriers by the majority in rural India - an unfinished agenda, since 1947, of India's development vision.

India's electricity consumption in 2001 was already twenty times more than what it was fifty years earlier. According to India's Integrated Energy Policy (IEP), published in 2006, which used eleven fuel-mix scenarios in estimating that, in order to sustain an economic growth rate of $8 \%$, the country's energy demand would have to increase from 513 million tonnes of oil equivalent (mtoe) in 2005-06 to between 1536 mtoe and 1887 mtoe in 2031-32 (Planning Commission, 2006). In the least energy-intensive scenario, the share of modern energy would increase from $3.8 \%$ to $7.6 \%$, whereas, in the most energy-intensive scenario, the share of modern energy was put at $10.9 \%$ by $2031-32$. India's energy demand could account for 13 $21 \%$ of the world's energy supply by this date. Given India's rapidly growing economy and the need to enhance access to modern energy carriers in rural areas of India, energy demand is undoubtedly going to grow into the foreseeable future. Unless the government is able to secure adequate supplies of energy and ensuring long-term energy security, there will be problems with India's economic and social development, raising doubts about whether the current low level of access to modern energy carriers will change in the rural areas.

Embedded in meeting future energy demand is the challenge of providing access to modern energy carriers in rural India. It is recognised that the level of energy access in rural India is similar to, and in some cases even lower than, that of some of the poorest countries in the world $^{8}$ (Sinha, 2010). The 2006 IEP indicated that nearly 77 million rural households (approximately $50 \%$ of rural households in India) had no access to electricity and about 120

\footnotetext{
${ }^{7}$ Energy security amounts to a sufficiency in energy availability through both indigenous energy sources (exploited through public investment in developing oil and gas fields, exploration and refining of oil and gas infrastructure, electricity generation, availability and its distribution infrastructure) and external sources through imports.

${ }^{8}$ It is estimated that nearly 1.5 billion people in developing countries do not have access to electricity and that nearly three billion people use traditional energy carriers to meet their cooking energy needs (IEA, 2009;UNDP/WHO, 2009).
} 
million households (about 80\%) used biomass energy for cooking. The recognition of energy poverty or of the limited access to modern energy carriers as an issue was first highlighted by the 1991 census, which showed that electricity was being used by about $31 \%$ of rural households, and LPG by less than 1\% of the rural households for cooking. In 2001, electricity access in Indian rural households had increased to about 43.5\% (Census of India, 2001a). According to the National Sample Survey Organisation's 2005 energy use survey (NSSO, 2007), India still faces the daunting task of bringing electricity to nearly $45 \%$ of rural households. These continue to increase in number, and hence there is a moving target in terms of the number of households. Moreover, even where electricity is available, the quality and reliability of supply are often far from ideal, with frequent power outages, especially after sunset.

In terms of clean energy for cooking, and helped by the subsidy on the price paid by consumers for an LPG cylinder and efforts to improve availability in rural areas, LPG use for cooking is increasing in rural households. LPG use has increased from 5\% of rural households in 2001 to nearly 9\% in 2005 (Census of India, 2001a;NSSO, 2007). Despite this increase in the household use of LPG, biomass energy carriers - collected or bought - remain the main source of cooking energy in rural India. There are growing concerns about biomass availability as its consumption is increasing beyond the supply from the natural ecosystem.

\section{Box 1.2: Low-Capacity End-Users}

The term 'low-capacity end-users' rather than 'rural poor' is used in this research to encompass the rural population that is either underserved or unserved in terms of access to modern forms of energy carriers.

a. 'Underserved' refers to that part of the rural population that uses small quantities of or has limited access to modern energy carriers and depends on traditional energy carriers to meet much of its energy needs. The term includes households in all income and social groups.

b. 'Unserved' refers to that part of the rural population that has no access to modern energy carriers - these being either unavailable or unaffordable - and therefore uses only traditional energy carriers to meet household energy needs.

Low-capacity end-users, as defined here, can include households from all income groups.

There is a large number of low-capacity end-users in India (Box 1.2), especially those with small disposable incomes (classified by the Government of India as below poverty line ${ }^{9}$ ), who have only limited access to modern energy carriers ${ }^{10}$. Given the data above, and as will

${ }^{9}$ The Government of India uses a threshold, known as the Poverty Line to indicate economic disadvantage and to identify individuals and households, with an income below this threshold, that are in need of government assistance and support to meet basic needs. This will be further explained in Chapter 3.

10 The only available data related to below poverty line household access to electricity are for households included in the national programme for rural electrification in states with low electricity access. In 2010, about 24 million below poverty line households were identified for household electrification under the national rural electrification programme, although only about 8 million (about 34\%) were actually provided with an electricity connection (Patil, 2010). However, it is important to note that the numbers given for below poverty line households are questionable because of inclusion and exclusion errors in the national census. This will be further discussed in Chapter 5. 
be further shown in Chapters 4 and 5, the government's objective, of moving them all out of energy poverty $^{11}$, appears not to be being met. This requires an assessment of the policies and programmes, which appear not to be working, and their implementation. Modern energy carriers are important for the social and economic development of rural areas, contributing both directly (cooking, safe water, lighting, transportation, etc.) and indirectly through employment and income generation (Johansson and Goldemberg, 2002;Price, 2000;Reddy, 1999). However, even if modern energy carriers are available, they have to be paid for, and many low-capacity end-users, often below the poverty line, find them difficult to afford, even when subsidies are available.

The quote from the Prime Minister at the beginning of this chapter hints at the energy policy changes that started in 2004, that themselves built on major policy reforms started in the 1990s (discussed in more detail in Chapter 4). These policy reforms had to balance, among other things, the issues referred to above: the country's energy security, economic growth, the effect of energy subsidies on the fiscal deficit and universal access to modern energy carriers. While recognising the linkages between these issues, the focus of this dissertation is on how to ensure access by low-capacity end-users. The reason for this will be elaborated upon in the next section.

\subsection{Problem Statement}

After India achieved independence from colonial rule in 1947, the government took on the responsibilities of being simultaneously the producer, distributor and regulator of various energy carriers. Both the central government and the state governments developed energy programmes that involved policy instruments such as entitlements, quotas, subsidies and cross-subsidies. The government's domination in delivering goods and services is reflected in the fact that, in India, only the government was considered capable of setting up large industries and economic infrastructure such as hydroelectric projects, railway lines and fertiliser plants that the country needed (Myrdal, 1965). The rationale for having the energy sector as a state-owned enterprise included its ability to meet the public policy goals of universal access and affordable services for the poor.

The late 1970s saw the beginning of a paradigm shift towards reducing the role of government, which spread to several countries, including India, in the 1980s and 1990s. New thinking about the complexities of economic, political and social issues emerged as a paradigm, which emphasised access to markets as a key factor in welfare and development (So, 1990;Strange, 1988). The paradigm shift was towards rolling back the state as the provider of economic growth and allowing a market economy to develop. In developing countries, many of whom (including India) had relied on a centrally planned economy, this meant that there was a need for a policy shift. This policy shift resulted in the emergence of public sector reforms within the national economies of both developed and developing countries, which redefined the role of the public sector and encouraged the privatisation of state-owned enterprises because, it was argued by policymakers and economists, that privatisation would function more effectively(van Dijk and Schulte Nordholt, 1994). The

\footnotetext{
${ }^{11}$ The energy access in rural India, which the government wants to improve is presented in Chapter 3.
} 
energy sector was a particular target for reform since it had been developed based on public or state ownership but was not providing universal access.

As shown in the previous section, very few households in rural areas had actually gained access to modern energy carriers before 1990. This raises a question as to why the government-driven programmes had failed to improve access to modern energy carriers in the rural areas. For the state electricity boards (SEBs) and state utilities that had been entrusted with supplying electricity to rural areas, it had been a loss-making proposition. Rural electrification was undertaken as a welfare measure and because of political compulsion. In other words, there was typically no market for 'selling' electricity at a price that covered costs. The story is the same for LPG and poor households in rural areas: an inadequate distribution infrastructure, a lack of cash income, and biomass available at zero cost and collectable by women in their 'free time'. Therefore, India embarking on energy sector reforms provided an opportune moment, given that the central and state government programmes had been unsuccessful in enhancing access to modern energy carriers in rural areas, to ask under what circumstances reforming the energy sector could be expected to boost modern energy access in rural areas.

Efforts to liberalise ${ }^{12}$ the energy sector at the central and the state levels were intensified from 1995 (D'Sa et al., 1999;Dubash and Chella Rajan, 2001;Sreekumar, 2002). The rationale in 1995 for reforming the energy sector was that government ${ }^{13}$ control over the provision of energy carriers distorted market prices and stifled competition.

The reforms were aimed at bringing changes to energy policy directed at creating an enabling framework for investing in new generation/production capacities, improving delivery mechanisms, correcting prices and bringing competition to the sector. The general expectation from policy reforms was that these measures would also improve access to modern energy carriers for low-capacity end-users. However, towards the end of 1999 and in early 2000, although there was limited empirical evidence to support this contention, concerns were voiced by influential commentators that energy access in rural areas was not a priority in the policy reforms ${ }^{14}$ (Reddy, 2000b). Despite concerns that the market was not working, government policy in India continued to reflect the dominant paradigm of the market as the provider of economic growth.

In 2004, prior to the national elections, the disconnect between the macroeconomic growth and micro-level development in rural India became increasingly evident. This gave rise to the view that the economic reforms had created an India of two parts: the urban "India", where the success of economic reforms was apparent, and the rural "Bharat", where the benefits of economic reforms were not yet visible. After the 2004 election, the paradigm of economic reforms was modified to one of inclusive development at the national and state levels. The voters rejected the populist policies, which had been a cornerstone of Indian politics since the

\footnotetext{
12 This is further explained in Chapter 4, in Sections 4.3.3 and 4.4.2 and in Box 4.4.

13 The rationale for limiting the role of the government was linked to improving the economic efficiency of the sector. This is further elaborated upon in Chapter 2.

${ }^{14}$ Similar views were also expressed regarding the impact of economic reforms on rural development in general (Chandrasekhar and Ghosh, 2002;Patnaik, 2006). 
1970s and designed to appease the rural population. The electorate began to demand the implementation of programmes that would bring social and economic development based on access to well-developed infrastructure, especially in terms of bijli (electricity), sadak (roads) and pani (water).

By 2004, almost a decade after the energy sector reforms had been initiated, as discussed in the previous section, there was a lack of progress in enhancing energy access in rural areas. As a result of this failure, and as part of the inclusive reform agenda, the government once again became the dominant actor in the energy sector, especially in supplying energy to rural areas. The Government of India initiated a new national programme for rural electrification with the focus on 'electricity for all' by 2012 and continued to provide subsidies for LPG and kerosene oil. The pricing of electricity, kerosene oil and LPG has been a political tool since the 1970s and their pricing continues to remain a contentious issue in energy sector policies, particularly as it contributes to the government's fiscal deficit ${ }^{15}$. An analysis of India's history of development policy shows that access to modern energy carriers in rural areas has been considered vital for rural development ${ }^{16}$. However, despite the policies and programmes, energy poverty in rural areas continues to be a significant concern especially since it acts as an impediment to improving the quality of life and wellbeing of low-capacity end-users, particularly those in remote rural areas.

The central focus of this dissertation is on the impact of the shifts in the policy framework in India's energy sector - increasing reliance on the market and decreasing intervention by the government from 1991 to 2004, and then the return to a greater role for the government while pursuing policy reforms from 2004 onwards - on energy access by low-capacity end-users. As such, the revised ${ }^{17}$ objective of this study became to identify under what circumstances can policy reform in India's energy sector lead to improved access to modern energy carriers and to sustainably meeting the energy needs of low-capacity end-users in rural India.

This dissertation covers India's energy policy from 1950 to 2010, and in particular two critical phases of policy reforms, before and after 2004. It analyses the factors influencing energy access in 2001-02, when there was a shift in energy policy that reduced the role of the state and put a strong emphasis on market forces (referred to here as the reform phase). It further analyses the implementation of policies (initiated since 2004 under the inclusive reforms phase) and their effect on energy access in 2008-09, when the government had a more active role and that of the market was limited. By examining energy access at two points in time, this dissertation provides a longitudinal analysis, a desirable feature that is often impossible in doctoral research, of the impact of policies on energy access by lowcapacity end-users.

\footnotetext{
15 This is further elaborated upon in Chapter 4.

${ }^{16}$ This is further elaborated upon in Chapter 4, Section 4.3.

${ }^{17}$ See Prologue for an explanation of this revision.
} 
The central hypothesis of this research is that, unless appropriate measures are applied, the energy policy reforms in India will not lead to improved access to modern energy carriers for the low-capacity end- users.

The aim of this dissertation is not so much to attack the reform policy ideologically, but to reflect on whether current policy approaches have succeeded in providing access to modern energy carriers in the rural areas of India, especially for low-capacity end-users. The objective and the central hypothesis of the study imply that energy policy in general, and policies for promoting access to modern energy carriers in particular, need to be analysed to understand how the interests of low-capacity end-users can be protected while pursuing policy reforms in India's energy sector.

This dissertation is rooted in the growing global concerns that the lack of access to modern energy carriers in developing countries is constraining the ability of low-capacity end-users in rural areas to be part of mainstream economic and social development. The value of energy in contributing to the economic and social development of humankind is well established and acknowledged (Reddy, 2000a;Saghir, 2005). Despite the apparent benefits of access to modern energy carriers in rural areas, especially by the low-capacity end-users, the transition to modern energy carriers remains slow. As mentioned earlier, the global community faces the daunting task of moving billions of people in developing countries out of energy poverty (IEA, 2009;UNDP/WHO, 2009). The current levels of energy access are increasingly viewed as unacceptable since they undermine social and economic development. As a consequence, the development discourse has increasingly incorporated energy as an important theme.

The Ninth Session of the Committee on Sustainable Development (CSD-9) recognised access to affordable energy services as a prerequisite for meeting the target of halving the proportion of people living on less than $\$ 1$ a day by $2015^{18}$ (CSD-9, 2002). Access to energy was not recognised in the Millennium Development Goals (MDGs) ${ }^{19}$ but was subsequently added in the Water, Energy, Health, and Biodiversity (WEHAB) Agenda at the World Summit on Sustainable Development in Johannesburg in 2002.

Since 2010, alleviating energy poverty by enhancing access to modern energy carriers has topped the agenda of national governments as well as of multilateral institutions (United Nations, 2010). Further, 2012 has been identified by the United Nations as the 'Year of

${ }^{18}$ In 2002, the Planning Commission of India prepared a development vision for India: Vision 2020. The vision aims at a targeted approach for moving millions of people out of poverty, eradicating illiteracy, creating new employment opportunities, improving healthcare, strengthening primary and secondary education, and enhancing energy access and energy security (Planning Commission, 2002b). India's National Action Plan on Climate Change, published in 2008, reiterates the need for an ecologically sustainable development pathway with poverty alleviation as the primary focus (GoI, 2008b;Planning Commission, 2002b).

${ }^{19}$ The Millennium Development Goals (MDGs) are eight international development goals agreed by countries to be achieved by 2015. The eight goals are: eradicating extreme poverty and hunger; achieving universal primary education; promoting gender equality and empowering women; reducing child mortality rates; improving maternal health; combating HIV/AIDS, malaria and other diseases; ensuring environmental sustainability; and developing a global partnership for development. 
Energy Access' to herald the start of a global campaign on 'Sustainable Energy for All', with the focus on energy access, renewable energy and energy efficiency (United Nations, 2010; United Nations, 2012).

The debate, so far, on energy and development has mainly focused on the macro- (national aggregate) level while neglecting the impacts of the energy - development linkage on the micro-level ${ }^{20}$. Historically, on the macro-level, economic growth has been seen as the engine of development, and growth in output was assumed to be dependent on growth in energy inputs (Barnett, 2000). Electricity in particular was regarded as an essential component of modernisation, not only in the context of economic production but also in the psychological sense as a clearly visible indicator of progress. At the macro-level, a strong empirical relationship has been established between gross national product (GNP) and energy use (Barnett, 2000).

However, on the micro-level, that is the level of villages and households, these linkages are far from obvious because the connection between limited access to modern energy carriers and the broader issue of development are interconnected in diverse, direct and indirect, complex ways that are not fully understood. At the household level, the linkages are complex in that improvements in energy access do not automatically translate to an increase in aggregate income or vice versa. Factors such as location, economic development, infrastructure and social norms, including gender, also affect energy access (Clancy et al., 2011). The linkages become even more complex because of differing, and at times conflicting, priorities set by the various members of a household, since these influence decision-making including choices about energy carriers.

The macro-analysis of the energy - development link fails to capture these micro-level influences on access to and use of energy carriers at the village level, at the household level and at the level of the individual members of a household (Ramani and Heijndermans, 2003). In part, this reflects the data collection methods that have been used in attempting to understand energy access ${ }^{21}$. What is required is empirical evidence that explains the complex interplay between factors that determine access to modern energy carriers by low-capacity end-users in rural India. Therefore, the central research question of this dissertation is framed as follows:

"How might future implementations of policy reforms in India's energy sector be adapted to achieve the dual objectives of improving the economic efficiency of energy supply and of improving low-capacity end-users' access to modern energy carriers?"

\footnotetext{
20 The energy and development link will be further elaborated upon in Chapter 2.

${ }^{21}$ The emphasis has been on developing indicators and analysis using secondary data to understand energy access. For example, Pachauri and Jiang (2010) put the emphasis in their analysis for India on it being a step towards filling the gap related to micro- and household level data. However, their analysis is based on secondary sources of large sample surveys on expenditure patterns and therefore ends up being a macro-level analysis. This will be further elaborated upon in Chapter 2. Another problem is that data collection often fails to uncover regional variations and sex-disaggregated information.
} 


\subsection{Structure of the Dissertation}

This dissertation is divided into two parts, each consisting of three chapters (Figure 1.1). The three chapters that make up Part I are this Introduction, Applied Concepts in Energy, Development and Policy Reforms, and finally the Research Methodology.

Chapter 1 (Introduction) presents the background, the rationale and the relevance of examining the link between access to modern energy carriers and energy sector reforms on the local level. The chapter also defines the main objective, the central hypothesis and the central research question of the study.

Chapter 2 (Applied Concepts on Energy, Development and Policy Reforms) presents the relevant literature on energy and development and explains the concepts behind policies related to energy sector reforms. These concepts form the basis for developing the analytical framework of the study. The chapter also subdivides the research objective presented above into three main research questions.

Chapter 3 (Research Methodology) describes the rationale behind the applied methods chosen and in the identification of the regions used in the case studies. The chapter also outlines the research techniques used for collecting data in 2001-02 and again in 2008-09, and for analysing the primary and secondary field data to answer the research questions.

Part II forms the core of the dissertation and provides an overview of India's energy policy for improving access to modern energy carriers and empirical evidence for the significance of these energy policies in providing energy access to rural India.

Chapter 4 (Rural Energy Policy: The Meek Shall Inherit) examines India's rural energy policies and their development over six decades (1950-2010), starting with the postindependence energy policy under a socialist and centralised approach, evolving to a liberalised and reformed economy after 1991, and then further reforms with a focus on inclusive growth since 2004. This chapter deals with the first research question and its three sub-questions.

Main Research Question 1: How have energy sector reform policies been formulated to address the weaknesses apparent in the policies of the pre-reform phase in terms of improving access to modern energy carriers by low-capacity end-users in rural areas?

Sub-question 1.1: What is the institutional setting for delivering energy carriers in rural India?

Sub-question 1.2: What motives have shaped energy policies in India in the prereform phase (1950-1991) and in the reform phase (1991-2010)?

Sub-question 1.3: What are the key elements of the energy policies enacted since 1991 for enabling low-capacity end-users to access modern energy carriers?

Chapter 5 (Understanding Energy Access: Evidence from Gosaba, Bastar and Kalahandi) presents the three case studies undertaken and provides empirical evidence on the contextual influences affecting access to modern energy carriers in three regions in India in 2001-02 and in 2008-09. Specifically, the chapter analyses access to modern energy carriers, the barriers to 
such access, and the drivers that have enabled such access in rural areas, all within the local contextual setting and at two points in time. The chapter addresses the second main research question and its three sub-questions.

Main Research Question 2: Have the energy policies enabled low-capacity end-users to gain access to modern energy carriers?

Sub-question 2.1: How do delivery pathways and enabling factors influence access by low-capacity end-users to modern energy carriers?

Sub-question 2.2: Who has access to modern energy carriers and why?

Sub-question 2.3: How do contextual influences affect low-capacity end-users' access to modern energy carriers?

Chapter 6 (Conclusions: Will Rural India Shine?) summarises the principal arguments of the earlier chapters and analyses the linkages between contextual influences and the enabling factors to answer the third main research question on the changes required in the enabling factors to enhance access to modern energy carriers by low-capacity end-users in rural areas.

Main Research Question 3: What changes are required in the enabling factors to enhance access to modern energy carriers by low-capacity end-users?

Building on the answers to the main research questions, the concluding chapter provides policy recommendations at three levels, namely national, state and local (block and village clusters). This final chapter concludes by presenting the contribution of this dissertation to studies on the political economy of policy reforms and on energy and development, in particular in India. 


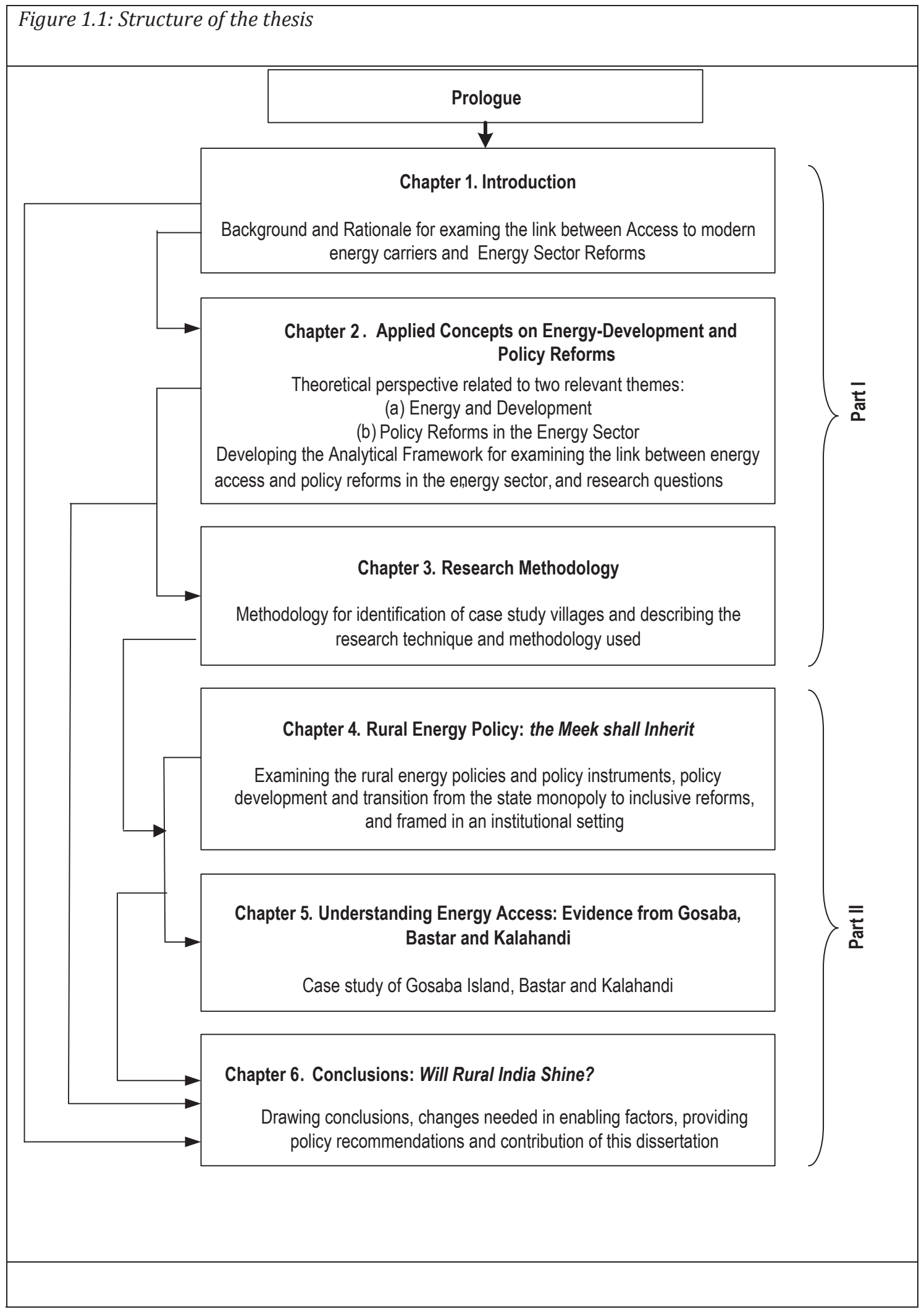




\title{
2. Applied Concepts on Energy-Development and Policy Reforms
}

\author{
"Reforms do not necessarily mean the retreat of the state from all areas; rather; it should \\ redefine the role of the state." (Tol, 2005, 18)
}

\subsection{Introduction}

In a developing country such as India, where more than one-third of the population live below the poverty line ${ }^{22}$, and nearly half the rural population lack access to modern energy carriers, the government's energy policy is particularly important in contributing to changing this situation. The need to enhance energy access for low-capacity end-users is relevant in the context of economic policy reforms and in particular energy policy reforms. The policy reforms become central to the debate on the role of energy in development and raise a critical question: can the government or the market deliver energy more efficiently in rural areas where access to modern energy carriers is limited?

Energy policy reforms are part of the larger discourse and debate on public policy reforms. In most developing countries, including India, energy sector reforms is a model borrowed from the limited experience of similar reforms in developed countries such as the United States and the United Kingdom ${ }^{23}$. Electricity sector reforms have been linked to a policy of 'commitment lending ${ }^{24}$ - only developing countries that followed the prescribed reforms would receive World Bank funds for the much-needed investment in their energy sector. However, the context and background of energy sectors are somewhat different in developing countries to those of developed countries. As outlined in the previous chapter, developing countries face the challenge of large numbers of their population being without access to modern energy. Further, the situation of the energy sector (the way it is organised), the social and economic profiles of users and non-users, and the overall policy context in developing countries (social problems such as access, equity, etc.) are different to those in the more

${ }^{22}$ Defined in Chapter 1, Footnote 9, and further explained in Chapter 3.

${ }^{23}$ Experience with energy sector reforms started largely with the electricity sector. In the US, the focus was on independent power producers, and in the UK, the reforms were driven by an emphasis on extracting additional efficiency gains out of an essentially well-functioning system. The emphasis was on making competition work in the electricity sector. In particular, the UK experiment was critical given the lack of any real experience with markets for the electricity sector. The UK experience in particular rapidly became the global benchmark (Dubash, 2005). Other related experiments were seen in Chile and Norway. Chile witnessed a competition-oriented electricity reform, and Norway introduced competition without privatising public-sector utilities (Williams and Ghanadan, 2006).

${ }^{24}$ The World Bank, in its 1993 electricity policy paper, emphasised transparent regulation, commercialisation, corporatisation and the encouragement of private investors as its guiding principle in finding solutions and fixing the problems of ailing electricity sectors in developing countries (World Bank, 1993). 
developed countries, which had well-functioning energy sectors prior to the initiation of reforms (Blauvelt, 2004;Williams and Ghanadan, 2006). The energy sector reform policies have met with resistance from different stakeholders, and the implications of these reforms have been questioned (Ahluwalia and Little, 2012;Chandrasekhar and Ghosh, 2002), especially in the context of their effect on access to modern energy carriers by low-capacity end-users in rural areas (Sankar, 2002b). Limited access to modern energy carriers in rural areas can be attributed to the policies and policy instruments adopted by government (Reddy, 2002). However, based on past experiences, and in relation to the question posed above, can one assume that those policy instruments that emerge from energy sector reforms will be sufficient to improve access to modern energy carriers for low-capacity end-users?

This chapter, based on a review of the literature, presents the analytical framework that will be used in this study to answer the central research question outlined in the previous chapter. Section 2.2 addresses the broader context of energy and development linkages. Section 2.3 brings out the policies and motives for government intervention in the delivery of energy carriers through providing policy instruments. Section 2.4 presents the institutional aspects of public sector reforms. Finally, Section 2.5 discusses the analytical framework used in deriving the three main research questions, which are then addressed in Chapters 4-6, and provides an introduction to Chapter 3 on the methodology used in this research.

\subsection{The Broader Context: Energy and Development}

As stated in Chapter 1, energy is vital for economic and social development. The conventional wisdom in the years after the Second World War equated development with economic growth. At the macro-level, economic growth required, among other things, an energy sector capable of delivering energy carriers and services to a wide range of end-users across economic sectors: industry, transport and communication, and agriculture.

Electrification plus the increased consumption of petroleum energy carriers was considered essential for realising the potential of industrialisation and economic growth (Barnett, 2000). Simultaneously, economic growth required a better quality of life and wellbeing for the people, and therefore it needed an energy sector capable of providing modern energy carriers to the people. Increased energy consumption can be seen as an indicator of improved human welfare. It appears that, without at least a minimal level of access to modern energy services (for consumptive uses such as lighting and cooking, and productive end-uses such as irrigation and industries), countries are unable to move out of subsistence economies (Goldemberg et al., 1987;Modi et al., 2005;Saghir, 2005).

However, the growing number of people classified as poor in developing countries in the 1970s, and the seeming inadequacy of the policy approaches that assumed a trickle down of benefits to these groups, led to a greater effort to directly improve income distribution. As such, the development paradigm shifted towards equitable economic growth in which social objectives were recognised as distinct from, and as important as, economic efficiency (Munasinghe, 2001). Moreover, drawing on several decades of development efforts, while at the same time trying to reconcile the tensions created in relation to environmental 
degradation, the concept of sustainable development ${ }^{25}$ emerged in the 1980s. This concept brought together the goals of economic and social development and environmental conservation.

\subsubsection{Energy and Development}

While the linear relationship between energy and economic growth has to a large extent been decoupled in developed countries, an increase in energy consumption continues to dominate the economic growth policies of developing countries ${ }^{26}$ (Toman and Jemelkova, 2003). Nevertheless, the impact of increased use of fossil fuels on environmental sustainability is also of paramount importance in the context of energy and development. In the rural areas of developing countries, energy access is an essential element of the social, economic and environmental dimensions of sustainable development. While access to modern energy carriers confers social and economic benefits, the lack of an energy transition from traditional energy carriers to modern energy forms is associated with environmental concerns related to health and ecosystem ${ }^{27}$ sustainability. Increased access to goods, services and information is considered essential in facilitating the eradication of poverty. However, the provision of these goods, services and information is hindered in part by a lack of access to improved energy services (Casillas and Kammen, 2010).

Energy contributes to social development by empowering people with knowledge, and by enhancing transport and communication facilities so that people are able to establish and maintain contacts and social relationships. The availability of modern energy carriers can strengthen local market infrastructure, education and healthcare facilities (Cabraal et al., 2005). It can not only have an indirect effect on the well-being of people through improved quality of life, it can also have a direct impact on gender equality through the availability of modern energy for meeting household energy needs and reducing women's drudgery (Cabraal et al., 2005;Matinga, 2010;Price, 2000). Energy can support economic development at the village level (Toman and Jemelkova, 2003) by improving productivity and enabling local income generation through increased agricultural outputs and through the creation of non-farm employment opportunities including micro-enterprise development (Johansson and

\footnotetext{
${ }^{25}$ Since its first emergence, in 1987, in the public arena, various authors have defined sustainable development differently(Pezzey, 1992). However, the definition "development that meets the needs of the present without compromising the ability of the future generation to meet their own needs" (WCED, 1987, 8) by the Brundlandt Commission (World Commission on Environment and Development, 1987) is most cited and the one used in this thesis. See Pezzey (1992) for a review of alternative definitions of sustainable development.

${ }^{26}$ Stern (2010), based on empirical literature, shows that energy used per unit of economic output has declined in developed and some developing countries. This is due to both technological change and to a shift from poorer quality fuels such as coal to the use of higher quality fuels, and especially electricity, as well as a transfer of the production of energy-intensive goods, such as steel, to developing countries.

${ }^{27}$ An ecosystem is a habitat that supports a particular set of species of plants, animals and microorganisms. Ecosystems provide many people, particularly the rural poor, with the necessities of life as well as providing sources of income. Ecosystems are considered instrumental for human wellbeing (Daily, 1997).
} 
Goldemberg, 2002). Indeed, non-farm employment is seen as an important contribution to making the transition from a subsistence economy (Rigg, 2006).

Energy is strongly linked to the environment, as the sound management of energy resources is essential if they are to be sustainable. Energy use affects the environment at local, national and global levels. The environmental impacts of energy use include indoor air pollution and poor urban air quality. At the national level, it includes resource degradation, such as an excessive use of freshwater, and air pollution due to industries, electricity generation and petroleum refining. Climate change impacts at the national level can have serious implications for food and water security in the medium to long term due to the variability in precipitation patterns and rises in temperature, which in turn will put additional pressure on natural resources (Mohan and Sinha, 2010). Emissions from fossil fuels transcend local and national levels boundaries to affect the global environment and contribute to climate change (Soni, 2007).

Despite the strong links between energy and the development of rural areas in developing countries, much of the debate on energy and development has remained confined to the macro- or national level (Barnett, 2000). The macro-level assessments of energy consumption and economic growth suggest that energy leads to development (rather than follows from, or being part of). However, at least at the national level, the evidence on causality is inconclusive (Kooijman-Van Dijk, 2008). In addition, the intricacies of energy and development at the village, or household, level, especially in terms of the intra-household dimension of gender equity, are less clear and under-researched.

Access to energy, although considered important in providing socioeconomic benefits, is missing from the United Nation's MDGs, which are aimed at reducing poverty and ensuring equitable social and economic development in developing countries (Modi et al., 2005). It has been argued that energy services are a "missing MDG" that needs to be addressed if countries are to achieve the sustained economic growth necessary to halve poverty and meet the other MDGs (Modi et al., 2005). As such, sustainable, reliable and low-cost energy services can be seen as an essential part of a multi-sectoral approach intended to meet the needs of social services $^{28}$, satisfy basic needs ${ }^{29}$ and promote productive uses of energy in agriculture, commerce and industry. Access to energy provides benefits to women and men in terms of reducing the physical effort and the time taken to perform many tasks related to their practical and productive needs ${ }^{30}$, and this will contribute to improving their well-being (Clancy et al., 2011).

${ }^{28}$ Such as clinics, schools and infrastructure related to clean drinking water.

${ }^{29}$ There is no universal agreement as to what constitutes a basic need, including whether or not energy should be included (Clancy, 2011).

${ }^{30}$ Practical needs are defined as those household end-uses that can be met by energy services, such as lighting, cooking and space heating/cooling. These energy services make tasks easier and can help save time and reduce drudgery. Access to these services has primarily a welfare function and does not challenge gender relations. Productive needs are end-uses which can also be met with lighting and space heating/cooling, as well as other services which save time and reduce drudgery (such as with transport, storage and processing). These energy services can increase production, improve the quality 
The assumption in the early years of development, that improvements in the economy through industrialisation, including large-scale energy infrastructure projects, would trickle down to benefit the poor proved false: there was little improvement in the lives of the poor including limited access to modern energy carriers (Goldemberg et al., 1987). Interventions related to rural energy have focused on the supply-side, with availability being the most important criterion, while demand-side issues such as equity of access have been largely ignored (Kooijman-Van Dijk, 2008). Recent data (UNDP/WHO, 2009 and IEA, 2010) show that vast numbers of poor people still lack access to any form of modern energy carrier for cooking (about 3 billion people) and lighting (about 1.5 billion people) despite the presence of country-level policies and programmes for universal electricity access and programmes for promoting clean cooking energy options. This limited access to energy results in two types of failures: firstly, an inability to meet the basic necessities of life; and, secondly, an inability, of the rural people in particular, to participate in economic activities that provide a reasonable rate of return on their produce and help them move out of poverty. With this lack of access to wider markets and a poor communications infrastructure, the rural population is unable to generate adequate surpluses.

At the local and household levels, the inequality in energy access forms another dimension of energy and development. This inequality is at two levels. Firstly, at the village level, only a few households have access to modern energy carriers and the majority have no access. To a large extent this can be viewed as the outcome of interventions by a government with limited budgetary resources and hence unable to create universal access. Secondly, at the household level, there are intra-household dynamics including the gendered division of roles and responsibilities, which usually places the responsibility for household energy provision on women and girls (Clancy et al., 2011). If dependency on biomass fuels continues, there are implications for health due to the resulting poor indoor air quality, which has been linked to high mortality rates ${ }^{31}$. The health implications are more severe for women and young children, especially infants, who are exposed daily to long periods of smoky conditions in kitchens (Haines et al., 2007;Smith, 2006;Smith et al., 2004).

\subsubsection{Energy Poverty}

There is no internationally agreed definition of energy poverty. However, a frequently cited definition is "the absence of sufficient choice in accessing adequate, affordable, reliable, high quality, safe and environmentally benign energy services to support economic and human development" (Reddy, 2000a, p 44). This definition of energy poverty provides a broader perspective on the issues of availability and affordability, and emphasises the ability to choose the form of energy for any specific end use. The definition also envisages an idealised

of products, and can create new economic opportunities, resulting in increased income (Clancy et al., 2011).

${ }^{31}$ Poorly ventilated kitchens and the inefficient combustion of biomass fuels (wood, crop residues and animal dung) can cause premature deaths and respiratory diseases (Smith, 2002). According to estimates, approximately 1.94 million premature deaths in developing countries can be attributed to indoor air pollution from the use of solid fuels for cooking (UNDP/WHO, 2009) 
situation and assumes that people are rational and use energy according to their paying capacity.

An alternative approach to understanding energy poverty would be to view it from the perspective of household energy security. Household energy security would include the basic minimum energy needed daily to cook sufficient food to meet nutritional needs, to boil enough water for drinking and hygiene, and to generate adequate lighting that allows people to extend their household activities beyond daylight hours for consumptive and productive end-uses. Below this level, a household can be considered to be in the state of energy poverty $^{32}$ (Clancy, 2011).

Reflecting on the attempts made to define energy poverty and the approaches used in the literature to measure ${ }^{33}$ energy poverty, this dissertation defines energy poverty in terms of low-capacity end-users access, viewed as a function of availability and affordability, to energy services. This definition of energy poverty is reinforced by the inclusion of links between energy access, gender and poverty that enhance the capability ${ }^{34}$ of low-capacity endusers to improve their quality of life. Energy poverty, when approached from the 'access'

${ }^{32}$ A similar approach was adopted in India for estimating the basic energy needs for cooking, lighting and heating, and so estimating norms for different end-uses. Based on these figures, estimates of energy needs and projected future energy demands, especially those of rural areas, were made. The report of the Advisory Board on Energy and the Energy Demand Screen Group used these per capita norms to define energy requirements and, moreover, the norms for entitlements and allocations of various energy carriers were based on these figures (GoI, 1985;GoI, 1986). In India, the Advisory Board on Energy (ABE) postulated a minimum level of energy consumption for the household sector, in terms of useful energy measured in kilocalories per person per day as $620 \mathrm{kcal}$ [0.72 kWh] for cooking, 30 kcal [35 Wh] for space heating and $30 \mathrm{kcal}$ for lighting (GoI, 1985). More recently, for household energy security, the Integrated Energy Policy (IEP) emphasises the need to provide lifeline energy for lighting and cooking requirements. The IEP postulates $30 \mathrm{kWh}$ of electricity per household per month for lighting and $6 \mathrm{~kg}$ of LPG, or its equivalent, per household per month for cooking (Planning Commission, 2006).

${ }^{33}$ In a review of the literature regarding the measurement of energy poverty, four approaches can be identified:

(a) Per capita energy required to meet the basic energy needs of cooking, lighting and space heating (Goldemberg et al., 1985; Revelle, 1976);

(b) Energy or fuel poverty line calculate from an income or expenditure poverty measure (Foster et al., 2000;Krugman and Goldemberg, 1983);

(c) Access to energy services (Annecke, 2003;Cecelski, 1995;Clancy et al., 2003); and

(d) An energy access - consumption/use matrix: a two-dimensional measure that divides the population into groups based on their access to different energy types and the useful energy per capita they consume (Pachauri and Spreng, 2004).

${ }^{34}$ There are number of ways in which poverty can be conceptualised. One approach that has been particularly influential within the development discourse is that of the Nobel Prize winning economist, Amartya Sen. Sen (1993) considers that poverty can be interpreted as a lack of capabilities. In particular, Sen argues that it is important to intrinsically value people's capabilities to function and not simply view poverty as only a matter of access to income, commodities or utilities (Sen, 1993). The issue of energy poverty can also be viewed from the perspective of capability: access to modern energy carriers enables the capability of people to move out of poverty. 
perspective, focuses on an individual's capacity to have a quality life. Building on Sen's (1993) definition of capability, and expanding that definition to include energy poverty (as defined in this dissertation) as: 'a reasonable quality of life can be conceptualised as a life free of factors such as indoor air pollution that affect health, having adequate nourishment from cooked food and safe drinking water, being informed and knowledgeable about social and economic development including access to price information, and enjoying personal security through improved illumination'.

Concerns related to energy poverty in the rural areas of developing countries started to gain momentum around 1995 when studies showed that a lack of access to sufficient and sustainable supplies of energy affected as many as $90 \%$ of the population (Barnes and Floor, 1996;Reddy, 2000a). A World Bank study in 1996 calculated that about 1.5 billion people, mostly in Asia and Africa, lacked access to electricity and more than 3 billion lacked access to clean and safe cooking fuels and depended on traditional biomass sources (World Bank, 1996). Recent studies from IEA (2010) and UNEP/WHO (2009) have indicated a similar number of people in developing countries still without access to modern energy carriers for cooking and lighting. One of the reasons for this apparent lack of change in levels of access is that the availability of modern energy carriers has not outstripped population growth. While there is progress in terms of enabling modern energy access globally, the sheer scale of energy poverty remains a concern. Energy poverty became a greater concern after 1999 as studies began to look at the linkages between the impact of the energy sector reforms and the role of energy in moving people out of poverty ${ }^{35}$. From a development perspective, energy sector reforms raised the question as to whether the private sector would be interested in addressing energy poverty given that, as a consequence of the reforms, they were expected to play a major role in the energy sector (Barnett, 2000;Tellam, 2000;World Bank, 2000).

Since 1945, energy access, particularly to electricity, has been considered as an important part of a broader 'social compact' between the state and society, and this was an important factor in governments becoming involved in energy delivery (see Section 2.3 and Chapter 4 for further explanation). However, at the time that policy reforms became part of a standard prescription for improving energy delivery, this social compact was unfulfilled in most developing countries. Despite the social concerns, energy policy was influenced by economic reforms and the issue of converting energy supply into a profitable business. The emphasis shifted to creating appropriate regulations for addressing the problems of inefficiencies in the energy sector and at the same time insulating the sector from political interferences.

${ }^{35}$ To move people out of poverty, energy access has to create economic opportunities, and these cannot be achieved through energy policies alone. Energy policies need to be supplemented and integrated with other development policies and programmes. A UNDP (2006) study shows that the scaling up, replicating and mainstreaming of energy services, provided by modern energy carriers, requires rural energy to be addressed as a rural development problem. In developing countries, the problems associated with rural energy are secondary to the livelihood needs (water, food, etc.) of communities. However, the origin of many development problems can be related to a lack of access to energy services provided by the modern energy carriers (UNDP, 2006). Energy access therefore becomes the entry point for other development interventions and simultaneously addresses the problems associated with the provision of energy services though the creation of complimentary inputs. 
On the global policy level, the interest in rural electrification and aspects of rural energy started to decline in the 1990s. However, as the policy shifts in the energy sector started to show negative impacts on energy access by poor households, coupled with political unrest in many developing countries, energy poverty linked to the lack of access to modern energy carriers returned to the political and global policy agenda (Barnes, 2007;IDS, 2003). This renewed attention to energy poverty was supported by the realisation that energy services are necessary to reach the $\mathrm{MDGs}^{36}$ (Modi et al., 2005).

Energy poverty became a part of the global policy agenda with the launch of a new global initiative by the United Nations Secretary-General in 2011. The new global initiative, "Sustainable Energy for All" by 2030 aims at mobilising ${ }^{37}$ action to address the issue of energy access by bringing together the critical actors - business, governments, investors, communities and academia. The objectives ${ }^{38}$ of the initiative are to (i) ensure universal access to modern energy services, (ii) double the rate of improvement in energy efficiency, and (iii) double the share of renewable energy in the global energy mix (United Nations, 2012). While a global consensus on addressing energy poverty emerged at the Rio+20 summit, the real challenge will be designing an action agenda to achieve these objectives. This will require a good understanding of the causes of energy poverty.

Broadly, three causes of energy poverty can be identified in the literature: (i) a rural subsistence economy and the cost of modern energy carriers (Barnett, 2000;Price, 2000;Reddy, 1999); (ii) the energy-gender linkage (Cecelski, 1995;Cecelski, 2004;Clancy et al., 2003); and (iii) a weak delivery infrastructure and weak institutional mechanisms (IEA, 2010; Jaccard and Mao, 2002;Saghir, 2005). These three causes are discussed in the remainder of this subsection.

\section{A Rural Subsistence Economy and the Cost of Modern Energy Carriers}

It has been argued that people are energy poor because they do not have the means to buy modern energy carriers even if they are available (Barnett, 2000). The availability of energy carriers in itself does not guarantee their adoption, primarily because households have to have the paying capacity (affordability). It is assumed that low-capacity end-users would use and

\footnotetext{
${ }^{36}$ Another trigger was the emergence of equity dimension in international climate policy. Developing countries emphasise their right to development, including the need to provide energy access to move people out of poverty (Casillas and Kammen, 2010;Haines et al., 2007).

${ }^{37}$ Since the launch of the Sustainable Energy for All initiative, other organisations and countries have launched programmes. The European Commission has announced a new initiative called 'Energising Development' that sets an ambitious goal - to help provide access to sustainable energy services to 500 million people by 2030. Brazil with its 'Light for All' programme has provided electricity to about 15 million people. India has recommitted itself to a national vision of electricity for all. Both China and India are taking key initiatives to increase the share of renewable energy in their energy mix and to develop policies and programmes to promote energy efficiency.

${ }^{38}$ The objectives of 'Sustainable Energy for All' are guided by three principles: (i) fostering a technologyneutral approach within a climate conscious setting; (ii) filling policy, capacity and financing gaps, and delivering transformational change; and (iii) encouraging a broad agreement and strong coordination with full discourse and transparency.
} 
benefit from modern energy carriers if they had the capacity to afford them. Another aspect is that it appears that the benefits generally only accrue if supported by complementary inputs ${ }^{39}$.

In rural areas, agriculture and forest products, and in some locations fishing, along with limited local economic opportunities, are the primary livelihood sources ${ }^{40}$. Most of these activities are part of a subsistence economy ${ }^{41}$ that does not generate surpluses and thus limits a household's purchasing power and ability to interact with markets beyond their immediate locale. In remote rural areas, many people depend largely on forest products to supplement subsistence agriculture, and again these are traded locally with limited opportunities to participate in markets. The lack of organised economic activities and small-scale enterprises, in which energy supply often plays a vital role, also restricts participation in more distant markets and the generation of economic surpluses (Kooijman-Van Dijk, 2008). Having a very limited disposable income restricts the capacity to buy modern energy carriers, and this in itself is a root cause of energy poverty. This negative coupling of a lack of income and a lack of modern energy carriers has been referred to as the 'vicious circle' of energy poverty (Figure 2.1).

Unlike modern energy carriers that have to be bought, traditional energy carriers such as biomass fuels are locally available and often gathered at zero monetary cost ${ }^{42}$. In addition to the up-front access costs for an energy carrier (for example LPG) or energy service provider

${ }^{39}$ The World Bank's EnPoGen report, based on fieldwork in rural China, identifies the key role of 'complementary inputs' alongside energy interventions in poverty and gender relations (IDS, 2003). These complementary inputs are location-specific. The complementary inputs that have been found to have an impact on energy access are the direct physical infrastructure, such as roads and communication, health clinics and schools, plus supporting facilities, such as markets, financing and credit mechanisms, training and skills development and qualified personnel. In this dissertation, complimentary inputs are viewed similarly to contextual influences, which will be discussed in Section 2.5.3.

${ }^{40}$ A livelihood comprises the capabilities, assets (including both material and social resources) and activities required for a means of living (Chambers and Conway, 1992).

${ }^{41}$ A subsistence economy amounts to production for self-consumption with low specialisation, traditional technological inputs, with a particular reliance on human or draft animals, and low productivity, and therefore results in very little cash income (Ben-David, 1998). The driving force in a subsistence economy is survival. However, many rural economies are of a dualistic nature with the subsistence economy often operating alongside a market economy producing commodities for urban and export markets. The dependency of people on the subsistence economy increases their vulnerability to any form of natural disaster, extreme weather event or political upheaval that leads to a loss of resources. In the context of India, the subsistence economy is closely linked to subsistence agriculture. Those who have access to small plots of land have limited means for production (often relying on manual labour and rain-fed crops) and the level of output is only sufficient for survival. Such households, relying on subsistence agriculture, plus landless households forms the majority of those classified by the government as Below Poverty Line (BPL).

${ }^{42}$ However, this does not take account of the cost of the time spent gathering biomass, or the loss of an economic opportunity because of the time spent elsewhere. As the resource becomes sparse, the time spent in gathering it increases. The monetary cost also fails to reflect the drudgery and danger in gathering energy carriers, especially for women and girls who generally have the responsibility within the household for collecting biomass (Clancy et al., 2011). 
(for example electricity), low-capacity end-users have to pay recurring costs (the cost of refilling an LPG cylinder or the monthly electricity bill) plus the investment required in new equipment and appliances to use with modern energy carriers (Price, 2000). This requirement for cash in order to access modern energy carriers can make them less appealing than biomass.

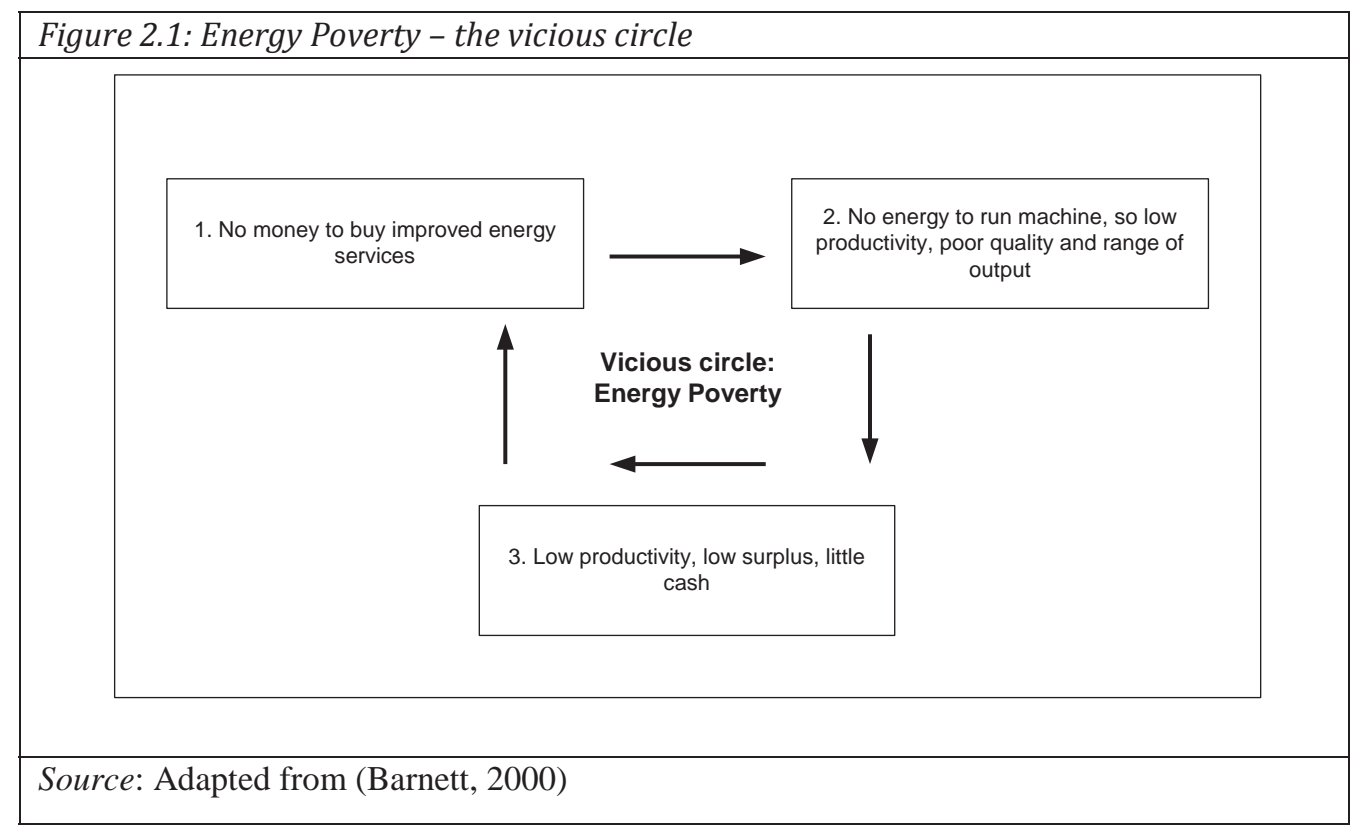

Energy prices have been identified as the main determinants of energy use and in the choice of energy carriers (Imran and Barnes, 1990). Studies have shown that the poor pay proportionally more for energy access ${ }^{43}$, either in monetary terms or in the form of labour (Saghir, 2005). Any change in energy prices (for example by reducing or removing subsidies) brings financial shocks to household budgets. Such shocks can have an adverse effect on modern energy access by low-capacity end-users, and may even result in a 'backward switch' to traditional energy carriers (Sathaye and Meyers, 1990). A household may also respond to such shocks by lowering its energy use, which could mean fewer cooked meals and less boiled water, with the consequent adverse effects on health (Clancy, 2011).

Low-capacity end-users, and particularly those un-served, generally lack access to the credit they need to pay the connection costs. Worldwide, the financial sector generally fails lowincome groups by developing financial products and solutions to which poor households are excluded because they are unable to meet the entry conditions (Price, 2000). Although efforts have been made to link micro-credit ${ }^{44}$ to energy access, the empirical evidence suggests that

\footnotetext{
${ }^{43}$ According to a World Bank study, poor households in India spend about 4\% of their household income on lighting compared to less than $0.5 \%$ by the wealthier households (World Bank, 2002).

${ }^{44}$ Micro-credit is the extension of very small loans to poor people who lack collateral and have very limited disposable income from their employment/livelihood activities (Sriram and Fisher, 2002). Micro-credit usually varies from a few dollars to hundreds of dollars, and often loaned for just a few 
micro-credit has not been effective in instigating a large-scale transition to modern energy carriers by households (Rao et al., 2009). This may be because the sums involved in microcredit are generally too small to enable energy access (Clancy, 2011).

\section{Energy - Gender Linkage}

Poverty related to access to energy has a particular gender ${ }^{45}$ dimension. Energy and gender are linked in many diverse ways, particularly through the nature of the energy resource base, characteristics of the household and community economies, features of energy policy, and the socially determined position of women in the household and in society. Energy services based on modern energy and improved technologies have the potential to positively influence two specific aspects of women's and men's lives: time-use, with its links to reduction in drudgery and improvements in wellbeing, and economic opportunities. These two issues are linked.

The continued use of traditional forms of energy carriers is associated with an undervaluation of women's time by the household. The linkage between the time that women spend collecting traditional forms of energy carriers and time spent in managing household energy has been neglected for many years in policy planning as well as in energy policy implementation (Clancy et al., 2003). Energy is a critical input at the household level, especially in the daily lives of women who need energy for their household activities such as cooking and space heating, for access to clean and safe drinking water, for activities associated with agriculture including post-harvest processing, and for commercial end-uses such as milling and activities that require process heat. Limited access to modern energy carriers has a disproportionate effect on women and girls because, in most societies, they carry the responsibility for household energy provision for the services energy provides for a family's wellbeing (Dutta and Oparaocha, 2010). In the absence of access to modern energy carriers and the services they provide, women devote long hours to unpaid household and farming tasks, leaving little time for other activities including recreation and leisure.

days. The scale of micro-credit depends upon various factors such as the deposit made by the members and their linkages with banks or other micro-finance institutions for leveraging loans/co-financing. In India, the Reserve Bank of India has defined micro-credit as the provision of very small amounts of thrift, credit and other financial services and products to the poor in rural, semi-urban and urban areas for enabling them to raise their income levels and improve their living standards (Reserve Bank of India, 2010). Poor households are unable to link energy access with micro-credit because poor households cannot borrow for consumptive purposes (such as household food delivery) since microcredit is targeted at productive end-uses.

${ }^{45}$ Gender is a concept that refers to a system of socially defined roles, privileges, attributes and relationships between men and women that are learned rather than biologically determined. Gender cuts across social identity, intersecting with a range of other identities including class, race and ethnicity, age, religion and family structures. Gender roles are not universal nor are they static: they vary in degree from society to society and change over time (Clancy, 2011). 
The energy-gender ${ }^{46}$ linkage encompasses the differences in the way energy is perceived by men and by women. Historically, issues related to energy access have been regarded as the preserve of men, and the differences between men and women, and between boys and girls, with regard to access and control over energy resources have not been recognised (Annecke, 2003). In fact, most of the early discourses on gender and energy were limited to women and energy with a focus on traditional energy fuels and devices (cookstoves, for example, were prominent). However, the emerging paradigm of gender and development served to extend the linkages to demand-side issues, and later it encompassed a broader range of issues including pricing, transport and modern energy carriers (Cecelski, 2004). Men and women not only have different energy needs based on the gender division of labour but also different access to resources and decision-making processes to satisfy those needs (Clancy et al., 2003).

The gender inequality in energy access is part of the gender inequalities prevalent in society and within households ${ }^{47}$. Decision-making in homes and at the community level places monetary decisions and control in the hands of men: women $^{48}$ have less access to productive resources as well as to education, training and information. The gendered division of labour in the household makes women responsible for household energy provision. However, even when an energy type or energy technology that is predominantly of direct relevance to women (for example in their traditional role in cooking) is to be bought, men $^{49}$ enter the decision making process (Clancy et al., 2003).

Another negative aspect of the limited transition to modern energy carriers concerns the trade-off between investing in time-saving energy carriers and the unpaid labour of women and children (especially girls). In rural areas, since most women's involvement in economic activities is in agriculture, and largely seasonal, women can spend several hours a day

${ }^{46}$ Despite efforts to move the debate on from women in development to gender and development, gender issues have largely been concerned with women, particularly women as a subordinated group.

${ }^{47}$ An important understanding of intra-household dynamics and negotiations comes from Amartya Sen's argument of cooperative conflict, which captures gender inequality within the family and ultimately in society at large. As Sen (1990) noted, women and men have both congruent and conflicting interests affecting family living. Given the extensive areas of congruent interests, decision-making in the family tends to take the form of the pursuit of cooperation, with some agreed solution, usually implicit, of the conflicting aspects (Sen, 1990). Extending the idea of cooperative conflict to energy access, it can be argued that enhanced access to modern energy might in itself contribute to changing power relationships at the household level.

${ }^{48}$ Women make up a significant majority of the economically poor, with limited rights to productive assets such as land, livestock and energy infrastructure. Women account for $70 \%$ of the 1.3 billion people living on less than a dollar a day, earn only $10 \%$ of the world's income, and own only $1 \%$ of the world's property; they account for two-thirds of all illiterate people and lack access to credit, jobs and business opportunities (Clancy et al., 2003).

${ }^{49}$ Although cooking is usually a woman's task, men will often determine the type of stove if one is to be purchased (Tucker, 1999) and when to buy it (Dutta and Oparaocha, 2010). However, in the case of a traditional mud stove, constructed at home by women, decisions on matters such as the source of raw material (obtained free of cost) and the location of the stove are all taken by women (Dutta and Oparaocha, 2010). 
collecting biomass. The argument for providing modern energy carriers is often linked to their adoption for economically productive purposes. However, the productive activities targeted tend to be those of men, for example agriculture, where the involvement of women is restricted to labour and constrained by the lack of land ownership ${ }^{50}$.

Despite concerns about the complexity of such interrelationships and the acknowledgement of the importance of including women's and men's interests, and needs, in energy policies and programmes, gender analysis has been largely excluded ${ }^{51}$. The emerging approaches to energy policy increasingly emphasise access to modern energy for energy services from an equity perspective, and the need to ensure that energy security enables low-capacity endusers to access modern energy. Within this emerging policy context, there is no place for social and cultural limits on the opportunity cost of women's labour; the emerging policy, for example, seeks to promote those end-uses of commercial energy that directly increase women's productivity in income-generating activities (Kelkar and Nathan, 2005). The resulting increase in the opportunity cost of women's labour is predicted to promote household adoption of improved biomass technologies, the commercialisation of fuels, and a switch to modern cleaner fuels with their attendant health benefits. Clancy et al., (2011) have argued that the lack of attention to gender in energy sector policy ${ }^{52}$ can be attributed to three reasons. First, the lack of gender-disaggregated data. Second, the lack of awareness of the benefits to be gained from incorporating gender analysis in energy policy and project design. Third, the energy sector lacks knowledge on gender mainstreaming.

\section{Weak Delivery Infrastructure and Organisations}

A third cause of energy poverty can be attributed to the limited availability of infrastructure and organisations involved in the delivery of modern energy carriers. Developing countries ${ }^{53}$ have weak and limited transport, communication and market infrastructures, which result in

${ }^{50}$ For example, in South Asia, land inheritance is male-dominated (Agarwal, 1994). Electricity connections for irrigation will be provided to landowners. Therefore, except in the relatively few women-headed households, land always belongs to the male member of the family, and the electricity utility will provide the electricity connection to the land owner and the connection for domestic supply to the head of the family. There is, however, some contrary evidence from urban areas in India with respect to LPG connections: before 1999, when LPG cylinders were always in short supply, urban households had multiple LPG connections, each in the name of a different household member (World Bank, 1999).

${ }^{51}$ In India, a gender audit of the national energy policy identified a lack of attention to gender and provided recommendations for integrating energy-gender linkages into the policymaking process (Parikh and Sangeeta, 2008).

${ }^{52}$ This is further discussed in Chapter 4 in the context of India's energy policy.

${ }^{53}$ In developing countries, a conventional development approach is followed where technical and financial support are channelled through national and sub-national level governments, with inadequate understanding of the contextual realities of rural areas (UNDP, 2006). The neglect of field realities results in unsustainable supply-driven energy delivery infrastructure, with organisations implementing top-down decisions with little flexibility to innovate. Having infrastructure and organisations available for energy delivery has a positive impact on energy availability and reliability, and this results in reduced poverty impacts (Brenneman and Kerf, 2002). 
the delivery of modern energy carriers being affected and often inefficient. According to a report by Practical Action ${ }^{54}$, multiple inter-related organisations are needed to deliver modern energy carriers (and associated equipment and appliances), for providing energy services, to people in rural areas. The absence of infrastructure and organisations results in either underdelivery of modern energy carriers or the use of alternative energy choices that provide suboptimal energy access. For example, in remote regions of rural areas, extending grid electricity is often considered economically unviable and, as a result, alternative decentralised energy options such as diesel, biomass, micro-hydro and solar lighting systems are used to provide electricity. Solar lighting systems, in particular, are used to provide electricity access because they are small-scale and modular and so can be installed at the individual household level. However, solar lighting systems are adequate only to meet basic lighting energy services and not able to meet other productive energy requirements or the main energy demand in households: cooking. Similarly, a lack of an adequate transport infrastructure results in intermittent supply of modern energy carriers such as LPG and kerosene oil to rural areas.

Organisations involved in the delivery of modern energy carriers also have an impact on energy access. As developing countries tens to follow a centralised planning model for development, organisations are driven by top-down policies and guidelines for the implementation and delivery of modern energy carriers. As a result of this top-down model, the organisations involved have limited institutional flexibility to modify or amend policies and programmes to meeting the local social and economic contexts. Governments in developing countries have often used externalities and the public benefits argument associated with modern energy carriers to provide energy access in rural areas (Jaccard and Mao, 2002) ${ }^{55}$. To provide these modern energy carriers, a range of organisational arrangements ${ }^{56}$ for their distribution, through a combination of technological solutions and economic instruments such as subsidies and entitlements, are created to make them affordable and available.

Studies reviewing developing country experiences in implementing energy access programmes have shown that a lack of an appropriate policy framework has resulted in additional bottlenecks in the form of inappropriately designed organisations for the delivery of modern energy carriers (IEA, 2010;Saghir, 2005). The availability of energy carriers is linked to the delivery organisations: a reliable delivery mechanism and the consistent

${ }^{54}$ The Poor People's Energy Outlook (PPEO) by Practical Action proposes, from an ecosystem approach, the concept of Total Energy Access and describes the inter-connected network of organisations working on supplying modern energy carriers to people. The report argues that the existing delivery infrastructure and organisations are weak with limited innovation and flexibility. If energy access at the scale desired is to be achieved, then there is a need for a transition to a vibrant network of interconnected organisations resulting in inclusive and sustainable market systems (Practical Action, 2012).

${ }^{55}$ This will be further elaborated in Section 2.3.

${ }^{56}$ Enhancing energy access does not necessarily require new delivery mechanisms or organisations. Enhanced energy access could be achieved by strengthening or re-orientating the capacity of existing organisations and establishing an enabling policy framework with an emphasis on decentralisation to improve energy availability and create choice for low-capacity end-users (UNDP, 2006). 
availability of energy carriers allow people to choose between energy carriers. Choice to decide on which energy carriers to purchase and use is an important dimension of energy access (Pachauri and Spreng, 2004). A report by UNDP (2009) states that national policies often neglect decentralised organisations and local actors in energy delivery and, as a result, energy delivery is inefficient. National policies that promote the decentralisation of development planning and service delivery could be effectively integrated in expanding energy access and creating choices for people in rural and remote areas (Havet et al., 2009). The current combination of infrastructure and organisations creates a weak delivery mechanism for modern energy carriers in rural areas and results in the energy sector being inefficient in terms of energy delivery. This combination of a weak delivery infrastructure and organisations further links with the economic efficiency argument for reforming the energy sector as discussed in Section 2.3.

\subsubsection{Energy Poverty and Policy Reforms}

The causes of energy poverty as presented above highlight the inequalities that need to be addressed in order to make energy policies effective and improve access to modern energy carriers. The lack of access to reliable and high quality modern energy carriers often acts as a barrier to the rural population participating in economic activities and improving their social wellbeing. Energy poverty is, in most respects, no different from poverty related to food and for that matter to other basic needs. However, whereas it has been possible to target nonenergy forms of poverty through transfers, subsidies and cash payments (Srinivasan, 1994), attempts to address energy poverty seem to have resulted in substantial benefits to the nonpoor, at the cost of the state exchequer.

Energy sector policies have been part of the larger public policy debate that is shaped by the different natures of organisations and views on workable solutions to the problem. At the core of the issue are the roles of the government and of the market. The way in which the energy sector is regulated, and prices are set, has important implications for access, both direct (affecting the affordability of access) and indirect (affecting the possibility of access). Another critical element in energy access is the energy-gender linkages and the involvement of women, an aspect that has been missing from the entire policymaking process (Dutta, 2004; Oparaocha and Dutta, 2011).

Energy policy needs to be aware of these issues. Merely emphasising energy supply and improving availability will not be sufficient because the availability of modern energy carriers will, in itself, neither reduce drudgery nor enhance women's participation in incomegenerating economic activities unless supported by mechanisation and access to appropriate technologies. The energy sector policy reforms that started in developing countries in the 1990s are aimed at removing economic inefficiencies, and these will be further discussed below (in Section 2.3). These policy reforms were expected to increase the prices of energy carriers in the short-term, but were seen as likely to benefit consumers in the longer term through better services and lower prices. Therefore, at least in the short-term, the energy reform policies could be expected to harm low-capacity end-users in terms of their ability to purchase modern energy carriers. Such a 'shock' could result in a backward shift away from modern energy carriers. The linkage between regulation of the energy sector and its 
implications for access is also determined by the characteristics, capabilities and culture of the modern energy carriers themselves, and this will be further discussed in Section 2.4.

\subsection{Institutional Aspects of Public Sector Reforms ${ }^{57}$}

After the Second World War, a trend began in which governments, particularly in countries that were emerging from a period of colonial occupation, established state-owned enterprises to provide many goods and services. In particular, those goods and services related to infrastructure, which were considered cornerstones of economic development: utilities (energy and water), transportation (railways, airlines and buses) and communications (telephone, telegraph and post) (Kohli, 1987;Stiglitz, 2002a). While for many governments the rationale was primarily ideological, there were also economic arguments advanced for this pattern of ownership in developing countries. Firstly, infrastructure development is capital intensive, and financial capital from private lenders was in short supply in developing countries so only the government was able to provide the necessary capital. There were also uncertainties about these economies, such as market size, unreliable supplies, lack of skilled labour and of technology that made outside investors reluctant to invest (Bardhan, 1992). Governments took on the role of supplying capital, either from the public purse or through soft loans from international lending agencies such as the World Bank.

As the development process began to unfold, it became apparent that those markets that were allowed to flourish outside the public sector were not necessarily producing and delivering certain essential or wanted goods and services, and nor were they producing a socially acceptable distribution of income. These so-called 'market failures" ${ }^{58}$ provided the rationale

${ }^{57}$ These institutional aspects of public sector reforms stem from New Institutional Economics, an idea that addresses government failures and economic efficiency. The main argument is that government ownership is a less efficient way of organising production than private ownership. New Institutional Economics is often associated with the works of Ronald H. Coase (1937), Frederick von Hayek (1948), Harold Demsetz (1967), Oliver E. Williamson (1975) and Douglas C. North (1990). These authors contend that the standard Neoclassical Economics approach, based on the rational choice model, needs to be extended and modified, but not completely abandoned: "The analytical framework for New Institutional Economics is a modification of neoclassical theory. What it retains is the fundamental assumption of scarcity, and, hence, competition and the analytical tools of microeconomic theory. What it modifies is the rationality assumption" (North, 1993: 359). While the New Institutional Economics approach addresses economic aspects, another dominant sub-stream that lends itself to addressing the institutional aspects of public sector reforms is the Neo-Institutional approach, which focuses on cultural and historical aspects of development.

${ }^{58}$ Market failure refers to situations where the assumptions of a perfect market (a market will reach an equilibrium in which the supply of every product or service, including labour, equals the demand at the current price) do not hold true. Market failures can be viewed as scenarios in which the individual pursuit of self-interest leads to inefficient results - ones that can be improved upon from the societal point of view (Krugman and Wells, 2006). Market failures are often associated with information asymmetries (Akerlof, 1970;Stiglitz, 1997), non-competitive markets, principal-agent problems, externalities and public goods. Market imperfection, as an economic notion, refers to possible mismatches between what the market supplies and what fully informed rational consumers would 
for a new round of government interventions. Intervention was also justified on the basis of a similar argument to that originally used for state ownership: that the government can mobilise more capital, and at a lower cost, spread the risk over all citizens, reduce duplication of resources in providing similar services, and protect consumers from the potential market power of producers (Jaccard and Mao, 2002). A model of government intervention ${ }^{59}$ in markets after the Second World War, coupled with state ownership of key resources and enterprises, was then integrated into a framework for development planning that would produce a path leading to the economic growth deemed necessary for development (Todaro and Smith, 2003). This model continued to dominate many developing economies for thirty or more years.

However, towards the end of the 1970s and at the beginning of the 1980s it appeared that government interventions were exacerbating rather than solving the problems linked to market failures. Empirically, it appeared that the developing countries that had prospered were those that had generally limited state interference and allowed the private sector a larger role in economic development (World Bank, 1991). These negative views about the role of government in the economy coincided with the re-emergence of free market economics as the dominant economic paradigm, particularly in the Bretton Woods institutions which began to attach conditionalities to loans, such as market liberalisation linked to public sector reform (Williams and Ghanadan, 2006). Since the 1980s, the trend worldwide has been to reduce the role of government based on the economic efficiency argument. However, the responses by developing countries have varied, to a large extent depending on their domestic economic situation as well as pressures from international lending agencies ${ }^{60}$.

\subsubsection{Economic Efficiency as a Motive for Reforms}

The free market paradigm drew on two propositions to support the arguments for public sector reforms: firstly that private enterprises are more efficient than public enterprises at organising production ${ }^{61}$, and secondly that governments would benefit from budgetary and administrative advantages (Frank and Bernanke, 2004;Stiglitz, 2002a). The theoretical

demand. This may be extended to include problems of missing markets, inequalities and lack of coordination (Shirley, 1999). Market failures indicate that the market has failed to produce and deliver certain necessary or wanted goods and services, and has not generated a socially acceptable distribution of income, thereby creating a situation in which governments, for political reasons, feel a compulsion to intervene.

${ }^{59}$ Such government interventions assumed that the government was able and committed to a policy aimed at maximising social and economic development and a fair and acceptable distribution of income.

${ }^{60}$ In the energy sector, and particularly in the electricity sector, privatisation and competition were viewed as important elements of the reform process, regardless of differences in the socioeconomic and political contexts of developing countries (ESMAP, 1999).

${ }^{61}$ Both the market and government interventions have their advantages and constraints (Buchanan 1988). Efficiency (or inefficiency) cannot alone be an independent criterion for market and government failure since other social and political factors influence these failures. "By comparison with idealised standards, both markets and politics (government) fail... such recognition directs attention to comparative institutional analysis and to the structure of the set of constraints within which either market or political (government) behaviour takes place" (Buchanan, 1988, 12). 
underpinnings of public sector reforms are based on three mainstream theories of New Institutional Economics: property rights, agency theory and transaction cost theory (Box 2.1). While the property rights literature and the agency theory focus on building incentives to promote economic efficiency, transaction cost theory argues for alternative modes in organising economic transactions to achieve efficiency.

\section{Box 2.1: Theoretical Underpinnings of Public Sector Reforms}

Property Rights: According to the property rights literature, government-owned enterprises are inefficient mainly because they lack a 'residual claimant': no one can clearly claim the residual benefits or surpluses (Shirley, 1999). Since nobody benefits from an efficient operation of government-owned enterprises, the management has no motivation to devise adequate incentives to motivate employees to improve their performance. Moreover, with no competition for corporate control, there are no threats to underperforming managers (Vickers and Yarrow, 1991). Policies for public reforms bring about changes in the allocation of property rights, which lead to clear goals and a different set of incentives for management and for introducing accountability.

Agency Theory: Agency Theory suggests that organisations face problems because principals entrust tasks to agents, which they do because the principals have neither the time nor the ability to undertake the tasks. As a result, agents have opportunities to misrepresent information and divert resources for personal benefit. A related theory of public choice suggests that stakeholders in a government-owned enterprise will use their powers to further their own interests rather than working towards boosting the efficiency of the enterprise or of the sector (Boycko and Vishny, 1996;Peacock, 1992).

Transaction Cost Theory: Transaction Cost Theory sees the transaction $\operatorname{cost}^{62}$ as the basic unit of analysis for the structure of an organisation or its operations. The theory holds that understanding how to economise on transaction costs is central to understanding organisations. Transactions costs make it possible to assess how the governance structures of an organisation serve to economise on costs (Williamson, 1997).

\section{"Private Enterprises are more efficient than Public Enterprises"}

The economic efficiency argument believes, since private enterprises are profit-oriented (and competitive) and can choose to operate on a scale determined by market forces, and so benefit from economies of scale, that they tend to be more efficient than the public sector 63

${ }^{62}$ The concept of transaction costs differentiates New Institutional Economics from the Neo-Classical approach (Rutherford, 1992;Rutherford, 1995). Ronald Coase is viewed as making the crucial connection between institutions, transaction costs and neo-classical theory (North, 1993;Rutherford, 1992). Initially, Coase observed that the information available (in markets) is incomplete and that there were costs incurred in obtaining such information. Transactions, and the associated costs, were the central object in Coase's analysis for explaining economic behaviour (Coase, 1937). According to Coase, an efficient market can only be achieved when there are zero transaction costs, and actors will only achieve an efficient equilibrium, regardless of the governance structure, when the conditions of costless bargaining are met. Coase argues that it is because transaction costs are never zero that institutions exist (North, 1990;North, 1993).

${ }^{63}$ This is a contested assertion. See, for example, Buchanan (1988) where the failures of both markets and governments are discussed. In the energy sector, the experiences with deregulation in the electricity sector and their failures in developed countries (California electricity crisis, market failures in highly 
(Boubakri et al., 2008). Competition and a profit orientation are considered to foster economic efficiency by forcing producers to innovate and adopt advanced technologies in order to give them the greatest likelihood of surviving and competing in the future (Schumpeter, 1942;Stoneman, 1983;Williams and Ghanadan, 2006). In contrast, public enterprises tend to be monopolistic and hence lack competition, as well as operating on a scale determined by the government that may well not be optimal, the result of which is economic inefficiency ${ }^{64}$.

A related argument for economic efficiency relates to transparency ${ }^{65}$. Transparency stems from the lack of public control over three critical governing processes: policymaking and decision-making, execution of the decisions made, and regulation of this execution. This lack of public control arises from inadequacies and the breakdown of mechanisms for ensuring transparency and accountability ${ }^{66}$ (Dixit et al., 2001). Public sector policies are considered to suffer from irrational decisions, and weak implementation and regulation, leading to inefficiencies. Public sector reforms often emphasise transparency in order to reduce the problems of rent-seeking and pilferage in implementation. In the absence of transparency (and accountability), there is a danger that policy reform efforts may lead to inefficiencies and imperfect market conditions.

\section{"Budgetary and Administrative Advantages"}

Government interventions involve the use of policy instruments to achieve policy objectives. In the process of compensating for market failures, governments absorb losses incurred by the public enterprises, provide subsidies to help those on low incomes to access essential goods and services, and make investments from the government budget to develop infrastructure. Therefore, it is argued, governments could, through public sector reforms, deliver budgetary advantages by reducing subsidies, cutting losses and possibly switching public funds to social sectors such as education and health in rural areas (World Bank, 2000). This budgetary advantage argument has been the most commonly used rationale for motivating governments in developing countries to reform the public sector (Jaccard and Mao, 2002). The administrative advantage comes from public enterprises being reformed or

competitive reform experiments such as in the United Kingdom and Norway) raised concerns regarding the market's ability to coordinate reliability and long-term planning (Williams and Ghanadan, 2006).

${ }^{64}$ Economic inefficiency implies the non-utilisation or incomplete utilisation of resources for production of goods and services, therefore creating an economic system which does not necessarily result in a socially desirable distribution of resources from an equality or wellbeing of society perspective.

${ }^{65}$ From a political economy perspective, transparency equates to the functioning of government, or any other organisation, in a manner where it is an open and easy process for others to see the actions that are being performed. If the actions of the government, its budget, its laws and its decisions are open to discussion and public scrutiny, then the system is judged as transparent and there is limited opportunity for the authorities to abuse the system for their own interests (Stiglitz, 2002b).

${ }^{66}$ A lack of transparency is also attributed to the absence of public participation in the policy process (Dixit et al., 2001). 
privatised, which then allows governments to reduce their size and to more optimally use their scarce resources (Birdsall and Nellis, 2003).

However, there are other rationales, including quality of service and management advantages, that can be advanced as arguments in favour of public sector reforms (Boorsma, 1994). Quality of service is linked to the structure and competition in the private sector, with competition delivering the motivation for change in service quality (Birdsall and Nellis, 2003). However, the quality of service will be dependent upon the nature of the policy reform and the characteristics of the goods and services affected by the reform (Boorsma, 1998). The management advantage, on the other hand, stems from the fact that private enterprises face less bureaucratic interference than government-owned enterprises (Boycko and Vishny, 1996; Soubbotina, 2004). Private enterprises use decentralised decision-making, and are therefore flexible in adjusting to market forces - providing services that respond to market demands. In government-owned public enterprises, not only bureaucratic and political interference but also the existence of hierarchical problems due to vertical integration make such enterprises less flexible and slower in responding to market demands.

In developing countries, the argument for increased market participation includes the raising of investment capital as private sector investment is seen as a supplement to government funding. At the same time, government budgets could be released to meet obligations for social-sector funding. Private sector investment (mostly through foreign direct investment) was seen as a way for governments to bridge the gap between the investments needed and the available public-sector funds (Williamson, 1994). Particularly in the energy sector, another set of arguments for market participation revolves around reducing political interference and corruption in addressing the problems of non-performing public investments, tackling issues such as rent-seeking, reducing losses, improving performance and streamlining operations (Phadke and Chella Rajan, 2003).

Public-sector reforms require a political will to implement the changes. The role of political power in the economy plays a critical function in shaping policies. In determining economic policies, there will typically be conflicts of interest among different groups and individuals in society: those who have the strongest political power ultimately determine the set of economic policies to be implemented. Especially in the context of developing countries, political influence on the functioning of public sector enterprises is very high, and reforms and policy measures can be seen as curtailing the power enjoyed by political actors (Bardhan, 1998;Bardhan, 2006;Kohli, 1989). The nexus between the bureaucratic and the political actors has been seen as the biggest obstacle to public sector enterprise reforms, and privatisation has emerged as a solution to break the nexus (Ramesh, 2004). Ideological perspectives also influence public sector reforms and these are influenced by political interventions, the environment and the context.

However, as the reform agenda gained prominence globally, several countries remained cautious in pursing reforms across the economic and social sectors of their economies, believing that the socioeconomic conditions and the political dimension were not ready for market reforms (Stiglitz, 2002a). In South Africa, for example, the electricity sector moved from being state-owned to a market organisation and then back to state control when the 
government recognised that privatisation alone would not address the challenges facing the electricity sector, unless it was supported by appropriate regulations from the state (Eberhard, 2005).

\subsubsection{Government Delivery of Energy Carriers}

Governments choose ${ }^{67}$ not only which goods and services to deliver to their citizens, but also how to deliver those goods and services. Governments, because there is no perfect market, intervene in the provision of goods and services through rules, regulations and policy instruments to counter market failures ${ }^{68}$. Developing countries are faced with the challenge of simultaneously addressing poverty eradication and economic growth. As was shown in Section 2.2, modern energy carriers are a key input for economic and social development, including poverty eradication, and these have therefore frequently been the focus of government interventions. Government intervention in the delivery of energy carriers, especially in the context of developing countries, rests on two sets of arguments. The first reason for intervening emerges from the public benefits that access to energy carriers can bring. Markets, on the other hand, view these social and public benefits as market distortions. The second reason for intervening relates to the barriers and transaction costs involved in gaining access to modern energy carriers. These two arguments have dominated the reasoning behind government interventions in the energy sector in developing countries (Bacon and Besant-Jones, 2001) and will consequently be elaborated upon in the next two subsections.

\section{Public Benefits of Energy}

In the arguments supporting a role for government in the energy sector, energy is considered a regulated public good ${ }^{69}$. As a regulated public good, energy has certain attributes that are of the nature of public benefits - providing access to services such as communications, health and education. Nevertheless, governments intervene in providing access to modern energy carriers, through subsidies for energy production and for extending energy distribution systems, for many reasons (Jaccard and Mao, 2002). Governments may subsidise energy carriers, and sometimes the acquisition of energy-efficient end-use devices, because they provide social and development benefits (improving indoor air quality, slowing deforestation,

${ }^{67}$ Economic theory offers three distinct justifications for government intervention: ensuring optimal production of goods and services, correcting or offsetting market failures, and subsidising goods and services for consumers who cannot afford them. Nevertheless, government failings in the energy sector, as in other economic and socials sectors, are also common, and often result from intervening inappropriately or with the wrong instruments (Stiglitz, 2002a).

${ }^{68}$ Traditional public finance theory states that such market imperfections may occur in any sector of the economy (Musgrave and Musgrave, 1973).

${ }^{69}$ Public goods have specific regulatory contexts that affect their provision, distribution and uptake (Drahos, 2004). In the energy sector, the organisations (whether government or private) involved in delivering energy carriers have the authority to review and make decisions (regulations) regarding their provision. Energy carriers can provide public benefits, but they need to be regulated to provide these benefits. It is only in a restricted sense that the services and benefits provided by energy, as a result of regulation, can be termed as a regulated public good. 
mitigating women's drudgery) by replacing the household use of biomass, in inefficient, traditional stoves, with cleaner and more efficient modern energy carriers (such as LPG) ${ }^{70}$. Such attributes tend to be undervalued by the market. To summarise, some of the benefits of modern energy carriers are that they enable:

i. advanced communication, education and training opportunities (using electricity);

ii. efficient domestic lighting and time savings in domestic chores (using electricity and LPG);

iii. productive and reliable production processes including mechanisation (using electricity); and

iv. social development benefits such as street lighting, health centres and drinking water (using electricity to provide lighting, to refrigerate the storage of medicines and vaccines and to pump water).

\section{Access Barriers and Transaction Costs}

The second argument for government intervention relates to access barriers and transaction costs (Williamson, 1996; Williamson, 1997). In a market economy, where energy prices are set by the market (in the case of a perfect market situation), low-capacity end-users, due to their low levels of disposable income, are necessarily more sensitive than the non-poor to 'shocks' as a result of changes in the prices of energy carriers. Further, the private sector does not see the poorest socio-economic sections of the society (and this is where the majority of the low-capacity end-users in the energy sector are located), as a lucrative market since their lack of purchasing power greatly constrains their inability to pay for having their demand satisfied. Ensuring that low-capacity end-users, who are primarily poor, have access to the social benefits of the goods and services provided by modern energy carriers is one of the reasons governments use to justify intervening in markets (Ahluwalia, 1999).

A second equally important barrier to modern energy carriers access by low-capacity endusers is the limited availability of energy services: a weak energy carrier distribution infrastructure has resulted in limited access and hampered the adoption of modern energy services, especially by low-capacity end-users in rural areas. In response, governments have established state energy utilities with the aim of improving the modern energy carrier infrastructure.

In many developing countries, there are a number of weaknesses in the market institutions that add to the costs of enterprises trying to do business. For example, the legal system that enforces contracts and validates property rights may not function well, and the banking and insurance sector may be weak and further suffer from currency instabilities. These weaknesses add uncertainty to doing business and create risks, which can lead to a reluctance to invest. Consumers and producers find it difficult (in other words it costs them time, effort and money) to obtain information about the prices of goods, and the quantity and quality of those goods that are available. These costs, related to uncertainty, risk and a lack of

\footnotetext{
${ }^{70}$ The energy and development linkages discussed in Section 2.2.1 relate to the argument for energy having public benefits.
} 
information, are collectively referred to as transaction costs (Coase, 1937;Williamson, 1981; Williamson, 1996).

The desirability for an enterprise of reducing or ideally eliminating transaction costs partly explains why activities are vertically or horizontally integrated. However, transaction costs can also be reduced by removing barriers through the use of policy instruments such as the certification of products, standardisation of contracts, and regulations with regard to the obligation of companies to provide product information and provide insurance schemes.

\subsubsection{Policy Instruments: Entitlements and Subsidies}

Policy instruments play a crucial role in linking policymaking with policy implementation. Governments use policy instruments as a tool to achieve policy objectives, such as removing access barriers and lowering transaction costs. Policy instruments can be classified based on the routes they take in influencing the actions and decisions of relevant actors (Box 2.2). These include regulatory (for example, standards, limits, and mandatory norms or quotas). economic (for example, tradable quotas, taxes, and subsidies) and suasive (such as awareness creation) instruments, which may be used in isolation or combined (Opschoor and Turner, 1994).

\section{Box 2.2: Policy Instruments}

Regulatory instruments ${ }^{71}$ such as standards, limits, norms, entitlements and quotas, alter the set of options available to actors. They identify the appropriate course of action and make particular forms of action mandatory. In the energy sector, in an ideal situation, an actor (an organisation for the delivery of energy carriers) would be left with no choice and have to either comply or pay penalties. Instruments can include the specification of an entitlement or a quota for targeted user groups, or for society in general.

Economic instruments such as changes in relative prices and financial transfers alter the relevant cost-benefit ratios of options using economic incentives or market stimuli. As such, they do not provide explicit directives that dictate a particular instrument to an energy carrier, but allow the actors to choose the method that is "best" in their particular circumstances. The built-in flexibility helps to achieve energy access at a lower cost. These instruments may be either market-creating (such as tradable quotas and permits) or non-market-creating (for example, taxes, subsidies and deposit-refund schemes). Economic instruments can be classified in various ways, each having different consequences for the understanding of the concept of subsidy (Gale and Barg, 1995;OECD, 1994).

Suasive instruments such as awareness creation alter the sensitivity to or preference for a given option in energy services using moral persuasion. They aim to internalise awareness and responsibility in decision-making actors (Opschoor, 1995) by applying persuasion, either directly or indirectly, to influence the market. For instance, in the energy sector, and especially with respect to rural energy, developing countries have invested in raising awareness regarding the adoption of energy-efficient technologies, such as improved cookstoves, in terms of benefits related to reducing women's drudgery in fuelwood collection, reducing indoor air pollution and the associated health benefits for women and children.

${ }^{71}$ In traditional economics, regulatory instruments are considered more effective whereas economic instruments offer an efficient way of achieving expected goals. However, this ignores issues such as uncertainty, feasibility, acceptability and market distortions (Coase, 1960;Pigou, 1920). Uncertainty may lead to preferring one instrument over another depending on the uncertainty, and the elasticity of damage and control functions (Adar and Griffen, 1976). 
Policymaking and policy implementation are usually mutually reinforcing since much policy cannot in reality be predetermined but has to be adapted to local situations to make it work. These experiences should also feed into the policymaking process, turning the relationship between policymaking and policy implementation into a mutual learning process rather than a one-sided relationship where policymaking dominates and fails to learn to adapt to local situations (Bressers, 2004;Bressers and O'Toole, 2005). The social and political acceptability, as well as the administrative feasibility, of policy instruments is critical. Interest groups with a stake in the policy instruments (demand-side) and decision-makers involved in their design and implementation (supply-side) may favour different instruments for different groups depending on their interests and motivations (Keohane et al., 1999).

The performance of policy instruments depends not only on their design and characteristics, but also on the context and the circumstances in which they are applied, including the existing institutions, the actors involved in or affected by policy implementation, and any political intervention. The limited use of political intervention is especially significant in the case of policies for enabling energy access by low-capacity end-users (United Nations, 2010). Rather, to counter the limited access to modern energy carriers among low-capacity end-users and to bring equity in access, governments have tended to rely on regulatory instruments, such as entitlements and quotas, and economic instruments, such as subsidies.

\section{Entitlements/Quotas}

The issue of equity is linked to poverty, and the issue of providing modern energy carriers and services to people who are too poor to buy them complicates the question of what the government should and should not do. One of the most important effects of poverty is to make public provision, with all its inherent problems, look attractive or even necessary in rural areas of developing countries (Ahluwalia, 1999). Being poor already greatly constrains demand, and low-capacity end-users are necessarily more sensitive than the non-poor to the prices of energy services. To counter the issue of limited access and to bring equitable access to low-capacity end-users, governments intervene through measures such as entitlements ${ }^{72}$ and quotas ${ }^{73}$. However, entitlements alone will not result in access. It may lead to availability, but people may still lack the means to buy modern energy carriers and therefore be unable to use them.

Entitlements, as used in this dissertation, are defined as the set of alternative commodity bundles that a person can command in a society using the totality of rights and opportunities that he or she faces (Sen, 1981). This definition of entitlements is descriptive rather than normative. Entitlements ${ }^{74}$ are derived from legal rights, or from provisions made by

\footnotetext{
${ }^{72}$ Entitlements also cover market and non-market ways of delivering goods and services.

${ }^{73}$ In the context of the energy sector, quotas are fixed entitlements that society as a whole, or specific sections, is provided with through a system of rationing. Quotas or entitlements are provided for a specific purpose and by their nature are not tradable, and therefore differ from tradable quotas.

${ }^{74}$ The concept of entitlements draws on Sen's seminal work in the context of poverty and famine in which entitlements are comprehensively placed in four categories: production-based entitlement (growing 
governments. Entitlements in the literature have largely been discussed in the context of poverty, food security and social sector development. Sachs and Silk (1990), in their analysis of food and energy, built their analysis on Sen's entitlements approach and argued that, while the entitlements approach was apt when addressing food availability, the real issue is not primarily availability, but whether it can be acquired by individuals and families. This acquirement requires, among other factors, an option for cooking the food available in the market, and consequently the entitlements approach to food should extend to energy carriers for cooking (Sachs and Silk, 1990). A person's entitlement set is the full range of goods and services that he or she can acquire by converting his or her endowments (assets and resources, including labour power) through exchange entitlement mappings (Devereux, 2001). The entitlements approach allows one to look at energy access from a fresh perspective. People who cannot gain access to modern energy, through either a lack of income or due to poverty, are affected even when energy carriers are available, supplies are adequate and markets are functioning well.

\section{Subsidies}

Subsidies are economic instruments introduced by governments to ease the provision of services to specific groups in society. Subsidies are the converse of indirect taxes and specific to goods and services ${ }^{75}$. Subsidies keep prices for consumers below the market price. Subsidies may lower the costs to consumers or for producers through direct or indirect support (de Moor and Calamai, 1997;OECD, 1996). Subsidies can be provided in different forms such as direct payments (tax concessions ${ }^{76}$ or allowances), the supply of goods or services at below market prices, guaranteed minimum prices, preferential procurement policies and cross-subsidisation ${ }^{77}$ (Moltke et al., 2004;UNEP, 2008).

The use of a subsidy indicates that the actual price paid for a good or service does not cover the real costs of providing that good or service (OECD, 1997). Energy subsidies ${ }^{78}$ are present in both developed and developing countries. Subsidies and cross-subsidies in energy pricing have often been introduced to enable governments to fulfil their social responsibility ${ }^{79}$ of

food), trade-based entitlement (buying food), own-labour entitlement (working for food) and inheritance and transfer entitlement (being given food by others) (Sen, 1981).

${ }^{75}$ Subsidies are different from transfer payments. Transfer payments are direct income supplements to individuals who are beneficiaries of the government's social sector obligations.

${ }^{76}$ In order to enhance generation capacity, governments provide incentives, in the form of tax benefits and favourable depreciation allowances, to the private sector to encourage investment in new projects and the introduction of renewable energy technologies.

${ }^{77}$ All three forms of subsidy are seen in the energy sectors of various developing countries.

${ }^{78}$ There is no single uniform definition of an energy subsidy. The most common definition is a direct cash payment by a government to an energy producer or consumer to stimulate the production or use of a particular fuel or form of energy (IEA, 2001).

${ }^{79}$ Although energy subsidies were introduced by governments to reduce the cost of energy carriers to consumers, the provision of subsidies is seen as a market distortion in the arguments for energy policy reform. It has been argued that the elimination of energy subsidies will reduce the pressure on the fiscal deficit and will result in a budgetary advantage, which the government can then use for socialsector development programmes. This is further discussed in Section 2.3.4. 
promoting energy access in rural as well as urban areas (UNEP, 2008).

Providing the poor with minimum consumption entitlements, or subsidising the items consumed by them, is an extremely important dimension of any fiscal welfare policy. Subsidies can correct for the under-consumption of goods that have positive externalities (Srivastava and Sen, 1997). However, benefits can be maximised only when the subsidies are transparent, well-targeted and designed for effective implementation that avoids pilferage and rent-seeking (Moltke et al., 2004;Morgan, 2004).

\subsubsection{Government versus Market: Arguments for Reforming the Energy}

\section{Sector}

The promotion of market participation in the energy sector is based on the argument that it will result in the better allocation of resources and thus improve services for users of energy carriers. In developed countries, where access is generally not a major concern, the emphasis in reforms has been on greater consumer choice, reduced prices and gaining additional efficiency gains out of an well functioning system (Dubash, 2005;Joskow, 1989). A focus in the debate on energy sector reforms is the issue of institutional reform ${ }^{80}$ and the economic efficiency of energy utilities. Energy sector reforms were initiated primarily to increase private sector investment, improve efficiency and services, and reduce the role of government (Littlechild, 2000). A reason given for government intervention is that this enables energy carriers to be available at stable prices because a government accepts responsibility for maintaining prices to protect the domestic industry and consumers. Further, the government is able and willing (for reasons of national energy security and independence) to stockpile oil reserves to manage unforeseen crises in supply, something the private producers cannot do or do not do. Such arguments have dominated government interventions in the energy sector ${ }^{81}$ in developing countries (Bacon, 1995;Bacon and Besant-Jones, 2001).

A natural monopoly was often assumed to exist in the energy sector, for example in the generation, transmission and distribution of electricity (since the duplication of distribution grids by competing firms would entail higher costs than a single grid owned by a monopoly) and in refining and distributing refined petroleum products. Government interventions in the energy sector resulted in the creation of government-owned monopolies or oligopolies through the formation of public-owned corporations based on the argument of the need to protect domestic industry in developing economies and consumers from the vagaries of the market. In addition, governments would often utilise public funds to expand the electricity grid to rural areas and formulate a pricing policy that protected consumer interests. However, monopolies and oligopolies create barriers that make it difficult (or impossible) for potential competitors to enter the market and hence the benefits predicted from competition are not able to materialise. However, there are other barriers to energy access, including a lack of

\footnotetext{
${ }^{80}$ Institutions play a critical role in the economy, and institutional economics focuses mainly on incorporating the theories of economics and institutions with the evolutionary approach (Dugger, 1990;Rutherford, 2001).

${ }^{81}$ Traditional public finance theory argues that such market imperfections can occur in any sector of the economy and forms the basis for government intervention or public action (Musgrave, 1959).
} 
physical and market infrastructures, technical and financial barriers, and cultural norms that inhibit entrepreneurial activities (GNESD, 2007;IPCC, 2011). Infrastructure-related barriers include the absence of roads, the lack of market linkages and inadequate transportation facilities especially for remote rural areas (Olz and Beerepoot, 2010;Owen, 2006). Technical and financial barriers relate to the cost and availability of resources, technical capacities, skills and a support system for operations and maintenance (Reddy and Painuly, 2004). Socio-cultural barriers include a lack of awareness and behaviours arising from cultural perceptions and acceptance patterns linked to societal and personal values and to norms (Olz and Beerepoot, 2010;Petersen and Andersen, 2009).

In the energy sectors of developing countries, government involvement has ranged from large infrastructure projects for energy exploration and generation to distribution services such as selling energy carriers, fixing energy prices and revenue collection. It is argued that, by reforming the energy sector, governments can use their scarce resources for tasks such as better regulating the sector (Soubbotina, 2004). In addition, governments would be able to reduce energy subsidies, cut losses, and possibly divert public funds to social sectors such as education and health in rural areas (World Bank, 2000).

Further, past government failures in the energy sectors of developing countries have reduced the arguments in favour of government intervention. Initially, the primary concern of energy sector reforms in developing countries was to find a way of raising capital to finance energy production (adding electricity generation capacity and petroleum energy development) to ensure energy security. Although the approaches to reforms in the energy sector have varied among countries, the main objective has been to improve economic efficiency (Bacon and Besant-Jones, 2001;Gabrielle, 2004).

In the context of this dissertation, it is important to distinguish between sector reforms and privatisation since they are not always the same thing. In general, energy sector policy reforms have amounted to liberalisation and/or privatisation (including deregulation) ${ }^{82}$. How privatisation is practiced varies from industry to industry, and from country to country, depending on the characteristics, culture and capacities of the goods and services to be privatised (Boorsma, 1994). Privatisation amounts to a transfer from the public sector to the private sector, and could range from a shift in responsibility, or the devolution of government power to the private sector, to a general transfer of business. The term privatisation is commonly used to indicate the latter. Deregulation, on the other hand, refers to lifting restrictions and is closely connected to liberalisation. Energy sector reform is a larger process of which privatisation may be a part. Especially in those developing countries that are undertaking energy sector reform, this debate is often characterised by some confusion over

\footnotetext{
${ }^{82}$ In developing countries, despite their different socio-political conditions and motivations for reforming the public sector, the reform measures were largely based on analysis and policy recommendations by economists drawing on experiences with deregulation in Europe and the US. The standard prescription underpinning reform measures aimed at creating competitive markets in already functioning energy sectors in order to maximise economic efficiency and reduce a government's role to that of a market referee (Hunt, 2002). The language and modalities of this standard prescription were incorporated into reform policies despite the mismatches with the expectations and capabilities of developing countries.
} 
the definition and scope of the terms "public" and "private", as well as related terms such as competition and privatisation, and the various meanings of "market" in the energy sector. Another policy dimension aspect of energy sector reforms covers corporatisation, commercialisation and the creation of competitive markets.

The debate about the merits and disadvantages of private and public sector ownership has largely remained inconclusive. Since the evidence shows that performance depends not only on ownership but also on the context in which a given enterprise operates (Boorsma, 1994; World Bank, 1995; Yarrow, 1999), it can be argued that economic efficiency (or inefficiency) is not a sufficient criterion for market or government failure, as other social and political factors also influence these failures (Bardhan, 2006;Kohli, 1989). Thus, while the need for economic efficiency plays an important role in policy development, other factors also play an important role in shaping public-sector reform policies (Yarrow, 1999).

\subsection{Characteristics, Capabilities ${ }^{83}$ and Culture}

Building on the arguments presented in the previous section, the scope and performance of public sector reforms should not in practice be determined solely on the need for economic efficiency. Public sector reforms should also depend on the state or the characteristics of the sector, the 'level of development' of both the public and the private sectors, that is, their capabilities, and the prevailing cultural context such as local political factors. An emphasis on the economic efficiency of the sector alone is not sufficient, especially in the context of the energy sector in developing countries, since one of the objectives is inclusive development as part of the reform measures. The availability of a model that would enable a critical analysis of reform measures, and their impact, by understanding the dynamics of the energy sector, the different socio-political and economic contexts, and the characteristics of the energy sector itself could lead to more effective policymaking. The 3-C model of Boorsma (1994) -

Characteristics, Capabilities and Culture - provides a promising framework for such an analysis.

Characteristics, Every economic good or service has its own characteristics in terms of how they are produced and distributed as well as in terms of their end-use applications. The characteristics of the goods and services influence decisions on whether, and how, the goods or services should be privatised or reformed (Box 2.3). This will depend upon the phases and functions of the goods or services. The characteristics include the organisation of the sector, the production, distribution and sale processes linked to the good (its phases), and the strategic management, planning and financing functions. Such characteristics differ for an energy carrier (traditional or modern), each has its own phases, functions, nature of the services they provide and the context they represent. The key issues with respect to the characteristics of modern energy carriers are the existing delivery pathways (public or

\footnotetext{
${ }^{83}$ The term "capabilities" is used differently in Boorsma's framework than in Sen's Capability approach. The latter use is more in the context of poverty and development, whereas capability is used in Boorsma's framework to refer to sectoral capacities. This is further explained later in this section.
} 
private) for providing energy carriers, the systems in use for modern energy delivery to consumers (entitlements in the form of rationing and quota systems), the availability of subsidies or market pricing, the political priorities accorded to the energy carriers and the political decisions regarding the energy sector in itself. Laws and regulations governing the sector influence the characteristics of energy carriers.

The concepts of phases and functions are explained in Box 2.3. In the context of energy access by low-capacity end-users, combining phases and functions provides insights into various forms of policy reform that are possible at each level. By making a distinction between the subsequent phases of the production process and its functions, the analysis offers greater insights into the impacts of the different options available in introducing policy reforms.

\section{Box 2.3: Phases and Functions}

\begin{tabular}{|c|c|c|c|c|c|}
\hline & & & \multicolumn{3}{|c|}{ Functions } \\
\hline \multirow{3}{*}{ 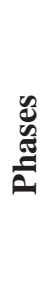 } & Procurement & $\begin{array}{l}\text { Production } \\
\text { Process }\end{array}$ & \multirow{3}{*}{$\begin{array}{l}\text { Strategic } \\
\text { Decision } \\
\text { Making } \\
\text { (related to } \\
\text { each Phase) }\end{array}$} & \multirow{3}{*}{$\begin{array}{l}\text { Operational } \\
\text { Planning and } \\
\text { Organising } \\
\text { (of each Phase) }\end{array}$} & \multirow{3}{*}{$\begin{array}{c}\text { Financing } \\
\text { (market } \\
\text { transactions/ } \\
\text { investments } \\
\text { decisions or } \\
\text { public } \\
\text { budget) }\end{array}$} \\
\hline & \multicolumn{2}{|c|}{ Distribution } & & & \\
\hline & \multicolumn{2}{|c|}{ Sale/Funding } & & & \\
\hline
\end{tabular}

Boorsma (1994) introduced the concepts of phases and functions to more systematically distinguish between them in the context of the privatisation of public organisations or public goods. He believed that the processes of privatisation should take account of the specific context as every organisation, or goods and services, will have different characteristics, capabilities and culture (of the country/society). The successive phases of procurement, production, distribution and selling follow a standard classification that can be refined for each good or service.

Every organisation, good and service has a production process, which begins with procuring the means of production needed (the first phase) and ends with distributing the products or services, either by sale at a market price or by being funded through a public budget. This whole production process and its subsequent phases have to be planned (through strategic decision-making), organised (by operational planning including daily management) and financed (either through market transactions and/or private investments or public budgets), and so these are the functions involved.

Source: (Boorsma, 1994;Boorsma, 1998)

Capabilities refer to the capacities (of employees) in the sector at different levels when going through the reform process, and the capacities of society, the domestic capital market and the private sector to cope with the reforms. Capabilities are reflected in a combination of enabling factors such as institutions, technologies, economic incentives and socio-political factors that influence the capacity of the sector, at various level of governance (central, state and local) to provide energy carriers and enable access by low-capacity end-users. Capabilities also reflect the capacity of the capital market, as a lack of the latter can be a constraint, especially in developing countries if the markets and institutions are not well 
established and the lack of capital in the energy sector has been a strong argument for reform. In the context of energy sector reforms and rural energy access, there are two key aspects of the capacities. The first relates to the existing capacities in the organisation ${ }^{84}$ at different levels of government, and in the organisations required to improve access to modern energy carriers in the rural areas. The lack of institutional capacity in some developing countries, especially to deal with issues of privatisation and economic reforms, should also be an important consideration for decision-makers when designing policies and programmes related to policy reforms. The second aspect deals with the capacity, or the capability, of the lowcapacity end-users themselves in terms of their ability to adopt modern energy carriers while the energy delivery systems undergo reform. The ability to adopt, as noted in Section 2.2.2, relates to the paying capacity of such users. Another aspect of capability is the level of awareness regarding the benefits of modern energy carriers. Finally, capability will also depend on the intra-household dynamics, as gender plays a critical role in determining energy access in the context of developing countries (see Section 2.2.2).

Culture involves understanding the way a society functions, and the laws that exist to address the concerns of society. In the context of the energy sector, culture addresses the interaction between the functioning of rural society and energy use, including the options and limitations of low-capacity end-users that either facilitate or inhibit their access to modern energy carriers. It also includes how society would respond, in terms of acceptance or resistance, to possible changes in the energy sector because reforms could bring changes that a society might find contrary to its culture and ability to adapt. Another aspect of culture is the power relationships in the sector as these play a critical role in addressing issues related to the transparency and functioning of organisations involved in energy delivery. Power relationships exist at all levels in society.

In this dissertation, the concept of phases and functions has been adapted in order to develop an analytical framework to analyse the different characteristics, capabilities and culture of each energy carrier in terms of how these enable access to modern energy carriers by lowcapacity end-users.

${ }^{84}$ It is important to emphasise the focus on organisations rather than on institutions. Although institutions are often associated with organisations, the two entities are different. The difference is that although both provide a structure that shapes human interaction, organisations primarily refer to groups of individuals bound by a common purpose (North, 1990). Organisations include political bodies (political parties, regulatory agencies), economic bodies (firms, trade unions, cooperatives), social bodies (churches, clubs) and educational bodies (schools, universities). Institutions constitute the underlying rules of the game in a society whereas organisations are bodies that play certain roles in the society under the existing rules of the game (North, 1990). This distinction is important in the context of this study because while it analyses the dynamic interactions between the rules of the game (policies for enabling modern energy access) within the political economy of India, it focuses on organisations (including their actors) that enable low-capacity end-users to access modern energy. 


\subsection{Analytical Framework}

The analytical framework of this dissertation is constructed around the linkages between policies that govern the energy sector and their effect on access to modern energy carriers by low-capacity end-users in rural areas. The literature on energy and development shows that access to modern energy is critical for attaining economic growth and social development (Section 2.2). At the macro-level, the linkages between energy and economic growth are clearly established; however, at the micro-level, the linkages become complex as there are demand-side issues that constrain access to modern energy carriers. Public-sector policy reforms that relate to a role for government are in response to perceived market failings - that markets do not work well in achieving social and environmental objectives - and the role of the government is therefore critical in developing policies to bring about economic development and social equity (Section 2.3). Public-sector reforms that rely on the principles of a market economy to implement the policies, view government intervention as the cause of problems that affect the market (Section 2.3). The market and the public sector thus provide two different pathways for implementing policies. Choosing the appropriate pathway is critical in striking the right balance between providing energy access to low-capacity endusers and achieving economic efficiency.

In the analytical framework, the linkages between energy sector policy and access to modern energy carriers are established through a combination of "delivery pathways", "enabling factors" and "contextual influences". Delivery pathways are the means of enabling access (availability and affordability) to modern energy carriers. Enabling factors are the combination of organisations and policy instruments that facilitate implementation of the policies and these are specific to each pathway. In a broader perspective, enabling factors encompass supply-side factors such as organisations (including technology, capacities ${ }^{85}$ and budgetary allocation) and policy instruments (subsidies, entitlements) that enable the implementation of policies to improve access to modern energy carriers. Contextual influences are those demand-side issues that affect the degree of access to modern energy carriers, and whether they are strong or weak influences the degree of access to modern energy carriers.

The analytical framework of the dissertation (Figure 2.2) is based on the linkages between the above three factors: delivery pathways, enabling factors and contextual influences.

\subsubsection{Delivery Pathways}

A delivery pathway, as defined in this dissertation, is a combination of a policy framework (government and market) and the characteristics, and phases and functions, of each energy carrier. A critical review of the theories on public sector reforms indicates that energy sector policies are formulated by two distinct ideologies - the public sector or the market as the appropriate mechanism for delivering goods and services (Sections 2.3 and 2.4). From the

\footnotetext{
85 The term "capacities” covers human skills, knowledge and management.
} 
energy sector perspective, the public sector and the market form the two ${ }^{86}$ delivery pathways that can be addressed in the formulation and implementation of energy sector policies. The public sector pathway is followed by governments to overcome or avoid the failures of the market, whereas the market reform pathway is followed by market ideologists believing that economic efficiency will offset government failures. However, in the energy sector, the pathways are not as straightforward as they first appear in Figure 2.2 because, for each main pathway, there are several modern energy carriers. Each energy carrier has its own characteristics, phases and functions, and these provide different end-use benefits (see Box 2.3). Consequently, within each pathway, the policies are likely to differ for each energy carrier. Not only do the characteristics differ, but the pathways also operate differently in particular contexts and at different times. As a result, the policy reforms for each energy carrier will vary depending on how the sector governing that particular energy carrier is organised and the range of instruments used in that sector for delivering energy carriers.

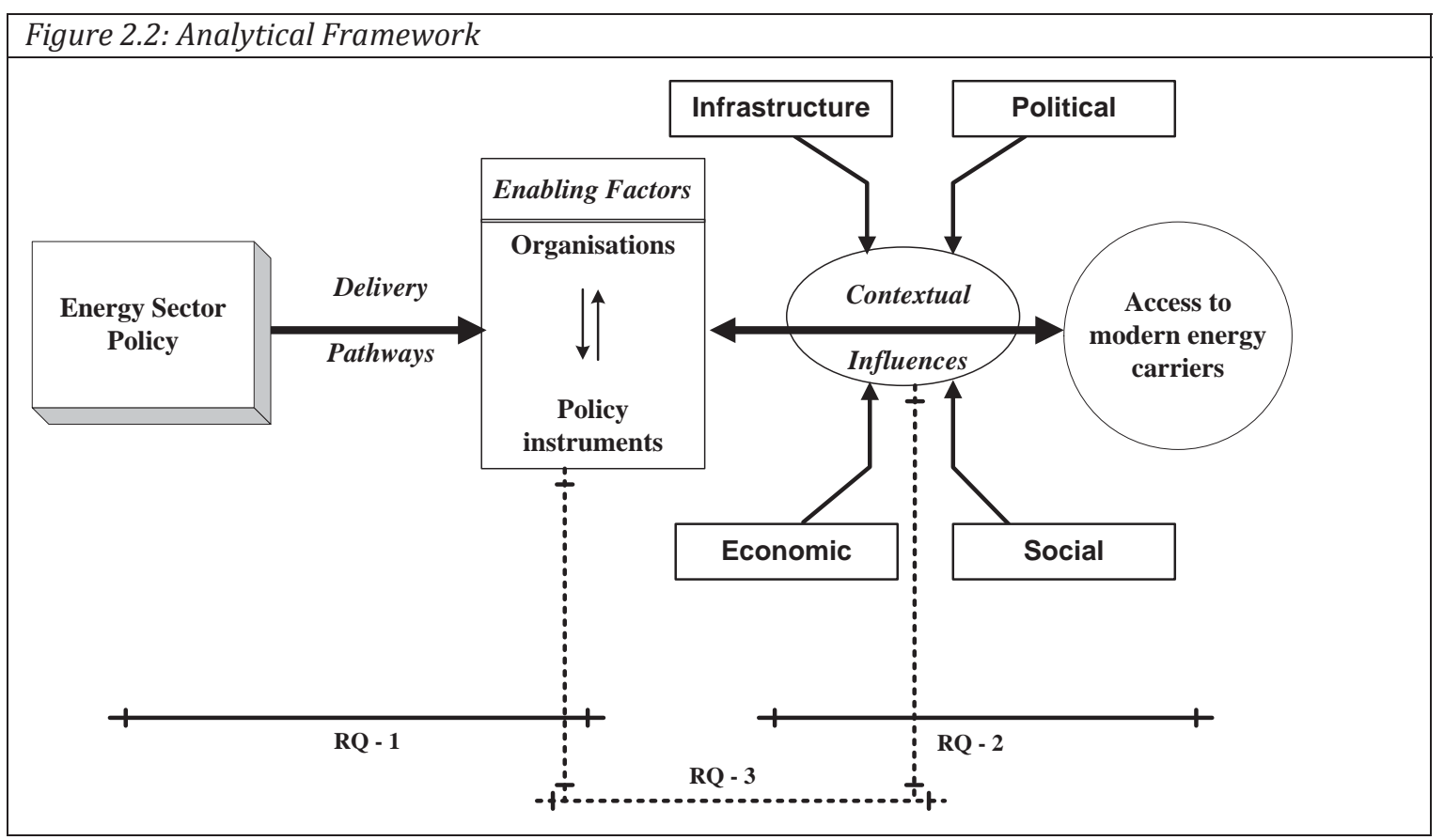

\subsubsection{Enabling Factors}

Enabling factors act as intermediaries between the delivery pathway (either the government/public sector or the market/private sector) and energy access in the rural areas by the low-capacity end-users. Enabling access to modern energy carriers depends on the

\footnotetext{
${ }^{86}$ From a rural energy perspective, there is also a third pathway that applies to biomass energy in the informal sector. Biomass as a fuel is gathered informally and at no monetised cost unless one recognises the value of the time spent, usually by women, in gathering biomass. However, increasingly, biomass is being commercialised with individuals becoming sellers and with the emergence of organised markets. At the same time, governments are intervening by investing in biomass plantations and biomass-based improved cookstoves.
} 
adoption of an appropriate delivery pathway and the adoption of enabling factors in the form of organisations and policy instruments (Section 2.3.3). Through the bundling of organisations and policy instruments, enabling factors provide responses to policy that enable modern energy carriers to be delivered to low-capacity end-users by addressing the contextual factors ${ }^{87}$.

Here, an organisation ${ }^{88}$ is interpreted as a vertical and/or horizontal combination of agencies and further incorporates technology, people and human capacity, and a budget. For each energy carrier, there will be such an organisation that is responsible for the physical implementation of policies to improve availability. For example, in the electricity sector, following the public sector pathway, the government formed vertically integrated stateowned electricity utilities that undertook the functions of generation, transmission and distribution. This organisation has to follow the rules and regulations for that carrier, through its own network and in line with the hierarchy operating in a country (at the centre, province/state and local levels). As such, a critical aspect of the enabling factors is the capability of such organisations (Section 2.4).

At the same time, organisations are also burdened with meeting social equity objectives. The basic premise of the reform agenda is that vertically integrated utilities are economically inefficient whereas organisations with clear accountability are economically efficient. The reform policies pathway therefore emphasises dismantling the vertically integrated utilities into separate organisations for generation, for transmission and for distribution on the basis that this will make them economically efficient. However, such a policy focus neglects social objectives, viewing them as distortions of the market and thus as economically inefficient.

Policy instruments are tools that assist organisations in implementing policies. Using the public sector policy pathway, policy instruments typically include entitlements and subsidies. The reform policies pathway views entitlements and subsidies as market distortions and treats these two policy instruments differently. Here, the emphasis is on subsidy reforms including targeting subsidies to overcome the limitations of entitlements. These again differ for different energy carriers.

${ }^{87}$ Bundling institutional, technical, commercial and social intermediations can break the vicious circle of energy poverty (see Section 2.2) (Barnett, 2000).

${ }^{88} \mathrm{It}$ is important to emphasise the focus on organisations rather than on institutions. Although institutions are often associated with organisations, the two entities are different. The difference is that although both provide a structure that shapes human interaction, organisations primarily refer to groups of individuals bound by a common purpose (North, 1990). Organisations include political bodies (political parties, regulatory agencies), economic bodies (firms, trade unions, cooperatives), social bodies (churches, clubs) and educational bodies (schools, universities). Institutions constitute the underlying rules of the game in a society whereas organisations are bodies that play certain roles in the society under the existing rules of the game (North, 1990). This distinction is important in the context of this study because while it analyses the dynamic interactions between the rules of the game (policies for enabling modern energy access) within the political economy of India, it focuses on organisations (including their actors) that enable low-capacity end-users to access modern energy. 
There are two critical observations with respect to enabling factors in the context of publicsector delivery of energy carriers. Firstly, the enabling factors are supply-side driven because they are designed to ensure that modern energy carriers are available. Secondly, the enabling factors do not consider demand-side issues, i.e. the contextual influences that affect access to energy carriers. If the enabling factors are weak, or are weakened by dominant negative contextual influences, access to modern energy carriers will be limited. Conversely, if the contextual influences are positive, they create the right combination of complementary inputs that enables access to modern energy carriers. Energy sector reforms can broaden the delivery mechanisms and create new enabling factors, or strengthen existing ones, to improve access to modern energy carriers by low-capacity end-users.

How policy instruments perform depends heavily on the way they are designed, implemented, enforced and monitored. A policy design can be deemed to be effectively implemented if it contributes to reaching the target set out by the policy. In the context of this dissertation, the effectiveness of a policy design is determined by whether or not it has resulted in improved access to modern energy carriers by low-capacity end-users. Since 'access' has been defined as a function of availability and affordability, the effectiveness and applicability of a policy design is assessed through this lens. The first sub-question posed is "to what extent has the availability of modern energy carriers improved? The second, "to what extent did the policy design (through policy instruments) address the issue of affordability of modern energy carriers?"; and the third, "how was the policy design applied in a specific socioeconomic (including geographical) situation?". In the context of this dissertation, the applicability of a policy design in terms of its implementation provides an understanding of whether a particular policy (including its instruments) was appropriate for improving low-capacity end-users access to modern energy carriers.

\subsubsection{Contextual Influences}

Contextual influences play a critical role in the degree of access to modern energy carriers. In the context of energy access in rural areas, four categories of contextual influences can be identified: economic, infrastructural, social and political. These are micro-level influences, and their strength, and whether they are positive or negative, will influence the degree of access to modern energy carriers.

Economic influences are local-level economic opportunities encompassing the basket of economic activities available for people in a region. If the economic activities in a region are dependent on agriculture and forest resources, with limited access to the market and fair prices, then the economic influence will be negative and restrict the ability to adopt modern energy carriers. If the local economic activities are mixed, and influenced by market forces, they can have a positive influence and make modern energy carriers affordable. Since energy access is a function of both affordability (economic influence) and availability, economic influences cannot alone improve access.

Infrastructural influences address the physical infrastructure such as access to roads, transportation, communication and markets. The availability of infrastructure reflects the delivery pathway set up by organisations for the delivery of energy carriers. If the physical 
infrastructure is weak, it acts as a barrier to improving access, and so limits people's ability to participate in the market and increase their potential to earn cash income. If the physical infrastructure is good, this creates opportunities and acts as a driver for organisations in delivering energy carriers. The delivery infrastructure relates to availability. In the case of energy carriers such as electricity, a delivery infrastructure can be provided, even in a weak physical infrastructure (as seen in remote geographical regions), by using alternative options (such as renewable energy based stand-alone electricity generation systems or local decentralised systems) to improve access. In the case of petroleum energy carriers, the delivery infrastructure is much more dependent on the physical infrastructure, especially in terms of roads and transportation. If the physical infrastructure is weak, it restricts the ability of the delivery infrastructure to set up local-level organisations as part of an improved delivery service.

Social influences include culture and the social fabric of society including the caste structure and, more specifically, the gender-energy linkages in the context of energy access in rural areas. Social influences are critical for the formulation and implementation of development policies and, if ignored, can lead to greater disparities in society. When following the government pathway, policy instruments play a mitigating role but, nevertheless, they may be inadequate. The reform policy pathway is particularly vulnerable to the ways in which the reforms address social influences. An inappropriate set of policy instruments and organisations can erode the social fabric of a society. The experiences of implementing reform policies have shown that if the social influences are ignored in favour of economic efficiency, society is put under stress as traditional authorities and relationships are challenged and reassessed.

Political influences relate to the role that political parties (and also other actors such as businesses, religious organisations, donor/funding agencies and NGOs) play in formulating and implementing policies so that the interests of different sections of society are protected. At the macro-level, national policies are sometimes influenced by changes in the international policy environment. At the micro-level, domestic political influences can intervene between policies and their implementation. If the political influences are strong and stable, they facilitate the formation of appropriate organisations and robust policy instruments, leading to improved access to modern energy carriers. If the political influences are weak and transient, as is often the case, short-term gains will be favoured with political influences tending to maximise benefits for selected individuals and groups in society, with the degree of access to modern energy carriers varying from one social group to another. The experience of the energy sector in India is that micro-level political influences have created a gap between those who have access to modern energy carriers and those who do not. Political support for specific policies such as subsidies often work in favour of the better-off and fail to benefit the low-capacity end-users (see Chapter 4). While the underlying reason for energy sector reforms aimed at insulating the sector from political interference, the experience shows that it is difficult to dispense with these political pressures. Political interferences are often get applied in different and potentially crippling ways on the energy sector reform policies. 


\subsubsection{Main Research Questions}

The analytical framework of this dissertation is set within the boundaries defined by the research hypothesis. The analytical framework attempts to develop an appropriate balance between the goals of energy sector policies and access to modern energy carriers by low-capacity end-users in rural India. Three main research questions stem from the central research question: "How might future implementations of policy reforms in India's energy sector be adapted to achieve the dual objectives of improving the economic efficiency of energy supply and of improving low-capacity end-users' access to modern energy carriers?"

Given the role of energy in contributing to development, it is important to understand how energy policies in India have evolved since the time of India's independence in 1947 and the extent to which these policies have been designed to address the energy needs of lowcapacity end-users in rural areas. As with the overall economic reforms in India, the energy policy is also being revisited. The energy policy that followed economic reforms in India favoured energy-sector reforms that involved privatisation, competition and deregulation. The later shift in policy focus to economic reform but with inclusive development, reinstated the role of government in delivering energy carriers while still pursuing energy sector reforms. The growing concern is what happens to energy access in rural areas in the context of these policy reforms and shifts, and how policy measures have responded to these concerns. Therefore, the first main research question (which will be answered in Chapter 4) has been formulated as follows:

Main Research Question 1: How have energy sector reform policies been formulated to address the weaknesses apparent in the policies of the pre-reform phase in terms of improving access to modern energy carriers by low-capacity end-users in rural areas? (RQ 1 in Figure 2.2)

Sub-question 1.1: What is the institutional setting for delivering energy carriers in rural India?

Sub-question 1.2: What motives have shaped energy policies in India in the prereform phase (1950-1991) and in the reform phase (1991-2010)?

Sub-question 1.3: What are the key elements of the energy policies enacted since 1991 for enabling low-capacity end-users to access modern energy carriers?

The argument being put forward is that the limited access to modern energy carriers and energy services results in energy poverty in rural areas. For the policies to overcome energy poverty, it is important to understand the nature and use of modern energy carriers in the rural areas by low-capacity end-users as well as the barriers faced by them in accessing modern energy carriers. Such an understanding of energy usage patterns and the factors that influence energy access would provide indications as to what form energy policies should take if they are to address access and availability barriers. The second main question, in essence, addresses the key issue of how to ensure sustainable development benefits, and this will be 
answered by understanding the way people have been using energy and how they have managed, or not, to access modern energy carriers. The second main research question (answered in Chapter 5) is formulated as follows:

Main Research Question 2: Have the energy policies enabled low-capacity end-users to gain access to modern energy carriers? (RQ 2 in Figure 2.2)

Sub-question 2.1: How do delivery pathways and enabling factors influence access by low-capacity end-users to modern energy carriers?

Sub-question 2.2: Who has access to modern energy carriers and why?

Sub-question 2.3: How do contextual influences affect low-capacity end-users' access to modern energy carriers?

The role of enabling factors should be to improve access to energy carriers. The policy reforms in the energy sector have broadened the delivery mechanisms from public actors to private actors, or to a combination of both. The second area of the research considers how energy policies could improve the access of low-capacity end-users to modern energy carriers. This is a pertinent issue since the ongoing policy reforms in India have raised concerns about such access. As such, two questions emerge in relation to the energy policy reforms. Firstly, have the policy reforms broadened or narrowed the choice of modern energy carriers? Secondly, have the policy reforms improved access to modern energy carriers, or have they had no effect on this? Since contextual influences affect access, the linkages between enabling factors and contextual influences are critical. Understanding the linkages between these two factors in terms of energy access is important when it comes to policymaking and policy implementation. Therefore, the third main research question (answered in Chapter 6) has been formulated as follows:

Main Research Question 3: What changes are required in the enabling factors to enhance access to modern energy carriers by low-capacity end-users? (RQ 3 in Figure 2.2)

The key issue is whether or not low-capacity end-users' access to modern energy services will improve under the current reforms policy. This will depend on the linkages between contextual influences and enabling factors. If the energy sector reform policy, and in particular the way this is being implemented, fails to address the issue of providing access to low-capacity end-users, then it will be necessary to reformulate policies and take measures that may even be contrary to the principles of market conformity. The final objective (addressed in Chapter 6) of this study is to identify under what circumstances can policy reform in India's energy sector lead to improved access to modern energy carriers and to sustainably meeting the energy needs of low-capacity end-users in rural India.

In answering the three main research questions, the research uses two levels of analysis: (a) an analysis of the energy-sector policies and programmes at national and state levels (in Chapter 4); and (b) an analysis of energy access by low-capacity end-users at the level of rural households (in Chapter 5). The rural household level analysis also includes linkages to 
In Pursuit of a Light Bulb and a Smokeless Kitchen

the enabling and contextual influences that affect adoption of, and transition to, modern energy carriers. The next chapter (Chapter 3) presents an overview of the research methodology with a focus on the rationale for selecting the case study regions and the techniques used in the research.

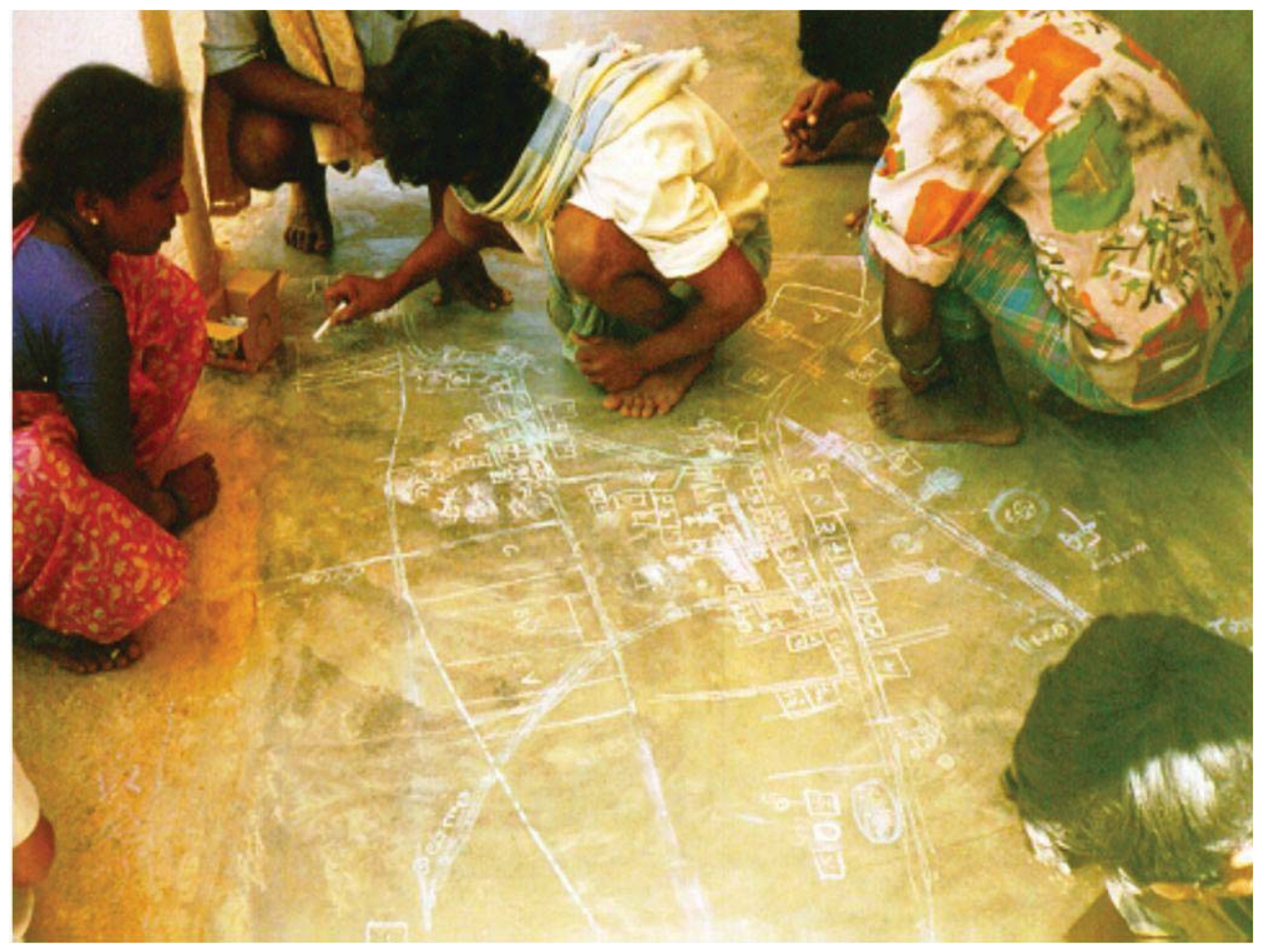




\section{Research Methodology}

On the International Crops Research Institute for the Semi Arid Tropics (ICRISAT) campus, where I had spent a year, there was a particular story of an interaction between a farmer and a researcher, which was narrated as a popular fable. A young researcher had once visited a neighbouring village to talk to farmers. One of the farmers asked the researcher about the purpose of his research. Intrigued by the question, the researcher asked the farmers why they wanted to know about the purpose. The farmer explained that if the research scholar was a Masters student, then their responses would be different from those given to a PhD student, and so on.

\subsection{Introduction}

The focus of this dissertation is on policies for enabling access to modern energy carriers in rural areas of India, with a special emphasis on low-capacity end-users. The collection of empirical data and their analysis, along with policy analysis, form the core of the study. To recap, access to modern energy has been defined in this research as a function of availability and affordability. Modern energy carriers, as shown in Box 1.1 of Chapter 1, are defined as electricity, liquefied petroleum gas (LPG) and kerosene oil. The term 'low-capacity endusers' covers those households who are unserved or underserved (Box 1.2, Chapter 1).

The approach followed in this dissertation is a combination of qualitative and quantitative methodologies as suggested by Yin (2003). The dissertation follows the approach of selecting case studies and then comparing cases to establish internal validity from the findings of field research (Yin, 2003). This approach enabled an appropriate selection of case studies while keeping an open approach to the findings from the field. During the initial part of the research, the approach and methodology to be followed for the selection of state, district and village clusters as case studies and for the sampling of household respondents were formulated.

Comparisons of household access to modern energy carriers between the various case-study regions (both within and between research locations) are made to analyse the different levels of household access to modern energy carriers, the various pathways of energy delivery, and the availability of formal and informal local organisational arrangements that enable access to modern energy carriers. States, districts/blocks and villages are selected based on certain criteria. First, the level of access to modern energy carriers has been used as the criterion for selecting states and districts. Next, differences in the delivery pathways for enabling access to modern energy carriers formed another criterion in the selection of states, districts/blocks and cluster of villages. The selection of village clusters was based on there being different formal and informal organisational arrangements for enabling access to modern energy carriers.

Based on the data collection between 2001 and 2002 and subsequent analyses of different case study regions and energy policies, the information obtained, as explained in the Prologue of this dissertation, can be categorised on two distinct levels. While the case studies identified a few interesting and prevalent practices that enhanced access to modern energy at the local level, the energy policy reforms at the state level lacked linkages with national policies. 
However, such analyses were not compatible and proved inadequate to address the research questions. Given that new policies and programmes emerged from 2004-05 onwards, a second period of field research was conducted in 2008-09 to discover whether energy accessibility had changed in the case study regions (see Box 3.1).

\section{Box 3.1: Approach, Method and Focus in the two field surveys}

\begin{tabular}{|c|c|c|c|}
\hline 2001-02 & $\begin{array}{l}\text { Household survey on access } \\
\text { to modern energy in three } \\
\text { case-study regions }\end{array}$ & $\begin{array}{l}\text { Delivery Pathways at } \\
\text { the State Level }\end{array}$ & $\begin{array}{l}\text { Review of Energy } \\
\text { Policy Reforms at State } \\
\text { and National Levels }\end{array}$ \\
\hline 2008-09 & $\begin{array}{l}\text { Revisiting case-study } \\
\text { regions, understanding } \\
\text { socioeconomic and political } \\
\text { changes, and household } \\
\text { survey (Case Stories) }\end{array}$ & $\begin{array}{l}\text { Review of Energy } \\
\text { Policy Reform and } \\
\text { Programmes at the } \\
\text { State Level }\end{array}$ & $\begin{array}{l}\text { Review of Energy } \\
\text { Policy developments } \\
\text { since } 2004 \text { at the } \\
\text { National Level }\end{array}$ \\
\hline
\end{tabular}

Section 3.2 outlines the selection of the states of West Bengal, Chhattisgarh and Orissa ${ }^{89}$, and their respective case-study regions; that is, the blocks of Gosaba, Bastar and Kalahandi. The section also presents the village clusters identified for the study and the household respondents selected in the case study regions. Section 3.3 presents the research techniques used to collect and analyse the empirical data and the techniques followed for policy analysis. As the ethos of social science research involves the search for objectivity and hinges on the validity and reliability of the data sources and the data collected, Section 3.4 assesses the validity and reliability of the data collection in this dissertation.

\subsection{Case Study Regions}

Case studies are defined as empirical inquiries that investigate a phenomenon within its reallife context. The case study approach is especially appropriate when the research: (a) focuses on contemporary issues, (b) aims at understanding complex relationships and processes, and (c) uses multiple sources of evidence (Yin, 2003). As such, the case study approach is a suitable and feasible research method for the matter under investigation for this dissertation. The dissertation aims to analyse the problems associated with access to modern energy carriers for low-capacity end-users, which is a contemporary topic in the context of the global and national discussion on energy and development. This analysis requires an understanding of the complex relationships among delivery pathways, enabling factors and contextual influences and their effect on access to modern energy carriers. In order to complete the analysis, the research uses multiple source of evidence - secondary information, household surveys, formal and informal consultations with stakeholders, content analysis of policies including interviews and participant observation. The research strategy is based on the use of

\footnotetext{
${ }^{89}$ On 4 November 2011, Orissa was officially renamed Odisha, after Presidential assent and notification in the official gazette. In this dissertation, the state is referred to as Orissa throughout. 
multiple case studies. The unit of analysis is rural households. The impact of energy sector policy on access to modern energy carriers by low-capacity end-users (at the household level) in rural India is regarded as the unit of analysis. The unit of observation in this dissertation is a geographical area, comprising a cluster of villages, and three such clusters in adjoining states in eastern and central India form the case-study regions.

\subsubsection{Selection of the States: West Bengal, Chhattisgarh and Orissa ${ }^{90}$}

The socioeconomic diversity, the wide geographical extent and the history of rural energy programmes for expanding access to modern energy carriers in the villages of India makes the task of selecting states for case-study-based research daunting. India has a large number of rural energy programmes, and the most extensive include the provision of electricity and the distribution of kerosene oil in villages. Other energy carriers, such as LPG for cooking and renewable energy technologies for multiple energy end-uses, are also relevant in the Indian context although their reach is more limited. The wide reach of rural energy programmes makes modern energy carriers accessible, at least in the physical sense, across most states of India.

From national and macro- perspectives, rural energy programmes have enabled access to modern energy carriers for a wide spectrum of people, across different social and economic groups. However, despite the large national rural energy programmes, there are significant differences in inter-state and intra-state accessibility to modern energy carriers ${ }^{91}$. For example, the level of access to electricity varied from 5\% to $95 \%$ of rural households (Census of India, 2001a). Similarly, within several states of India, access to modern energy carriers for cooking is limited to urban areas, and mostly to medium and high income households (NSSO, 2007;Pachauri and Jiang, 2008). Further, rural household access to LPG varies from less than $1 \%$ in most states to a maximum of 23\% (Census of India, 2001a).

In order to identify states from which to further select the case-study regions, an analysis was undertaken using two indicators: electrification of rural households and rural poverty rate (see Figure 3.1). It is important to emphasise here that rural households' access to LPG was not used as an indicator because the level of LPG accessibility in nearly all the states, was extremely low with very little variation ${ }^{92}$. The spatial mapping of the states led to their categorisation into four types:

i. $\quad$ states with a high percentage of rural household electrification and a high rate of rural poverty;

ii. States with low rates of household electrification and low rates of rural poverty;

iii. states with low levels of household electrification and high poverty rates; and, finally, iv. states with high rates of household electrification and low rural poverty rates.

\footnotetext{
${ }^{90}$ Annex I provides a detailed profile of the case study regions.

${ }^{91}$ In Annex II, data related to energy access in India, including variations across states, is presented.

92 However, the delivery pathways and local organisational arrangements for LPG delivery in rural areas was an important factor in selecting case-study regions. This is further explained in Section 3.2.2.
} 


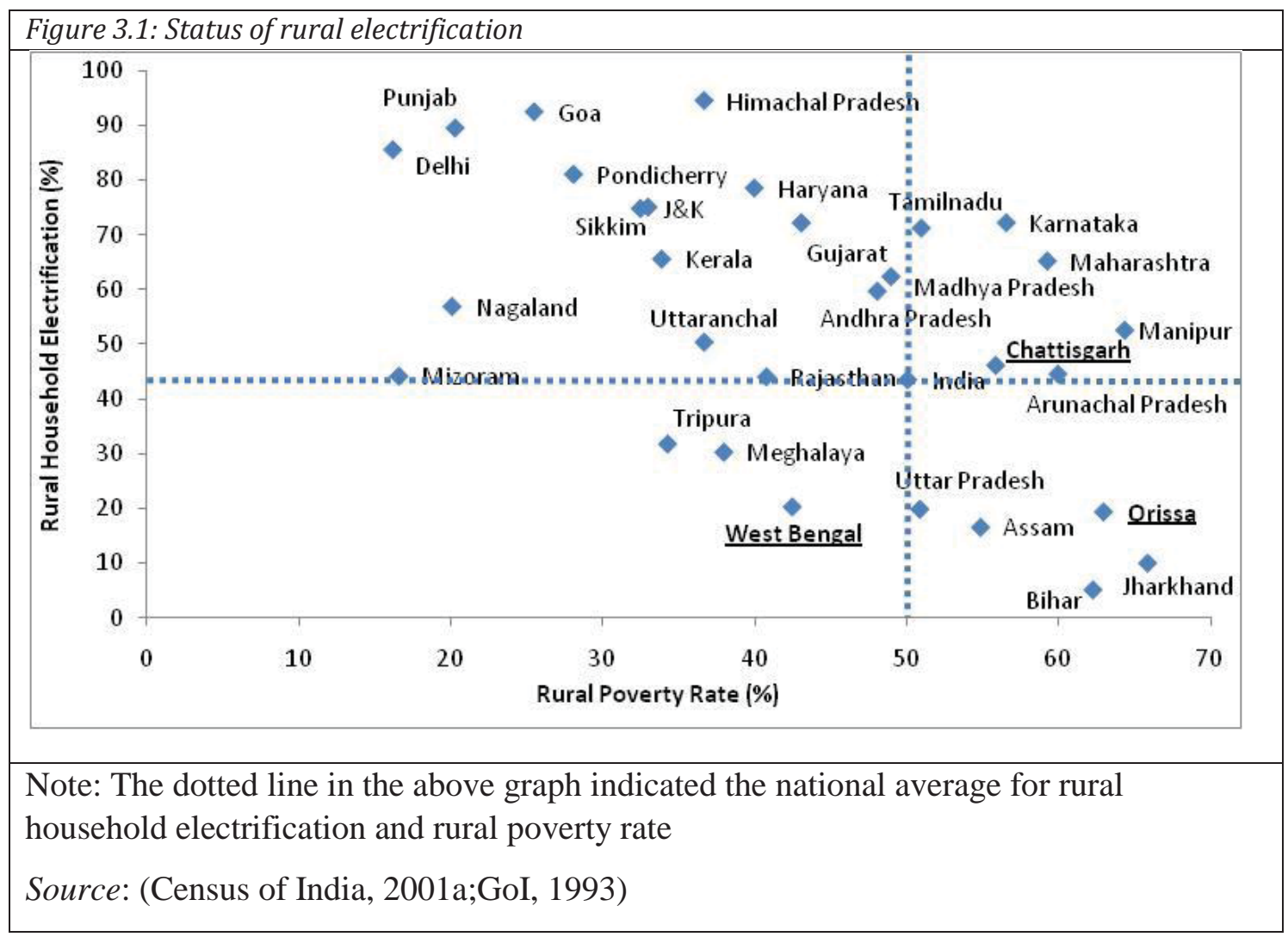

As the objective of this dissertation was to look at access to modern energy carriers in the context of energy policy reforms, information on energy policy, and especially related to the electricity sector, was also critical in the selection of states. When the policy reforms started in India (after 1991), a few states (Orissa, Haryana and Andhra Pradesh) started to explore privatisation by unbundling their electricity sector. Among these states, Orissa was the only state to have privatised its sector as of 1999. To meet the objectives of this research, it was important to understand the impact of the privatisation of electricity distribution on access to electricity. Therefore, Orissa was identified as an appropriate state for further study to understand the impact on accessibility by low-capacity end-users of a restructured energy distribution system. Interestingly, as Figure 3.1 shows, Orissa has low levels of accessibility to household electricity in rural areas (19.4\%) and a high rural poverty rate (63\%).

As rural access to household electricity remained low in many states, new approaches for enhancing access to electricity were introduced. One such approach was the setting up of small-scale decentralised power generation systems and establishing a local electricity distribution grid. The state of West Bengal, in eastern India, initiated such a programme for decentralised rural electrification using biomass and solar energy. It started with a model of electricity cooperatives for managing electricity generation and distribution in villages. The study of such decentralised models for electricity generation and distribution would enable this research to fulfil its objective of analysing enhanced accessibility to modern energy carriers. The state of West Bengal also has a very low level of rural household electrification 
(20.3\%) and a rural poverty rate (42.5\%) lower than much of the country. On this basis, the state of West Bengal was identified as another state in which to identify a case-study region.

In the context of energy policy, the government plays a dominant role in enhancing access to modern energy and it is therefore valuable to study a state in which the government has been involved in enhancing energy accessibility. Given that, with the exception of Orissa, all the state governments were involved in electricity distribution, it was decided to look at a state that had a high level of rural household electrification alongside a high rate of rural poverty. Keeping in mind the desire to investigate the role of the state in providing access to modern energy carriers, Chhattisgarh with its high rural poverty rate (55.9\%) and relatively high level of rural household electrification (46.1\%) was a suitable state in which to identify the third case-study region for this dissertation. A further, practical, consideration was that Chhattisgarh shares a border with Orissa and, therefore, all the three case-study regions were relatively close to each other making it easier to conduct fieldwork.

Another reason for selecting these three states emerges from an ideological perspective rooted in India's constitution and development paradigm for poverty alleviation. The objective of this dissertation, as defined in Chapter 1, emphasises the need for policies to address the problems of rural low-capacity end-users. As such, the policy design needs to ensure that the programmes formulated within the policy framework reach the poorest of the poor. Each of these three states have regions (districts and blocks) which are either remote and have limited infrastructural development (such as the Sundarbans Islands in West Bengal and the tribal districts of Bastar in Chhattisgarh) or have high incidences of poverty (such as districts of western Orissa). Therefore, from an ideological point of view, focussing on such regions within the states enables one to understand and draw lessons regarding the effectiveness and applicability of central and state government policies in enhancing access to modern energy forms in regions where the development issues of poverty and growth are a concern.

The three states, West Bengal, Chhattisgarh and Orissa, while having varying levels of accessibility to household electricity, are similar with regard to their accessibility to LPG for cooking. In West Bengal, 20.3\% of rural households have access to electricity, while in Orissa it is only $19.4 \%$, rates far below the national average of $43.5 \%$ (Table 3.1). In Chhattisgarh, $46 \%$ of the rural population have an electricity connection, slightly above the national average. Access to LPG in all three states is below the national average of $5.7 \%$ of rural households. In West Bengal, 2.3\% of the rural households use LPG for cooking, whereas in Chhattisgarh and Orissa it is only about 1\% (Table 3.1).

However, there are wide regional variations in these states and several districts have extremely low rates of accessibility to modern energy carriers even when the state average appears reasonable. The characteristics of the states also have a bearing on the accessibility of modern energy carriers. In all three states, there are geographical regions which are remote, have limited economic infrastructure, which influences energy delivery pathways, and low per capita incomes. This low level of access (due to a combination of dispersed spread of villages and limited availability) to modern energy carriers, makes it possible to study rural 
In Pursuit of a Light Bulb and a Smokeless Kitchen

areas that are socioeconomically similar but with and without access to modern energy carriers in the three states of West Bengal, Chhattisgarh and Orissa.

Table 3.1: Access to Modern Energy Carriers and Rural Poverty Rate

\begin{tabular}{|c|c|c|c|c|}
\hline Energy Carrier & All India & West Bengal & Chhattisgarh & Orissa \\
\hline \multicolumn{5}{|c|}{ Energy Access** (per cent of rural households - 2001) } \\
\hline Electricity & 43.5 & 20.3 & 46.1 & 19.4 \\
\hline Kerosene oil (lighting) & 55.6 & 79.2 & 52.9 & 79.8 \\
\hline LPG & 5.7 & 2.3 & 1.0 & 1.0 \\
\hline $\begin{array}{l}\text { Kerosene oil } \\
\text { (cooking) }\end{array}$ & 1.6 & 0.6 & 0.7 & 0.7 \\
\hline Biomass fuels & 90.0 & $84.2^{93}$ & 88.6 & 74.8 \\
\hline $\begin{array}{l}\text { Rural Poverty Rate*** } \\
\text { (percentage of rural } \\
\text { households - 1993) }\end{array}$ & 50.1 & 42.5 & 55.9 & 63.0 \\
\hline
\end{tabular}

\subsubsection{Selected Case Study Regions: Gosaba, Bastar and Kalahandi Blocks}

Gosaba (in West Bengal), Bastar (in Chhattisgarh) and Kalahandi (in Orissa) as case study regions have different levels of access by rural households to modern energy carriers. Map 3.1 presents the locations of the case study regions where the detailed field-study research was conducted. Since the focus of the research is on accessibility in the context of energy policy, selecting these three regions as case studies makes it possible to understand the problems of improving access to modern energy as well as the opportunities that need to be grasped through different initiatives to overcome these problems. The regions contain rural households with and without access to modern energy, as well as programmes for delivering modern energy to various economic groups. By comparing these three distinct regions, a wider understanding of the problems related to energy access by various economic groups becomes possible.

A second reason for this selection of regions is that these three case studies provide the opportunity to study different delivery pathways for enhancing access to modern energy, especially electricity: decentralised generation and distribution, distribution by private company, and distribution by state-owned utility. As such, these three case studies could provide specific lessons for policymakers that would enable them to develop energy programmes for enhancing rural electricity accessibility.

At the policy level, if policies are both effective and applicable, then they should result in enhanced access to modern energy. If policies fail to enhance access then this is either due to

\footnotetext{
${ }^{93}$ In West Bengal, these include firewood, crop residues and cow dung cakes. In the other two states, it is predominantly firewood. 
an ineffective policy design, inappropriate implementation, or to a lack of a proper analysis prior to implementation. The following two subsections provide details on levels of access to modern energy carriers and the delivery pathways for each of the three case-study regions.

\section{Energy Access}

Gosaba Island in the Gosaba block of South 24 Parganas is part of the Sundarbans delta region. The region has a heterogeneous demographic profile with migrants settled on the islands. The backward classes, including scheduled castes (SCs) and scheduled tribes (STs), form the dominant social groups on the island (Block Development Office Gosaba, 2001). Agriculture (rain-fed, mono-cropping) along with fishing, especially of bagdha mach (tiger prawn seeds), are the main economic activities and sources of livelihood (Danda, 2007). Other livelihood opportunities include forest produce collection and marketing, government service and business. Despite its inaccessibility, the local economy is developed and robust, and the literacy rate of the region is 68\% (Census of India, 2001a). Gosaba being a river island has a poor transport infrastructure, but is relatively well off compared to other islands in the Sundarbans delta. In 1997, a decentralised power generation unit based on biomass energy was set up, although it now operates mostly on diesel, providing electricity to 273 domestic households. Further, about 400 solar photovoltaic home lighting systems have been installed (Sinha, 2001;TERI, 1998).

Access to modern energy for lighting at the time of the first fieldwork period was high in Gosaba, with about 36\% of households using local grid electricity and/or solar photovoltaic (SPV) systems. In the district of South 24 Parganas, where Gosaba is located, only $17.4 \%$ of rural households have access to electricity less than the state average of West Bengal (20.3\%, see Table 3.2). On Gosaba, 15\% households use LPG for cooking, a much higher percentage than in the overall district of South 24 Parganas (2.4\%) and in the state of West Bengal as a whole. In the absence of electricity and LPG, $82.3 \%$ of rural households in the district use kerosene oil to meet their lighting requirements, a higher figure than for the state as a whole. To meet their cooking needs, $87.5 \%$ rural households in the district use biomass (wood). Remaining households use kerosene oil and other forms of traditional energy carriers such as dung cakes and crop residues including saw dust.

The Bastar district is predominantly a tribal district with $70 \%$ of the population belonging to scheduled tribes (Census of India, 2001b). Although 45\% of the rural population in the district are literate, the literacy rate among the tribal people is as low as $14 \%$ (Census of India, 2001b). Bastar district is rich in minerals and forest resources. Agriculture and the collection and marketing of minor forest produce are the main livelihood sources. The economy of the district suffers from underemployment and the collusion between bureaucrat and traders who manipulate the market forcing households into the distress selling ${ }^{94}$ of agricultural and forest products. The district is connected through a highway from the state

${ }^{94}$ Distress selling usually occurs when a household sells its agriculture or forest products (especially those which are perishable) due to a lack of adequate storage facilities or other opportunities to add value to these products. The household receives a low price. Another reason for distress selling is to meet immediate cash needs or to repay debts. 
In Pursuit of a Light Bulb and a Smokeless Kitchen

Map 3.1: Location of Case Study Regions in India

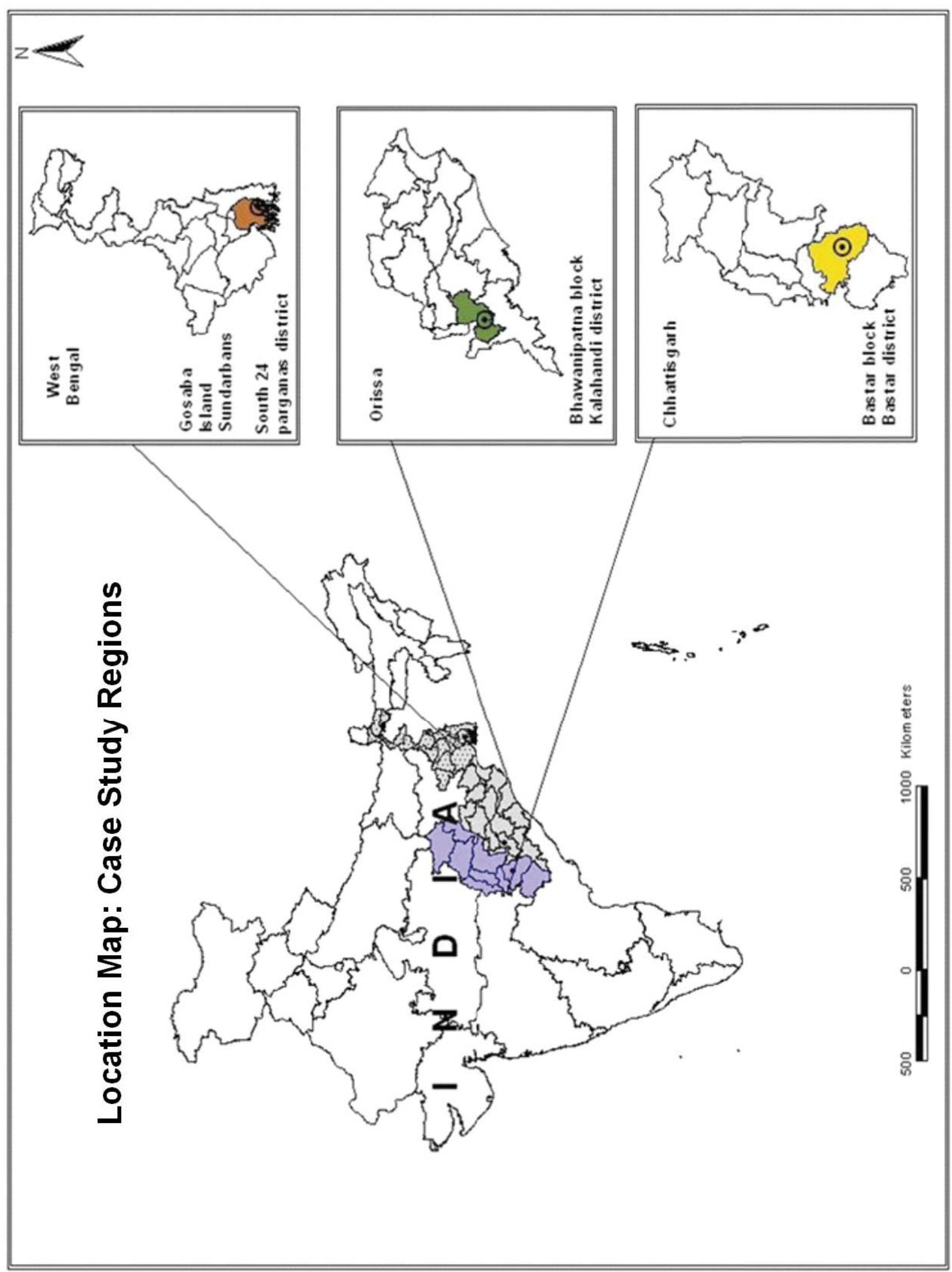


capital, however, the district does not have adequate rail connectivity. The communication as well as road infrastructure within the district, is still underdeveloped.

In Bastar, 29\% of rural households use electricity (see Table 3.2), which is quite low compared to the state of Chhattisgarh average (46\%, see Table 3.2). Only $0.8 \%$ of rural households in Bastar use LPG for cooking, similar to the state average. Kerosene oil is used for lighting in 69.7\% of rural households in Bastar, and 97.9\% use biomass for cooking, which are much higher levels than those seen at the state level.

The Kalahandi district is part of western Orissa and is one of the most backward districts in the state and indeed the country. While $44 \%$ of the district population comprise SCs and STs, the rest are made up of the other backward classes (OBCs) plus landlords known as gonthiyas (Census of India, 2001b). The literacy rate in the rural area of the district is $46 \%$ (Census of India, 2001b). The rural population is dependent on subsistence farming, with more than half of the rural households being small and marginal farmers (with less than 2 hectares of land), and about 32\% of households being landless. In the absence of economic activities in the district, there is increasing evidence of out-migration in the rural areas. In terms of accessibility, the district is remote: road and rail connectivity along with the communication infrastructure is poor, and particularly so in forest villages.

In Kalahandi, only $10.2 \%$ of rural households have access to electricity (Table 3.2), only half the state average (Table 3.1). Only $0.8 \%$ of rural households in Kalahandi use LPG, which is similar to rural households in rest of the State. In Kalahandi district, 89.4\% rural households use kerosene oil for lighting and $96.1 \%$ on biomass fuels for cooking, much higher percentages than the state averages.

\section{Table 3.2: Access to Energy Carriers for Cooking and Lighting}

(\% of rural households) - 2001

\begin{tabular}{|l|l|l|l|}
\hline Energy Carriers & \multicolumn{3}{|c|}{ Districts } \\
\hline Electricity & South 24 Parganas & Bastar & Kalahandi \\
\hline Kerosene oil (lighting) & $17.4(-2.9)$ & $29.0(-17.1)$ & $10.2(-9.2)$ \\
\hline LPG & $82.3(+3.1)$ & $69.7(+16.8)$ & $89.4(+9.6)$ \\
\hline Kerosene oil (cooking) & $2.4(+0.1)$ & $0.8(-0.2)$ & $0.8(-0.2)$ \\
\hline Biomass fuels & $87.5^{95}(+3)$ & $0.8(+0.1)$ & $0.4(-0.3)$ \\
\hline $\begin{array}{l}\text { The figures in parentheses show the position relative to the state average. A positive (+) value indicates } \\
\text { that district penetration is higher than in the state. }\end{array}$ \\
Source: (Census of India, 2001a)
\end{tabular}

\section{Delivery Pathways}

Delivery pathways, as explained in Section 2.4, form the critical part of energy policies in delivering and enhancing access to modern energy carriers by low-capacity end-users in rural

\footnotetext{
95 In South 24 Parganas, this includes firewood, crop residues and cow dung cakes. In the other two regions, firewood predominates.
} 
areas. In India, both the central and state governments play a role in delivering energy carriers $^{96}$. The role of the state government lies in the distribution of energy carriers and ensuring that policies and programmes address the principles of equity across different sections of society and especially the economically weaker sections.

In Gosaba, the delivery pathway for electricity distribution involves an electricity cooperative that manages a decentralised off-grid biomass gasifier power plant. This electricity cooperative and its off-grid power plant were the first decentralised biomass ${ }^{97}$ gasifier rural electrification initiative in the State. The electricity cooperative is responsible for the generation and distribution of electricity on the island. The cooperative also manages the commercial and revenue aspects of electricity distribution involving meter reading, bill distribution and revenue collection. Another interesting element of the delivery pathways is the development of an informal arrangement with a boatman for LPG distribution in the absence of any formal delivery organisations.

In Bastar, the delivery pathway for electricity distribution involves the state electricity board. The Chhattisgarh State Electricity Board (CSEB) is responsible for the generation, transmission and distribution of electricity. Since the paying capacity of the rural households in Bastar is low, the CSEB's electricity circle in Bastar initiated a unique system of bill payments that enabled households to pay their bills on a monthly or a quarterly basis. The Large Areas Multi Purpose Society (LAMPS), a formal organisation, manages the delivery pathway for the public distribution system (PDS) enabling improved access to essential commodities and kerosene oil as per the paying ability of the rural households.

In Kalahandi, the delivery pathway for electricity distribution involves a private distribution company - the Western Orissa Electricity Supply and Distribution Company (WESCO). The Village Bidyut Sangha (VBS) was established by a third party organisation, the Xavier Institute of Management (XIM), in the service area of the distribution utility. VBS is a village-based electricity committee responsible for managing the commercial aspects of rural electricity distribution on behalf of WESCO (XIM, 2001). They function as an intermediary of the distribution company and are responsible for meter reading, bill distribution, revenue collection and handling consumer grievances. Kalahandi therefore provides an interesting delivery pathway of an informal village-level organisation working with a private electricity distribution company.

The case-study regions (Gosaba, Bastar and Kalahandi) represent large parts of rural India in that they continue to suffer from limited access to modern energy. Therefore, by focussing on these three case-study regions, this research can investigate different levels of energy access and different delivery pathways for the distribution of electricity, LPG and kerosene oil. Despite the differences in the delivery pathways, these regions are similar and this can assist

\footnotetext{
${ }^{96}$ See Chapter 4 for a discussion on policies and programmes related to rural energy in India.

${ }^{97}$ The decentralised power generation project was set-up as a biomass-based gasifier. However, this project did not have an adequate and reliable biomass supply chain and, as a result, the decentralised power plant operates mostly on diesel rather than biomass. This will be further discussed in Section 5.2 where energy delivery pathways in the Gosaba case study are addressed.
} 
in understanding how contextual influences affect access to modern energy carriers by lowcapacity end-users. The combination of these three case studies will allow the results from the case studies to be generalised, leading to policy recommendations for similar rural areas.

\subsubsection{Village Selection and Field Surveys}

A group of villages with a common local delivery pathway made up a research location. This grouping is termed a 'village cluster' within the case study regions in this research. This prioritisation of delivery pathway as the means for selecting research locations followed from the understanding that the presence of an enabling organisation is a key factor in a household's access to modern energy carriers. It is important to evaluate the perspective of households, not only to gain deeper insights into their motivation for adopting modern energy carriers and their perceptions of the benefits that these forms of energy could provide, but also to gain an understanding of the reasons for the inability of some to gain access to modern energy. To analyse the contrast between underserved and unserved rural households, it is necessary to select village clusters that have access to modern energy but where accessibility is an ongoing process.

The village clusters were selected in 2001. Using the information available through the Census, and from statistical and energy studies, a number of villages in the three districts were inspected. As part of these initial visits, discussions were held with government officials, non-governmental organisations (NGOs) and Gram Panchayats (GPs) to understand development priorities and the role of energy in village development.

The first trip to Gosaba Island was undertaken in March 2001. Here, the selection of villages was restricted to those that were served by the electricity grid or had been identified for grid extension. Using this criteria, Gosaba and Rangebelia were identified as village clusters. Discussions were held with Rupayan - a grassroots organisation, the field centre of the Ramakrishna Mission (R K Mission) and the Electricity Cooperative to understand the current extent of electrification and the plans for future electrification. At the same time, discussions were also held with two schoolteachers ${ }^{98}$ who provided information regarding the delivery of LPG and kerosene oil.

In Bastar, two reconnaissance visits were made to identify villages. The first visit was made in July 2001, which was used to familiarise myself with the region by meeting government officials and NGOs. Detailed interactions and discussions were held with the Adivasi Harijan Kalyan Samiti (AHKS), the R K Mission and Vikas Mitra to understand the extent of energy use in the villages and the socioeconomic conditions in three blocks: Bastar, Kondagaon and Narayanpur. The second visit was made in December 2001, when additional information was collected and visits to other villages were made with the help of government officials in

98 The researcher was already familiar with Gosaba Island as he had been working on this island since 1996. He was involved in a study on the impact of solar lighting systems for an Indo-US project. Studies were undertaken in 1996 before lighting systems were installed, and then in 1997-98 when solar lighting systems were in use by households. The two schoolteachers were familiar to the researcher from these previous research studies. 
Bastar block and with Vikas Mitra, a grassroots organisation in Kondagaon block. Initially in Bastar district, three village clusters were identified: the Kudalgaon and Tikhralohanga cluster in Bastar block, the Kondagaon village cluster in Kondagaon block, and the Abhujmand village cluster in Narayanpur block. In the final survey, the Kondagaon and Abhujmand clusters were not included on the advice of district officials, as the village clusters lay within forests in a Naxal-affected area ${ }^{99}$. From a security perspective, it was not feasible to live in these villages and, therefore, the study was limited to those village clusters identified in the Bastar block. The main sources of information in government departments were the office of the district collector and the block development office. Visits to the village clusters were coordinated with the help of village extension officer attached to the GPs and the field staff of the NGOs.

Kalahandi was visited in November/December 2001. Two organisations, the office of the Xavier Institute of Management (XIM) Project and Antyodaya, an NGO in Bhawanipatna, were contacted and initial visits were made to the two villages of Laxmipur and Janakpur. Discussions were held with members of the local VBS to gain an understanding of electricity accessibility and energy use pattern in the villages. Based on these discussions, two village clusters Laxmipur and Janakpur which, along with their surrounding villages, had no access to electricity and LPG were identified.

This resulted in a selection of six village clusters:

i. In Gosaba: (1) the Gosaba village cluster comprising Gosaba and its five padas (Arampur, Malopara, Kathakali, Gosaba-I and Gosaba-II); and (2) Rangebelia village.

ii. In Bastar: (1) the Kudalgaon village cluster comprising the main Kudalgaon village and its two padas (Kudalgaon, Kudalgaon-1 and Kudalgaon-2); and (2) Tikhralohanga village cluster comprising the main village of Tikhralohanga and its pada Tikhralohanga -1 plus Ghatlohanga main village and its pada Ghatlohanga-1.

iii. In Kalahandi: (1) the Laxmipur village cluster comprising Laxmipur and the small villages of Gotbhata, Bhairavpur and Ranikota; and (2) the Janakpur village cluster consisting of Janakpur, Icchapur and Balrampur villages.

The village clusters selected in the three case study areas provide a combination of unserved and underserved households and different delivery pathways for modern energy carriers. The village clusters met the required conditions needed to answer the research questions previously presented in Chapter 2. Annex 1 provides information about the socioeconomic conditions in the case study regions. Chapter 5 presents detailed information on the backgrounds of the village clusters and also focuses on the energy delivery pathways in the village clusters that are relevant when it comes to interpreting the findings of this research.

\footnotetext{
${ }^{99}$ Naxal-affected areas are those regions where the Naxalites, also called Maoists, are present. Naxalites are members of an extreme left-oriented group that are in armed conflict with the state administration and police.
} 


\section{Field Surveys}

As noted at the beginning of this chapter, field surveys were conducted in two different periods. The first round of surveys, which provides the core information for each case-study region, was undertaken between 2001 and 2002.

i. In Gosaba, the field survey was undertaken between March and June 2001. Due to state assembly elections in early May 2001, the survey was temporality discontinued and was resumed in the last week of May 2001.

ii. In Bastar, a detailed field survey was carried out in Kudalgaon and Tikhralohanga village clusters between mid-April 2002 and June 2002.

iii. In Kalahandi, field surveys were undertaken in the two village clusters between February and March 2002.

\footnotetext{
The Role of Field Assistants

In each of the three case study regions, village youth were employed as field assistants to help with the household survey and in identifying key informants. In selecting the field assistants, it was natural to identify a local person, someone who was familiar with the village(s) as well as having information about households and other key informants. In Gosaba, the field assistant was a solar energy technician, trained by the R K Mission to provide technical support to their solar energy programme. In Bastar, two field assistants were hired. The one in the Kudalgaon village cluster was a postgraduate student active in village development programmes. The second field assistant was hired in Tikhralohanga village cluster, and was an unemployed graduate. He was involved in helping the Panchayat officer and, therefore, familiar with the village and with various rural development activities. In Kalahandi, the field assistant was an experienced researcher who had previously worked with NGOs in the district on rural development programmes.

The advantage of having field assistants belonging to the case study regions was their familiarity with the local language and their knowledge of the region and the villages. Further, the author comes from the eastern part of India and has previously worked in the rural areas of this region. As such, he is familiar with the local languages of Bengali, Oriya and Hindi. In addition, most of the households in these three areas understand Hindi and, therefore, the interviews were not complicated by language issues.
}

The second survey of the village clusters_was undertaken between September 2008 and January 2009. The policy context for rural energy changed in 2004 with the launch of national rural electrification programmes (see Section 4.4.2), the Rural Electrification Policy 2006 and the Integrated Energy Policy 2006. The introduction of new policies and programmes were aimed at enhancing access to modern energy carriers in the rural areas of India. In order to understand how the new policy measures and programmes were intended to improve accessibility to modern energy, an additional round of surveys was undertaken to gather information from organisations involved in the delivery of energy carriers and from households in the village clusters.

i. In Gosaba, the survey was undertaken during September-October 2008. During this field study, discussions were held with staff of the Gosaba Electricity Cooperative, LPG dealers in Gosaba market, the representatives of the Fair Price Shop (FPS), and with local shopkeepers to understand the changes that had occurred in energy supply 
and distribution since 2001. In addition to this, households whose case stories form the narrative of this dissertation were re-interviewed to understand the changes between 2001 and 2008.

ii. In Bastar, the survey was undertaken during December 2008-January 2009. The continuing and growing activities by Naxalites in Bastar and surrounding districts, and counter-operations by the police, meant it required caution when visiting the region. To find out about the organisations involved in the delivery of energy carriers, meetings were held with officials in Raipur and interviews conducted with households in the village clusters of Kudalgaon and Tikhralohanga who had been the basis of case stories in the first round.

iii. In Kalahandi, the survey was undertaken during November-December 2008. Meetings were held with the Western Orissa Electricity Supply Company (WESCO), LPG dealers, and the Food and Civil Supplies department in Bhawanipatna. Interviews were again conducted with the households who formed the case stories based on the first round of surveys. The purpose of the interviews with the households was to understand the changes in energy access and reasons for these changes.

\section{Field Assistants during 2008-2009}

A new set of field assistants were recruited for the second phase of the survey. In Gosaba, I was assisted by a field staff of the Sundarbans Climate Change Programme of the World Wide Fund for Nature (WWF) - India. In Bastar and Kalahandi, the field assistants were from a local NGO working in villages in the Bastar and Kalahandi districts. All the three field assistants were familiar with the region, and were trained in conducting household surveys. They were also familiar with the context of energy and development issues in the region. This was extremely useful in obtaining detailed information within a short period.

\subsubsection{Sampling Households}

The survey for collecting empirical data had to provide a good spread to enable one to understand the extent of energy usage and the causes for any shifts between the various energy carriers. The identified households (the sample) had to represent the users and nonusers of modern energy carriers in the rural areas. To delineate the population, from which the sample was to be drawn, the definitions of a low-capacity end-user and of underserved and unserved populations were used in identifying village households. The household respondents were purposively selected to represent the underserved, with different levels of access to modern energy, and unserved households within the village clusters. In addition to the household survey, semi-structured interviews and open discussions with key informants and discussion groups at the village level, as well as observations, served to improve the internal validity of the data through triangulation. Additionally, interviews with government officials and organisations involved in energy delivery, as well as official statistics and reports, helped assess the extent and quality of the current interventions, and in some cases acted as a check on the village-level data. 
Identifying representative households in the case study villages was a two-step process. An exhaustive list of low-capacity end-users was prepared with the help of the field assistants and crosschecked with key informants and the Gram Panchayat ${ }^{100}$ (GP) . In Gosaba, a list of households with electricity connections was obtained from the electricity cooperative while details of those having solar lighting systems were obtained from Rupayan. Further, the names of two private retailers selling solar lighting systems in Gosaba market and of households using LPG were acquired from the boatman who ferried cylinders and from the private-sector LPG dealer. In Bastar, households with access to electricity and LPG were identified with the help of the GP. In Kalahandi, the study by XIM (2001) provided a list of households having electricity in each village(XIM, 2001). The key informants further helped in identifying households that were using LPG at the time of the field survey.

In the formulation of rural energy programmes, economic status and distinct policy instruments, either in the form of a programme or subsidies, are emphasised. The government uses the criteria of Above Poverty Line (APL) and Below Poverty Line (BPL) ${ }^{101}$ to classify the population when providing benefits under the public distribution and other government programmes (Planning Commission, 2002c). This information is available within the GP as they are involved in undertaking surveys and preparing the list of BPL households. In each of the three case study regions, BPL household lists were obtained from the local GP and these together with the information on underserved and unserved households were used to identify the samples of household respondents.

Applying the economic status criterion also meant that there was saturation in the information collected (Yin, 2003). The underserved low-capacity end-users include those with access to electricity (including SPV systems) and to LPG. The unserved households include those who had no access to modern energy carriers. In Gosaba, the survey included 63 underserved households, who were found to be using electricity, LPG, SPV or a combination of these energy carriers, and 31 unserved households, both groups including APL and BPL households. In Bastar, 89 households were surveyed made up of 48 underserved and 41 unserved households. In Kalahandi, 92 households were surveyed with 48 being underserved and 44 unserved.

${ }^{100}$ A Gram Panchayat (GP) is a local self-governance institution and is the lowest tier in implementing government programmes. A GP may typically cover a cluster of villages or a village itself, depending upon the population size. A GP organises gram sabhas to solicit people's participation in identifying priorities for development programmes, and in acquiring state funding.

${ }^{101}$ The Expert Group, constituted by the Government of India in 2000, recommended that rather than relying on measures such as income or expenditure to identify the poor, socioeconomic indicators reflecting the quality of life should be used to identify village BPL households. In practice, the Planning Commission opted for uniform cut-off thresholds, rather than adopting intra-state variation, partly due to limited information on living standards on a sub-state basis, and partly in response to political economy concerns about sections of richer states missing out (Jalan and Murgai, 2007). 


\subsection{Research Techniques}

The research techniques used can be described as a combination of quantitative and qualitative $^{102}$, an approach often used for developing an understanding of a problem that emerges from primary data systematically gathered and analysed (Yin, 2003). In the dissertation, the qualitative techniques involving interviews with the households and key informants in the villages are dominant. The ongoing interactive process between empirical data and analytical concepts during the research process allows an understanding to emerge.

\subsubsection{Research Techniques for Village Clusters}

At the village cluster level, interviews formed the basis for collecting empirical data. A semistructured survey instrument guided the interviews. The first set of interviews involved faceto-face discussions and interaction with households. The second set of interviews was with organisations involved with the delivery of modern energy carriers in the village clusters, and the final set of interviews was with the key informants in the village.

Since the focus of the household interviews was on access to modern energy carriers, respondents were both male and female. In some households, women were the lead respondents but in the majority of the households the male member of the family responded. In gathering information related to cooking energy, responses were always obtained from the women members of the household. For household interviews, the first part of the semistructured instrument ${ }^{103}$ focused on information related to socioeconomic data such as head of family, education, main source of income and assets. The second part of the survey instrument focused on access and use of different forms of energy. Then, if households were using modern energy carriers, the third part of the survey instrument was used to seek information on the choice of modern energy carrier, the year of its acquisition, experience and perception on energy use, and factors that motivated them to start using modern energy carriers. For households not using modern energy carriers, the focus was more on understanding the reasons for this, especially in terms of whether it was due to physical constraints or a lack of affordability. The final part of the semi-structured instrument focused on issues related to development, problems and opportunities within the village cluster or in the district, allowing an open discussion and getting views on themes not covered in the survey. While the semi-structured instrument helped in guiding the household survey, the interviews were conducted in a manner that the prepared questions did not limit the information obtained, which was guided more by the circumstances of the household.

The primary approach for collecting data at the household level was kept simple. The focus was on understanding how energy access transition took place. The semi-structured interviews were complemented with informal conversations and discussions with the respondents. This involved listening to their problems and how they had found solutions or what they thought the solutions should be. One should also understand that while economic

\footnotetext{
102 The process of combining different research techniques as part of the research methodology contributes to the process known as triangulation (Babbie, 2003).

103 The semi-structured instrument used for household survey is presented in Annex III. 
reforms in India were already more than a decade old (starting in 1991), the public perception of the reform policies is that they are focussed on urban areas. Given that the reform processes in the electricity sector were different in the three case study regions, the focus of the discussions varied accordingly. In Kalahandi, where distribution of electricity was privatised, the discussions focused on gaining an in-depth understanding of the changes resulting from privatisation. In comparison, the discussion in Gosaba focused on the role of the electricity cooperatives, and in Bastar on the State Electricity Board (SEB).

The second set of semi-structured interviews was conducted with organisations involved in the delivery of modern energy carriers. This round of interviews was not a one-off event, but carried out on a number of occasions to help understand how the energy delivery system operated. The interviews focused on data related to energy access: sources of energy, energy supply, energy consumption and utilisation, energy prices and factors changing energy use by households, commercial establishments, rural industries and the agricultural sector.

The third set of interviews at the village cluster level were with key informants. These were selected based on their potential knowledge, either by virtue of their position in society or because they had a good overview of development problems in the region. The interviews with key informants focused on a range of issues related to the changes and developments in the region, and the potential for change and the role of energy in meeting future development issues. The key informants included schools teachers, local doctors, village leaders, local politicians, Gram Panchayats and NGO staff. For example, in Gosaba, key informant interviews were held with schoolteachers ${ }^{104}$ and a doctor ${ }^{105}$ active in various rural development and education programmes, and in local politics. An informal discussion was also conducted with the former chairperson of the Panchayat Samiti ${ }^{106}$ who was involved in establishing the biomass gasifier power plant and setting up the electricity cooperative. The discussions generally revolved around the research themes but incorporated other issues that were considered important.

Information was also collected through informal discussions with villagers, a process that came easier if one lived in the village. Conversations over cups of tea at a stall in Gosaba market, late in the evening, with people joining and leaving the discussion on the electricity cooperative and distribution of kerosene oil were extremely informative. These conversations were useful in finding out about the politics involved in the management of the electricity cooperative and about the lack of a role for block development officials in controlling the pilfering of kerosene oil. In Bastar, discussions with villagers before and after the meeting of the Gram Panchayat showed how several efforts to enhance income-generating opportunities had been thwarted by connivance between government officials and traders. In Kalahandi, a

\footnotetext{
${ }^{104}$ Discussions were held with three schoolteachers from Gosaba and Rangebelia High School who were active in local development initiatives with NGOs and village institutions. Discussions were also held with two retired schoolteachers, who were also active at different times in local politics. These discussions were held between 25 May 2001 and 4 June 2001.

${ }^{105}$ Dr Barman has been associated with the island for the last fifty years; he manages the Gosaba Trust and offers free medical services to the local population.

${ }^{106}$ Interview held on 4 June 2001.
} 
conversation at the village shop with a BPL household provided information on how BPL households were pledging their ration cards in return for securing a loan. Several of these households were then having to purchase their food and kerosene oil requirements at a much higher price from the market, and often in very small quantities (for example, Rs 10 of rice, Rs 3 of sugar, Rs 2 of salt and Rs 3 of kerosene oil).

\subsubsection{Research Techniques for Policy Analysis}

\section{Content Analysis}

In this research, formal energy policies were important sources of information. A content analysis of the policies within India's overall developmental policy was conducted in order to understand the changes in the national energy policy. The narrative is based on a review of policy documents, legislation and statutes, and an analysis of budgetary allocations by the government for modern energy carriers.

The technique of content analysis was applied to analyse information from documents ranging from those related to previous studies (publications on case study regions) to government policy documents (constitutional provisions, acts, legislation, policy documents and reports). The sources of this information include published documents, archives, gazettes, web-based documents, newspaper articles, project documents and non-peer-reviewed literature. By applying this technique, this dissertation has benefited by drawing on replicable and valid inferences from texts related to the context of their use. Background information on important variables such as energy access, energy distribution infrastructure and rural development activities was collected from energy statistics and reports available at the block, district, state and national administrative levels. Secondary information sources included government records.

\section{Interviews}

In addition to interviews with key informants at the village-cluster level, interviews were also conducted with officials from government, the public sector and the private sector at the national and state levels on energy policies and programmes. The interviews with policymakers were conducted in order to understand energy policies, as well as the influence and effect of existing and emerging policies ${ }^{107}$.

\section{Participant Observation}

Between 2005 and 2010, the author was professionally involved in several capacities working on energy policy that cut across rural electrification, energy sector reforms, energy pricing, renewable energy and climate policy. In these various tasks, I worked with officials from central government ministries and state government departments, and those involved with energy utilities. My participation in these projects and policy dialogues has been useful for this dissertation. For example, working on the Eleventh Five-Year Plan, as a member of the

\footnotetext{
${ }^{107}$ The interviews with the governmental officials (central and state) were conducted on a non-attributable basis to encourage open and candid discussions. As such, individual comments have not been quoted. 
sub-committee on rural electrification, involved analysing the national rural electrification programme. Issues such as the management of electricity distribution through franchisees, tariffs and subsidies were discussed at length in the sub-committee meetings. The views of the various experts provided new insights into analysing policies related to rural electrification. Similarly, working on climate policy involved working and interacting with policymakers on issues of energy access as part of national climate change policy as well as on reforming fossil fuel subsidies.

Research organisations, policy institutes, international lending agencies and national policymakers made up the key group of stakeholders, and their perspectives on energy reforms and their impact on energy access in rural areas have been incorporated. I also actively participated in policy debates and policy formulation related to the topic of this dissertation. The overview of the data collection techniques used in this research and the data sources are given in Table 3.3.

\section{Table 3.3: Research Techniques}

\begin{tabular}{|c|c|c|c|}
\hline $\begin{array}{l}\text { Research } \\
\text { question }\end{array}$ & \multicolumn{2}{|l|}{ Technique } & Sources \\
\hline \multirow[t]{2}{*}{$\begin{array}{l}\text { Research } \\
\text { question } 1 \\
\text { Rural energy } \\
\text { policy in India }\end{array}$} & \multirow[t]{2}{*}{ Qualitative } & $\begin{array}{l}\text { - } \quad \text { Content } \\
\text { Analysis }\end{array}$ & $\begin{array}{l}\text { - Government policy documents and } \\
\text { legislation } \\
\text { - Review and critique of policies by energy } \\
\text { experts }\end{array}$ \\
\hline & & $\begin{array}{ll}\text { - } & \text { Key informants } \\
\text { interviewed }\end{array}$ & $\begin{array}{l}\text { - Government; energy sector stakeholders } \\
\text { (public and private sector) }\end{array}$ \\
\hline \multirow{5}{*}{$\begin{array}{l}\text { Research } \\
\text { question } 2 \\
\text { Energy access } \\
\text { by low- } \\
\text { capacity end- } \\
\text { users }\end{array}$} & \multirow[t]{2}{*}{ Qualitative } & $\begin{array}{ll} & \text { Content } \\
& \text { Analysis }\end{array}$ & $\begin{array}{l}\text { Published energy studies, reports, energy } \\
\text { statistics including budgetary allocations } \\
\text { from ministries and government } \\
\text { departments and public records in } \\
\text { government library }\end{array}$ \\
\hline & & $\begin{array}{l}\text { - } \quad \text { Key informants } \\
\text { interviewed }\end{array}$ & $\begin{array}{l}\text { Government departments and energy } \\
\text { sector stakeholders (suppliers and } \\
\text { distributors of energy carriers) }\end{array}$ \\
\hline & \multirow[t]{3}{*}{ Quantitative } & $\begin{array}{l}\text { - } \begin{array}{l}\text { Case study } \\
\text { approach }\end{array}\end{array}$ & $\begin{array}{l}\text { - Structured and semi-structured survey } \\
\text { instruments on energy access by low- } \\
\text { capacity end-users and group discussions }\end{array}$ \\
\hline & & $\begin{array}{ll}\text { - } & \text { Key informants } \\
\text { interviewed }\end{array}$ & $\begin{array}{ll}\text { - } & \text { NGOs and village institutions; and local } \\
\text { energy suppliers and distributors }\end{array}$ \\
\hline & & - Observation & $\begin{array}{l}\text { Energy collection, gathering, purchase } \\
\text { and use }\end{array}$ \\
\hline
\end{tabular}

Discussions involved interviews and presentations. Discussions were held with research staff, and presentations were made between February 2001 and July $2004^{108}$ in research organisations and institutes, followed by further discussions in 2008 and 2009. Similar

${ }^{108}$ Presentations on the research were made in July 2003 at the Institute for Social and Economic Change (ISEC) in Bangalore as part of the Faculty Recruitment Seminar; in October 2003 at the 2003 Open Meeting in Montreal; in February 2005 at Institute of Rural Management, Anand (IRMA); and at several workshops and conferences between 2005 and 2010 in India and elsewhere. 
discussions were held with international agencies between February 2001 and February 2003 and between 2008 and 2010. National policymakers in central government ministries were interviewed and discussions were held with senior government staff at the beginning of field activities in the following periods: January-February 2001, June-July 2004, 2006-2007 as part of the subcommittee on Rural Electrification during the Eleventh Five-Year Plan, and 2008-2010 during discussions on energy and climate policy.

\subsection{Validity and Reliability}

An important issue in social science research is the validity and reliability of the data sources used. In order to assess the quality of the research, social science applies four criteria (Denzin and Lincoln, 1998):

i. internal validity: the degree to which the findings correlate to the research phenomenon in question;

ii. external validity: the degree to which the findings can be generalised to other similar settings - or the robustness of the findings;

iii. reliability: the extent to which the findings can be replicated by another inquirer; and

iv. objectivity: the extent to which the findings are free from bias.

Internal validity is not only relevant in terms of the primary field data but also with qualitative techniques, and especially those involving key informant interviews. The household interviews and interviews with key informants were systematically compared across different groups of respondents. In the process of data collection during key informant interviews and surveys, triangulation was used to ensure the validity of the information collected. For example, when households offered information regarding price and quantity of kerosene oil purchased from PDS, or LPG from a distributor, or electricity from a distribution utility, these were crosschecked with their ration card records, LPG passbooks and electricity bills. In the case of key informant interviews pertaining to policy issues at the national and state levels, the information gained was compared with policy documents. Through lengthy stays in the villages of the case study regions, observational consistency was enhanced. Information was crosschecked with other groups of respondents and with observations and available public records. For example, the household respondents often found it difficult to identify the year in which they obtained an electricity connection. Such information was crosschecked with other respondents since most of the households were connected in the year that the village gained an electricity connection. The year of electricity connection was also verified by checking the electricity poles since these are inscribed with the year in which they were erected. Another problem often faced was inconsistency regarding the prices paid for energy by the respondents. This was crosschecked across different categories of respondents and with the retailers/dealers of energy carriers since it is mandatory for them to display prices on their information boards.

Another concern in social science research is related to the external validity of the empirical findings. The primary concern related to external validity is not just the issue of 
generalisation, but also the robustness of the empirical findings (Brinberg and McGrath, 1985). In this research, the emphasis has been on understanding the circumstances (opportunities or constraints) related to improving energy access in rural areas in specific case areas, and these may differ when comparing one case study with another. The recommendations from this study for improving energy access are based on the findings and results concerning the linkages between enabling factors and the contextual influences. The recommendations are rooted in the context of the factors affecting energy access and focus on solutions that can be adapted to improve energy access. This approach when drawing inferences from the results allows generalisation (i.e. external validity) of the findings to regions in India that may have different contexts while sharing similar challenges in terms of limited energy access. The recommendations made in this dissertation are based on the evidence from the three case study regions and are directed towards making modifications to the existing policy design and policy framework so as to make implementation more effective and applicable in improving energy access.

Not only is validity a concern, but also the reliability of the information collected. The reliability of the secondary data is questionable because they lack consistency and are often outdated. For example, when totalled, the disaggregated village electrification data provided by the West Bengal Rural Energy Development Corporation (WBREDC) did not match the overall data on village electrification given for the state. Similarly, the data for household energy access used during the second fieldwork period was taken from the 2001 Census, which was by then outdated but remained the most reliable and comprehensive available. In general, using multiple sources of data and triangulation enhances the reliability of empirical findings and these approaches were adopted in this research. Yet another fundamental problem facing social science research is objectivity or, in other words, avoiding bias (Myrdal, 1969). This research would have been biased if energy reform perspectives were adopted as a straightjacket approach, and assumed to improve energy access by low-capacity end-users. Similarly, if the energy poverty perspective was accepted, and the energy reforms consequently rejected based on the views of the low-capacity end-users, the study would have again lacked an objective approach.

While trying to retain validity, the methodology allowed deviations by providing space for respondents to interact and listen to other's views and opinions. By living in the case-study villages and having regular communications with the villagers, a relationship was established with the inhabitants. This enabled open and candid discussions with the communities, simultaneously yielding meaningful and interesting findings and triangulating the household interviews. The expression of views allowed deviations to come to light and made it possible to look at the issues that concerned the villages from an integrated development perspective, rather than from a simpler energy viewpoint, and this helped in the analyses and in formulating recommendations based on the study. 
In Pursuit of a Light Bulb and a Smokeless Kitchen

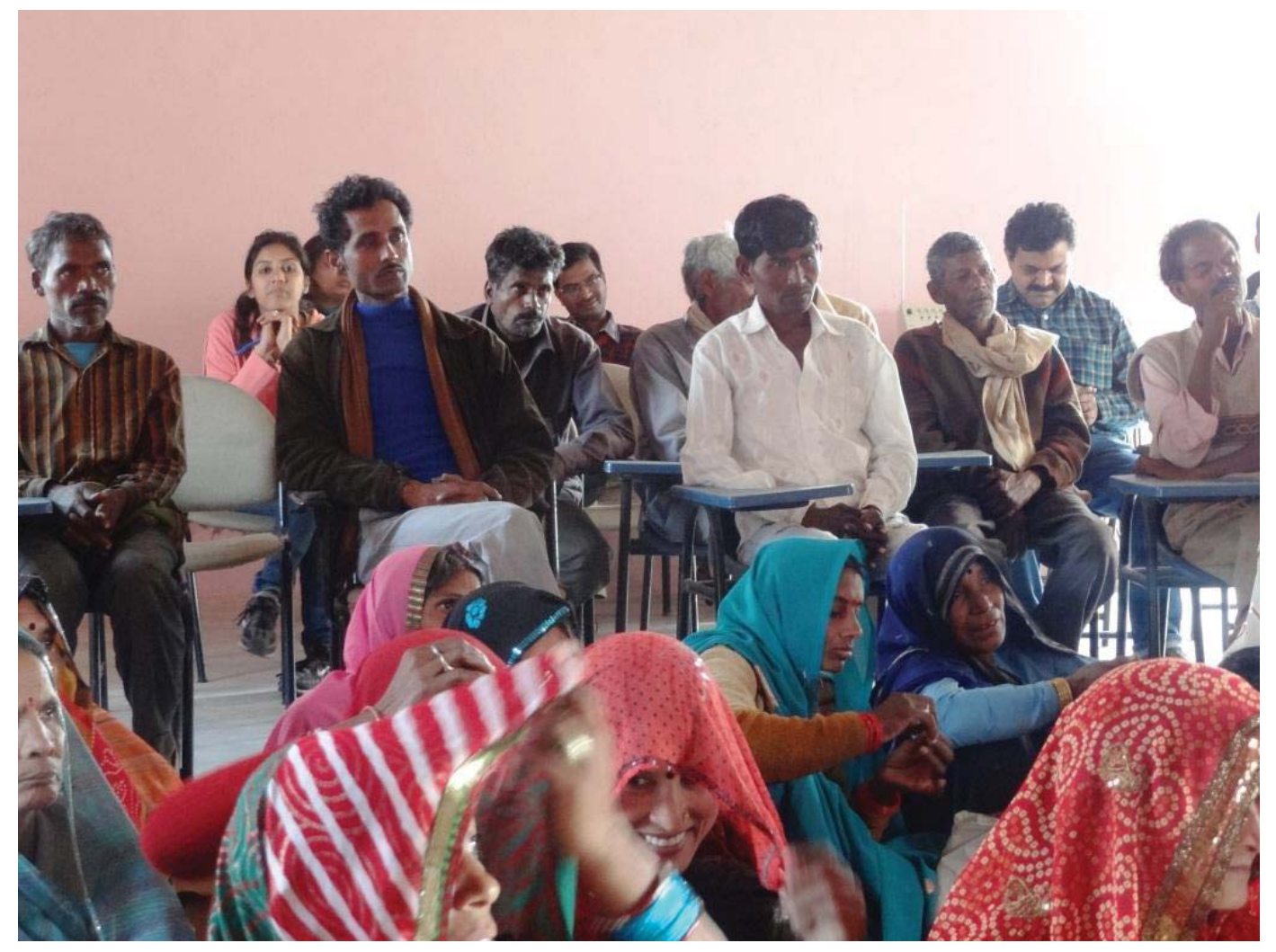




\title{
4. Rural Energy Policy in India: The Meek Shall Inherit
}

\author{
"No Sir! There is no power problem in our village. The rural electrification project was never \\ implemented!" - a caption on You Said It! cartoon by R K Laxman, Times of India, April 16, 2000
}

\subsection{Introduction}

Policy measures and programmes for ensuring energy access in rural areas are extremely relevant in the context of energy poverty in rural India given the disparity in access to modern energy carriers. Such an agenda has become even more significant in the context of the debate on the role of the government and the market in this area. It was established in Chapter 2 that the government and the market provide two different delivery pathways for the implementation of policies. The role of the government, in this context, is to correct market failures. Markets often do not work well in achieving non-economic policy objectives (for example in ensuring social equity and protecting the environment). Therefore, the role of government is critical in creating policies that can regulate markets and balance policy objectives, such as economic development and social equity. However, today, public sector reforms rely on the principles of a market economy to make the policies effective since the underlying rationale behind a government's failure to deliver effective reforms is considered to lie in the unyielding allocation of resources in sectors that, in the context of this dissertation, includes the energy sector.

Since Independence, India's development policy has focussed on the alleviation of poverty and attaining rapid and sustained economic growth (Bajpai and Sachs, 2000;Dandekar, 1992;Sachs, 2005;Srinivasan and Bhagwati, 1995). A review of India's public policy for rural development indicates that rural energy programmes, since Independence, have been considered vital for the social and economic development of the rural areas. As described in Chapter 1, modern energy carriers have been perceived as contributing towards rural wealth creation by powering the key economic activities, as well as bringing social development to rural areas. The government took on the responsibility for investments needed to develop the infrastructure of strategic sectors, including energy, through the creation of state-owned enterprises. Given the levels of investment required, it was deemed that only the state was capable of raising the required capital (Kohli, 1987).The government invested in electricity, petroleum and coal, with the objective of making India self-sufficient in energy.

Recognising the key role that rural India would play in the economic growth and development of the country, the provision of modern energy carriers has been included in development plans since the drafting of the First Five-Year Plan (FYP) covering the period 1950-55. National policies for improving access to modern energy carriers have formed an important component in the development programmes initiated by the government over the past six decades, particularly with regard to planning and the development of rural areas. However, India does not have an explicit integrated vision and approach for rural energy. Rather, the vision and approach amounts to a set of policies and programmes specifically delineated for each energy carrier, along with their respective delivery mechanisms: 


\section{In Pursuit of a Light Bulb and a Smokeless Kitchen}

i. $\quad$ electricity through state electricity boards (SEBs) and electricity distribution utilities;

ii. kerosene oil through fair price shops (FPS) which are a part of the public distribution system (PDS);

iii. other petroleum products, such as LPG, diesel and petrol marketed through a retail network of dealers and distributors appointed by national oil and gas companies; and

iv. renewable energy technologies and energy-efficient devices delivered partly through government programmes and partly through public-private partnerships.

However, the emphasis on energy security has dominated the energy policy, resulting in supply-side issues being pre-eminent over demand-side concerns, such as enhancing energy accessibility, and ensuring and improving the availability and the efficient distribution of energy. However, governmental interventions in the delivery of energy carriers in the rural areas have seen a series of institutional and policy failures such that rural energy remains accessible only to the economically better off. The rural poor ('the meek') inherited the legacy of programmes which, although designed to protect their interests, did not provide substantial benefits either directly or indirectly. For example, around half of rural households still have no access to electricity, and more than $80 \%$ still depend on woody biomass and other forms of inferior quality biomass fuels to meet their cooking energy needs (Patil, 2010;Reddy, 1999). The continuing drudgery facing women in managing household energy services, and the increasing stress on them due to environmental and resource degradation, can be attributed to the failure of government programmes to meet household-level cooking energy needs Most of these households belong to the category of low-capacity end-users.

This chapter analyses the energy policy in rural areas with regard to electrification, petroleum fuels and renewable energy. India's energy policy has gone through various phases and, with the evolution of macro-economic and development policies over the last six decades, energy policies, and those specific to rural energy, have changed. By capturing the journey of India's energy policy for rural energy from 1950 to 2010, this chapter answers the first main research question of this study:

Main research question 1: How have energy sector reform policies been formulated to address the weaknesses apparent in the policies of the pre-reform phase in terms of improving access by low-capacity end-users in rural areas to modern energy carriers?

Sub-question 1.1: What is the institutional setting for delivering energy carriers in rural India?

Sub-question 1.2: What motives have shaped energy policies in India in the prereform phase (1950-1991) and in the reform phase (1991-2010)?

Sub-question 1.3: What are the key elements of the energy policies enacted since 1991 for enabling low-capacity end-users to access modern energy carriers?

The chapter is organised in five sections. In Section 4.2, the organisational setting, including the constitutional provisions, of India's energy sector is described. In Section 4.3, the political economy of energy policies for rural areas and the shift from a state monopoly to inclusive reforms is discussed. In Section 4.4, policies and programmes that have been 
formulated to enhance access to modern energy carriers from 1950-2010 are explained. Finally, in Section 4.5, answers to Main Research Question 1 and its sub-questions are presented.

\subsection{Organisational Setting for Rural Energy}

The institutional and organisational settings related to rural energy in India that have evolved since Independence can be delineated on three levels: macro (national), meso (state) and micro (local). National, state and local level energy delivery organisations include those established within the provisions of constitutional powers, and their processes and functions are determined according to the centre-state relationship. For instance, on the micro-level, formal organisations include local institutions empowered by the Constitution, such as the Panchayati Raj Institutions (PRIs) and cooperative societies, and informal organisations such as user-group associations and other forms of informal arrangements to improve service delivery. New forms of organisations, especially those belonging to the private sector and ones created through constitutional amendments have emerged since 1991 as part of the institutional reforms in the energy sector on the centre, state and local levels.

\subsubsection{Constitutional Provisions}

In the context of the Constitution of India with its quasi-federal character, the organisational approach within the energy sector focuses on the financial and political relationships between the centre and the states, the balance of political power between them, and issues of decentralisation linked to the role of local government (Box 4.1). The Constitution of India includes detailed provisions regarding the relationship between the centre and the state governments. The distribution of powers between the union parliament (the legislative body of the central government) and the state legislatures are dealt with in Articles 245 and 246 of the Constitution of India. Article 245 empowers the parliament to make laws for the whole or part of the country, and the state legislature for the whole or part of the state. Article 246 (1) gives the union parliament exclusive powers to make laws with respect to any matter enumerated in List I of the Seventh Schedule, also known as the Union List. The union or any state legislature also has, according to Article 246 (2) of the Constitution, concurrent powers to legislate on any matters on List III of the Seventh Schedule, also known as the Concurrent List. Likewise, Article 246 (3) of the Constitution bestows powers on the state governments for making laws on matters on List II of the Seventh Schedule, known as the State List.

The Constitution includes provisions related to energy, such as entry 38 in the Concurrent List, entry 53 in the State List, entry 53 in the Union List and the Constitution (Seventy-Third Amendment Act) 1992. Entry 38 in the Concurrent List specifies electricity to be the responsibility of both the centre and the states, providing legislative authority to the central government and state governments to formulate policies for the development of the electricity sector. Entry 53 in the State List, gives the state governments legislative powers 'for taxation on the sale and consumption of electricity'. Entry 53 in the Union List gives the central government legislative authority over 'regulation and development of oilfields, petroleum and petroleum products'. The Constitution (Seventy-Third Amendment Act) 1992, enacted 
In Pursuit of a Light Bulb and a Smokeless Kitchen

by the parliament in 1993, inserted a Part IX into the Constitution of India giving powers to the PRIs. The PRIs are a three-tier system of organisations, including the Gram Panchayat (at the village or village cluster level), block Panchayat (block level) and Zilla Panchayat (district level).

\section{Box 4.1: Constitutional Provisions}

\begin{tabular}{lccc}
\multicolumn{1}{c}{ Energy } & $\begin{array}{c}\text { Central } \\
\text { Government }\end{array}$ & State Government & $\begin{array}{c}\text { Panchayati Raj Institutions } \\
\text { (PRIs) }\end{array}$ \\
Electricity & $\sqrt{ }$ & $\sqrt{ }$ & $\sqrt{ }$ \\
Petroleum fuels & $\sqrt{ }$ & X & X \\
Renewable energy & $\sqrt{ }$ & $\sqrt{ }$ & $\sqrt{ }$
\end{tabular}

The Constitution has further been amended to reflect the paradigm shift from a planned central economy to a market-based economy. The Electricity Act 2003, enacted by parliament in 2003, mandated the restructuring of the State Electricity Board (SEB) into separate utility units for generation, for transmission and for distribution. The Rural Electrification Policy 2006 emphasises decentralisation and the involvement of local institutions in managing electricity distribution.

The constitutional provisions with respect to policies for the petroleum sector rest solely with the central government. The state governments do influence policies indirectly through being responsible for the allocation and clearance of permits for setting up retail outlets for petrol, diesel, kerosene oil and LPG, and for identifying and selecting the Fair Price Shops (FPS) to sell subsidised kerosene oil and other food items under the Public Distribution System (PDS). State governments also allocate quota, or per capita, entitlements for each consumer for kerosene oil supplied under the PDS. Further, the Gram Panchayats are responsible for identifying and categorising the population within their jurisdictions into those Above Poverty Line (APL) and Below Poverty Line (BPL) - or Annapoorna and Antyodaya - for the distribution of food and non-food items under the PDS. As such, the PRIs also play an indirect role in policymaking related to the petroleum sector.

Article $243(\mathrm{G})$ addresses the powers of the PRIs with respect to preparing plans and implementing schemes related to economic development and social justice. The Eleventh Schedule includes twenty-nine topics of which four are particularly relevant to the energy sector: Entry 12 (Fuel and Fodder), Entry 14 (Rural Electrification, including the distribution of electricity), Entry 15 (Non-conventional Energy Sources) and Entry 28 (Public Distribution System). Although the PRIs potentially have constitutional powers to plan and implement rural energy programmes, such powers have to be transferred or devolved by the state legislature. Even though the PRIs have these powers bestowed by the Constitution, they lack the internal capabilities required to plan and implement energy sector programmes. In 
addition, their decisions can be influenced by government officials on the block and district levels (Oommen, 2004).

\subsubsection{Central and State Organisations}

In accordance with the constitutional provisions, the responsibility for rural energy policies and programmes in India is divided between three ministries ${ }^{109}$ : the Ministry of Power (MoP), the Ministry of New and Renewable Energy (MNRE) ${ }^{110}$ and the Ministry of Petroleum and Natural Gas (MoPNG). The Planning Commission ${ }^{111}$ provides the overall framework for planning and growth in accordance with the central government's policies and priorities as outlined by each ministry. These policies and priorities are set out in the form of five-year plans that specify the objectives and targets to be achieved by each sector of the economy within that period based on the identified strategies and other measures, and using the allocated resources. The plans provide an institutional framework for development.

Figure 4.1 illustrates the relationships between organisations on the three levels according to their functions related to policy, regulation, planning, coordination and control. Given the perspective of this study, only organisations involved in the rural supply and distribution of energy carriers are presented. At the central level, there are the three ministries, plus the Planning Commission (see Figure 4.1: I), that formulate policies and programmes. State-level agencies that plan and coordinate the implementation of rural energy programmes appear in the middle of the figure (4.1: II), while the organisations undertaking rural supply and distribution are shown at the bottom (4.1: III). These include both government agencies and private sector organisations. The arrows show the linkages between the different organisations: solid lines indicate linkages related to government programmes, whereas the broken lines show private-sector activities.

The administrative structure for rural energy in India is further governed by the roles and responsibilities of the organisations on each level. The following sub-sections explain the role of the organisations involved in policy (level I), in regulation, planning and coordination (level II) and in rural supply distribution (level III) for the various modern energy carriers.

\footnotetext{
${ }^{109}$ The energy sector as a whole falls under the remit of four ministries and a central department. Besides the MoP, the MoPNG and the MNRE, discussed further, there are the Ministry of Coal and the Department of Atomic Energy. In the context of this dissertation, which focuses on rural energy, only the first three ministries are relevant.

${ }^{110}$ The Ministry of Non-Conventional Energy Sources was renamed the Ministry for New and Renewable Energy (MNRE) in 2008.

${ }^{111}$ The Government of India established the Planning Commission in 1950 to promote a rapid rise in living standards through the efficient exploitation of the country's resources, by increasing production and by offering employment opportunities to all. The Planning Commission was given the responsibility of assessing all the resources of the country, augmenting deficient resources, formulating plans for the most effective and balanced utilisation of resources, and determining priorities.
} 


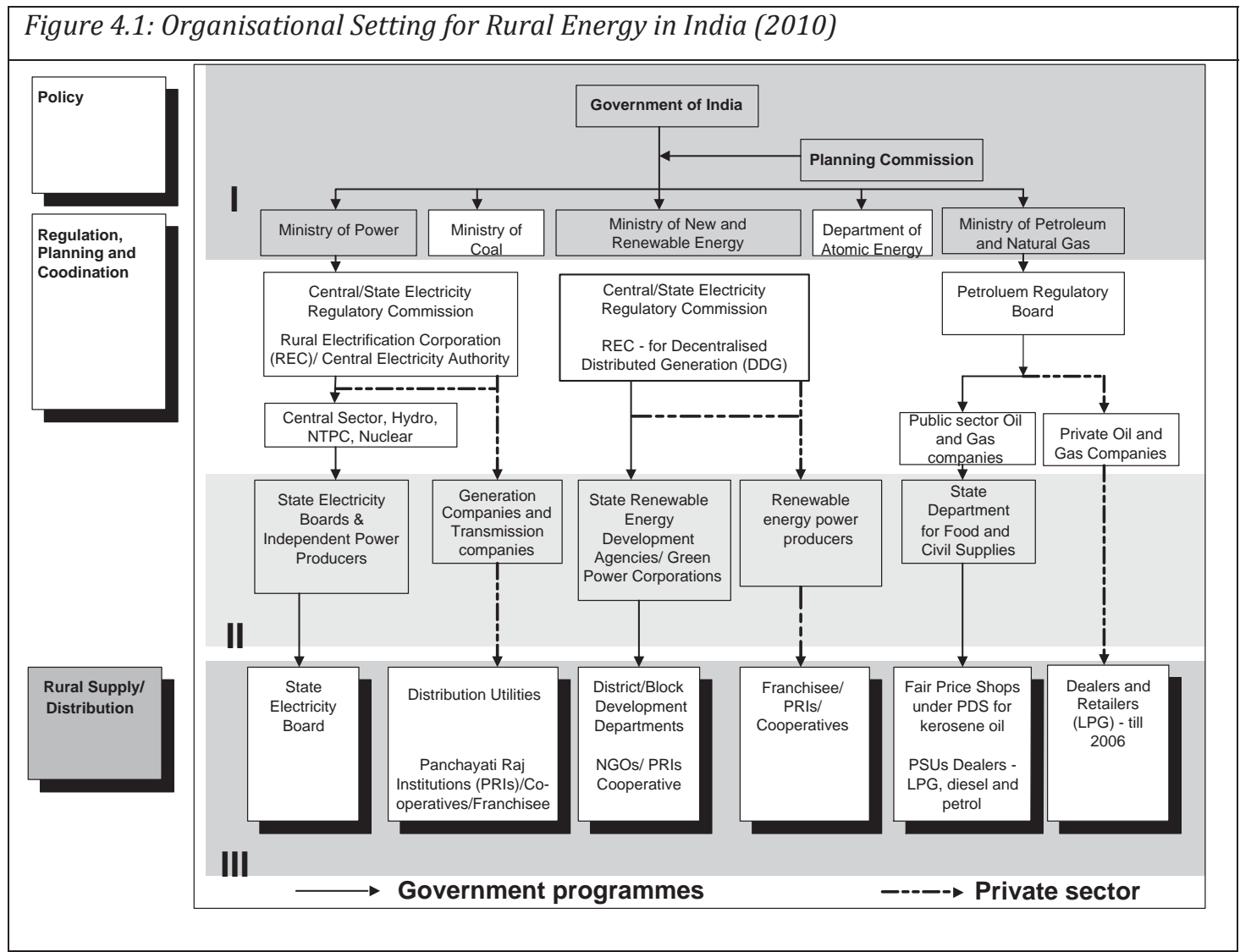

\section{Electricity Sector}

The MoP is the nodal agency for electricity administration in the country ${ }^{112}$. As such, it has responsibility for the governance of the whole sector, including long-term planning, designing policies and programmes for the development and regulation of the sector, as well as issuing new policy guidelines. This Ministry is responsible for the Rural Electrification (RE) programme, which it implements through other central-level organisations such as the Rural Electrification Corporation (REC), the Central Electricity Authority (CEA) and the public-sector power generation utilities. The REC was created in 1969 as a wholly government-owned enterprise and nodal agency responsible for financing and implementing rural electrification programmes. Since its creation, the REC is India's main financing institution in this field, and it administers grants and provides loans to the SEBs for investment in the rural electrification infrastructure.

At the state level, the SEB formulates policies and strategies for RE programmes. The SEB is responsible for electricity generation and the grid infrastructure for the transmission and

\footnotetext{
${ }^{112}$ The Ministry of Power (MoP) was once part of the Ministry of Irrigation and Power, which was split in 1985 with the portfolio related to the energy sector transferred to the MoP. However, in 1992, the MoP was further divided to create a Ministry of Non-Conventional Energy Sources (MNES). This ministry is now known as the Ministry of New and Renewable Energy (MNRE). This change reflects a growing interest in renewable energy technologies (RETs) in India.
} 
distribution of electricity. In order to strengthen and speed up the process of rural electrification, the REC has provided financial support to the SEBs.

Electricity sector reforms, since 1991, have resulted in the creation of new institutional structures. The central government passed the Electricity Commission Act 1998 that established the Central Electricity Regulatory Commission (CERC), with powers to determine the tariff policy for central generation utilities and for the inter-state transmission of electricity. At the state level, state governments passed legislation to establish State Electricity Regulatory Commissions (SERCs) and to unbundle the vertically integrated SEBs. While all the state governments established SERCs, not all of them opted to unbundle their SEBs. Those states that initiated reform policies between 1995 and 2004 followed the same structure, with multiple generation companies, a single transmission company and multiple distribution utilities. The CERC regulates power-related activities on the central and interstate levels, while the SERCs address state-level licensing and electricity tariffs.

As noted earlier, under the provisions of the Electricity Act 2003, it became mandatory for all states to restructure their electricity boards into separate utilities for generation, transmission and distribution. The distribution utilities have attempted to bring about decentralisation of electricity distribution through smaller local institutional structures such as cooperatives, franchises, user associations and Gram Panchayats. The role of these institutions is to manage both electricity supply and revenue collection. Most of the electricity cooperatives established during the 1970s became financially non-viable in the 1990s and were subsequently dissolved by their respective state governments. Their operations were then integrated with the distribution utilities. An exception in this regard was the state of West Bengal, which created a Rural Energy Distribution Corporation in 2001 with the mandate to set up electricity cooperatives for managing electricity distribution. Further, in the restructuring of the state's electricity sector in 2008, this rural energy distribution corporation was allowed to continue to function until 2013 to oversee the implementation of the existing RE programme, after which it would be merged with the distribution utility. The Electricity Act 2003, and subsequent policies formulated within this framework, emphasises decentralisation and the involvement of local institutions in the management and distribution of electricity in rural areas.

Having underlined the role of electricity in the economic and social development of rural areas, the central government included rural electrification under Bharat Nirman, a national programme for building rural infrastructure, and has supported it through a series of central government assisted programmes. In 2004, the central government initiated a national rural electrification programme called the Rajiv Gandhi Grameen Vidyutikaran Yojana (RGGVY). The REC is the nodal agency for the implementation of the RGGVY, and is responsible for financing the programme and for coordination with the MoP and the MNRE. Under the RGGVY, state governments have the responsibility of implementing the programme through their SEBs or utilities. Those central public-sector undertakings (PSUs) responsible for power generation or transmission can also assist state governments in implementing the programme. In 2009, the Government of India passed a Decentralised Distributed Generation (DDG) 
Policy within the framework of RGGVY. To ensure the success of the RE programme in remote villages, the REC works with MoP and MNRE.

\section{Petroleum Sector}

The Ministry of Petroleum and Natural Gas (MoPNG) is responsible for the development of the petroleum sector and ensuring the security of supply of petroleum fuels. The ministry formulates policies and programmes to develop and regulate the oil and gas sector, as well as for the refining and marketing of petroleum products. With an increasing demand for petroleum products and a decline in indigenous production, the ministry also formulates appropriate import policies. National oil and gas companies ${ }^{113}$ implement the government's petroleum sector programmes through their extensive exploration and refining capacity and distribution networks. These companies are also responsible for establishing a market network for the sale of petroleum products, based on their own assessments of the market and its potential. There are inter-state variations in the infrastructure for the distribution of petroleum products. Since private petroleum companies had previously been nationalised, the competition in the sector was limited. The emphasis had effectively shifted to maintaining security of supply, to keep pace with the growing demands from economic activities, and to ensuring availability, at subsidised prices, to remote regions and logistically difficult areas. Drawing attention to the structural changes in the petroleum sector ${ }^{114}$, the Oil Prices Committee (OPC) 1974 recommended the setting up of an Oil Coordination Committee $(\mathrm{OCC})^{115}$ to play a key role in decision- making processes in the downstream sector, with particular reference to planning, coordinating and monitoring functions, including administering the Oil Pool Account (OPA).

Since petroleum is a subject on the Union List, state governments are not directly responsible for formulating separate or additional policies for the petroleum sector. State governments do however have a direct role in the distribution of petroleum products and in setting entitlements to kerosene oil, which is on the list of essential commodities to be supplied to BPLs to meet their basic needs. At the state level, the Department of Food and Civil Supplies is responsible for the distribution of essential commodities, including kerosene oil, through

${ }^{113}$ The oil companies were nationalised in 1974 through special statutes passed by parliament. Two national oil companies - Hindustan Petroleum Company Limited (HPCL) and Bharat Petroleum Company Limited (BPCL) - were created. HPCL was formed through two special statutes - the Esso (Acquisition of Undertaking in India) Act, 1974 and the Caltex (Acquisition of Shares of Caltex Oil Refining India Limited and all the Undertakings in India for Caltex India Limited) Act, 1977. BPCL was created through the government's acquisition of Burmah Shell through the Burmah Shell (Acquisition of Undertaking in India) Act, 1976.

${ }^{114}$ These structural changes were triggered by the 'Energy Crisis' linked to the first oil crisis (1973-74) when OPEC increased the price of crude oil. As a consequence of this action, oil prices in India quadrupled with a consequent deterioration in the balance of payments together with vulnerability in its crude oil supplies.

115 The OCC was set up in July 1975 through a Government of India (Ministry of Petroleum and Chemicals) Resolution dated 14 July 1975. The OCC was not responsible for formulating policy, but assisted the ministry in the framing of policy by providing necessary inputs and coordinating implementation. 
the FPS under the PDS. The Department of Food and Civil Supplies allocates quantities of commodities to wholesalers and retailers based on local population density and the number of ration-card holders. The department also acts as a regulator and is responsible for ensuring that the national oil companies deliver kerosene oil to wholesalers and to the FPS, and for preventing pilferage and the diversion of fuel to the open market. For other petroleum products, such as LPG, diesel and petrol, the national oil and gas companies have established dealers and retail outlets within the state ${ }^{116}$.

In 1993, in order to reduce imports, the government opened up upstream exploration and production, as well as midstream refining, to the private sector with the aim of expanding domestic capacity for oil and gas production. In addition to improving the availability of kerosene oil and LPG, the government also allowed private-sector oil and gas companies in the downstream sector to market kerosene oil and LPG. This process, known as the Parallel Marketing Scheme (PMS) was started in 1993. Through this scheme, the government also allowed private-sector companies to develop their own infrastructure for importing, refining, bottling and marketing kerosene oil and $\mathrm{LPG}^{117}$. In 2003, the MoPNG reviewed its PMS policy and advised the Standing Committee of Parliament on Petroleum and Chemicals that the PMS has outlived its usefulness. The MoPNG also stated that subsidies on petroleum products, especially on kerosene oil and domestic LPG, could not be extended to private players. As a result of these policy developments, most of the parallel marketers, starting in 2006, left the domestic LPG market and focused on industrial and commercial applications.

In 2002, both the Administered Pricing Mechanism (APM) ${ }^{118}$ and the OPA were dismantled. Through this action, the OCC also ceased to exist, and the Petroleum Regulatory Board was established in its place ${ }^{119}$. Since 2002, the national oil and gas companies are allowed to review their prices of petroleum products on a fortnightly basis to reflect the import parity price of crude oil in the international market. However, this empowerment is de jure, and the decision to revise the price of petroleum products is, de facto, still taken by the MoPNG. This can be seen in the pricing of petroleum fuels between 2004 and 2008, which were based on political expediency rather than economic principle. Since 2004, the central government has constituted various committees to review its policies on allocating and pricing petroleum fuels. These committees have recommended reforming the distribution mechanism for subsidised fuels, especially kerosene oil, as the present system fails to deliver subsidised fuel or to prevent pilferage in the system resulting in a loss to the exchequer. However, no restructuring of the distribution system has so far been undertaken. In order to increase the

\footnotetext{
${ }^{116}$ The dealers and retailers have to obtain a licence from the Food and Civil Supplies Department and the Explosives Department.

${ }^{117}$ The Government created the Parallel Marketing Scheme (PMS) by passing two orders: The Kerosene (Restriction on Use and Fixation of Ceiling Price) Order, 1993; and The LPG (Restriction on Use and Fixation of Ceiling Price) Order, 1993.

${ }^{118}$ See section 4.4.2 for a further discussion on dismantling the Administered Pricing Mechanism (APM).

${ }^{119}$ The Petroleum Regulatory Bill was passed in 2006. The bill focused on the upstream (oil and gas production) and midstream (refining) sectors of the petroleum industry. The MoPNG remains the main policy and regulatory agency for downstream aspects - for fixing the retail prices for petroleum products.
} 
use of LPG in rural India, the central government launched the Rajiv Gandhi Grameen LPG Vitrak Pariyojana scheme in 2009. This scheme focuses on creating a LPG distribution network in rural areas of India.

\section{Renewable Energy Sector}

Policies and programmes for the promotion of renewable energy sources are the prime responsibility of the MNRE ${ }^{120}$. The Planning Commission in the Sixth Five-Year Plan (198085) identified the need to develop alternative forms of energy to meet the growing energy demand and stressed the promotion of non-conventional energy sources for meeting rural energy needs (Planning Commission, 1980). The MNRE implements renewable energy programmes through the State Renewable Energy Development Agencies (State REDAs) ${ }^{121}$. For some specific technologies, such as biogas and solar photovoltaic, MNRE also implements related programmes through non-governmental organisations (NGOs). Under the constitution, state governments have powers to formulate their own policies and programmes for the promotion of renewable energy technologies in addition to the centrally sponsored schemes. State governments provide additional financial assistance in the form of subsidies to promote renewable energy technologies. The State REDAs implement the central and state government-funded programmes through involving rural development authorities that come under the state government and through NGOs.

The central government established the Indian Renewable Energy Development Agency (IREDA) in 1987 as the financing arm of the MNRE, with responsibility for promoting the commercialisation of renewable energy technologies. IREDA, in turn, (in the first phase of its programmes) forged alliances with non-banking financial companies (NBFCs) and subsequently included other stakeholders from the financial sector, such as national banks, regional banks, microcredit institutions and cooperative banks, as well as NGOs and renewable energy technology providers. In 1992, the government selected three renewable energy technologies - SPV, small hydro and wind energy - for commercialisation, on the basis that these technologies were considered mature (Sinha, 1997).

The initiative taken by IREDA to enhance the accessibility of renewable energy created incentives that attracted the private sector to participate as independent power producers. Since 2004, supported by legislation and regulations, the renewable energy sector in India, especially for electricity generation, has moved from being viewed as insignificant to being seen as mainstream. Today, renewable energy generation accounts for $12 \%$ of India's installed capacity. The policies and programmes since 2004 have created an enabling

${ }^{120}$ Initially, all the programmes on non-conventional energy sources were carried out by the Department of Non-Conventional Energy Sources (DNES), within the MoP. The DNES was then converted into a fully-fledged ministry: the Ministry of Non-Conventional Energy Sources (MNES). The MNES also inherited programmes and projects from the Planning Commission in 1993 including the Integrated Rural Energy Programme, which was a pilot project designed to provide energy through the use of renewable energy sources for meeting domestic energy needs and other productive end-uses. In 2008, the MNES was renamed the Ministry of New and Renewable Energy (MNRE).

${ }^{121}$ Before the creation of separate State REDAs, renewable energy programmes came under either statelevel Departments of Science and Technology or Energy Departments. 
framework for the growth of the renewable energy sector in India. This will be further discussed in Section 4.4.2.

\subsubsection{Local Organisations}

At the local level, there is a wide range of organisations implementing various rural energy programmes formulated by the three energy ministries and the associated state government departments (Figure 4.1: III). These local organisations are on three levels: district, block and village/village clusters. There are inter-state variations in the design and structure of these organisations. At the district and block levels, the organisations are extensions of state government departments. In addition to such organisations, there are the three tiers of PRIs that work with these departments.

\section{Electricity Sector}

The SEB, through its rural electrification unit, is responsible for providing grid connectivity to rural areas. In some states, the SEB, with financing from the REC, has established rural electricity cooperatives. In eastern India, where the supply of electricity is erratic, or there is no supply, private entrepreneurs have set up small diesel generators and supply electricity to a small cluster of consumers. Distribution utilities in those states where electricity sector reforms have been initiated are responsible for rural electricity distribution. In states such as Orissa, distribution companies are encouraging the formation of Village Bidyut Sanghas (VBS) to function as an intermediary between the consumers and the utility, with powers to prevent electricity pilferage and to undertake commercial activities on behalf of the distribution company ${ }^{122}$ (Rao and Govindrajan, 2003).

The Electricity Act 2003, and the subsequent Rural Electrification Policy 2006, focus on distributed generation and the decentralised management of electricity in rural areas. The Rural Electrification Policy 2006 and the RGGVY both focus on setting up franchisees for managing electricity distribution, with the electricity utilities having the option of deciding the franchising model. The most common franchisee model is based on revenue collection, where the utility appoints either an individual or an organisation (sometimes a PRI or PRIappointed representative) to distribute electricity bills and collect revenue on behalf of the utility for a small fee. The other model is for an input-based franchisee, where the entrepreneur takes over full responsibility for electricity supply, meter reading, billing and revenue collection, and for taking steps to reduce technical and commercial losses (such as electricity theft).

\section{Petroleum Sector}

In villages, kerosene oil is distributed at subsidised rates through retail outlets called FPS. In addition to the FPS, village shops (general stores) also stock kerosene oil. The availability of LPG is made possible through appointed dealers of the national oil and gas companies. However, most dealers are based in urban settlements, and there are very few dealers in rural

\footnotetext{
${ }^{122}$ Similar initiatives such as the Transformer User Association (TUA) in Madhya Pradesh and Gram Vidyut Pratinidhi (GVP) in Karnataka have been started.
} 
areas. They are more interested in developing a network with other dealers to maintain a supply stock so as to be able to cater for any demand. Other petroleum products, such as diesel and petrol, are made available through petrol/diesel pump stations. However, private sector companies were setting up rural retail networks and, at the time of the first field survey period (2001-02), this parallel marketing of petroleum products was having a positive effect by improving the availability of LPG in the rural areas within the case study regions ${ }^{123}$. In comparison to this, the parallel marketing of kerosene oil had not taken off in most of the rural areas, and there were no retail networks selling kerosene oil, except in few coastal states of India, which had ports where private sector players were importing and selling white kerosene oil. Parallel marketing of kerosene oil resulted in widespread adulteration with diesel for transport sector and eventually became the reason for central government's decision to stop the parallel marketing scheme for kerosene oil.

\section{Renewable Energy Sector}

Block development agencies and district rural development authorities are the main agencies for implementing the government's renewable energy programmes. At the state level, state nodal agencies also promote decentralised power generation through the involvement of community-based organisations either in the form of a cooperative or as a user group. In some states, NGOs are working with the appropriate government departments and with private-sector companies to implement programmes. In a few states, the State REDAs have established a small number of decentralised power plants based on biomass gasification with localised grids or photovoltaic and individual solar home systems for the electrification of remote villages. The State REDAs has established cooperatives to manage the technical operation and functioning of the system, as well as be responsible for revenue collection.

\subsubsection{Implications of the Organisational Setting}

The role of the government in both the pre- and post-reform periods has been key in creating rural access to modern energy carriers. Energy carrier availability depends on a multilevel organisational structure with central, state and local organisations involved in planning and implementation. Each organisation has its own roles and functions. The organisational setting has resulted in a top-down approach to programme implementation. Such an institutional structure, particularly in the context of the vast geographical spread of India, results in a lack of coordination between the different ministries and departments. For example, when it comes to remote village electrification, both the MoP and the MNRE have designated roles but there is no clear delineation of responsibilities between them. Similar disconnects have

${ }^{123}$ However, during the second fieldwork period (2008-09), it was found that many of the private LPG dealers had stopped supplying the household sector and were now targeting industrial and commercial users. The explanation for this switch in marketing lies in the continuation of subsidies to the public sector companies for supplying household users, despite policy statements to the contrary (GoI, 2003). However, this appears not to have affected availability in rural areas, as the public sector dealers have replaced private sector in supplying LPG to household consumers. In 2009, the Government of India introduced a new programme called Rajiv Gandhi LPG Vitrak Pariyojana for creating a distribution infrastructure for LPG distribution in rural areas. This is further detailed in Section 4.4. 
been observed when looking at electricity and groundwater in agriculture, which involves at least three departments - electricity, irrigation and agriculture - that have no mandate to work together or address problems holistically.

Such an organisational structure requires all those involved to have the capacity to fulfil their roles. The need for capacity development appears not to have been considered when this structure was being established. This lack of capacity is particularly noticeable in the locallevel organisations. In practice, these local organisations are not involved in the planning, which continues to be top-down and driven by targets. The local-level organisations are not able to take decisions based on local needs, nor do they have opportunities to feed data and priorities to the state- and central- level planners. As a consequence, demand-side issues are overlooked in rural energy planning. The experiences of energy sector reform show that, while there are some indications of restructuring in the organisational setting, the process is still ongoing.

\subsection{Political Economy of Rural Energy Policy: Transition from State Monopoly to Inclusive Reforms}

The foundation for rural energy policy was laid in the first Five-Year Plan (1950-55), with the social and economic development of rural areas at the core of India's development plans (Planning Commission, 1950). The national development policies were formulated with a vision of a modern and secular India. The state was endowed with the task of bringing development into what was then considered a poor and backward society (Corbridge and Harris, 2000). The development policy in India, since independence to the present day, can be considered to have had various phases ${ }^{124}$. In this dissertation, a modified form of the World Bank framework outlined in the footnote is used that better reflects the developments within the energy sector (see Figure 4.2). In the years between 1950 and 1990, development programmes in India were an instrument of government-led initiatives, which shifted from a socialist, centrally planned economy, approach under Nehru (1950-69) to a second phase of political populism with pro-poor development initiatives under Indira Gandhi in the 1970s. Crucially, the Garibi Hatao period and the period of a spending boom and fiscal deficit (as mentioned in the footnote) have been combined into one phase, labelled Political Populism, with a slightly altered duration (1969-91) to reflect changes in the energy sector. Further, the

${ }^{124}$ In mapping India's development policy, a World Bank study divided India's development policy into four stages (World Bank, 1997):

(a) The Nehru Years (1947-64): characterised by a planned economy, with the public sector as temples of growth, centralised planning and the trickle-down approach;

(b) The Garibi Hatao period (1966-77): emphasising poverty alleviation and redistribution as an instrument for economic growth and development;

(c) The period of spending boom and rising fiscal deficit (1977-91), a period in which government spending on state-sponsored schemes increased, resulting in a fiscal deficit and a near-bankrupt national economy;

(d) The Reforms Period (1991-), earmarked by liberalisation and reform measures, de-licensing, divestment and the privatisation of state-owned enterprises. 
Reforms period (as mentioned in the footnote) is divided into a Reforms phase (1991-2004) and an Inclusive Reforms phase (2004 - ) to reflect changes that occurred after the World Bank had produced its mapping. Post-1991, a third phase emerged when India's overall development policy adopted a liberal reformist posture. This further changed in 2004 (the start of the fourth phase) to an emphasis on inclusive development, with the government once again becoming the dominant policymaker as well as the implementer of policies and programmes, albeit continuing with the reform measures.

Although the national policies for the energy sector have developed in tandem with the wider political economy and development policy in the country, they have been influenced by external factors. External factors, such as oil crises (two in the 1970s and one at the beginning of the 1990s), have added to the complexity of the development and implementation of energy policy, and have also influenced policy changes in the energy sector. The following sub-sections describe the transition of India's energy policy from the phase of state monopoly through to the phase of inclusive reforms.

\subsubsection{Phase I: Centralised Planning (1950-69)}

The first phase covers the period between Independence and the late-1960s, when India was preoccupied with institution building across various economic sectors, followed by a centralised planning approach for all sectors, including energy. It was during this period that the planners gave shape to the concept of direct state intervention in the energy sector (Kelkar and Sarma, 1996). In post-independent India, the creation and development of a modern India were at the core of the ideology of the political leaders and policymakers. Government policies and programmes were implemented through a centrally planned economy and a trickle-down approach. This led to massive state-directed investments and government intervention in heavy industries and the creation of public sector companies.

In the energy sector, government interventions, with the overall objective of maintaining energy security, included building an infrastructure for electrification based on large power generation plants and grids to provide electricity to the rural areas, and exploring and developing indigenous oil and gas reserves. Rural electrification became one of the key programmes for the development of rural areas. Electricity, with its connotations of modernity, was considered to bring social change by improving the quality of life and creating new economic opportunities in agriculture, as well as in rural industries and enterprises.

The consecutive droughts between 1965 and $1967^{125}$ resulted in a shortage of food grains, and India had to rely on poor quality imports (Abdul Kalam and Rajan, 1998). In order to avert any future food grain crises, agricultural development and achieving self-sufficiency in food grain production became a major focus of government policies. It was recognised that, for agriculture to develop, irrigation capacity needed to expand. In this context, electricity for

\footnotetext{
${ }^{125}$ Between 1965 and 1967, India faced drought in two consecutive years and had to depend on imported wheat from the USA. At one point, due to US policies, India had only two weeks stock of food grains (Swaminathan, 1993)
} 
irrigation became vital to agricultural growth, and rural electrification programmes were expedited by the setting up of the REC in 1969. The premise was that since surface irrigation was not possible in every village, access to electricity was important for pump-set operation to extract the relatively abundant groundwater resources. Energisation of irrigation pump-sets became integral to the rural electrification programme with the objective of creating economic opportunities in the agriculture sector not only by increasing output but also by creating agro-processing units and an improved food grain storage infrastructure. This was made possible by the expansion of grid electricity in the rural areas, linked to multi-purpose irrigation projects, the ready availability of pump-sets on the market and access to subsidised credit.

\subsubsection{Phase II: Political Populism (1969-91)}

The second phase in energy policies and programmes had two major triggers. First, the need to achieve food security increased investment in expanding rural electrification to support irrigation through surface and groundwater sources. The second trigger was the oil crises of 1973 and 1977. This political populism phase that lasted for just over two decades witnessed an enhanced role for the government in the energy sector. This was linked to a paradigm shift in general development ideologies - from one of the trickle-down of economic and development benefits to one of a focus on abolishing poverty within the framework of centralised planning. This initial focus continued the policy from the first phase of energy security through measures aimed at maximising energy availability from indigenous sources. The central government's control of the economy also increased during this phase. In the period between 1973 and 1979, the development of oil and gas resources ${ }^{126}$ was expedited and, simultaneously, the government nationalised ${ }^{127}$ the coal and oil industries ${ }^{128}$. Through the creation of public sector companies ${ }^{129}$, the central government ventured into power generation.

In the early 1970s, India witnessed shortages in food grain production and rising levels of income poverty. This led to the shift noted above in the development paradigm of centralised planning and trickle-down benefits to one that included an increased role for the government and political populism. Earlier the emphasis was on social development through providing low cost housing, basic services and cooking energy at the household level, electricity connections for household and agricultural work, safe water supplies and sanitation facilities;

\footnotetext{
126 The development of Bombay High - an offshore drilling operation off the Arabian coast.

127 Private sector participation in key infrastructure sectors such as banking, electricity generation and distribution, and petroleum products marketing was present. However, there was a growing concern that private companies were not catering to the growing demand for such services in the rural and nonviable areas, and that such services could only be provided by the government. This eventually resulted in the nationalisation of infrastructure sectors.

128 The government nationalised the operations of private-sector multinational oil companies, and adopted measures to boost exploitation of national petroleum reserves and enhance its own energy security (GoI, 1974)

${ }^{129}$ Power sector undertakings (PSUs) such as the National Thermal Power Corporation (NTPC) and the National Hydro Power Corporation (NHPC) were created.
} 
and it was assumed that poverty could be alleviated and basic human needs met (Beall, 1997). Midway through this phase, the focus on abolishing poverty, redistribution and nationalisation of infrastructure sectors shifted to a system of controls and permits, which became known as the 'permit raj' ${ }^{130}$. The government introduced price controls and subsidies for energy carriers to promote their adoption and diffusion (Srinivasan and Bhagwati, 1995).

As part of the government's policy to eradicate poverty from the rural areas, a range of economic and social programmes were initiated with the objective of creating rural employment and meeting the welfare needs of the rural population. These included energy programmes targeted at BPL households such as:

i. subsidies for kerosene oil through the introduction of a Public Distribution System (PDS) in rural areas;

ii. expansion of the rural electrification programme (Kutir Jyoti programme) for socially and economically weaker sections of society, subsidised under the Minimum Needs Programme;

iii. cross-subsidies for domestic and agriculture electricity connections; and iv. an energy programme for dissemination of renewable energy technologies.

In the sixth Five-Year Plan (1980-85), the Planning Commission proposed that the central government adjust its energy pricing so that energy prices reflected the actual price of energy carriers at the point of delivery to the end-users (Planning Commission, 1980). However, the government did not heed these recommendations and, instead, policies became more protectionist towards poor households. Nevertheless, there was a radical policy shift towards the adoption of renewable energy sources to meet rural energy needs, which resulted in the formulation of a national programme, known as Integrated Rural Energy Planning (IREP), under the Planning Commission. This can be seen as part of yet another paradigm shift: from imported fossil fuel dependency to greater energy self-sufficiency including indigenous natural resources such as solar and biomass energies. An important element of the developments on the rural energy front was the use of an 'integrated' approach, in comparison to previous national programmes such as those on biogas and on improved cookstoves. The large national biogas and cookstoves programmes were never integrated, and could end up competing against each other, and took a supply-side approach, such that social issues such as gender were never taken into account.

The poverty reduction and protectionist policies resulted in increasing fiscal deficit and brought into question the government's role in the delivery of goods and services (Hansen and Bower, 2003). Key policymakers, such as the Ministry of Finance and the Prime Minister's Office, argued for liberalisation, market deregulation, privatisation, and a reduction in the size and scope of the public sector (Beall, 1997;Hansen and Bower, 2003). However, the dominant propertied classes, especially the rural elites and industrial leaders, used their political influence to continue receiving subsidies for energy carriers and

\footnotetext{
130 'Permit raj' was the name given to the licensing policy where a permit or license regulation was exploited by the bureaucracy. 
fertilisers, as well as for trade protection that helped to reinforce the government's role in economic policymaking. Populist schemes and measures dressed up as poverty alleviation and equity, coupled with fiscal deficits and rising subsidy bills ${ }^{131}$, political interference, permits and controls, affected the economics of the country. By mid-1991, the policies adopted by the government had begun to have a serious effect on the performance of the energy sector and on the quality of services: there were frequent power cuts, the nonavailability of LPG and kerosene oil, and energy carriers were frequently diverted for profiteering. The performance of the energy sector was a reflection on the performance of the entire economy. The inward and populist policies pursued by the government between 1973 and 1991 were at the root of the economic crises that emerged in 1990 and ushered in the next phase, the Reform Phase.

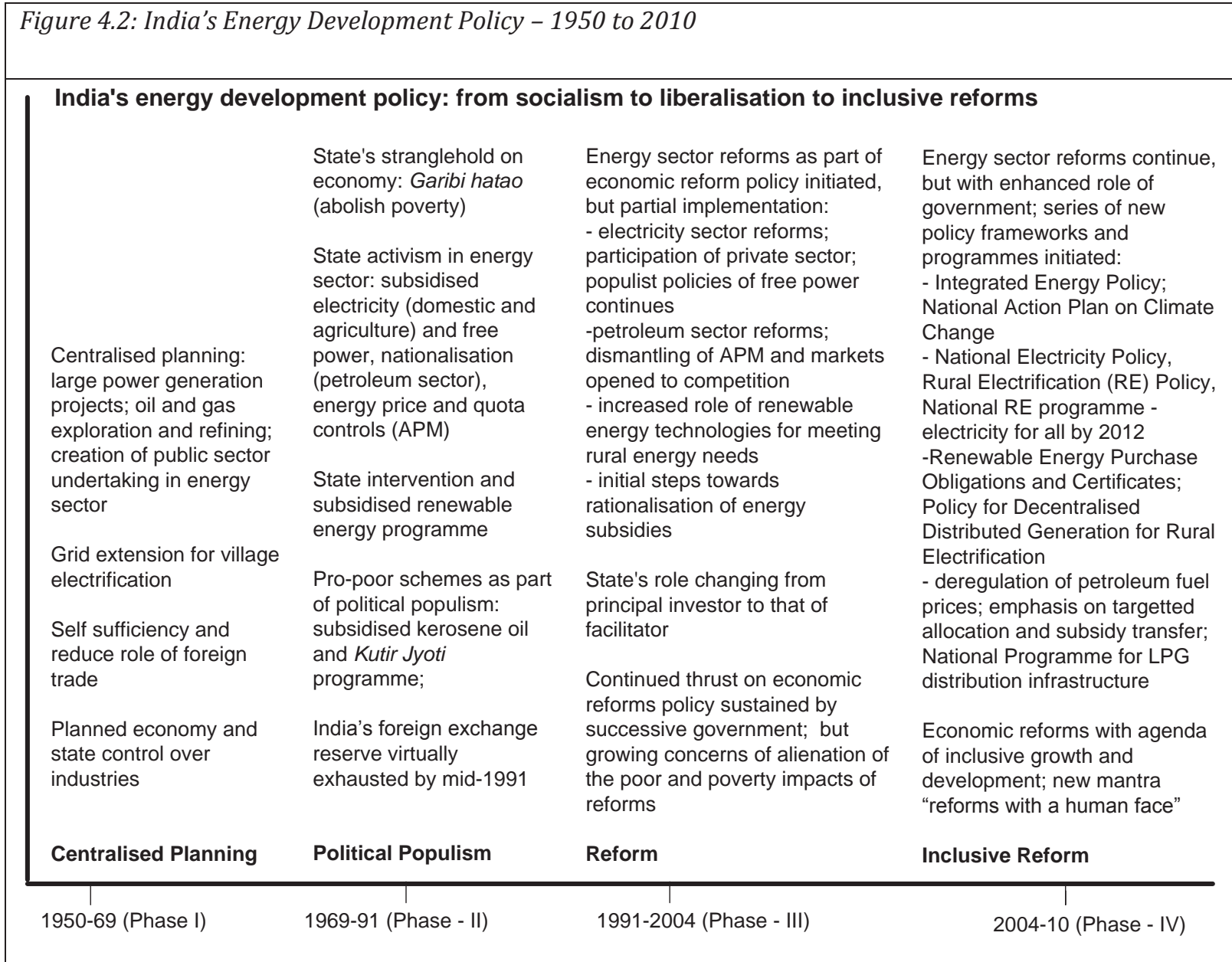

${ }^{131}$ In 1989, subsidies accounted for almost a quarter of all government expenditure (Chibber, 1995). 


\subsubsection{Phase III: Reform (1991-2004)}

The third phase in the development of energy policy in India began in 1991. It was carried out in tandem with economic policy reforms to counter the economic crisis ${ }^{132}$. The energy sector reforms in India were thus carried out in the wake of the economic crisis that the country faced in early 1990-91. The crisis of 1990-91 was as much an energy crisis as it was an economic one. Firstly, the fiscal deficit was substantially accentuated by the high oil prices following the Gulf War (1990-91). Secondly, the energy deficit in physical terms was steadily increasing and had reached $20 \%-30 \%$ of demand. Thirdly, the financial situation of the publicly owned energy utilities made it impossible to generate resources to augment the dwindling budgetary support. Thus, the rationale for reforming the energy sector was analogous to the rationale for the economic reforms in the country. The government identified a reliable and affordable energy supply as necessary for economic growth ${ }^{133}$. Starting in 1991, a package of liberalisation and reform measures were initiated by the central government in response to the economic crisis (Box 4.2).

The post-1991 progress of economic reforms has been mixed, but is considered to have contributed significantly to the economic growth and development of the country (Ahluwalia, 2000). In 1994, a brake was put on reforms by the then governing Congress Party whose leaders attributed the electoral losses that the Party had suffered in the state assembly elections to its policies on economic reform (Jenkins, 1999).

${ }^{132}$ The economic crisis in 1990-91 had two components: an increasingly unmanageable fiscal deficit and a Balance of Payment (BoP) crisis. In 1990-91, the total gross fiscal deficit of the government (centre and states) reached $10 \%$ of GDP, and the annual rate of inflation peaked at nearly 17\% in August 1991. The BoP crisis saw the current account deficit double from 1.3\% of GDP during the first half of the 1980 s to $2.2 \%$ during the second half of the 1980s. For the first time in its modern history, India was faced with the prospect of defaulting on external financial commitments since its foreign currency reserves had fallen to $\$ 1$ billion by mid-1991. The BoP came under stress due to liquidity crises experienced in mid-January 1991 and again in late-June 1991. On both occasions, the foreign exchange reserves dropped significantly and the government had to resort to measures such as using its gold stock to obtain foreign exchange, utilising special IMF facilities and emergency bilateral assistance from a number of countries, including Japan and Germany (Bajpai, 2002). The fiscal deficit and the BoP crises were accentuated by weak government at the national level (in 1990-91, there was an unstable minority government, supported in Parliament by the Congress Party), an importdependent economy and excessive protection of domestic industry from modernisation and efficiency improvements.

${ }^{133}$ While it is true that the impending fiscal crisis triggered the implementation of economic reforms in 1991, an earlier attempt to reform the economy was made in the second half of 1980 when trade and industry liberalisation policies were initiated. However, there was widespread opposition to the 1985 liberalisation policy, due to the fear of PSUs and small industries being taken over by large domestic business enterprises as well as Indian industries being fearful of competition from the international market. The faltering of the liberalisation initiatives was seen as a result of "society hitting back" (Kohli, 1989;Pedersen, 2000). 


\section{Box 4.2: Economic Reforms Measures of 1991}

The macroeconomic crisis of 1991 triggered an economic reforms programme that aimed to achieve macroeconomic stability through economic efficiency and a higher rate of economic growth (Srinivasan 1995). The key elements of the economic reform measures included:

- $\quad$ Correcting fiscal imbalances: reducing the fiscal deficit as a percentage of GDP.

- Reforms in industrial policy: de-licensing, opening up of public sector to private sector participation $^{134}$, and easier access to foreign technology.

- Foreign investment policy: creating enabling policies for foreign investment and investment by Indian companies.

- Tax reforms: reforms in personal and corporate taxation and reforms in customs and excise duties to promote exports.

- Public Sector reforms: divestment and strategic sales of poorly performing public-sector undertakings

Sources: (Ahluwalia and Little, 1998;Bajpai, 2002;Joshi and Little, 1993;Ministry of Finance, 1995;Sachs et al., 1999;Srinivasan and Bhagwati, 1995)

In 1996, when the Congress Party-led ${ }^{135}$ central government lost the national elections, policymakers and international lending agencies expressed concerns regarding the likely continuation of the economic reform measures in the country. However, contrary to the pessimism expressed by some commentators in 1996, successive central government led by various political parties have persisted with the economic reforms (Little, 1996;Patnaik, 2006). Although a minority government, the United Front-led ${ }^{136}$ government, between 1996 and 1998, continued with the economic and energy reform policy decisions taken by the previous government. The prices of petroleum fuels were increased in 1997 as part of the agreed dismantling of the Administered Pricing Mechanism (APM). Despite widespread protests from trade unions and political parties against the price increases, the government did not reduce prices. In 1997, at the Chief Ministers' conference called by the Prime Minister, all parties agreed, for the first time, that, in order to make them financially viable, the SEBs would be restructured and a minimum tariff imposed on agricultural use of electricity. In 1998, when the National Democratic Alliance (NDA), led by the Bhartiya Janata Party (BJP), came to power, it continued with the existing reform policies and at the same time ushered in the next generation of reforms. India's economic growth during this period (19982004) was $8 \%$ per annum, almost double the growth rate recorded during the first three

${ }^{134}$ Prior to the economic reforms, eighteen important industries were wholly within the public sector. As part of the reform measures, this was reduced to six strategic industries. The liberalisation policy allowed private investment, including foreign investment, in certain areas including electricity generation and distribution, and petroleum exploration, development, refining and marketing (Ghosh, 2002)

${ }^{135}$ Although economic reforms were initiated by the Congress Party, it did not include economic reforms in its election manifestoes for the successive national elections in 1998 and 1999.

${ }^{136}$ After the 1996 general elections, no political party in India held a clear mandate to form a government. The Bharatiya Janata Party (BJP) emerged as the single largest party and was invited to form a government, but the BJP-led government fell after thirteen days, and other parties met to find a solution. Janata Dal became the leading political party in the resulting United Front coalition that was supported by the Congress Party and the Communist Party of India (Marxist). The United Front had two Prime Ministers in its two years of heading the government. 
In Pursuit of a Light Bulb and a Smokeless Kitchen

decades of the planned economy. The government continued with a series of reforms in the key infrastructure sectors such as roads, telecommunications, electricity and petroleum.

Table 4.1: Electricity Subsidies 1996 -2002

INR Billion

\begin{tabular}{|l|r|r|r|r|r|}
\hline Year & Gross subsidy & $\begin{array}{l}\text { Budgetary } \\
\text { support received } \\
\text { from states }\end{array}$ & Net subsidy & $\begin{array}{l}\text { Cross- } \\
\text { subsidy from } \\
\text { other sectors }\end{array}$ & $\begin{array}{l}\text { Uncovered } \\
\text { subsidy }\end{array}$ \\
\hline $1996-97$ & 202.10 & 66.31 & 135.80 & 77.74 & 58.05 \\
\hline $1997-98$ & 234.22 & 63.65 & 170.57 & 90.10 & 80.46 \\
\hline $1998-99$ & 274.82 & 103.51 & 171.31 & 83.45 & 87.85 \\
\hline $1999-2000$ & 310.03 & 112.64 & 197.39 & 53.07 & 144.31 \\
\hline $2000-01$ & 350.80 & 74.65 & 276.15 & 57.47 & 218.67 \\
\hline 2001-02 & 407.21 & 83.40 & 323.82 & 57.43 & 266.39 \\
\hline
\end{tabular}

Despite the implementation of economic reforms, the government's inability to control its expenditure, especially in terms of subsidies and fiscal expenditure, continued to slow improvements in economic efficiency and growth (Chandrasekhar and Ghosh, 2002;Patnaik, 2006). This lack of fiscal control was apparent in all economic sectors but especially in relation to energy sector policies. For example, in the electricity sector, the gross subsidy bills for the states increased from Rs 202.10 billion in 1996-97, when the distribution reforms were initiated, to Rs 407.21 billion in 2001-02 (Table 4.1). This increase was largely due to the continued subsidies on domestic and agriculture connections. Despite the state budgetary support and the cross-subsidy from other sectors, the uncovered subsidy ${ }^{137}$, which amounted to a commercial loss for the SEBs, was still rising. The uncovered subsidy increased from Rs 58.05 billion in 1996-97 to Rs 266.39 billion in 2001-02, due primarily to two reasons: a decrease in the cross-subsidy from other sectors, and especially the industrial sector ${ }^{138}$; and lower state budgetary support because of the overall decline in state financial resources.

As the national focus on the social sector declined, especially as it related to rural development and agriculture, an agrarian crisis emerged (Chandrasekhar and Ghosh, 2002;Patnaik, 2006). This, however, was overlooked in the high economic growth rate data and an increase in foreign direct investments in the country (Sen, 2003b;Vaidyanathan, 2006).

Even though reform measures were pursued and implemented during this phase, political populism continued to influence the rationale of energy pricing and the use of subsidies. Most of India's central governments have been multi-party alliances, and they are constantly under pressure from their alliance partners to stop increases in the prices of energy carriers. For

\footnotetext{
137 The uncovered subsidy amounts to the difference between the Net subsidy (Gross subsidy - State subvention) and the cross-subsidy from other sectors (industrial and commercial). The uncovered subsidy is the amount that either the SEBs is unable to collect from the consumers or from the state governments, which therefore appears in the SEBs' books as a commercial loss.

${ }^{138}$ Due to electricity shortages and deficits, the industries established their own captive electricity generation facility and reduced their grid purchases. 
example, the decisions by the government not to revise the prices of kerosene oil in 2001 and LPG in 2002 and 2004, in line with the spiralling global crude oil prices, were at the insistence of their political allies. In 2002, the government had proposed an increase in the price of LPG, but it immediately had to halve the original amount planned because of pressure from its political allies. Around the same time, immediately before state assembly elections, several state governments waived the electricity arrears for agricultural connections (Punjab in 2002, Madhya Pradesh in 2003, and Karnataka in 2004) to appease farmers and hopefully secure their votes. This was despite the fact that the Chief Ministers of all the states had agreed a minimum tariff for the agriculture sector at the Chief Ministers' conference in 2001. As such, this agreed decision was not implemented. In states such as Andhra Pradesh and Maharashtra, where state assembly elections were held in 2004, the Congress Party offered free electricity for farmers if the Party was voted into power.

Owing to these political decisions and interference, reform policies were set back, and mechanisms that were needed to improve the delivery of energy carriers were ignored. This represented a missed opportunity to explore alternative mechanisms for reducing budget deficits while not disadvantaging the poor in terms of energy carrier availability. The government's failure to provide the investments required in rural areas to develop economic as well as social infrastructures, such as education and health ${ }^{139}$, had a spiralling effect. Growth in the agricultural sector declined along with employment opportunities in rural areas. As a result, rather than "India shining", there was an adverse impact on the poor.

\subsubsection{Phase IV: Inclusive Reform (2004-2010)}

The national elections of 2004 were another turning point in the reforms. The National Democratic Alliance (NDA) went into the national elections with the campaign slogan of 'India Shining, ${ }^{140}$, whereas the Congress Party used the platform of 'aam aadmi' (referring to the ordinary citizens of India). While the NDA focused on a feel-good factor of a rising India with stable economic growth, Congress focused on highlighting the reality that the common man was not benefiting from the ongoing macro-level economic development and growth, and that there was a need for a balanced, rural-biased and pro-poor economic strategy ${ }^{141}$. Political pundits were surprised when the NDA lost the election because India had witnessed economic growth and stability in the six-year period (1998-2004) that the Alliance was in

139 Amartya Sen (1999) raises these concerns when comparing the progress made by China and by India. Both countries started their economic reforms at almost the same time, but with different outcomes: China has progressed better. He further argues that the difference can be explained by the fact that China started its reforms with a large literate population and a stable healthcare system in the rural areas, whereas India had been weak on both fronts (Sen, 1999).

140 See Chapter 1.

${ }^{141}$ An ironic aspect of the election campaign strategies was Congress Party's attack on the economic reform agenda pursued by the NDA since this was a continuation of economic reforms initiated by Congress in 1991. The campaign of the Congress Party indicated that it had chosen ideological clarity in place of the ambiguity. This can be interpreted as a party torn between its claim to be the initiator of economic reform and its realisation that advocating economic reform might not be politically expedient. 
power. One interpretation of the election results was that the Indian electorate was sending a message to the political classes that, unless the benefits of macroeconomic growth and development reached the poor, economic reforms had little meaning (Patnaik, 2006).

In 2004, the Congress Party thus formed the central government, as a multi-party alliance under the umbrella of the United Progressive Alliance (UPA). The UPA drafted a Common Minimum Programme (CMP) incorporating some of the electoral promises made by the alliance partners in their election manifestoes and speeches. The focus of planning shifted to inclusive growth and development, and brought a people-centric approach to economic reforms, which were popularly referred to as 'reforms with a human face'142. The broader framework of development planning, at the political ideological level, also changed with the emphasis now on reforms with a human face. However, in reality, the elements of inclusive development were ignored and the government continued to implement a similar neo-liberal reform programme to that adopted by the $\mathrm{NDA}^{143}$.

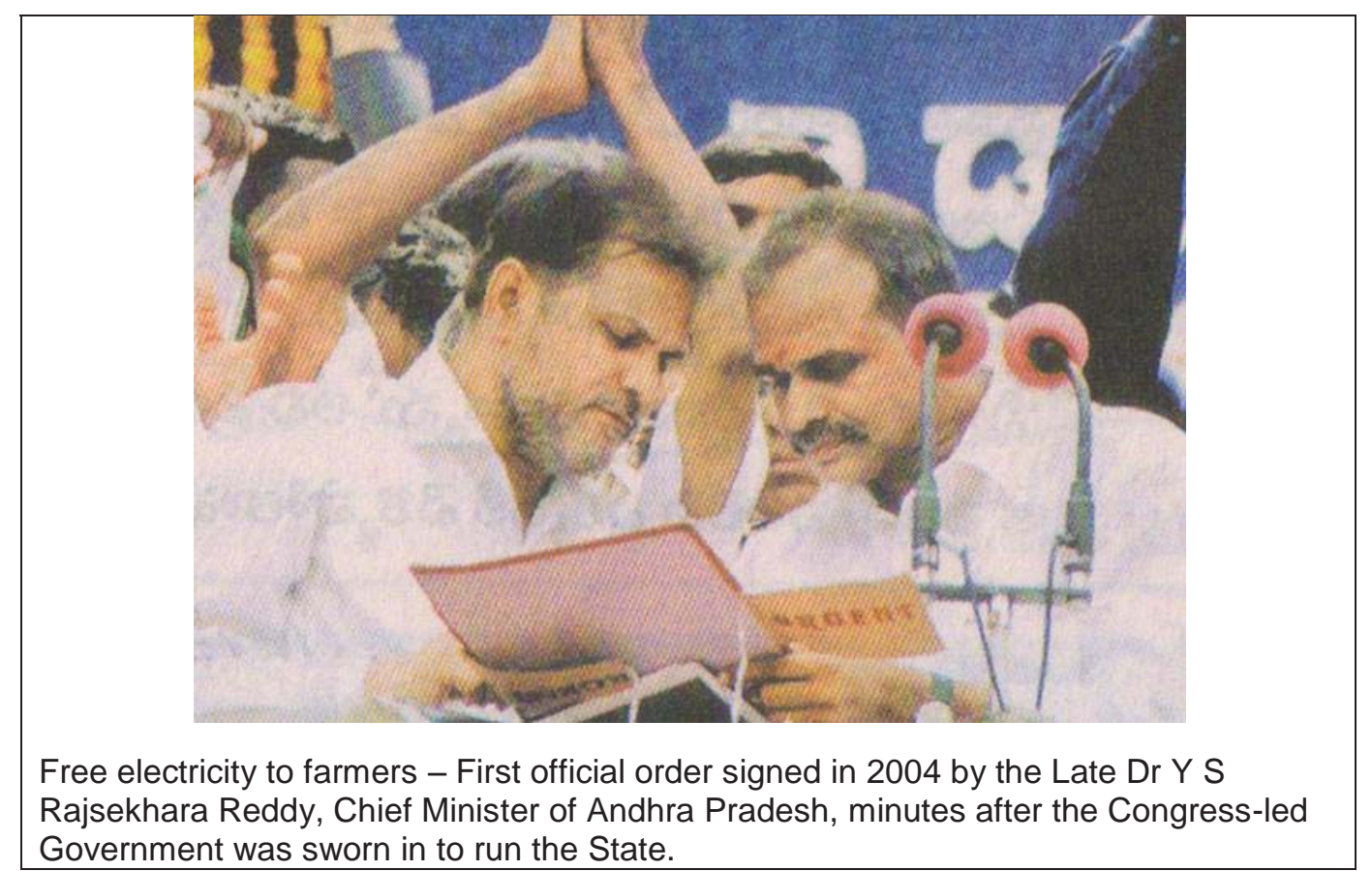

${ }^{142}$ While Congress focused on balanced economic development, left-leaning political parties emphasised the human face of economic development. The Common Minimum Programme was therefore a strange concoction of different political ideologies, coming together for the sake of forming a government. However, this arrangement did not last its full term and, in 2009, the alliance partners went into national elections not as an alliance but as opposing parties.

${ }^{143}$ C P Chandrasekhar, a noted economist, argues that the UPA government showed same haste and same contempt for mass pinion as the previous government did. It was observed that the UPA government pushed ahead with measures of liberalisation, in the form of divesting equity in profit making public sector units, hiking FDI caps in crucial sectors including telecom and banking, and, above all, diluting and for all practical purposes shelving the promised Employment Guarantee Act. In the energy sector, it pushed for the existing form of restructuring of the electricity sector rather than reviewing the Electricity Act 2003 (Chandrasekhar, 2005). 
From the energy sector perspective, the period between 2005 and 2010 has seen significant change in terms of energy policies and programmes, and this has brought greater clarity in the governance and implementation of energy sector reforms. The government has continued with reforms in the energy sector through regulatory frameworks and policy incentives, but there is an enhanced facilitating role for government through policy frameworks as well as implementing programmes directed towards rural areas. In 2004, the government announced a national rural electrification programme called Rajiv Gandhi Grameen Vidyutikaran Yojana (RGGVY). The programme aimed at electricity for all by $2009^{144}$ and a strengthening of the rural electricity distribution infrastructure. Mandated by the Electricity Act 2003, the Ministry of Power developed the National Electricity Policy 2005, the Rural Electrification Policy 2006 and a policy on Decentralised Distributed Generation, each creating an enabling environment for enhancing rural electricity access.

The Planning Commission formulated the Integrated Energy Policy 2006, which was approved by the cabinet in 2008 and, with this, five decades of disjointed energy policies came to an end. In the renewable energy sector, pursuant to the Electricity Act 2003, the State Electricity Regulatory Commissions initiated new measures by introducing renewable energy tariff orders to attract investment in clean energy generation. The SERCs also stipulated renewable energy purchase obligations for increasing the role of renewable power in energy distribution. In 2010, the Central Electricity Regulatory Commission created a framework for trading renewable energy certificates.

In 2008, India announced a National Action Plan on Climate Change (NAPCC) that laid down a framework for an ecologically sustainable development pathway and a balanced approach to addressing mitigation and adaptation to climate change, while protecting the poor and vulnerable sections of society through an inclusive and sustainable development strategy.

The least progress in terms of distribution reforms was made in the petroleum sector. The central government failed to reform the pricing policy for reasons of political expediency, and effectively pushed solving the problem into the future. However, minor developments have occurred since 2009, when the central government initiated the "Rajiv Gandhi Grameen LPG Vitrak Pariyojana" national programme aimed at creating an LPG distribution infrastructure in rural areas. It finally removed the price controls from petroleum fuels in 2010, instead linking prices to import costs, and also agreed a systematic phasing out of subsidies on LPG. Following the recommendations of committees constituted by the Government of India since 2005, the government is now planning an alternative subsidy transfer mechanism and the efficient distribution of energy carriers such as kerosene oil. Further, a gender audit of the national energy policy has provided recommendations for integrating energy-gender linkages into the policymaking process as well as into implementation (Parikh and Sangeeta, 2008).

In the most recent decade (2001-10), as the government continued with the implementation of energy policy reforms, the policies brought some subjective changes in approach and design. However, the basic objectives of the rural energy programmes have remained

${ }^{144}$ The target of electricity for all by 2009 was amended in 2008 and the revised target year was changed to 2012. 
unchanged. The rural energy programmes are essentially extensions of the pre-reform programmes. The fundamental difference is that there is now a conscious effort to fine tune the policies to make rural energy programmes more effective in terms of improving access and targeting subsidies (Planning Commission, 2006). Meanwhile, government interventions continue in all the major rural energy programmes related to rural electrification, petroleum energy carriers (kerosene oil and LPG), and renewable energy technologies. One change was made when the central government stopped subsidising the national programme for improved cookstoves in 2001. In the post-reform period, private-sector participation in rural energy programmes has started, but with little success. In terms of renewable energy technologies, the involvement of the private sector is mostly confined to solar PV systems and biomass energy systems for decentralised electricity generation and distribution. The Electricity Act 2003 set in motion the establishment of ground rules for involving the private sector, village institutions and government agencies in the expansion of the rural electrification programme, both through the extension of the electricity grid and through decentralised generation and distribution.

\subsection{Policies and Programmes for Rural Energy Access}

\subsubsection{Phases I and II (1950-1991)}

\section{Rural Electrification Programme}

Immediately after Independence, the availability of electricity in India was confined to the urban and peri-urban areas. However, providing rural areas with electricity was considered vital to improve the quality of life of the rural population and the development of local economic opportunities by creating an enabling environment for the adoption of electricity by agriculture (irrigation and farm mechanisation) and rural industries. Consequently, the rural electrification programme ${ }^{145}$ included village and household electrification, electricity for social and public infrastructure such as schools, health centres and public lighting, electricity for irrigation pump-sets and for small village and cottage industries. The first Five-Year Plan (1951-56) provided a budget of Rs 0.73 billion and the Second (1956-61) a budget of Rs 0.75 billion for these programmes. The rural electrification programme measures were supported by economic incentives for users and industry. For the users, economic incentives were in the form of subsidies and cross-subsidies in energy prices. The electricity industry received fiscal incentives from the government in the form of concessional loans and grants to expand electricity access. Figure 4.3 summarises the policies and instruments used for rural electrification from when the first Five-Year Plan was formulated in 1951 through to the initiation of reforms in 1990.

\footnotetext{
${ }^{145}$ The financial allocation for the programme has increased significantly since the second Five-Year Plan, with the rural electrification programmes receiving between 15 and 20 per cent of the total plan budget allocation during 1955 and 1969 (Govinda Rao et al., 1998-99). The rural electrification programme received additional support after 1969 when the Rural Electrification Corporation (REC) extended financial assistance to the State Electricity Boards for expanding electricity access in rural areas.
} 
In line with the changes in policy ideology, towards pro-poor interventions, the rural electrification programme went through significant changes in the mid-1970s, and again in the 1980s. Citing the dispersed electricity connections and high transaction costs in meter reading and bill distribution in rural areas, Uttar Pradesh, a northern Indian state, was the first to shift to a flat tariff in this period ${ }^{146}$ (Shah, 2001). By the early 1980s, the flat tariff system had become a political tool in the southern Indian states of Andhra Pradesh and Tamil $\mathrm{Nadu}^{147}$. In Andhra Pradesh, during the 1977 elections, the Congress Party as part of its strategy offered a flat-rate tariff to farmers. In the neighbouring state of Tamil Nadu, the Chief Minister started to expand the provision of free electricity, which could be construed as an election strategy to gain farmer's votes.

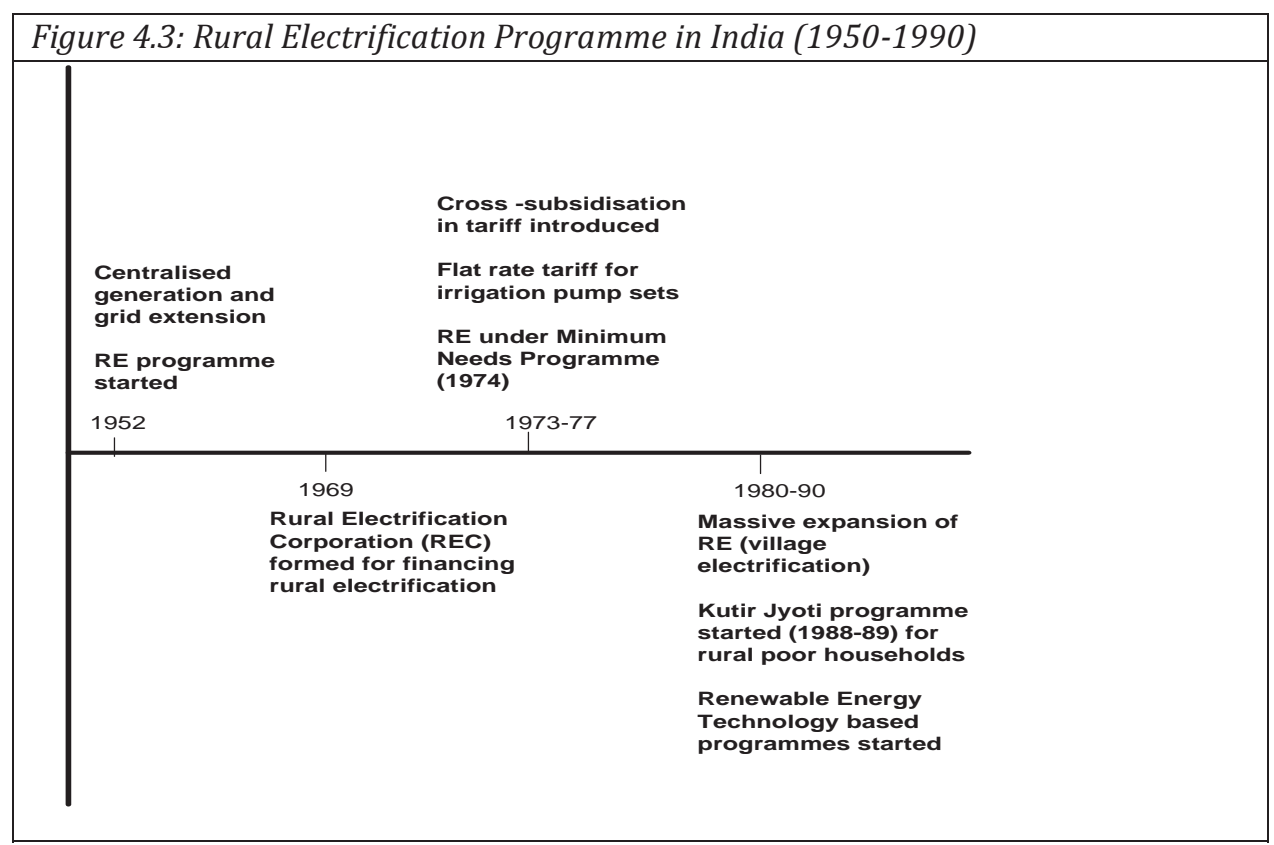

In addition to the ongoing rural household electrification programme, the government initiated in 1988-89 a pro-poor household electrification programme called Kutir Jyoti. The Kutir Jyoti (KJ) programme provided a non-metered connection for a single (one) light bulb and was specifically designed for socially and economically backward households. It is a subsidised scheme with the central government covering both the costs of the connection and

${ }^{146}$ A flat tariff is a non-metered billing system and is calculated in the case of an irrigation connection on pump-set capacity (per horsepower), while for a household connection it is based on a minimum unit (kWh) of consumption per month (load factor), and not on the basis of the actual consumption of electricity. The flat tariff billing resulted in over consumption of electricity either by under-reporting the pump-set size and capacity (for example, using a five horsepower capacity pump-set, while declare the capacity to electricity utilities as three horsepower) and using more number of load points at household level, but paying lower amount of money.

${ }^{147}$ In the three case-study regions of this thesis, these issues did not arise as electrification levels were low and the use of electricity in agriculture was very limited. 
In Pursuit of a Light Bulb and a Smokeless Kitchen

the wiring. Annexure IV provides an overview of the various rural electrification programmes introduced in the period between 1950 and 1990.

Table 4.2: Plan Budget for Rural Electrification in India (1951-90)

\begin{tabular}{|l|r|r|r|}
\hline \multirow{2}{*}{ Five Year Plan } & \multicolumn{3}{|c|}{ Plan Budget (Rs Billion) } \\
\cline { 2 - 4 } & Total Public Sector & Power Sector & Rural Electrification \\
\hline 1st (1951-56) & 20.68 & 1.28 & 0.73 \\
\hline 2nd (1956-61) & 48.00 & 4.27 & 0.75 \\
\hline 3rd (1961-66) & 80.94 & 10.19 & 4.05 \\
\hline 4th (1969-74) & 159.02 & 24.47 & 7.75 \\
\hline 5th (1974-79) & 392.87 & 72.93 & 15.76 \\
\hline 6th (1980-85) & 957.00 & 192.65 & 21.08 \\
\hline 7th (1985-90) & 1800.00 & 342.73 & \\
\hline Source: Collated from Five-Year Plan documents \\
\hline
\end{tabular}

Rural electrification programmes have been supported by budgetary allocations from the central and state governments. Table 4.2 provides the planned budgets for rural electrification and its share of the power sector budget from 1951-56 (first Five-Year Plan) through to 1985-90 (seventh Five-Year Plan). As Table 4.2 shows that while investment in rural electrification has increased, rural electrification's share of the budget has generally declined. In the pre-reform period, the one exception was the fourth Five-Year Plan, when both the budgetary allocation for rural electrification and the power sector's share increased, with the central government provided additional support for the Rural Electrification Corporation (REC) and the pump-set energisation programme. The REC's main instrument for funding the RE programme was in the form of loans to state governments. However, post-1980, disbursements from central government to state governments declined as the states would be unable to repay such loans. This was mainly because most of the SEBs were functioning in a constrained policy environment where the cost of supplying electricity was more than the revenue this realised. As a result, the financial position of the SEBs worsened year on year.

\section{Petroleum Sector Programme}

Historically, a few Anglo-American companies had controlled the Indian petroleum industry and these maintained their dominance until the end of the 1950s. After India's Independence, the government made clear its aspirations and future plans for core strategic industries, such as petroleum, in the industry policy resolutions of 1948 and 1956. All future developments of the petroleum industry were to be reserved for Public Sector Undertakings (PSUs).

Government intervention in the petroleum sector has been in the form of public sector investment directed at ensuring energy security as well as providing economic incentives in the form of subsidies to consumers. In the period between Independence and the first oil crisis of 1973, foreign oil companies largely controlled the marketing of petroleum 
products $^{148}$. During this period, petroleum product prices were not regulated. Public sector participation in the marketing of petroleum products started in 1959, when the Indian Oil Corporation (IOC) was set up ${ }^{149}$. In the period between the 1973 oil crisis and the second oil crisis of 1979, government policy was directed towards the acquisition of foreign-owned oil companies, although it was only after 1979 that the petroleum sector came fully into public ownership. In 1977, the central government introduced the Administered Pricing Mechanism (APM) in order to protect the interests of the domestic petroleum sector companies and consumers. After the introduction of the APM, subsidies on each of the petroleum energy carriers were adjusted under the Oil Pool Account (OPA) (Box 4.3). Rather than a direct subsidy from the central government budget, the APM provided a cross-subsidy system within the petroleum sector. Financial inflows and outflows were accounted for through the OPA, separate from the overall budget. The Oil Coordination Committee (OCC) managed the OPA.

\section{Box 4.3: Administered Pricing Mechanism and Oil Pool Account}

Until 1939, there were no controls whatsoever on the pricing of petroleum products. Between 1939 and 1948, the oil companies themselves maintained pool accounts for major products without any intervention by the government. In 1948, for the first time, an attempt was made to regulate prices by linking the domestic energy prices with import parity price. The Shantilal Shah committee, set up in 1969 to address the issue of the pricing mechanism, did not favour using the import parity price as a benchmark for domestic pricing, since domestic refining capacity had significantly increased (India Info Line, 2000). However, this recommendation was not acted upon. Again in 1976, the Oil Pricing Committee (OPC) recommended the ending of the import parity principle and suggested that the domestic cost of production should be the determining factor in the pricing of petroleum products. The Administered Pricing Mechanism (APM) evolved from a recommendation by the OPC and came into existence on 16 December 1977. The implementation of the APM went smoothly since, by then, all the foreign oil companies had been taken into public ownership by the Government of India, which meant that the government had complete control over prices. Price-controlled products included petrol, diesel, kerosene, LPG and aviation fuel. The main features of the APM were:

- Consumer prices of certain products such as petrol were fixed at a level higher than the import parity price.

- $\quad$ Consumer prices of certain products such as kerosene oil, under the PDS, and domestic LPG were fixed at levels below than the import parity price.

- $\quad$ Prices for consumers were equalised across all refinery locations in the country, ensuring stable prices and insulating the domestic market from price volatility on the international market.

- $\quad$ Refineries paid international prices for crude oil, including indigenous crude oil; and they received import parity prices for controlled products sold to marketing companies.

From 1982-83 onwards, the OPA started to generate surpluses. As a result, the Oil Coordination Committee (OCC) made large deposits in the Public Account of India. The deposits in the Public Account payable to the OCC in 1989 reached a level of Rs 89 billion. However, from 1989-90 onwards, the OPA started recording a deficit as the government failed to increase the price of subsidised petroleum energy carriers to reflect increases in the price of crude oil on the global market.

${ }^{148}$ Prior to Independence, refining and marketing of petroleum products in India were exclusively reserved for foreign oil companies, including Burmah Shell (since 1921), Standard Vacuum Oil Company (since 1933) and Caltex (since 1937). In the period between 1951 and 1953, the government signed agreements with all three companies to establish refineries and market their petroleum products in the country. For details see (Kelkar and Sarma, 1996).

${ }^{149}$ The IOC was set up under an arrangement with the Soviet Union for the marketing of certain critical imported petroleum products. For details see (Kelkar and Sarma, 1996). 
In principle, petroleum sector programmes do not differentiate between rural and urban areas but, in practice, the programmes have been largely influenced by the demand for petroleum energy in urban areas. Figure 4.4 gives a schematic overview of the different interventions made in the petroleum sector, along with their significance for rural energy.

Subsidies for some petroleum products were considered necessary for two reasons: on socioeconomic grounds and to contain the inflationary pressures in the economy. The arguments advanced varied among petroleum products. Kerosene oil was subsidised because it constituted the main fuel for lighting for the economically weaker sections of society and because it was used for cooking in rural and urban areas that lacked sufficient biomass resources. A subsidy on domestic LPG was provided because it was the main source of energy for cooking for the urban rich and middle classes. The subsidy on diesel was considered important due to its central role in the economy as the main fuel for transportation of goods, and a rise in diesel prices would result in increased commodity prices.

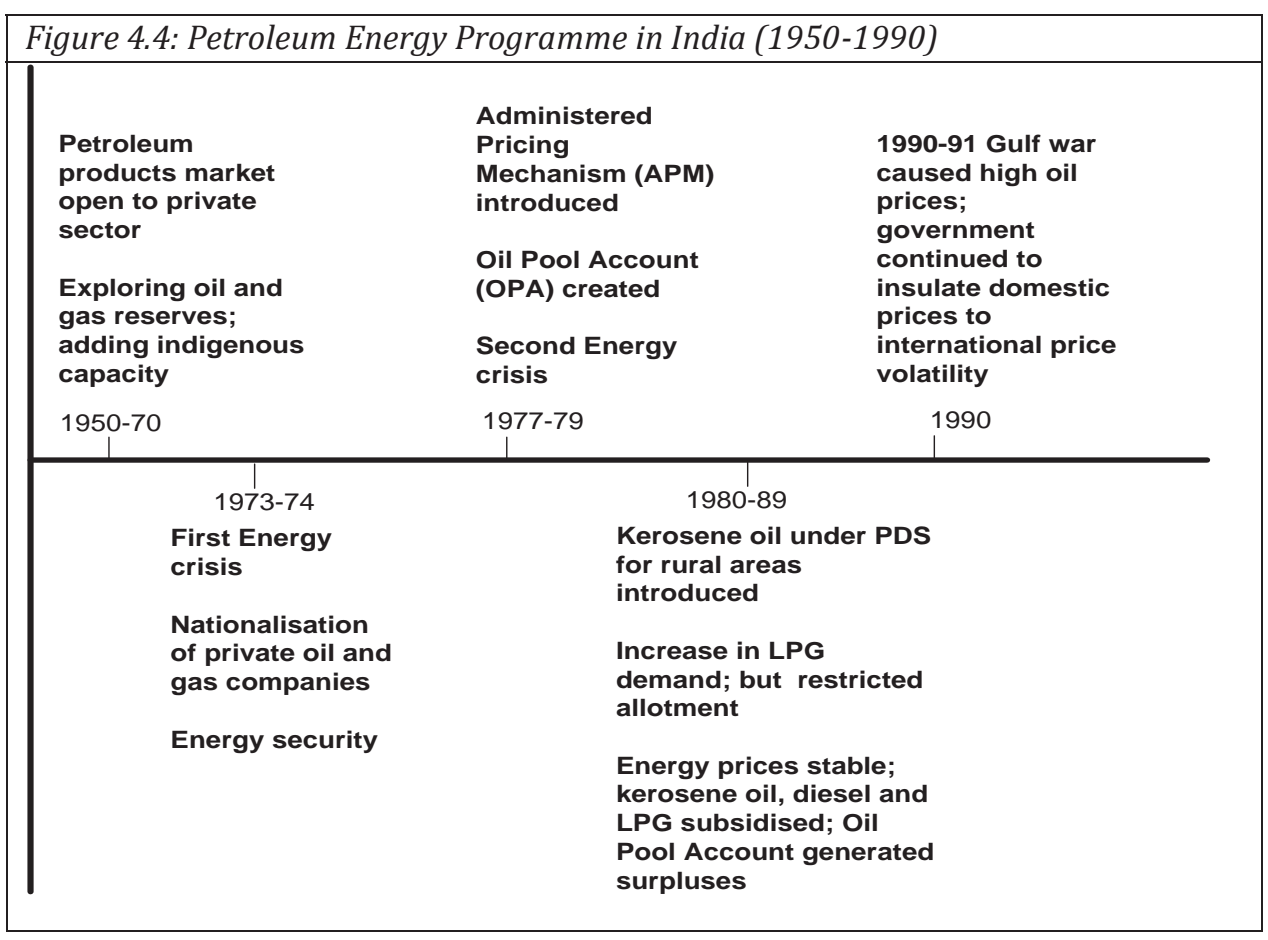

The extension of the PDS to the rural areas in the early 1980s, through the establishment of FPS, improved the availability of kerosene oil in the villages (Radhakrishna and Subba Rao, 1997). State governments determined the entitlements to kerosene oil (on a per capita basis or per ration card) for each ration cardholder and the frequency of supply (monthly or bimonthly) ${ }^{150}$. Other petroleum products such as LPG, diesel and petrol were available through

\footnotetext{
${ }^{150}$ Entitlements for rural and urban areas are different. There are also significant inter-state variations in entitlements and the form of delivery systems. The rural/urban differentiation is based on an assumption that, in rural areas, demand for kerosene oil is primarily for lighting, whereas in urban areas it is also used for cooking. 
the retail distribution networks of the national oil companies, most of which were located in urban settlements. In order to balance the rising demand for petroleum products and the level of subsidy, the government introduced regulatory measures such as restrictions on the quantity of kerosene oil that a ration cardholder could buy under the PDS and on the allocation of new LPG connections. In terms of LPG allocation, a geographical limit of 15 $\mathrm{km}$ from the location of a dealer was introduced to restrict the services offered and hence balance supply and demand. Since the majority of the LPG dealers were based in urban areas, this amounted to a clear urban bias in terms of LPG use.

\section{Renewable Energy Programme}

Development and promotional work on renewable energy technologies ${ }^{151}$ was initially carried out by individuals and institutions inspired by Gandhian ideals. The focus was on biogas to improve sanitation and on improved cooking stoves to reduce smoke emissions. The major boost to the development of renewable energy technologies on a national scale came after the Planning Commission stressed the need to develop alternative sources of energy to meet the growing demand in rural areas (Planning Commission, 1980). As such, interest in renewable energy resources and technologies increased after the second oil crisis of 1979. However, systematic efforts to develop and disseminate renewable energy technologies (RETs) only started after the establishment of the DNES in late-1981. The first two major programmes were the National Programme on Biogas Development (NPBD) ${ }^{152}$ in 1982 and the National Programme on Improved Cookstoves (NPIC) in $1983^{153}$. Besides these two programmes, the DNES also started demonstration programmes in the latter half of the 1980s that included SPV systems ${ }^{154}$, solar cookers, solar water heaters, windmills and wind generators. The Planning Commission further initiated the Integrated Rural Energy Planning (IREP) programme to provide an integrated solution to the energy needs of rural areas through a combination of RETs and energy efficient devices.

Renewable energy programmes were implemented with financial support from the central government in the form of budgetary support for research and development (R\&D), for programme implementation and as direct subsidies for beneficiaries. In order to offset the high initial cost of RETs, beneficiaries were provided with direct cash subsidies under various technology dissemination programmes (Venkata Ramana, 1998). In the seventh FiveYear Plan (1985-90), the budget for renewable energy was Rs 4.12 billion, equivalent to $0.23 \%$ of the total public sector budget of Rs 1800 billion. The renewable energy budget included provision for programme support and support for R\&D. Annual targets were set for the various programmes that were implemented through state nodal agencies and subordinate local institutional structures. In 1987, IREDA was set up by the central government as a

\footnotetext{
${ }^{151}$ See Venkata Ramana (1998) for an assessment of renewable energy technologies in rural India including a historical perspective.

152 The NPBD was initiated by the Ministry of Agriculture and then transferred to the DNES in 1982.

153 The NPIC started as a demonstration programme in 1983 and became a full-fledged implementation programme in 1985.

154 SPV systems came into prominence in 1975, when they found applications in the space, telecommunication and defence sectors in India. For details, see Sinha et al. (1998).
} 
public-owned financial company for the promotion of RETs on a commercial basis. As such, until the beginning of the economic reforms in 1991, the various programmes concerned with promoting RETs were based on subsidies.

\subsubsection{Phases III and IV (1991-2010)}

Following the initiation of economic reforms in 1991, it was realised that a poor infrastructure was a critical bottleneck in modernising the economy and that the reforms might well flounder due to the country's inability to provide reliable infrastructural services such as energy, communications and transportation (Sinha, 1996). Consequently, a new phase of the economic reform programme saw the government paying particular attention to the development of power generation and reducing its fiscal liabilities by deregulating and delicensing the energy sector ${ }^{155}$. The essential aspects of the energy sector reform policies were incorporated in the Industrial Policy Resolution (IPR) announced in 1991 (Kelkar and Sarma, 1996). In the case of electricity, both generation and distribution activities were opened up for private sector participation. In the petroleum sector, the IPR opened up both the upstream refining and downstream marketing activities to the private sector, subject to licensing requirements, while continuing to exclusively reserve the exploration and development of oil and gas fields for the public sector.

\section{Box 4.4: Reform Measures in Electricity and Petroleum Sectors}

\section{Electricity Sector Reforms}

- Unbundling of vertically integrated State Electricity Boards (SEBs) into separate generation, transmission and distribution companies

- Private sector participation in generation and distribution

- Competitive bidding for new generation capacity

- Establishment of autonomous regulatory body

- Reform of electricity tariff at the bulk power, transmission and retail levels

- Distribution system reforms including governance and tariff reforms: power for all by 2012

- Enactment of Electricity Act 2003, with its special emphasis on separate national policies for rural electrification and distributed generation and distribution

- Integrated Energy Policy 2006 with a focus on access to energy in rural areas and an emphasis on renewable energy based decentralised generation and distribution

- National Electricity Policy 2005 and Rural Electrification 2006; Rajiv Gandhi Grameen Vidyutikaran Yojana (RGGVY) and Decentralised Distributed Generation (DDG) Scheme; Remote Village Electrification Programme (RVEP)

\section{Petroleum Sector Reforms}

- Decontrol of petroleum products

- Parallel marketing scheme in 1993 allowing the private sector to develop its own infrastructure and import facilities to market LPG and kerosene oil

- Special licences for importing products

- Opening up of the refining sector

- New exploration and licensing policy (NELP) in 1997 to attract investments for exploration of oil and gas reserves

- Dismantling of the APM by 2002; limited subsidy on LPG and kerosene oil, other petroleum products linked to import parity price

- Disinvestments in the national oil companies

- Integrated Energy Policy 2006

- Rajiv Gandhi LPG Vitrak Pariyojana in 2009 to improve LPG availability in rural areas

- Decontrol of petroleum fuel prices in 2010, prices linked to import parity price, phased elimination of LPG subsidy, alternative options for delivery of kerosene oil to check pilferage, recommendation for subsidised kerosene oil only for BPL households

\footnotetext{
155 The fundamental argument by policymakers for energy sector reform was based on the economic efficiency argument (see Section 2.3, for the theoretical underpinnings of public sector reforms).
} 
Clearly, reforms in the electricity sector, the petroleum sector and in renewable energy have followed different pathways. This is mainly due to the distinct characteristics of the different energy carriers and due to variations in the policy approaches adopted for their promotion, and the division of constitutional responsibilities between the centre and the state. External agencies such as bilateral and multilateral development agencies have also played a critical role in influencing the reforms process. The main elements of the electricity sector and petroleum sector reforms are presented in Box 4.4.

The tenth Five-Year Plan (2002-07) identified 'electricity' as a critical input for the social and economic development of the rural areas and in removing poverty. The Plan made significant pronouncements regarding energy prices and subsidies, which would have significant implications for government finances (Planning Commission, 2002d). Criticising the fallacy of subsidising services in the name of the poor, the Plan stated that the argument for not charging appropriate user charges had essentially been based on equity considerations. However, the Plan ignored the fact that the better-off sections of society consume most of such energy services and therefore benefit from the subsidies associated with these services. In fact, if the better-off were made to pay, it would then become possible to provide essential services to the poor (Sainath, 1998). In 2004, a central government paper on subsidies indicated that the misdirected subsidies on kerosene oil and LPG have resulted in economic inefficiencies (Ministry of Finance, 2004). While the Planning Commission recommended the use of smart subsidies to ensure that only the intended beneficiaries received them, political interference in policymaking, especially in the pricing and expansion of energy, have resulted in economic inefficiencies in the system with the better-off sections in society capturing the benefits.

In 2006, the Planning Commission of India formulated its Integrated Energy Policy (IEP) that provided a comprehensive energy roadmap until 2030 (Planning Commission, 2006). The IEP identifies several energy challenges that need to be addressed, including meeting energy demands, securing supply, mitigating climate change and promoting renewable and alternative energy. The IEP 2006 sets out several policy choices, specifically with the objective of spurring investments in renewable energy and focusing on a range of renewable sources including fuelwood, biogas, biomass gasifiers, biofuels, SPV and solar thermal. The IEP 2006 clearly states that solar energy can eventually provide energy independence.

Recognising the role of energy access, the policy suggests meeting the objectives of universal access to meet energy needs through household electrification and by creating appropriate technology choices and fuel supply options for meeting cooking energy needs through fuelwood plantations within a kilometre of habitation. Further, the easy availability of the amount of clean energy required to maintain life should be considered as a necessity.

The IEP 2006 places a special emphasis on decentralised energy systems (for improving access to electricity, energy for cooking and thermal applications for village industries) as it expects the dispersed nature of renewable energy to be able to provide many socioeconomic benefits. To expand electricity access, the IEP puts forward a clear policy signal in favour of decentralised generation as such systems have the ability to take electricity to the villages more quickly than the grid. Not only can decentralised systems encourage local electricity 
generation and create opportunities for diversified economic activities, including small and medium enterprises; these local generation systems can also feed the grid with any surplus power. The IEP 2006 further states that grid-connected decentralised renewable energy electricity generation units have the possibility to improve the quality of supply and provide system benefits by generating electricity at the extreme ends of the grid.

\section{Rural Electrification Programme}

\section{Electricity Sector Reforms and Rural Electrification}

Since both central and state governments are constitutionally responsible for the electricity sector, reform measures were initiated on both levels. The initial focus of the electricity sector reforms in 1991 was on adding additional power generation capacity and encouraging private sector participation (including foreign investment) in the form of independent power producers (IPPs) ${ }^{156}$ (Dubash and Chella Rajan, 2001). When the high cost of power from the new power plants became apparent, the euphoria over the IPP strategy soon subsided among various stakeholders, and especially within the SEBs. Further, as the IPP strategy proceeded, it became increasingly clear that while the private sector had been initially interested in investing in generation, they were becoming increasingly reluctant when it emerged that they had to sell the electricity to the SEBs, which were already incurring financial losses and had limited capacity to pay the IPPs for the electricity generated.

The inefficiencies in the Indian electricity sector were aggressively addressed by the multilateral funding agencies, which linked the provision of investment funds for electricity generation to restructuring the SEBs (Dubash and Chella Rajan, 2001;Rajan, 2000;Tellam, 2000). In order to offset the rising cost of subsidies and the SEBs' poor financial position (see Table 4.1), the government adopted a Common Minimum Action Plan for power sector reforms. This plan, approved in 1996, listed various policy measures to be adopted by the state governments.

Policy initiatives were further supported by the policy and regulatory framework for rural electrification (Box 4.5). Specifically, these initiatives aimed to introduce a minimum tariff for agricultural consumers and an increased tariff for household consumers, while rationalising the tariffs in other sectors. However, several state governments, for political reasons, did not implement these policy measures for fear of a consumer backlash. Some state governments, such as Orissa, initiated electricity sector reforms by unbundling their vertically integrated SEBs into separate generation, transmission and distribution utilities. Although the distribution reforms, including the privatisation of electricity distribution, were initiated in

\footnotetext{
${ }^{156}$ The incentives offered to IPPs were a minimum $16 \%$ return on equity used for plants operations, fiveyear tax holidays, two-part tariff structures and selective counter-guarantees from the central government. By mid-1995, 189 projects, with a cumulative capacity by $75 \mathrm{GW}$, were in the pipeline, from which agreements/intents had been signed for 48,137 MW of capacity by the state governments. However, most of these projects never came to fruition due to bureaucratic delays. The problems faced by Enron Corporation, which was the first IPP following the 1991 liberalisation policy, in negotiations with the state government, and its further problems with the central government, sent negative messages to other potential IPPs. Another problem was the poor fiscal health of the SEBs. 
1999, no states other than Orissa and Delhi, had privatised their electricity distribution as of 2006. In order to support these reform measures, the central government created separate funds, such as the Accelerated Power Distribution and Reforms Programme (APDRP), for investing in improving the supply and distribution infrastructure.

\section{Box 4.5: Policy and Regulatory Framework for Rural Electrification - After 2004}

As part of the reforms, the Government of India took initiatives to develop an appropriate policy and legislative framework for the electricity industry as a whole, and for rural electrification in particular. In 2003, the Government of India notified the Electricity Act 2003, which provides an overall policy and regulatory framework for the industry. The Act provides policy provisions including measures for strengthening the distribution infrastructure and rural electrification.

In 2005, the Government of India published the National Electricity Policy (NEP) 2005, which laid down policy goals and programmes for rural electrification and the mainstreaming of renewable energy power generation. The NEP 2005 also emphasised that the provision of electricity to all (including rural dwellers), as mandated in Section 6 of the Electricity Act 2003, remained mandatory.

Within Sections 4 and 5 of the Electricity Act 2003, the Government of India formulated the Rural Electrification (RE) Policy 2006. The RE Policy states as its goals: (i) the provision of access by all households to electricity by 2009; (ii) good quality and reliable power supply at reasonable rates; and (iii) minimum lifeline consumption of one kWh of electricity per household per day. The RE Policy 2006 provides an overall framework for implementing the RGGVY, including setting out the roles of PRIs in managing the implementation of the programme. Section 9 of the RE Policy 2006 addresses the issue of managing electricity distribution through local institutions. Section 8 of the RE Policy 2006 provides for policy provisions that permit standalone systems based on renewable energy technologies for rural areas.

In terms of budgetary support for rural electrification in the post-reform period, the budget in the eighth Five-Year Plan (1992-97) was Rs 40 billion, 5\% of the power sector's budget (Table 4.3). During the ninth Five-Year Plan (1997-2002), the budget for rural electrification almost doubled to Rs 74.59 billion. This was largely due to an increased allocation in 2000 when the central government provided additional budgetary support for rural electrification. The budget for rural electrification in the ninth plan period was about $6 \%$ of the power sector's total budget. Continuing the momentum established towards the end of the ninth planning period, the budget for rural electrification improved significantly during the tenth Five-Year Plan. In 2002, the government provided an overall budget of Rs 6.27 billion for Kutir Jyoti and Rs 5.64 billion for the Accelerated Rural Electrification Programme. In the last two years of the period covered by the tenth five-year plan, the government introduced a new national programme under the RGGVY with a budgetary allocation of Rs 50 billion. The tenth Five-Year Plan also saw many rural electrification programmes being added, although most of these eventually merged with the RGGVY (Annexure IV). In the eleventh Five-Year Plan (2007-12), the central government set a budget of Rs 280 billion as capital subsidy for implementing the RGGVY. This included a budget of Rs 5.4 billion for decentralised distributed generation projects aimed at the electrification of remote villages. 
In Pursuit of a Light Bulb and a Smokeless Kitchen

Table 4.3: Plan Budget for Rural Electrification in India (1992-2012)

\begin{tabular}{|l|r|r|r|}
\hline \multirow{2}{*}{ Five Year Plan } & \multicolumn{3}{|c|}{ Plan Budget (Rs Billion) } \\
\cline { 2 - 4 } & Total Public Sector & Power Sector & Rural Electrification \\
\hline 8th (1992-97) & 4341.00 & 795.89 & 40.00 \\
\hline 9th (1997-02) & 8592.00 & 1245.26 & 84.59 \\
\hline 10th (2002-07) & 14841.31 & 2702.76 & 280.00 \\
\hline 11th (2007-12) & 36451.18 & 5726.48 & \\
\hline Source: Collated from Five Year Plan documents \\
\hline
\end{tabular}

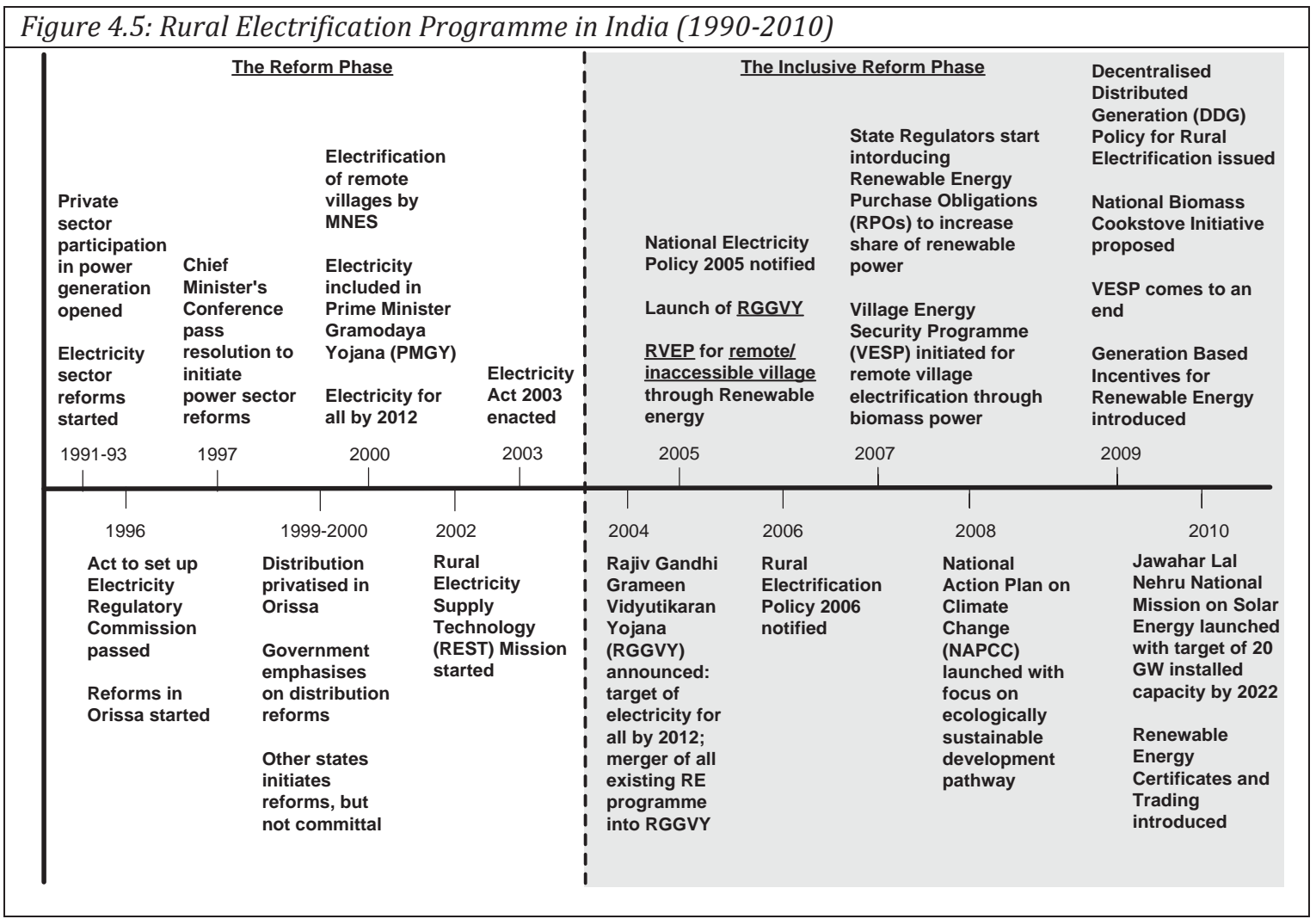

\section{Initiatives for Rural Electricity Access}

The initial focus of the electricity sector reforms was to attract private sector investment for adding new electricity generation capacity. Distribution reforms in the electricity sector brought renewed focus on the problems of rural electrification. However, a major bottleneck was the poor financial position of the SEBs. Rural electrification programmes for village and household electrification (including Kutir Jyoti) were continued, but the pace of these programmes slowed during the 1990s due to reduced public sector investment. In line with the reform measures, the central and state governments agreed on a common minimum action 
plan to bring reforms and to rationalise the electricity tariffs ${ }^{157}$. The chronology of major reform measures in the electricity sector and their influence on rural electrification is presented in Figure 4.5.

The Planning Commission for the tenth Five-Year Plan raised concerns regarding the progress and pace of rural electrification, especially during the eighth and ninth five-year planning periods (Planning Commission, 2002d). To meet the target of electrifying more than 70,000 villages ${ }^{158}$, the Plan sought greater coordination between the MoP and the MNRE, especially in the electrification of 18,000 remote villages. The definition of village electrification used by the government was that 'a village is deemed to be electrified if electricity is used for any purpose whatsoever within the revenue boundary of the village'. The revised definition, adopted by the central government in 2004, says that for a village to be deemed electrified 'at least $10 \%$ of households or a minimum of ten households in an inhabited village is a must for declaring a village electrified'. The MoP, in accordance with the central government goal of 'Power for all by 2012', set up a Rural Electricity Supply Technology (REST) Mission. The mandate of the REST Mission was to develop technological solutions for decentralised and distributed generation based on renewable energy systems in both electrified and non-electrified areas ${ }^{159}$.

Annexure IV provides an overview of the rural electrification programmes in the post-reform period (1990-2010). In this period, there has been an increasing emphasis on strengthening the distribution infrastructure, including that needed for rural electrification. The Government of India linked access to electricity to social and economic development and, as a result, the existing Minimum Needs Programme and the KJP were continued and merged into the RGGVY programme in 2004-05.

In the post-reform period, it was expected that reforms would create an environment and framework for private-sector participation in electricity distribution, including rural electrification. However, private-sector participation in rural electrification programmes has been rather limited. Distribution privatisation in Orissa saw most rural electrification programmes come to a standstill (Kannungo Committee Report, 2001). The main criticism of the electricity reform policies is that reforms have ignored the public benefits associated with electricity access, with public benefits being treated as a market distortion (Byrne and Mun, 2003;Reddy, 2002;Sankar, 2002b). In response to these criticisms, rural electrification programmes in the post-reform period continue to evolve although the overriding delivery pathway continues to be through government programmes. In order to implement the

${ }^{157}$ One of the policy decisions was to charge a minimum tariff of Rs $0.50 / \mathrm{kWh}$ unit for an irrigation pumpset connection. Despite this agreement, Punjab and Tamil Nadu continued with free electricity connections as part of "political largesse" although Punjab introduced a minimum tariff in 2002 and Tamil Nadu in 2003.

158 These numbers are based on a previous definition of village electrification. Using the new definition adopted by the government in 2004, the revised number of non-electrified villages is approximately 125,000, including 40,000 remote villages.

159 Section 4 of the Electricity Act 2003 envisages a similar role for rural areas and non-conventional energy systems when formulating a policy on stand-alone systems. 
RGGVY, and especially to meet the target for household access to electricity, the central government subsidises the rural electrification programme (Figure 4.6). In 2004-05, when the programme was launched, the subsidy was Rs 2 billion and, in order for the programme to meet its target, the subsidies have increased each year. In 2009-10, the subsidy for rural electrification had increased to Rs 63 billion. In 2009, under the RGGVY programme, a separate scheme for electrifying non-electrified remote villages, the Decentralised Distributed Generation (DDG) scheme, was introduced with a 90\% capital subsidy.

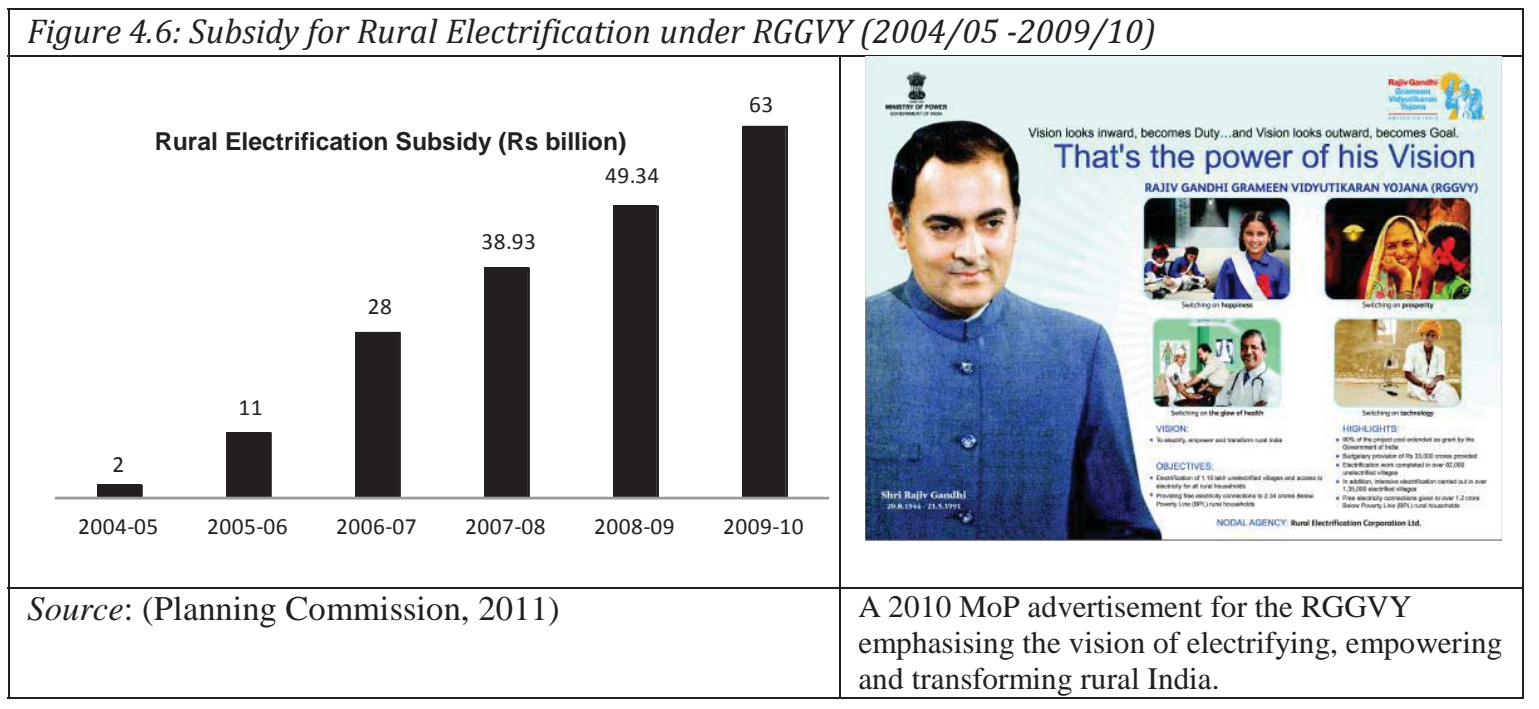

While the RGGVY has been able to make significant investments (see Figure 4.6) in rural electrification, the qualitative transformation that the programme had aimed to bring about is not really happening. The large energy deficits mean that the state governments are unable to provide electricity when it is needed. Anecdotal evidence suggests that, in a few states, households covered under the RGGVY have indicated to the REC evaluation team that the electricity should be 'taken back' as the electricity supply is only on for a few hours after midnight, and therefore considered as of no use. Similarly, the RGGVY-DDG scheme has yet to take off, with not a single rural electrification project approved under this scheme by 2011 .

The Planning Commission's mid-term review of the eleventh Five-Year Plan noted, "it is important that the households electrified under the scheme should also get energised at the earliest so as to avoid de-electrification of infrastructure created under the scheme". Another failure has been in reaching the goal of electricity for all by 2012. Against the target of connecting 119,000 non-electrified villages, only about $65 \%$ of all villages had been electrified by 2010. In terms of connecting BPL households, only about half of the targeted 23.4 million households have been connected so far, and only 38\% of the 354,000 villages identified for intensive electrification. As such, the task of providing electricity to all by 2012 may prove impossible. Further, even if the connection targets are met, making electricity available when it is needed most will be a problem given the national electricity deficit. 


\section{Petroleum Sector Programme}

\section{Petroleum Sector Reforms}

Table 4.4a: Central Government Subsidies on PDS Kerosene oil and LPG (1993/94 to 2003/04)

\begin{tabular}{|l|r|r|r|r|r|r|r|r|r|}
\hline $\begin{array}{l}\text { Petroleum } \\
\text { products }\end{array}$ & $\begin{array}{l}\text { 1993- } \\
\mathbf{9 4}\end{array}$ & $\begin{array}{l}\text { 1994- } \\
\mathbf{9 5}\end{array}$ & $\begin{array}{l}\mathbf{1 9 9 5 -} \\
\mathbf{9 6}\end{array}$ & $\begin{array}{l}\mathbf{1 9 9 8}- \\
\mathbf{9 9}\end{array}$ & $\begin{array}{l}\mathbf{1 9 9 9 -} \\
\mathbf{0 0}\end{array}$ & $\begin{array}{l}\text { 2000- } \\
\mathbf{0 1}\end{array}$ & $\begin{array}{l}\mathbf{2 0 0 1}- \\
\mathbf{0 2}\end{array}$ & $\begin{array}{l}\mathbf{2 0 0 2}- \\
\mathbf{0 3}\end{array}$ & $\begin{array}{l}\mathbf{2 0 0 3} \\
\mathbf{- 0 4}\end{array}$ \\
\hline $\begin{array}{l}\text { Total Fiscal } \\
\text { Subsidy } \\
\text { (Rs billion) }\end{array}$ & 65.96 & 65.6 & 93.6 & 83.7 & 177.1 & 230.91 & 111.4 & 44.96 & 62.92 \\
\hline $\begin{array}{l}\text { PDS Kerosene } \\
\text { oil (Rs billion) }\end{array}$ & 37.73 & 37.4 & 41.9 & 57.7 & 81.51 & 75.22 & 53.1 & 20.98 & 26.57 \\
\hline $\begin{array}{l}\text { LPG (Rs } \\
\text { billion) }\end{array}$ & 12.61 & 14.1 & 16.3 & 26.0 & 44.93 & 67.24 & 58.3 & 23.98 & 36.35 \\
\hline
\end{tabular}

Table 4.4b: Central Government Subsidies on PDS Kerosene oil and LPG (2004/05 to $2009 / 10$ )

\begin{tabular}{|l|r|r|r|r|r|r|}
\hline Petroleum products & $\mathbf{2 0 0 4 - 0 5}$ & $\mathbf{2 0 0 5 - 0 6}$ & $\mathbf{2 0 0 6}-\mathbf{0 7}$ & $\mathbf{2 0 0 7 - 0 8}$ & $\mathbf{2 0 0 8}-\mathbf{0 9}$ & $\mathbf{2 0 0 9 - 1 0}$ \\
\hline $\begin{array}{l}\text { Total Fiscal Subsidy (Rs } \\
\text { billion) }\end{array}$ & 29.3 & 26.62 & 25.24 & 26.41 & 26.88 & 27.7 \\
\hline PDS Kerosene oil (Rs billion) & 11.47 & 10.57 & 9.7 & 9.78 & 9.74 & 9.55 \\
\hline LPG (Rs billion) & 17.83 & 16.05 & 15.54 & 16.63 & 17.14 & 18.1 \\
\hline \multicolumn{2}{|l|}{ Source: (Petroleum Planning and Analy Cell, 2011) } \\
\hline
\end{tabular}

The driving force behind the petroleum sector reforms was the rising subsidy bill funded by the central government. In response, to curtail its fiscal deficit, the government initiated measures to dismantle the APM. The reform policies included measures to deregulate the sector and to allow private sector participation through establishing a Parallel Marketing Scheme (PMS) for kerosene oil and LPG (Kelkar and Sarma, 1996;Sundarajan, 2000). Table 4.4a provides the details of the subsidy on kerosene oil and LPG between 1993-94 and 200304. Before 1993-94, the petroleum subsidy was absorbed within the Oil Pool Account (OPA), and the government made disbursements to the national oil and gas companies. The kerosene oil and LPG subsidies accounted for $76.3 \%$ of the total petroleum subsidy bill in 1993-94. In 1998-99 and in 1999-2000, the subsidy bill increased because the government allowed national oil and gas companies to release the quota of outstanding applications for LPG connections and made a one-off adjustment in the kerosene oil quota for all the states. Since 2002, following the dismantling of the APM, the subsidies ${ }^{160}$ on LPG and kerosene oil are partly met from the central budget (Table 4.4b).

160 The Ministry of Petroleum and Natural Gas vide Gazette Notification number P-20020/18/2001-PP (dated 28.01.2003) approved the 2002 PDS Kerosene and domestic LPG Subsidy Scheme for administering subsidies on PDS kerosene oil and domestic LPG. The subsidy is met from the central government' fiscal budget and is fixed at a specific rate. The average subsidies during 2002-03 were Rs 2.45 per litre on PDS kerosene oil and Rs 67.75 per LPG cylinder for domestic use. The flat rate 


\section{Initiatives for Rural Petroleum Products Access}

In order to meet the growing demand for petroleum products, and as part of its reform measures, the government allowed private sector participation in the marketing of kerosene oil and LPG. As such, in the post-reform period, the government initiated two significant policy measures for the downstream sector. The first policy measure was to reduce the fiscal subsidy burden, caused by cross-subsidisation, through a phased dismantling of the Administered Pricing Mechanism (APM). The second policy measure was to allow the private sector to market kerosene oil and LPG under the Parallel Marketing Scheme (PMS) to meet the growing demand for petroleum energy carriers and to reduce petroleum imports (Box 4.6).

\section{Box 4.6: Policy Reform in Petroleum Sector - Before and After 2004}

\section{Dismantling the Administered Pricing Mechanism (APM) and the Parallel Marketing Scheme (PMS)}

In June 1997, the oil pool deficit reached a level of around Rs 180 billion. With a view to containing this deficit and enabling the oil companies to maintain uninterrupted supplies of petroleum products, the government introduced a series of reform measures, including the formation of a so-called ' $R$ ' group, and later an expert committee, to suggests way of restructuring the APM (MoPNG, 2002). Based on the recommendation of the committees, the central government decided to dismantle the APM, phase-out subsidies on controlled products and link the price of products to the international crude oil price.

Effective from 1 March 2002, the government dismantled the APM, abolished the role of the Oil Coordination Committee (OCC) and proposed a bill in Parliament to form a downstream petroleum regulatory board that would act as a regulator. The prices of all the products were to be linked to the import parity price, and price fluctuations were to be passed on directly to the consumers.

Nevertheless, the end-user (consumer) prices of kerosene oil and LPG were still determined by the central government. Further, the government fixed an upper limit on its subsidy. Consequently, if additional subsidies were required due to fluctuations in global crude oil prices, they would have to be borne by the national oil companies.

In February 1993, the central government announced the introduction of the Parallel Marketing Scheme (PMS) ${ }^{161}$ for kerosene oil and LPG with a view of closing the wide gap between the supply and demand for these products. Under the PMS, private companies were allowed to import and market both these energy carriers at market-determined prices. The private companies were required to develop their own infrastructure for importing, storage and marketing.

Private sector oil and gas companies were not required to obtain approvals from the MoPNG but were required to obtain a 'rating' from the notified agencies before starting any activity related to kerosene and LPG under the PMS. They were also required to obtain necessary clearances, for example over safety standards from the statutory authorities. In order to make it distinct from the kerosene supplied under the PMS, the Public Distribution System (PDS) kerosene oil was coloured with blue dye. Further, the LPG Control Order 2000 (this Order revised the earlier Order of 1993) specified that the cylinders, regulators and valves used by private LPG companies had to be distinct from those used by the national oil companies.

subsidies were reduced by one-third in both 2003-04 and 2004-05. Since 2004-05, the subsidies have been maintained at Rs 0.82 per litre of kerosene and Rs 22.58 per LPG cylinder.

${ }^{161}$ Kerosene (Restriction of use and Fixation of Ceiling Price) Order, 1993 and LPG (Regulation of Supply and Distribution) Order, 2000. The LPG Order, 2000 was a revision of the LPG (Regulation of Supply and Distribution) Order, 1993. 
In the reform phase (1991-2004), there were two parallel initiatives in the rural areas. First, the government was subsidising LPG and kerosene oil under the Public Distribution System (PDS) and, second, there was parallel marketing of LPG and kerosene oil by private sector oil and gas companies. Figure 4.7 provides an overview of the policy changes from 1991-93 through to 2010 in the petroleum sector including policy decisions that influenced rural access to LPG and kerosene oil.

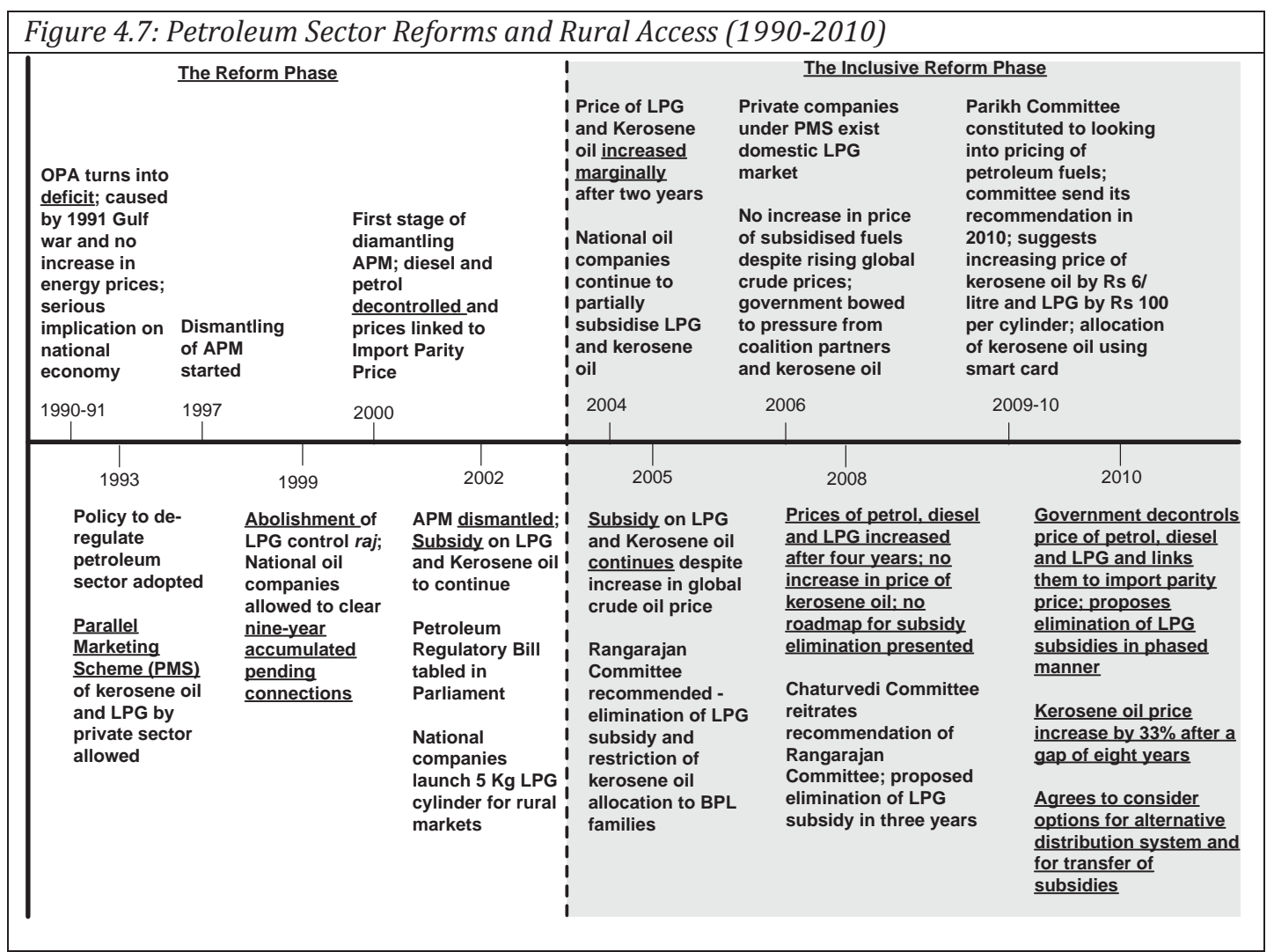

Although, as noted above as part of the policy reforms, the central government dismantled the APM in 2002, it continued to provide subsidies, on a fixed pro-rata basis, for PDS kerosene oil and LPG. As part of its disinvestment policy and to open up the sector to competition, the government provided the national oil and gas companies with greater autonomy while simultaneously allowing the private sector, including foreign oil companies, to set up distribution networks in India.

In order to restrict the diversion and pilferage of kerosene oil, the Government of India piloted a Jan Kerosene Yojana scheme in a few states in 2005. However, the cost of implementing the scheme was much higher than the regular PDS scheme, and it was consequently dissolved in 2006. In 2006, the parliament approved the formation of a Petroleum Regulatory Board but, despite this change, the pricing of petroleum energy carriers is still regulated by central government. Given that the government has continued to keep prices below the cost of crude oil, the national oil and gas companies have to share in the subsidy burden. At the same time, the continuation of government subsidies has distorted the 
market in favour of public sector companies since the private sector is ineligible for subsidies under the PMS. Consequently, starting in 2006, the private LPG companies have been exiting the domestic market and instead are focusing on non-subsidised market segments.

In order to improve the availability of LPG, as a clean cooking fuel, in rural areas, the Government of India launched the RGLV Pariyojana in 2009. This rural LPG scheme aims to establish small-scale LPG distribution agencies to increase rural penetration and to cover remote areas as well as those with low potential (locations with a potential of less than 600 cylinder refill sales per month). The scheme ${ }^{162}$ is designed with the idea that these distributors will be based in rural areas where regular distributorships would not be viable due to the scale of operation and investment required. The scheme envisages a distributor having a consumer base of 1500 households in a cluster of villages.

\section{Politics of Kerosene Oil and LPG Pricing}

In 2004, the Ministry of Finance commissioned a study to review central government subsidies. The review proposed that policy instruments providing blanket subsidies should end and, instead, targeted subsidies be provided to only BPL households (Ministry of Finance, 2004). In 2004, the government increased the prices of all petroleum fuels and this met widespread opposition, including from political allies of the UPA and Left parties. Between 2004 and 2008, as global crude oil prices continued to rise, the price of Indian crude oil increased from \$36 per barrel in June 2004 to \$129 per barrel in June 2008. Despite this, in this period, the government only once, in November 2004, raised the price of petroleum fuels. As such, between 2004 and 2008, in spite of increase in Indian crude oil prices, the government chose not to intervene to adjust kerosene oil and LPG prices to reflect market changes $^{163}$.

During this period, the government established two committees, the Rangarajan Committee in 2006 and the Chaturvedi Committee in 2008, to give recommendations on reviewing prices and the financial implications for national public sector oil and gas companies. The Rangarajan Committee 2006 recommended that the LPG subsidy should be removed and that the supply of subsidised kerosene oil should be restricted to BPL households. Further, the Committee did not propose changing the entitlement/quota for BPL households or the level of subsidy on kerosene oil. The Committee argued that by restricting the kerosene oil supply to only BPL households, the government would be able to target its subsidies effectively. However, the government did not act on these recommendations. The Chaturvedi Committee in 2008 reiterated the views of the Rangarajan Committee and even went a step further and recommended eliminating LPG subsidies over three-year period. Again, the central government did not act on the recommendations of a committee it had established. Domestic

\footnotetext{
${ }^{162}$ The scheme makes an interesting provision in the guidelines for selecting distributors. In order to empower women in rural areas, the scheme states that the distributors will be in the joint names of wives and husbands.

${ }^{163}$ The domestic prices of petrol and diesel were increased in June 2006. Later, the prices of petrol and diesel were revised downwards in both November 2006 and February 2007.
} 
pricing continues to be a politically sensitive topic, with a broad consensus across the political spectrum to avoid any upward revision of prices (Figure 4.8).

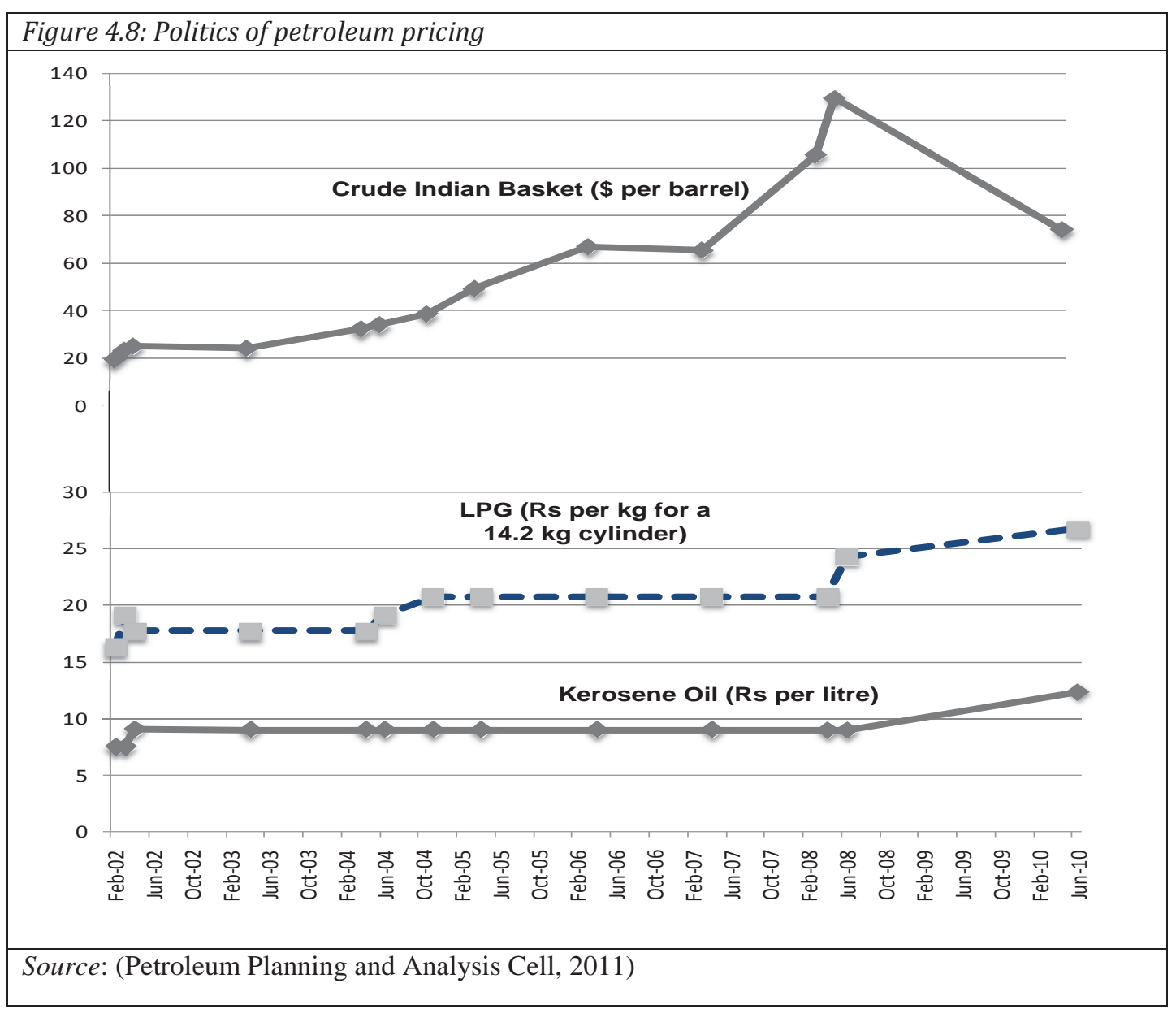

In June 2010, the government acted on the Parikh Committee report, decontrolled the prices of petrol and put in motion a phased decontrol of diesel prices. It also increased the price of LPG and kerosene oil ${ }^{164}$. Despite this being the first time in eight years that kerosene prices had been increased, there was widespread opposition to the price increase as the country was already reeling under the high costs of many essential commodities and inflation. Responding to the rising opposition from political parties, the government issued a public advertisement seeking to justify its actions and presenting its plan for enhanced LPG coverage in rural areas. In 2008, after a period of almost four years, the central government did revise the prices of petroleum fuels. The main reasons for this increase were the rising global oil prices, the fiscal deficit due to the rising bill to cover the under-recoveries ${ }^{165}$ of the national oil and gas

\footnotetext{
${ }^{164}$ The price of LPG was increased by Rs 50 per cylinder instead of the recommendation of Rs 100 per cylinder. The price of kerosene oil under PDS was increased by Rs 3 per litre instead of the recommendation of Rs 9 per litre.

165 "Under-recoveries" are the financial losses incurred by public-sector oil marketing companies from the selling of petroleum energy carriers at below cost price. The under-recoveries due to subsidised LPG
} 
companies and the early signs of a global economic crisis. However, several state governments either provided additional subsidies from their own budgets ${ }^{166}$ or reduced their state-level taxes. In most of these cases, the main motive was fear of losing power in the forthcoming State Assembly elections.

In 2009, the government formed the Kirit Parikh Committee to review the pricing mechanism. The Kirit Parikh Committee submitted its report in 2010 and recommended that the government implement its 1997 decision to decontrol fuel prices fuels and link them to the import parity price. It also recommended that the price of LPG should be increased by Rs 100 per $14.2 \mathrm{~kg}$ domestic cylinder, and of kerosene oil by Rs 9 per litre ${ }^{167}$, and that the prices of petrol and diesel be linked to the import parity price as determined by the market. The Committee's report also recommended reviewing the allocation of subsidised kerosene oil to the various states based on progress with the Rural Electrification (RE) programme.

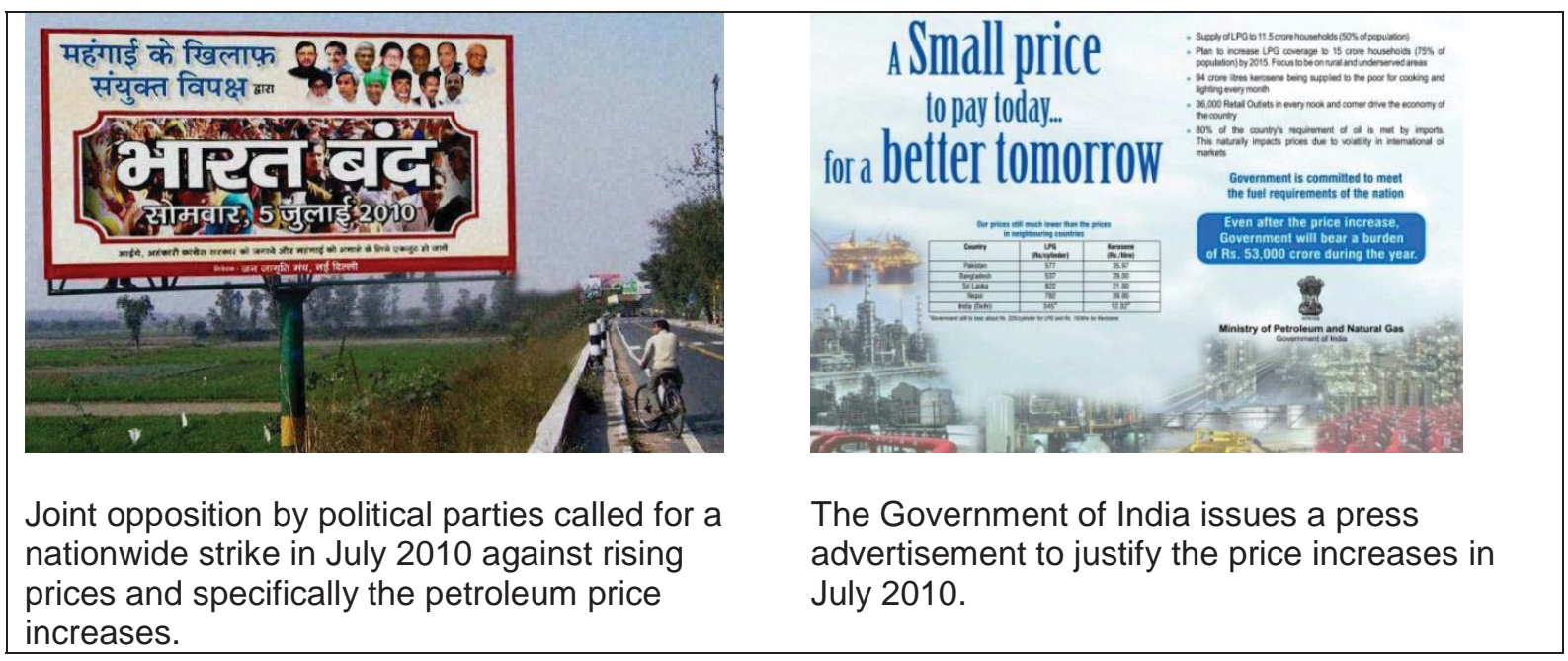

\section{Renewable Energy Programme}

In the renewable energy sector, the need to reform the policies and programmes emerged from an initiative by the central government. Renewable energy programmes and RETs had been implemented across the country under a subsidy provided by the central government. In order to reduce the fiscal deficit, the central government later initiated measures to phase out

and kerosene oil approached 0.75\% of GDP in 2007 (The Indian Economy Blog, 2008). In 2011-12, the under-recoveries amounted to $0.8 \%$ of the GDP (GoI, 2012).

${ }^{166}$ For example, in 2008, the state government of Delhi provided additional subsidy of Rs 40 per LPG cylinder. Again, this can be seen as an attempt to influence voters since assembly elections were due by the end of 2008.

167 The price of domestic LPG cylinder was Rs 345 and that of subsidised kerosene oil under PDS was Rs 9 per litre in 2010 when the Kirit Parikh Committee made its recommendation. In the case of subsidised kerosene oil, the Committee recommendation was to double the price and for LPG increase by one-third, but link the price to import parity, so whenever there is an increase or decrease in global crude basket, the domestic prices could be adjusted accordingly. 
subsidies and to identify commercially viable technologies. Stemming from the reform measures, starting from 1993, two parallel renewable energy programmes were initiated:

(i) a socially oriented programme, supported through government schemes for dissemination of RETs, including capacity building through R\&D activities and the training of beneficiaries and technicians; and

(ii) a commercially oriented scheme that aimed to commercialise selected RETs: namely, wind energy, small hydro and solar photovoltaic (Sinha and Ramana, 1997).

As part of the changing energy policy in India, the role of renewable energy has shifted ${ }^{168}$. There is now a strong focus on RETs for the electrification ${ }^{169}$ of remote villages through decentralised electricity generation, distribution and management (Chaurey et al., 2002).

The states' nodal agencies and other institutions with central government and state government subsidies implement the socially orientated dissemination programme. The market-oriented scheme is implemented by a combination of local institutions with financial assistance (concessional loans and grants) from IREDA, financial institutions and international multilateral and bilateral agencies (Sinha, 2004;Velayudhan, 2003;Venkata Ramana, 1998).

Following the policy shift and programme support during the eighth Five-Year Plan (199297), the renewable energy budget increased to nearly three times the level of the previous Plan period. The budget for renewable energy was Rs 11.62 billion, or $0.27 \%$ of the overall total public sector budget of Rs 4341 billion. However, the renewable energy budget was reduced to Rs 9.03 billion ( $0.10 \%$ of the total public sector budget of Rs 8592 billion) in the ninth Five-Year Plan (1997 -2002). The main reason for the drop in the budget allocation for renewable energy was the decision to reduce subsidies for programmes promoting solar photovoltaic, biogas and improved cookstoves.

Starting in 1999, the integration of renewable energy programmes into the mainstream energy policy was made possible by the recognition that RETs would be the optimum technological solution for providing electricity to 18,000 remote villages where grid extension would not be economically viable. With RETs being seen as the mainstream intervention for electricity access in rural areas, other schemes to address the energy needs of low-capacity end-users have been withdrawn or had their mandates reduced. This includes the NPIC (energy efficiency, biomass reduction and removing indoor air pollution) and the solar lanterns (basic minimum lighting) programmes.

Both central and state governments have been creating enabling policy environments for electricity generation from renewable energy sources. In the post-reform period, the

168 Since 2001, the MNRE has not provided subsidies for improved cookstoves disseminated under the National Programme on Improved Chulha (NPIC) and, from 2002, there is no longer subsidy support for the solar lanterns programme.

169 The draft Renewable Energy Policy Bill, tabled in 2003, aimed to ensure that at least $10 \%$ of power generation capacity installed between 2000 and 2012 should come from renewable energy resources. Section 5 of the Electricity Act 2003 emphasises a separate policy for distributed generation, including from renewable energy resources. 
Electricity Act 2003 provides the State Electricity Regulatory Commissions (SERCs) with powers to promote and govern renewable energy electricity generation. The SERCs are responsible for determining a renewable energy purchase obligation for distribution utilities, specifying a minimum purchase of electricity from renewable energy sources in the overall energy mix of the utility (Box 4.7). As part of the overall policy, the renewable energy budget in the tenth Five-Year Plan (2002-07) increased to Rs 71.67 billion ( $0.48 \%$ of the total public sector budget of Rs 14,841 billion). Given that the electrification of remote villages was made a priority, the renewable energy plan budget included Rs 7.35 billion for the electrification of 5000 villages and a provision of Rs 34.17 billion for IREDA, as an interest subsidy (low interest rate, typically less than 5\%) and for soft loans promoting private sector participation in renewable energy electricity generation.

\section{Box 4.7: Renewable Energy Obligation - After 2004}

The enactment of the Electricity Act 2003 resulted in a significant policy shift towards renewable energy power generation through a renewable energy obligation and involvement of the private sector in renewable-energy-based power generation. Section 86 (1) (e) and Section 61 (h) of the Electricity Act 2003 requires the State Electricity Regulatory Commissions to encourage investment in renewable energy.

The National Electricity Policy (NEP) of 2005 reasserted the government's intent to promote renewable energy. The NEP 2005 states that, since renewable sources of energy are the most environmentally friendly option, there is an urgent need to promote generation of electricity based on such sources of energy by providing adequate promotional measures for developing the technologies. The NEP 2005 also states that, to achieve sustained growth in the use of these renewable energy sources, participation by the private sector should be encouraged through suitable promotional measures to increase the overall share of renewable energy sources in the electricity generation mix. The NEP 2005 also includes a mandatory provision for states to specify a percentage of power purchased from renewable energy sources. It further gives power to the state electricity regulatory commissions to determine competitive tariffs for renewable energy electricity generation.

The National Tariff Policy (2006) restates the importance of renewable energy in electricity generation and the subsequent benefits for the country. The NTP makes provision for the Appropriate Commission to fix a minimum percentage of purchased electricity from such sources, taking into account the availability of such resources in the state.

On the policy level, there has been a considerable push from the centre for renewable-energy-based power generation through a series of policy measures such as renewable energy certificates and feed-in tariffs. Further, renewable energy has also received a stimulus from state-level policies on renewable energy obligations.

\subsection{Conclusions: Answer to Main Research Question 1}

Based on the analysis of India's energy policy from 1950 to 2010, as presented above, Research Question 1 and its sub-questions can now be answered.

\section{Sub-question 1.1: What is the institutional setting for delivering energy carriers in rural India?}

The organisational setting for delivering modern energy carriers in rural areas of India involves a complex arrangement with multiple players (Section 4.2) and is designed for the 
top-down implementation of policies and programmes which are based on a traditional supply-side approach. The role and responsibilities for rural electrification, for petroleum energy and for renewable energy programmes fall under separate ministries and government departments at the national and state levels. The organisational setting is further complicated by the involvement of political actors at the state, district and block levels. The number of organisations involved in the delivery pathways increases at the village level, and this results in a lack of coordination between organisations. In particular, the organisational structure lacks clear lines of responsibility and the capacity to enforce laws and regulations, and this has opened the way for rent-seeking in the delivery of energy carriers (Section 2.3). This has resulted in low-income households not receiving their entitled subsidised allocations and having to pay higher prices for accessing modern energy carriers. There is a lack of coordination not only at the implementation level, but also at the policy planning and coordination level. This is exemplified in the electrification of remote villages, where the Planning Commission had to intervene to resolve the different opinions of the Ministry of Power (MoP) and the Ministry of New and Renewable Energy (MNRE). The differences were related to the appropriate definition, identification and listing of remote villages and the implementation of the remote village electrification programme.

As energy reforms are being implemented, new measures are emerging for developing institutional capacity at the village level to make the delivery pathways for distribution of modern energy carriers more effective. Under the Rajiv Gandhi Grameen Vidyutikaran Yojana (RGGVY), electricity distribution through the involvement of franchisees is appearing, at least as part of policy and programme design, as a step towards improving electricity distribution, as well as addressing the concerns regarding poor services in rural areas. A recent programme of the Ministry of Petroleum and Natural Gas (MoPNG), establishing a rural distribution network for LPG, also aims to improve availability and reduce transaction costs for rural households. Given that the energy sector reforms are being implemented alongside a focus on decentralisation, the programmes are also focusing on involving the Panchayati Raj Institutions (PRIs) at the village level to improve the institutional arrangements for delivering modern energy carriers.

While the organisational setting for sectoral reforms continues to evolve, the literature emphasises that the reforms were expected to bring in competition, particularly by involving the private sector as a means of improving energy delivery (Section 2.3.1). However, in the case of India, a truly competitive multi-actor environment has generally eluded the energy sector. Instead of creating competing stakeholders, policy reforms in the energy sector have resulted in parallel power structures. For example, in the electricity sector, institutional reforms have meant a transition from one monolithic power utility controlled by the state to another, still controlled by the state, or one controlled by the private sector (a situation contrary to the motives behind public policy reforms, Section 2.3.1). Contrary to the expectations that led to the electricity sector reforms, the private sector has distanced itself from rural electricity distribution. This remains the general response, even after significant policy inducements have been provided for increasing the role of the private sector in decentralised electricity generation and distribution (Section 4.4.2). However, in the petroleum sector, private companies did target the rural LPG market in the late-1990s and 
early-2000s; but they then exited the rural markets when the government failed to amend its subsidy policy due to political considerations (Section 2.3.2 and Section 4.4.2).

The developments since 2004 in the energy sector envisage a much larger role for public sector organisations in energy delivery. Whether these evolving and complex organisational arrangements are effective in enhancing energy access remains to be seen. The next chapter will bring out the practical realities.

\section{Sub-question 1.2: What motives have shaped energy policies in India in the pre-reform phase (1950-1991) and in the reform phase (1991-2010)?}

Before 1990, access to modern energy became synonymous with rural electrification (Sections 4.3.1, 4.3.2 and 4.4). The desire to enhance access to modern energy meant the electrification of villages and the energisation of irrigation pump-sets. The main use of electricity in rural India was seen as irrigation, which could enhance crop yields and consequently lead to self-sufficiency in food grain production (Sections 4.3 .1 and 4.3.2). From a country suffering from a food deficit in 1966-67, India developed a food surplus owing to the spread of a rural electricity network. However, according to the 1991 census, the main beneficiaries of rural electrification were the well-off farmers and households, with rural households and small enterprises largely missing out. Men generally benefited more than women did since agriculture is primarily a man's responsibility, and they benefited from improved irrigation, while drinking water for the household was the women's prime responsibility, and this continued to be drawn from a well or pumped by hand. The failure to provide wider access to electricity was addressed by supplying subsidised kerosene oil to meet rural lighting needs. The availability of LPG in the country has always been limited, and it has remained an energy carrier for urban households, with little effort to promote its use in rural areas. Again, rural women largely failed to benefit from these reforms. From the late1970s onwards, there has been a shift in India's political system, and state-specific political parties have emerged. With this shift, party political decisions increasingly influenced the functioning and governance of the energy sector. This political interference was reflected in selective energy pricing (free electricity for farmers, highly subsidised fuels such as kerosene oil). This eventually resulted in poor performances by state electricity boards and inadequate public distribution systems (Section 2.3.1 and Section 4.4.2).

The motives for the energy reforms starting in 1991 were to correct the inefficiencies of the energy sector, improve the performance of electricity utilities and public distribution systems and keep energy prices down (Section 4.3.3). The energy sector reforms were built on the premise that government ownership results in non-optimum ways of providing services (Section 2.3.1). The property rights literature (Box 2.1) explains the performance of the State Electricity Boards (SEBs). The government intervened through policies such as those offering electricity for agriculture and to rural users at very low rates and removing electricity meters to reduce the transaction costs of meter reading, bill distribution and revenue collection. As a result of these measures, the SEBs had little incentive to be efficient or to reduce costs (Section 2.3.1). Since the commercial losses due to the subsidised energy pricing were to be borne by the government, the SEBs had no incentive to increase revenues from 
consumers. Any effort by the SEB staff to improve performance through revenue collection or by checking on electricity thefts would only lead to reprimands and the transfers of officials showing such initiative - a clear deterrent to improving performance. As a result, the SEBs were effectively bankrupt, there was no progress on enhancing new electricity connections in rural and urban areas, technical and commercial losses were high, and there were large peak energy deficits. As such, the situation in the electricity sector was precarious and it required restructuring to make the sector viable (Section 4.4.2). In the petroleum sector, there were growing demands for LPG and kerosene oil, and India's refining capacity was unable to meet these demands. The policy of isolating domestic prices from international price volatility meant that the Oil Pool Account (OPA) was in deficit, and this provided a driving force for reform (Section 4.4.2).

The energy sector in India presents two examples that can be addressed in the context of Agency Theory (Box 2.1): the SEBs, and the Public Distribution System (PDS) for kerosene oil through the Fair Price Shops (FPS). The SEBs in India were vertically integrated organisations, with accountability passing from senior management (the principals) to the field staff made up of linesmen (the agents). The SEBs often neglect to respond to the needs of rural consumers since operations in rural areas are non-remunerative because of populist policies and measures introduced by the government (Box 2.1). Given the disinterest shown by the SEBs, the linesmen find themselves in the position of being the most approachable agents when consumers want to solve problems related to repairs and maintenance of lines, or related to electricity bills. The linesmen are then able to use this assumed power for their own benefit by misrepresenting information and claiming kickbacks from payments that are in fact meant for the SEB. Farmers are reluctant to install meters for their irrigation pump-sets, mostly because of the subsequent harassment meted out by linesmen and meter readers (Shah et al., 2003). Anecdotal evidence from Orissa suggests that, in distributing electricity in rural areas, the stiffest resistance to reform comes from the operational field staff (linesmen) and middle management.

Similar conditions prevail in the distribution of kerosene oil. The state government (the principal), based on socioeconomic conditions and the overall supply of kerosene oil to the state, sets different per capita entitlements for consumers in rural and urban areas. However, this differential entitlement and allocation encourages pilfering, and this is made easier by the mechanism employed to distribute kerosene oil in rural areas. The distributors and FPS (agents) divert the supplies meant for rural areas and sell them on the open market for personal gain (rent-seeking) (Box 2.1).

In responding to the crisis in the energy sector, the government initiated a series of reforms ranging from restructuring, private sector participation and reform of energy subsidies. However, as the reform policies were being implemented, there was a growing concern that the policies were alienating the rural population. In the wake of the economic reforms (1991 to 2002) and of specific reforms in the energy sector to attract foreign direct investment, the emphasis on rural energy declined. Attention switched to enhancing the generating capacity and making the energy sector financially viable so that the sector could be opened up for competition (Section 4.4.2). However, there was still no competition, nor any improvement in 
the government's budgetary resources. The problems that affected India's energy sector in 2003-04 were similar to those present in 1990-91. The conditions - a disparity in energy access, large losses, subsidies and cross-subsidisation - together with political resistance were not suitable for the reform model. This was also true in general for the Indian economy. Initial lessons, drawn from assessing India's economic reforms, started to appear around 2001-02 and they showed growing disparity between rural and urban areas. At the same time, growing evidence of an agrarian crisis and its impact on rural growth (Section 4.3.4) also affected development policies.

The experiences in pursing economic and energy sector reforms during 1991-2004 showed that the government still had a role in developing rural infrastructure. As the development paradigm shifted after 2004, towards inclusive growth and balanced development with propoor reforms, the role of government increased in delivering modern energy carriers (Section 4.3.4). The policies and programmes that have been formulated since 2004 clearly indicate that the main aim is to provide villages with electricity and LPG for domestic lighting and cooking. Such modern energy carriers are also seen as necessary for productive end-uses, specifically targeting the development of economic activities within a given rural area (Section 2.2 and Section 4.4.2). The argument for rural electrification is linked to the need to reverse the downward trend in agricultural growth. Enabling access to affordable and reliable electricity is expected to meet the energy requirements of the agricultural sector by providing energy for irrigation pump-sets, as well as for small and medium-sized industries, storage infrastructure for agricultural products, health centres and schools (Section 2.2). In the growing Indian economy, rural households and the rural economy continue to play a critical role in India's overall economic development. The emphasis on decentralisation and the involvement of local organisations in improving delivery are expected to create employment opportunities within rural areas. The overarching objective is to see an overall social and economic development of villages and their rural populace (Section 2.2).

To summarise, a closer assessment of the motives shaping India's energy policy shows a twotrack approach: measures to reduce market failures, and reforms that focus on overcoming imperfections in the role of government in ensuring accessibility to modern energy carriers.

\section{Sub-question 1.3: What are the key elements of the energy policies enacted since 1991 for enabling low-capacity end-users to access modern energy carriers?}

Two key elements have emerged in India's energy policy since 1991, and more specifically since 2004, aimed at enabling low-capacity end-users to access modern energy carriers (Sections 4.4 and 4.4.2). One element is to improve the availability, and the second is to ensure its uptake and make energy affordable.

i. Policies measures to improve the availability of modern energy carriers in rural areas of India include:

- Improving the infrastructure by enhancing the distribution network through programmes such as the RGGVY, the RVEP and the Rural LPG scheme. The focus is on improving the availability of electricity and LPG to low-capacity end-users for 
domestic consumption, as well as for productive end-uses, by establishing a distribution backbone across the country.

- Improving energy supply to reduce the mismatch between energy supply and needs. This includes measures such as promoting electricity grids based on decentralised renewable energy at the village level and ensuring that there is storage capacity for energy carriers such as LPG and kerosene oil to improve the availability of modern energy carriers. Other examples include policy directives that stipulate a minimum of six to eight hours of electricity supply daily, a free electricity connection for BPL households under the RGGVY, and schemes for the efficient distribution of subsidised kerosene oil that prevent rent-seeking.

- Improving energy delivery management by involving local institutions to reduce the transaction costs associated with energy delivery. Under the RGGVY, the focus is on managing energy distribution through franchisees, and under the RVEP on involving community organisations and PRIs. Under the Rural LPG scheme, the focus is on the creation of LPG distributors in village clusters.

ii. Policy measures aimed at making modern energy carriers affordable for low-capacity end-users.

- Effective mechanisms for targeted subsidies and the transfer of these subsidies so that the intended target groups benefit. Here, the central government has established a Task Force to give recommendations for subsidy reforms. The Task Force, in its recommendations, has proposed a roadmap for phasing out energy subsidies (especially subsidies on LPG and kerosene oil) through effective targeting and the use of advanced technologies such as biometric cards and the digitisation of beneficiary household information. The proposals also recommended considering alternative models for the transfer of subsidies in the form of direct or conditional cash transfers. Some specific ideas included restricting subsidies on LPG and kerosene oil to BPL households, or reducing the number of subsidised cylinders per year for APL households, so that the subsidies could be directed towards BPL households and at the same time reduce the government's fiscal deficit.

\section{Main Research Question 1: How have energy sector reform policies been formulated to address the weaknesses apparent in the policies of the pre-reform phase in terms of improving access to modern energy carriers by low-capacity end-users in rural areas?}

Between 1950, when India initiated its planned economy, and 1990, when India faced a major economic crisis, the focus within rural energy shifted from that of investing to enhance energy access to that of populist measures to appease voters. Reforms in India's energy sector from 1991 aimed to revive the sector and address the policy failures and gaps. Following the political economy changes in 2004, principles of inclusive growth and development, together with reforms, influenced energy sector policies.

The energy sector policies in India from 1950 to 1990 followed a centralised planning approach based on the idea of trickle-down benefits. The emphasis in the energy policy 
resonated with India's overall development strategy, which focused on modernisation through self-reliance while enhancing social and economic equity (Section 4.3). From the energy sector perspective, this forty-year period of development saw two distinct phases. In Phase I (1950-69), or the 'Centralised Planning' phase, the energy sector was predominantly driven by the government to create an infrastructure for rural electrification by grid extension and a public distribution system for the delivery of kerosene oil (Section 4.3.1). Rural electrification received government attention as it was linked to food security, creating employment opportunities and improving the quality of life of the rural population (Section 2.2.1). Providing villages and rural households with energy was seen as having widespread development and economic benefits in moving people out of poverty and, if left entirely to private sector, there was a fear of under-provision. Thus, India embarked on a development strategy with government- and state-owned enterprises occupying the commanding heights of the economy (Section 2.3.2).

In Phase II (1969-90), or the 'Political Populism' phase, energy sector policies were driven by India's national policy on poverty alleviation and the nationalisation of key sectors, including the energy sector. Rural electrification expanded to help meet the country's goal of self-sufficiency in food grain production, with electricity being needed to exploit the irrigation potential of groundwater. This policy view was further strengthened by the first oil crisis of 1973. Starting in 1973, India's energy policy underwent a phase where state-owned enterprises (SEBs, oil and gas companies, the public distribution system) became vehicles for implementing populist decisions by state and central governments (Section 4.3.2). The political imperatives had a significant bearing on the electricity sector with the revenue collected by SEBs being well below their operational expenses, This created a vicious cycle of poor performance, no (or little) progress in extending electricity to rural areas, and high commercial and technical transmission and distribution losses. Although the domestic market was insulated from the global price volatility in the petroleum sector, two problems emerged. First, with demand for energy increasing within India, subsidised fuels were being diverted for profiteering ${ }^{170}$. Second, since India continued to rely heavily on fuel imports, the 1990-91 Gulf War further worsened India's balance of payments sending the economy into a crisis. While the overall goals and plans for India's development strategy up to 1990 were prudent, there were problems with the quality of implementation. Further, the extensive government involvement created vested interests and interventions were distorted by political imperatives (Singh, 2008).

Starting from 1980s, the gap between energy supply and demand started to grow. In order to bridge the gap due to the growing demand for modern energy carriers, the government imposed a rationing system. The combination of a rationing system and subsidies led to rentseeking (corruption, black marketing, hoarding, the diversion of energy carriers, excessive charges, etc.) and unreliable and inefficient delivery mechanisms. The mechanisms adopted in rent-seeking varied according to the characteristics of the energy carrier. For example, in

\footnotetext{
${ }^{170}$ In a 2005 study conducted by the NCAER, it was estimated that 39\% of subsidised kerosene failed to reach the targeted population, involving profiteering to the tune of Rs 100 billion per annum (NCAER, 2005).
} 
the case of electricity distribution, unauthorised connections increased in rural areas with people able to gain access to electricity through illegal connections in collusion with local utility staff, who 'charged their own fee' to allow such thefts. In distributing kerosene oil through the public distribution system (PDS), wholesalers, distributors and retailers would all resort to pilfering and hoarding to divert subsidised kerosene oil and then sell it at local and urban markets at higher prices. Shortcomings in the delivery pathways were aggravated by populist policies that encouraged free riding, pilfering and resistance to paying for the energy carriers (Swamy, 1998). These aspects together resulted in the vicious circle of poor service quality, poor financial management and overall mismanagement. The spiralling effect of these inadequacies prevented low-income rural households and those living in remote villages, as economically and socially weaker segments of the population, from gaining easy access to modern forms of energy and further made their supply unreliable. As a result, the rural population had to continue to rely on traditional energy carriers, spending a significant amount of their time on accessing them.

The government's involvement in the delivery of energy services, to an extent driven by political motivations and populist energy pricing, was intended to provide access to modern energy services in rural areas. However, the politicisation of delivery mechanisms and the inability of the public enterprises to recover their costs from consumers put additional pressure on the government's financial resources. The combination of politically motivated energy pricing and interference in energy delivery and operations resulted in governmentowned energy utilities being unable to improve their performance or efficiency.

Consequently, energy access (and hence the subsidies on energy carriers) remained limited to the better-off households in rural areas, while the poorer households remained dependent on traditional energy carriers (or having to switch to expensive alternatives such as renewable energy). In practice, limited access to modern energy services in rural areas is linked not only to the purchasing power of users, or the affordability of energy carriers, but also to the latter's availability.

Starting in 1991, in Phase III, the 'Reform' phase, India initiated a series of policy measures for reforming its economy. In the energy sector, reforms have ranged from the unbundling of SEBs, private sector participation, restructuring the energy distribution mechanism, tariff reforms and reforming fossil fuel subsidies (Section 4.3.3). The initiation of these policy reforms was driven by the desire for greater economic efficiency, primarily focusing on reducing the inefficiencies of public enterprises (SEBs and national oil and gas companies) and on cutting the government's budgetary deficits. Ideas that found expression in India's energy sector reforms stemmed from institutional aspects of public sector reforms (Section 2.3, especially Section 2.3.1). For policies to be effective, they need appropriate regulatory frameworks. However, India's energy sector reforms were off-the-shelf models from other countries, and these prescriptive reform measures failed to take account of the initial conditions: the state of the energy infrastructure, the inequity in energy access and the large unserved population. Thus, while the energy policy reforms theoretically provided signals that would result in improved access to modern energy in rural areas, the reality was different. Rural energy became an outcome of policy reforms more by default than by design. At the same time, by 2001-02, there were growing signs of an economic crisis in the rural 
areas. Despite the political 'India Shining' campaign, in reality the rural areas were suffering from indebtedness, a lack of development and a lack of economic opportunities.

The outcome of the elections in 2004 led to a shift in the development strategy towards inclusive growth and pro-poor economic reform (Section 4.3.4). The shift towards a balance between economic reforms and inclusive development, resulting in Phase IV or the 'Inclusive Reforms' phase, saw changes in the approach towards the energy sector. These were reflected in policies and programmes for enhancing access to modern energy carriers in rural areas. Starting in 2004, the government further reformed the institutional and regulatory framework of India's energy sector. While the Electricity Act of 2003 provides the overall regulatory framework for the functioning of the electricity sector and policy reforms in that sector, the National Electrification Policy (NEP) of 2005 states that the key objective of the power sector is to supply electricity to all areas, including rural areas. The Rural Electrification Policy of 2006 focuses on providing electricity to all households by $2012^{171}$, ensuring both quality and reliable power at reasonable rates, and a minimum lifeline consumption of $1 \mathrm{kWh}$ per household per day as a merit good by that time. These policies were also expected to improve the financial and institutional status of the state utilities and widen the scope of state governments to take action in rural electrification efforts.

The 2006 Integrated Energy Policy (IEP) provides a broader roadmap and framework for energy sector development in India through to 2031-32. This policy strongly emphasises universal energy access through multiple choices and focuses on household electrification, appropriate technology choices, and fuel supply options for cooking (including on biomass supply to reduce women's drudgery of walking long distances to get biomass). The IEP also emphasises the need for policies and programmes to address gender-energy linkages, especially in context of cooking energy. However, despite these measures, there is a lack of attention to gender in energy policy formulation in India (Parikh and Sangeeta, 2008). The national government has also launched a new programme for strengthening LPG distribution in rural areas by creating a distribution infrastructure in rural areas otherwise unserved.

To summarise, India's energy policies have evolved significantly over the past six decades and more specifically in the most recent one (2001-10). In particular, energy policies since 2004 have energy security at their core (Section 4.4) and indicate a strong focus on enhancing access to modern energy in rural areas as part of the overall development policy of inclusive growth. Nevertheless, the policy adopts a supply-side perspective on energy access. There is no systematic collection of gender-disaggregated data and, as a consequence, gender and energy linkages are missed. The lack of demand side focus acts as a barrier to access even when the availability issues have been resolved. Further, the intra-household dynamics and the concepts of 'cooperative conflicts' (see Section 2.2.2) which may have an affect on energy access get overlooked when adopting a supply-side perspective on energy policy. The energy policies also fail to take into account the development and presence of informal

${ }^{171}$ The stated goal of the 2006 Rural Electrification Policy was to ensure all households were electrified by 2009. However, the deadline was extended to 2012 at the beginning of the Eleventh Five-Year Plan (2007-2012). 
mechanisms for delivering modern energy carriers in the context of formal organisations failing to deliver on their responsibilities. The supply-side focus and a lack of attention to demand-side aspects can bring out the barriers related to energy access by low-capacity endusers. This is critical when the overall development ideology is focussed on inclusive reforms: if energy policy with a human face is to be effective, it needs to understand the demand-side issues.

Policies for rural energy in India continue to evolve, and have come a long way from the protectionist policies of the post-Independence period to the current policy of inclusive development (Section 4.3, Figure 4.2). Concerns surrounding energy access, which became a victim of energy reforms, have started to influence present policies where the focus is on equity and equitable access. These are in tune with the government's long-term objective of improving access to modern energy carriers in order to develop economic opportunities and enhance the quality of life of its rural people. Nevertheless, it is important to bear in mind that the problems confronting the energy sector are symptomatic of an overall economic, social and political malaise. Addressing the problems of energy access in rural areas is linked to the overall scenario. Policy reforms would need to understand and include factors (economic, social, political and local context) influencing energy access them and develop (policy) responses on the basis of such an analysis. The effectiveness of a policy design can be assessed by its implementation. The analysis presented in this chapter shows that India has formulated policies with the aim of enabling low-capacity end-users to access modern energy carriers. In the next chapter, the focus will be on the implementation of these policies by analysing empirical evidence from three case study regions to see if the policy objectives are being achieved. 
In Pursuit of a Light Bulb and a Smokeless Kitchen

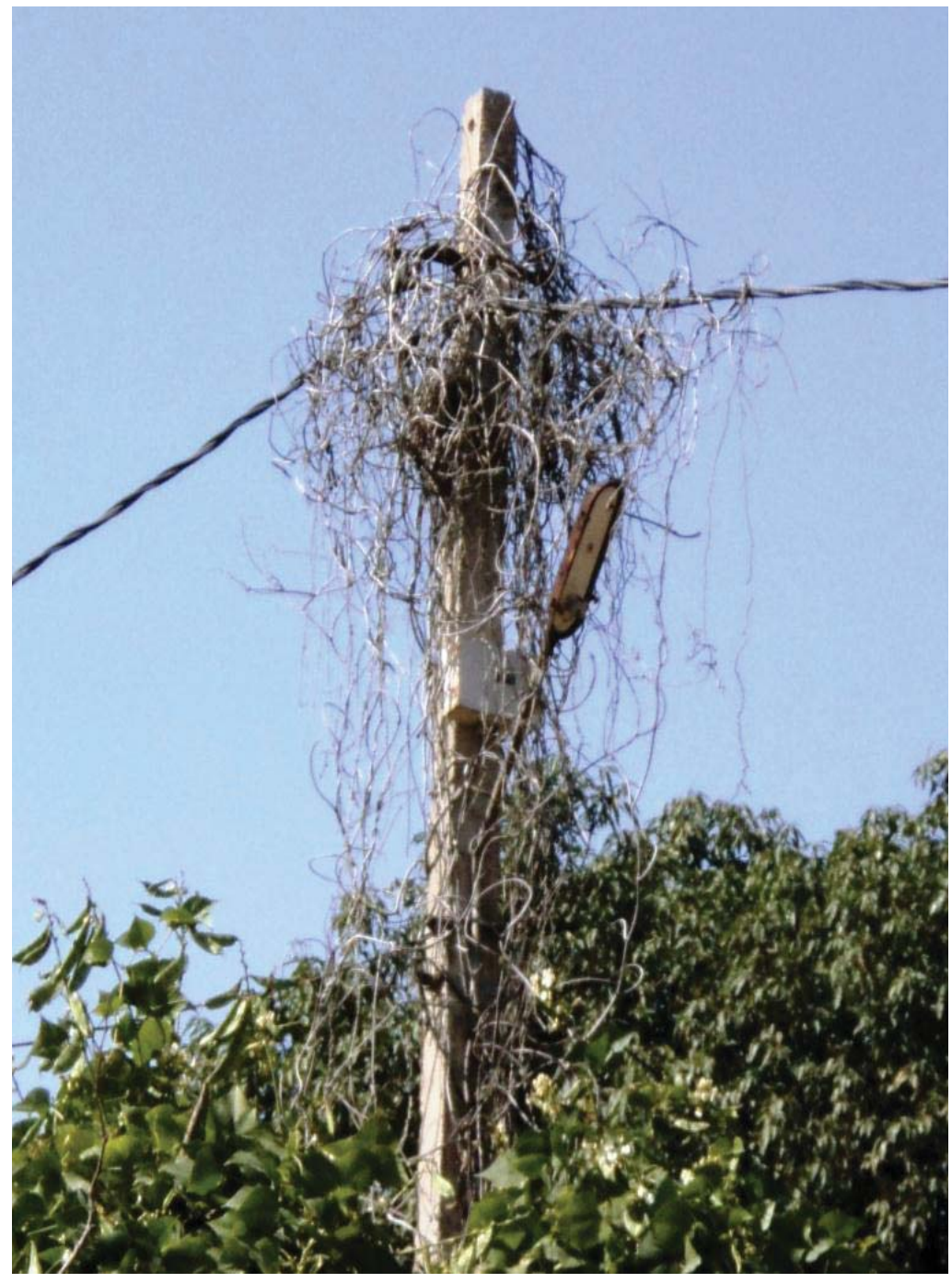




\title{
5. Understanding Energy Access: Gosaba, Bastar and Kalahandi
}

\begin{abstract}
A song composed by a tribal women self help group in Bastar in Gondi language to describe electricity as - Tare Tare Kiss - the fire (kiss) that goes through wire (tare tare) - demanding electricity for their un-electrified village located in an electrified area from the district and electricity utility officials.
\end{abstract}

\subsection{Introduction}

Understanding energy access in rural areas, especially the factors that influence this access, is extremely relevant in the context of energy poverty ${ }^{172}$ and the content of energy policy reforms in India. In Chapter 4, when analysing India's rural energy policy and programmes, it was shown that, during the planning process, the government has prioritised access to modern energy carriers and rural energy with the objective of attaining rural, social and economic development. Despite the good intentions of the government, there have been growing concerns regarding the effectiveness of these policies in enabling access to modern energy carriers by low capacity end-users in large parts of rural India (Khandeker et al., 2010;Planning Commission, 2006;Reddy, 2000b;Sinha et al., 2009;Srinivasan and Bhagwati, 1995; Srivastava and Sen, 1997).

The policy reforms in India's energy sector are based on arguments that aim to promote economic efficiency and growth. As such, the emphasis has been on the market instruments of price correction, by phasing out subsidies, improving performance efficiency and allowing private-sector participation in the delivery of energy carriers. However, a closer analysis of the energy sector's reform policy shows that the social aspects, that is enhancing access for the public benefit and especially improving access for low-capacity end-users, do not appear on the agenda. Contrary to the objectives of private-sector participation, the Indian experience shows that, even after initiating reform policies, the government continues to be the dominant agency when it comes to implementing energy policies and programmes (Dubash and Chella Rajan, 2001;Rakhmanto, 2009;Sankar, 2002a;Singh, 2008).

From the analysis in Chapter 4, it can be concluded that there are appropriate energy sector policies at the national level that do aim to improve energy access in rural areas. Moreover, in India, as described in Section 4.1, the institutional setting and the regulatory regime differ for each modern energy carrier. Electricity is classified in the Constitution as a subject matter where both central and state governments have discretionary powers to formulate policies. However, policies related to electricity distribution and user charges are the responsibility of state governments. Petroleum energy carriers on the other hand are classified as a subject matter of the central government, and the central government thus decides alone on the relevant policies. As such, in relation to the research objectives which are on the district level,

\footnotetext{
${ }^{172}$ See Chapter 2, Section 2.1.2, where three aspects of energy poverty have been identified.
} 
conclusions based on national-level policy designs will not be sufficient as the evidence regarding the applicability and effectiveness of policy implementation would be missing. In early 2000, almost a decade after economic reforms were started in India, it was not apparent whether the energy reform policies were translated into effective implementation plans. What was apparent was that there were differences between states in their approach to dealing with the impacts and benefits of economic reforms (Ahluwalia, 2000;Datt and Ravallion, 1998). Ahluwalia (2000), a well-known Indian economist and policymaker, indicated that while the economically developed states had responded and accelerated development through policy reforms, the economically weaker states, such as West Bengal, Chhattisgarh and Orissa, had seen a slowdown in growth and development. However, post-2004, economic growth and development have accelerated in some states, including Chhattisgarh and Orissa, but there has been little change in West Bengal (GoI, 2008a;GoI, 2010a;Planning Commission, 2011). In addition to the inter-state variations and regional imbalances within a state, there are also inter-district differences with respect to economic development that seem to depend upon the characteristics of a district. These differences may have an impact on the ways policies are implemented, or the changes that need to be integrated in the policy design and implementation if it is to ensure access to modern energy carriers by low capacity end-users. Since the case studies are conducted at the district level, these characteristics need to be taken into account in examining the quality of both the design and the implementation of energy policies. This chapter provides empirical evidence from three case studies regarding policy design and policy implementation at the district level. Hence, this chapter will answer to the second main research question of the study:

Main Research Question 2: Have the energy policies enabled low-capacity end-users to gain access to modern energy carriers?

Sub question 2.1: How do delivery pathways and enabling factors influence access by low-capacity end-users to modern energy carriers?

Sub-question 2.2: Who has access to modern energy carriers and why?

Sub-question 2.3: How do contextual influences affect low-capacity end-users' access to modern energy carriers?

Data for the case studies were collected from three districts, each with different contextual influences and characteristics as presented in Chapter 3. The villages studied as part of the three case-study areas are located in Gosaba Island (West Bengal), Bastar (Chhattisgarh) and Kalahandi (Orissa). The case-study villages were selected to represent remote villages in rural areas where the rural population, at the time the research was initiated, had limited access to modern energy carriers (see Section 3.1 for the selection criteria).

This chapter is subdivided into five sections. Sections 5.2, 5.3 and 5.4 provide the empirical evidence from Gosaba Island, Bastar and Kalahandi respectively. In each case study, the empirical evidence is presented under five topics: (a) an introduction to the case-study villages; (b) energy availability, with a focus on the delivery pathways; (c) access to modern energy carriers, especially who has access and why; (d) contextual influences affecting 
energy access; and (e) policy design in relation to implementation. Section 5.5 provides answers to Research Question 2 and its sub-questions.

\subsection{Gosaba Case Study ${ }^{173}$}

This section describes access to modern energy carriers plus contextual and enabling factors that influences energy access by households living on Gosaba Island. The island is in the Sundarbans delta region of the South 24 Parganas district in the state of West Bengal. Gosaba Island is located in a river and forms part of the Gosaba Block. The Sundarbans delta region is located in the estuary of the Ganga-Brahmaputra river system that flows into the Bay of Bengal.

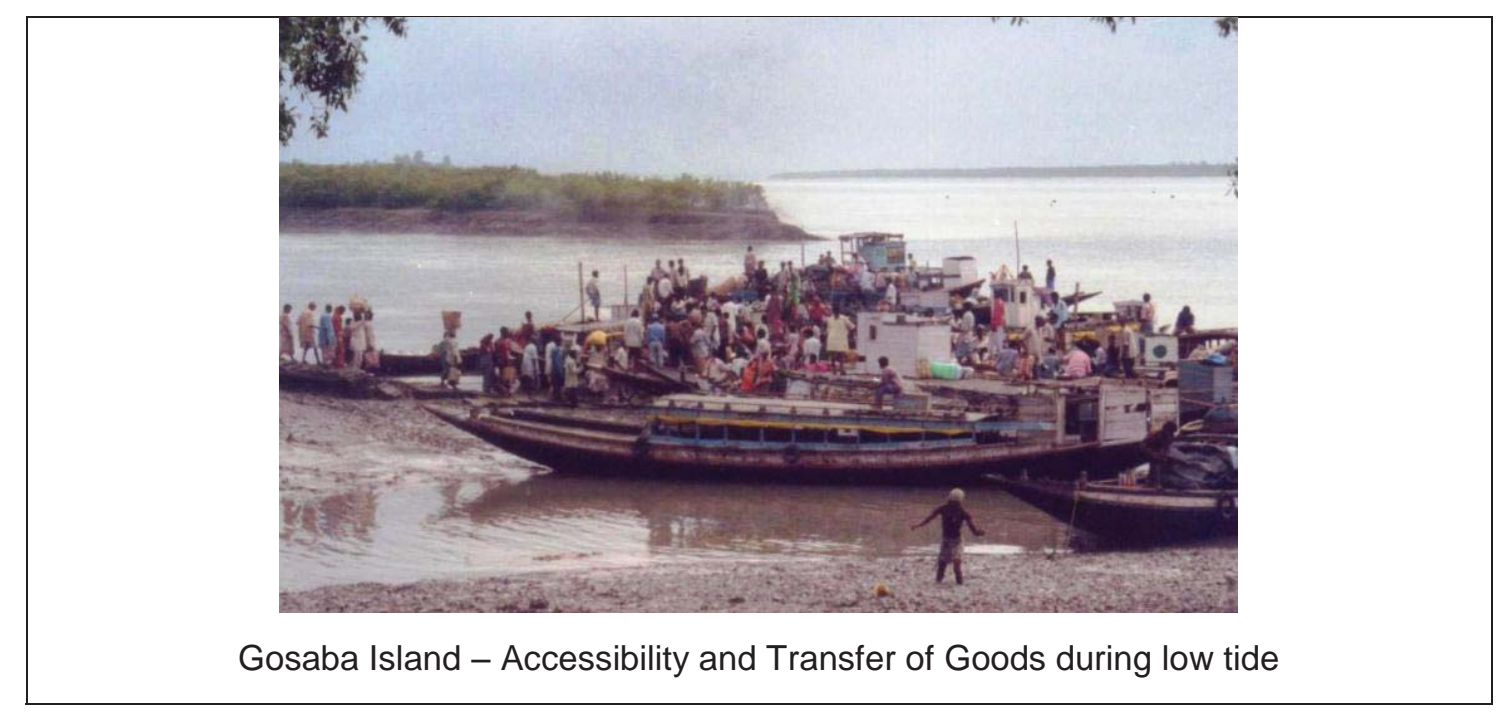

The villages of Gosaba and Rangabelia form the basis for the Gosaba case study. Map 5.1 provides an overview of the two villages. These villages are made up of both underserved and unserved households, with varying levels of access to modern energy carriers.

Gosaba lies on the banks of the River Bidya, and at the confluence of the Basanti and Kartal rivers. Gosaba hosts a number of state government organisations: department offices, a block development office, a government-run hospital, primary, middle and high schools, a public sector bank, and the Gosaba Gram Panchayat office. In addition, there is a school and a health clinic managed by the Gosaba Estate. The organisations that deliver energy carriers the Fair Price Shops (FPS) and the LPG dealers are located in the market in Gosaba. The electricity cooperative managing the decentralised biomass gasifier power plant is located adjacent to the market.

\footnotetext{
${ }^{173}$ Annexure I provides a detailed profile of Gosaba Island, covering its socioeconomic profile, its development deficits and its economic and infrastructure development (Banerjee et al., 2002;Chandrasekhar and Ghosh, 2003;Danda, 2007;GoI, 1997;GoI, 2002;Hamilton, 1937;Harriss, 1993;Mazumder, 1932;Patel and Rajagopalan, 2009;Sarma and Sarma, 2007;UNDP, 2004a;UNDP, 2004b).
} 
The village of Rangabelia forms part of the Rangabelia Gram Panchayat. This village is also located on the banks of River Bidya at a distance of $5 \mathrm{~km}$ from Gosaba, and the two villages are connected through a metalled road. The village has a hospital run by a non-governmental organisation (NGO), and a government high school.

Two infrastructure developments can be identified that have given a critical boost to the local economy, as well as improved services for the rural population of Gosaba Island. First, the commissioning of the Telephone Exchange in Gosaba Island improved communication linkages with the rest of the country. The availability of telecommunications has benefited the businesses and shopkeepers based in the market at Gosaba by enabling them to place orders for goods from Kolkata over the telephone rather than having to travel there, saving them time and money. As Sujit Sur, a retired schoolteacher, commented, "there is no commodity that you cannot buy in the local market today; if it is not available, it will get delivered in a few days, and one does not have to go to Kolkata"174. The communication infrastructure has been further enhanced with the introduction of a mobile telephone network in the region.

The second significant development was electricity becoming available from a decentralised renewable energy power plant set up by the state government and managed by an electricity cooperative that supplied electricity for six hours per evening ${ }^{175}$ from 1997 onwards. The local economy and the market in particular have benefited from the availability of electricity. Prior to this development, most shops in Gosaba market had access to electricity for four to five hours a day, supplied from a diesel generator set (Sinha et al., 2000). After the commissioning of the biomass gasifier ${ }^{176}$ power plant in 1997 and electrification of parts of the island, the quality and reliability of the electricity supply improved significantly. As a result, the market's trading hours have been extended and there is increased activity in the evening. Most of the shops are open until 10:30 p.m. in comparison to the pre-electrification phase when they would close by 9:00 p.m. The shopkeepers' perceptions are that business during the evening hours (in terms of the number of people visiting the market and sales) is greater than in the daytime. However, this does not necessarily translate into increased sales, it may be that consumers have shifted to more comfortable (i.e. cooler) or convenient hours to visit the market.

\footnotetext{
${ }^{174}$ Interview on 27 May 2001.

${ }^{175}$ Consumers had been demanding supply for sixteen hours a day but, following increases in the price of diesel and the expansion of the grid in 2003-04 to the neighbouring village of Rangabelia, the electricity supply was increased to twelve hours.

${ }^{176}$ Although the decentralised electricity generation project was based on renewable energy in the form of biomass, in reality the plant has mostly operated on diesel fuel. The main reason, as observed during the first period (in 2001) of field research, was the non-availability of biomass linked to the lack of a biomass supply chain as part of the electricity cooperative. Plant operation, as observed in 2008 during the second fieldwork period, was much as before and the plant continued to operate on diesel.
} 
Understanding Energy Access: Gosaba, Bastar and Kalahandi

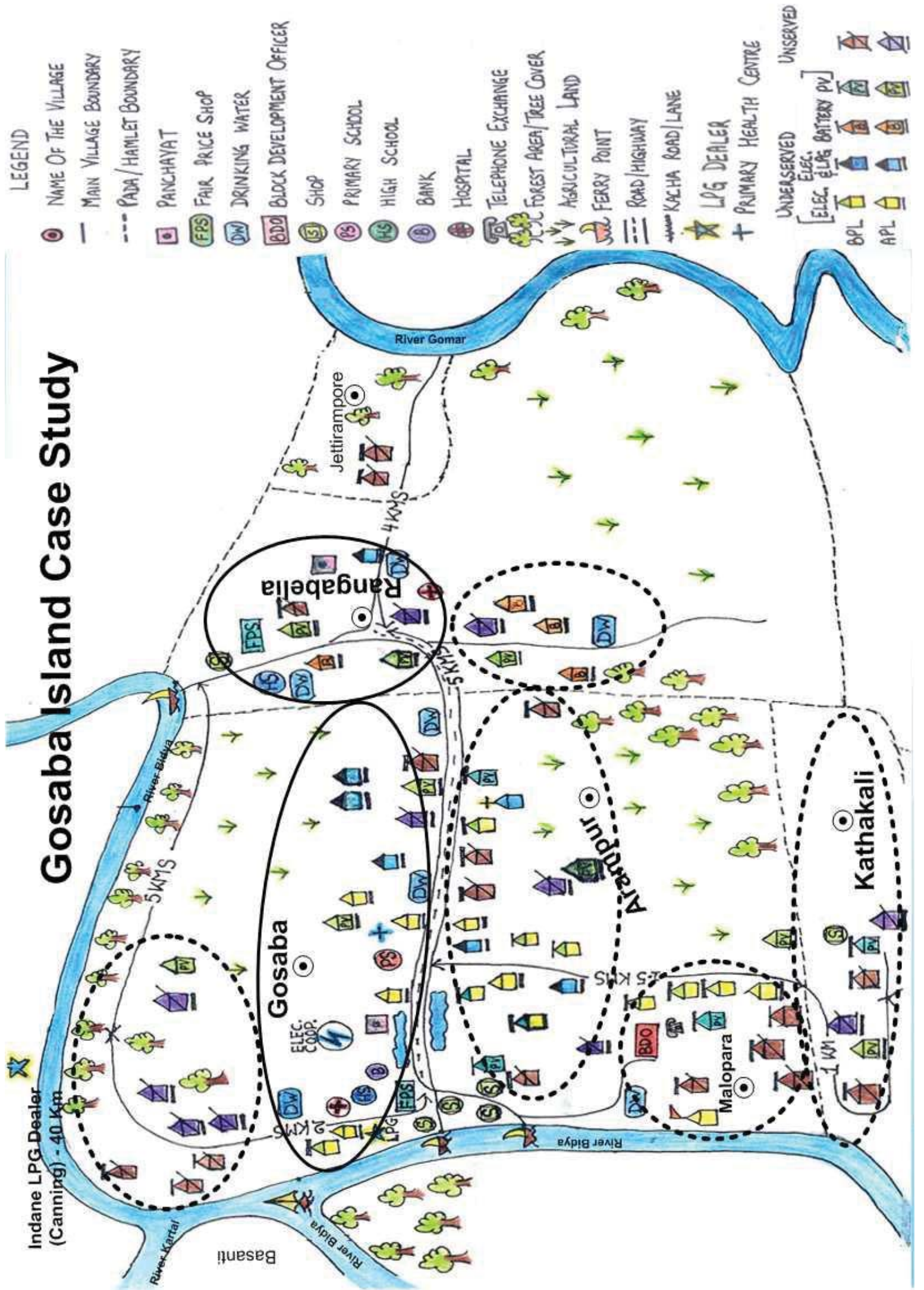

Map 5.1: Map of Gosaba case-study villages 


\section{In Pursuit of a Light Bulb and a Smokeless Kitchen}

The availability of electricity has also resulted in entrepreneurship and business

diversification. For instance, most sweet sellers now have a refrigerator, increasing the shelf life of products and giving them the option of stocking chilled beverages during summer months. An example of the growing number of entrepreneurs on the island is the Mondal family in which all four sons are graduates. Prior to grid electricity, they were all unemployed but, in 1997, by acquiring an electricity connection, they started to diversify their traditional family business of tailoring to include a photo studio, a photocopying shop and a telephone booth. Another such entrepreneur is Sarkar who set up a battery assembly unit in 2000 in Gosaba market. The batteries are used by many of his customers for watching television. He sells these batteries to non-electrified households, and to electrified households who use them with an inverter as a power back-up supply.

The telecommunication expansion, especially of the mobile services in rural areas, has had a positive effect on the local economy. This together with an increase in electricity supply to twelve hours a day (since 2003) had led to a widespread diffusion of the mobile telephone network on the island as observed during second fieldwork in 2008.

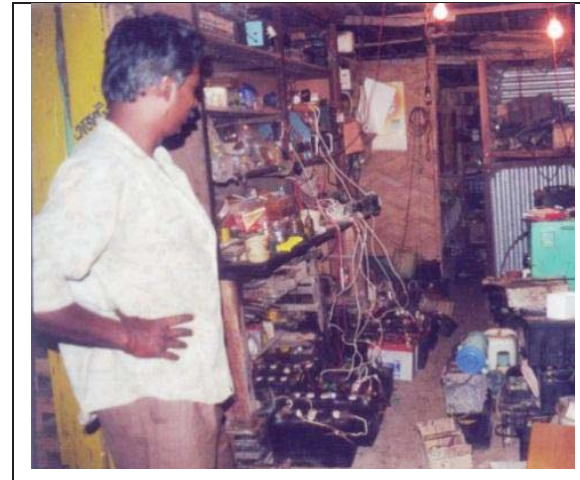

Battery charging in evening hours

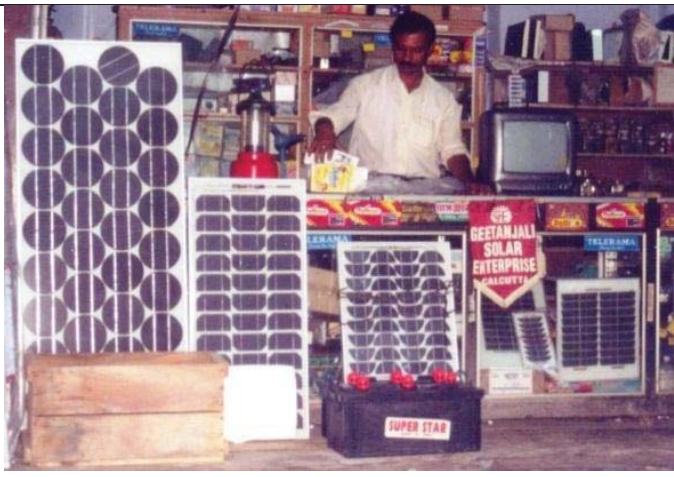

Solar PV shop in Gosaba market

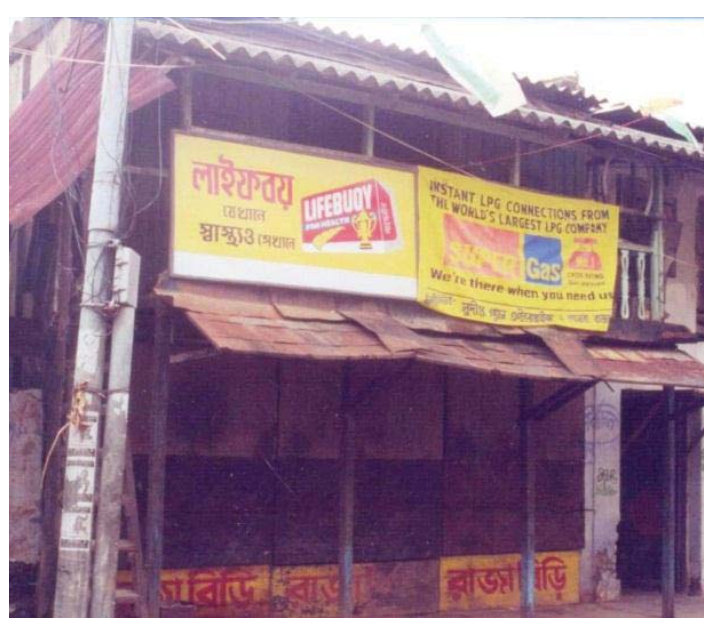

Private LPG distributor on Gosaba Island prior to 2004 


\subsubsection{Delivery Pathways - Before and After 2004}

This subsection describes the delivery pathway - and the organisations and policy instruments - for energy carriers. The availability of, as well as access to, modern energy carriers on Gosaba Island, as elsewhere, is a function of the delivery pathways that exist. Table 5.1 provides an overview of the organisations, both public and private, involved in the supply and distribution of energy carriers. On Gosaba Island, households use modern energy carriers - LPG and electricity (decentralised grid, solar PV lighting systems and batteries) for meeting various energy services. Nevertheless, biomass fuels remain the predominant energy carriers for cooking, and kerosene oil provides household lighting through kerosene lamps and dhibris.

Table 5.1: Delivery Pathways and Policy Instruments (2001-02 and 2008-09)

\begin{tabular}{|c|c|c|c|c|c|c|c|}
\hline \multicolumn{8}{|c|}{ Delivery Pathway } \\
\hline \multirow{7}{*}{ 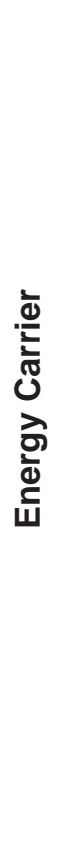 } & \multicolumn{3}{|c|}{ 2001-02 } & \multicolumn{2}{|c|}{ 2008-09 } & \multirow[b]{2}{*}{$\begin{array}{l}\text { No separate programme or } \\
\text { policy instrument, even } \\
\text { after RGGVY introduced }\end{array}$} & \multirow{7}{*}{ 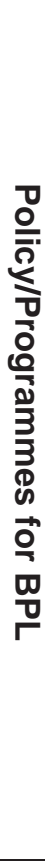 } \\
\hline & $\begin{array}{l}\text { Grid } \\
\text { Electricity }\end{array}$ & $\begin{array}{l}\text { Gosaba El } \\
\text { Cooperati }\end{array}$ & ricity & $\begin{array}{l}\text { Gosaba Ele } \\
\text { Cooperativ }\end{array}$ & ricity & & \\
\hline & Solar PV & WBREDA & $\begin{array}{l}\text { Local } \\
\text { retailers } \\
\text { (Tata BP, } \\
\text { WEBEL) }\end{array}$ & WBREDA & $\begin{array}{l}\text { Local } \\
\text { retailers } \\
\text { (Tata BP, } \\
\text { WEBEL) }\end{array}$ & $\begin{array}{l}\text { No separate programme or } \\
\text { additional subsidy }\end{array}$ & \\
\hline & Battery & Local Sup & & Local Supp & & & \\
\hline & LPG & Indane & Super Gas & Indane and & harat Gas & $\begin{array}{l}\text { No separate programme or } \\
\text { policy instrument }\end{array}$ & \\
\hline & $\begin{array}{l}\text { Kerosene } \\
\text { Oil }\end{array}$ & \multicolumn{2}{|c|}{$\begin{array}{l}\text { Fair Price Shop / Public } \\
\text { Distribution System }\end{array}$} & \multicolumn{2}{|c|}{$\begin{array}{l}\text { Fair Price Shop / Public } \\
\text { Distribution System }\end{array}$} & $\begin{array}{l}\text { No separate entitlement or } \\
\text { subsidy }\end{array}$ & \\
\hline & Biomass & \multicolumn{2}{|c|}{$\begin{array}{l}\text { Saw Mills (Wood) } \\
\text { Local Shops (Dung cake) } \\
\text { Rice Mills (Crop residue) } \\
\text { and Private Collection }\end{array}$} & \multicolumn{2}{|c|}{$\begin{array}{l}\text { Saw Mills (Wood) } \\
\text { Local Shops (Dung cake) } \\
\text { Rice Mills (Crop residue) } \\
\text { and Private Collection }\end{array}$} & & \\
\hline & & \multicolumn{2}{|c|}{$\begin{array}{l}\text { Government/Public } \\
\text { Sector }\end{array}$} & \multicolumn{2}{|c|}{ Private Sector } & & \\
\hline
\end{tabular}

\section{Electricity}

Historically, various initiatives have been undertaken to provide electricity to Gosaba Island. In the period between 1947and 1950, a few households on the Hamilton Estate had electricity connections that were powered by a diesel generator. In 1981, an electricity supply company, the Sundarbans Electricity Supply Company (SESCO), under a licence from the Ministry of Power was set up by a private entrepreneur to generate and distribute electricity on the island. The SESCO installation included a diesel generator that then distributed electricity through a local grid. However, SESCO's operation only run for slightly over a year when the 
entrepreneur withdrew the diesel generator set for repair and maintenance and never reinstalled the unit. One reason for this withdrawal was the consumers' refusal to pay an increased tariff to cover increased fuel costs. This made it economically unviable for SESCO to continue generating electricity. At the same time, some of the shopkeepers in the market with SESCO connections were accusing SESCO of having indulged in malpractices by installing defective meters and false billing, as a result of which consumers stopped paying.

In the period between 1983 and 1997, several attempts were made to revive SESCO. The State Electricity Board (SEB) and the state administration were involved; but none of these entities was willing to take on the responsibility for managing the system. This opened up an opportunity for small diesel genset operators to develop small energy service companies. These operators started to sell electricity to shops in the market area of Gosaba Island. As of 1996, there were four genset operators serving the market as well as some nearby households (TERI, 1998). They supplied electricity for four to five hours per evening throughout the year and, in the summer season, they provided electricity for an additional four daytime hours. A fixed rate (in Rupees per load point) was used, and fees were mostly collected on a daily basis although a few shops and eleven households paid weekly or monthly (TERI, 1998). In practice, the electricity supply from these operators was unreliable and the quality was poor due to excessive loads resulting in frequent breakdowns. Further, the tariff charged was considered high in comparison to what those in the grid-connected rural areas of the state were paying.

Given the geographical remoteness and topography, it is not considered economically viable to extend the grid from the mainland to the islands. Villages in the Sundarbans delta region have been categorised by the state government as remote areas, and hence should be electrified using decentralised distributed generation (WBREDA, 2001). Since $1995^{177}$, local grids on some of the islands have been initiated under a central and state government-funded programme, using decentralised renewable energy technologies for generation. Under different renewable energy programmes for rural areas, two types of technology have provided electricity on Gosaba Island since 1991: more than 400 households on Gosaba Island (spread across all eight villages) have solar photovoltaic home lighting systems; and a decentralised 500 kWe gasifier power plant and local grid provide electricity in Gosaba village $^{178}$ (see Map 5.1). Using Boorsma's framework ${ }^{179}$, the phases and functions of electricity distribution in Gosaba are presented in Table 5.2.

\footnotetext{
${ }^{177}$ Between 1995 and 2002, a decentralised power generation programme, based on solar and biomass energy technologies, was introduced as a joint initiative of the central and state governments. The central government provided a capital subsidy on solar and biomass technologies while the other implementation costs were subsidised by the state government. Since 2002, the electrification of remote villages falls under the Remote Village Electrification Programme (RVEP). Under the RVEP, the central government provides $90 \%$ of the capital costs of the project as a grant, and the remaining $10 \%$ can be contributed either by the state government or by the project's beneficiaries themselves (MNES, 2006 545).

${ }^{178}$ In 2003-04, the electricity grid was extended to Rangabelia village.

${ }^{179}$ The use of the Boorsma framework is discussed in Box 2.4 of Chapter 2. 
The decentralised electricity generation and distribution system was set up under the Cooperatives Act in 1997. Drawing on Boorsma's framework, the strategic and operational management functions related to electricity distribution, and responsibility for selling electricity (sales phase) fall to the Gosaba Rural Electricity Cooperative Society Limited (Table 5.2). The Cooperative is responsible for electricity power generation and for managing commercial activities. This includes grid expansion, allocation of new connections, meter reading, bill generation and distribution, and revenue collection. The West Bengal Renewable Energy Development Agency (WBREDA), a state government department, is responsible for the strategic functions related to setting up the power plant and providing the public budget for financing the plant (Table 5.2). WBREDA also assists the Cooperative with the technical aspects of the plant's operation and management.

Table 5.2: Phases and Functions of Electricity Distribution

\begin{tabular}{|c|c|c|c|c|c|c|c|c|}
\hline \multirow{6}{*}{ 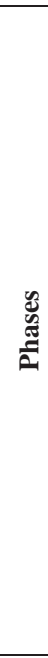 } & \multirow{2}{*}{\multicolumn{2}{|c|}{ Production }} & \multicolumn{6}{|c|}{ Functions } \\
\hline & & & \multicolumn{2}{|c|}{ Strategic Management } & \multicolumn{2}{|c|}{$\begin{array}{l}\text { Operational Planning and } \\
\text { Organizing }\end{array}$} & \multicolumn{2}{|l|}{ Financing } \\
\hline & $\begin{array}{l}\text { Decentralised } \\
\text { Grid }\end{array}$ & Solar & $\begin{array}{l}\text { Decentralised } \\
\text { Grid }\end{array}$ & Solar & $\begin{array}{l}\text { Decentralised } \\
\text { Grid }\end{array}$ & Solar & $\begin{array}{l}\text { Decentralised } \\
\text { Grid }\end{array}$ & Solar \\
\hline & $\begin{array}{l}\text { Generation } \\
\text { and } \\
\text { Transmission }\end{array}$ & Procurement & $\begin{array}{l}\text { WBSEB } \\
\text { WBREDA } \\
\text { Gosaba } \\
\text { Electricity } \\
\text { Cooperative }\end{array}$ & WBREDA & $\begin{array}{l}\text { Gosaba } \\
\text { Electricity } \\
\text { Cooperative }\end{array}$ & WBREDA & $\begin{array}{l}\text { Public } \\
\text { Budget }\end{array}$ & $\begin{array}{l}\text { Public } \\
\text { Budget }\end{array}$ \\
\hline & \multicolumn{2}{|l|}{ Distribution } & $\begin{array}{l}\text { Gosaba } \\
\text { Electricity } \\
\text { Cooperative }\end{array}$ & $\begin{array}{l}\text { WBREDA } \\
\text { Block } \\
\text { Development } \\
\text { Office }\end{array}$ & $\begin{array}{l}\text { Gosaba } \\
\text { Electricity } \\
\text { Cooperative }\end{array}$ & WBREDA & $\begin{array}{l}\text { Public } \\
\text { Budget }\end{array}$ & $\begin{array}{l}\text { Public } \\
\text { Budget }\end{array}$ \\
\hline & \multicolumn{2}{|l|}{ Sale } & $\begin{array}{l}\text { Gosaba } \\
\text { Electricity } \\
\text { Cooperative }\end{array}$ & $\begin{array}{l}\text { WBREDA } \\
\text { ADITYA } \\
\text { Solar Shop } \\
\text { Dealers of } \\
\text { Solar Energy } \\
\text { Companies }\end{array}$ & $\begin{array}{l}\text { Gosaba } \\
\text { Electricity } \\
\text { Cooperative }\end{array}$ & WBREDA & $\begin{array}{l}\text { Public } \\
\text { Budget }\end{array}$ & $\begin{array}{l}\text { Public } \\
\text { Budget }\end{array}$ \\
\hline
\end{tabular}

The strategic management decision over fixing electricity tariffs for the different consumer groups is taken by WBREDA (Table 5.2). In 1997, when the power plant started supplying electricity, the electricity tariff was fixed at Rs 3.25/kWh for domestic users and Rs 3.75/kWh for commercial users. These tariffs remained in force until 2001, when a small increase of Rs $0.50 / \mathrm{kWh}$ was imposed for both consumer categories. The minimum charge for domestic users was also revised from Rs 75 to Rs 110 per month in 2001. The Cooperative's records show that, in 2001, it supplied electricity to 273 domestic consumers and about 350 commercial users. The tariffs were further revised in 2006 and increased to Rs 5.60/kWh for domestic consumers, Rs 6.75/kWh for commercial consumers and Rs 8/kWh for industrial users (a new category). At the time of the second fieldwork, in 2008, the total number of consumers had increased to 1177 (733 domestic consumers, 428 commercial and 16 industrial). The industrial consumers were mainly the operators of telecom towers and owners of processing units located at Gosaba market.

\footnotetext{
${ }^{180}$ Includes a subsidy from the central government and, for a few schemes, an additional subsidy from the state government.
} 
One of the key operational management functions involves determining the minimum number of supply hours. This decision was taken by WBREDA, in consultation with the Cooperative (Table 5.2), and the supply hours were fixed in 1997 at the time of commissioning of the plant. From 1997 to 2003, the Cooperative supplied electricity for a fixed period of six hours between 5 p.m. and 11 p.m., primarily to align with household needs for lighting and entertainment ${ }^{181}$. In 2003, the Cooperative increased the supply hours from six to twelve (11:30 a.m. to 11:30 p.m.). However, consumers have indicated that, in reality, there are fewer supply hours due to frequent breakdowns and also routine maintenance.

At the time of the first fieldwork period, the coverage of the local electricity grid was very limited, with less than $6 \%$ of the island's households having a grid connection. The main reasons for this limited household connectivity appear at first sight to be technical and financial. The technical reason was that the $500 \mathrm{kWe}$ power plant lacked sufficient capacity for the grid to be extended throughout the island. This basic technical limitation was also compounded by financial constraints as neither WBREDA nor the West Bengal State Electricity Board (WBSEB) had budgeted for expanding the grid across the island ${ }^{182}$. Although the power plant and electricity distribution on the island come under the state's rural electrification programme, the Cooperative did not receive separate entitlements and subsidised tariffs for BPL households, such as under the Kutir Jyoti scheme in other parts of the state. This situation had not changed by 2008. According to a key informant, 'schemes such as Kutir Jyoti are the reasons for electricity theft in rural areas and this is why this scheme was not introduced in Gosaba, nor is it likely to be introduced on any other island where renewable energy-based power plants are established ${ }^{183}$.

On Gosaba Island, the electricity grid covers parts of the Gosaba, Arampur and Malopara hamlets (Map 5.1). At the time of the first fieldwork period, those other hamlets that are closer to the banks of River Bidya (Gosaba - I and II) and remaining parts of Malopara and Kathakali were not connected to the grid. At the time the power plant was commissioned in 1997, electricity was provided to all households that applied for a connection in the area covered by the grid. From the time when the initial electrification phase was completed in 1999, until 2004, the grid was not expanded even though there was demand from households $^{184}$. In comparison to Gosaba with its local grid, less than $10 \%$ of the households in Rangabelia village and its hamlet had electricity at the time of first fieldwork, and this from solar PV home systems. During the second fieldwork period, it was found that previously un-electrified hamlets of Gosaba and Rangabelia village were now connected to the electricity grid.

\footnotetext{
${ }^{181}$ In the initial period, the use of electricity for productive purposes was restricted to lighting in the commercial sector, mainly for shops in the market.

${ }^{182}$ Finance for the power plant and the local grid came from the public budget of WBREDA and WBSEB. WBREDA received financial assistance from the Ministry of New and Renewable Energy.

${ }^{183}$ Interview with S P GonChoudhary, Managing Director, WBREDA on 14 June 2001 in Kolkata.

${ }^{184}$ Interviews in May 2001 with unserved households as well as open-ended interviews with the Cooperative management on its future expansion plans. The electricity grid was expanded in 2003-04. 
The use of solar PV home systems has been growing steadily. Around 1992-93, a few households bought $35 \mathrm{Wp}$ capacity domestic solar home lighting systems under a subsidy programme of the central and state governments (Sinha et al., 2000). Here, WBREDA was responsible for all the strategic and operational functions across all the solar PV dissemination phases (Table 5.2). Since the solar PV programme is subsidised by the central and state governments, finance for the programme comes from the public purse. At the time of the first fieldwork (2001), about four hundred solar home systems were in use on Gosaba Island, with Gosaba village and Arampur hamlet having more than a hundred systems between them. A major triggering factor in the increase of solar home lighting systems was the 1997 Indo-US Cooperative PV Project ${ }^{185}$, under which 100 solar home lighting systems were installed in Gosaba and Kathakali. Further, a battery-charging unit, also using PV technology, was set up in Gosaba within the Rupayan premises (Sinha et al., 2000). The growing market for PV systems provided an opportunity for local manufacturers of solar systems in Kolkata to create a dealer network on the island for the promotion of the technology and after sales service (Chaurey, 2001). During the second period of fieldwork, discussions with local dealers of solar PV systems indicated that approximately 750-800 solar lighting systems were in use in households.

\section{$L P G$}

On Gosaba Island, LPG has been in use as a cooking fuel since 1991, even though the first LPG dealership was only established in 1994-95. Almost all the initial households that used LPG sourced their refills through relatives in Canning, the location of the nearest dealer, some $40 \mathrm{~km}$ by boat from Gosaba Island. The first private sector LPG distributor (Vishal Gas) was setup on the island in 1994-95 ${ }^{186}$. A study of household energy use in the Sundarbans shows that, in 1997, about 40 households on Gosaba Island were using LPG for cooking (TERI 1998). Since $1999^{187}$, there has been a significant increase in the number of households using LPG. In 2001, at the time of the first survey, more than 300 households were using LPG on the island, and this number had doubled by 2008. Two reasons explain the increased adoption of LPG: firstly, the improved availability of LPG connections and, secondly, an increase in the paying capacity of middle-income households. However, a number of other factors have hindered the development and further growth of the LPG market in Gosaba Island. Firstly, there has been only limited infrastructural development, particularly in terms of transportation. The Ministry of Petroleum and Natural Gas (MoPNG) and public sector undertakings (PSUs) in the sector are responsible for strategic decisions

185 The Indo-US Cooperative PV Project was a joint programme in which the US provided solar PV panels and charge controllers, and the Government of India contributed to the cost of the battery and installation. The Ram Krishna Mission, an NGO, through their Centre in Gosaba (called Rupayan) implemented the scheme. Under the scheme, 300 solar home lighting systems were installed in Gosaba, Satjelia and on Molakhali Island. It also included a solar battery-charging station, lighting for a health centre, for a women's weaving unit and for a women's training centre (Stone et al., 1998)..

${ }^{186}$ Vishal Gas has not distributed since 1999, and LPG users have switched to Indane Gas or Super Gas.

${ }^{187}$ See Box 4.6 regarding the regulations that allowed a Parallel Marketing Scheme (PMS) that led to an increase in LPG availability in rural areas. 
related to creating rural distribution infrastructure, but, in the absence of clear policy directives, LPG dealers are not to be found in rural markets. Biomass fuels - firewood, crop residues and animal dung - are sufficiently available to ensure that biomass fuels remain the main energy carriers used for cooking. There are also social factors that influence the transition to this modem energy carrier, and these are discussed in Section 5.2.3. The phases and functions observed in LPG and kerosene oil distribution in Gosaba are summarised in Table 5.3.

As of 2001-02, there were two main suppliers of LPG: one public (Indane Gas) and one private (Super Gas). The Indane Gas distributor was located in Canning, as was the nearest dealer. The distributor was responsible for the operational management of the distribution and sales phases (Table 5.3). A local boatman ferried the cylinders on a weekly basis from Canning to the island. Indane supplies $14.2 \mathrm{~kg}$ capacity cylinders ${ }^{188}$, which were priced at Rs 250 per refill in 2001. In addition to the cylinder costs, households also had to pay for transportation. This amounted to a Rs 25 charge per cylinder for the boatman plus Rs 10 for the delivery of the cylinders from the ferry ghat, either by rickshaw or by head-loading. Therefore, by the time a LPG cylinder reached a household, the price paid varied between Rs 275 and Rs 285, an increase of 10\%-15\% over the price in Canning. This combination of boatman and rickshaw/head-loader completed the sales phase, and amounted to an informal mechanism developed by the consumers to compensate for the LPG dealers failure to provide a formal delivery system.

The second LPG supplier was Super Gas, which supplied LPG cylinders to about 75 households. Super Gas was a private LPG dealer representing the SHV Energy Company, a Dutch energy company that marketed LPG under the Parallel Marketing Scheme (PMS). Super Gas, under the PMS, was responsible for the strategic, operational and financial management functions for different phases of LPG delivery (Table 5.3). Super Gas established a dealership on Gosaba Island in 2000, and supplied to households on the island (Map 5.1) as well as to households on neighbouring islands ${ }^{189}$. Super Gas supplied $12 \mathrm{~kg}$ cylinders ${ }^{190}$ and consumers paid up to Rs 285 per cylinder including delivery.

Apart from these two main suppliers of LPG cylinders, there were other private LPG companies that sold LPG in smaller $2 \mathrm{~kg}$ and $5 \mathrm{~kg}$ cylinders. Most of these small cylinders

\footnotetext{
${ }^{188}$ An LPG connection cost from Indane varies between Rs 2000-Rs3000 depending on whether it is a single or double cylinder connection and on the costs of the stove. Most Indane connections on Gosaba Island are double cylinder connections.

${ }^{189}$ Super Gas closed its operation on the island in 2003-04.

${ }^{190}$ Super Gas provided only a single cylinder connection. However, since the dealer was on the island, cylinder availability was not a constraint as households could replace an empty cylinder on an asneeds-basis rather than having to wait for a cylinder to arrive from the mainland. This is a distinct advantage for a user since there is no warning that a cylinder is about to run out; and without such a warning households run the risk of having no fuel with which to cook. For the dealer, cylinder availability gives a certain degree of security in the market. Super Gas's initial connection fee was Rs 1500 in 2001.
} 
were used by tea vendors, as well as by some households and by fishermen who carry LPG stoves in their boat for preparing their food.

On Gosaba Island, public sector oil and gas companies are currently the main distributors of LPG. Before 2001, there was a considerable waiting time of four to five years for public sector dealer to provide new connections. As a result, private sector gas dealers saw an opportunity to enter the rural market by providing instant connections. In 2004, when the central government phased out the PMS and failed to implement subsidy reforms, Super Gas stopped supplying LPG to Gosaba. The private-sector LPG consumers then switched to the public sector with LPG connections provided by Indane and by Bharat Gas. Bharat Gas belongs to BPCL, a public sector oil and gas company that set up a new dealership in Canning. From the household perspective, while the presence of a private sector dealer improved availability, households preferred to have LPG from public sector dealers for the reasons outlined below.

Table 5.3: Phases and Functions in LPG and Kerosene oil distribution

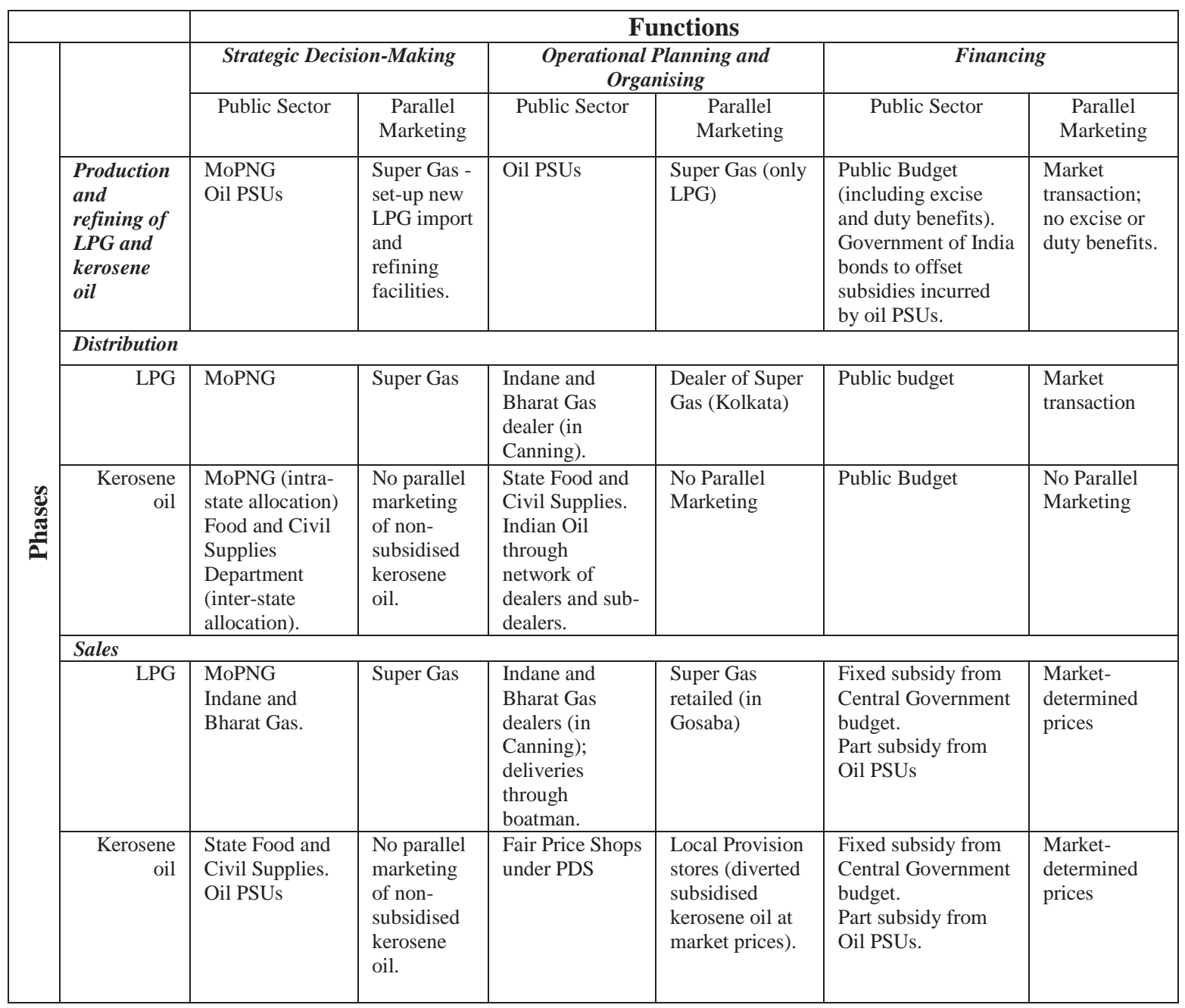


The main reasons for a household preference for the public sector pathway were as follows:

i. $\quad$ PSU dealers provide $14.2 \mathrm{~kg}$ capacity cylinders compared to the private sector dealers who marketed either 11 or $12 \mathrm{~kg}$ cylinders. The former are more convenient for a household since they last longer under a regular usage pattern;

ii. PSU connection costs per cylinder are cheaper than private sector ones. The PSU cylinders are also subsidised by the government, making the unit cost of gas (and hence energy) cheaper than from private-sector dealers. This was very apparent to the users since the smaller private sector gas cylinders cost the same or more to refill/replace than the larger PSU cylinder;

iii. PSU connections are usually a double one, allowing two cylinders to be connected. This means that it is always possible to have gas available in the household. In comparison, private sector dealers only provided single cylinder connections and household would experience supply gaps until an empty cylinder could be replaced;

iv. PSU dealers are more credible than the private sector ones as they have been present for longer, and are seen as part of the government's supply network.

v. The PSU dealers are considered more reliable than private ones because past experiences with private sector dealers were not positive. If a private dealer stops supplying LPG, as was the case with Vishal Gas (as observed during the first fieldwork) and then Super Gas (during second fieldwork), households using private dealers incur additional costs for a new connection;

vi. Since LPG is often used in combination with biomass in meeting cooking needs, one cylinder lasts for more than one and half months ${ }^{191}$ for nearly two-thirds of households (Table 5.2). The households prefer to have an LPG supply from the PSU dealer as they get double cylinder connections and there is always an LPG cylinder available.

\section{Kerosene oil}

On Gosaba Island, kerosene oil is supplied ${ }^{192}$ under the Public Distribution System (PDS) through a network of Fair Price Shops (FPS). The PDS and FPS fall under the Department of Food and Civil Supplies, and this state government department is responsible for the strategic decision-making related to intra-state (district) allocation. The state department also makes strategic decisions over the allocation norms (per capita or per ration-card holder) for rural and urban households, as well as the duration (number of times in a month) of the sales of kerosene oil through FPS (see Table 5.3). The Indian Oil Corporation is responsible for kerosene distribution in the State of West Bengal and operates through a network of dealers and sub-dealers that distribute/supply kerosene oil to FPS across the state. Three FPS located in Gosaba market and one in Rangabelia serve the households on Gosaba Island (see Map

\footnotetext{
191 The private LPG dealers provided single cylinders in rural areas primarily because a cylinder lasts a household a considerable period. For the private dealers, having cylinders with customers for long periods means that they need a large stock of expensive cylinders and this reduces their profitability.

${ }^{192}$ The Ministry of Petroleum and Natural Gas (MoPNG), takes strategic decisions related to the inter-state allocation of kerosene oil for further distribution.
} 
5.1). They are responsible for the operational management function in selling kerosene oil to ration-card holders (see Table 5.3). All the three FPS are located in the main Gosaba market. In order to serve the hamlets and households across the island, these FPS have set up subdealers. In West Bengal, the distribution system notionally makes kerosene oil available to ration-card holders twice a month, in the first and the third weeks. On Gosaba Island, however, there are no fixed days due to uncertainty over supplies from the mainland ${ }^{193}$.

In terms of entitlement, the West Bengal government's allocation norm for kerosene oil is one litre per person per month. However, there is widespread disparity between the state government's norm and the actual disbursement of kerosene to BPL households. The FPS dealers reported that they received kerosene oil based on an allocation of 0.9 litres per person per month ${ }^{194}$. However, the quantity of kerosene oil supplied to each ration-card holder by the FPS dealer in Gosaba is only 0.8 litres per person per month. Therefore, in the distribution process, 0.2 litres of kerosene oil (20\% of the allocation) is pilfered before it reaches the consumers. The pilferage is the result of the collusion between the various intermediaries, including the FPS dealers, in the supply chain. At 2001 prices, the losses incurred by the government, based on the analysis by the author, worked out as Rs 1.30 per subsidised litre, whereas retailers and FPS dealers shared the profit made by selling the diverted kerosene oil.

Observations by the author in Gosaba market and the household survey reported here substantiate this pilferage of kerosene oil. Almost all the shops selling groceries and commodities for everyday use in Gosaba market also stock kerosene oil. The kerosene oil sold by these grocery shops is blue ${ }^{195}$ in colour, identifying it as kerosene oil intended for the FPS. The price of kerosene oil under the PDS allocation in 2001 was Rs 9.50 per litre and this reflected a government subsidy of Rs 6.50 per litre. Part of this subsidy comes from the central government's budget and the remainder is cross-subsidised by the oil and gas PSUs. In Gosaba market, kerosene oil ranged in price from Rs 16 to Rs 18 per litre in $2001^{196}$. Kerosene oil prices were not revised until 2008, and the subsidy burden had by then increased to Rs 17 per litre.

Under the PDS, an average family of five should receive their entitlement of five litres of kerosene oil for Rs 47.50 a month prior to 2008. In reality, these households were getting only four litres for which they paid Rs 38 per month. If they purchase more, then this will be from the open market at Rs 16 to Rs 18, costing them an additional Rs 6.50 to 8.50 per litre compared to the PDS price. If they buy an extra litre, to restore their official entitlement, their

\footnotetext{
${ }^{193}$ Kerosene oil barrels are delivered by road from the distributor in Kolkata to the FPS dealers in Sojnakhali. From Sojnakhali, these kerosene oil barrels are transported to the islands by boat.

${ }^{194}$ Interviews with district official in Alipore, Kolkata on 18 May 2001, and three dealers in Gosaba on 1 June 2001.

${ }^{195}$ Blue dye is added to differentiate subsidised kerosene oil sold through the PDS from the non-subsidised kerosene oil sold under the parallel marketing scheme (white kerosene oil).

${ }^{196}$ The grocery shops claimed to sell kerosene oil at Rs 12 per litre. However, the households who purchased from these shops reported that they paid between Rs 16 and 18 per litre and that the price increased further during the festive seasons, when as the demand increases. In 2008, it was observed that households were paying between Rs 25-Rs 30 per litre on the open market.
} 
expenditure will be $14 \%$ to $18 \%$ above their expected monthly expenditure on kerosene oil, which is significant for low-income households. Further, since $90 \%$ of all households (BPL and APL) buy kerosene oil from the PDS, the impact of this pilferage is significant ${ }^{197}$ and the government's subsidy is captured by high-income groups. As such, its abuse provides a windfall profit for FPS dealers and others in the supply chain, and has a negative impact on BPL household budgets.

At the time of the first fieldwork, it was found that more than $40 \%$ of households regularly purchased kerosene oil from the open market, with most of the other households purchasing kerosene oil on an intermittent basis, especially during festive seasons (Table 5.3). The majority of the low-income households, especially those paid on a daily basis, purchased kerosene oil from the market based on monetary outlay (Rs 2 - Rs 5) rather than by volume. In most households, kerosene oil usage for cooking is minimal, and only in an emergency. The purchasing pattern had not changed between 2001 and 2008, and a similar number of households purchased kerosene oil on the open market.

\section{Biomass Fuels}

Irrespective of the economic status of a household, biomass energy carriers are used for cooking and for other thermal applications, such as water heating. Biomass energy carriers are also used for cooking in restaurants. In Gosaba, nearly $40 \%$ of the households are able to gather biomass from within one kilometre of the household. Woody biomass, such as firewood and sawdust, are used for high temperature cooking whereas crop residues are used for simmering applications, such as the preparation of parboiled rice. The use of dung cakes is limited. Firewood is mostly purchased in bulk for use during the monsoon season. The main sources of purchased firewood and sawdust are the sawmills in Gosaba and Rangabelia.

However, from the household surveys in 2001 and 2008, it appears that the type of biomass fuel used has changed over time and that the quality of the fuel has declined. Since the availability of wood is now limited, households are using a combination of twigs and branches, dung, crop residues and sawdust as fuel. The other noticeable significant change has been in the shift from free collection ${ }^{198}$ to the purchase of all these biomass fuels by BPL households, especially landless ones. The majority of the APL households collect biomass from their badi (homestead) or from agricultural land. In the APL households, the biomass fuels that are gathered from one's own farmland or common land include leaves, bush and shrubs plus twigs and branches. APL households also purchase biomass fuels, especially firewood and dung cakes, from the local market.

\footnotetext{
197 As noted in Chapter 4, a 2005 study by the National Council for Applied Economic Research estimated that, at the all India level, about 39\% of the subsidised kerosene oil did not reach the targeted consumers. In monetary terms, this was equivalent to Rs 100 billion per annum.

${ }^{198}$ Free in the sense of at no monetary cost, but this neglects the opportunity cost of women's time. This issue is discussed in Sections 5.2.2 and 5.2.3.
} 


\section{Delivery Pathways in 2008}

As the central government has focused on an inclusive development agenda in the rural areas, the delivery pathways have shifted towards the public utilities (Section 4.3.3). The change in delivery pathways is significant in the context of energy sector reforms. In Gosaba, the delivery pathways for solar PV and kerosene oil have remained largely unchanged since 2001 (See Chapter 4). In addition, the policy instruments have remained the same for these carriers. As such, the functions and phases for these two energy carriers (solar PV and kerosene oil) have remained unchanged between the two fieldwork periods.

In the case of electricity, while the delivery pathway remained the same, with the Electricity Cooperative still being responsible for generation and distribution, changes have been made in the hours of supply and in the tariff. In responding to consumer demand for enhanced hours of energy supply, the Cooperative extended supply from six hours to twelve hours per day. The Cooperative also extended electricity supply to Rangabelia, and there were 1177 electricity consumers (all categories) on the island in 2008, representing an increase of $87 \%$ on 2001. The other significant change is an improvement in accessibility by a few lowcapacity end-users in the non-electrified hamlets of Gosaba and parts of Rangabelia village. However, the rural electrification programmes (such as RGGVY and RVEP) that include the principle of universal energy access, as mandated by the RE Policy 2006, are yet to be implemented in Gosaba. BPL households, despite being prioritised under national programmes for electricity access, have yet to benefit. As such, the ongoing rural electrification activities in Gosaba do not comply with the national rural electrification policy. This will be further discussed in Chapter 6 .

The delivery pathway for LPG in Gosaba has changed since 2004. Solely the state-owned oil and gas companies (public sector) now drive the LPG delivery pathway, which at the time of the first fieldwork period (in 2001) was a combination of public and private sectors. Super Gas, the private LPG dealer in Gosaba in 2001, ceased its operations in 2004, as it could no longer compete in the market with the subsidised LPG offered by public sector companies. The Indane dealer based in Canning continued to supply LPG in Gosaba and also added new LPG consumers who shifted from the private sector supplier. Another state-owned oil and gas company (Bharat Gas) started to deliver LPG in Gosaba since 2006.

\subsubsection{Access to Modern Energy Carriers: Who Has Access?}

Access to modern energy carriers on Gosaba Island is characterised by the presence of both the underserved and unserved categories of low capacity end-user households. An aggregated picture of access to modern energy carriers in the case-study area, as tabulated during the two study periods, is presented in Table $5.4^{199}$. At the time of the first fieldwork study (2001), 273

199 Data related to the number of households are based on statistics available to the Gosaba and Rangebelia Gram Panchayats for 2001 (Block Development Office Gosaba, 2001). Household numbers related to grid electricity connection are based on information from Gosaba Electricity Cooperative. Information on solar PV is based on data collected from the Rupayan Centre of the Ram Krishna Mission, the Tagore Trust, Rangabelia, and retailers and dealers in PV systems in Gosaba market. Information on LPG households was compiled from the Super Gas dealer in Gosaba and from the boatman who ferries 
out of the 1115 households in the Gosaba Gram Panchayat had access to grid electricity and 130 households were using solar PV lighting systems. By 2008, 523 households had access to grid electricity and 274 had solar PV lighting. LPG was used for cooking by 170 households in 2001, and this category had increased to 323 households in 2008. In Rangabelia, 25 households were using solar PV lighting systems and 15 households using LPG for cooking in 2001. In 2008, after village electrification, 210 households were using grid electricity, 89 households had solar PV lighting systems and 83 households were using LPG for cooking. While the absolute number of households with access to modern energy carriers had clearly increased between 2001 and 2008, the percentage of households with access had not improved to the same extent because the total number of households ${ }^{200}$ had also increased over the period.

\section{Table 5.4: Energy Carriers used in Gosaba}

2001 and 2008

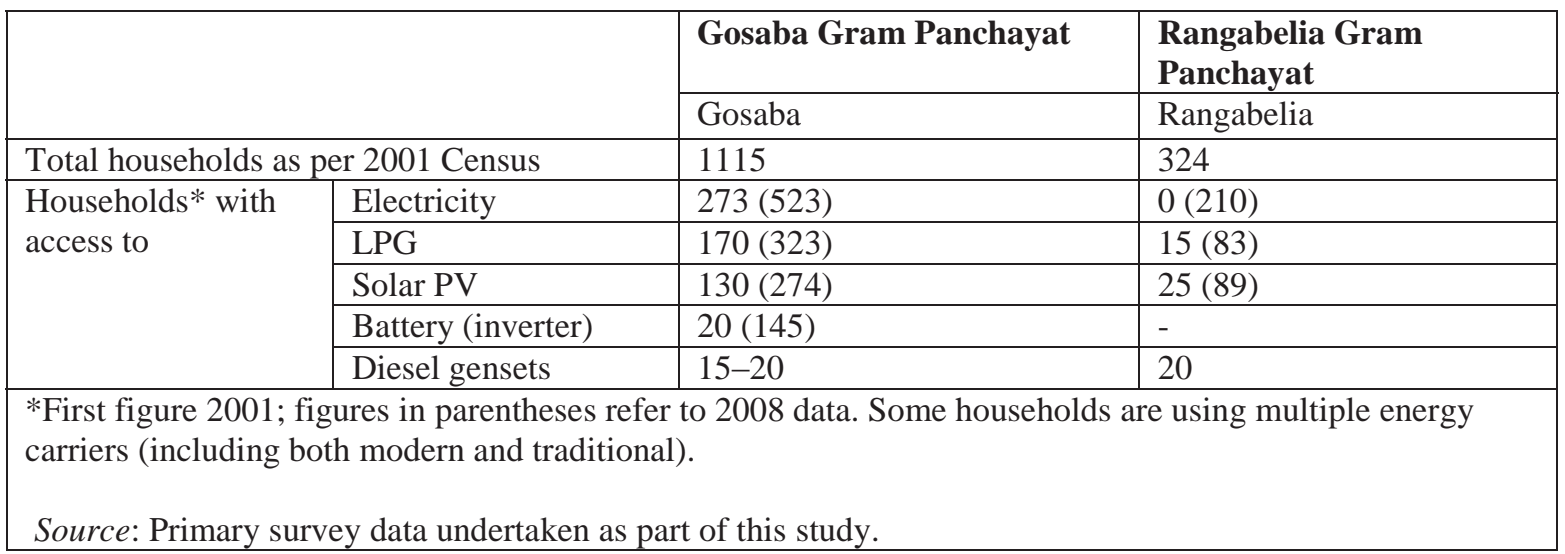

Table 5.4 also shows that while households with access to modern energy carriers has increased between 2001 and 2008, the percentage of households with access is still very limited. While the delivery pathways described earlier do have a role to play in enabling access to modern energy carriers, at least in the sense of improving availability, the local economy and the cost of energy carriers play an important role in determining access. In order to understand access to modern energy carriers in the case-study area, a detailed enduse energy survey, to identify the factors that influence access to modern energy carriers, was carried out in a sample of the households. Table 5.5 provides information about the 94

cylinders. Household numbers using a battery/inverter system were collected from the local battery supplier in Gosaba, and households with diesel genset connections from the generator owners. Information about kerosene oil was collected from the four FPS in Gosaba and Rangabelia.

${ }^{200}$ The most accurate information on the total number of households is provided by Census of India surveys. At the time of writing this dissertation, the latest available information is for 2001, with information from the 2011 census still provisional and lacking village-wise household census details. Therefore, 2001 total household census data has been presented, although it was clear that the number of households had increased by 2008. 
households surveyed as part of the Gosaba Island case study in 2001 and their status in terms of access to modern energy in 2008.

Table 5.5: Low-Capacity End-Users in Gosaba Island

2001 and 2008

\begin{tabular}{|c|l|l|l|}
\hline Underserved & $\begin{array}{l}\text { Households with access to electricity } \\
\text { (including those with solar PV home } \\
\text { lighting systems) and sometimes LPG }\end{array}$ & Electricity and LPG & $35^{*}(41)^{* *}$ \\
\cline { 3 - 4 } & Only Electricity & $28^{*}(34)^{* *}$ \\
\hline Unserved & $\begin{array}{l}\text { Households with no access to electricity (using kerosene oil for lighting) and no } \\
31 *(19) * *\end{array}$ & access to LPG (using biomass fuels for cooking and thermal energy needs)
\end{tabular}

As can be seen from Table 5.5, 63 out of the 94 households surveyed were classified as underserved in 2001, with access to electricity and some of these households also used LPG; and this number had increased to 75 in 2008.The main reason for the improved situation was greater access to electricity due to the grid having been expanded. A further ten households were using a battery inverter system, mostly for watching television. The number of households with LPG connections had increased from 35 in 2001 to 41 in 2008 and most of these were APL households. In 2001, the remaining 31 households surveyed were unserved and using kerosene oil for lighting and biomass energy carriers for meeting all their cooking needs. By 2008, only 19 households remained completely unserved. This change reflected a situation in which more households had started to use electricity and in some cases also LPG.

Barnett (2000), in his analysis of energy poverty, observes that rural people are unable to shift from traditional energy carriers to modern energy carriers because they have limited purchasing power and become trapped in a vicious circle of high energy costs and low surplus income (see Chapter 2). Based on Barnett's conclusions, one would anticipate that it would be the APL households in Gosaba that had access to modern energy carriers, and the BPL households that remained unserved. Table 5.6 shows the distribution of access to energy carriers in terms of APL and BPL households, further differentiated by the primary occupation of the household. This table provides a slightly different picture for the villages on Gosaba Island than what one might expect from Barnett's findings. On Gosaba, there are BPL households with access to modern energy carriers. At the same time, there are unserved APL households, although admittedly considerably fewer in number in comparison to BPL households. The motivations cited for the shift to modern energy carriers by APL households were: convenience, time-saving, and providing study time for children ${ }^{201}$ (Box 5.1) and cleanliness (Box 5.2). By 2008, all the APL households that had been unserved in 2001 had switched to modern energy carriers and were using electricity and LPG. In some of the APL households, factors other than affordability had been the reason for non-use in 2001 (Box 5.3,

\footnotetext{
${ }^{201}$ Convenience and improved lighting for children to study were also identified as motivations for electricity access by BPL households.
} 
case of Amiyon Mandal). Other unserved APL households switched to electricity when the local grid expanded.

Table 5.6: Mapping Energy Access by Economic Status and Occupation

2001 and 2008

\begin{tabular}{|c|c|c|c|c|c|c|}
\hline \multicolumn{2}{|c|}{+2} & $\begin{array}{c}\text { Government } \\
\text { Service / } \\
\text { Service (26) }\end{array}$ & $\begin{array}{l}\text { Agriculture } \\
\text { (21) }\end{array}$ & $\begin{array}{l}\text { Commerce } \\
\text { (20) }\end{array}$ & $\begin{array}{l}\text { Non-farm } \\
\text { (Fishing) (9) }\end{array}$ & $\begin{array}{c}\text { Farm/Non- } \\
\text { farm labour } \\
\text { (18) }\end{array}$ \\
\hline \multicolumn{7}{|c|}{ Underserved* (63) } \\
\hline \multirow{3}{*}{ APL } & $\begin{array}{l}\text { Electricity (or PV), } \\
\text { LPG and Biomass (30) }\end{array}$ & 10 & 8 & 12 & - & - \\
\hline & Electricity and LPG (5) & 5 (incl. 2 PV) & - & - & - & - \\
\hline & Only Electricity (12) & 6 & 2 & 3 & 1 & - \\
\hline \multirow[t]{2}{*}{ BPL } & Electricity and LPG (0) & - & - & - & - & - \\
\hline & Only Electricity (16) & 2 & 6 & 3 & $\begin{array}{l}3 \text { (including } 2 \\
\text { PV) }\end{array}$ & 2 (both PV) \\
\hline \multicolumn{7}{|c|}{ Unserved* (31) } \\
\hline \multicolumn{2}{|c|}{ APL (6) } & $2(* * \wedge)$ & $1(* *)$ & $1(* \wedge)$ & $2(* * \wedge)$ & - \\
\hline \multicolumn{2}{|c|}{ BPL (25) } & $1(* *)$ & $4(2 *)$ & $1(* *)$ & $3(2 * *)$ & 16 \\
\hline \multicolumn{7}{|c|}{ BPL households purchasing biomass } \\
\hline \multicolumn{2}{|c|}{ Underserved (6) } & 2 & 2 & 1 & - & 1 \\
\hline \multicolumn{2}{|c|}{ Unserved (12) } & - & - & - & 2 & 10 \\
\hline \multicolumn{7}{|c|}{$\begin{array}{l}\text { * Includes } 89 \text { households where kerosene is also being used for lighting } \\
* * \wedge \text { Includes } 6 \text { households who in } 2008 \text { use electricity and LPG - transition from unserved to underserved } \\
* * \text { Includes } 6 \text { households who in } 2008 \text { use electricity - transition from unserved to underserved }\end{array}$} \\
\hline \multicolumn{7}{|c|}{ Source: Primary survey } \\
\hline
\end{tabular}

For BPL households, the cost of modern energy carriers continues to remain a critical access barrier. However, some BPL households are buying biomass and so a lack of capacity to pay is not always a barrier. The barriers to electricity access are more complex than cost alone, as shown by the fact that, as the electricity grid expanded, a few of the unserved BPL households acquired a connection.

As was noted earlier, the presently installed generating capacity is insufficient to meet any substantial increase in electricity demand. Since the Cooperative does not generate a financial surplus to upgrade and expand the system's capacity, the power plant capacity and the grid can only be augmented through investments from the state or central governments. Of the 31 unserved households, more than $75 \%$ expressed a willingness to pay for an extension to the grid $^{202}$. Indeed, as the electricity grid expanded to Rangebelia village, and covered previously non-electrified padas of Gosaba, twelve of these surveyed households did in fact move out of the category of unserved low-capacity end-users. There are also households that are willing to pay for an electricity connection, but are not willing to pay for the grid to be extended. These

202 WBREDA guidelines indicate that the capital expenditure required for expansion will be of the order of Rs 15,000 - 16,000 per kilometre. Economic viability can be justified when there are at least 15-16 connections per electricity pole. The household connection cost was Rs 420 in 2001, including the cost of the meter and wiring from the nearest electricity pole to the consumer's meter. 
households feel it is the responsibility of the Cooperative, or the government, to make the electricity infrastructure available.

LPG access also shows some interesting patterns. As of the second survey, there were no BPL households using LPG, although some of these households buy energy carriers in the form of biomass for cooking. Given that BPL households find the cost of electricity and LPG a barrier, it is surprising to find some households actually buying biomass energy carriers, particularly since biomass is not in short supply on the island. More surprisingly perhaps, there were APL households that were not using LPG. Availability is no longer an issue since delivery from the mainland has improved and, therefore, other factors must play a role. Several other APL households use both LPG and biomass as cooking energy carriers.

Access to modern energy carriers is influenced by availability and affordability factors; and intra-household dynamics also play a crucial role in influencing access. A key element here is the linkage between gender roles and energy, and the influence of this linkage when it comes to decision-making over purchasing, or shifting to, modern energy carriers. While the primary data collected provides some understanding of these gender and energy dynamics, it is not sufficiently detailed, and therefore, the thesis draws on other research to explain the findings.

In Gosaba, the emergence of bhadralok, or the middle-income class, has initiated a transformation in gender roles and relationships. Irrespective of the societal changes that have taken place since Independence, the procurement of energy carriers, especially of fuelwood, is still primarily the responsibility of women. However, in those middle-income households where both LPG and biomass are used, it is mostly female domestic helpers who are involved in biomass collection and then use this biomass in cooking. When the woman of the house would have to collect the biomass, only LPG is used for cooking (see Box 5.3 and Box 5.4). Table 5.7 presents the survey data from Gosaba regarding access to modern energy carriers in terms of economic classification and women's employment status.

An analysis of the data shown in Table 5.7 shows that having a woman involved in incomegenerating activities and belonging to an above poverty line household is not a prerequisite for switching to modern energy carriers, at least when it comes to cooking. The 2001 household survey found that women were not involved in income-earning activities in twothirds of the 35 APL households where both electricity and LPG are used, and an analysis of the 2008 data shows that this proportion has increased to three-quarters. In these households, cultural norms assign men the role of providing for the family, and women of taking care of home. Further, the community does not look upon women participating in economic activities favourably. To make the transition to modern energy carriers requires a reliable and continuous source of income, a situation enjoyed by working women in APL households. However, BPL household incomes are low and vulnerable. For example, women involved in bagdha fish collection earn between Rs 10 and Rs15 for a hard day's labour and wading in the river for four to five hours. This level of earnings is often insufficient to meet a household's daily needs and makes it impossible to accumulate sufficient financial assets to enable a switch to modern energy carriers - both in terms of upfront and then operating costs. 
In Pursuit of a Light Bulb and a Smokeless Kitchen

Table 5. 7: Energy Access and Women in Income/Non-Income Earning Activities

2001 and 2008

\begin{tabular}{|c|c|c|c|c|c|}
\hline & \multirow[t]{2}{*}{ Total } & \multicolumn{3}{|c|}{ Underserved (63) } & \multirow[t]{2}{*}{ Unserved (31) } \\
\hline & & $\begin{array}{l}\text { Electricity and } \\
\text { LPG }\end{array}$ & $\begin{array}{l}\text { Only } \\
\text { Electricity }\end{array}$ & Only LPG & \\
\hline \multicolumn{6}{|c|}{ Women in income-earning activities } \\
\hline APL & 19 & 11 & 8 & - & - \\
\hline BPL & 35 & & 12 & - & $23\left(4^{* *}\right)$ \\
\hline \multicolumn{6}{|c|}{ Women in non-income-earning activities } \\
\hline APL & 34 & 24 & 4 & - & $6(6 * * \wedge)$ \\
\hline BPL & 6 & - & 4 & - & $2(2 * *)$ \\
\hline \multicolumn{6}{|c|}{$\begin{array}{l}\text { ** Unserved BPL households in } 2008 \text { that have acquired electricity } \\
* * \wedge \text { Unserved APL households in } 2008 \text { where both electricity and LPG are now used }\end{array}$} \\
\hline
\end{tabular}

In the BPL households surveyed in Gosaba, the use of modern energy carriers is restricted to electricity and to households where the woman is working in government service. In the other BPL households, where women work as domestic labour, as farm labourers, in bagdha fishing and in small businesses, the wages are low but, while insufficient to purchase LPG, are sufficient for purchasing biomass. As was observed earlier, an economic valuation of women's labour promotes the transition to purchased energy carriers.

Dutta (1997) believes that the decision-making over the adoption of modern energy carriers depends on intra-household power relationships and where the decision-making authority rests. Some elements of this situation are visible in Gosaba. A woman's involvement in income-earning activities does not mean that they can automatically spend the money on buying modern energy carriers; decisions on such purchases are not determined by contributions to household income but on joint prioritisation and household decisions. However, in practice, it is often men who have the final say, including about purchasing items that fit within the traditional spheres of women's influence such as the kitchen (Clancy et al., 2011).

\subsubsection{Contextual Influences Affecting Energy Access}

The analytical framework used in this dissertation (Section 2.5) considers that the availability of modern energy carriers alone is not sufficient to ensure access, and that a number of micro-level factors influence the level of household access to modern energy carriers. Four groups of micro-level factors, collectively known as contextual influences, were considered to affect access: infrastructure, economic, social and political factors. This section presents an analysis of the survey data to identify the effect of these contextual influences on access to modern energy carriers on Gosaba Island. How the interplay among contextual influences affects access to modern energy carriers in Gosaba is shown in Figure 5.1. 


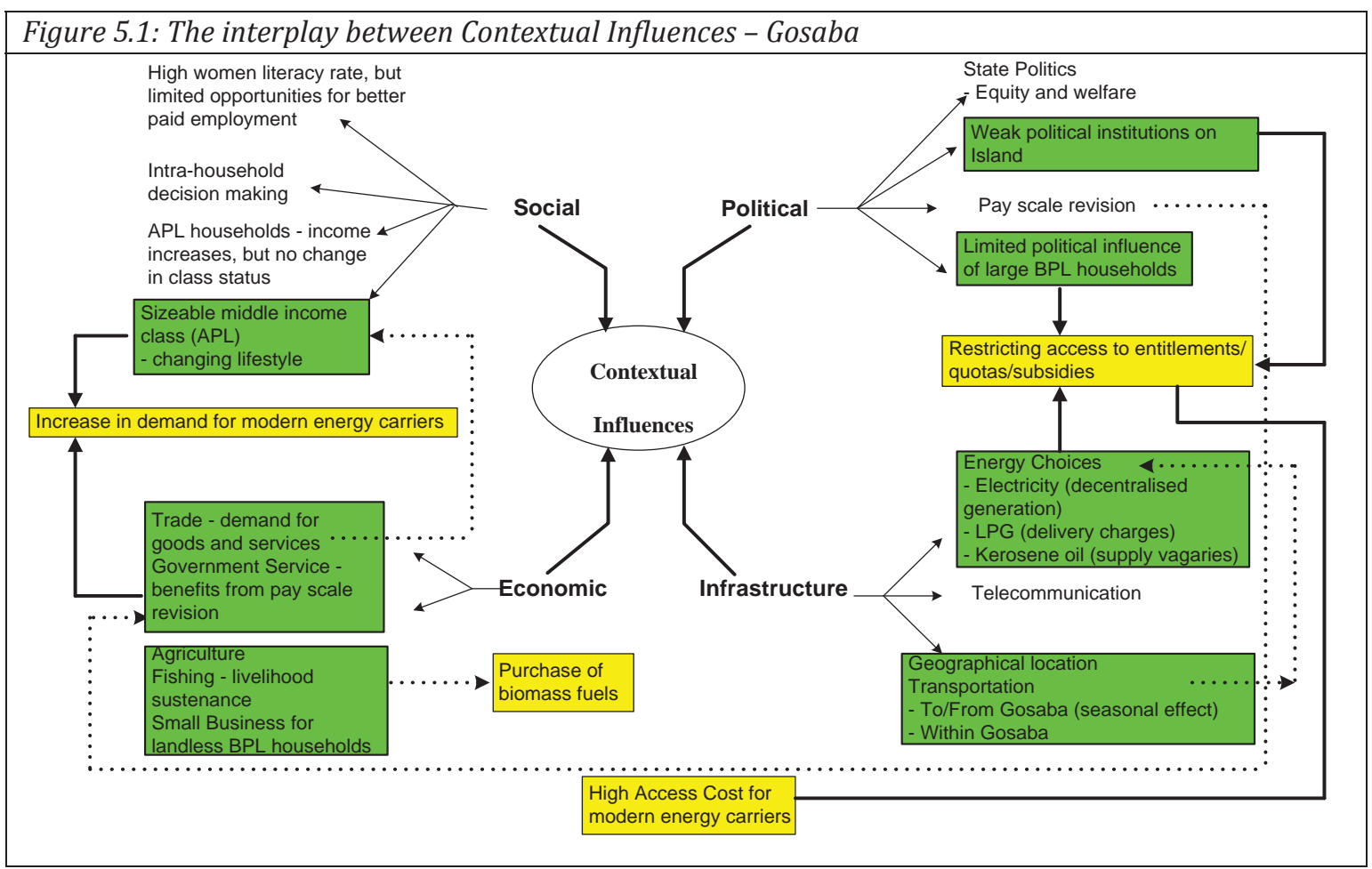

The availability of modern energy carriers in Gosaba improved between the two fieldwork periods. However, the availability is not universal across the island. Policies and programmes, including micro-level political influences, have been able to improve the availability, and to some extent access, but the gap between those who have access and those who do not remains significant. At the time of the first fieldwork period, households had just started adopting modern energy carriers. By 2008, during the second period of fieldwork, there had been further improvements in availability. The delivery pathways and organisations involved in the delivery of the energy carriers have remained largely unchanged, with the notable exception of LPG. The period between 2001 and 2008 has seen some upgrading of the facilities and certainly the telecommunications system has transformed the island's economy in terms of timely shipment of goods to market, reduced number of trips to urban centres (increasing income) and in the bringing of goods, including energy carriers, to the island (improving living standards).

The infrastructure has had a significant influence on access to modern energy carriers on Gosaba Island. It has had a direct effect on the availability as well as on the choice of delivery pathway. Given that the extension of the electricity grid to the island is not economically viable, decentralised energy carriers, through either a local decentralised grid or stand-alone systems, were the options for providing access to electricity.

In the case of the petroleum energy carriers, LPG and kerosene oil, transport remains by boat, which makes delivery dependent on the vagaries of the weather and the tides. Although LPG delivery through the boatman is quite reliable, there are intermittent delays in supply, and this 
has had some effect on household energy choices. The transportation infrastructure within the island is also weak, which again affects the availability and delivery of energy carriers. In the case of LPG, there is an additional cost for transportation and handling fees. The lack of a reliable transportation infrastructure also increases the cost of energy access for low-capacity end-users, especially with regard to kerosene oil.

There are three examples of decentralised/local energy delivery systems on Gosaba Island. The Electricity Cooperative and the PV retailers have enabled some households to access electricity. In the case of solar PV, the local retailers are providing backup and maintenance services close to the point-of-use, rather than users having to wait for a technician to come from the mainland. As a result of electricity access, there has been an improvement in the quality of light in households, and access to entertainment and business information. The informal delivery arrangement between LPG consumers and the distributor involves the services of a boatman for a small fee. Although this increases the cost for the consumers, this is compensated for by the reliable availability of LPG.

The presence of telecommunication facilities has also benefited households in terms of ensuring LPG availability. The shopkeepers in the market claimed they were enjoying improved business ${ }^{203}$ through having access to improved lighting in the evenings, allowing them to extend their hours. Further, the telephone (including mobile telephone) services have opened up new business opportunities for a few entrepreneurs and reduced transaction costs associated with commuting between Kolkata and Gosaba. Fishing households have also benefited because they can now find out what the daily fish prices are in Kolkata, and then decide whether to take their catch to market.

Gosaba Island provides a range of local economic opportunities that influence energy access. The decentralised energy generation only provides electricity in the evening hours when it is most needed. As a result, electricity availability is limited and the ability to participate in those economic activities where electricity can contribute to productive use and associated benefits is restricted to certain sections of the population who can time their activities to match the supply hours. Market traders benefit from having an electricity supply in the evening, but for other productive activities, such as agriculture and small-scale industries, this schedule is far from ideal. Further, the supply is single phase, and many industries (for example, small industries, oil expellers, hullers, etc.) require a three-phase supply. In addition, single-phase motors are less common and are more expensive than a similar size three-phase motor. Between the two survey periods, the oil expeller unit based in Gosaba

${ }^{203}$ There is no empirical evidence to substantiate the shopkeepers' claims. However, the visual observations by the author of the functioning of the Gosaba market in the evening hours showed an increased footfall of villagers coming to the markets and shops. The shopkeepers' observations of improved business due to improved lighting and the use of electricity for productive end-uses contradict the findings of Kooijman-van Dijk (2008), who observed that the availability of electricity made no difference to the shopkeepers of villages in the hill districts of West Bengal. A plausible reason for this difference is that the context and the role of the contextual influences are different in Gosaba. Further, the Gosaba market acts as a hub for several village markets on other islands and provides goods and services for these markets. 
market had bought a single-phase motor and acquired an electricity connection. However, such economic activities are limited. The improvement in electricity supply together with the diffusion of mobile telephone services in the region has rapidly improved communication facilities, and the provision of these services has emerged as a new economic activity. Despite these changes in economic activities, the situation is still inadequate (in terms of employment opportunities and remuneration) to enable people to escape the vicious circle of energy poverty.

\section{Box 5.1: Binoy Bhushan Jana - A Combination of Modern Energy Carriers}

Binoy Bhushan Jana's primary occupation is teaching at the Rangabelia High School. He also farms as an additional source of income. Binoy Bhushan Jana lives in a multi-storeyed house with his family of four in Gosaba. At the time of the first fieldwork, the family was using grid electricity for lighting, entertainment and pumping water to an overhead tank to meet the household's water needs. There was also a solar PV system to extend electricity access beyond the grid supply hours to meet lighting needs. Cooking was done on LPG. Binoy Bhushan Jana's arguments for using modern energy carriers were straightforward. He feels that he needs to provide adequate opportunities for his children to study in a better environment and therefore uses a combination of both grid electricity and solar PV. Use of LPG eases the pressure on his wife from using biomass fuel for cooking and the availability of electricity in the kitchen has added to the convenience. Both benefit. She has more time for watching television, and he gets his meals on time!

In 2008, Binoy's household continue to use a combination of modern energy carriers. The use of electricity has increased following the increase in supply hours to about 10-12 hours a day. The solar PV system is still in use, but mainly as a back-up option.

\section{Box 5.2: Ashwani Kumar Paul - Choice of LPG for Cooking}

Ashwani Kumar Paul and his wife are schoolteachers at the Government school in Gosaba. In this family of four, all the cooking in 2001 was done over LPG. A kerosene stove acted as a back-up when LPG was not available. The household obtained the LPG connection in 2000 from the Indane supplier in Canning. While they had always been aware of LPG as a cooking option, its non-availability was the main barrier for not using it earlier. Previously, they had used biomass fuel for cooking, which they purchased rather than gathered. Mrs Paul said that an additional benefit of using LPG over biomass was that, when she now goes to school in the morning after cooking for the family, her clothes do not smell of smoke.

By 2008, Mrs Paul had completely switched over to using LPG for cooking. The kerosene stove was abandoned in 2005. However, she felt that the cost of cooking on LPG had gone up, as their usage had increased to almost two cylinders per month. In 2008, the cost of a $14.2 \mathrm{~kg}$ refill cylinder was Rs 410 including transportation. She indicated that having got used to cooking on LPG that she was unlikely to shift back to other fuel options, even if there was a further increase in LPG prices. It will be more expensive, but the convenience outweighs the cost.

At the household level, in those houses where there is a steady source of income from either one or more occupations, households are able to use their growing economic status to access modern energy carriers. The stories of Binoy Bhushan Jana (Box 5.1) and Ashwani Kumar Paul (Box 5.2) are examples of such households who not only have the economic capabilities to use modern energy carriers, but have also spent additional amounts on acquiring either a solar PV system or a battery inverter to increase their access to energy services. 
Having a sufficient level of income also allows the purchase of multiple energy carriers to ensure continuity of energy service. This can be seen in Box 5.1, where the Binoy Bhushan Jana family has solar PV to provide back-up lighting, and in Box 5.2 where the family of Ashwani Kumar Paul has a back-up for cooking. The energy carrier choice is quite dynamic where multiple energy carriers are available, and households shift backwards and forwards depending upon the context in which the energy is to be used.

\section{Box 5.3: Mangali Biswas - Reducing Energy Poverty}

Mangali Biswas is a government service employee and the head of a BPL household. She acquired an electricity connection in 2000 to reduce household expenditure on kerosene oil. Mangali Biswas's monthly electricity bill in 2003 was Rs 80, reflecting the minimum supply offered by the Cooperative, and this was sufficient to meet the basic evening lighting needs of her family. Prior to this, the household would purchase about 15 litres of kerosene oil a month from both the PDS and the open market at a total cost of about Rs 200. With the electricity connection, she was able to restrict the purchase of kerosene oil to their PDS entitlement (Rs 36 per month), which was used for lighting in the early morning hours and late into the night after the supply from the Cooperative ended at $11 \mathrm{pm}$. Further, the availability of kerosene oil gave a sense of energy security and another option if grid electricity was not available.

As of 2008, reliance on kerosene oil had been further reduced in Mangali Biswas's house as the electricity supply hours had increased. While the household continues to procure its quota of kerosene oil from the PDS, it is now used not only for lighting but also for some cooking, so reducing their energy poverty.

\section{Box 5.4: Amiyon Mandal and Anita Shikari - Reasons for not using LPG}

Amiyon Mandal, living in Rangabelia village, is a farmer and agriculture is his family's livelihood. This APL household is a large joint family of seven members, owning more than 7.5 acres (3 hectares) of agricultural land. At the time of the first survey, the family did not have an LPG connection despite the daughter-in-law having used LPG for cooking before her marriage into the family and, according to Mrs Mandal in 2001, there being sufficient finances. Rather, it was the household's food requirements that acted as a barrier. Food was not only cooked for family members but also for the labourers working in the fields. The large utensils used were not suitable for an LPG stove. Therefore, it would not just a matter of changing fuel; a range of other changes would be needed in the kitchen that would also incur costs. They further estimated that, if they used LPG, they would need at least two cylinders every month, which they thought would make cooking expensive, an illustration of imperfect information acting as a barrier (Section 2.3).

However, in 2004, Amiyon Mandal's house acquired an LPG connection and now uses both biomass and LPG for cooking. LPG is used for cooking a few essential items and especially those that are cooked by Mrs Mandal. An LPG cylinder lasts them about four months. The rest of the cooking is done using biomass by the domestic help, whose responsibility extends to collecting the biomass.

Anita Shikari, in Kathakali village, lives in a household where the livelihoods are based on a small business and agriculture. In 2001, she was aware of the use and benefits of LPG as several of her relatives living outside of the island were using it. According to Anita Shikari, food cooked on LPG does not taste the same as when cooked on a biomass stove, and cooking with LPG was, she believed, associated with some negative health impacts (again an example of imperfect information, Section 2.3).

In Anita Shikari's house, this remained the situation in 2008. Biomass was the only fuel used for cooking. However, with a total monthly household income of Rs 3000, it would be very difficult for them to purchase a LPG connection for cooking purposes. Therefore, both the upfront as well as the recurring costs of LPG cylinders act as a barrier, alongside the social concerns, in this household. 
However, cost is not always a barrier since there are some BPL households that access the electricity grid (see Box 5.3) or that own solar PV home lighting systems. In the case of BPL households with electricity access, the occupation category does not seem to make a significant difference, with electricity access by BPL households on Gosaba Island found among all the occupational categories. The electricity is used for consumption purposes (lighting and entertainment) and for children's education (homework enabler). Where the grid is not available, some households use solar PV for lighting. These households mostly purchased their solar PV systems under the Indo-US project or through the state government programme. This programme lowered the costs of solar PV lighting systems and introduced the option of paying in monthly instalments, which was more feasible for BPL households. As such, a financing policy instrument helped in access.

Between these two extremes, there are other households who can afford modern energy carriers but do not have access because either the local grid is not available or other contextual (social and political) factors dominate. In households such as those of Amiyon Mandal (Box 5.4) the economic activities provide sufficient income to afford modern energy carriers, but contextual influences, the lack of electricity grid infrastructure and a large household size, restrict their ability to shift to modern energy carriers in 2001. Another economic factor that can influence access to modern energy carriers is the classification of APL and BPL households, and the application of this classification in providing entitlements and subsidies. APL households that are just above the poverty line have insufficient incomes to shift modern energy carriers and are excluded from subsidies.

Nevertheless, there are still economically weaker households that are unable to escape of energy poverty. These households are dependent on subsistence agriculture, small-scale fishing, and farm and non-farm labour ${ }^{204}$. Such households, such as those of Shanti Pal and Subhash Mandal (Box 5.6), derive insufficient surpluses from their economic activities to break out of a subsistence existence. A low disposable income restricts their choice in buying modern energy carriers, but some of these households are clearly desirous of modern energy carriers (Box 5.6, case story of Subhash Mandal) for improved lighting for household activities and for their children's education.

Social status and the fabric of rural society have an influence on access to energy carriers. Dandekar (1992) and Shah (2001) have shown how the dominant social groups in a village derive benefits from any government subsidies and how they are the first to benefit from any government programme, such as rural electrification. Examples of this phenomenon were present on Gosaba Island where the social status of the households influenced the decision on whether and where to extend the grid. A group of fishing households, who had gradually moved into the APL economic category, but were still members of a lower social caste, applied for an electricity connection in 1999. Despite these households being only approximately two kilometres from the end of the grid, their applications were rejected. The Cooperative declared that it had no budget for grid expansion, although these households

\footnotetext{
${ }^{204}$ These observations in Gosaba are consistent with the rationale used by Barnett (2000) in discussing the vicious cycle of energy poverty.
} 
could be accommodated if they were prepared to pay for the cost of the grid extension themselves. However, at the same time, the Cooperative extended the grid to provide electricity to the house of a doctor in Arampur (one kilometre from the existing grid). The doctor belongs to the upper class and has a high social status due to his profession. At the time of the first fieldwork, the doctor was however, not linked to the grid, feeling that his solar PV system was sufficient to meet his needs. The cost of extending the grid to provide electricity to that one household was approximately Rs 16,000. The Cooperative apparently used different decision-making criteria in extending the electricity grid depending on the social class/caste of the intended end-user. The failure of the fishermen to have the grid extended to their hamlet can, at least in part, be attributed to their weak social and political influence. One should note, however, that both the fishing households and the doctor had a grid connection by the time of the second fieldwork.

\section{Box 5.5: Sojit Das - Continuing with Biomass and LPG for Cooking}

In the household of Sojit Das, a businessperson with a jewellery shop in Gosaba market, a combination of both LPG and biomass fuels were used in 2001 for cooking. LPG was used for making a few smaller dishes or for food that has to be prepared quickly. As there were seven family members, cooking was mainly done using biomass. Both gathering the biomass from the family-owned land and badi (house) and cooking with it involved the family's domestic help.

In comparison to other APL households, where changes in their use of energy carriers for cooking could be found, the energy use pattern in Sojit Das's household remained unchanged in 2008. A combination of biomass and LPG is still used for cooking, and biomass is still the main fuel. The household continues to have easy access to biomass, which is collected by the hired help and then used by the domestic help for cooking.

Another important element in the social influence on energy access is the intra-household gender and energy linkages. Sen (2005) noted that gender is certainly a contributor to social inequality, but that it does not act independently of class. In households such as those of Ashwani Kumar Paul (Box 5.2), women's participation in income-earning activities did influence the decision to acquire LPG and electricity. In some households, the current levels of income are sufficient to generate a surplus that can be spent on activities, such as leisure, and goods that go beyond mere subsistence. In Binoy Bhushan Jana's household (Box 5.1), increasing the leisure time available to both men and women by using electricity and LPG was a valuable objective in itself. The contribution of women's income to the household purse helps to build any financial surplus. In the case of low-income households where women are engaged in income-generating activities, such as collecting prawn seeds as unskilled labourers, there is an increasing trend towards purchase a large portion of their biomass fuels, rather than gathering them for free. Two factors play a role here. Firstly, there is an increasingly limited area of common/public land with standing biomass from where fuelwood can be collected. Secondly, as Kelkar and Nathan (2005) have argued, this can be seen as both a timesaving strategy and a reflection of an increase in the opportunity cost of women's labour. Further, the cost differences between LPG and biomass are sufficiently large to make LPG an unattractive option. It makes greater economic sense for the household to purchase fuelwood, and thereby save women's time in its collection, if this allows them to 
participate in income-generating activities where the rate of return on these activities exceeds the cost of the biomass.

Household size appears to influence the choice of cooking energy carrier. If meals have to be prepared for a large number of people, the LPG stove, unlike the biomass stove, is not well adapted for cooking large quantities of food (see Box 5.4). Further, there are misconceptions about the use of LPG, for example over its safety and also health issues (for example, Anita Shikari (see Box 5.4) thought food cooked on LPG was not as nutritious as when cooked on biomass).

A household may have its own biomass supply and, if so, may prioritise other purchases over a modern energy carrier. The position of the person responsible for cooking in the household also influences the transition to LPG. In a household where cooking is done by the woman of the house, personal preferences, such as not wanting to smell of smoke, can be a factor in promoting the transition. However, if cooking is done by hired help, such issues are not considered important and transition is not a priority (see Box 5.5). The case story of Sojit Das also reflects the reality that many households use multiple sources of energy carriers, and continue to rely on low-cost energy carriers even if they could afford to change to higher quality energy carriers (Section 2.2).

Political influence was seen on two levels: in policy interventions and in local politics. The political foresight of the President of the Block Panchayat, elected in 1997, resulted in the setting up of the decentralised power plant in Gosaba. This decision was in line with central and state government policies, which provided funds to allow for the partial electrification of the island. The central and state governments' policies of identifying the island as suitable for decentralised energy power generation and then creating incentives were effective in creating choices and options for the local people. Gosaba Island has also benefited from the decision of the central government to broaden delivery pathways by allowing the parallel marketing of LPG. This decision not only resulted in the private sector setting up a dealership on the island, it also saw the introduction of private sector competition which encouraged the national oil and gas companies to allocate more LPG connections to rural areas. As a consequence, the public sector LPG dealers are now consolidating on Gosaba what the private sector LPG dealer started. Rural LPG distribution was launched in 2009, and is expected to further improve LPG availability on Gosaba. The price reforms, in particular the phasing out of subsidies on domestic LPG, have not so far been implemented due to a lack of political will. However, if the LPG prices are increased, it is possible that a backward fuel shift to biomass in households will occur.

The policy decisions by the state government in non-energy sectors have also played an indirect role in enabling access to modern energy carriers. For example, the implementation of the recommendations of the Fifth Pay-Scale Commission created a sizeable middle-income class with surplus income (an economic factor) and brought in lifestyle aspirations (a social factor) which contributed to an increased demand for modern energy carriers. However, local political institutions, such as the Panchayat, have not been very effective in ensuring social equity in terms of access to modern energy carriers. On Gosaba Island, despite the policies and programmes aimed at providing social equity in access to modern energy carriers, there 
is a small group of haves and a large group of have-nots. This is largely because the majority have little political influence while the upper class and upper castes dominate local-level political institutions, and use these to serve their own interests. For example, schemes such as Kutir Jyoti could easily be extended if the local political institutions, including the Panchayat, were motivated to lobby the state government for its extension to the island.

\section{Box 5.6: Shanti Pal and Subhash Mandal - Opposite Faces of Willingness to Pay}

Shanti Pal is a daily wage labourer and works in two households as a domestic help. In between these jobs, she is also involved in the collection of tiger prawn seeds. Her husband works as a contracted staff member on the ferry between Gosaba and Sojnakhali. In 2001, her husband's daily income varied between Rs 50 and Rs 60, and she earned Rs 75 from each household each month. On alternate days, they purchased Rs 5 of kerosene oil, and the balance of their household money was spent on food and other groceries. They bought kerosene oil from the open market and did not receive their PDS entitlement because they could not purchase kerosene oil when it was available on the allocated days as they did not have sufficient money to buy their share of entitlement. There was not enough left from their joint income to save up and meet the upfront costs, let alone the recurrent costs, associated modern energy carriers.

By 2008, Shanti Pal's son was also working as a wage labourer earning Rs 1000 per month. However, this additional income has not led to an energy transition, and kerosene oil and biomass remain the main energy sources for lighting and cooking. Shanti also felt that not only would it be economically difficult for them to purchase modern energy carriers, but that these were also not essential and not needed. They continue to buy kerosene oil from the open market, at Rs 30 per litre, because their problems with purchasing from the public distribution scheme have not gone away.

Subash Mandal is a landless labourer and part of a five-member family household. While Subash is mostly engaged in agricultural work, he also works part-time as a labourer on the market. His wife is involved in the collection of bagdha fish seedlings. Subash also collects the fish seedlings when he cannot get work on the market. In 2001, the household was not electrified. They used kerosene oil for lighting inside the house, and had a torch for outside the house. At the time of the first fieldwork, Subash had applied for a solar PV system under the 2001 state government scheme, which was targeted for BPL households to coincide with the state election. Subash was able to obtain biomass from the agricultural land where he worked as a labourer, but the availability was seasonal. At times, the family purchased sawdust and rice husks as a cooking fuel. A bag of sawdust or rice husk lasted for four days

In 2008, Subash still had no solar lighting system as the state government had not continued to implement the scheme after the assembly election. Subash's disappointment with the state government was visible although he tried to cover it up by claiming that 'kerosene oil for lighting is good'. The household also continues to purchase biomass fuels from the market.

Similarly, the local political institutions, as well as state government departments, have not been very effective in controlling corruption related to kerosene oil. An increase in the price of kerosene oil along with the failure of the PDS to provide a reliable supply of kerosene oil has had a significant impact on BPL households. They have been forced to purchase kerosene oil on the open market and at a higher price than from the PDS. The frequency at which unserved households purchase kerosene oil on the open market has increased for two reasons. Firstly, the available entitlement is not sufficient to meet their lighting needs. Secondly, these households, and especially the BPL ones, are often unable to purchase kerosene oil from the PDS/FPS on days when the oil is available because their cash flow is irregular. The 2001 survey found that 19 of the 31 unserved BPL households purchased kerosene oil more than once a week. On an evening in Gosaba market, it would be a common sight to see men 
walking into grocery stores with small bottles to purchase a fixed amount of money's worth of kerosene oil. The case story of Shanti Pal is a typical example of such households in Gosaba (See Box 5.6). Often the purchase would be in the range of Rs 3 to Rs 5, which would buy between $200 \mathrm{ml}$ and $400 \mathrm{ml}$ of kerosene oil. This equates to between Rs 15 and Rs 20 per litre, around double the subsidised price of Rs 9.50 per litre.

The impact of institutional failure is borne by the most vulnerable BPL households as they end up paying more for energy carriers than the policy intends. As such, subsidies are often not reaching the low-capacity end-users in Gosaba. This is somewhat ironic in the political context of Gosaba and West Bengal which, until 2009, had a Left Front government whose political philosophy is based on the principles of equity and safeguarding the welfare of the poor.

\subsubsection{Policy Design in relation to Implementation}

Our second main research question asks whether or not the energy policies are enabling lowcapacity end-users to access modern energy carriers. In this section, the focus is on understanding the linkages between policy and implementation in the context of Gosaba. The study of energy access in Gosaba has provided valuable insights into the relationship between policy design and implementation. The analysis of the policy design, in relation to implementation, draws on Boorsma's 3-C framework - characteristics, capabilities and culture - for each modern energy carrier. Using the lens of the 3-C framework provides an opportunity to identify elements of policy design, in relation to their implementation, that aim to improve access to modern energy carriers. In subsequent paragraphs, culture is reflected through the effect of social influences on access to modern energy carriers.

The characteristics of electricity supply in Gosaba are represented by the chosen delivery pathway: decentralised energy generation and distribution. In the absence of a grid infrastructure, the availability of electricity would depend on either the provision of standalone solar lighting systems or a local diesel genset, providing a few hours of lighting services to households. The decision at the state government level to establish a decentralised electricity generation and distribution system, under a cooperative management, reflected a transition from the past approach, of a government-owned system, to a public-private model. The primary reason for this transition was that it was considered a more effective way to improve access to electricity and to utilise local capacities to manage electricity distribution. In other words, the state government accepted the dominant economic discourse of the day that the private sector was a more effective deliverer of services. This delivery pathway, given the geographical context of a remote island, and the use of locally available renewable energy resources (biomass), as well as the choice of an electricity cooperative to manage local distribution, constitutes elements of a policy design that were both effective and applicable in the local context. In other words, the decision-making at the state government level recognised the realities on the ground and, on that basis, selected the best-suited option for rural electrification. In Section 2.3.3, drawing on the work of Bressers (2004), it was argued that, in translating policy design to implementation, policy instruments play a critical role in improving access to modern energy carriers. The characteristics of the policy instruments for electricity distribution in Gosaba- a non-subsidised electricity tariff, no free 
electricity and no ration/quota for certain social/economic population categories -provided an alternative mechanism for electricity distribution in rural areas.

However, at the same time and despite electricity being a regulated public good (Section 2.2), the analysis of the policy design and policy instruments shows that a large number of unserved low-capacity end-users on the island, and especially the poorest households, are unable to benefit. As such, the policy design and its implementation contravene the universal service obligation and minimum lifeline electricity to BPL households, as articulated in the Rural Electrification Policy 2006. This has resulted in poor implementation, with the adopted approach keeping electricity access limited to a few high income, high class/caste households. While the political priority given to electricity has enabled decentralised distributed generation, WBREDA's control over the Electricity Cooperative (both technical and commercial decisions) has restricted operations and local decision-making. The functions and powers of the Cooperative are thus curtailed, restricting its abilities to respond to the local circumstances of which it has good knowledge. While the Cooperative has increased the hours of electricity supply, it has been unable to meet the demands for improved services such as new connections and grid expansion. This would require financial support from the state government or from national programmes, such as RGGVY and RVEP, but the Cooperative is not allowed to approach them independently.

The delivery mechanism for solar PV lighting systems is through the state government providing a subsidy to reduce the upfront costs to low-capacity end-users. The delivery involves technology providers who have created local distributors for after sales service. However, the use of subsidy as a policy instrument constrains the diffusion as it limits the number of systems that can be supported. In other words, while the decision by the government to promote solar PV as an option to meet lighting needs is an effective policy design, the policy constrains implementation. Further, since the government provides subsidies, this is also prone to political influence and interference, especially to gain electoral benefits. Box 5.7 summarises the applicability and effectiveness of the policy design with respect to implementation in Gosaba.

The characteristic of the LPG delivery mechanism in Gosaba has seen transitions: from being public-owned, to both public and private sector involvement, and eventually back to the public sector alone. This transition, in the context of energy sector reforms, is quite significant as it brings out elements of the policy design. In Gosaba, in the absence of publicsector distribution, due to a lack of clear policy signals for the rural LPG market, a space was created for private sector participation. The policy design at the time of the first fieldwork period had created a parallel space for two different delivery mechanisms (public and private), with different characteristics and policy instruments. In the case of the public sector, since there was no dealer based on Gosaba, communities organised their own informal delivery system. The policies at that time were ambiguous and did not provide clear signals to the public sector LPG dealers to organise a distribution infrastructure in Gosaba, even though there was a demand. 
Box 5.7: Policy Design and Implementation in Gosaba

\begin{tabular}{|c|c|c|c|}
\hline \multirow{3}{*}{\multicolumn{2}{|c|}{$\begin{array}{l}\text { Policy Design } \\
\text { Decentralised } \\
\text { Electricity } \\
\text { Generation and } \\
\text { Distribution }\end{array}$}} & \multicolumn{2}{|r|}{ Policy Implementation } \\
\hline & & Applicability & Effectiveness \\
\hline & & $\begin{array}{l}\text { Decentralised electricity } \\
\text { generation, with local } \\
\text { distribution, is suitable and } \\
\text { adequate for the region based } \\
\text { on local knowledge in the } \\
\text { absence of grid electricity } \\
\text { and the high cost of grid } \\
\text { extension }\end{array}$ & $\begin{array}{l}\text { Availability limited to a few households; large } \\
\text { number of APL and BPL households without } \\
\text { electricity access } \\
\text { - Limitation in project design, unable to extend } \\
\text { electricity grid and connections beyond the } \\
\text { current load } \\
\text { Tariff higher than the rural tariff in rest of the } \\
\text { state; failure to comply with energy policies } \\
\text { effective since } 2006\end{array}$ \\
\hline \multicolumn{2}{|c|}{$\begin{array}{l}\text { Stand-alone } \\
\text { Solar PV }\end{array}$} & $\begin{array}{l}\text { Suitable for off-grid regions } \\
\text { to meet basic lighting energy } \\
\text { needs and as an approach for } \\
\text { pre-electrification }\end{array}$ & $\begin{array}{l}\text { Few households have access to solar PV; limited } \\
\text { due to subsidy involved } \\
\text { BPL households cannot afford as the unsubsidised } \\
\text { cost has to be paid upfront; no financial linkages } \\
\text { for unserved BPL families }\end{array}$ \\
\hline \multirow[t]{2}{*}{ LPG } & $\begin{array}{l}\text { Public } \\
\text { Sector }\end{array}$ & $\begin{array}{l}\text { Public-sector dealer at a } \\
\text { distance with no formal } \\
\text { system for delivery; forcing } \\
\text { users to develop informal } \\
\text { delivery mechanism } \\
\text { Distribution norms for public } \\
\text { sector dealers excluded rural } \\
\text { consumers although this was } \\
\text { changed in } 2006\end{array}$ & $\begin{array}{l}\text { - Availability has improved with an increase in the } \\
\text { number of LPG dealers } \\
\text { Access limited to APL households who can afford } \\
\text { the upfront and recurring costs (including } \\
\text { transportation); BPL households continue to use } \\
\text { biomass } \\
\text { - No scheme/provision for introducing small } \\
\text { capacity cylinders }\end{array}$ \\
\hline & $\begin{array}{l}\text { Private } \\
\text { Sector }\end{array}$ & $\begin{array}{l}\text { Able to cater for the latent } \\
\text { demand for LPG and } \\
\text { established a local dealer }\end{array}$ & $\begin{array}{l}\text { Improved availability; but could not continue due } \\
\text { to unfavourable change in overall policy } \\
\text { Cylinder refill cost higher than from the public } \\
\text { sector; so only a few APL households took a } \\
\text { connection }\end{array}$ \\
\hline \multicolumn{2}{|c|}{$\begin{array}{l}\text { PDS/FPS } \\
\text { Kerosene Oil }\end{array}$} & $\begin{array}{l}\text { FPS and norms (per capita } \\
\text { allocation and supply timing) } \\
\text { for kerosene oil did not } \\
\text { match household energy } \\
\text { needs }\end{array}$ & $\begin{array}{l}\text { Availability is a major constraint due to pilferage } \\
\text { along the supply chain } \\
\text { - Per capita norms violated and kerosene diverted to } \\
\text { the open market; inflexible distribution timing } \\
\text { - Subsidies effective for APL and BPL households; } \\
\text { but many BPL households unable to draw their } \\
\text { entitlements }\end{array}$ \\
\hline
\end{tabular}

As political priorities outweighed the policy decision to phase out subsidies in 2004, the level playing field between the public and private sectors became unbalanced. The rising global prices of petroleum fuels since 2003 has meant that the private sector has had to revise their prices, and the high prices for private LPG cylinders has affected the capabilities of rural households to continue using LPG. The political decision by the central government (even after a change in its political composition) to continue to provide subsidies eventually led to the private sector withdrawing from Gosaba. Hence, the public sector has again become the main service provider. This has been coupled with a new programme, launched in 2009, to improve LPG distribution in rural areas. 
Kerosene oil distribution on the island has a very different characteristic to LPG. The pricing of kerosene oil is highly sensitive politically. From the low-capacity end-users' perspective, the government's decision to provide subsidies and entitlements/quotas for households has enabled energy access. The problem lies in the implementation of these policy instruments. By selling kerosene oil through the PDS, with several intermediaries involved in its distribution, the policy design, and its implementation, has created opportunities for rent seeking. Another aspect of the delivery mechanism is the decisions taken over the timing of the selling of subsidised fuel, as well as users forfeiting their entitlements if they do not purchase at the time the fuel is supplied.

Therefore, while the policy instruments are designed to enable access, their implementation has constrained the capabilities of low-capacity end-users, as they are often unable to draw their entitlements. The inflexible and inconvenient mechanism for the delivery of kerosene oil (see Section 5.1.2) has had a significant impact on BPL households, who instead buy their fortnightly/monthly allocation from the market at a higher price. The analysis for Gosaba indicates that there are policies that are effective and applicable in improving energy access (decentralised electricity systems and private LPG) and also ones that are not (the failure to provide pro-poor programmes, such as electricity for BPL households, and to establish a level playing field for private LPG suppliers). At the same time, Gosaba provides examples of effective and applicable implementations (Electricity Cooperative) and others (the failure to halt the pilferage of kerosene oil) that constrain low-capacity end-users and result in them spending more money than they need on energy access.

\subsection{Bastar Case Study ${ }^{205}$}

The villages of Kudalgaon, Ghatlohanga and Tikhralohanga together form the case study area of Bastar. These villages are part of Bastar block in Bastar district of the state of Chattisgarh. The village of Kudalgaon is a Gram Panchayat. The villages of Ghatlohanga and Tikhralohanga form part of the Tikhralohanga Gram Panchayat. In these three villages and their hamlets, both groups of low-capacity end-user households (underserved and unserved) are present. Map 5.2 provides an overview of the locations of the village clusters in Bastar. Kudalgaon and Ghatlohanga are on the banks of the River Indravati, whiles Tikhralohanga is within its catchment area and has areas of forest that are managed by the village committee.

\footnotetext{
${ }^{205}$ Annex I provides a detailed profile of Bastar district covering its socioeconomic profile, regional livelihoods and development challenges in the district. The profile also describes an environmentdevelopment conflict and the local Naxalite conflict (AHKS, 2002;Bastar District Profile, 2002;Bhogal, 2000;Bhogal, 2001;Dandekar, 1994;Ganguly and Chaudhary, 2003;GoC, 2002;Guha, 2006;Human Rights Watch, 2008;Mukherjee and Shah, 2003;NABARD, 2001a;Patnaik and Mehrotra, 2010;Planning Commission, 2008;PwC, 2002;Ramesh, 2010;Ramnath, 2003;Sundar, 1997;Sundar, 2001; Sundar, 2006). 


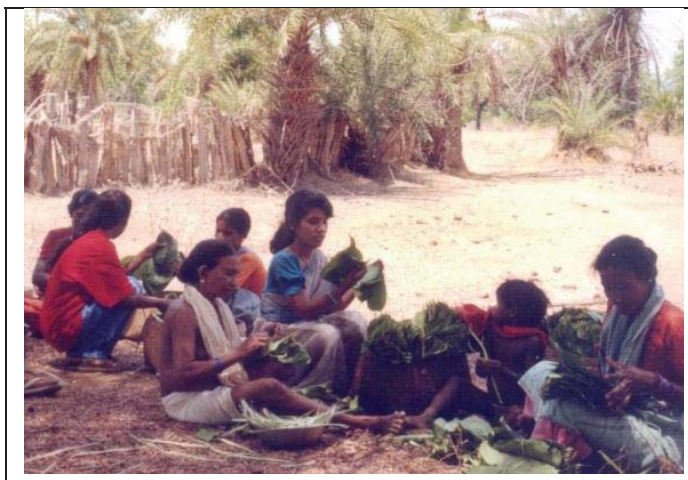

Minor Forest Product (tendu leaves) collection and selling is a source of livelihood

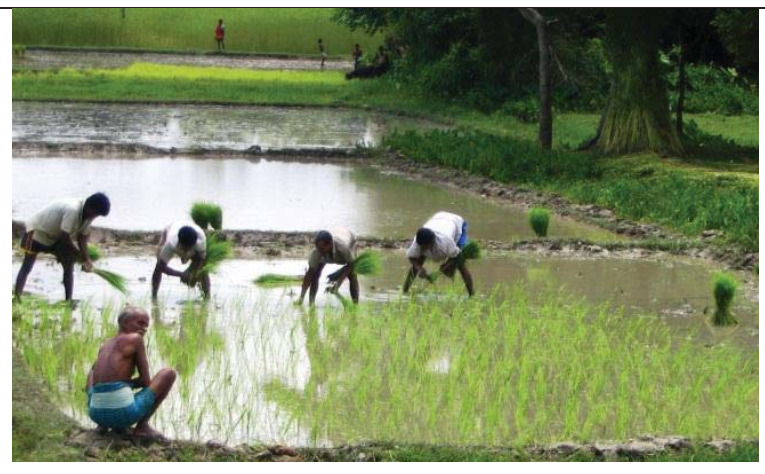

Bastar has a high potential for agriculture development - farmers and labourers sowing paddy

The village of Kudalgaon has three hamlets (padas) including the main village, which is 12 kilometres from Jagdalpur (the district headquarter) and 20 kilometres from Bastar (the block headquarter). The Kudalgaon GP office is located in the main village. The main Kudalgaon village also has a Fair Price Shop (FPS) managed by Large Area Multi-Purpose Cooperative Societies (LAMPS) under Public Distribution Systems (PDS), an Anganwadi school, a primary school and a health centre. Since the village is on the National Highway, there are also a few shops along the main road including general merchant, a tailor, tobacco outlets and dhabas, catering to both villagers as well as others. The other two village padas are shown as K1 and K2 on the map. Pada K2 lies on the other side of the national highway, and is not electrified as there is no grid line in the near vicinity. The main village of Kudalgaon and pada K1 both have a mix of underserved and unserved households.

Ghatlohanga and Tikhralohanga villages are part of the Tikhralohanga Gram Panchayat. Ghatlohanga and Tikhralohanga villages each have two padas, including the main village. At the time of the first fieldwork, there was no FPS operating under LAMPS/PDS in Ghatlohanga $^{206}$ and village households utilised the services of the LAMPS/PDS dealer based in Tikhralohanga or the main LAMPS/PDS office in Bastar. The latter is 15 kilometre from the main village and could be reached by road using one's own transport, cycle rickshaws or shared jeeps. The main Ghatlohanga village with 96 households has both underserved and unserved low-capacity end-users. Pada G1, shown on Map 5.2, houses 75 Scheduled Caste (SC) and Scheduled Tribe (ST) families. This pada, contains a high school with a students' hostel, and this has had grid electricity since 2000. The grid was extended from the main Ghatlohanga village, which got electricity towards end of 1980s. Five households lying between the main village and the school also acquired an electricity connection under the KJ programme between 1999 and 2000. These were the only five households in pada G1 electrified at the time of the first period of fieldwork and in 2009, at the time of the second fieldwork phase, the level of electricity access had not changed. These households do not

206 The FPS dealer was suspended in 2001, since the Large Area Multi Purpose Cooperative Societies (LAMPS)/PDS felt that there were some irregularities in the allocation of food grains in Ghatlohanga and not with kerosene oil. A new dealer was appointed under the Gram Panchayat and the FPS is operational since 2004 and at the time of the second fieldwork, this new dealer was functional. 
own agricultural land and depend on farm and non-farm labour for their livelihoods. Between 1985 and 1990, the state government provided them with land to build houses under the Indira Awas Yojana (IAY) ${ }^{207}$. Pada G1 is located along the main national highway and this opens up income-generating opportunities, and ten households ${ }^{208}$ have set up shops providing services including tailoring, dhabas and general provisions. The pada also includes a rice/flour mill, which does get electricity from the main Ghatlohanga village, but none of the shops along the national highway has electricity.

The adjoining village of Tikhralohanga hosts the Gram Panchayat office covering both Ghatlohanga and Tikhralohanga villages. The village is 15 kilometres from Bastar, and nearly three kilometres of the linking road are un-metalled. The village consists of has two padas, including the main village. The main village has a primary school, a LAMPS/FPS and a general shop. Tikhralohanga village consists of 75 households that are a mix of underserved (48 households) and unserved (27 households) but none at the time of the first fieldwork had an LPG connection. The other pada (identified as T1on the map), is about two kilometres from the main village, and has 30 households, all of which are unserved by modern energy carriers. The pada was still non-electrified as of 2009.

\subsubsection{Energy Availability in Bastar: Delivery Pathways}

The delivery pathways - the organisations and policy instruments that ensure the availability of and access to energy carriers in Bastar - involve a combination of public and private initiative (see Table 5.8 for an overview of the organisations involved).

Table 5.8 shows that state government agencies and departments are involved in the delivery of all modern energy carriers: electricity, renewable energy technologies/systems, LPG, kerosene oil and biomass are all supplied through various governmental organisations. At the time of the first fieldwork, in 2002, private sector companies were also involved in the delivery of LPG but they ceased their operations in 2006 (see the sub-section below on LPG). Some households in all three case-study villages use modern energy carriers in the form of electricity and LPG although the use of the latter is particularly limited. Despite the availability of modern energy carriers, household energy consumption in the case-study villages is dominated by biomass fuel. The reasons for these patterns of energy carrier use are explained in the next section.

Not all the households have access to electricity. Some are located in non-electrified padas, a consequence of these padas only being established as formal settlements post-electrification of the village. The distances of these padas from the existing grid are considered by the state electricity board (SEB) to make grid extension economically non-viable unless subsidised by

\footnotetext{
${ }^{207}$ The Indira Awas Yojana (IAY) scheme was funded by the central government to provide housing for the landless and for below poverty line (BPL) households.

${ }^{208}$ In Ghatlohanga, the houses along the national highway were expected to be relocated closer to the village due to the widening of the road. However, such plans have been thwarted by constant resistance from the occupants since they see less potential for business if moved away from the road. In Kudalgaon, households will not be affected since these are located further from the national highway and only shops and dhabas need to be relocated. 
the government. Under the Rajiv Gandhi Grameen Vidyutikaran Yojana (RGGVY), projects have been sanctioned for electrification of un-electrified padas and households but, as of 2009, these projects had yet to be implemented.

Table 5.8: Delivery Pathway and Policy Instruments (2001-02 and 2008-09)

\begin{tabular}{|c|c|c|c|c|c|c|c|}
\hline \multicolumn{8}{|c|}{ Delivery Pathway } \\
\hline \multirow{6}{*}{ 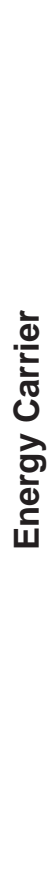 } & \multicolumn{3}{|c|}{ 2001-02 } & \multicolumn{2}{|c|}{ 2008-09 } & & \\
\hline & $\begin{array}{l}\text { Grid } \\
\text { Electricity }\end{array}$ & \multicolumn{2}{|c|}{$\begin{array}{l}\text { Chattisgarh State } \\
\text { Electricity Board }\end{array}$} & \multicolumn{2}{|c|}{$\begin{array}{l}\text { Chattisgarh State } \\
\text { Electricity Board }\end{array}$} & $\begin{array}{l}\text { No separate } \\
\text { programme or policy } \\
\text { instruments/ RGGVY } \\
\text { projects identified, but } \\
\text { not implemented }\end{array}$ & 을 \\
\hline & Solar PV & \multicolumn{2}{|c|}{$\begin{array}{l}\text { Chattisgarh Renewable } \\
\text { Energy Development } \\
\text { Agency }\end{array}$} & \multicolumn{2}{|c|}{$\begin{array}{l}\text { Chattisgarh Renewable } \\
\text { Energy Development } \\
\text { Agency }\end{array}$} & $\begin{array}{l}\text { No separate } \\
\text { programme or } \\
\text { additional subsidy }\end{array}$ & $\frac{\overline{0}}{0}$ \\
\hline & LPG & $\begin{array}{l}\text { Indane/ } \\
\text { Bharat/ } \\
\text { HP Gas }\end{array}$ & $\begin{array}{l}\text { Hind Gas/ } \\
\text { Chattisgarh } \\
\text { Gas }\end{array}$ & \multicolumn{2}{|c|}{ Indane/Bharat/HP Gas } & $\begin{array}{l}\text { No separate } \\
\text { programme or policy } \\
\text { instrument }\end{array}$ & $\begin{array}{l}\frac{2}{3} \\
\stackrel{\mathbb{D}}{\mathrm{B}} \\
\overrightarrow{0}\end{array}$ \\
\hline & $\begin{array}{l}\text { Kerosene } \\
\text { Oil }\end{array}$ & \multicolumn{2}{|c|}{$\begin{array}{l}\text { LAMPS/Public } \\
\text { Distribution System } \\
\text { (PDS) }\end{array}$} & \multicolumn{2}{|c|}{$\begin{array}{l}\text { Public Distribution } \\
\text { System (PDS) }\end{array}$} & $\begin{array}{l}\text { No additional } \\
\text { entitlement or subsidy }\end{array}$ & $\underset{\Gamma}{0}$ \\
\hline & Biomass & $\begin{array}{l}\text { Forest } \\
\text { Departme } \\
\text { nt/Commu } \\
\text { nity Forest }\end{array}$ & $\begin{array}{l}\text { Private } \\
\text { Collection }\end{array}$ & \multicolumn{2}{|l|}{$\begin{array}{l}\text { Forest } \\
\text { Departme } \\
\text { nt/Commu } \\
\text { nity Forest }\end{array}$} & & \\
\hline & & \multicolumn{2}{|c|}{$\begin{array}{l}\text { Government/ Public } \\
\text { Sector }\end{array}$} & \multicolumn{3}{|c|}{ Private Sector } & \\
\hline
\end{tabular}

\section{Electricity}

The Chhattisgarh State Electricity Board (CSEB) ${ }^{209}$ manages electricity distribution in the case-study villages. The CSEB uses an administrative unit known as an Electricity Circle. ${ }^{210}$ Each Circle is responsible for electricity distribution, and for electricity bill preparation and distribution. It also functions as a revenue collection centre, where consumers pay their electricity bills. The Electricity Circle also manages consumer grievances within its area of

${ }^{209}$ As per the provisions of the Electricity Act 2003, the state government restructured its power sector in 2009. The Chhattisgarh State Power Distribution Company Limited (CSPDCL) has managed electricity distribution since 2009. However, this dissertation refers to the Chattisgarh State Electricity Board (CSEB) as this was responsible for distribution at the time of both fieldwork periods in 2002 and 2009.

${ }^{210}$ An Electricity Circle is the lowest administrative unit in the hierarchy of an SEB. It has technical staff and linesmen, plus administrative staff for billing and revenue collection. The geographical coverage of an electricity circle varies and is linked to the number of electricity consumers. The Bastar Electricity Circle covers all the consumers in Bastar block. 


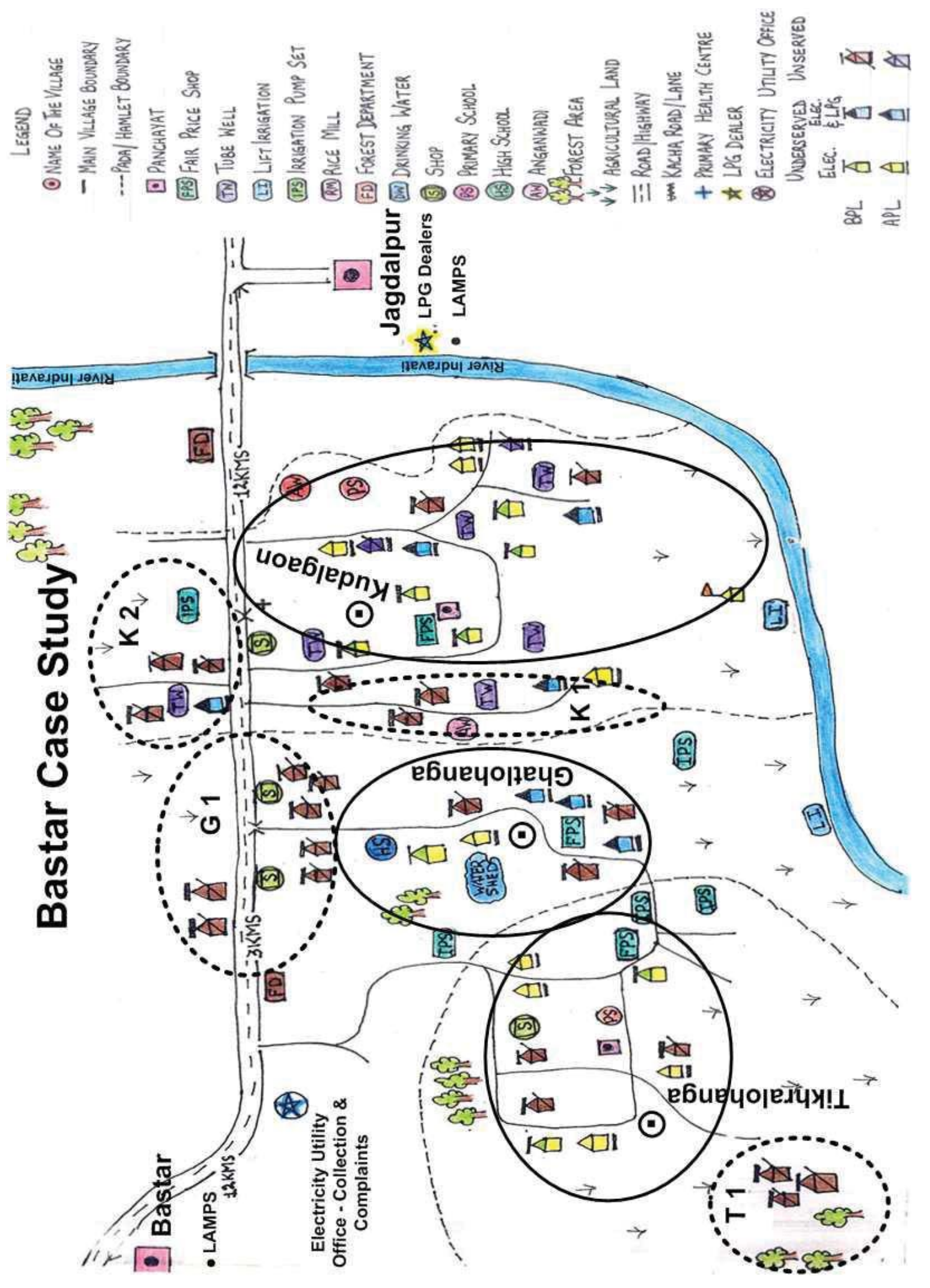

Map 5.2: Map of Bastar Case Study Villages 
operation. The case study villages all fall under the Bastar Electricity Circle. Table 5.9 summarises the phases and functions of electricity distribution carried out by the CSEB in Bastar.

Table 5.9: Phases and Functions of Electricity Distribution

\begin{tabular}{|c|c|c|c|c|}
\hline \multirow{5}{*}{ 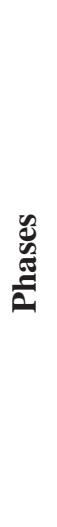 } & & \multicolumn{3}{|c|}{$\begin{array}{l}\text { Functions } \\
\end{array}$} \\
\hline & Production & $\begin{array}{l}\text { Strategic } \\
\text { Management }\end{array}$ & Daily Management & Financing \\
\hline & $\begin{array}{l}\text { Generation } \\
\text { and } \\
\text { Transmission }\end{array}$ & CSEB & CSEB & $\begin{array}{l}\text { Public Budget - central and state } \\
\text { government support for electricity } \\
\text { generation }\end{array}$ \\
\hline & Distribution & CSEB & $\begin{array}{l}\text { CSEB (Bastar } \\
\text { Electricity Division and } \\
\text { Circle) }\end{array}$ & $\begin{array}{l}\text { Public Budget - state government } \\
\text { budget for transmission and } \\
\text { distribution }\end{array}$ \\
\hline & Sale & CSEB & $\begin{array}{l}\text { CSEB (Bastar } \\
\text { Electricity Circle) }\end{array}$ & $\begin{array}{l}\text { Public Budget - state government } \\
\text { subsidies under rural electrification } \\
\text { programme }\end{array}$ \\
\hline
\end{tabular}

Chhattisgarh was only created as a new state in 1999 and, since then, the CSEB has focussed on the electrification of non-electrified padas in electrified villages. Despite this, progress with pada electrification has been very slow ${ }^{211}$ for the following the reasons:

i. Planning procedures and institutional mechanisms: once the grid reaches a village, the target of village electrification is considered to have been achieved. There is no requirement for the utility to promote access for households;

ii. Financial: electricity utilities have limited budgets and intensive electrification depends on funds being available; and

iii. Political environment: even when projects are planned and financial resources are available, contractors and other implementing agencies are not willing to take the risk of commissioning such projects if the political environment is not seen as conducive.

Village electrification in the rural areas of Bastar started after 1980, and coincided with the peak period for village electrification in India (see Chapter 4, Section 4.4.1 and Figure 4.3). However, the figure often quoted, of the number of villages electrified, does not provide the real picture of electricity access at the household level. Data available at the Gram Panchayat offices do not reveal the number of village households electrified. Information from district statistics suggests that $90 \%$ of the 90,839 connected electricity consumers in Bastar district are households. This total includes both metered domestic consumers and Kutir Jyoti (KJ) consumers. Of the 82,000 connected households, 56\% are KJ consumers who, at the time of the first fieldwork, had access to a single light point (one $40 \mathrm{~W}$ connection) and were paying a flat-rate Rs 300 a year. The remaining $44 \%$ are metered domestic/household consumers.

${ }^{211}$ Between 1999 and March 2002, only one-third (1288 padas) of the 3843 padas were electrified (CSEB, 2002). 
The CSEB's average electricity tariff for metered household consumers was Rs $1.56 / \mathrm{kWh}$, and the CSEB was therefore cross-subsidising (based on the combined cost of generation and distribution) these consumers by Rs 1.41/kWh. By the time of the second field survey, the CSEB had been asked by the state government to ensure a regular supply to all naxaliteaffected districts, including Bastar. For KJ consumers, the CSEB increased the number of lighting points to three (with a $120 \mathrm{~W}$ connection) but they were now only entitled to $30 \mathrm{kWh}$ of free electricity per month. For any excess electricity consumption, such households had to pay the regular domestic tariff which by this time varied from Rs 1.80 - Rs 2.00 per kWh.

At the time of the first fieldwork, none of the non-electrified padas in the case-study villages had been included in the electrification plan of the CSEB. According to the CSEB, pada electrification was a low priority as the non-electrified padas were unlikely to provide good returns on the capital investment given that their main demand was for lighting. The Chief Executive Officer of the Bastar Zilla (district) Panchayat said, 'What is left is pada electrification and electrification of all the households in the villages. The Janpad (block) and Zilla have no plans to undertake this. The electrification of padas and households is done slowly with the funds available under the Member of Legislative Assembly Local Area Development (MLA LAD) or the Member of Parliament Local Area Development (MP LAD) schemes, or funds coming under some other central or state government sanctioned scheme for rural electrification"212. Nevertheless, by 2009, electrification plans for all the non-electrified villages, padas and households in electrified villages had been prepared and included for intensive electrification under the RGGVY ${ }^{213}$.

Although the KJ connections are unmetered, CSEB monitoring had shown that some of the households had illegally added extra light points and other electrical appliances resulting in electricity consumption over and above $30 \mathrm{kWh}$ per month. Any unauthorised expansion leads to commercial losses for the CSEB (as these are not paid for by consumers) and makes the system unreliable for legal users. Electricity is not used extensively for agriculture, and only $1.5 \%$ of the connected consumers are farmers. This is extremely low compared to the national average, where 30\% consumers are farmers (Shah et al., 2003). In the survey area, the agricultural connections, along with industrial consumers, are concentrated in the Jagdalpur Block. In the case-study villages, only a few farmers have installed pump sets for irrigation.

For the regular domestic connections in Bastar, the consumers receive a monthly electricity bill based on their average annual consumption, and every quarter an electricity bill based on actual consumption. The consumers have a choice whether to pay their bills monthly ${ }^{214}$ or quarterly. If a consumer opts to pay at the end of each quarter, then they pay a penalty of Rs 5 for each unpaid bill. Households indicated that this kind of billing system enabled them to pay their monthly electricity bills on a regular basis, a claim supported by the Electricity

\footnotetext{
${ }^{212}$ Interview with Chief Executive Officer of Bastar Zilla Panchayat on 17 April 2002.

${ }^{213}$ Interview with Executive Engineer, Jagdalpur on 18 December 2008 and Chief Executive Officer of Bastar Zilla Panchayat on 19 December 2008.

${ }^{214}$ The average monthly electricity bill for the surveyed households was found to be in the range of Rs 65Rs 75. 
Circle in Bastar achieving a collection efficiency of more than 95\%. Following the revision of the electricity tariff in the state, the typical monthly bill is between Rs 115 and Rs 125 per month. The CSEB through the Electricity Circle has also started monthly billing so that it is easier for consumers with a low disposable income to pay their electricity bills on time.

Consumers in the case-study villages indicated that the electricity supply had improved in terms of quality (stable voltage) and reliability (fewer black outs) since 2000 (at the time of the first survey) and further since 2006 (reported in the second survey). According to information available from the CSEB, electricity blackouts were typically in the range of 2-3 hours per day, and the frequency of power cuts was higher during the monsoon months because of distribution lines failing. Since 2006, the state government has asked the CSEB to ensure a regular electricity supply to the district, as a step towards building the confidence of local communities as well as from a security perspective as it falls within a Naxal-affected region.

\section{$L P G$}

LPG distribution in Bastar district is organised by dealers of the public sector oil and gas companies and by private sector dealers. The three public sector oil and gas companies Indane, HP Gas and Bharat Gas - all have dealers based in Jagdalpur. At the time of the first fieldwork, two private LPG dealers - Hind Gas and Chattisgarh Gas - were active in the district and supplied LPG from Jagdalpur. The public sector oil and gas companies' dealers had also identified 'contacts' in Kondagaon - a general store and a cloth merchant. The delivery trucks of the public sector oil and gas companies left cylinders at these contact locations, basing quantities on the number of consumers. The presence of such contacts demonstrates that there is a market for LPG. However, the lack of a well organised distribution infrastructure acts as a barrier in promoting the wider adoption of LPG in rural areas. As a consequence, the private sector dealers focussed on villages that close to Jagdalpur. Table 5.10, summarises the phases and functions in the distribution of LPG and kerosene oil in Bastar.

During the two fieldwork periods (2002 and 2009), the use of LPG as a cooking fuel in rural households was mainly to be found in the villages around the two urban settlements of Jagdalpur and Kondagaon. Since 2000, there has been an increase ${ }^{215}$ in the use of LPG. Public sector oil and gas companies provide a $14.2 \mathrm{~kg}$ cylinder, which had cost Rs 272 in 2002 and this had risen to Rs 385 in 2009. The public sector companies provide two options for consumers: a single cylinder connection or a double cylinder connection. Rural households can choose which type of connection to have. If they opt for a single cylinder connection, the connection cost is Rs 1800, including a security deposit for the cylinder regulator, and a double cylinder connection costs Rs 2800. The initial connection cost was not subsidised by the government.

\footnotetext{
${ }^{215}$ There is no available secondary data that shows the number of new connections. The estimate is based on discussions with LPG dealers in Jagdalpur, who indicated that, since 2000, the number of people coming from nearby villages for an LPG connection had increased. The LPG dealers did not have separate lists for rural and urban consumers.
} 
Private sector dealers, on the other hand, only offered a single cylinder connection. Further, the cylinder capacity also varied according to the supplier. The connection cost from the private sector dealer in the case study villages was Rs 3000. At the time of the first fieldwork, Chhattisgarh Gas provided an 11 kg cylinder costing Rs 275, and Hind Gas marketed a 15 kg cylinder for Rs 325. In both cases, there were no subsidies. In 2006, when these private suppliers ceased their operations, the cost had risen to Rs 600 for a $15 \mathrm{~kg}$ cylinder. In the rural areas, at the time of the first fieldwork in 2002, neither the public nor the private sector dealers offered cylinder delivery ${ }^{216}$ to rural households. Households had to use either cycle rickshaws or their own mode of transportation (usually a motorbike or scooter) for ferrying cylinders from the dealers. Since many roads are un-metalled, getting LPG cylinders becomes difficult in the monsoon period. In 2008, the situation had not changed.

In the case study villages, most LPG connections prior to 1999 were supplied by the public sector dealer. At that time there was a considerable waiting of up to five years for a public sector connection and so households that wanted LPG connections went to the private sector dealers after they entered the market in 1999. Nevertheless, households would still prefer a PSU connection since their cylinder is cheaper than the private sector one due to government subsidies. However, the private sector dealers did also provide incentives, such as deferred payments for installation costs, discounts on instalments, and promotional offers, such as free household goods and kitchenware.

However, once the government phased out the parallel marketing scheme but continued to provide subsidies for domestic consumers, the private sector no longer found it competitive and withdrew from the domestic LPG market. Many consumers felt the impact of the private sector withdrawal, as they had to then apply for an LPG connection from the public sector gas companies, requiring a second upfront payment.

\section{Kerosene oil}

In Bastar, kerosene oil is supplied under the Public Distribution Systems (Table 5.10). The Public Distribution Systems (PDS) operate through a network of the Large Area MultiPurpose Cooperative Societies (LAMPS)/ration shops supervised by community institutions such as Gram Panchayats. The LAMPS were set up by the state government of Madhya Pradesh under its Societies Act ${ }^{217}$. The LAMPS are local organisations that provide a range of services for agriculture including the supply of seeds, fertilizers, and other inputs; credit and banking services. They also help the government in distributing food and non-food commodities under the PDS. The LAMPS/PDS are located in block headquarters and in

\footnotetext{
${ }^{216}$ Public sector dealers were constrained by a norm established by MoPNG, which stipulated that they could provide new LPG connection to consumers within a $30 \mathrm{~km}$ radius of the dealer.

${ }^{217}$ In 2001, the state government privatised the PDS, by issuing licences to private dealers. In 2004, the state government, reversed its earlier order and entrusted the ration shops under PDS to community institutions such as Gram Panchayats, Self-Help Group and Van Suraksha Samitis. 
Table 5.10: Phases and Functions of LPG and Kerosene Distribution

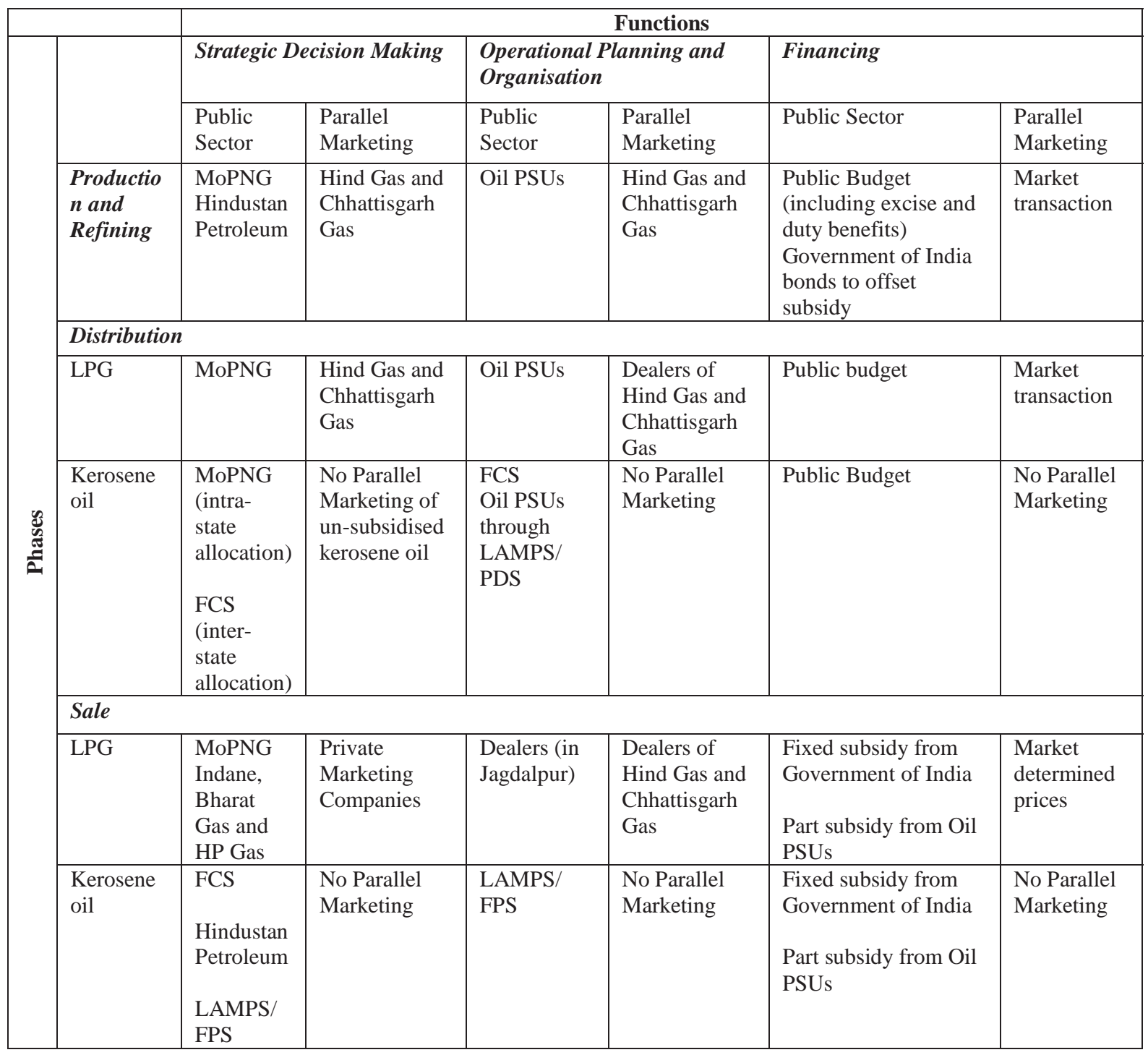

villages that are well connected by the state or national highway. Depending upon the number of villages and ration cards, the LAMPS/PDS will each have three or four village-level Fair Price Shops (FPS) or ration shops dealers who sell subsidised food grains and kerosene oil. Village FPS dealers only operate for two days each fortnight, and these days are not fixed but are announced by posting them on the FPS notice board, as well as at the office of the Gram Panchayat. In order to maintain transparency, the village FPS also display the quantity of each commodity in stock, as well as their prices. The FPS dealers in Ghatlohanga and Tikhralohanga both complied with these procedures.

In the villages, all households are provided with ration cards, the category being based on whether the household's economic classification is APL or BPL. However, irrespective of their economic classification, a household possessing a ration card is entitled to five litres of 
kerosene oil at the subsidised price of Rs 9 per litre every month ${ }^{218}$. The kerosene oil entitlement (5 litres per month per ration-card holder) has remained unchanged over the two fieldwork periods (2002 and 2009). Ration-card holders can claim the allotted quantity either in a single transaction or in smaller quantities over a one-month period from the FPS outlet. Alternatively, households can purchase their allotted quota directly from their LAMPS/PDS office (in Bastar for Tikhralohanga and Ghatlohanga, and in Jagdalpur for Kudalgaon.

In Bastar, all the 89 households surveyed in the three case study villages bought kerosene oil from the LAMPS-operated FPS in 2002. A few APL and BPL households (fewer than $20 \%$ of those surveyed) also bought additional kerosene oil from the open market at higher prices either weekly or monthly. Five of the underserved and seven of the unserved households indicated that they purchased kerosene oil on a weekly basis from the open market, usually to meet immediate needs when the LAMPS/FPS were closed ${ }^{219}$. Some households indicated that there are times when they were not able to buy kerosene oil from the LAMPS/FPS for want of cash, and times when they forget to take their ration card. Twenty-five households bought from the LAMPS/FPS outlets on a fortnightly basis and 59 on a monthly basis. Of the latter, 47 are electrified households and use kerosene oil as a backup. By directly purchasing from the FPS in the village, the households avoid the transaction costs of buying from the LAMPS.

It was interesting to find that, in 2009 during the second fieldwork period, that the purchasing pattern for kerosene oil in the surveyed households had not changed. Due to the ongoing conflicts in the area, there are sometimes delays in availability but these delays have not had a significant impact on purchasing kerosene oil in the studied villages. Another factor that has seen a fall in the demand for kerosene oil was the decision by the state government to provide an uninterrupted electricity supply to villages in naxal-affected districts.

\section{Biomass Fuels}

Fuelwood and other forms of biomass are the main energy carriers used by the households in all three villages. More than $97 \%$ of the households use biomass fuels for cooking.

Households use two types of biomass fuels: fuelwood collected from forest areas, and a shrub (besharam) which grows wild along the roadside. In the case-study villages, neither crop residues or animal dung are used as a fuel. Crop residues are left standing in the field and animal dung is used as manure.

Biomass energy carriers are usually gathered by women. In the case-study villages, more than $85 \%$ of the households gather it from the forest. More than half of the surveyed households travel less than two kilometres to collect fuelwood. This way of collecting fuel started in 1990 and is still followed. Earlier, there was a system called "Koop" introduced by the forest department in which each household was given the right to harvest trees identified by the

\footnotetext{
${ }^{218}$ Under the PDS, entitlements and the prices of commodities differ only in the case of food grains where APL households have less subsidy than BPL households. For example, an APL household can buy rice at Rs 9 per kg, whereas BPL households pay only Rs 6 per kg. However, the entitlement and subsidies for kerosene oil for APL and BPL households is same.

${ }^{219}$ The LAMPS/PDS are open Monday to Saturday between 10 a.m. and 5:30 p.m. The FPS, which operates two days in each fortnight, also opens between 10 a.m. and 5:30 p.m. 
Forest Department. The number of trees allotted to a household was based on family size and although there was no gender differentiation in who had right of access, men were mostly involved in harvesting wood since this involved logging trees. However, the Koop system resulted in forest resources being exploited for commercial purposes rather than for household energy use.

In 1990, with the introduction of participatory forest management practices, the State Forest department abandoned the Koop system, and created alternative mechanisms. In Kudalgaon, now only women are allowed to enter the designated forest areas and collect fuelwood. This new mechanism is observed and a forest protection committee has been set up in coordination with the Gram Panchayat. The committee checks on a random basis to ensure that the women are collecting only twigs and branches, and that axes are not being used. While this mechanism seemed to work in the sense of protecting forest resources, many women have complained of harassment by the men involved with the forest protection committee ${ }^{220}$. In Kudalgaon, in order to minimise this problem, women go as a group to collect biomass.

The villages of Ghatlohanga and Tikhralohanga have a different mechanism, in which they allow all the households to participate in an annual lopping of a designated forest area. The wood collected is then divided equally amongst the households.

However, since 2005 and due to the escalation of conflicts between the police and naxalites, the forest department has started to make fuelwood available from its depots and most households now purchase their fuelwood requirements ${ }^{221}$. This is a change since, at the time of the first fieldwork in 2002, fuelwood purchase was mostly confined to the APL households in Kudalgaon and Ghatlohanga. Biomass fuels are now purchased in bulk, especially during the monsoon months, when fuelwood collection is a problem due to the un-metalled roads and the wood cannot easily be dried. The fuelwood depots are located on the National Highway. Most of the Ghatlohanga and Tikhralohanga households purchase from a depot which is three kilometres from Bastar, while households in Kudalgaon purchase fuelwood from the depot located two kilometres from Jagdalpur.

\section{Delivery Pathways in 2009}

At the time of the second period of fieldwork, the delivery pathway for modern energy carriers had remained broadly unchanged in Bastar district. The Electricity Act 2003 led to the Government of Chhattisgarh restructuring the CSEB into five utilities. Electricity distribution in the state is now the responsibility of the state-owned Chhattisgarh State Electricity Distribution Company Limited (CSEDCL). Renewable energy continues to be coordinated by the Chhattisgarh State Renewable Development Agency (CREDA). The two

\footnotetext{
220 There are no women members of the committee.

${ }^{221}$ Another reason cited by some of the Kudalgaon households during the 2009 survey was that there were increasing incidences of harassment and molestation of women by security forces in local villages. While many households in Kudalgaon village did not report such incidents, women in the village had stopped going to collect biomass since it was also now available through the Forest Department. The Gram Panchayat, in consultation with the Forest Department, has created a register of each household and a household can obtain 1 quintal (100 kg) of woodfuel per month from the depot.
} 
private LPG suppliers, Hind Gas and Chhattisgarh Gas, ceased their operations sometime around 2005-06. The three public sector oil and gas companies - Indane, HP Gas and Bharat Gas - all have dealers who are the main providers of LPG throughout the district.

The state government has increased the number of lighting points from one bulb (40 Watt) to three bulbs (40 Watts each) per BPL household, although only $30 \mathrm{kWh}$ of free electricity per month is provided. If consumption exceeds this level then the BPL connections are charged as regular domestic consumers. In 2005, the CSEB drew up project proposals under the RGGVY for rural electrification aiming to cover all non-electrified households and complete the metering of all consumers. The Rural Electrification Corporation had approved these projects and, for Bastar, a project worth Rs 2.21 billion has been sanctioned in 2007 for electrification of non-electrified villages, non-electrified households in electrified villages, and BPL households. However, contracts for these projects had not been issued as of 2009 due to the ongoing conflicts in the district.

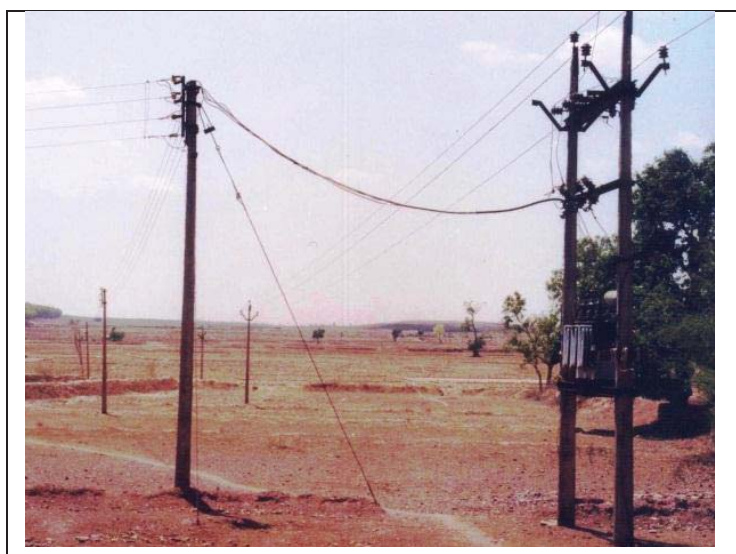

Electricity distribution infrastructure in Bastar

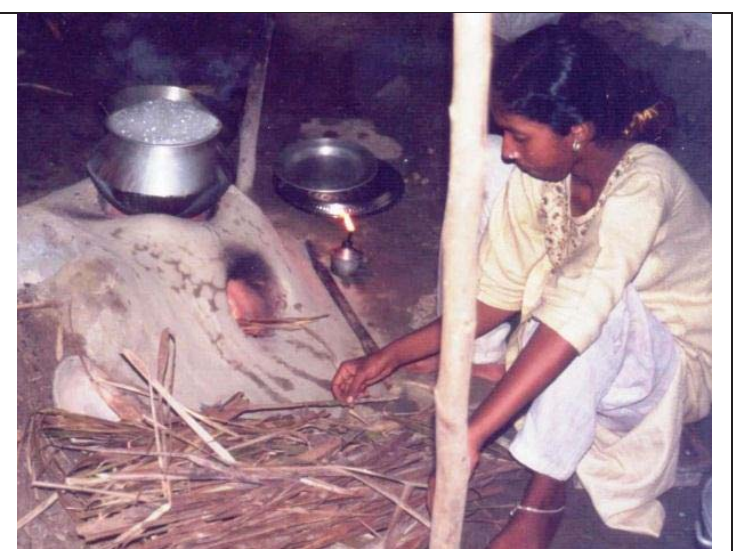

Cooking with biomass fuels

\subsubsection{Access to Modern Energy Carriers: Who Has Access?}

In the case study villages of Kudalgaon, Ghatlohanga and Tikhralohanga, electricity, LPG and kerosene oil are available and used by some households despite there only being lowcapacity end-users present in these villages. The availability of modern energy carriers and an aggregated picture of access in the case study villages is presented in Table 5.11. At the time of the first fieldwork, $90 \%$ of the households in Kudalgaon had access to electricity, whereas less than 10\% used LPG for cooking. In Ghatlohanga, nearly $51 \%$ of households had electricity, and about 6\% were using LPG. In Tikhralohanga, 46\% of households used electricity although no one was using LPG for cooking. Kerosene oil was used by all the households in all three villages but only for lighting. Access to modern energy carriers in the case-study village households had not changed between 2002 and 2008/09 with the exception of one household, which has stopped using LPG for cooking (see Box 5.9 Case Story of Rita Baghel). 
Table 5.11: Energy status in case-study villages of Bastar

2002 and 2009

\begin{tabular}{|c|c|c|c|c|}
\hline \multicolumn{5}{|r|}{ Tikhralohanga } \\
\hline \multicolumn{2}{|l|}{ Total number of households } & 276 & 171 & 105 \\
\hline \multirow[t]{3}{*}{ Households with access to } & Electricity & 250 & 87 & 48 \\
\hline & LPG & 25 & $10 *$ & - \\
\hline & Kerosene & 276 & 171 & 105 \\
\hline \multirow{3}{*}{$\begin{array}{l}\text { Period carrier had been } \\
\text { available (in years) prior to } \\
2002\end{array}$} & Electricity & $>15$ & $2-12$ & $>12$ \\
\hline & LPG & $<3$ & $<3$ & - \\
\hline & Kerosene oil & $>12$ & $>12$ & $>12$ \\
\hline \multicolumn{5}{|c|}{ * Includes one household which was not using LPG for cooking in 2009} \\
\hline
\end{tabular}

Table 5.12: Low-Capacity End-users in Bastar

2002 and 2009

\begin{tabular}{|c|c|c|c|}
\hline \multirow{3}{*}{$\begin{array}{l}\text { Underserved } \\
\text { (48) }\end{array}$} & \multirow{3}{*}{$\begin{array}{l}\text { Households with access to } \\
\text { electricity, LPG or both }\end{array}$} & Electricity and LPG & $13(12 * *)$ \\
\hline & & Only Electricity & $34\left(35^{* *}\right)$ \\
\hline & & Only LPG & 1 \\
\hline $\begin{array}{l}\text { Unserved } \\
(41)\end{array}$ & \multicolumn{3}{|c|}{$\begin{array}{l}\text { Households with: } \\
\text { - No access to electricity and using kerosene oil for lighting } \\
\text { - No access to LPG and using biomass for cooking and thermal energy needs }\end{array}$} \\
\hline
\end{tabular}

In terms of access to modern energy carriers by low-capacity end-users, where availability does not form a constraint, other factors sometimes inhibit access. In order to understand the linkages between availability of modern energy carriers and factors that influence access, a sample household survey was carried out in these villages. Table 5.12 classifies the households surveyed as low-capacity end-users in these three villages in terms of their energy status. At the time of the first fieldwork, the 48 households surveyed that were underserved in terms of the energy categories applied in this thesis, all had access to electricity, LPG or a combination of both. The remaining 41 households surveyed were unserved and all these used kerosene oil for lighting and depended on biomass energy carriers for meeting their cooking needs (as did many of the underserved). Unserved households were to be found in all the padas making up the three villages, but were mostly concentrated n three padas: K2 G1, and T1. At the time of the second fieldwork in 2009, none of the surveyed households had transited from unserved to underserved, or vice versa.

In the case of electricity, households are generally unserved because there is no nearby grid and they are unwilling or unable to invest in grid extension due to the costs involved ${ }^{222}$.

222 The CSEB estimated that, in Bastar, grid expansion would cost about Rs 11,000-Rs 15,000 per kilometre. It is only considered economically viable when there are at least twelve connections per electricity pole. The connection cost in 2002 for a household was Rs 2000, which included a meter and wiring from the nearest electricity pole to the consumer's meter. With rising costs and the ongoing conflict, most of the contractors who had been involved in completing the connections lost interest due to the low rate paid by the CSEB. 
These unserved households felt the state government should provide an electricity connection, since it had provided the electricity connections to other parts of the village. In terms of electricity distribution, the entitlement of BPL households to benefits falls under the Kutir Jyoti (KJ) programme. Although this entitlement was originally to a single lighting point, evidence from Kudalgaon showed that some of these KJ consumers were using multiple light points and, in a few households, other appliances such as a fan or a TV were being used. In order to address the problems of over consumption of electricity by KJ consumers, the CSEB, in 2006, increased the allowable connected load for BPL households from $40 \mathrm{~W}$ to $120 \mathrm{~W}$, and fixed an upper limit of free power to $30 \mathrm{kWh}$ per month. In the case of LPG, there is no differentiation in entitlement between APL and BPL households. All LPG consumers receive the same subsidy, provided by the central government. The same situation applies to kerosene oil. Table 5.13 maps access to modern energy carriers by both household economic status (APL and BPL) and by occupation category. As the household survey shows, 13 out of the 48 underserved households were using both electricity and LPG in 2002, and all of these were APL households. Electricity was used in another 34 out of the 48 underserved households, including in 23 BPL households with KJ connections.

Table 5.13: Mapping Energy Access to Economic Status and Occupation

2002 and 2009

\begin{tabular}{|c|c|c|c|c|c|c|}
\hline & & $\begin{array}{l}\text { Government } \\
\text { service (16) }\end{array}$ & $\begin{array}{l}\text { Agriculture } \\
\text { (44) }\end{array}$ & $\begin{array}{l}\text { Business } \\
\text { (8) }\end{array}$ & $\begin{array}{l}\text { Non-Farm -Minor } \\
\text { Forest Produce } \\
\text { (MFP) } \\
\text { collection/selling (6) }\end{array}$ & $\begin{array}{l}\text { Farm/Non- } \\
\text { farm labour } \\
(15)\end{array}$ \\
\hline Un & rserved (48) & & & & & \\
\hline & $\begin{array}{l}\text { Electricity and } \\
\text { LPG (13) }\left(12^{*}\right)\end{array}$ & $4\left(3^{*}\right)$ & 7 & 2 & - & - \\
\hline 党 & $\begin{array}{l}\text { Only Electricity } \\
(11)\left(12^{*}\right)\end{array}$ & $3\left(4^{*}\right)$ & 6 & 2 & - & - \\
\hline & Only LPG (1) & 1 & - & - & - & - \\
\hline 1 & $\begin{array}{l}\text { Electricity and } \\
\text { LPG (0) }\end{array}$ & - & - & - & - & - \\
\hline 象 & $\begin{array}{l}\text { Only Electricity } \\
\text { (23) }\end{array}$ & 4 & 11 & 3 & 2 & 3 \\
\hline Un & rved (41) & & & & & \\
\hline AP & (9) & 3 & 7 & 1 & - & - \\
\hline $\mathrm{BP}$ & $(32)$ & 1 & 13 & - & 4 & 12 \\
\hline & $\begin{array}{l}\text { households also } \\
\text { udes one househo }\end{array}$ & $\begin{array}{l}\text { ed kerosene oi } \\
\text { which switche }\end{array}$ & $\begin{array}{l}\text { r lighting } \\
\text { ack to biom }\end{array}$ & from LPC & rior to 2009 & \\
\hline Sol & e: Primary survey & & & & & \\
\hline
\end{tabular}

Table 5.14 presents data from the case-study villages regarding access to modern energy carriers in those households where women are involved in income-earning or other activities. In the case of the APL households, it appears that, for a woman, being engaged in incomeearning activities does not access to LPG and electricity. In fact, LPG is used in more households (11) where women are not involved in income-earning activities than where they are (2). In fact, a household's social status and economic status seem to play a critical role in 
determining whether LPG is used for cooking since such households belong to upper caste and higher economic groups.

Table 5.14: Energy Access and Women in Income/Non-income Earning Activities 2002 and 2009

\begin{tabular}{|c|c|c|c|c|c|}
\hline & \multicolumn{4}{|c|}{ Underserved (48) } & \multirow[t]{2}{*}{ Unserved (41) } \\
\hline & Total & $\begin{array}{c}\text { Electricity } \\
\text { and LPG }\end{array}$ & Only Electricity & Only LPG & \\
\hline \multicolumn{6}{|c|}{ Women in paid employment } \\
\hline APL & 14 & $2(1 *)$ & $4(5 *)$ & - & 8 \\
\hline BPL & 45 & & 21 & - & 24 \\
\hline \multicolumn{6}{|c|}{ Women not in paid employment } \\
\hline APL & 20 & 11 & 7 & 1 & 1 \\
\hline BPL & 10 & - & 2 & - & 8 \\
\hline \multicolumn{6}{|c|}{ * 2009 figures (reflecting the household where the main cooking fuel went from LPG to biomass). } \\
\hline \multicolumn{6}{|c|}{ Source: Primary survey } \\
\hline
\end{tabular}

Further, there is a strong gender-division in intra-household decision-making; based on the traditional roles in which men's responsibility is to earn and provide for the family's welfare, and women's responsibility is to take care of the home. As such, energy procurement and use have distinct gender dimensions. The procurement of fuelwood is the responsibility of the women in a household but, when it comes to modern energy carriers, the connections (electricity and LPG) are in the name of the male head of the family. In some households, energy decisions, and especially for purchase of an LPG connection, is a joint decision but in most cases the decision, as well as payments, are made by the men in the family.

In the case of BPL households, there is a considerable blurring of gender roles in terms of contributing to household finance. In the surveyed BPL households where women were involved in paid work, the use of modern energy carriers was restricted to electricity. These households have electricity because of the KJ programme, and so the involvement of women in income-earning activities has no direct bearing on access to electricity. In the case of BPL households, the women who were working received low and irregular wages from both farm and non-farm labour, and a few from small-scale businesses selling MFP. A woman labourer at the time of first fieldwork period earned Rs 35- Rs 40 per day as a farm labourer. Since women have to balance household chores and income earning, they often do paid work for half-a-day, for which they receive about Rs 15-Rs 20, and spend the rest of the day on household chores. There are also some BPL households where women are working in government services.

\subsubsection{Contextual Influences that Affect Energy Access}

This section analyses the four contextual influences - economic, infrastructure, social and political - that are considered to have an effect on access to modern energy carriers. In the villages of Bastar, access to modern energy carriers is influenced by the local economy as it intertwines with social factors (Figure 5.2). 


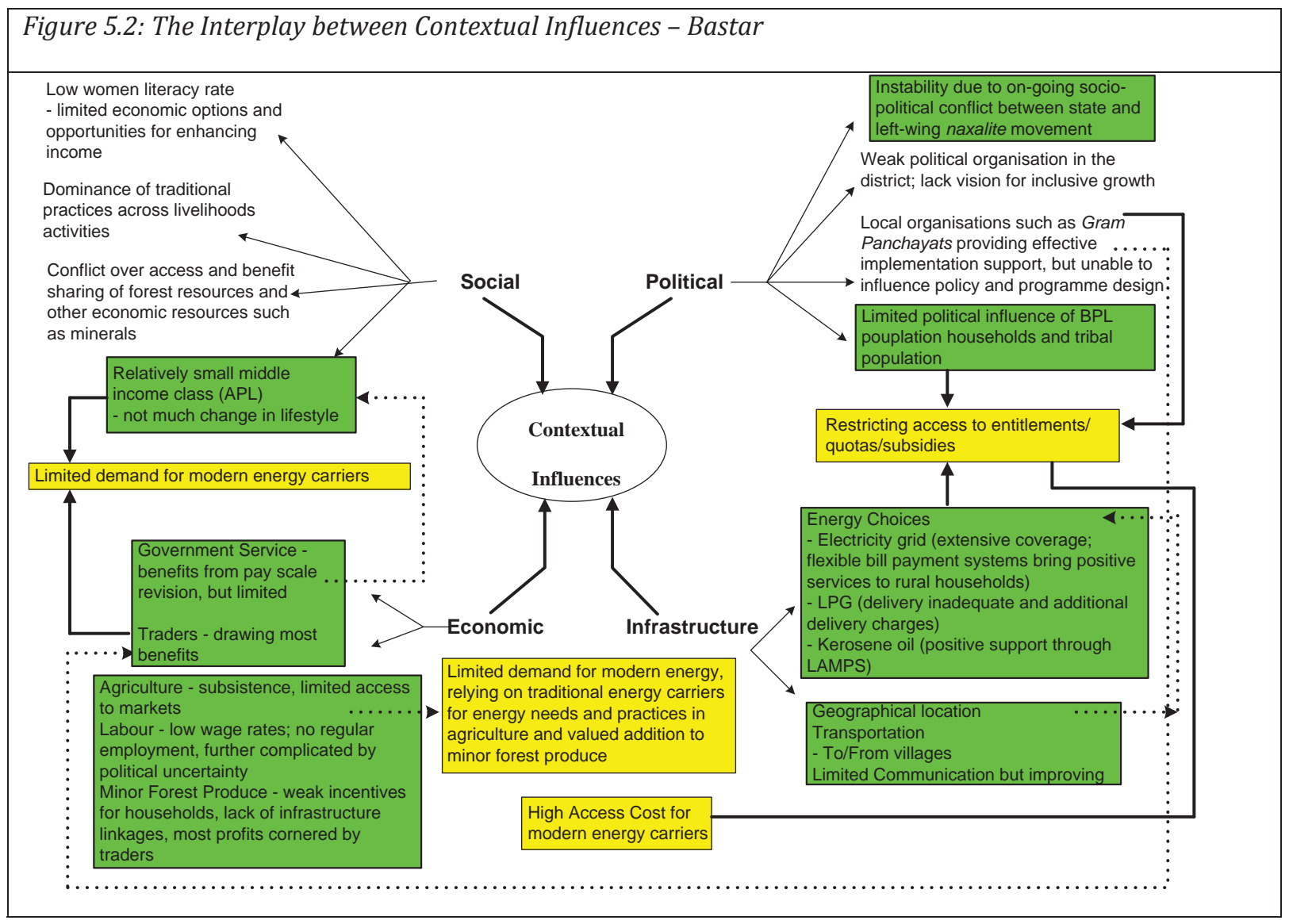

Infrastructure plays a significant role in ensuring that energy carriers, especially those that have to be transported and transmitted from outside the district, are available for consumption in the villages. The infrastructure is not a constraint in the case-study villages but it, or rather the lack of it, is a barrier in the more remote villages located in forest areas, where availability is also affected by social and political problems. Since Bastar is located in a terrain where extending the electricity grid is viable, the grid has been extended to all villages where it is economically feasible under the rural electrification programme. At the time of the first fieldwork, the reason for the non-electrified padas and households in electrified villages was the lack of funding or a CSEB programme for village electrification. By the time of the second fieldwork, projects for village, pada and household electrification had been developed under the RGGVY, but the padas and households had not been electrified because of political instability. Despite the availability of grid electricity in the villages for some time, the use of electricity remained mostly for consumptive purposes (lighting and entertainment).

Electricity usage for productive ends, such as irrigation and small-scale industries or microenterprises, is limited due to a lack of appropriate market linkages. As a consequence, there is still only limited participation by local people in the market economy; and so they are unable to generate cash surpluses and remain trapped within the vicious circle of poverty and energy poverty. However, for some households there are income-generating opportunities along the highway and hence they resist when threatened with being forced to move. 
The delivery infrastructure for petroleum energy carriers (LPG and kerosene oil) is stable in the district. The LAMPS network in the district and the storage facilities for kerosene oil in the few LAMPS locations on the major road has enabled kerosene oil to be available. A major constraint is the lack of transportation facilities within the villages and also connecting them to the major town of Jagdalpur. As a result, households have to pay additional transportation and handling fees for LPG. The ongoing conflict in the region has had some impact on the movements of LPG trucks and kerosene oil tankers, resulting in intermittent supplies.

Although Bastar has many economic opportunities, these do not provide sufficient cash surplus for households to be able to move out of the vicious circle of energy poverty. Households, especially those where members are in government service or business, have multiple income sources, and households are leveraging their growing economic status to access modern energy carriers. The case story of B S Thakur (Box 5.8) is an example of such households where modern energy carriers contribute to an improved lifestyle as a result of a change in their economic capabilities.

\section{Box 5.8: B S Thakur - A Combination of Modern Energy Carriers}

B S Thakur is a doctor who is employed by the state health department. Thakur lives in Kudalgaon village in pada K1. Thakur's wife is a schoolteacher at the High School in Ghatlohanga. In this family of four, electricity and LPG are used to provide energy services, which the family attributed to their social and economic status. They obtained the electricity connection in 1987, and typically pay around Rs 135 per month for electricity. Electricity is used primarily for lighting, a television and cooling (a water cooler is used during summer months). LPG is the sole fuel used for cooking and they replace the cylinder every month, using their motorcycle for transport.

The energy mix in Thakur's household has remained unchanged. Between 2005 and 2007, the truck movements bringing LPG cylinders into Jagdalpur were often disrupted and, during this period, one might have to wait nearly three weeks for an LPG cylinder. During this period, the household often had to use fuelwood for cooking. In 2007, they decided to switch to a double cylinder connection so that one cylinder would always be available for cooking. The reasons for adding another cylinder were that, since everyone in the family was now working, they could afford it, and it was difficult to manage cooking on fuelwood.

The high upfront costs of obtaining an LPG connection, as well as the cost of refilling the cylinder $^{223}$, often act as a barrier to access. The average monthly income of the APL households surveyed that were using LPG was in the range of Rs 5000-Rs 7000, and expenditure on LPG for these households amounted to no more than $5 \%$ of their income. The APL households surveyed that were not using LPG had incomes ranging from Rs 2500 to Rs 7000 .

However, cost is not the only barrier. In some of the APL households, it is not so much an insufficient capacity to pay, but the easy availability of alternative and cheaper energy carriers. In the villages, the households had various reasons for not using LPG: (a) easy availability of biomass fuels, (b) availability of time that women and girls could utilise to

\footnotetext{
${ }^{223}$ Interview with the dealer of Hind Gas on 5 May 2002. The dealer could not be located in 2008-09.
} 
collect fuelwood, (c) problems in getting a connection, and (d) a negative perception of LPG, such as concerns over its safety, based on hearsay. While the growing economic status of households can act as a trigger to shift to modern energy carriers, the increasing prices act as a deterrent, and we saw that one of the economically better-off households had given up their LPG connection.

The issue of the upfront LPG connection costs had been addressed by the private LPG suppliers by allowing customers to pay in instalments spread over six months. However, households, especially those that bought their LPG connections from private suppliers, found it difficult to afford the rapidly increasing cost of cylinder refills seen between 2000 and 2006, and decided to stop using LPG (see for example the case of Rita Baghel in Box 5.9).

\section{Box 5.9: Rita Baghel - Shifting back from LPG to Biomass for Cooking}

Rita Baghel is a schoolteacher at the Anganwadi centre in Ghatlohanga. Her husband is also in government service and works in the postal department. There are seven members of the family. This household has a regular electricity connection, as well as LPG. They purchased an LPG connection in 2000 from Hind Gas against an initial charge and deposit of Rs 2750 for a $15 \mathrm{~kg}$ cylinder. In 2000, the cost of a cylinder refill was Rs 165. In 2002, they were paying Rs 335 for a refill, replacing the cylinder every month. According to Rita, switching to LPG was not her decision alone, but a joint family decision. She already knew about LPG and its uses. The promotional offer from Hind Gas provided an additional incentive for them to shift to LPG. While most of the cooking was done on LPG, they sometimes also used biomass. Previously, they had also used a kerosene oil stove. Rita felt that one of the main advantages of LPG was that is eased her household chores, and she was able to more effectively balance her time between home and work.

In 2004, Hind Gas raised the price of an LPG cylinder to Rs 415, and further increased it to Rs 525 in 2005 and to Rs 600 in 2006. Rita's family then stopped using LPG for everyday cooking and shifted back to using biomass. This was not as convenient, but the LPG was expensive and the supply was somewhat irregular. In 2006, Hind Gas ceased its services in the district. Rita's family failed to get their security deposit refunded by Hind Gas. In 2007, they approached the dealer of the public sector company, HP Gas, to convert their existing LPG connection. However, in order to obtain an HP Gas connection, they would have to make a fresh application and pay a new deposit as a connection cost. As a consequence, in Rita's household, there is a cylinder and cooker, but no gas to cook on, and the family now cook using biomass purchased form the fuelwood depot.

Some households are also unserved because of the policies and norms followed by CSEB for providing electricity connection to a household which relocates to a new house. The case story of Mandhar (see Box 5.10) in Kudalgaon village is an example of becoming unserved from underserved having moved to a new house (constructed under the Indira Awas Yojana, a government scheme for rural housing) and the electricity connection in the old house not being transferred. The CSEB guidelines indicate that households within 30 metres of an electricity pole should be provided with either a regular domestic or a Kutir Jyoti electricity connection (depending upon the economic status of the household), and that households further away have to pay for the connection. In cases where households already had an electricity connection, but relocate, then the CSEB classifies them as new customers, and expects them to pay a fresh set of connection charges. This becomes difficult for BPL households as they feel that since the government initially had provided free electricity connections to some BPL households, it should extend the same benefits to other BPL households. 


\section{Box 5.10: Mandhar - Inability to Pay the Electricity Connection Cost}

Mandhar is a farmer with a small land-holding who also works as an agricultural labourer. He belongs to the Dhurwa tribe and lives in a BPL household. In 1995, Mandhar got a KJ electricity connection. In 1999, he also got a grant under the Indira Awas Yojana scheme to construct a new house, which is located in a different part of the village. In 2001, he moved with his family to the new house; but there is no electricity connection. His existing connection could not be transferred as the CSEB classified his request as a new connection. Consequently, Mandhar would have to pay Rs 2000 for a new connection, and this would be classified as a metered domestic connection.

In 2009, Mandhar's new house still lacked an electricity connection despite the CSEB having included his house as part of the intensive village electrification programme in 2006 under the RGGVY.

\section{Box 5.11: Mahesh Ram and Phulmati - Inability to Buy Modern Energy Carriers}

Mahesh Ram belongs to a landless BPL family. Although there is grid electricity in the village , their house does not have a connection. There are five adult members in the family - three men and two women -all engaged in economic activities. While most of the male members of the family work as daily wage labourers in Jagdalpur, the women work as farm labourers in Kolchur. In 2002, when the household was interviewed for the first time, Mahesh Ram's wife Phulmati had returned from half a day's work in Kolchur for which she had been paid Rs 20. The monthly household income was in the range of Rs 1800-Rs 2000, just sufficient for them to meet their food and other basic needs, leaving little to save for modern energy carriers.

In 2008-09, the household was still not electrified. They have applied twice to the Tikhralohanga Gram Panchayat, but have still not received a connection. According to Phulmati, an electric pole needs to be installed to bring electricity to their house. She also reported that they have received money under the Indira Awas Yojana ${ }^{224}$ programme for constructing a house but, so far, they had only constructed a toilet. Once the remaining money is released, they will complete the construction.

For other households in Bastar, their main sources of income are agriculture, the mainstay of the local economy, and the collection and selling of MFPs. The lack of irrigation facilities restricts the tribal population from growing crops during the Rabi season. Other possible occupations include involvement in government-sponsored rural employment programmes and working as casual labour in Jagdalpur or Bastar. These economic activities offer only temporary employment. The maximum monthly income of the BPL households is around Rs 2000, but most have no fixed source of income and this makes it difficult to accumulate sufficient financial assets to purchase an LPG connection (see Box 5.11). The main reasons offered as to why such BPL households do not use LPG are: (a) a lack of capital to invest in a connection; (b) a lack of surplus income to pay for the cylinder refills; and (c) the easy availability of wood.

The dependency on agriculture and MFPs, results in serious under-employment and low wages. The market for such products is monopolised by local traders who are able to manipulate prices to keep them artificially low. In other words, the market is not working. Since these low-income households have no cash reserves, they cannot afford to stock products for long periods and a lack of storage facilities further compounds their problems.

${ }^{224}$ Indira Awas Yojana (IAY) is a rural housing programme, under which BPL households receive a grant for building a house. The grant does not include the cost of an electricity connection since these costs should be covered by the distribution utility's rural household electrification scheme. 
As a result, these households resort to selling to the traders at below market prices. One of the NGOs that have worked with the tribal population observed that, "households sell, for example, mahua for Rs 3 per kg during the season, and after a few months they buy it back from the traders at Rs 6 per kg" ${ }^{225}$. Efforts to organise village cooperatives to procure, add value and market MFPs under Van Dhan Samiti ${ }^{226}$ have failed due to collusion between the Van Dhan Samiti members, market traders and government officials, who created an artificial market that brought down the buying prices (Bhogal, 2001;Ganguly and Chaudhary, 2003). Since 2004, there have been several attempts at organising village-level enterprises for processing MFPs but they have met with little success as traders want to purchase raw tamarind at a low price rather than processed products. However, local NGOs have initiated micro-level development planning, as a bridge between the Gram Panchayat and the district administration, to inform policymaking. These efforts are at an early stage in the district and are so far very limited with no evaluation having been made (Patnaik and Mehrotra, 2010).

Electricity access could play a role in the development of Bastar because of its potential to influence the mainstay of the local economy - agriculture and minor forest products. Electricity can aid agricultural development by improving irrigation, processing and storage facilities. At the same time, electricity could enable local people to access information regarding the market prices of forest products and commodities. Access to such information can help reduce the power of intermediaries and traders who offer low prices. However, electricity alone is not sufficient to bring economic development, as development requires the presence of other contextual influences in the form of integrated rural development. Some of the constraints are due to communities following traditional practices and norms that lead to resistance to participation in economic activities. However, with awareness and education, some of these practices can be changed, and these changes can lead to new economic opportunities. In moving from a subsistence economy to a more-balanced economy, access to modern energy carriers, among other things, will however be limited.

In Bastar, while class and caste are not major issues in the tribal population, their social practices and norms have not allowed people to break away from a subsistence economy. Cultural attitudes can sometimes act as a retarding force, but sometimes as an enabling force, in the take up of modern energy carriers. Resistance attributed to 'cultural attitudes' may be disguising other issues. The current lifestyle of tribal households is organised around daylight hours, with families traditionally going to bed around $9 \mathrm{pm}$. As such, their requirement for lighting is restricted to a few hours in the early morning and a few hours in the evening. Some community members see the introduction of new technologies, such as the electric light, as a threat to their traditional way of living. ${ }^{227}$

Others are more proactive, a women's self-help group in the neighbouring Dantewada district took the lead in bringing electricity to their village by creatively lobbying district officials

\footnotetext{
${ }^{225}$ Interview with Mr M A Iqbal of Adivasi Harijan Kalyan Samiti on 7 May 2002.

${ }^{226}$ See the profile of Bastar district in Annex I for information on Van Dhan Samiti.

${ }^{227} \mathrm{~A}$ study found similar lack of change in the daily routine in electrified areas of rural Bolivia (Sologuren, 2006). 
(Sinha, 2003). However, most of the women members of the self-help group do not know what to do with electricity and LPG other than use them for lighting. Ideas on the productive uses of electricity and LPG are limited, which makes the utilities reluctant to invest. Local initiatives of this nature usually need inputs from external agencies, and such support is generally lacking in Bastar as many agencies are not interested in working in the area due to the ongoing social and political conflict.

There are of two kinds of political factors to consider, especially at the micro-level of Bastar: policy interventions and local politics. While the policy interventions by the state government, such as the LAMPS/PDS, have facilitated and improved access to kerosene oil, the state government has been less effective in exploiting the LAMPS/PDS for the delivery of a range of energy carriers. The state government took a decision in 2002 that, prior to initiating electricity sector reforms, it would have to understand and then address the problems related with electricity distribution. In retrospect, this decision has paid dividends since the distribution infrastructure has enabled improvements in electricity supply. The policy decision of the central government to implement the parallel marketing of LPG resulted in improved access, at least for wealthy households, in rural areas through the presence of private-sector dealers. While the primary focus of these private sector dealers was the urban markets, their dealers based in Jagdalpur felt that there were opportunities for expanding services to nearby villages.

The local political institutions that have been involved in village development have been far less effective in removing some of the organisational and implementation barriers to improved access to modern energy carriers. The Gram Panchayats of Kudalgaon and Tikhralohanga have been active in implementing the government programme, but they have been unable to lobby for inclusive growth due to their limited political powers and so unable to influence policy and programme design. The local political representation in the State Assembly and in the Central Parliament has largely been dominated by one tribal leader, and the political representation has not been very effective in bringing new programmes and funding to the district. Rather, these political representatives have tended to focus on their own self-interest rather than that of the tribal groups they are supposed to represent.

A combination of social and political factors, including Naxalism, has started to affect the delivery of modern energy carriers. As mentioned in the introduction to the case study, Bastar is going through a phase of environment or development tensions, where the state government believes it needs industries to bring economic growth, while local communities are fighting for their rights to local resources such as land and forests. Bastar's development challenges were further compounded by the Salwa Judum ${ }^{228}$ movement that became active in $2006^{229}$, and resulted in the displacement of people and political instability due to the conflict

\footnotetext{
${ }^{228}$ Salwa Judum, or the peace initiative, was a movement that started in 2006 as a people's resistance to the left-wing naxalites. Salwa Judum was supported with training and ammunition from the police. This is further explained in Annex I, as part of the Bastar district profile.

${ }^{229}$ The Supreme Court of India passed a judgment in July 2011 that declared the Salwa Judum as illegal and unconstitutional. The Court asked the state government of Chhattisgarh to immediately stop the operation and retrieve all its arms and ammunition from the Salwa Judum activists.
} 
between the administration and the naxalites. Prior to 2007, the naxalite group was not actively disrupting energy delivery infrastructure but more focused on destroying government buildings and trucks carrying tendu leaves. However, in 2007, and for the first time, the naxalite group destroyed three electricity pylons. This plunged the district into darkness and brought industry in Bastar, as well as in the neighbouring district of Dantewada, to a halt. A similar disruption occurred in June 2008. This growing social-political problem, if not resolved, could have a downward spiralling impact on economic activities, on livelihoods and on the quality of life of people in Bastar.

\subsubsection{Policy Design in relation to Implementation}

This section deals with the broader question of the effectiveness and applicability of policy design, in relation to implementation in Bastar, based on the information presented in Sections 5.3.1-5.3.3. In the Bastar case-study villages, there is evidence of effective policy design (allowing private LPG dealers and setting up the LAMPS/PDS) and of relatively weak or lacking policies (pada and household electrification). At the same time, Bastar provides examples of effective and relevant implementation (access to kerosene oil through the LAMPS/PDS, an electricity billing and payment system that matches household cash flows, incentive-based LPG promotion by the private sector) and some ineffective implementation (non-expansion of the grid and the lack of LPG delivery arrangements for villages). Box 5.12 provides an overall summary of the applicability and effectiveness of policy and implementation in Bastar.

Bastar is connected to the state's main electricity grid, and only forest villages remain unconnected since the grid had not, as of 2009, been extended. The electricity billing and payment system introduced by the Circle office in Bastar provides an example of an applicable and effective policy design and implementation package that matches the economic conditions and paying capacity of the local people. A weakness of the current electricity distribution system is its inability to expand the grid to non-electrified padas and households. The Electricity Circle office in Bastar has limited powers and while it has recommended projects under the RGGVY, it is unable to implement them unless contracts are issued for implementation. Another limitation of electricity distribution in the district is its inability to stimulate productive uses of electricity for agriculture, irrigation and smallscale industries, or for the exploitation of forest products. As such, the electricity board only facilitates, it does not go beyond its distribution function and link with other state government departments to provide integrated rural development.

In the case of LPG, the limited presence and delivery by public sector dealers can be viewed as weak implementation as a result of an ineffective policy design. The private sector did step in to improve access. The private sector dealer in Bastar understood the economic conditions, the paying capacity and the potential for LPG in rural households, and introduced several incentives, such as the option of paying the upfront costs in instalments and providing free cooking pots and pans. This resulted in more village households using LPG. A current limitation of the LPG policy is that the subsidy is only given to consumers served by public 
Box 5.12: Policy Design and Implementation in Bastar

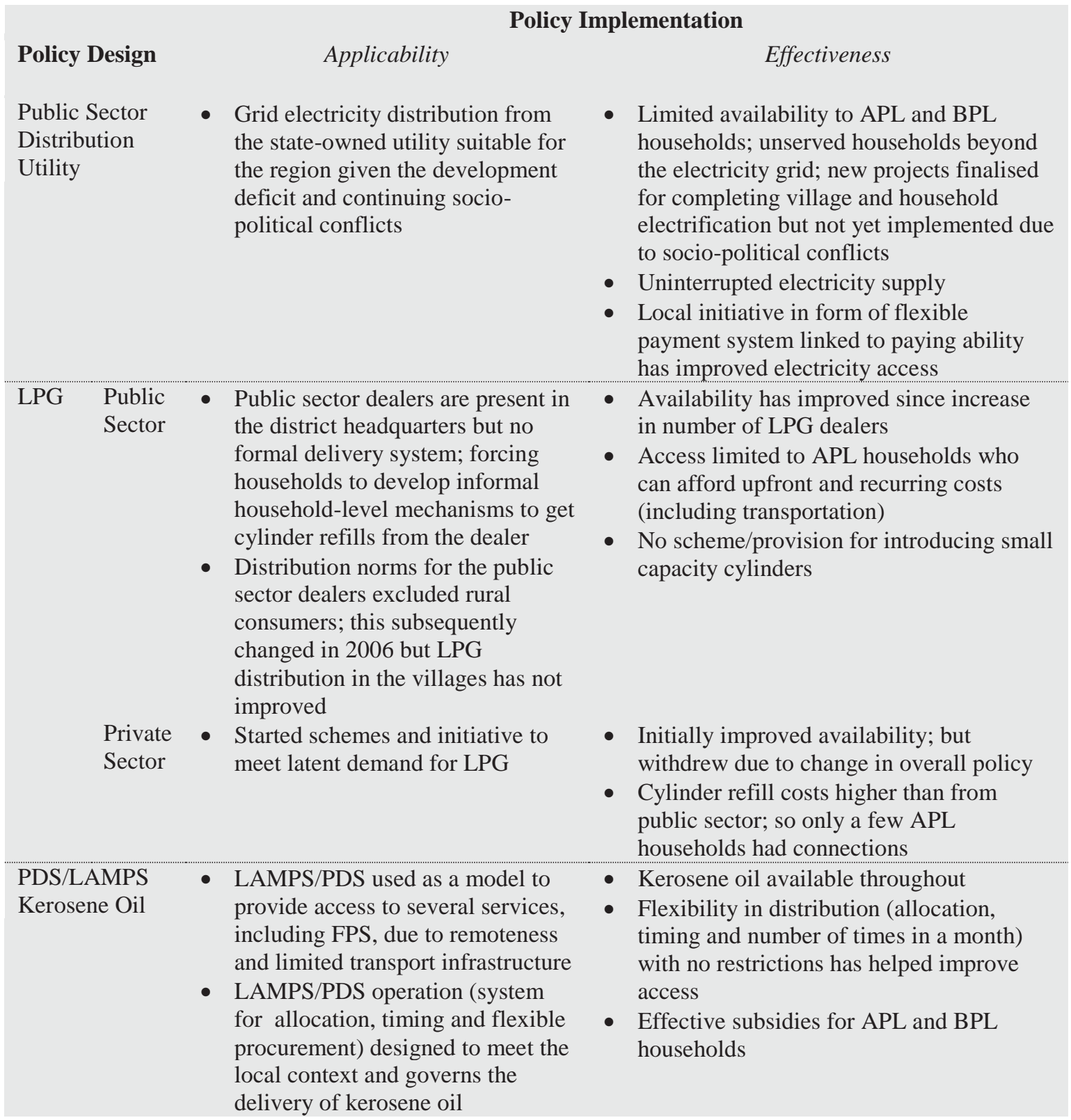

sector dealers. Since the outreach of public sector dealers is limited, the benefits of the subsidy are enjoyed by a limited number of households. Further, post 2006, the private LPG dealers withdrew from the market and those households that had a private connection had to take a new connection from a public sector dealer if they wanted to continue using LPG. This change in policy affected households by creating the addition financial burden of meeting a new connection cost. Increased prices have caused some (see Box 5.9, case story of Rita Bhagel) to switch back to using biomass.

A clear example of applicable and effective policy design and implementation is the delivery mechanism for kerosene oil through the LAMPS/PDS. This has resulted in ensuring that kerosene oil is available in the rural areas and households have the flexibility to purchase 
kerosene oil in quantities that reflect the money they have available at any given time. This flexible and convenient mechanism has had a significant impact on BPL households since they no longer have to buy kerosene from the market at a higher price. This has also stopped pilferage from the kerosene oil distribution in Bastar. Indeed, in the few instances of foodgrain pilferage from an FPS being reported, the LAMPS/PDS have stepped in and effectively dealt with it. The most significant finding from Bastar concerns the payment system for energy services. Local-level interventions addressing the billing system for electricity delivery, kerosene oil and LPG (the upfront cost by the private dealer) avoided people having to make large payments. While the electricity billing system and the role of LAMPS in kerosene oil supply have not changed during the research period, the opportunity to pay for an LPG connection in instalments for LPG is no longer available. Overall, Bastar provides some interesting examples of institutional flexibility in policy and programme implementation that take account of the paying capabilities, including cash flow patterns, of rural, and especially BPL households.

\subsection{Kalahandi Case Study ${ }^{230}$}

The villages of Ranikota, Bhairavpur, Gotbhata, Laxmipur, Icchapur, Janakpur and Balrampur form the two village clusters ${ }^{231}$ that make up the Kalahandi case study. These villages are part of the Bhawanipatna block in the Kalahandi district of the state of Orissa. In these villages, households use a combination of modern energy carriers and biomass fuels to provide their energy services. In the Bhawanipatna block, the villages are all small, varying in size from 40-100 households, and therefore more villages are covered in the Kalahandi case study than in the other two. Map 5.3 provides an overview of the seven villages and their connectivity to Bhawanipatna where the WESCO office and the LPG dealer are located.

These seven villages are all close to one another, but the social structures and livelihood options vary as one move from Ranikota to Balrampur. Electricity availability in the district had not changed between 2002 and 2008 (the two fieldwork periods). Further, in the casestudy villages, there is a distinct pattern in access to modern energy carriers. At one extreme, in the tribal village of Ranikota, 28 of the 30 households are unserved by electricity and LPG, and the other two use batteries for operating televisions. At the other extreme, Balrampur, with its combination of upper caste large farmers (gonthiyas), a few households with members in government service and a group of 25 landless Scheduled-Tribe (ST) households, has both underserved and unserved households. The primary occupation of the ST households is farm and non-farm labour, the latter including making grinding stones for household use to be sold at the Bhawanipatna market. The village, which is just off the state highway, is partly electrified. The non-electrified households include fifteen of the ST

\footnotetext{
${ }^{230}$ Annex I provides a detailed profile of Kalahandi district including its socioeconomic profile, agriculture and development deficits, and especially the environment-development conflict in the district (Banik, 2001;Currie, 2000;Government of Orissa, 2002;Mishra, 2001;Mukherjee and Joshi, 2009;NABARD, 2001b;Nayak, 2002;OWDM, 2004;Sainath, 1998).

${ }^{231}$ The villages have been grouped together into a cluster for the purposes of analysis in this dissertation. 184
} 
households who live away from the grid. In all seven villages, one can find both unserved and underserved households.

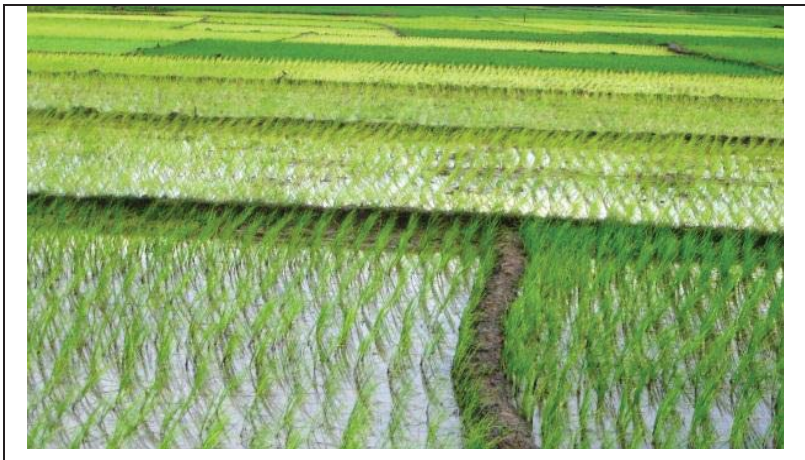

Kalahandi has high agriculture productivity

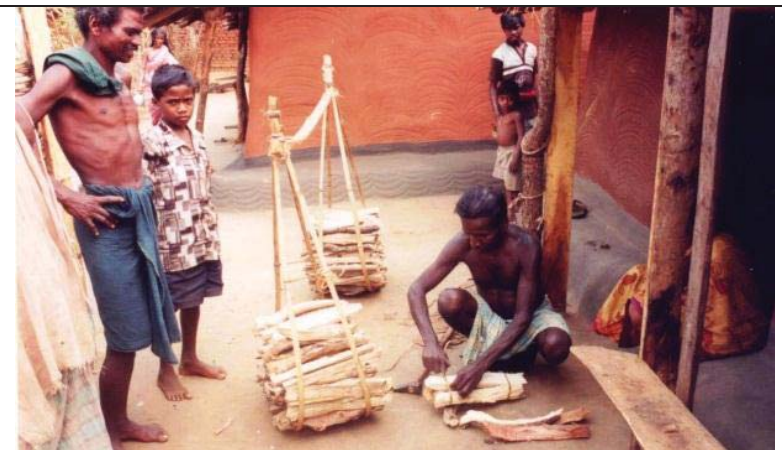

Selling fuelwood is a source of livelihood

Ranikota, a small village of 30 Scheduled-Tribe households located in the foothills, has its own Gram Panchayat. The primary occupation of all the households is slash-and-burn cultivation in the nearby hills. The households have no formal land tenure. Slash-and-burn cultivation begins around the month of January, when trees are felled and cleared. Sowing starts in February-March, and crops, which are mostly paddy and vegetables, are harvested before the onset of the monsoon in June. In addition to agriculture, other important sources of livelihood include selling fuelwood in Bhawanipatna, selling non-timber forest produce such as bamboo and tendu leaves and seasonal employment as farm and non-farm labour in nearby villages and under government programmes. Some households in this village also sell locally brewed alcohol in the surrounding villages and in Bhawanipatna. Apart from a mud road connecting the village to Bhawanipatna and two hand pumps for drinking water installed under a government programme, the village has no other social infrastructure. The nearest primary school is $8 \mathrm{~km}$ away in Laxmipur, and higher-level students have to travel $12 \mathrm{~km}$ to Bhawanipatna.

Ranikota village is non-electrified but two households use car batteries to power television sets and have to travel to Bhawanipatna to get them recharged. Kerosene oil is the main energy source for lighting, and households have to travel $4 \mathrm{~km}$ to Bhairavpur to purchase kerosene oil from the Fair Price Shops (FPS). In the village, firewood is used for cooking on traditional mud-based stoves. Women collect firewood on a regular basis, headloading the wood to the village. During the period when the forest is being cleared for agriculture, men are involved in transporting felled wood logs to the village.

Bhairavpur, comprising 35 households, is separated from Icchapur by a small hillock and is part of the Laxmipur Gram Panchayat. The village is not electrified but does host the FPS for the distribution of kerosene oil and food grains. With the exception of two households who are both FPS dealers, all the other households earn their livelihoods from working as farm and non-farm labourers and/or by selling fuelwood. Almost all the households have very small landholdings, which are cultivated (with paddy during kharif) to meet their subsistence needs. In the absence of assured employment, both men and women (but mostly the men) 
migrate beyond the district to work as either seasonal or long-term labourers. Seasonal migrant labourers are unskilled and work in construction, or as daily wage labourers in a range of business establishments in cities such as Delhi, Mumbai and Raipur or in small-scale industries such as brick kilns in Andhra Pradesh. Longer-term migration often starts as seasonal migration, and includes skilled or semi-skilled labourers, who work mostly as electricians and plumbers in different urban areas both within the state and beyond.

The adjoining villages of Gotbhata and Laxmipur are part of the Laxmipur Gram Panchayat. Laxmipur hosts the Gram Panchayat office, and the FPS dealer is located in the main village of Gotbhata. Laxmipur also has a kirana (a Hindi term for a general store selling groceries and essential commodities) on the main road and a rice mill. Gotbhata also has a SC/ST pada (G1 on map 5.3). The SC/ST pada consists of 28 households and is not electrified as the electricity grid has not been extended that far. In the SC/ST pada, livelihood options included labouring, selling biomass, tailoring and the making and selling clay tiles. Laxmipur and the main Gotbhata village both have a combination of underserved and unserved households. Laxmipur and Gotbhata have a mix of livelihood options with households involved in farming (gonthiyas), business (shops, rice mill and brick-making units), services (government offices, school, NGOs and the Western Orissa Electricity Supply Company [WESCO]), and farm and non-farm labour. In Laxmipur, the gonthiyas cultivate during both the kharif and rabi seasons. Paddy is the main crop during the kharif season, and farmers grow a combination of paddy and mustard during rabi.

The villages of Icchapur, Janakpur and Balrampur are all part of the Balrampur Gram Panchayat, and are located close to the state highway. Janakpur, at $10 \mathrm{~km}$, is furthest from Bhawanipatna. Janakpur comprises a main village, which has a primary school, and a small pada of 25 ST households. Most of the households in the main village are involved in agriculture, banking services, teaching or business (trade). The FPS and a health centre are located $4 \mathrm{~km}$ away in the neighbouring village of Udaipur, although there is a homeopathy doctor in Janakpur. In terms of electricity access, both the main village and the ST pada of Janakpur have both underserved and unserved households. Only eight households in the main village have access to LPG.

Icchapur and Balrampur are relatively large villages, with 125 and 100 households respectively, and both have pada (I1 and B1 on map 5.3). The shared Gram Panchayat office is located in Balrampur and the FPS shop in Icchapur. Although grid electricity is available in these two villages and their padas, there are still unserved households. In terms of LPG, only eighteen households in these two villages use it for cooking. Several households use electricity for cooking although this is illegally tapped. Icchapur has a primary school, a youth club and shops that sell regular grocery items. Other shops sell seeds and fertilisers as these villages fall on a fertile lower slope of the local terrain. Farmers use groundwater for irrigation. Balrampur has a similar economic profile to Icchapur but is also home to a number of large gonthiyas who own tractors, and a privately owned rice mill. 

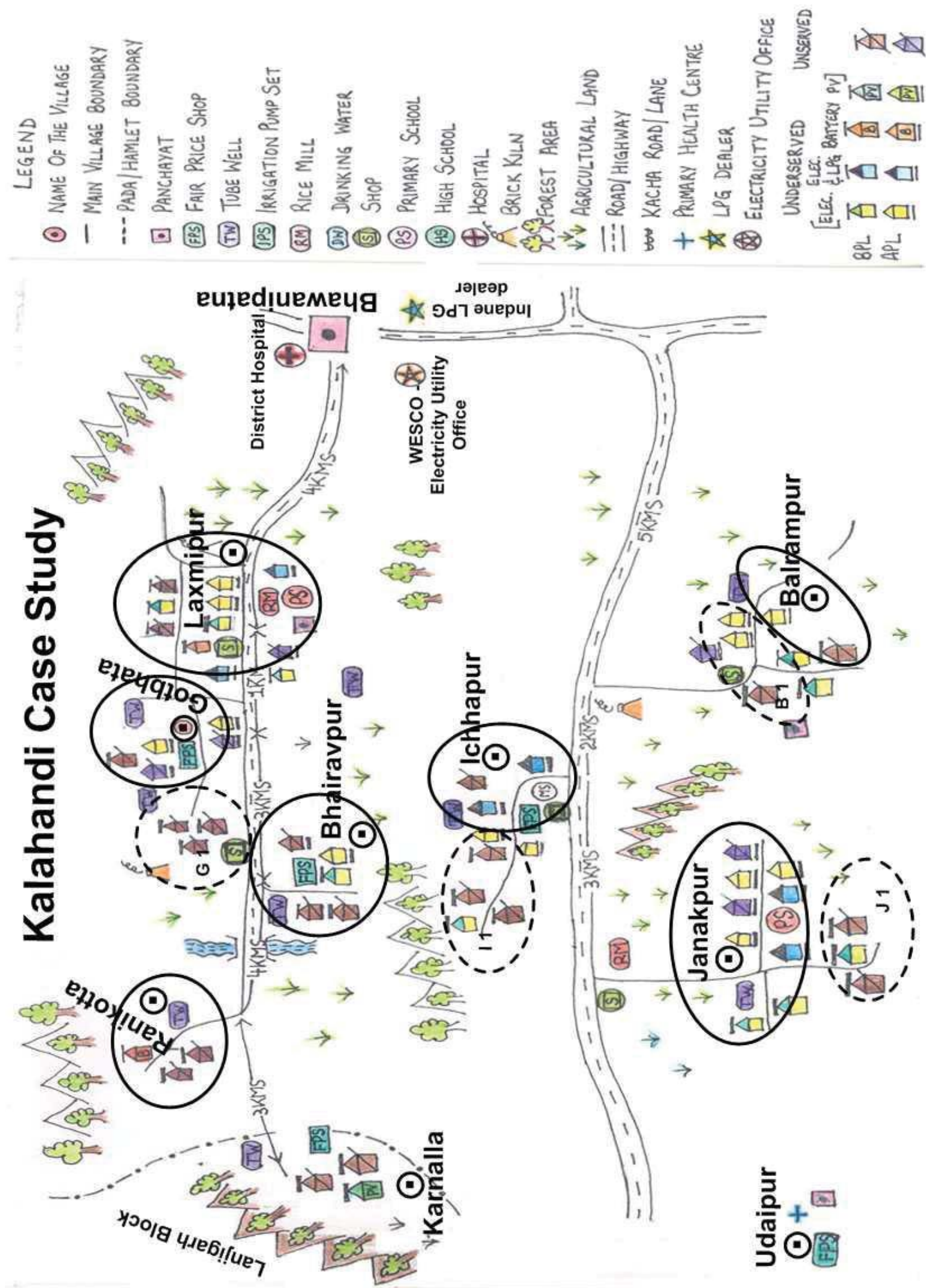

Map 5.3: Map of Kalahandi Case-Study Villages 


\subsubsection{Energy Availability in Kalahandi: Delivery Pathways}

Only a low percentage of rural households have access to electricity and LPG in the Kalahandi district ${ }^{232}$. As a result, households depend upon kerosene oil for lighting and biomass fuels for cooking. While electricity and LPG are available in many parts, there are several padas in otherwise electrified villages, and a few remote villages, which are yet to be electrified. Biomass and kerosene oil dominate the energy supply and energy use in the village clusters that make up the Kalahandi case study. Where electricity is absent, kerosene oil is the primary energy source for lighting. However, kerosene oil supply remains erratic, and this was partly attributed to malpractices and rent-seeking in its distribution. Fuelwood, animal dung cakes and crop residues are the main sources of energy for cooking and heating. The delivery pathways for modern energy carriers are presented in Table 5.15.

Table 5.15: Delivery Pathway and Policy Instruments (2001-02 and 2008-09)

\begin{tabular}{|c|c|c|c|c|}
\hline \multicolumn{5}{|c|}{ Delivery Pathway } \\
\hline \multirow{5}{*}{ 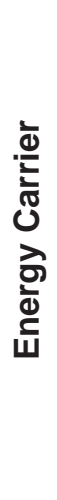 } & \multicolumn{3}{|c|}{2002 and 2008} & \multirow{5}{*}{ 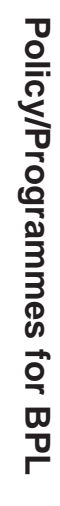 } \\
\hline & Grid Electricity & $\begin{array}{l}\text { Western Orissa Electricity Supply } \\
\text { Company (WESCO) }\end{array}$ & $\begin{array}{l}\text { No separate programme or policy } \\
\text { instrument. } \\
\text { RGGVY projects being developed }\end{array}$ & \\
\hline & LPG & Indane Gas & $\begin{array}{l}\text { No separate programme or policy } \\
\text { instrument }\end{array}$ & \\
\hline & Kerosene Oil & $\begin{array}{l}\text { Fair Price Shops/Public Distribution } \\
\text { System }\end{array}$ & $\begin{array}{l}\text { No additional entitlement or } \\
\text { subsidy }\end{array}$ & \\
\hline & Biomass & Private Collection & & \\
\hline & & $\begin{array}{l}\text { Government/ } \\
\text { Public Sector }\end{array}$ & & \\
\hline
\end{tabular}

\section{Electricity}

It is difficult to obtain accurate information on electricity access by rural households. According to the Census of India 2001, about 10.2\% of rural households in the district had access to electricity. At the same time, a study conducted by the Xavier Institute of Management, Bhubaneswar (XIMB) found that, in the Kalahandi electrified villages, only about $8.5 \%$ of rural households had an electricity connection (XIM, 2001). In 2002, OREDA identified 865 villages in the Kalahandi district as having the potential for electrification through decentralised renewable energy sources (OREDA, 2002). According to this OREDA report, 865 of the 2068 villages in the district were un-electrified, or which 641 were in the

\footnotetext{
${ }^{232}$ See Chapter 3, Table 3.2 188
} 
forest and hill areas ${ }^{233}$. Another study was carried out the district level for planning the rural electrification programme in 2004. This concluded that 2236 villages would be electrified in Kalahandi, including 216,253 BPL households, through the REC. Forty-six villages were identified for electrification through renewable energy sources under the RVEP. As one can see, the status of village electrification in the district varies according to the source used. According to data available from the regulatory commission, $54 \%$ of the villages in the district were electrified ${ }^{234}$ as of 2001 (GRIDCO, 2002), and the OREDA (2002) report puts village electrification in the district at $58 \%$. The statistics provided by the local administration for the district put the percentage of electrified villages at 69\% (Kalahandi District Profile, 2002).

Rural electrification in the district mostly took place during the period between 1980-81 and 1990-91. Post-1991, the rate of rural electrification slowed, particularly after the electricity distribution system was privatised, and the state government closed the rural electrification cell $^{235}$ at the Orissa State Electricity Board (OSEB). No new rural electrification programmes were initiated after the state's electricity reforms. After 1999, when WESCO took over electricity distribution, no additional villages or padas were electrified by the end the second fieldwork period in 2008. While electrification projects under the RGGVY were developed between 2005 and 2008, their implementation was delayed (Khemka, 2009). The main reason for these implementation delays was the lack of clarity over disbursing loans and grants from the REC (implementing agency for RGGVY) to the private distribution utilities in Orissa.

The percentages of pada and of households electrified are slightly less than 25\%. The XIMB study estimated that in the district, the total number of electricity consumers (authorised and unauthorised) is 40,288 , about $24 \%$ of potential consumers (XIM, 2001). The rural household sector alone accounts for $55 \%$ of all connections in the district. Further, the Kutir Jyoti connections for the economically and socially backward communities account for about $13 \%$ of the electricity connections in the district.

The use of electricity in the district is mainly for consumptive energy services (such as lighting, fans and entertainment) and to a limited extent for productive energy services such as irrigation, small industries and allied agricultural activities. From observations in the case study villages, there are only a few private irrigation pump sets (3hp - 5hp capacity), even in the villages where a water supply for irrigation is assured. Village industries typically use rice mills (typically a 10hp motor) or rice haulers (up to $3 \mathrm{hp}$ ), and these were not found in all the case-study villages. One reason for this is the limited access to markets for agricultural surpluses and a limited infrastructure for adding value to agricultural produce as well as minor forest products.

\footnotetext{
${ }^{233}$ Since the classification was based on the location of villages in forest and hill areas and their distance from the nearest electricity grid, the report does not indicate specific renewable energy sources or technologies to be used in this electrification.

${ }^{234} 1115$ out of 2015 villages electrified in the district.

${ }^{235}$ This cell for rural electrification used to plan, coordinate, implement and monitor village and household electrification.
} 
Orissa was the first state in India to privatise electricity distribution. Prior to 1999, the state owned Orissa State Electricity Board (OSEB) was responsible for providing electricity and expanding rural access, for which it received funds from the state government through loans from the Rural Electricity Corporation (REC). Unbundling the vertically integrated OSEB resulted in the formation of two generation companies (thermal and hydro), a single transmission company and four distribution utilities. Responsibility for rural electrification falls to the distribution utility in this arrangement. In the Kalahandi district, the Western Orissa Electricity Supply Company (WESCO), a private company ${ }^{236}$, took over the electricity distribution from the OSEB.

Another state agency, the Orissa State Renewable Energy Development Agency (OREDA), implements the renewable energy programme of the central and state governments, which is mainly financed by the central government. OREDA's main programme in the district has focused on stand-alone solar photovoltaic lighting systems, biogas and improved cookstoves. Table 5.16 summarises the above description of the functions of different actors and phases in electricity (both grid-based and renewable) distribution in Kalahandi.

Table 5.16: Phases and Functions of Electricity distribution

\begin{tabular}{|c|c|c|c|c|c|c|c|c|c|}
\hline \multirow{6}{*}{ 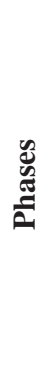 } & \multirow{2}{*}{\multicolumn{2}{|c|}{ Production }} & \multicolumn{7}{|c|}{ Functions } \\
\hline & & & \multicolumn{2}{|c|}{ Strategic Management } & \multicolumn{2}{|c|}{ Daily Management } & \multicolumn{3}{|c|}{ Financing } \\
\hline & Grid & Solar & Grid & Solar & Grid & Solar & $\mathrm{G}$ & & Solar \\
\hline & $\begin{array}{l}\text { Generation \& } \\
\text { Transmission }\end{array}$ & Procurement & $\begin{array}{l}\text { Orissa } \\
\text { GENCO } \\
\text { and } \\
\text { TRANSCO }\end{array}$ & OREDA & $\begin{array}{l}\text { GENCO } \\
\text { and } \\
\text { TRANSCO }\end{array}$ & OREDA & Private & & Public \\
\hline & Distribution & & WESCO & OREDA & WESCO & OREDA & Donor & Public & Public \\
\hline & Sale & & WESCO & OREDA & $\begin{array}{l}\text { WESCO } \\
\text { (and VBS) }\end{array}$ & OREDA & WESCC & & Public \\
\hline
\end{tabular}

The electricity supply problem in the district is not only related to the physical availability of electricity in the villages, but is also compounded by the existence of unauthorised consumers, by legally connected households stealing electricity and by the non-payment of electricity bills. An independent electricity census in the district in 2001 by Xavier Institute of Management (XIM) concluded that there is one unauthorised consumer for each authorised consumer of electricity and five non-consumers for every consumer (authorised or unauthorised) (XIM, 2001). The XIM study also found evidence of rent-seeking behaviour by electricity company staff, including linesmen and revenue collection staff, who tolerate electricity theft and divert the utilities' resources for personal gain. This is a typical example of Agency theory where, in the absence of control, an agent misrepresents information and directs resources for their personal benefit (see Box 2.1, Chapter 2). Sreekumar (2002) and Katiyar (2005) showed in their work in Orissa and Rajasthan that illegal connections by rural

\footnotetext{
${ }^{236}$ WESCO was originally a subsidiary of the Bombay Suburban Electricity Supply Company Limited (BSES). BSES was taken over by Reliance Energy in 2003. Reliance Energy is one of the two private sector distribution companies in India (along with Tata Power) who have set up distribution utilities. 190
} 
electricity consumers is common practice and that electricity consumed through these illegal connections explains the largest proportion of unaccounted energy.

According to WESCO, only $47 \%$ of the rural domestic sector and about $60 \%$ of the Kutir Jyoti connections are actually billed (based on either energy use or a flat-rate tariff). This non-billing represents a significant revenue loss for the distribution company. About $40 \%$ of consumers are billed based on actual consumption, and the remaining $60 \%$ on a flat-rate tariff. The latter group includes those without meters, with non-functional meters and the Kutir Jyoti consumers. According to WESCO and the XIM study, most defaulters are to be found among the flat-rate consumers. In some cases, the arrears exceed Rs 10,000. From the perspective of an electricity distribution company, these non-recovery costs are very high. Adopting the household-level perspective, especially of those who are willing to pay off their arrears, there is a need for an innovative solution from WESCO that would allow repayment in small instalments. Another group of households feel that the problem is with the billing system, and that errors have been made by the distribution utility, which is why they have not paid, and also do not see why they should be penalised by having to pay the arrears.

\section{Box 5.13: Functions of the Village Bidyut Sangha}

- Metering of the authorised and unauthorised connections and meter reading

- Bill distribution and revenue collection; supporting WESCO staff during the revenue collection camps

- Conflict resolution between consumers and WESCO

- Identification of economically and socially weaker consumers and potential consumers (nonelectrified households)

A Village Bidyut Sangha (VBS) has been formed in each electrified village. Each VBS appoints a technically qualified village youth as the Village Contact Point (VCP). The VCP's primary responsibility is to undertake all the functions of the VBS. In 2002, a VCP received one rupee per meter reading and one rupee per distributed bill. However, neither the VBS nor the VCP receive an incentive payment if revenue collection improves as a result of their initiatives.

In the post-reform scenario, the utility's aim was to stop power thefts, reduce technical and commercial losses, improve revenue collection and build a relationship with electricity consumers. This gave rise to a new institutional arrangement in the form of a village-level organisation - the Village Bidyut Sangha $(\mathrm{VBS})^{237}$ - positioned as an intermediary between rural electricity consumers and WESCO (Harper, 2000). The formation of the $\operatorname{VBS}^{238}$ (see Box 5.13) as an institutional intermediary in late-1999 was first initiated by the Xavier

\footnotetext{
${ }^{237}$ In terms of function and phases, Village Bidyut Sangha (VBS) is represented at the 'sale' phase and responsible for supporting WESCO in the daily management of electricity distribution.

${ }^{238}$ The model of intermediation through community institutions was based on the experience of the village of Shahjbhal in Bolangir district of Orissa where the village community came together to address problems related to electricity supply (Rao and Govindrajan, 2003). Subsequently, the Xavier Institute of Management, Bhubaneswar (XIMB) scaled up the implementation of this model to 4000 villages in the WESCO distribution area and 1500 villages in the distribution area of North Eastern Electricity Supply Company (NESCO) (Sinha et al., 2004).
} 
Institute of Management, Bhubaneswar (XIMB), based in Orissa, with a mandate and financing from BSES.

Rural electrification in Orissa has slowed following the electricity sector reforms. The Kannungo Committee, which was set up by the Orissa government in 2000 to review the reform process, noted that all stakeholders had been responsible for the poor progress with power reforms in the state. In particular, the committee considered that "unintentionally, rural power distribution has become the worst casualty of the reforms process" (Kannungo Committee Report, 2001). It went on to add that, between 1999 and 2001, the distribution companies had failed to bring in new funds for expansion and at the same time failed to improve efficiency through management skills, which was a justification for privatisation. The Kannungo Committee Report found that the technical and commercial losses remained high and that there was no improvement in revenue collection. Therefore, despite regular tariff increases, there has been no overall improvement in the utility's financial performance. Therefore, the expectations that electricity reforms involving the privatisation of distribution would improve rural and household electrification have largely been disappointed. Table 5.17 summarises the problems related to electricity privatisation in Kalahandi.

Table 5.17: Problems Related to Grid Electricity Privatisation

\begin{tabular}{|c|c|c|c|}
\hline Problem & Actions taken & $\begin{array}{l}\text { Problem } \\
\text { solved? }\end{array}$ & Remarks \\
\hline $\begin{array}{l}\text { Only } 10 \% \text { of } \\
\text { households } \\
\text { have a grid } \\
\text { connection }\end{array}$ & $\begin{array}{l}\text { WESCO formed } \\
\text { Village Bidyut } \\
\text { Sangha (VBSs) } \\
\text { to address rural } \\
\text { electrification }\end{array}$ & No & $\begin{array}{l}\text { - No grid extensions to un-electrified villages or to non- } \\
\text { electrified households in electrified villages. } \\
\text { WESCO has not initiated any new rural electrification } \\
\text { programmes since it took over responsibility for } \\
\text { distribution }\end{array}$ \\
\hline \multicolumn{4}{|c|}{ Finances } \\
\hline \multicolumn{4}{|c|}{ (a) Poor Financial Control } \\
\hline $\begin{array}{l}\text { (i) Illegal } \\
\text { Connections }\end{array}$ & $\begin{array}{l}\text { Setting-up } \\
\text { Village Bidyut } \\
\text { Sangha (VBS) } \\
\text { and appointing } \\
\text { Village Contact } \\
\text { Point (VCP) }\end{array}$ & Partially & $\begin{array}{l}\text { When the VBS/VCP model was first implemented, it } \\
\text { managed to identify illegal connections, but it was only } \\
\text { partially successful in converting illegal connections to } \\
\text { regular ones. In one instance, the VCP (in Bhairavpur } \\
\text { village) had an illegal connection for his shop, and the } \\
\text { VBS, which notionally controls the VCP, was unable to } \\
\text { exercise its functions. }\end{array}$ \\
\hline $\begin{array}{l}\text { (ii) Non- } \\
\text { payment }\end{array}$ & $\begin{array}{l}\text { Setting-up } \\
\text { Village Bidyut } \\
\text { Sangha (VBS) } \\
\text { and appointing } \\
\text { Village Contact } \\
\text { Point (VCP) } \\
\end{array}$ & Partially & $\begin{array}{l}\text { VBSs in many villages were able to create a link between } \\
\text { WESCO and rural electricity consumers. However, } \\
\text { WESCO failed to satisfy consumer demands for an } \\
\text { amnesty scheme with part payment and part waiver, } \\
\text { despite it having such a scheme for urban users and } \\
\text { industrial defaulters. }\end{array}$ \\
\hline $\begin{array}{l}\text { (iii) Poor staff } \\
\text { supervision }\end{array}$ & $\begin{array}{l}\text { WESCO created } \\
\text { a grievance } \\
\text { reporting system } \\
\text { as part of its } \\
\text { reforms }\end{array}$ & No & $\begin{array}{l}\text { Despite a grievance mechanism, village-level collusion } \\
\text { continues, allowing illegal connections, theft and false } \\
\text { reporting of electricity consumption. }\end{array}$ \\
\hline (b) Tariff & $\begin{array}{l}\text { WESCO Annual } \\
\text { Tariff Order }\end{array}$ & Partially & $\begin{array}{l}\text { Tariff revisions reflect the cost of electricity generation, } \\
\text { transmission and distribution. There is a mismatch between } \\
\text { the paying capacity of rural households and the new tariff. }\end{array}$ \\
\hline $\begin{array}{l}\text { Technical } \\
\text { losses }\end{array}$ & $\begin{array}{l}\text { Upgrading } \\
\text { distribution } \\
\text { infrastructure } \\
\end{array}$ & Partially & $\begin{array}{l}\text { A major part of the technical losses continue to stem from } \\
\text { electricity theft, which has also been supported by } \\
\text { WESCO's distribution staff for small financial gains. }\end{array}$ \\
\hline
\end{tabular}


The Village Bidyut Sangha (VBSs) were established to improve electricity access by users and, at the same time, improve WESCO's commercial viability. The experience is that the VBS, as a community organisation, has met with limited success. While they have been able to identify and use coercive measures to regularise some of the unauthorised connections, they have not been effective in addressing the overall problem of billing disputes, resolving conflicts over arrears or improving revenue collection. In the case study villages, several reasons were identified for the ineffectiveness of VBSs. In Laxmipur, where there is a VBS, none of the surveyed households even knew of its existence. In other villages, the VBS was found to be ineffective in convincing unauthorised consumers or those with arrears to pay. For example, in Balrampur, the VBS's Village Contact Point was found to have an illegal connection and used electricity for lighting in his shop, ignoring the VBS's mandate against power theft. Members of the VBS in Janakpur and Icchapur said that its structure made it ineffective in resolving problems, even though conflict resolution was listed as one of the functions. The main reason being that the VBS does not have the power to resolve conflicts, as this rests either with XIMB (a third-party agency) or with the distribution utility (WESCO). Therefore, while VBSs were set-up to act as an intermediary between electricity consumers and WESCO, as a way of improving access and serving consumers better, they have been largely ineffective.

The villages in the Kalahandi district (and the rest of rural Orissa) have since 2004 been entitled to coverage under national rural electrification programmes (RGGVY and RVEP). Initially, WESCO did not approach the RGGVY for developing rural electrification projects due to a lack of clarity in the RGGVY guidelines over financial support for private distribution companies. Once the guidelines were clarified, WESCO prepared a programme for submission to RGGVY. However, as of 2008-09, implementation had yet to start. Provided the programme is implemented, rural electrification in Kalahandi (and the wider state) will serve as an interesting model of public sector funding of implementation by the private sector. The Kalahandi experience reinforces the argument (see Section 2.3.2) that there remains a role for government in ensuring village access to electricity.

\section{$L P G$}

In the case study villages, and indeed in the entire district, there is only one LPG dealer ${ }^{239}$ based in Bhawanipatna. The dealer belongs to Indane, the public sector oil and gas company. In 2001, the dealer started to have sub-distributors in the block headquarters, but these subdistributors were not able to store LPG cylinders. As of 2002, sub-distributors were only present in the four main towns of the Kalahandi district, which were also the block headquarters. In 1999-2000, a private LPG Company, Mapusa, extended its distribution to villages around the Lanjigarh block, but the company stopped supplying cylinders in 2001 due to limited demand. Since then, there have been no new initiatives by any private sector gas company in the district. The limited infrastructure for LPG delivery in the district is due

\footnotetext{
${ }^{239}$ The Super Gas Agency is the Indane dealership in Bhawanipatna. Interviews were held with the dealer on March 7, 2002 and March 24, 2002. This is the name by which the dealer is registered and should not be confused with Super Gas, a private LPG company.
} 
to a low demand, not just in the rural areas but also in the urban settlements. According to the current LPG dealer, on average 2000 cylinders are sold each month in the district but only around150 of these are delivered to the rural areas ${ }^{240}$.

Table 5.18: Phases and Functions of LPG and Kerosene oil distribution

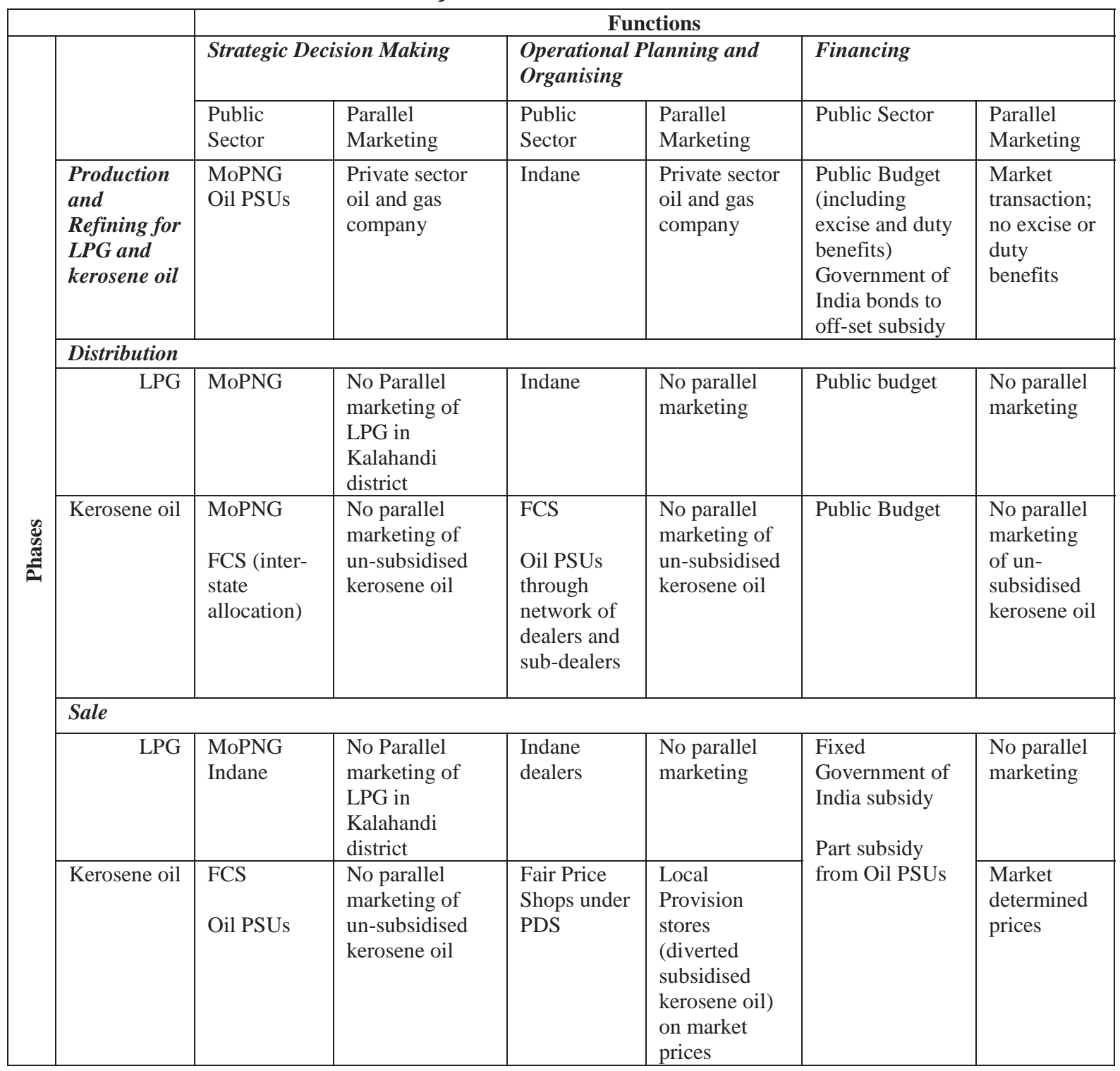

The use of LPG as a cooking fuel is limited to a few households in the villages around Bhawanipatna and in the block headquarters. The dealer offers a $14.2 \mathrm{~kg}$ cylinder and the charge for a connection ranges from Rs 1000 to Rs 3000 depending on whether the consumer opts for a single or double cylinder and the type of stove. In February 2002, following the Union Finance Minister's announcement of the 2002-03 Union Budget, the price of an LPG

${ }^{240}$ Based on an interview held on March 7, 2002. The figures for rural areas are an estimate, as the dealers do not maintain records that distinguish between urban and rural consumers. 
cylinder was increased from Rs 251 to Rs 291. However, due to intense political pressure from allied political parties ${ }^{241}$, the central government halved the increase to Rs 20 , leaving the selling price at Rs 271 per cylinder. Table 5.18 summarises the phases and functions in LPG and kerosene oil distribution in Kalahandi district.

In the village clusters making up the Kalahandi case study, LPG was used in 11 out of the 92 households surveyed during the first fieldwork period (5 in Laxmipur and 6 in the villages of Janakpur, Icchapur and Balrampur. The number of households using LPG had increased to 13 at the time of the second fieldwork. LPG is used only in APL households and all the households using LPG have a reliable income as they are in government service, have their own business, are large farmers, or have some combination of these income sources.

LPG in the rural areas has continued to be distributed by the dealer of the public sector gas company. In the villages, the households identified three problems related to adopting LPG: (i) high transaction costs related to cylinder transport, which can be as much as Rs 40 per cylinder; (ii) the refill cost (Rs 271 in 2002 which had increased to Rs 366 in 2008) inhibits access by many households; and (iii) biomass energy is available at zero cost.

\section{Kerosene oil}

In the rural areas of the Kalahandi district, kerosene oil is the most widely used petroleum fuel with $90 \%$ of the rural households relying on kerosene oil for lighting. However, it is rarely used for cooking. Kerosene oil is supplied through the Fair Price Shops (FPS) or ration shops established under the Public Distribution System (PDS) ${ }^{242}$. Within the state administration, the PDS comes under the Department of Food and Civil Supplies (FCS), which has a supervisory function in ensuring proper allocation and distribution, and ensuring that there are no malpractices in the distribution and pricing of kerosene oil (Section 4.1). Despite this function, the Department has no instruments in place to check the effectiveness of the delivery mechanism or to control pilferage.

According to the FCS guidelines, every ration-card holder is entitled to four litres ${ }^{243}$ of kerosene oil per month. This allocation is available to households as two litres every fortnight with the distribution through the FPS taking place in the first and the third weeks of each month. However, the FPS distributes the kerosene oil on only two days, with the actual dates being decided by them but within the period stipulated by the FCS. Most of the FPS operates on fixed dates which are known in the villages. If villagers fail to buy their entitlement of two

\footnotetext{
${ }^{241}$ The argument used for reducing the price increase was that it would affect the middle-income class, who are the largest group of the LPG consumers predominantly found in urban areas (Section 4.3.3). The initial price increase was effective from March 1, 2002 and the downward revision was introduced two weeks later on March 15, 2002.

${ }^{242}$ Diverted kerosene oil from the FPS is also mixed with diesel and used as a transportation fuel.

${ }^{243}$ This follows from a National Human Rights Commission (NHRC) directive in 1997, which stated that no two individuals could be treated differently and hence the allocation should not be on a per capita basis but rather a fixed allocation (per ration card). This norm ensures equity in access irrespective of household size or economic status. Previously, middle- and high- income households would often misrepresent the names on their ration cards to increase their entitlement.
} 
litres, or buy only part of that entitlement, then they lose the remainder for that fortnight. The price of subsidised kerosene oil in February 2002 was Rs 8.50 per litre. In March 2002, after the price revisions proposed in the 2002-03 Union Budget, the price increased to Rs 10 per litre under the PDS and was unchanged until at least $2009^{244}$. In the villages surveyed, none of the BPL households were receiving their full kerosene oil entitlement/quota, or at the price fixed by the government. Further, the situation deteriorated as one moved from the district headquarters to the more remote villages. The majority of the households never get more than two litres per month, and the FPS retailer argued that this was because he did not receive the full allocation from the distributor. The households also paid Rs 1- Rs 1.50 per litre more than the PDS price. The higher price was "justified" on the grounds that the retailers incur additional transport costs.

Kerosene oil is also available on the open (black) market, with shops selling kerosene oil diverted from the PDS at between Rs 15 and16 per litre. However, in the case-study villages and elsewhere the district, there is no parallel marketing of kerosene oil despite a scheme being introduced by the central government ${ }^{245}$.

\section{Box 5.14: Darshan Chachang: Forfeiting Kerosene Oil Entitlement}

Darshan Chachang was part of a landless BPL household and, at the time of the first fieldwork, his primary source of livelihood was making roof tiles. Besides this, he and his wife sold fuelwood, which they collected from forest areas, in Bhawanipatna. Darshan would mostly sell the wood during the monsoon period, whereas his wife sold it on virtually a daily basis. As with many other BPL households, their ration card had been deposited with the local general merchant's shop in Laxmipur. Darshan, or his wife, purchased kerosene oil two or three times a week, paying Rs 5- 6 during each purchase. So, in a week they spent between Rs 15-18 for purchasing kerosene oil. They had not purchased kerosene oil from the PDS since 2000. The kerosene oil sold is not measured accurately and, for Rs 3, Darshan got anywhere between $150 \mathrm{ml}-200 \mathrm{ml}$. This indicates that Darshan was paying Rs 15-20 per litre, compared to the Rs 10 he would pay under the PDS.

In 2008, during the second fieldwork period, other villagers said that Darshan Chachang had left Kalahandi in 2006 as there was insufficient work. He had moved to Nuapada district, which borders on the state of Chattisgarh, where new industrial activities have provided employment opportunities.

The APL households all buy from the FPS and they are able to obtain their full quota. The unserved BPL households are the ones who most frequently purchase kerosene oil on the open market, often because they are unable to purchase from the FPS when the kerosene oil is available for two reasons. First, some of the BPL households had pledged their ration cards to obtain credit from local moneylenders (mostly village shopkeepers) and could not collect their entitlements without them. The shopkeepers would also use these ration cards to buy subsidised kerosene oil which they then sell on the open market. Second, some BPL

\footnotetext{
${ }^{244}$ The variation in kerosene oil prices under the PDS is due to state taxes that vary from state to state. In addition to these taxes, the Department of Food and Civil Supplies also adds a margin to cover the transportation and handling costs of the Fair Price Shop retailers.

${ }^{245}$ See Chapter 4 for a description of the Parallel Marketing Scheme introduced as part of the petroleum sector reforms. 
households would not have the cash available on the days when the FPS would be selling kerosene oil. Consequently, many low-income and landless households end up buying kerosene oil from these shopkeepers and not from the FPS, as in the case of Darshan Chachang of Gotbhata village (Box 5.14).

\section{Biomass Fuels}

Fuelwood is the main source of energy for cooking in the case-study villages. Fuelwood is not only an energy carrier as it has also become the main basis of earning a daily income for the majority of the landless households due to increasing unemployment and a lack of other economic opportunities. Other biomass fuels, such as dung cakes and crop residues, are not commonly used for cooking, but are used for productive uses such as tile making (the slow burning of dung cakes enables uniform baking) and in brick kilns (crop residues, especially rice husks). A few households in Laxmipur village also used charcoal for cooking, which was locally produced in the neighbouring villages.

More than $95 \%$ of the households in the case study villages gather biomass fuels from forest resources. Over half of the households interviewed travel less than $2 \mathrm{~km}$ to collect biomass but its gathering can involve walking distances of up to $15 \mathrm{~km}$. Men are also involved in collecting wood logs from longer distances, usually during the pre-jhum period when the forest is cleared. In addition to short daily trips, $40 \%$ of the households also collected biomass on a weekly basis, usually at distances beyond $6 \mathrm{~km}$. Some of the wood collected is sold in the local market and urban markets for fuel and for other wood-related activities including carpentry and house construction. In Kalahandi in particular, the selling of fuelwood has become one of the main non-farm economic activities, and some household members continue with this activity during the farming season as the number of sellers then reduces and so the price increases. It is estimated that on average 100 shoulder-loads of fuelwood (about $4000 \mathrm{~kg}$ ) come into Bhawanipatna town every day. In urban markets, fuelwood sells for Rs 2-3 per kg. Although it is notionally free in the rural areas, villagers frequently have to pay bribes to the forest guards.

\section{Delivery Pathways - 2008-09}

The delivery pathways of the energy carriers in Kalahandi have gone through minor changes in the period between 2002 and 2008. While, at a national level, the priority was to enhance electricity access to all by 2012 under the RGGVY, this programme had, as of 2009, not even started in Kalahandi. While the distribution company, WESCO, has been successful in improving revenue collection, electricity distribution had not improved much in the district over the intervening years. Weak maintenance systems and poor implementation of system improvements continue to plague rural electricity distribution. Village Bidyut Sangha, which were established as an interface between consumers and WESCO, have not operated since 2004. The poor incentive structure for the VCP and a lack of clear role for the VBS can be seen as the main reasons for this initiative failing. WESCO was largely interested in the VBS as a way of improving revenue collection. The VBS were externally managed by XIMB and when the funding ended, and they pulled out of the project in 2003-04, the entire system collapsed. However, the delivery pathway for LPG distribution has improved in Kalahandi 
because of a rationalisation of the norms in setting-up LPG distribution by the public sector gas companies. From the one public sector dealer based in Bhawanipatna in 2002, there are now three more dealers in the district including another one in Bhawanipatna. The delivery pathway and policy instruments for kerosene oil have not changed in the district and, despite its availability, access for BPL households is still problematic.

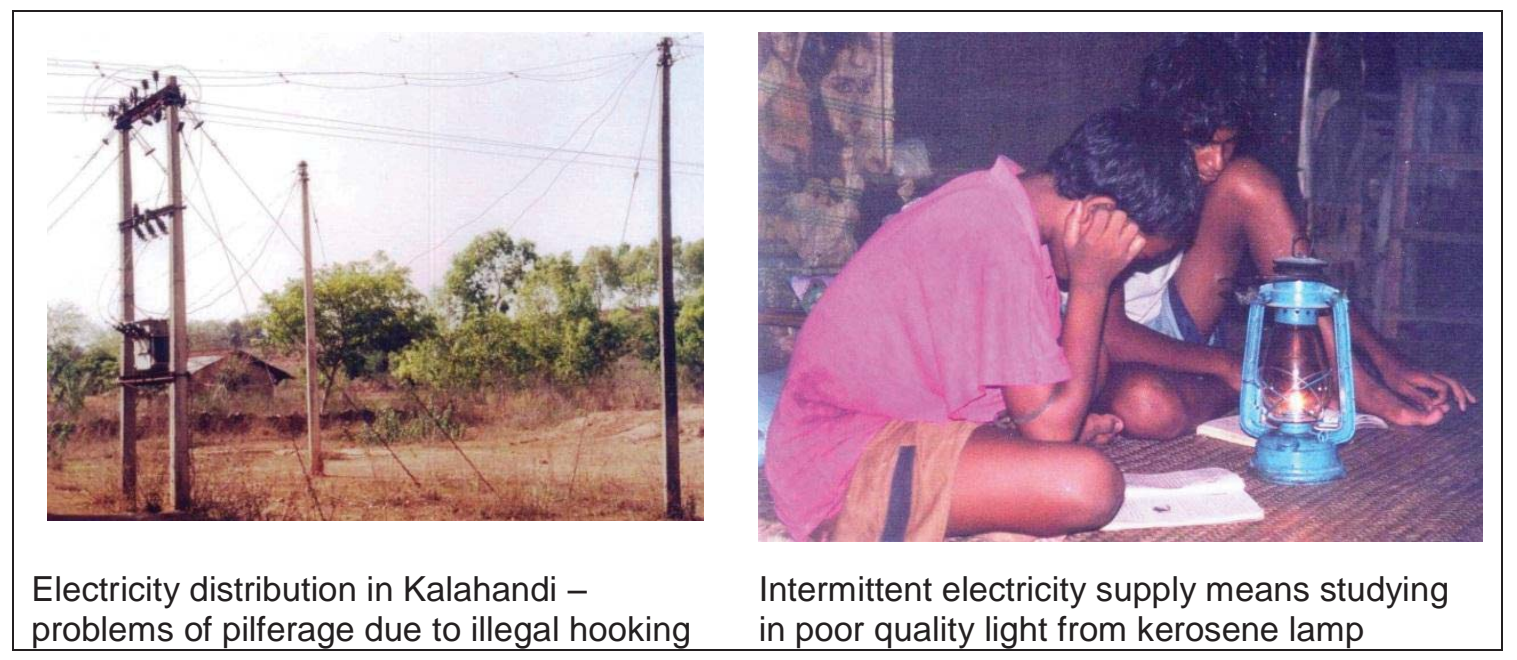

\subsubsection{Access to Modern Energy Carriers: Who Has Access?}

Most of the non-electrified households are located in those padas and villages that the grid has not reached. The lack of access to LPG on the other hand has more to do with the availability of a cheaper alternative (fuelwood) than with poor availability or a lack of a delivery mechanism for the villages. The FPS is the main legal suppliers of kerosene oil, but some of this oil is diverted to the open market by the FPS and also by the village shopkeepers and then sold at a higher price.

Table 5.19: Energy status in village clusters of Kalahandi

2002 and 2008-09

\begin{tabular}{|l|l|c|c|c|}
\hline \multicolumn{2}{|l|}{} & \multicolumn{2}{c|}{ Village Cluster } \\
\hline \multicolumn{2}{|l|}{} & $\begin{array}{c}\text { Laxmipur - } \\
\text { Ranikota }\end{array}$ & Laxmipur & Janakpur \\
\hline \multirow{2}{*}{ Villages } & Ranikota & $\begin{array}{c}\text { Bhairavpur, Laxmipur } \\
\text { and Gotbhata }\end{array}$ & $\begin{array}{c}\text { Icchapur, Janakpur and } \\
\text { Balrampur }\end{array}$ \\
\hline \multicolumn{2}{|l|}{ Total households } \\
\hline \multirow{2}{*}{$\begin{array}{l}\text { Households } \\
\text { with access to }\end{array}$} & Electricity & 0 & 159 & 285 \\
\cline { 2 - 5 } & LPG & $0(0)$ & $78(78)$ & $206(206)$ \\
\cline { 2 - 5 } & Battery & $2(4)$ & Not used & Not used \\
\cline { 2 - 5 } & Kerosene oil & $30(30)$ & $159(159)$ & $285(285)$ \\
\hline
\end{tabular}

First figure 2002, figure in parentheses 2008.

Ranikota has been shown separately in the above table as this village was without electricity access and the electricity grid was not available at the time of the initial survey; and this was still the situation in 2008.

Source: Primary Survey 
Table 5.19, provides an overview of the access to energy carriers in the case-study villages. As described earlier, Ranikota and Bhairavpur are non-electrified villages. Unlike in Bhairavpur, where the households were not connected to the electricity grid, $63 \%$ of the households in Laxmipur and Gotbhata, located within the same Gram Panchayat as Bhairavpur, have access to electricity. In the villages of Icchapur, Janakpur and Balrampur, nearly $72 \%$ of the households use electricity. Overall, less than $4 \%$ of the households use LPG for cooking in these village clusters. The fact that all the households use kerosene oil is a reflection on the frequent power cuts and load-shedding that occurs during evening hours. The use and availability of modern energy carriers, and especially LPG, are limited by the low capacity of the households and the availability of free fuelwood for cooking. Another reason for the limited availability of LPG in the case study villages is the lack of a support infrastructure especially in terms of roads and transportation. Others have found similar reasons for the limited availability of LPG in the rural areas of Tamil Nadu, another Indian state (Parikh and Laxmi, 2000). Since 2002, there has been some fresh effort to increase LPG availability with the public sector dealers having established sub-dealers at block headquarters. Since 2006, new public sector dealers have been established in the district and this has resulted in new rural LPG consumers. However, the distribution infrastructure of LPG is still in a nascent stage.

Table 5.20, provides information on the 92 low-capacity households surveyed as part of the case study. In the case-study villages, 48 households of the surveyed households (52\%) belonged to the underserved category and, of these, only 11 used both electricity and LPG, while the remainder had access only to electricity. The underserved households include those with an illegal connection to the WESCO grid who would mostly use electricity for cooking, lighting and watching television. The remaining 44 surveyed households belonged to the unserved category. Unserved households were to be found in all the seven villages.

\section{Table 5.20: Low-Capacity End-Users in Kalahandi}

\begin{tabular}{|c|c|c|c|}
\hline \multirow{2}{*}{$\begin{array}{c}\text { Underserved } \\
48\end{array}$} & \multirow{2}{*}{$\begin{array}{l}\text { Households with access to } \\
\text { electricity, LPG or both }\end{array}$} & Electricity and LPG & $11\left(13^{*}\right)$ \\
\hline & & Only Electricity & $37\left(35^{*}\right)$ \\
\hline $\begin{array}{c}\text { Unserved } \\
44\end{array}$ & \multicolumn{3}{|c|}{$\begin{array}{l}\text { Households with: } \\
\begin{array}{l}\text { i. No access to electricity and using kerosene oil for lighting } \\
\text { ii. No access to LPG and using wood/ biomass fuels for cooking/thermal energy }\end{array}\end{array}$} \\
\hline \multicolumn{4}{|c|}{ * Reflects that two households switched to using LPG for cooking between the fieldwork periods } \\
\hline \multicolumn{4}{|c|}{ Source: Primary survey } \\
\hline
\end{tabular}

In the Kalahandi case-study villages, the economic status of being either an APL or a BPL household is not reflected in terms of access to modern energy carriers. At the policy level, Kalahandi has always been considered an economically backward district, and therefore has been a prime beneficiary of development programmes including the Kutir Jyoti programme under the government rural electrification plans. For kerosene oil and LPG, there are no separate entitlement schemes or price differentials for APL and BPL households. Table 5.21 
In Pursuit of a Light Bulb and a Smokeless Kitchen

maps the access to modern energy carriers of the surveyed households by the occupation of the household and by their economic classification (APL or BPL). The APL households have a more steady and regular income than the BPL households, and a greater incidence of access to modern energy carriers is also to be found. BPL households' use of modern energy carriers is limited to electricity.

Table 5.21: Mapping Energy Access by Economic Status and Occupation 2002 and 2008-09

\begin{tabular}{|c|c|c|c|c|c|c|}
\hline & & $\begin{array}{l}\text { Government } \\
\text { service (14) }\end{array}$ & $\begin{array}{l}\text { Agricultu } \\
\text { re (31) }\end{array}$ & $\begin{array}{l}\text { Business } \\
\text { (11) }\end{array}$ & $\begin{array}{l}\text { Minor Forest Produce } \\
\text { (MFP) collection \& } \\
\text { selling (5) }\end{array}$ & $\begin{array}{l}\text { Farm/Non- } \\
\text { farm labour } \\
\text { (31) }\end{array}$ \\
\hline Unde & erved & & & & & \\
\hline APL & $\begin{array}{l}\text { Electricity and LPG } \\
\text { (11) }\end{array}$ & $2\left(3^{*}\right)$ & 4 & $5\left(6^{*}\right)$ & - & - \\
\hline & Electricity (14) & $2\left(1^{*}\right)$ & 9 & $3(2 *)$ & - & - \\
\hline BPL & Electricity and LPG (0) & - & - & - & - & - \\
\hline & Electricity (23) & 4 & 6 & 1 & 2 & 10 \\
\hline Unse & & & & & & \\
\hline APL & & 4 & 8 & 2 & - & - \\
\hline BPL & & 2 & 4 & - & 3 & 21 \\
\hline $\begin{array}{l}\text { All } 92 \\
* \text { Ref } \\
\text { Sourc }\end{array}$ & $\begin{array}{l}\text { couseholds also used kerc } \\
\text { cts households that only } \\
\text { Primary survey }\end{array}$ & $\begin{array}{l}\text { ne oil for ligh } \\
\text { d access to ele }\end{array}$ & icity in 2 & but wel & ing LPG for cooking & 2008. \\
\hline
\end{tabular}

In terms of access to modern energy carriers, the connections are in the name of male head of the family. Table 5.22 gives information for the case study area regarding access to modern energy carriers based on whether the women in the household are involved in income-earning activities. Female literacy in the villages of the Kalahandi district is very low (between $12 \%$ and 20\%) compared to state and national averages. There is little emphasis on girls' education as they are expected to help the family with daily chores, including the collection of biomass fuels.

Table 5.22: Energy Access and Women in Income/Non-income Earning Activities 2002 and 2008-09

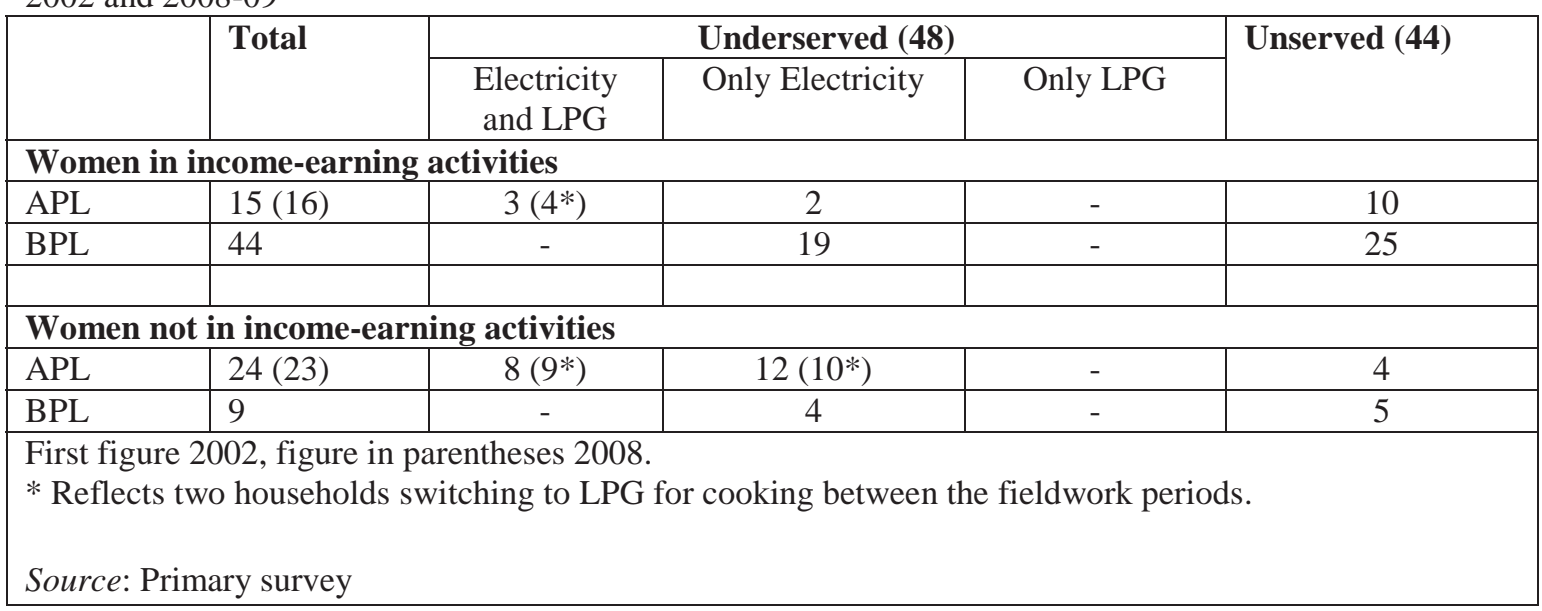


An analysis of Table 5.22 shows that, in the case of the APL households, whether there is a woman working does not affect access to LPG and electricity. This observation in Kalahandi is similar to those made to in Gosaba and Bastar case studies. Here, in fact, the number of households where LPG is used and women are not involved in paid work is higher than in the other two studies. The households using LPG belong to upper caste and economic groups where men take on the role of earning an income to support the family, while the women's role is to take care of the home. While the women members in a few households in Icchapur and Janakpur felt that the availability of LPG has reduced drudgery and the time spent collecting fuel, in another household in Janakpur the woman respondent was indifferent to the use of LPG, and felt that it came with economic status. In addition, in this household, the woman did not cook herself as they had a domestic help. Despite the fact that most of the women in BPL households are involved in paid work, use of modern energy carriers is limited to electricity. These households have electricity because of the KJ programme, and the incomes the women earn do not make sufficient difference to the household income to enable them to afford LPG.

The difference between the two categories can be traced to the nature of the paid work that women in APL and BPL households do, again a similar finding the other two case studies. Women in BPL households generally work as farm and non-farm labourers for very low wages, typically in the range of Rs 35 - 40 per day. In the APL households where women are working, they are employed in government services, schools, and hospitals and health centres, all of which provide a steady income, unlike in the BPL households where the income varies. This income vulnerability, along with other more pressing economic needs, restricts LPG adoption by women in BPL households.

However, even if women are working, and earning a good income, it does not mean that they can spend the money on buying modern energy carriers since such decisions are not dependent on their contribution to the household economy but on intra-household roles in decision-making. As an example, the women members of a self-help group involved in trading agricultural commodities said that they prefer to use the money they earn for personal items. None of these women had invested in a LPG connection, nor did they plan to invest, since they felt this would require a decision to be taken by their husband. As such, women's involvement in income-earning activities does not seem to be a sufficient condition to ensure a shift to modern energy carriers. While it has been argued that women's economic empowerment, for example through paid work outside the home, can lead to a change in their status in the home, including increasing their influence in decision-making about major purchases including energy carriers; this appears not to have happened in the villages surveyed in Kalahandi. Decisions about using money within a household remain with the men.

\subsubsection{Contextual Influences that Affect Energy Access}

The interplay of the four contextual influences - infrastructure, economic, social and political - affected access to modern energy carriers in Kalahandi (see Figure 5.3). Here, a contributing factor to changing the delivery of electricity was the policy decision to privatise the electricity sector. The impact of this political factor needs to be looked at together with 
the local economy, or rather the lack of significant economic activities at the village level. A weak local economy, and the consequent low financial returns, impacts on the infrastructure development required to deliver energy carriers. A weak local economy also limits the ability of people to afford modern energy carriers.

Infrastructure plays a significant role in ensuring that energy carriers, especially those that are transported and transmitted from outside the district, are available in the villages. In the case of Kalahandi, the lack of physical infrastructure was a barrier in those villages located in the hilly areas of the district and, as a result, these villages do not have electricity or other modern energy carriers due to transportation difficulties.

Since grid extension was considered the best approach for providing electricity access in villages, electricity was available in villages where the OSEB had extended the grid.

However, as a large number of villages and households remain non-electrified, there is still a wide scope for grid extension in the district. The limited electricity expansion is not a problem of infrastructure alone; it also reflects policy decisions and the availability of programmes. In the state of Orissa, since the electricity sector has been privatised, grid expansion is no longer contingent on the availability of government funds, but is driven by the efficiency and profitability of the private distribution company. The non-electrified padas and the non-electrified households in villages with a supply remain because there have been no new initiatives to electrify these households. In villages such as Ranikota, which is nonelectrified and does not feature in WESCO's electrification plans, households are using alternative options to meet their energy needs. For example, in Ranikota, two households are using batteries to operate televisions (see Box 5.15).

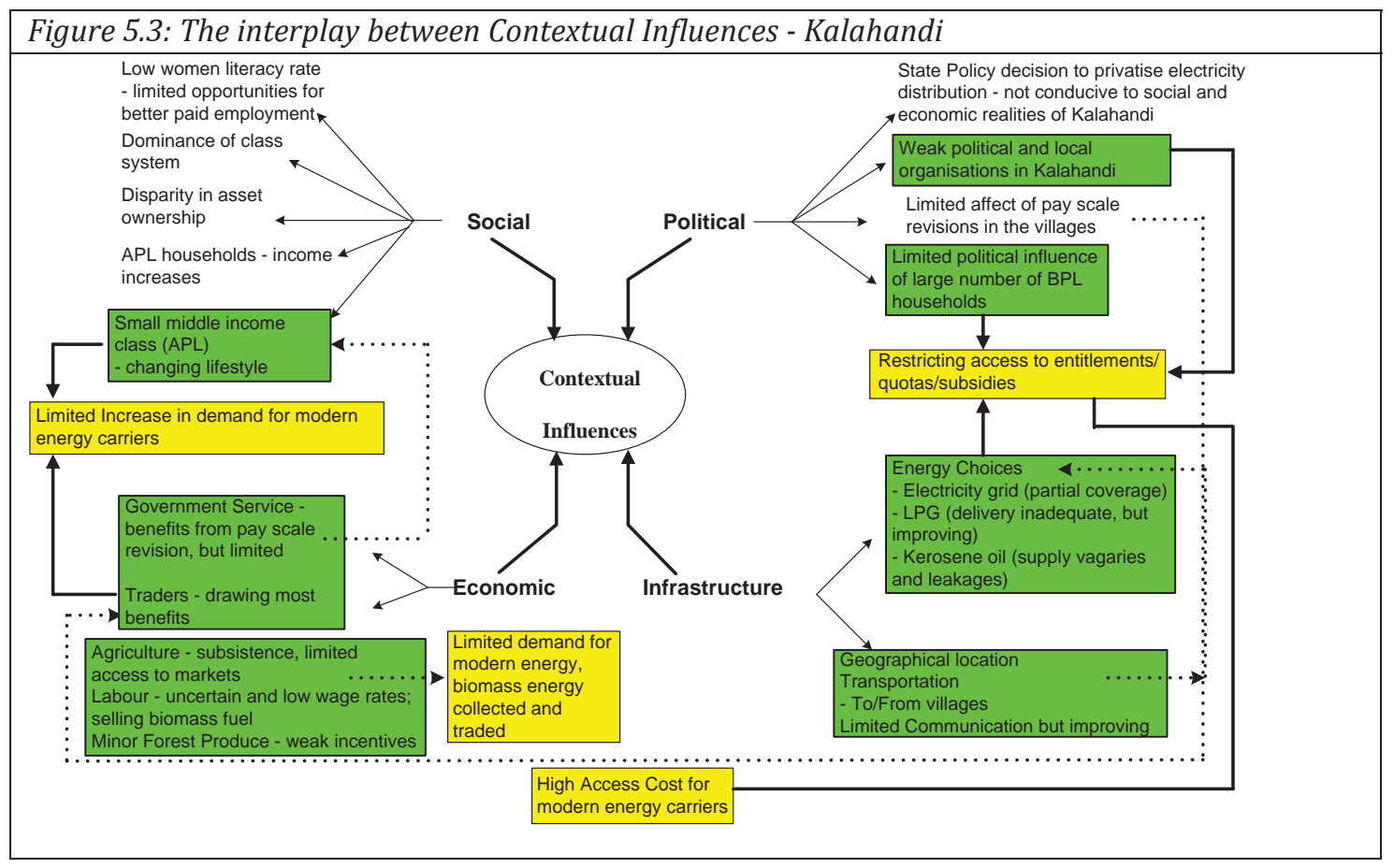




\section{Box 5.15: Bal Majhi - A battery to run a Television}

Bal Majhi is a small landholding agricultural farmer living in Ranikota. At the time of the first fieldwork (in 2002), Ranikota was not electrified and Bal Majhi was using a battery to operate a television. A battery typically lasted him four to five days, and then he had to take the battery to Bhawanipatna market and pay Rs 35 for it to be recharged. His monthly expenditure on battery charging was around Rs 140, not dissimilar to the electricity bills of equivalent households.

In 2002, Bal Majhi was elected unopposed to the Gram Panchayat, and he tried to get electricity for the village but was not successful. Since 2007, he is no longer a Panchayat member. As of 2008, despite the emphasis on enhancing electricity access through the national rural electrification programme, Ranikota was yet to be electrified.

Bal Majhi now works as part of the national rural employment scheme, which assures him work for 100 days a year. Bal Majhi, and his wife and daughter, work as hired labour in addition to working their own agricultural land. He continues to use a battery and now pays Rs 50 per charge, totalling between Rs 150 and Rs 200 per month. He continues to believe that if he had received support from the district's elected political representatives, and from WESCO, that his village would now have electricity.

Despite the availability of grid electricity in many of the villages, electricity is mostly used for consumptive purposes (lighting and entertainment). Use for productive purposes such as irrigation, small-scale industries and micro-enterprises is limited but did begin to increase in 2005. A further problem is that the electricity distribution infrastructure has seen very little investment in its upgrading, resulting in frequent blackouts and brownouts.

The delivery infrastructure for petroleum energy carriers (LPG and kerosene oil) has been fairly stable during the research period up to the level of the district headquarters. There is only one LPG dealer (Indane) in the entire district and even though the dealer has informal arrangements in a few other towns in the district, the delivery of LPG to rural areas is a major constraint. The non-availability of a reliable transport infrastructure often results in an intermittent supply of these energy carriers and this, in turn, affects people's choice and decisions regarding energy carriers as well as at times increasing their access costs. The negative impact of unreliable transport on supply came out clearly in Ranikota village where kerosene oil is not supplied. For LPG, there is an additional cost to cover transportation and handling fees paid to the rickshaw pullers. With kerosene oil, the inadequate implementation and monitoring of the public distribution system (by the principals), plus an irregular supply, allows FPS retailers (the agents) to use the conditions to their advantage and indulge in pilferage.

In the Kalahandi villages, one finds different levels of economic opportunities, and this influences access in various ways. The mainstay of the rural economy is to an extent mixed in a few villages and more generally largely dependent on subsistence agriculture and minor forest produce collection. The stories of Loknath Mishra (Box 5.16) and Bhibhuti Deo (Box 5.17) provide examples of households that have a stable income due to combining various livelihood activities and are able to benefit from their consequent economic wellbeing by utilising modern energy carriers. These households include some with members in government service and/or in business, as well as the gonthiyas, who own land and benefit from mixed economic activities. 


\section{Box 5.16: Loknath Mishra - A Combination of Modern Energy Carriers}

Loknath Mishra is a businessman involved in the trading of agricultural inputs such as fertilisers and seeds, and his household is in Icchapur. He also owns five acres of land and has a tractor. Despite these assets, Loknath Mishra admitted during the interview as part of the first field study that he held a BPL ration card. His household was the only one in the village to have a colour TV.

The switch to LPG came after the marriage of his elder son since it then suited the changing social and economic profile of the household. Most of the household members were unwilling to spend time searching for biomass and so they started to buy fuelwood from other villagers. In 2004, LPG was used to cook one meal a day and other meals were cooked using biomass. A new cylinder was on average required every month. They paid Rs 255 for a refill which would be obtained when a male member of the household was going to Bhawanipatna.

At the time of the second fieldwork, Loknath's household was now using LPG regularly for cooking. The availability of LPG had improved and refill cylinders were easily available. The price of a $14.2 \mathrm{~kg}$ LPG cylinder was Rs 366 in 2008, and a cylinder lasted the family for about 25 days. Electricity supply continued to be intermittent with frequent disruptions, and the household continued to rely on kerosene oil for lighting.

\section{Box 5.17: Bhibuti Deo - Choice of LPG for Cooking}

Bhibuti Deo is a schoolteacher in Janakpur's primary school. Besides this income source, he also has five acres of land and practices alternative medicine. His household has five members, and they switched to LPG for cooking in 2001, not long before the first fieldwork period. However, there were still occasions when biomass and kerosene oil were used. On average, an LPG cylinder was lasting a month and they were paying Rs 255 for a refill plus Rs 10 in transportation charges.

By 2008, access, especially in terms of LPG availability from the dealer, had improved and cylinders were available practically on demand. In 2008, Bhibuti Deo was spending Rs 25 per cylinder as transportation cost.

The APL households that are unserved by electricity are in this position due to the lack of a nearby grid. These households are mostly in the non-electrified padas. APL households who do not use LPG for cooking identified the following reasons: (i) easy availability of biomass energy which they either collect or purchase from other villagers, as in the case of P N Behera (see box 5.18); and (ii) the high upfront costs of switching to LPG (investment in connection, gas stove and cooking vessels) plus recurring cylinder refill and transportation costs.

\section{Box 5.18: P N Behera - Biomass for Cooking}

P N Behera lives in Laxmipur village and has a grocery shop in the village. At the time of the first fieldwork, his family used biomass, sometimes in the form of charcoal, for cooking their meals. He had considered getting a LPG connection, but had decided against as it was expensive and biomass, including charcoal, was readily available at an affordable price in the village.

On returning to the village in 2008, there is no change in the fuel use pattern in Behera's house. Cooking was still done using fuelwood and charcoal. However both his sons were now working and Behera felt that, when they get married, their choice would be to have LPG for cooking. 
The second period of fieldwork revealed that a few households had, between 2002 and 2008, switched to using LPG for cooking. In Laxmipur, Bhawani Mishra's household had started to use LPG, but had not completely given up using biomass. In Gotbhata, Sudhanshu Sekhar Mund's family had switched to LPG following changes in the household but were considering reverting to biomass (see Box 5.19). In terms of cooking energy, it can be seen that households do not only climb the energy ladder, at times they step back, such that shifting between biomass fuel and LPG is not one-directional. This is mainly driven by the relative availability of competing fuels and changing economic circumstances within the household.

\section{Box 5.19: B Mishra and S Mund - Backward and Forward Shifts in Cooking}

Bhawani Mishra was, in 2002 at the time of the first fieldwork, a government employee and also a largescale farmer in Laxmipur. The household had electricity but biomass was readily available, and they had labourers working on their fields who would collect it for them. Being in government employment, Bhawani was spending a lot of time outside the village, whereas his family remained in the village. In 2005, he retired from government service and moved back to village. During his postings, he had used LPG for cooking and the household took a connection in 2006. The reasons for his decision included the added convenience in cooking and the easy availability of LPG from the dealer. His son now runs a small shop in the village and, as he regularly travels to Bhawanipatna, he can bring a new LPG cylinder when required. While LPG was increasingly being used for more of the cooking, the household was still using some biomass in 2008 since it was easily obtained.

In 2002, Sudhanshu Mund lived in the village of Gotbhata, and was a farmer and also a PDS retailer. His family used only biomass for cooking. At the time of first fieldwork, Sudhanshu indicated that he could easily afford LPG but that he felt that the initial and recurring costs were on the high side. However, for him the main barrier to LPG adoption was the difficulty in obtaining an LPG connection (availability) from the dealer. The household did eventually decide to switch to LPG in 2006 because new dealers in Bhawanipatna were offering LPG connections and LPG now seemed readily available. Sadly, Sudhanshu Mund passed away in 2008, and his wife was contemplating giving the connection to her son who lives in Bhawanipatna as she could not afford to pay for new cylinders. The FPS, which was allotted to her husband under the PDS, has now been allotted to another person and her main source of income is from a smallholding.

Many households, such as those of Darshan Chachang (Box 5.14) and Bal Majhi (Box 5.15), depend upon subsistence agriculture, working as farm labourers, collecting and selling minor forest products, collecting and selling of firewood and sometimes working as migrant labourers. These households are unable to adopt modern energy carriers because livelihoods do not generate sufficient, if any, surplus income.

In Kalahandi, the social and caste structures do have an impact on access to modern energy carriers. The district's dominant social caste, the gonthiya, initially benefited most from the government programmes. The introduction of the KJ programme did however enable the Scheduled Castes to access electricity in the main villages. However, in all the case study villages, it was notable that the un-electrified padas were those belonging to Scheduled Castes and Scheduled Tribes. A case in point here is the delay in providing electricity to the village of Janakpur despite five Schedule Tribe households depositing the appropriate connection fees. The grid was not extended because the utility claimed it was unable to provide the poles. Eventually, these households used bamboo poles to extend the grid at their own cost. 
The role of intra-household attitudes as a social factor is less clear in the case of Kalahandi. In the high-income households, access to modern energy carriers seems to be driven by their growing economic and social status. However, anecdotal evidence provides some interesting changes in social relationships and their impact on intra-household decision-making. Increasingly, families from outside Kalahandi are refusing to allow their daughters to marry into Kalahandi families if the households do not have electricity and LPG. In some cases, the families provide LPG connections as part of their wedding gifts, but the new husbands are reluctant to accept such gifts because they will have to bear the future recurrent costs. In some BPL households, the income from the economic activities of both the men and the women is sufficient to purchase modern energy carriers.

Political factors, and especially policy interventions and local politics, have affected access to modern energy carriers. The decision of the state government to implement power sector reforms was driven by the desire to attract private sector investment in the power sector and other infrastructure developments in the state. However, in the process, the state government failed to consider whether conditions across the state were suitable for electricity privatisation, especially in western Orissa with its high incidence of poverty. Rural electrification can be seen as a market distortion since it requires incentives and subsidies (see Sections 2.3.1 and 2.3.3). Nevertheless, a senior WESCO official did remark that the company viewed rural electrification as vital, and as part of their corporate social responsibility. At the local level, the weak political influence of local institutions has largely been responsible for the failure to check leakages in the public distribution system. Gram Panchayats have not addressed the problem of households who have pledged their ration cards and are thus unable to access subsidised food and kerosene oil, which in then diverted and sold at a profit. There is a general lack of checks and balances to ensure that subsidies remain targeted and so reach those households who need and would benefit from them.

The principles of gender equality and women's rights are also ignored when FPS dealerships are not transferred to a woman on her husband's death. Widowhood is one of the routes down which women enter poverty. Sudhanshu Mund's wife (Box 5.19) illustrates this point in that she will be forced back into energy poverty when financial reasons force her to relinquish her LPG connection.

\subsubsection{Policy Design in relation to Implementation}

This chapter started with a broad question on policy design in relation to its implementation. Based on the information presented in Sections 5.4.1 to 5.4.4, this question on policy design can be answered with respect to implementation in Kalahandi, and the findings are summarised in Box 5.20.

The poverty seem in Kalahandi is somewhat paradoxical given that the district is rich in forest and mineral natural resources, and has a large labour force. The district is the second largest producer of rice in the state but still the people are trapped in a vicious circle of poverty (more than $85 \%$ of people are classified as below the poverty line). Although access to modern energy could assist in alleviating poverty, the state needs to create an enabling 
policy environment. The state-level decision to privatise electricity distribution has clearly had no positive affect on electricity access in the district.

Reflecting on the analysis for Kalahandi indicates that there is evidence of some effective policy design (the privatisation of electricity at the sectoral level) but also some ineffective policy design (the formation of Village Bidyut Sangha). Kalahandi also provides examples of implementations which were ineffective and inapplicable (privatisation of electricity distribution, and the inability to check pilferage of kerosene oil).

\section{Box 5.20: Policy Design and Implementation in Kalahandi}

\begin{tabular}{|c|c|c|}
\hline \multirow[b]{2}{*}{ Policy Design } & \multicolumn{2}{|c|}{ Policy Implementation } \\
\hline & Applicability & Effectiveness \\
\hline $\begin{array}{l}\text { Electricity - } \\
\text { Distribution } \\
\text { Privatisation }\end{array}$ & $\begin{array}{l}\text { Privatisation as appropriate reform } \\
\text { model in the context of electricity } \\
\text { sector distribution and commercial } \\
\text { losses and the need for a viable and } \\
\text { functioning sector } \\
\text { - Not applicable nor suitable for } \\
\text { Kalahandi region by failing to take } \\
\text { account of the district's } \\
\text { socioeconomic context and } \\
\text { development deficit }\end{array}$ & $\begin{array}{l}\text { - No post-privatisation change in } \\
\text { availability; a few BPL households } \\
\text { disconnected } \\
\text { - Mediation through VBS successful } \\
\text { in the initial stages in improving } \\
\text { services; but became ineffective in } \\
\text { the long-term } \\
\text { - Intermittent electricity supply } \\
\text { especially in the evenings } \\
\text { Revised electricity tariffs fail to take } \\
\text { account of people's ability to pay }\end{array}$ \\
\hline $\begin{array}{l}\text { LPG - Public } \\
\text { Sector }\end{array}$ & $\begin{array}{l}\text { Public sector dealer as the } \\
\text { distribution model is appropriate } \\
\text { given Kalahandi's socioeconomic } \\
\text { context } \\
\text { Distribution norms for public sector } \\
\text { dealers excluded rural consumers; } \\
\text { this was changed in } 2006 \text { and has } \\
\text { improved LPG delivery } \\
\text { infrastructure }\end{array}$ & $\begin{array}{l}\text { Availability has improved in some } \\
\text { places with more dealers providing } \\
\text { LPG } \\
\text { Access limited to APL households } \\
\text { who can afford initial and recurring } \\
\text { costs (including transportation } \\
\text { charges) } \\
\text { No scheme for provision of small } \\
\text { capacity cylinders }\end{array}$ \\
\hline $\begin{array}{l}\text { PDS/FPS } \\
\text { Kerosene Oil }\end{array}$ & $\begin{array}{l}\text { FPS-based model ensures delivery } \\
\text { and distribution; however the norms } \\
\text { (per capita allocation and timing of } \\
\text { supply) governing delivery } \\
\text { mismatch with household energy } \\
\text { needs and cash flow patterns }\end{array}$ & $\begin{array}{l}\text { Availability fails to match allocation } \\
\text { due to pilferage in the supply chain } \\
\text { and diversion to the open market } \\
\text { - Inflexibility in timing and } \\
\text { distribution days } \\
\text { - Subsidies notionally improve access } \\
\text { for APL and BPL households; but } \\
\text { many BPL households forfeit their } \\
\text { entitlements }\end{array}$ \\
\hline
\end{tabular}

Irrespective of the motives of the state government in reforming its electricity sector, the policy decision to privatise the electricity sector at the state level was an effective and applicable policy design in view of the need to improve the efficiency of the electricity sector. The accompanying decision by the state government to detach itself from the electricity sector, especially in terms of rural electrification when a large number of villages and households were yet to be electrified, was not an effective policy decision, because this resulted in a large number of underserved and unserved households. While the motives for 
the power sector reforms were to make Orissa an investment friendly state, the failure to recognise the problems of an ailing and inefficient distribution infrastructure did not help in ensuring that the policy decision to privatise the sector brought benefits to both the sector and to its consumers. Although the decision to establish Village Bidyut Sangha (VBSs), as intermediaries between consumers and WESCO, appeared to be an applicable and effective organisational model, its design was flawed and its functions and powers were so curtailed that it could not take independent decisions. In some villages, electricity consumers were even unaware of the presence of a VBS. In those villages where electricity consumers were aware of the VBS, they were not clear as to its role and functions. Incentives for improving WESCO's revenue collection, and reducing theft and commercial losses, should have gone to the VBS. Instead, these went to XIMB and so any village-level initiatives were driven by XIMB, a third party agency, and not by the VBS. As a result, when the pilot phase with XIMB's involvement ended in 2004, the VBS system in Kalahandi collapsed.

In the case of LPG, the presence of only one public sector dealer reflects the limited demand for LPG by local households. Although a parallel marketing scheme for private sector participation applies to all states, private LPG dealers and suppliers, as of 2009, have not established a presence in Kalahandi. One explanation is that the private LPG companies do not see Kalahandi as a lucrative market given its very high incidence of BPL households. Further, now that the public supply chain has improved, households would in any case prefer to have a LPG connection from the public sector dealer and so benefit from subsidies.

A clear case of an inapplicable policy design followed by ineffective policy implementation can be seen in the delivery of kerosene oil. While the state government equally allocates kerosene oil, the greater demand from higher income households, coupled with poorer households using their ration cards to secure credit, has allowed kerosene oil to be diverted onto the open market. The inflexible delivery mechanism and the diversion onto the open market has had a significant impact on BPL households, who end up buying the oil they were entitled to at a subsidised price from the market at a higher price.

The Kalahandi case study provides evidence that the social aspects of enhancing access to electricity for public benefits, and especially for improving access for low-capacity end-users, do not appear on the reforms agenda of the private sector. This has implications for expanding electricity delivery in the rural areas and for providing access to the unserved households who lack the capacity to pay for electricity. If the unserved BPL households are to be moved out of energy poverty, access to modern energy needs to be enabled so that they can improve their quality of life and, through new economic activities, generate a cash surplus. Therefore, in the future, the inclusion of social benefits (including the gender dimensions of energy access) is essential in policy design and implementation. This topic will now be addressed in the final chapter of this thesis.

\subsection{Conclusions: Answering Main Research Question 2}

Understanding energy access in the surveyed villages, spread across three districts and three states, requires peeling away several layers of village dynamics plus similarities and 
dissimilarities in policies and programmes and in their implementation. The evidence from this process, as presented in Sections 5.2-5.4, provides sufficient data to answer the second main research question and its sub-questions. Information on the delivery pathways, access to modern energy carriers, and contextual influences affecting this access by low-capacity endusers in each of the case-study regions, when analysed together, allows conclusions to be drawn on the design and implementation of energy policies both before and after 2004.

\section{Sub-question 2.1: How do delivery pathways and enabling factors influence access by low- capacity end-users to modern energy carriers?}

In the three case-study regions, a combination of public and private sector delivery pathways for modern energy carriers were found. When comparing the two fieldwork periods, there has been, since 2004, a visible shift towards a greater role for the public sector in providing modern energy carriers to the low-capacity end-users in rural India. Due to the different organisational settings (Section 4.2) governing these energy carriers as well as their different characteristics, including different phases and functions (based on Boorsma's 3-C framework, Section 2.4 and Box 2.3), the delivery pathways (Section 2.5.1) vary across the three casestudy regions for each modern energy carrier. In a few instances, the delivery pathways have enabled access by low-capacity end-users but, in others, the delivery pathways have actually had a negative effect on energy access. As explained below, these positive and negative effects are due to a combination of factors that influence organisations and policy instruments.

\section{Role of Enabling Factors: Organisations}

Various types of organisations with different functions were responsible for electricity delivery in the case-study regions during the two fieldwork periods due to different phases. The organisations uncovered included decentralised cooperatives managed by the state government (in Gosaba), publically owned bodies (Bastar) and privately owned distribution organisations as in Kalahandi. The operational structure of these organisations differed, and comparing the different electricity distribution approaches brings out the contrasts in how these organisations are either enabling or failing to enable energy access. The publicly-owned distribution organisation in Bastar enables electricity access through policy instruments such as allowing payment in small instalments at the village level to address the issues of affordability for low-capacity end-users. Electricity distribution in Gosaba, on the other hand, is a combined effort of the state government and an electricity cooperative, set-up by the block Panchayat in line with constitutional provisions (Box 4.1). Here, the West Bengal state government takes decisions on crucial issues such as tariff revisions and on spreading electricity access to non-electrified households. The cooperative implements the decisions of the state government, but plays no role in formulating policies, so it is unable to inform policymakers about the contextual influences that are acting as barriers to access. Therefore, the inclusion of decentralisation and local governance, as laid down in the constitutional provisions (Section 4.2.1), is not achieving the objectives. 
The structure for electricity distribution in Kalahandi reflects the post-reform model of privatisation. In order to facilitate electricity distribution in the villages, the private distribution utility involved a community organisation, the VBS. However, evidence from Kalahandi shows that the VBS model (Section 5.4.1) has been driven by the commercial interests of the private-sector organisation, and that the VBSs have had limited functions and also limited capacity to take on the roles assigned. As the analysis shows, the driving force for the utility was to improve revenue collection. The distribution utility had limited interest in improving the quality of electricity supply or in enabling access by the unserved lowcapacity end-users. The utility was similarly not interested in finding solutions to grievances of existing consumers related to supply hours and electricity bills. This lack of a consumer orientation is an example of market failure. This VBS model was externally designed by a third organisation, with no connection or coordination role with the utility, and funded by an external donor, and then was embedded in the utility's distribution system. The utility did not invest in building the capacity of the VBSs to fulfil their functions. Further, the payment structures for the VBSs can be considered as inadequate since they failed to provide an incentive to function effectively. The model was not appropriate in the sense that it did not recognise local capacities and motivation. Consequently, when the supporting agencies involved in the design of the VBS model withdrew, the private distribution utility lost interest and the VBS model became ineffective and non-functional. The experience in Kalahandi shows that if a proper analysis of the characteristics and capabilities (Section 2.4) of the electricity distribution had been undertaken prior to the privatisation of electricity distribution, then this would have helped in designing a more effective implementation.

The organisations involved in LPG delivery also changed between 2001 and 2008/09, with a shift in the delivery pathways from a combination of public and private sector organisations back to public sector organisations. During the first fieldwork period (2001-02), both the public and private sectors were involved in LPG delivery in Gosaba and Bastar, while in Kalahandi it was only the public sector. Post-reform policy changes (in Phase III, and specifically between 1991 and 1999) had created an enabling environment for private sector participation in LPG delivery by removing access barriers.

Public-sector dealers had to follow certain guidelines in distributing LPG, which were decided on the central government level and, due to institutional inflexibilities, dealers had to adhere to these guidelines and, as a result, local dealers found themselves unable to serve the rural areas. This created an opportunity for the private sector to enter the market. The topdown organisational structure for LPG distribution in rural areas is an example of the rationales often applied in public sector reforms (Section 2.3). This shift towards allowing the private sector into the market (under PMS, Section 4.4.2 and Box 4.6) has increased LPG availability. The PMS involving the private sector brought a greater focus on the unserved rural markets since the private LPG companies had the option of targeting these markets. The further liberalisation of norms since 2004, such as those related to market restrictions and the allowable delivery distances for the public-sector dealers, has also helped in improving LPG availability for rural households (Section 4.4.2), as seen in the case stories of Amiyon Mandal (Gosaba, Box 5.4), and Bhibhuti Deo (Box 5.17) and Bhawani Mishra (Box 5.19) in Kalahandi. 
However, the reforms have not dealt with some important issues such as the delivery of LPG cylinders in rural areas which, even in 2010, remains a critical bottleneck with regard to availability. Even though the Rajiv Gandhi Rural LPG Vitrak Scheme (Section 4.4.2), initiated by the central government in 2009, aims at strengthening the distribution infrastructure in rural areas by establishing dealers for clusters of villages, the scheme makes no provision for the delivery of cylinders to rural households. Households have to make their own arrangements for getting their cylinders refilled, a process which has its own dynamics and can be influenced by intra-household relationships. Informal arrangements, based on local entrepreneurial activities, for the delivery of LPG cylinders exist but add to the transaction costs for low-capacity end-users. As an example, since an increased number of rural households in Gosaba have started using LPG for cooking, local delivery mechanisms have been set-up and institutionalised. In comparison, fewer households use LPG in the villages in Bastar and Kalahandi, and so informal arrangements involving a third party for LPG delivery have not yet emerged. Households still have to collect the cylinders themselves, and this requires intra-household negotiation.

The organisation of kerosene oil delivery is part of the government's Public Distribution System (PDS) and, across the three case-study regions, there has been no change in the delivery pathway between the two fieldwork periods. Since kerosene oil distribution is driven by public sector policies and government interventions, its availability was not found to be a constraint in any of the regions. However, the final stage of the delivery pathways in Gosaba and Kalahandi for low-capacity end-users has been seriously undermined. Since kerosene oil is the main energy source for lighting, for both APL and BPL households, a parallel market has emerged due to a lack of adequate control by the government authorities (at state, district and block levels) over the distribution of entitlements that has enabled pilfering and rentseeking. Further, kerosene oil is distributed fortnightly in Gosaba and Kalahandi, and this does not match the paying abilities of BPL households, who forego their entitlements and more frequently buy small quantities of the kerosene oil that has been diverted from the PDS to the open market. In comparison, the last step in kerosene distribution is managed in Bastar by LAMPS/PDS, supervised by people institutions as part of PDS reforms in the state, and is designed in such a way that it ensures availability throughout the month. LAMPS/PDS in Bastar also provides the flexibility to low-capacity end-users to purchase kerosene oil as and when their cash flow allows (multiple visits to purchase small quantities). The procedures and processes adopted by LAMPS/PDS for the distribution of kerosene oil has resulted in a lack of rent-seeking and no leakage of kerosene oil to local markets.

\section{Role of Enabling Factors: Policy Instruments}

The policies and programmes that have created the enabling framework operate differently in the three case-study regions with consequent differing results. In Gosaba, the electricity cooperative was found to have limited discretionary powers to modify programmes so as to enable electricity access by low-capacity end-users. Nevertheless, in 2004, in consultation 
Table 5.23: Delivery Pathways and Enabling Factors - Comparative Analysis 2001-2009

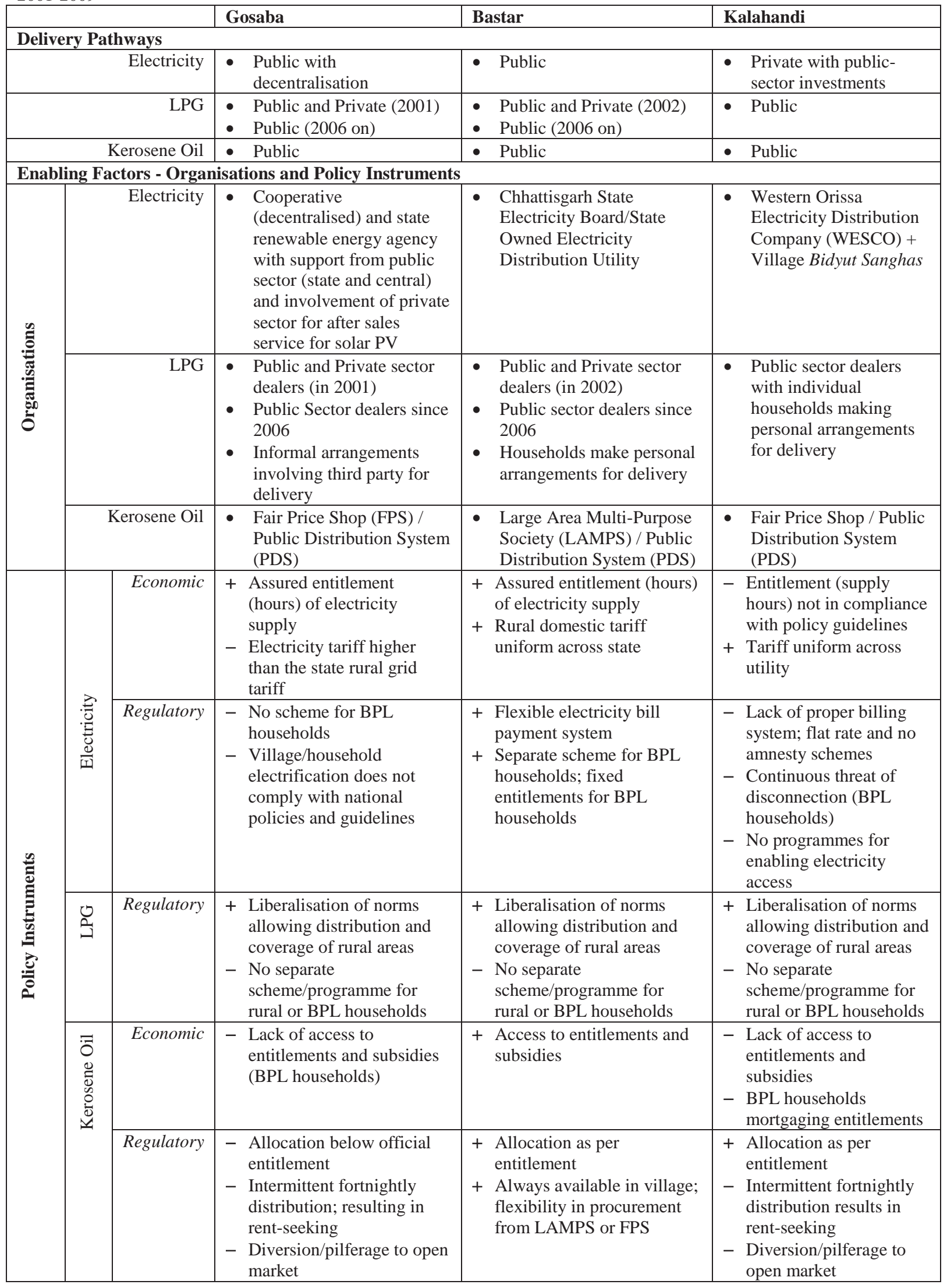


with the state government, the cooperative increased the entitlement (of hours of electricity supply) on the island to address the demand of existing users and also to extend electricity to Rangabelia village. The cooperative's policies, especially when it comes to coverage of BPL households and tariffs, do not comply with the new rural electrification policy guidelines although it should be noted that the policy is somewhat ambiguous regarding the applicability of its guidelines to decentralised rural electrification projects established before 2006.

In Kalahandi, the policies and programmes of the private distribution company have resulted in a slowing of the expansion of rural village electrification. The policies have also resulted in the disconnection of some existing single-light (Kutir Jyoti) BPL households. In order to improve its revenue collection, the distribution utility has emphasised recovering arrears from existing rural consumers, without creating easier options for these consumers to pay. This exclusion of some rural households from the public benefits of electricity is in line with the arguments discussed in Chapter 2 regarding programmes that target specific groups being seen as market distortions. Further, the utility initiated measures to reform the tariff structure that included increasing the electricity price for consumers. The combined impact of these policy measures has resulted in the energy service delivered in rural areas failing to comply with the service obligations defined in the policy guidelines (Patil, 2010). The existing consumers continue to default on payments and fail to repay arrears. As a result, inadequate electricity distribution continues in villages in the Kalahandi case-study region.

Contrary to this, in Bastar, the electricity utility has introduced a flexible payment option for the rural consumers linking it to the local economic conditions and the paying capacity of households. As a result, the electricity consumers do not default on their payments and the distribution utility provides services including an uninterrupted electricity supply in the villages. In Bastar, the policy instruments, especially those developed at the distribution level in the form of a monthly/quarterly payment system, have helped low-capacity end-users to afford electricity as the payment system matches their income patterns.

Despite the objective of the national rural electrification programmes, such as the RGGVY and the RVEP, being to improve electricity access (Section 4.4.2), there is little evidence of the programme being implemented in the case-study regions. The reasons for nonimplementation are different in each case-study region. Given that the state government has earmarked Gosaba Island for decentralised off-grid electrification, it appears an ideal case for the RVEP. However, at the time of the second fieldwork period, the state government had not initiated programmes/projects for improving electricity access on the island under the RVEP, with the electrification plans still under preparation. In Bastar, although the distribution utility had at the time of the second fieldwork period planned intensive household electrification projects in electrified villages under the RGGVY, the implementation was being delayed by the ongoing social-political disturbances in the district. In Kalahandi, it took until 2009 before the distribution company agreed to develop village electrification projects and to boost access levels in existing electrified villages under the RGGVY. One problem in the Kalahandi situation was the lack of clarity in the RGGVY guidelines over providing subsidies to a private distribution utility to improve electricity distribution. 
The policy instruments developed for LPG and kerosene oil have involved regulatory (entitlements) and economic (subsidies) aspects. However, it has not used suasive instruments to overcome LPG barriers such as 'the food does not taste the same' and 'it's not safe to cook on LPG'. Subsidies have been a major policy instrument used by the government to achieve social equity objectives (Section 4.4). The government has also introduced entitlements in the allocation of subsidised kerosene. At the macro-level, the Government of India provides subsidies, as well as oil bonds, to public sector companies to enable them to sell petroleum products at subsidised prices (Section 4.5). However, in Gosaba and Kalahandi, the subsidised kerosene oil, intended for rural areas and BPL households in particular, was found to be misdirected and ended up in APL households.

The policies and programmes for kerosene oil appear to work well in Bastar because of the role LAMPS/PDS plays in the distribution, including creating options for low-capacity endusers to purchase quantities that reflect their ability to pay. In contrast, in Gosaba and Kalahandi, the policies and programmes related to kerosene oil have proven incapable of improving access and led to problems of rent-seeking. The policies governing LPG have changed since $2006^{246}$ and, as a result, private LPG companies have stopped operating in the rural market (Section 4.4.2). While the gap seems to have been filled by an increase in the role of the public sector, there is now a threat that the subsidies will be phased out, or restricted, since they are considered unsustainable (GoI, 2010b). This information asymmetry (lack of complete information relate to merits and demerits of LPG use as well as about price and subsidy) creates uncertainty (Section 2.3.1) and consumers are unsure whether to make the switch to LPG, which feeds through to dealers when assessing the potential size of the market. A policy consensus is emerging that is focussing on restricting the number of subsidised cylinders provided in a year or targeting the subsidised cylinders at rural households (Ministry of Finance, 2011). However, the impact of implementing such a policy could be that households revert from the regular use of LPG to a combination of cooking fuels. Similar transitions have already been observed during the second fieldwork period in the case-study regions.

\section{Sub-question 2.2: Who has access to modern energy carriers and why?}

The longitudinal data on access to modern energy carriers by low-capacity end-users in the three case-study regions demonstrate that the outcome is dependent on the economic status as well as the social class and gender status of the users, and these aspects are in turn influenced by public policies and by contextual influences (Table 5.24). The evidence from the casestudy regions shows that it is the availability of surplus income that primarily enables access

\footnotetext{
${ }^{246}$ In view of the growing concerns over diesel being adulterated with kerosene oil available under the PMS, the $45^{\text {th }}$ report of the Parliamentary Task Force on the Parallel Marketing System made a series of recommendations with regard to abolishing the sale of kerosene oil through the PMS. At the same time, the central government decided to continue subsidising LPG for domestic consumers. Consequently, private sector companies decided to focus only on commercial and industrial sectors.
} 
to modern energy carriers although, as will be shown below, which modern energy carrier is selected depends on who in the household decides on how to spend that surplus.

APL households vary across the three case-study regions and can be differentiated in terms of occupation (which also links to caste). The type of occupation influences the level and pattern of income flow. Using the data from the case-study regions, APL households can be divided into two groups: those with access to modern energy carriers (underserved) and those without access (unserved). The main occupations of members of those APL households with access to electricity include government service, agriculture, fishing (specifically in Gosaba), and commerce. The use of both electricity and LPG is found only in APL households, and especially in households where the primary occupation can be categorised as government service, agriculture, commerce, or a combination of these livelihoods. In these APL households, the nature of the occupation provides a reliable source of income such that the family not only has sufficient financial resources to afford the upfront connection costs and buy appliances but also has the capacity to pay the recurring energy bills. This observation is consistent with Barnett (2000), in that this group of low-capacity end-users is able to move out of the vicious circle of energy poverty by having a surplus income.

Given the above conclusion, it may appear surprising that households where agriculture and fishing are the primary sources of income do have access to modern energy carriers (mainly electricity) since such households are often characterised by irregular cash incomes ${ }^{247}$ (Section 2.2.2). However, in my research, such households were found to have multiple sources of income, and some households consisted of extended families that pooled resources to access electricity. This development has not extended to cooking, as these households have not switched to LPG but continue to use biomass. One reason is that some of these APL households have large (extended) families requiring the use of large pots and pans that do not fit on LPG stoves. Other reasons found were the easy availability of biomass and intrahousehold dynamics including the gender division of labour and the value of women's time (as mentioned by Kelkar and Nathan, 2005).

The second group is made up of those APL households without access to modern energy carriers (the unserved). The analysis of the data collected over the two fieldwork periods shows that being an APL household does not automatically translate into having access to modern energy carriers. A number of APL households in the three case-study regions are unserved by modern energy carriers. The most obvious explanation for those APL

${ }^{247}$ Rural incomes are particularly prone to fluctuations due to seasonal effects, which increases household vulnerability and negatively impacts on household members' well-being (Narayan et al., 1999). However, it is recognised that diversification by a rural household of its income generating sources is used as a strategy to smooth out fluctuations in cash flow as well as to move out of poverty (Rigg, 2006; World Bank, 2007). This diversification includes many rural families, who might classify themselves as farmers, who have either out of choice or necessity diversified their activities away from agriculture, to a range of activities such as trading and manufacturing in small-scale cottage industries. It appears that it is primarily the wealthier households that are benefiting from income diversification (World Bank, 2007). 
households without access to electricity is the lack of the electricity grid in their pada (hamlet), and indeed all the unserved APL households are located in such pada(s).

Some of these APL households are in government service, but their incomes are insufficient to afford the upfront costs of an LPG connection and cylinder refills (Section 2.2.2). This perhaps reflects problems in BPL/APL classification ${ }^{248}$. As such, it is important to note that not every household in the APL category can accumulate sufficient financial reserves to pay the up-front costs and recurring costs of accessing modern energy carriers. However, the most common reason given for not shifting to LPG was the easy availability of biomass fuels, particularly from their own land (often collected by the household's labourers), at zero financial cost, coupled with the assumption that women have the time required to cook using biomass. The observations made here regarding unserved APL households contradicts Barnett (2000) in that some APL low-capacity end-users remain within the vicious circle of energy poverty, even when they have moved away from the subsistence economy and have cash surpluses. This observation however does concur with earlier findings by Clancy (2011) and Dutta (2010).

In terms of energy for cooking, the longitudinal data provide two other interesting observations. First, forward and backward shifts can be found between biomass and LPG as cooking fuels, but for different reasons. In Gosaba, some of the APL households were already using a combination of LPG and biomass for cooking in 2001, but this was mainly due to the household status of the person responsible for cooking (case story of Sojit Das). If the cooking was done by female members of the family, LPG was used. If a domestic servant was responsible for cooking, then they used biomass. In some of the APL households in Bastar that had switched to LPG for cooking by 2001-02, a shift back to biomass energy was found in 2008. The main factor for this backward shift was an inability to afford LPG. This was in some cases due to the increased cylinder refill price charged by the private sector and, further, when the private sector stopped supplying LPG, these households had to re-invest (if they could afford to) in a new connection from the public sector or revert to biomass (case story of Rita Baghel). Another reason for forward and backward shifts ${ }^{249}$ between LPG and biomass for cooking in Bastar was the intermittent supply of LPG due to the conflicts in the district.

${ }^{248}$ The $11^{\text {th }}$ Five-Year Plan (2007-12) recognised exclusion and inclusion errors in identifying households above and below the poverty line. The plan documents note that more than half of poor households are excluded from BPL benefits because they either have no BPL card or have been given APL cards. Further, almost $60 \%$ of the BPL cards have been given to APL households (Planning Commission, 2007).

${ }^{249}$ Research papers analysing trends in household energy patterns have argued that total household energy use per capita does not vary that much across income levels (Pachauri, 2004;Pachauri and Jiang, 2008). This they argue is because, as incomes rise, households switch to using more efficient energy forms. In theoretical terms, such linear transitions are possible. The limitation of these papers is that they rely on secondary data (collected on a sample basis and using recall methods) and as such fail to capture the dynamic shifts in low-capacity end-users' use of energy for cooking (and for lighting) found in the case studies. The reasons for these dynamic shifts are linked to both energy supply and affordability. 
In Kalahandi, both forward and backward shifts between LPG and biomass for cooking have been observed. Some APL households have shifted to using LPG for cooking (case story of Bhawani Mishra) because its availability has improved. Conversely, other APL households, that had switched to LPG due to the improved availability, were shifting back to biomass energy as they are unable to afford the cylinder refill costs (case story of Sudhanshu Mund).

The evidence from the three case-study regions shows that policies and government interventions (Section 4.5) play a critical role in providing and improving access to modern energy by low-capacity end-users. For those energy carriers where government policies and programmes (either in the form of entitlements and subsidies) are in place, there is an improvement in energy access, and this improvement is independent of a household's economic status. This is true in the case of kerosene oil despite the problems with its delivery pathway. Evidence shows that BPL households in Kalahandi and Gosaba do not claim their entitlements/subsidies but pay more in purchasing kerosene oil from the market. Although the problems with PDS distribution have been recognised in the policy debate for quite some time in India, one should note that the identified need for PDS reforms has yet to be acted upon (Bhattacharya and Rana, 2008;Kotwal et al., 2011).

Government intervention in rural electrification programmes has enabled access by both APL and BPL households (Sections 4.4.1 and 4.4.2). Without government programmes, there is limited or no access to electricity as the market is not interested in supplying low-capacity end-users (the experience of Kalahandi). Therefore, without government intervention, there would be problems of inequity and a lack of public access to the benefits of energy carriers. Electricity delivery in Gosaba is inequitable since it has focussed on access to only those households who can afford to pay, and at times is also moderated by class politics. The exclusion of BPL households and some households because of their social class amounts to a failure to comply with state/national policy guidelines. The experience with the privatisation of electricity distribution in Kalahandi brings out similar lessons as, both immediately after privatisation (in 2002) and after six years of reforms (in 2008), electricity access in villages had improved for some APL and BPL households but deteriorated for other BPL households. This deterioration has largely been in situations where the private distribution utility has disconnected the single-light connections of BPL households as servicing these was not economically viable. Similarly, due to increases in the LPG price, modern energy access in some APL households in Bastar and Kalahandi has changed, with some households reverting to using biomass for cooking.

The lesson to be learnt from the three case-study regions is that even when the delivery pathways are 'working well' in terms of improving availability, as aspect on which the policy has been focussing (Section 4.5, answer to Sub-question 1.3), contextual influences play a crucial role in accessing modern energy carriers. That is, a complex set of factors determines whether unserved APL and BPL households will adopt modern energy carriers, an aspect which will be discussed in answering the next sub-question. 
Table 5.24: Factors influencing Energy Access - Comparative Analysis

2001-2009

\begin{tabular}{|c|c|c|c|c|}
\hline \multirow{2}{*}{\multicolumn{2}{|c|}{ Underserved }} & Gosaba & Bastar & Kalahandi \\
\hline & & & & \\
\hline \multicolumn{2}{|c|}{$\begin{array}{r}\text { Multiple Modern } \\
\text { Energy Carriers }\end{array}$} & \multicolumn{3}{|c|}{$\begin{array}{l}\text { - APL households with livelihoods mostly from government, business and large agriculture; } \\
\text { reliable and assured source of income }\end{array}$} \\
\hline \multicolumn{2}{|r|}{ Only Electricity } & $\begin{array}{l}\text { Majority of APL } \\
\text { households plus a few BPL } \\
\text { households }^{251}\end{array}$ & $\begin{array}{ll}\text { - } & \text { APL and BPL } \\
\text { households }\end{array}$ & $\begin{array}{l}\text { - APL and BPL households } \\
\text { (but only those who } \\
\text { benefited from pre-reform } \\
\text { privatisation) }\end{array}$ \\
\hline \multicolumn{2}{|r|}{ Only LPG } & $\begin{array}{l}\text { APL households }{ }^{253} \text { with } \\
\text { government organisation } \\
\text { and business/trade as } \\
\text { occupation }\end{array}$ & $\begin{array}{l}\text { - APL households }{ }^{254} \text { with } \\
\text { government } \\
\text { organisation as } \\
\text { livelihood occupation }\end{array}$ & $\begin{array}{l}\text { - APL households with } \\
\text { government or public sector } \\
\text { organisation as livelihood } \\
\text { occupation }\end{array}$ \\
\hline & Kerosene & \multicolumn{3}{|c|}{$\begin{array}{l}\text { - Used by APL and BPL households as secondary source for lighting (when electricity supply is } \\
\text { not available) or for cooking (occasional) by a few APL and BPL households } \\
\text { - Dedicated public-sector programme (entitlements and subsidies) }\end{array}$} \\
\hline \multicolumn{5}{|c|}{ ( } \\
\hline \multirow{2}{*}{ 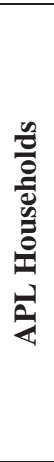 } & Electricity & \multicolumn{3}{|c|}{$\begin{array}{l}\text { - Large distance from electricity grid or non-availability of grid or no new connections or } \\
\text { programmes for intensive electrification } \\
\text { - Lack of cash income, some APL households economically not very different from BPL } \\
\text { households } \\
\text { Consequence: Reliance on kerosene oil and batteries to meet basic lighting energy needs }\end{array}$} \\
\hline & LPG & \multicolumn{3}{|c|}{$\begin{array}{l}\text { - Upfront costs and high recurring costs together with imperfect information regarding benefits } \\
\text { of LPG as a cooking fuel } \\
\text { - Non-availability of LPG as well as difficulty in obtaining a connection if available from the } \\
\text { LPG dealer } \\
\text { - Additional transportation or 'last mile' access costs } \\
\text { fonsequence: Reliance on traditional energy sources such as biomass for cooking or kerosene oil } \\
\text { for cooking }\end{array}$} \\
\hline \multirow{2}{*}{ 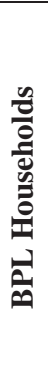 } & Electricity & \multicolumn{3}{|c|}{$\begin{array}{l}\text { - Large distance from electricity grid or non-availability of grid or no new connections } \\
\text { - Failure to implement schemes for BPL households } \\
\text { - Lack of surplus cash income to invest in electricity access } \\
\text { Consequence: Reliance on kerosene oil for meeting basic lighting energy needs, often at a high } \\
\text { price }\end{array}$} \\
\hline & LPG & \multicolumn{3}{|c|}{$\begin{array}{l}\text { - Insufficient household income to meet high upfront and high recurring costs of LPG cylinder } \\
\text { - Reliance on biomass fuels for cooking due to low purchasing capability of these households } \\
\text { Consequence: Biomass fuels purchased by some BPL households with no access to land and with } \\
\text { members involved in multiple economic activities (resulting in a lack of time for } \\
\text { collecting/gathering biomass) }\end{array}$} \\
\hline
\end{tabular}

${ }^{250}$ In these households, changing lifestyles together with greater disposable income is influencing the demand for energy services delivered by modern energy carriers (see the case stories of Binoy B Jana in Gosaba, B S Thakur in Bastar and Lok Nath Mishra in Kalahandi).

${ }^{251}$ Especially in those padas where the electricity grid is available, and by households who earlier had purchased solar PV systems under the central/state government subsidy programme.

${ }^{252}$ In BPL households due to dedicated public-sector programme with entitlements and subsidies.

${ }^{253}$ In a few households, a combination of LPG and biomass is used and the choice is linked to the person responsible for the cooking.

${ }^{254}$ However, a move away from LPG use in households where recurrent costs of LPG are beyond the household's budget. 


\section{Sub-question 2.3: How do contextual influences affect low-capacity end-users' access to modern energy carriers?}

Contextual influences - infrastructural, economic, social and political - play a considerable role in energy access by low-capacity end-users. As the analysis of the three case-study region shows, these contextual influences act as 'complimentary inputs' (see Section 2.2.2). These contextual influences are location specific, and they can have either a positive or a negative effect on energy access. The inter-linkages between these contextual influences are interesting and provide reasons for low-capacity end-users' energy access or lack thereof.

The availability of an adequate infrastructure enables access to modern energy carriers. The infrastructure that enables energy access, and allows users to benefit from modern energy carriers, is more than the energy supply infrastructure: it includes complimentary inputs such as connectivity and access to markets and transport. The combination of these infrastructural components influences economic activities in a region. In all three case-study regions, agriculture is the mainstay of the rural economy, and crops and other agricultural outputs are produced with high productivity. However, the farmers receive low prices due to the absence of sufficient infrastructure and market linkages.

Underinvestment ${ }^{255}$ results in agriculture remaining on a subsistence basis and, as a consequence, typical incomes from farming outputs are insufficient to give agricultural households economic space to participate in market-related activities through earning surpluses. In some cases, underinvestment is also due to the presence of certain social classes (gonthiyas, large landowners) and the lack of land reforms or the redistribution of agriculture land. As a result, there are many households without access to land in Kalahandi. If India's villages are to be economically developed, public investments in the agriculture sector will have to increase. Any increase in investment in agriculture would be better focussed on building infrastructure for storage, processing and market linkages, so that the farmers can achieve better returns, than on subsidising electricity for irrigation and fertilisers and supporting the prices of a few cash crops. Public investments need to be made in order to build a supporting infrastructure, and modern energy carriers can play an important role since they can facilitate economic diversification in agricultural activities (Sinha et al., 2006).

As seen in Gosaba (to an extent due to the concentration of households), as a local economy diversifies (for reasons such as increases in the pay of government employees and the positive impact this has on local economy) one can see a gradual shift towards modern energy carriers. The decision of the state government to revise the pay scale of government employees created a middle-income class, which then had cash surpluses. The purchasing power of these households in turn provides a stimulus to the local economy, promoting diversification. In Bastar and Kalahandi, such diversification is less visible and,

\footnotetext{
255 Public investments in India's agricultural sector reflect phases of stagnation and then decline between 1980-81 and 2000-01. Public investments in agriculture as a per cent of GDP increased during 2004-05 to 2006-07, but then declined. Investments in the agriculture sector are currently less than 3\% of GDP, which can be seen as low in terms of equity since $58.2 \%$ of the population are employed in the agricultural sector (GoI, 2012).
} 
consequently, enhanced economic returns are also less pronounced. Costs, both upfront and recurring, are increasingly a major constraint for BPL households and also some APL households. Since the economic activities of BPL households provide only low levels of income, they have little surplus cash to invest in modern energy carriers, although some BPL households do purchase biomass energy carriers (in Gosaba, see Section 5.2, the case story of Subash Mandal).

Economic opportunities and income diversification are often viewed as critical to break the vicious circle of energy poverty and, at the same time, energy is seen as necessary to create economic opportunities. Here, the three case-study regions provide mixed empirical evidence in respect of these contentions. In Gosaba, between 1997 and 2002, due to a combination of economic, infrastructural and social influences, a small group of households did manage to move out of the vicious circle of energy poverty. However, by 2008, similar transformations were no longer taking place in the remaining households, who remain trapped in the vicious circle of energy poverty, and some were even entering into energy poverty (due to the price rise of LPG). The main reason for this situation is that there have been no new investments in the local economy and the main economic activities of the local people have remained unchanged. Further, no capacity has been added to the electricity distribution infrastructure to improve electricity availability, as had been envisaged as a consequence of market liberalisation. The situation in Gosaba in 2008 with regard to energy access is similar to the observations from Bastar and Kalahandi in 2002. This reinforces the point that energy access can bring economic transformation and improve the quality of life. However, the availability of modern energy carriers cannot alone sustain the transformation and result in improved quality of life. In order to achieve this, bundles of other contextual influences (Barnett, 2000) are needed $^{256}$. Energy is a facilitator and, when bundled with other contextual influences, it has the ability to contribute towards economic and social development.

Social structures also play a significant role in influencing energy access and, perhaps not surprisingly, it is the upper social classes that derive the maximum benefit from both energy access and the infrastructure created by the government. The lower social classes across the three case-study regions continue to have limited or no access to modern energy carriers, remaining unserved. In Gosaba, even when the economic status of some groups improved, their social class meant they had little political influence and had hardly any impact on how public sector energy programmes were implemented to provide energy access. For example, the APL households living in Gosaba that belonged to the scheduled caste and whose primary occupation was fishing were unable to persuade the cooperative to extend the electricity grid to their pada, even though they could afford to pay. In Gosaba, the changes affecting the middle class, and the participation of women in income-earning activities, have played a role in the adoption of modern energy carriers such as LPG for cooking. Lifestyle changes in all three case studies were found to influence demand for modern energy carriers. The influence of gender on intra-household decision-making related to energy is not, as is often contended, based on economic status. Gender relations need to be seen in the broader background of the

\footnotetext{
${ }^{256}$ A similar observation was also made with respect of modern energy access and small enterprise activities in India's mountain states (Kooijman-Van Dijk, 2008). 
prevailing class systems, of society at large and the cooperative conflict of congruent and conflicting interests in a household (Sen, 2003a).

As observed earlier, policy decisions, including political considerations, at the state and local levels also impact on delivery pathways and on the development of infrastructure and economic activities (Section 2.3.1). Local political institutions, when involved, enable improved energy access, as was seen in Gosaba (the setting up of a decentralised power plant by the Block Panchayat) and Bastar (improvements to the public distribution system for kerosene oil). In contrast, when local political institutions are weak they fail to enforce effective implementation or ensure the transfer of entitlements to low-capacity end-users. For example, in both Gosaba and Kalahandi, local political institutions (Block and Gram Panchayat) have been unable to prevent rent-seeking linked to kerosene distribution, and this has negatively affected low-capacity end-users, and especially the unserved BPL households. Similarly, the weakness of political institutions on Gosaba Island have meant that they have not been effective in pressurising the state government to implement national rural electrification programmes on the island, or force the state government to monitor what is going on at the periphery. For example, while the West Bengal government has been implementing the RGGVY programme since 2005 in the rest of the state, similar actions for BPL households in Gosaba have not been implemented. The state government has earmarked islands such as Gosaba to be part of the remote village electrification programme (Section 4.3.3). Further, the rural electrification policy (as a targeted programme) makes provisions and provides mechanisms for equity in electricity tariffs, the extension of rural electrification programmes for BPL households, and for a universal service obligation providing transparent services (Section 4.4.2). However, as a result of institutional failures, the decentralised electricity distribution system does not comply with the rural electrification policy.

\section{Main Research Question 2: Have the energy policies enabled low-capacity end-users to gain access to modern energy carriers?}

As is already apparent from the answers to the three sub-questions, the overall answer to the second main research question is complex. This dissertation encompasses two fieldwork periods and captures what I labelled as the public sector reforms phase (Phase III) and the inclusive reforms phase (Phase IV) in the case-study regions. Policies and programmes for modern energy carriers at the national and state levels have been designed with the intention of improving the availability of and access to modern energy carriers in rural areas. The longitudinal analysis clearly shows that some policies have enabled access and others have failed to achieve this goal. There are also gaps where policies have neglected contextual factors.

The analysis of the case-study regions shows that limited access to modern energy carriers in the rural areas is a function of multiple contextual influences and further interlinked with problems associated with delivery pathways. Energy is a facilitator and access to modern energy carriers will not on its own alleviate the problems confronting India's rural areas. It is generally accepted that access to modern energy carriers provide public benefits (Sections 2.2 and 2.3), and for this reason the government has been involved in energy delivery through a 
combination of policy instruments (Section 4.4). Before the energy sector reforms were introduced in 1991, rural areas had limited access to modern energy carriers because of their dispersed nature, low energy demands and limited ability to pay. Even in the current context (based on a comparison of energy access scenarios between 2001-02 and 2008-09, and in view of the policy changes since 2004), the factors that influence access have not changed significantly in the case-study regions, and the implementation problems that new energy policies will face similarly remain unchanged.

In reality, and as presented in response to sub-question 2.3, some of the changes needed in the villages are beyond the domain of the energy sector and, hence, bundling will be needed (Barnett, 2000) through public investments in other sectors to bring an overall change in the economic conditions of the villages. Further, some of the reforms in the energy sector have resulted in increased energy prices, as a consequence of which the unserved and underserved low-capacity end-users are changing their purchasing patterns. For example, in all the three case-study regions, there is a significant shift in the purchasing pattern of kerosene oil, with households, and especially BPL ones, buying kerosene oil on the open market. This frequent purchase from the open market has a significant bearing on household expenditure (see the case stories of Shanti Pal in Gosaba and Darshan Chachang in Kalahandi) and, at the same time, raises questions on the effectiveness of the existing delivery pathways.

Policies formulated during the reforms phase for electricity distribution (i.e. privatisation) and for LPG (parallel marketing by private sector) have yielded mixed results. The policy of using a decentralised model for electricity generation and distribution (in Gosaba), together with state government agency involvement, was a step towards moving away from the monopolistic public sector model typically followed in rural electrification prior to the reforms. The two fieldwork periods show that, in the period up to 2003, the cooperative was able to enhance electricity access by low-capacity end-users, but that the main beneficiaries were the underserved and unserved APL households who had the ability to pay. Initially, the rural electrification initiative in Gosaba did not include a dedicated scheme/programme (such as the Kutir Jyoti) for electricity access by BPL households, despite such a programme being implemented in the rest of the state. Post-2006, when the Rural Electrification Policy came into force and national programmes in the form of RGGVY and RVEP (Section 4.4.2) were being implemented, it was expected that decentralised rural electrification initiatives would comply with the new policy (universal energy access) and programme (mandatory coverage of BPL households) guidelines. However, the 2008 fieldwork found that electricity access by BPL households in Gosaba had not changed since 2002. As such, the electricity access situation in Gosaba conflicts with policies and contradicts the social and development objectives of inclusive growth (Chapter 4). Despite the policy design for decentralised rural electrification being applicable to the geographical context of Gosaba, its effectiveness has clearly been limited as only a few underserved APL households have benefited from electricity access (Section 5.2.4, Box 5.7).

The experiences from Kalahandi of privatising electricity distribution raise a broader question regarding the applicability and effectiveness of such a policy for rural areas (Section 5.4.1, Section 5.4.4, Table 5.17 and Box 5.20). The question is not about the reform model followed 
in Orissa, or if privatisation is the answer to removing inefficiencies in the electricity sector, but rather it is the relevance of privatisation in a context where the socioeconomic conditions are unable to support such a policy measure. Observing electricity distribution privatisation in Kalahandi confirms the need for a careful analysis of the characteristics (Boorsma 1994) and the phases and functions of electricity sector before initiating energy sector reforms (Chapter 2, Box 2.3). The evidence gathered during the two fieldwork periods shows that while efforts were made to improve electricity access through the intermediation of VBS between 20012003, these had failed to improve access to electricity by 2008. On the contrary, the evidence from the villages is that the private distribution company disconnected a few BPL households (Kutir Jyoti consumers), that village electricity supplies in the evening remained intermittent, that no new investments in enhancing electricity access in rural areas were made, and that some of the existing problems related to electricity bills remained unaddressed. As such, unserved and underserved APL and BPL households continued to suffer due to a lack of inclusion by the private distribution utility, a situation at odds with the government's policy.

The 1993 policy of parallel marketing of LPG through private sector participation can be considered a positive measure in that it assisted in improving LPG availability in the rural areas. Before 1999, public sector organisations were unable to establish distribution/delivery systems in villages due to the then prevailing guidelines, this created space for private sector players to target the rural market. In Gosaba and Bastar, LPG availability improved due to the implementation of a parallel marketing scheme. Nevertheless, since the cost of LPG cylinders from the private sector was higher than from the public sector, only a few households took private LPG connections. In 1999, the Government of India, made amendments in its guidelines for LPG distribution and allowed the public sector oil and gas companies to release all pending LPG connections and it also relaxed norms for geographical coverage a dealer could service. This policy shift resulted in diffusion and adoption of LPG in rural areas from the public sector. However, the presence of the private sector created a choice for rural households, and this encouraged the public sector to improve their LPG distribution networks in the villages due to competition from the private sector (an argument linked to the rationale for public sector reforms). One should also remember that it is inherently easier to implement competition in LPG than in electricity (Chawla et al., 2005) and so this model is not necessarily transferable.

The policy agenda changes in 2004 (see Section 4.3.4) resulted in a shift in government policies and reform measures related to fossil fuel subsidies. Nevertheless, the price of LPG was not increased for the public sector outlets, with the central government continuing to provide subsidies in contradiction of its own policies (Chapter 4, Figure 4.8). The private sector consequently found the domestic LPG market to be an uneven playing field, and they were unable to compete with subsidised prices, especially as global prices kept rising. As a result, the private sector withdrew from the rural market. Moreover, the public sector was increasing its presence in rural markets following a rationalisation of earlier norms that allowed LPG dealers to increase their geographic coverage. The new government programme, launched in 2009 and aimed at creating an LPG distribution infrastructure in rural areas, is expected to improve availability for low-capacity end-users. However, drawing on the experiences in the three case-study regions over the two fieldwork periods, the 
availability of LPG may not be sufficient for low-capacity end-users to gain access. Some evidence was also found of households giving up their LPG connection. In 2002, a major concern for the households was the recurring costs and this concern has grown since 2008 when the government started to reduce subsidies and, further, there are new proposals for introducing subsidy reforms (Ministry of Finance, 2011). Such a change in policy will negatively affect LPG access by the low-capacity end-users in the rural areas.

The evidence from the case-study regions partly explains the policy shift - from the government, to the market, and then back to the government - concerning the key player in LPG delivery. As the results of policy reforms emerged, it started to become clear, if energy access was to be increased for low-capacity end-users, that the government would have to continue playing a critical role. The evidence from the case-study regions suggests that access to modern energy carriers is generally enhanced when the government is involved in energy carrier delivery (with the exception of electricity distribution in Gosaba and kerosene oil distribution in Gosaba and Kalahandi) in comparison to it being left to the private sector (electricity distribution in Kalahandi). Summarising the conclusions to sub-question 2.2, energy access is better where the government (at the national and local levels) has intervened. The policy designs creating entitlements and subsidies for kerosene oil and targeting electricity at BPL households haves ensured the availability of these energy carriers in the rural areas, but there are weaknesses in the implementation (RIS, 2010). The BPL households in Gosaba and Kalahandi often fail to draw their entitlements and benefit from subsidies on kerosene oil. Kutir Jyoti implementation has resulted in electricity access by BPL households. Although the government programmes are intended to bring equity in energy access, this research shows that the policies and programmes are not always implemented effectively and sometimes not applicable. As a consequence, large numbers of unserved and underserved low-capacity end-users (APL and BPL) remain.

In conclusion, an important finding that emerged from the three case-study regions in relation to energy poverty is that there is a need to reconsider the use of the APL/BPL poverty line classification for energy access. This classification of households by a single poverty line, which is followed by the central government in providing benefits through social and development programmes (and also used as a means to limit fiscal deficits), is not effective from an energy access perspective. This classification fails to recognise that, at least in the case-study regions, there are a number of APL households whose incomes are very close to those seen in BPL households. Since the public policies and programmes target only BPL households, these APL households will not get connected to the electricity grid or be provided with subsidies that would enable them to switch to modern forms of cooking energy (Prayas Energy Group, 2012). That is, those APL households that are just above the poverty line will have no means to access modern energy carriers and will remain unserved. Such households will be unlikely to escape energy poverty unless supported by public policies and government interventions in the energy sector and by policies outside the energy sector (for example through investments in agriculture and related market infrastructure as discussed at the beginning of this section). 
National programmes, such as the RGGVY and the RVEP, will eventually bring electricity to unconnected villages but an intermediate group, which are officially classified as APL households, are unlikely to be able to afford the upfront connection costs and some of them not even the recurrent electricity charges. This raises the question over the use of a single poverty line as the basis for economic classification and for the allocation of entitlements and subsidies across all sectors and programmes. Dreze and Sen (2011) have identified the pitfalls of a single poverty line, including the problems of inclusion and exclusion. An initial concern is that there is no reliable way of identifying poor households. Second, India's poverty line is set so low that even if all households were correctly allocated, large numbers of people who are in dire need of social support, but just above the APL threshold, would be excluded from governmental entitlements and subsidies (Dreze and Sen, 2011). A growing view in India is that the official poverty line does not reflect poverty but rather destitution (Patnaik, 2011).

Another important lesson from the experiences with privatising electricity distribution in Kalahandi is that the involvement of external agencies in designing mechanisms and schemes (social intermediation) and the implementation structure (through Village Biduyt Sanghas) leads to failures. The main reason for this failure is a lack of understanding of the contextual influences affecting energy access, the lack of involvement of implementing agencies (the distribution utility in this case) while designing and implementing, and the limited duration (due to operating in project mode) of the external agency's interest. As a result, such approaches fail to demonstrate a successful alternative model for the decentralised management of electricity distribution, and neither are they are able to address and solve the existing problems.

Finally, the evidence from the three case-study regions shows that the policy design (delivery pathways, organisations and policy instruments) remains top-down. Implementation of policies and programmes is only decentralised in the sense that a distributed network of organisations is involved. However, the decentralisation is largely in terms of delivery of energy carriers - implementing policies, schemes and measures still decided at the top - rather than contributing to policy formulation. The problem seems to be that there is a lack of space and channels for those organisations that are involved in delivery to influence policy based on local contextual factors. In situations where the delivery organisations have been involved in adjusting policy guidelines to meet the local contextual factors, such initiatives have been effective in improving access. This failure of contextual factors to influence policy formulation also negates the basic premise of "policy reforms with a human face", which has notionally been part of the government's inclusive development agenda since 2004.

The analyses from the case-study regions provide evidence on the implementation of policies and programmes (Chapter 4, Section 4.5) for energy access by low-capacity end-users. The linkages between policy design and policy implementation, and the changes required to enabling factors in order to respond to contextual influences are discussed in the final chapter. 


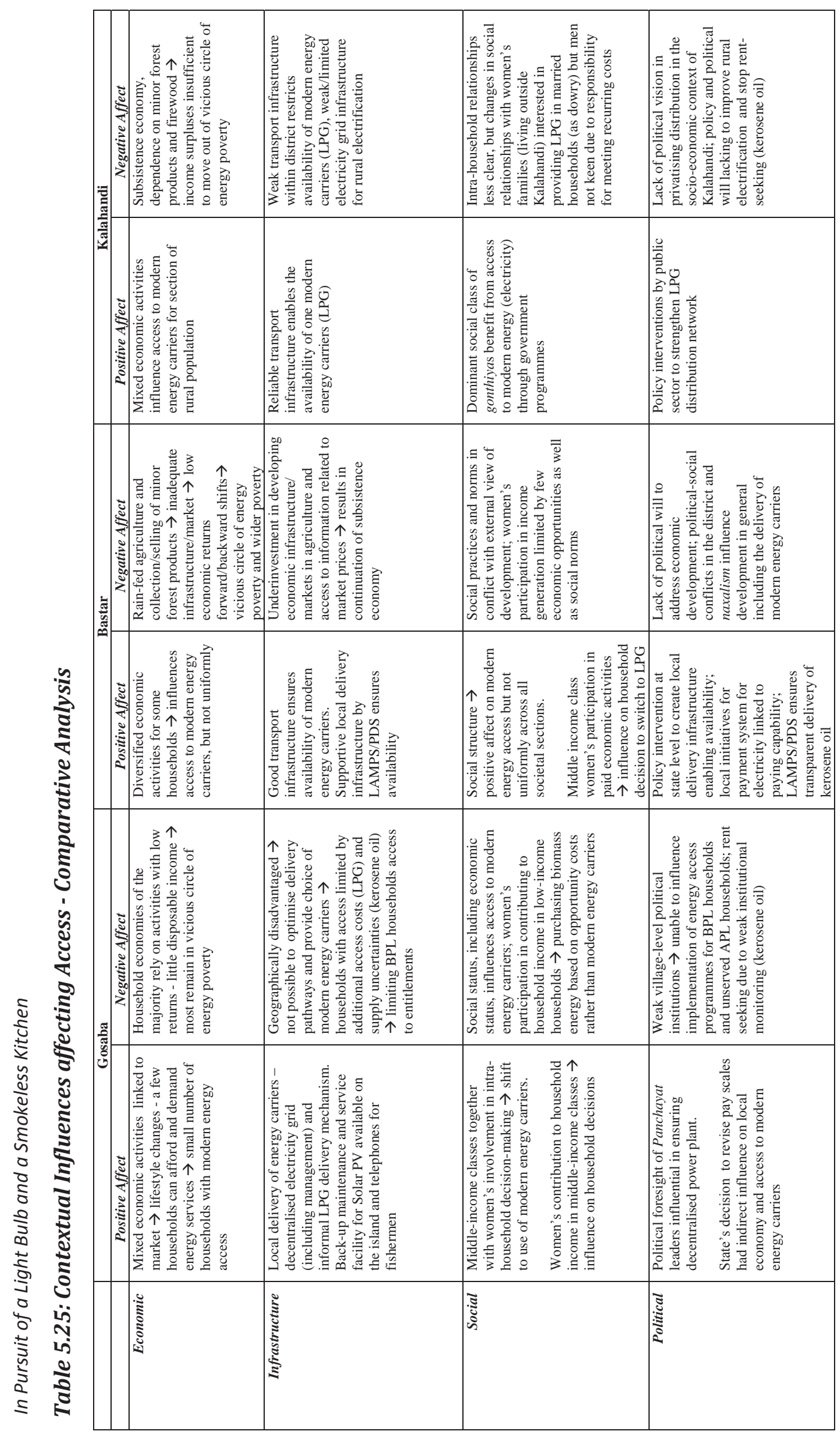




\title{
6. Conclusions and Recommendations: Will Rural India Shine ${ }^{257 ?}$
}

\begin{abstract}
"... in an unequal society with unequal distribution of income and assets, it will not be politically feasible to adopt a purely economic model for energy pricing. What this means is that whatever subsidies we offer to consumers must be offered transparently and be justified on stated economic, social and political grounds. Today we are offering subsidies to a wide range of users without a proper analysis of their economic and social rationale." (Manmohan Singh, 2004, 2)
\end{abstract}

\subsection{Introduction}

Reflecting on the empirical evidence gained over two fieldwork periods from the case-study regions on issues affecting energy access, and a review of the energy policies, one tends to agree with Manmohan Singh, the Indian Prime Minister's statement above that there is a need for a proper analysis, and specifically of micro-level empirical evidence which appears to be lacking in the literature. The objective of this dissertation is to offer such in-depth analysis of factors influencing access to modern energy carriers at the village and household levels and insights into the dynamics of energy policy and its transition in India. The analysis as presented in previous chapters reflects on India's political and economic development paradigm, and of the energy sector and rural energy in particular, by identifying the factors that influence energy access for low-capacity end-users and the relationship between policymaking and policy implementation.

In order to be able to present its results in a logical fashion, this dissertation is structured in such a manner that first, in Chapter 2, an analytical framework is derived from the applied concepts of energy-development linkages at the micro-level and institutional aspects of public sector reforms. The energy-development linkages show that access to modern energy carriers is a critical input for achieving social development and economic growth (Section 2.2). Within the context of energy poverty, an important element in the energy-development and policy reforms is the complexity of the micro-level linkages. Currently, it is estimated that 1.5 billion people globally are without electricity access and over 3 billion people using traditional energy carriers for cooking (IEA, 2009;UNDP/WHO, 2009). These people are living in energy poverty and, as a consequence, do not experience development.

Governments are well aware of the public benefits modern energy carriers help deliver. They also recognise that delivering this type of benefit is not of direct interest to markets, and respond through intervening with public-sector policies (including instruments) to compensate for these market failures (Section 2.3).

\footnotetext{
257 'Shine' is used as a metaphor. It should not be immediately associated with lighting and electricity.

'Rural India shining' should not be interpreted as an electrified rural India, but as a development which moves people out of poverty and provides a sense of wellbeing, reduces women's drudgery by removing the dependency on biomass fuels for cooking, and improves health conditions and access to economic opportunities.
} 
Governmental intervention was the dominant paradigm in economic development from the Second World War until the early 1980s, when empirical evidence appeared to show that such interventions were not achieving their objectives, indeed might even be making the situation worse (government failures). The economic development paradigm shifted to one of rolling back the state and allowing the market to deliver growth (Section 2.3). In order for this to happen, substantial reforms of public-sector policies were needed in which the objectives should be focussed on ensuring economic efficiency, primarily through institutional reforms (Section 2.3). However, some economists (Boorsma, 1994) have argued that, in terms of improving economic performance, it is not solely an issue of public versus private ownership, but also one of the context (characteristics) in which a given enterprise operates, the way it responds to its context (capabilities) plus social and political factors (culture) (Section 2.4). The analytical framework used in this thesis (Figure 2.1) draws on the concepts of energy-development and public policy reforms, with access to modern energy carriers by low-capacity end-users at its core and with attention to delivery pathways, enabling factors and contextual influences. The analytical framework leads to the formation of the three main research questions for this research.

In Chapter 3, the arguments for selecting the case-study regions are presented, thus enabling conclusions based on empirical evidence to later be drawn. The case-study regions - Gosaba Island (state of West Bengal), Bastar (state of Chhattisgarh) and Kalahandi (state of Orissa) were identified using criteria related to energy access by low-capacity end-users and delivery pathways for modern energy carriers. These three case-study regions represent large parts of rural India that continue to suffer from limited access to modern energy. Despite differences in the delivery pathways for each modern energy carrier, these case-study regions can be compared to help understand how contextual influences affect accessibility to modern energy carriers by low-capacity end-users in the context of the policy frameworks for each energy carrier.

Further, an ideological perspective, rooted in India's constitution and development paradigm of poverty alleviation, influenced the selection of the case-study regions. India is a welfare state and, as such, the objectives of policies and programmes should reach the poorest of the poor. By focusing on these three case-study regions, it is possible to assess the impact of policies in enabling energy access in some of the remotest regions of India. The chapter also presents the research techniques used in conducting the fieldwork in the three case-study regions and the techniques followed in policy analysis.

The first main research question is addressed in Chapter 4. Here, the analysis of India's energy policy answers the first research question (presented in Section 4.5), and shows that over the four development phases (centralised planning, political populism, reform and inclusive reform) policies have addressed access to modern energy carriers by low-capacity end-users through programmes and budgets, but not sufficiently to create universal access. In particular, the energy policy changes in the last two phases (before and after 2004) have been designed to improve access, bring development and deliver transitions in the organisations responsible for energy delivery (Section 4.5). Specifically, since 2004, the policy reforms have been formulated with the political ideology of reforms having a human face and 
addressing the agenda of inclusive development. The analysis of the energy policies for the period addressed in this thesis has shown that programmes including policy instruments, delivery pathways and institutions for improving access to modern energy carriers were in place, but that it was not clear how effectively these policies had been implemented.

In Chapter 5, the second main research question is answered (summarised in Section 5.5). The evidence shows that despite there being policies and programmes in place for improving energy access in rural areas, their implementation has been oblivious to local conditions. Although improvements in the policies and programmes can be seen, the evidence from the three case-study regions shows that these policies and programmes lack the flexibility required to address the contextual influences. While the theory (Bressers, 2004, see Section 2.3.3) suggests that policy making and policy implementation should be a mutual learning process, the analysis from the case study region (Section 5.5) shows that current experiences with policy implementation are one-sided. In other words, the local contextual influences which affect implementation are not feeding into policy making. As a result, while availability has improved in many places, access to modern energy carriers by low-capacity end-users remains limited.

After answering the first two main research questions, it is now possible to answer the third main research question, the central hypothesis and, finally, the central research question of this dissertation. This concluding chapter is structured in five sections. The next section (6.2), through an analysis of the linkages between contextual influences and enabling factors, identifies the changes needed in the enabling factors to enhance modern energy carrier access. The section, thus, answers the third main research question of this dissertation: What changes are required in the enabling factors to enhance access to modern energy carriers by low-capacity end-users? In answering this research question and identifying the changes needed in organisations and policy instruments, this dissertation addresses (in Section 6.2) the central hypothesis of this research: that, unless appropriate measures are applied, the energy policy reforms in India will not lead to improved access to modern energy carriers for the low-capacity end- users.

The central research question of this dissertation as stated in Chapter 1 is how might future implementations of policy reforms in India's energy sector be adapted to achieve the dual objectives of improving the economic efficiency of energy supply and of improving lowcapacity end-users' access to modern energy carriers? Section 6.3 provides an answer to this central research question by drawing on the analysis used in answering the three main research questions, and makes key policy recommendations for the national and state levels that address the stated objective of this dissertation "under what circumstances can policy reform in India's energy sector lead to improved access to modern energy carriers and to sustainably meeting the energy needs of low-capacity end-users in rural India”.

The penultimate section (Section 6.4) of this chapter reflects on the research results and presents the contribution of this dissertation to the discourses on energy and development and on public policy reforms, and to studies and policy debates surrounding India's rural energy and international policy with its growing emphasis on energy access. Finally, in Section 6.5, concluding remarks as an overall reflection on this research are presented. 


\subsection{Changes Required in Enabling Factors: Answer to Main Research Question 3}

The analysis of contextual influences, and their effect on enabling factors, provides an opportunity to reflect not only on the existing but also on possible future policies such that the latter are effective in enhancing access to modern energy carriers. The analysis of data from two fieldwork periods provides an understanding of the organisations involved in the delivery of modern energy carriers in the changing policy environment context (Section 5.5). Similarly, identifying policy changes that have taken place over the two fieldwork periods covered in this research presents an insight into how the policies have been adapted (Section 4.5). The understanding of how the enabling factors work is supplemented by insights into the interplay and cross-linkages between contextual influences in the case-study regions.

Based on the data from the three case-study regions, two inter-related aspects of enabling factors emerge: organisational inflexibilities and the weak implementation of policies and programmes. Some organisations ${ }^{258}$ have been effective in improving equitable access to modern energy carriers and, similarly, a few programmes ${ }^{259}$ have improved availability and access to modern energy carriers. However, the evidence gathered from the case-study regions also bring out examples ${ }^{260}$ of organisations and policy instruments which have been ineffective in improving energy access.

The failures of many organisations and policy instruments can be attributed to the top-down approach that energy sector organisations continue to take when implementing policies and programmes as well as to inappropriate policy formulation. The top-down model with a uniform approach places too much emphasis on fulfilling targets. Venkata Ramana (1998) noted in his thesis that these organisations, at the end of the 1990s, were incapable of adapting their strategies to suit location-specific conditions. This thesis has found that little has changed nearly fifteen years later: the energy sector organisations that were unable to enhance energy access were found to lack the flexibilities required to modify and adapt implementation to take account of local contextual influences. As shown in all the three casestudy regions, local contextual influences, in the form of complimentary inputs, do affect household access to modern energy carriers. In those case-study regions where access to modern energy carriers has been enhanced, organisations have shown institutional flexibility in developing mechanisms and modifying implementation processes to accommodate contextual influences and the local context.

Given the fact that the social structures and economic capabilities within the case-study regions, and in particular those of the households, differ, there is also variability in how these contextual influences affect energy access for groups of low-capacity end-users. This

\footnotetext{
${ }^{258}$ The electricity cooperative and informal arrangements for LPG delivery in Gosaba, electricity distribution by the State Electricity Board and kerosene oil distribution by LAMPS/PDS in Bastar.

${ }^{259}$ Electrification programme with a focus on BPL households, flexibility in electricity bill payments and kerosene oil procurement in Bastar.

${ }^{260}$ Electricity distribution in Gosaba, kerosene oil distribution through PDS in Gosaba and Kalahandi, and the private electricity distribution utility in Kalahandi. 
complexity is linked to the different characteristics, capabilities and cultures of each of the modern energy carriers. Drawing inferences from the effects that the contextual influences have on access to modern energy carriers makes it possible to draw lessons, presented below, for changing enabling factors at the local level (clusters of villages or clusters of households) so as to achieve universal access, the dominant paradigm in energy and development (Section 2.2).

\subsubsection{Changes Required in Organisations}

Organisations, as defined in Chapter 2, are intermediaries that enable the implementation of policies and programmes. The organisations for delivering electricity in the case-study regions differed in terms of the nature of their ownership: state-owned and managed by a cooperative (in Gosaba), state-owned electricity distribution utility (in Bastar) and private electricity distribution company (in Kalahandi). These three organisations displayed different characteristics in delivering electricity and, therefore, the changes required also differ.

In Gosaba, the electricity cooperative, given its mandate laid down in policies and the available capacity of the grid, has been effective in managing electricity distribution on the island. The success of this model can be attributed to the policy of decentralisation which included the transfer of responsibilities (including billing) and accountability for financial management, together with training and capacity building that ensured that the local-level organisations were adequately empowered to manage electricity generation and distribution. However, the experience from Gosaba also shows that the cooperative's mandate was limited, and this has resulted in restricted availability throughout the island. The cooperative has little control in terms of adding new generation capacity and being then able to add new consumers. As such, achieving universal access will require the transfer of additional responsibilities and decision-making powers (supported by investment) if the cooperative is to become more effective in improving electricity access by low-capacity end-users.

Simultaneously, the capabilities of the cooperative need to be enhanced so that it can increase electricity access in the rest of the island through the support of WBREDA and the state electricity distribution utility under the RGGVY and RVEP national programmes. Another important aspect, as explained in Chapter 4, is that, with a transfer of functions to the cooperative, the PRIs should be involved in providing the necessary checks and balances. These organisations are relevant institutions (North, 1990) and, sometimes, without adequate checks and balances (see Agency Theory and the Property Rights literature, Box 2.1), informal institutions can dominate and open up opportunities for rent-seeking. Fortunately, the Rural Electrification Policy 2006, and the RGGVY and RVEP guidelines, not only provide space and flexibility for local organisations to be involved, but also for PRIs to have a role in village-level electricity distribution.

In Bastar, the state distribution utility had already prepared a plan for grid extension in 2008, but implementation remains delayed due to ongoing social-political conflicts in the district. Therefore, the physical availability of electricity, through grid extensions, is unlikely to improve in the immediate future for unserved low-capacity end-users unless the contextual influences improve. This supports the assertion in Section 2.3 that it is not only the form of 
ownership that affects the performance of an organisation, but that social and political institutions also matter. In terms of changes in the organisational arrangements, electricity distribution and services could benefit from the creation of another level of intermediary organisation. Currently, scattered households have to travel up to twenty kilometres to pay electricity bills, and there is a potential for local organisations, such as franchisees or Gram Panchayats, to become involved and improve services ${ }^{261}$.

The RGGVY provides mandatory guidelines for the involvement of local organisations in electricity distribution and management. Given that the experiences with rural electricity distribution in Bastar have been positive, the situation could be further improved through the setting-up of local-level distribution franchisees ${ }^{262}$ or pratinidhi (appointed representatives) of the Gram Panchayat. Then, when rural electrification is implemented through RGGVY projects, additional capacities and functions (such as metering, maintenance and addressing grievances) could be transferred from the distribution utility to the franchisee or Gram Panchayat pratinidhi. An indirect benefit of such energy-development linkages (Section 2.2) is that such a model has the potential to create employment opportunities for village youth ${ }^{263}$ and diversify livelihood activities in Bastar. This is potentially of great value since the lack of employment opportunities is considered as one of the root causes of the current socialpolitical conflicts.

Organisational changes for improving electricity access by the low-capacity end-users in Kalahandi will be even more complex than in Bastar, and potentially difficult to implement. As explained in Section 5.5, the privatisation of electricity distribution is not applicable given the socioeconomic context of the district. The first essential change is to address the perceptions of the private distribution company that providing electricity in rural areas inevitably leads to theft and non-payment ${ }^{264}$. Electricity provides wide-ranging

${ }^{261}$ Alternative options for improving payment systems include the use of mobile phones, as has been demonstrated in Africa. This would require an appropriate telecommunication infrastructure. In India, especially in urban areas, Indian companies have similarly developed disruptive innovations to improve the delivery of infrastructure services (Joshi et al., 2008).

${ }^{262}$ In Uttarakhand, a Himalayan state, the state-owned distribution utility involved women Self Help Groups (SHGs) as franchisees for managing bill distribution and fee collection, and this resulted in improved services at the consumer level as well as increased revenues for the distribution utility (Sinha and Khanna, 2007). Bastar district has a similar network of women SHGs and such a model could be considered by the distribution utility as a way to improve services.

${ }^{263}$ The importance of income diversification as a strategy by households to move out of poverty has long been recognised (Rigg, 2006). This was certainly found to be the case in Krishna's study in 35 north Indian villages (Krishna, 2004).

${ }^{264}$ These negative perceptions of utilities towards end-users has been reported by other researchers (Clancy et al., 2007;Kooijman-Van Dijk and Clancy, 2010). There are examples of utilities working together with consumers to find a win-win situation. In Buenos Aires, Argentina, the utility decided to address the issue of illegal connections, which was a drain on their finances, by working together with consumers. They offered four and half thousand households who had a history of non-payment and/or illegal connections the chance of having their debt cancelled in return for agreeing to have a prepayment meter installed. A survey of 150 consumers found 90\% of respondents to be happy with the scheme much preferring to have legal connections (Annecke and Endelli, 2006). 
socioeconomic or public benefits, but these are not the prime concern of the private sector (Section 2.3). As a consequence, there is a need for government intervention to provide the investment needed to improve access to electricity by low-capacity end-users. Somehow, the private distribution company needs to be convinced that it should change its strategies and capitalise on the investments for rural electrification available under the national rural electrification programme, where the government provides funds for developing the distribution infrastructure and to cover the access costs for BPL households.

A problem common across all the three case-study regions was the lack of a formal system for delivering LPG to villages by the organisations involved in its distribution. While informal arrangements involving third parties had evolved in Gosaba, this was not the case in Bastar and Kalahandi. In the latter two areas, households had to organise the collection of cylinders, and such arrangements would involve intra-household negotiations. In terms of changes at the organisation level to improve access to LPG in all the three case-study regions, there is a need for local dealers, based in a village or for a cluster of villages. Setting-up such a network of local dealers would improve the physical availability of LPG as well as reducing the transaction costs for households. Another important change at the organisation level would be to include the household-level delivery of LPG cylinders. Such services can help to improve both the availability and the reliability of LPG in rural areas.

Organisational change with regard to kerosene oil is part of the larger debate about reforms to the Public Distribution System. Common characteristics of the three case-study regions are their remoteness and the poor transport and communications infrastructure, which for kerosene oil (and LPG) can negatively influence availability. The organisational model adopted by LAMPS/PDS in Bastar has found an effective solution to the vagaries of kerosene oil supplies through the use of storage tanks. LAMPS was also effective in dealing with problems of pilferage, as it took stringent action against defaulting Fair Price Shop (FPS) or their employees (see Section 5.3, Bastar Case Study, where the LAMPS/PDS suspended a FPS for pilferage and malpractices) based on assessment of the Gram Panchayat. Such a model is currently missing in Gosaba and Kalahandi but could be instituted in the FPSs. Such a strengthening of the distribution infrastructure would not only assist in improving kerosene oil availability but would also allow unserved (and underserved) low-capacity end-users to access their kerosene oil entitlements and subsidies in a pattern that matches their irregular cash flows. At the same time, it would reduce the rent-seeking that arises due to the ineffective government interventions (see Agency theory, Section 2.3).

\subsubsection{Changes Required in Policies and Policy Instruments}

The analysis from the case-study regions presented in Chapters 5 and particularly in Section 5.5, shows that while policies to address low-capacity end-users' access to modern energy carriers have evolved at the national level over four phases (Chapter 4, Section 4.5), implementation remains weak. One reason is the top-down approach to policymaking, leading to a disconnect between the conditions in the villages and the conditions included in shaping policies. As explained in Chapter 4, energy policy reforms were expected to bring changes and address the problems of top-down policy design and implementation. However, 
even after nearly two decades of policy reforms, the gaps in policy design and policy implementation remain unresolved.

Policy reforms in the energy sector, as the analysis from the three case-study regions shows, have so far failed to address this top-down approach and the context-reality of villages. However, from the government's perspective, top-down implementation is attractive because it allows greater control over the fiscal deficit given that subsidies in the energy sector contribute significantly to this deficit (Chapter 4). In response, the government tries to minimise the unwanted distributive effects of these subsidies through policy instruments such as setting entitlements and targets. However, as illustrated in Section 5.5, there are methodological difficulties in accurately identifying BPL households, which results in errors in including and excluding low-capacity end-users from energy entitlements, and this allows some wealthier APL households to capture benefits intended for poorer households.

Another reason that can be given for the disconnect between policy design and implementation is that the existing policies and guidelines are recommendations and not mandatory and are therefore open for interpretation differently (in comparison to original policy and guidelines) at the each levels of implementation. As described in Chapter 4, the definition of village electrification was modified in 2004 such that a village can now be termed as electrified if a minimum of ten per cent of households are electrified, a distribution infrastructure (transformers and lines) is provided in the inhabited locality, including in the pada (hamlet) where the socially backward classes live, and electricity is used in public places and public institutions. The RGGVY programme covers the cost of providing electricity access to BPL households, and implementing agencies have focussed on connecting the minimum number of BPL households. This allows the state utility, the state government and the central government to declare these villages electrified. However, the reality of electricity access, or rather lack of it, for households is different to the one presented by statistics. While the openness of the policy guidelines has allowed a flexible interpretation in implementation, this has resulted in a minimalist approach and a failure to provide universal access.

Moreover, in the case of access to electricity, it is not so much changes in policies that are needed, but compliance with existing elements of the Rural Electrification Policy 2006 and the RGGVY guidelines. The Rural Electrification Policy 2006 and the RGGVY guidelines mandate electricity access for BPL households, specify a minimum period of electricity supply, including evening hours, and parity in electricity tariffs, and particularly when it comes to decentralised off-grid renewable energy electricity projects.

In Gosaba, on this basis, the cooperative should comply with the guidelines related to universal electricity access by meeting the specific targets for BPL households. To comply, the cooperative would also need to reduce its electricity tariff to be on a par with the state's rural electricity tariff since the guidelines state that there cannot be differential tariffs in a distribution area. For this to happen, the cooperative would need to be compensated for the difference between generation costs and the state tariff. This is not impossible since there is provision for such compensation in the RGGVY guidelines. In Bastar, the distribution utility has complied with the policy guidelines by providing incentives for the metering of BPL 
households and by combining this with an upper limit (a fixed number of units) on free electricity. In Kalahandi, the private distribution utility would need to improve its electricity distribution coverage in the villages and provide improved services in the form of electricity supply to become compliant with the policy guidelines.

Turning to LPG, and again drawing from the three case-study regions, the time series information shows that there are at least five barriers that influence access. One is the transportation infrastructure which lacks any mechanism for delivering LPG to rural households (this is linked to delivery organisations). Partly, this problem could be addressed with the implementation of the 2009 LPG distribution policy and through the network of dealers as discussed in section 6.2.1. Second, there are the up-front costs and, more significantly, the recurring expense of refilling cylinders. The third aspect, which came out of the case stories across the three case-study regions was that, in a majority of the low-capacity end-users, the use of LPG for cooking is limited (needs-based) and also class dependent (who in the household is responsible for cooking). In only a very few low-capacity end-user households was cooking done entirely on LPG.

The present distribution policy has so far focussed on providing standard 14.2 kg LPG cylinders to rural households, although the policy also allows for the provision of small (5 kg) LPG cylinders ${ }^{265}$. As such, the oil and gas companies could introduce the smaller LPG cylinders for low-capacity end-users. The introduction of smaller cylinders would provide multiple benefits: it will help to reduce the transportation problems, and these small cylinders are cheaper. A policy change to more actively encourage the availability of these small cylinders could improve both the availability as well as the adoption of LPG by low-capacity end-users.

The fourth aspect relates to information asymmetries and the lack of awareness, with households identifying safety and food taste as reasons for not adopting LPG. Finally, the fifth aspect relates to the social situation of women as well as intra-household dynamics. As such, the introduction of the policy measures outlined earlier may help to improve the availability of LPG in the villages but not be sufficient to improve access. Addressing these additional factors requires other solutions, which may lie outside the energy sector. For example, despite the apparent benefits of LPG for cooking, households may not change for reasons such as an undervaluation of the time women spend in collecting biomass and then in cooking with it, the easy availability of biomass energy and food preferences. As was pointed out in Section 4.5, the lack of attention to gender in energy policy formulation does not help find solutions to non-technical barriers.

To improve access to kerosene oil, a systematic reform of the different organisations and intermediaries involved in distribution is required. This reform would be useful in improving the functioning and services of the public distribution system. Policy instruments such as entitlements and subsidies need to be continued, but with more effective targeting of low-

\footnotetext{
265 Small cylinders have been successfully introduced in the rural areas of the Himalayan states (D'Sa and Murthy, 2004;MoPNG, 2009). The topography of the Gosaba, Bastar and Kalahandi regions is similarly remote, with inadequate transport infrastructures, so small cylinders could be an alternative.
} 
capacity end-users in transferring subsidies. The issue of targeting entitlements and subsidies will be further discussed in the next section.

The findings discussed in this dissertation support the assertion that it is not merely a question ${ }^{266}$ of whether the ownership of an enterprise is in the public or the private sector this research has found examples of both types of enterprises improving access to modern energy carriers as well as failing to deliver. The findings presented above and the arguments for changing the enabling factors are based on contextual influences as measures that can improve access to modern energy carriers by low-capacity end-users.

The availability of appropriate measures had been proven by examples drawn from the casestudy regions that demonstrate the potential to improve energy access. They show that if policies and programmes neglect or underestimate the role of contextual influences, and do not allow flexibility to be introduced at the local level, then the implementation of energy policy reforms will remain constrained in enhancing access by low-capacity end-users to modern energy carriers. However, while there is a need for institutional flexibilities, these also need to be accompanied by appropriate systems of checks and balances. To achieve this, national/state policies and instruments need to be adjusted. The need for such policies and instruments, adjusted based on the local context, confirms the hypothesis of this study: that, unless appropriate measures are applied, the energy policy reforms in India will not lead to improved access to modern energy carriers for the low-capacity end- users.

\title{
6.3 Policy Recommendations
}

\begin{abstract}
"I will give you a talisman. Whenever you are in doubt, or when the self becomes too much with you, apply the following test. Recall the face of the poorest and the weakest man [woman] whom you may have seen, and ask yourself, if the step you contemplate is going to be of any use to him [her]. Will he [she] gain anything by it? Will it restore him [her] to a control over his [her] own life and destiny? In other words, will it lead to swaraj [freedom] for the hungry and spiritually starving millions? Then you will find your doubts and your self melt away." (Mahatma Gandhi, 1948)
\end{abstract}

Gandhi gave this talisman, in 1948, to the Indian leaders of the day and of the future to guide them in making decisions that would ultimately lead to the empowerment of the vulnerable (both economically and socially) disadvantaged people of India. Now, more than six decades later, it is quite clear that the political classes, planners, bureaucrats and stakeholders involved in India's development, and in particular rural development, have failed to follow this talisman. This is certainly true in terms of modern energy access for the poorest and weakest (the low-capacity end-users as defined in Chapter 1) in rural India.

\footnotetext{
${ }^{266}$ This question was raised in Section 2.1: who can deliver energy more efficiently in the rural areas: the government or the market? 
The dynamics of access to modern energy carriers by low-capacity end-users and the motives that influence them to access, or not, as presented above, allow an answer to be offered for the central research question of this study: how might future attempts at implementing policy reforms in India's energy sector be adapted/changed to achieve the dual objectives of improving the economic efficiency of energy supply and improving the access of low-capacity end-users to modern energy carriers?

The answer to this central research question, which is provided as a set of policy recommendations, is not a talisman. However, it is believed that the recommendations could bring genuine changes, or at least trigger changes, in relevant elements of energy policies that would move low-capacity end-users in rural India out of the vicious circle of energy poverty, and in turn fulfil the Mahatma Gandhi's vision of swaraj from poverty. The objective of this research was to understand the circumstances under which policy reforms in the energy sector can lead to improved access to modern energy carriers for low-capacity end-users. The main findings regarding the motives shaping energy policies, access to modern energy carriers and the changes needed in enabling factors indicate a complexity requiring the circumstances to be addressed, and this requires an analysis of the role of contextual influences.

The organisations and policy instruments that connect the delivery pathways to the lowcapacity end-users need to be strengthened such that they are more effective in delivering universal access while resulting in inclusive development with a human face. Using the analytical framework (Figure 2.1), and building on the analysis in previous chapters (Chapters 4 and 5), it is possible to formulate potential policy adjustments (Figure 6.1) that could improve access to modern energy carriers by low-capacity end-users and so answer the central research question.

The proposed policy adjustments are seen as practical solutions to make energy policies more effective; they draw on research in the case-study regions and benefit from the longitudinal information gathered between 2001 and 2010. As such, the recommendations made here are rooted in context. These recommendations focus on those policy solutions that could be adopted to improve energy access for the low-capacity end-users. The recommendations are of a nature that allows modification to the existing policy design (within the ambit of constitutional provisions, Box 4.1) and the policy framework so as to make implementation effective and applicable within a local context. The proposed recommendations come under three headings:

1. Enabling regulatory framework (for policy design and policy implementation);

2. Local organisations as intermediaries (in energy delivery as well as in contributing to policy design); and

3. Making subsidies and entitlements work better (the need for targeting). 


\subsubsection{Enabling Regulatory Framework}

Policies for enabling modern energy carriers have evolved since 2004 together with the country's economic development policy. The policy continuum requires an enabling regulatory framework that reduces the uncertainties that make investors and end-users (see Chapter 5) reluctant to invest in delivery pathways (Section 2.3) and in accessing modern energy carriers. National policies are unidirectional (i.e. top-down) both in their formulation and in their implementation. The policies have focused on the supply-side, with availability being the most important criterion, whereas demand-side issues such as equity have been largely ignored (Kooijman-Van Dijk, 2008) which is rather at odds with a stated aim of policies with a 'human face'. As a consequence, policies are not informed by experiences in a local context. As such, policies are likely to result in an enhanced physical availability but not in significantly greater access. Improving energy access requires an understanding of contextual influences and their integration in the design and implementation of energy policy.

In a large diverse country such as India there are different sets of contextual influences and, within the development discourse, integrating the effect of these influences in national- and state-level policymaking is now considered as critical for sustainable development (Section 2.3). The recognition of these influences at the national and/or state levels will create a favourable regulatory framework by creating space for flexibility in implementation. Since 2004, there have been some efforts to improve the policy design and the approach taken, but implementation remains a concern (Prayas Energy Group, 2012).

Policy implementation needs regulation, provisions for which have been made in the Constitution of India as well as in the Regulatory Acts governing the energy sector and in specific guidelines for national programmes (Dixit and Sreekumar, 2011). Such changes in the regulatory environment will play a critical role in addressing the underserved and unserved among the low-capacity end-users. The argument presented here is consistent with the emerging view in India that there is no need for separate new regulations, but that modifications in the responsibilities and functions set out in the existing regulations, policies and programmes, and the actors involved, would be sufficient to strengthen the regulatory regime. For example, the Constitution (see Section 4.2) makes provision for decentralisation and the involvement of Panchayati Raj Institutions (PRIs). However, decentralisation in its full sense has yet to be achieved. While there is decentralisation in terms of distribution and in the delivery of energy carriers through a network of organisations, these organisations are excluded from contributing to policy formulation and so unable to bring their understanding of the contextual influences to the table.

There are two specific recommendations for policy adjustments regarding rural electrification. The first concerns the emphasis in rural electrification policy and in the RGGVY guidelines on the mandatory electrification of all BPL households but these do not appear to reach all those living in energy poverty. As seen in the case-study regions, these result in the exclusion of some poor households who, because they are classified as APL, are not entitled to this benefit. Given that, due to both inclusion and exclusion errors, there is widespread ambiguity in the classification of households, and so in the identification of target beneficiaries, it is proposed that in implementing the RGGVY and the RVEP, the policy be 
revised to make provision for the electrification of all households irrespective of their economic status. For APL households, the policy change could provide either a partial or a full subsidy of the up-front connection costs of electricity, but not offer the entitlement to a fixed number of electricity units as provided to BPL households ${ }^{267}$ (Section 5.5). An associated benefit of this approach would be that, once universal coverage is achieved, the linesmen (the agents) would have little or no opportunity for rent-seeking, and the distribution utilities (the principals) ${ }^{268}$ would benefit from improved revenues ${ }^{269}$.

The second potential policy level change that can be affected pertains to giving responsibilities and power to organisations involved in electricity delivery, especially at the level of the village or a cluster of villages to have flexibility to design their own electricity billing and collection system. Such a provision allows a local organisation to develop and design a system that meets the local socioeconomic conditions, that is a system with a 'human face'. However, this requires building the capacity of such organisations to perform these functions (see Section 6.3.2).

An enabling policy environment for LPG and kerosene oil needs to focus on improving the delivery of these energy carriers in rural areas so that low-capacity end-users can access them. The policy uncertainties have resulted in many low-capacity end-users being unable to gain the benefits of the entitlements and subsidies provided by the government. Despite this, subsidies on kerosene oil and LPG constitute a significant part of the central government's fiscal deficit. In response, the central government has recommendations from the committees and task force it set-up to advise on reforming the distribution of LPG and kerosene oil, including appropriate subsidy reforms ${ }^{270}$.

There is a need to create a policy framework that is built on the principle of providing equitable energy access through a transparent system for transferring subsidies and the involvement of local institutions as intermediaries. For example, under a pilot initiative in

${ }^{267}$ It may seem contradictory that such a recommendation is being made, given the problems with inclusion and exclusion error in categorization of households into APL and BPL. However, the reasoning behind this recommendation is that the ultimate objective is providing universal electricity access, which appears to be reasonable in the given context. It is also important to recognize that correction in categorization of APL and BPL households is beyond the scope and mandate of energy sector policy. Once the categorization is corrected (which has political and fiscal implications), energy policy can be suitably modified to match the new categorization.

268 This argument draws on Agency Theory, see Box 2.1.

${ }^{269}$ While rent-seeking could be checked, the utility will have to invest in a flexible but robust billing system for the revenues to improve. This would require changes within organisations and in policy instruments (as discussed in Section 6.2).

${ }^{270}$ In nature, the recommendations are to improve distribution and delivery through effective targeting and efficient transfer of subsidies. However, the principal motive behind these recommendations is to reduce the central government's fiscal deficit that stems from subsidies. The recommendations made here on targeted subsidies for BPL households, if implemented properly, could be effective in improving access. However, the withdrawal of LPG subsidies from all APL households will affect many of the rural APL households who are just above the poverty line and can also be construed as living in energy poverty. 
Rajasthan, a Gram Panchayat is implementing a direct cash transfer scheme to all households as a subsidy on kerosene oil (Agarwal, 2012). All the households in the pilot initiative purchase kerosene oil at the full market price and the subsidy is directly transferred to their bank accounts. A similar pilot initiative has been started in Karnataka (Mysore district) for selling LPG at the market price and then directly reimbursing subsidies to the users' bank accounts (Ministry of Finance, 2012). The experience with initiatives of this nature, combined with some of the field practices seen in distribution, could be useful in developing a policy framework that enables access to modern energy carriers while better targeting governmental subsidies and entitlements.

\subsubsection{Local Organisations as Intermediaries}

Top-down policy design and implementation of policy instruments, as discussed in the previous section, in general fail to capture the local-level realities and dynamic complexities of human actions and the local-level effects of contextual influences. This necessitates a shift in focus towards involving entrepreneurs and local institutions, such as those established in governance structures, in both policy design and implementation arrangements. The Panchayati Raj Institutions (PRIs), which are the lowest tier in the Indian governance structure, possess an understanding of the village-level realities including class, gender, caste and economic status of local households.

After more than two decades of efforts towards decentralisation, capacity building and the transfer of roles and responsibilities, the PRIs have started to bring social transformation to Indian rural society. There are examples where the involvement of Gram Panchayats have been effective in improving access to public goods and services (Sinha and Khanna, 2007). For example, in Karnataka, the Gram Panchayats have appointed village youths (both young women and young men) as Gram Vidyut Pratinidhi (GVP) to mediate between the electricity distribution utility and rural consumers. The GVP model created employment opportunities and at the same time improved services for rural households.

Similarly, the evidence from West Bengal (where the Gosaba case study is located) shows that social sector programmes (such as those on health, education and agriculture) administered by the Gram Panchayats were reasonably well-targeted at the poor (especially the BPL households).

These Gram Panchayats initiated programmes had significant positive effects in terms of the subsequent growth in farm productivity and incomes, as well as in improved education and health services in the villages. The benefits were widely diffused among farms within a village, with a bias in favour of small and marginal farmers (Bardhan and Mookerjee, 2006). There are also examples related to natural resource management systems, such as watershed developments, water user associations and joint forestry management, where PRIs have become an effective local institutional model for implementation.

In the energy sector, such experience is limited. However, the $73^{\text {rd }}$ Amendment of the Constitution of India, and various new policies and programmes (Rural Electrification Policy 2006, the RGGVY, the RVEP, and the Rajiv Gandhi Grameen LPG Vitaran Yojana) for the energy sector since 2004 have identified a role for PRIs. If this is to prove successful, the 
Conclusions and Recommendations: Will Rural India Shine

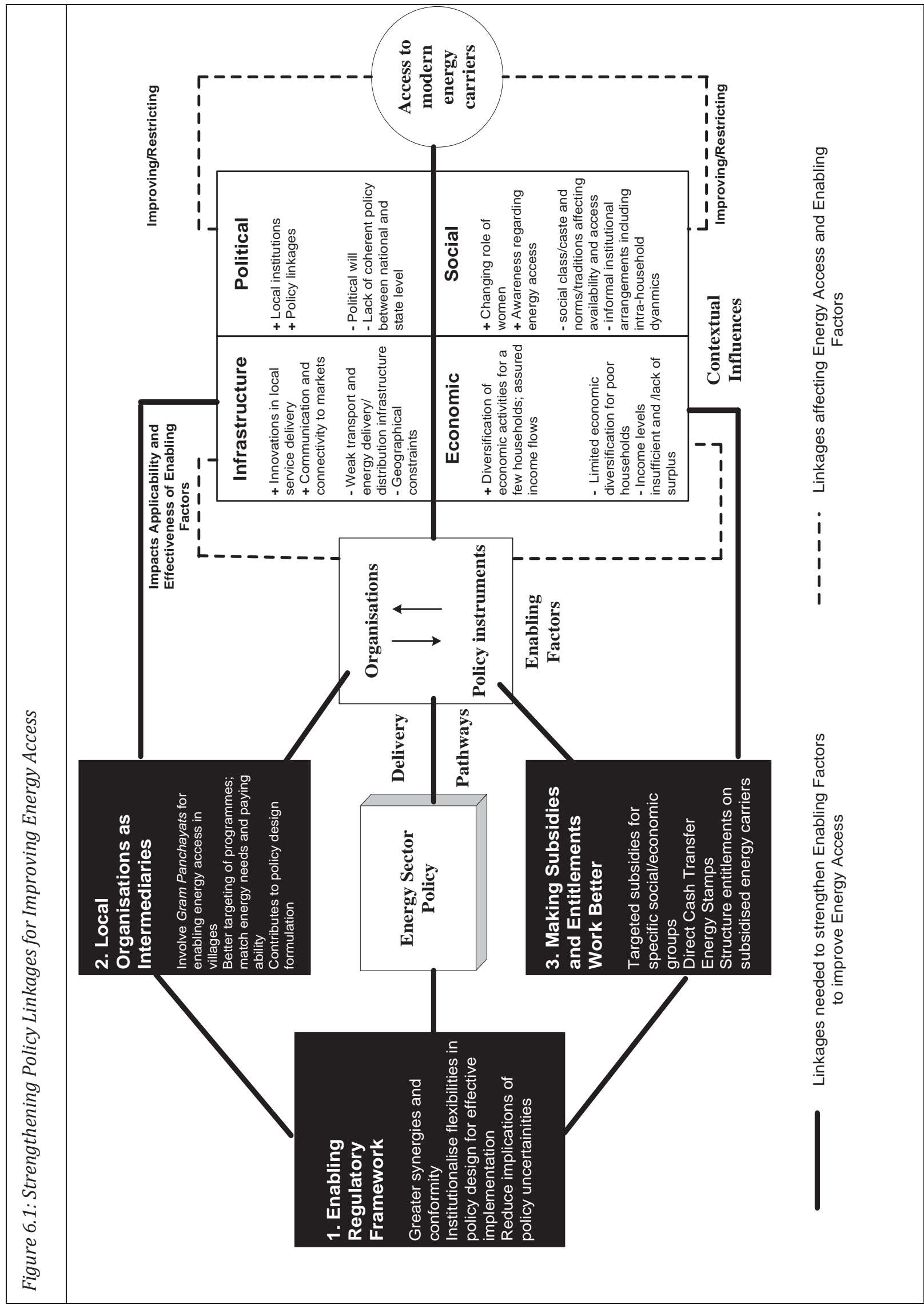


PRIs will need to be strengthened and empowered so that they can become involved in the design and implementation of energy access policies and programmes, as a means to overcome the existing access problems (Sections 5.5 and 6.2). A first step in this direction would be to devolve power and transfer roles and responsibilities, currently vested in organisations on the central and state levels, to PRIs. This devolution of power will not be easy as state governments have generally resisted changes in their roles and any devolution of their powers (IRMA, 2008). Actions will be needed by the central and state governments to ensure that there is a systematic and phased devolution of power to PRIs so that the decentralised organisations can become involved in energy delivery and distribution.

The involvement of PRIs in energy delivery would also mean their engagement with distribution utilities (in the case of electricity) and dealers (for LPG and kerosene oil). For this, capacity building will be needed to provide the necessary skills for the PRIs to take on these new roles and responsibilities as well as for utilities and dealers to accept the participation of PRIs in energy delivery and distribution (see Sections 5.4.4 and 5.5 regarding the problem related to Village Bidyut Sangha in Kalahandi). The state governments and organisations such as electricity utilities and public sector oil and gas companies could take the lead in providing this capacity building. However, the experience with building the capacity of PRIs in the country has shown that these processes are time intensive and that the transfer of functions and powers need to be gradual and phased.

Including PRIs in the energy delivery process is expected to result in more effective implementation of energy access programmes and reduce the current organisational complexities. PRIs can act as an interface between the energy policies and their implementation. They can be responsible for the aggregation, or bundling, of complimentary inputs and contextual influences, and work towards translating energy policies and programmes into effective and applicable implementation mechanisms. PRI involvement, especially at the level of the Gram Panchayats, could help in adapting the energy policies and programmes so as to mitigate or enhance the contextual influences as required.

As illustrated in the case studies, energy policies have brought enhanced access to modern energy when flexibility has been introduced by the local organisations. The Gram Panchayats can assist in reducing implementation barriers, by matching energy needs with the paying ability of households, and in further improving the accuracy of the economic classification into APL and BPL ${ }^{271}$ households. Such reclassification could assist in better targeting subsidies and the transfer of entitlements (this will be further discussed in Section 6.3.3 below). From a social equity perspective, the PRIs have in-built mechanisms for representing women and different social classes in local governance. Studies on implementation involving PRIs with a focus on inclusion and exclusion have shown that, where women and backward social classes have been part of the Gram Panchayat leadership, there has been enhanced access to publicly delivered goods and services (Baviskar and Matthew, 2009). Therefore, if local institutions in the form of PRIs can actively participate in

\footnotetext{
${ }^{271}$ This would also require central government to revisit the definition and the threshold setting the Poverty Line.
} 
energy delivery, through the intervention of the central and state governments, then one would expect the cohesive dynamics of the PRIs to be utilised for ushering in improved energy access for all in villages across India, and especially for the poorest and the weakest that Gandhi emphasises in his talisman.

\subsubsection{Making Subsidies and Entitlements Work Better - Need for Targeting}

As presented in Chapter 5, the current system of subsidy provision has resulted in subsidising a section of the low-capacity end-users who could afford modern energy access even without subsidies. Conversely, it has excluded a section of the population, including both BPL and APL households, for whom subsidies can enable their access to modern energy carriers. Further, given the impact that subsidies have on the overall fiscal deficit of the central and state governments, there is a growing view that the subsidies cannot continue in their current form.

Therefore, reforming energy subsidies is seen as an essential element of any energy policy reforms. In the context of energy access for low-capacity end-users, two specific recommendations are suggested: better targeting and transfer of subsidies, and a cap on entitlements. The targeted transfer of subsidies needs to be primarily initiated on the centralgovernment level, but would also require the involvement of state governments and villagelevel organisations, such as PRIs, in order to properly identify those households falling within the targeted groups. Implementation of this policy reform option would also require the identification of appropriate village level organisations who could facilitate the transfer of subsidies.

Other aspects in targeting the transfer of subsidies include whether to use direct cash transfers or conditional transfers through coupons or energy stamps. Both energy stamps/coupons and direct cash transfers could work efficiently in the cases of kerosene oil and electricity, where either a coupon/stamp is issued which can be exchanged for the product or the subsidy is directly transferred to the beneficiary. Direct cash transfers could also be effective in enabling access to LPG. However, to make them effective, direct cash transfers should be made to the women members of the household since this is more likely to lead to the purchase of modern energy carriers ${ }^{272}$. The advantage of targeted subsidies is that they will result in differential schemes for APL and BPL households (Kapur, 2011;Kotwal et al., 2011). Implementing targeted subsidy transfers will also require a complementary infrastructure such as banks and people's access to banking facilities.

\footnotetext{
${ }^{272}$ This would mark an extension of the use of conditional cash transfers. While this policy instrument has gained ground as a mechanism for social protection, it has generally been part of programmes targeted at children focusing on the cash to be used for their education, health and nutrition. It could be argued that access to LPG and electricity can contribute to all three areas. Programmes that involve cash transfers to women appear to have generally welcomed by the recipients. Concerns have been expressed that women's access to cash can lead to domestic violence. The evidence is mixed, although it is recognised that this is an area that is hard to document (Molyneux, 2009).
} 
The second recommendation is to structure the entitlements for each modern energy carrier. This structuring of entitlements would involve setting an upper limit ${ }^{273}$ for each modern energy carrier, but in a manner that it does not perpetuate energy poverty and targets those low-capacity end-users who do not have the paying capacity. The low-capacity end-users, who consume more than that entitlement ${ }^{274}$ then would pay the full market price. For example, subsidised LPG cylinders (14.2kg) could be capped at a fixed number per household per year, and any consumption above the upper limit would require the household to pay the full market price. Since it is mainly households who have some financial capability that use LPG, this could immediately be implemented with existing users ${ }^{275}$. As an alternative, government policy could restrict the sale of the smaller $5 \mathrm{~kg}$ cylinders to rural households only or introduce a different colour coding for standard LPG cylinder (14.2kg) for rural households and make subsidies only available for them.

A problem in reforming energy subsidies for any of the modern energy carriers is that this would need to be accompanied by more accurate identification of the intended beneficiaries (BPL and APL households) in order to make implementation effective. So far, a single poverty line has been used in all the social welfare programmes that are subsidised by the government in India. The application of this single poverty line classification in providing entitlements and subsidies has been shown to be ineffective in enabling access to energy and reducing energy poverty. A pitfall of adopting a single poverty line, which is set at an extremely low level in India, is that it excludes a large number of households from having access to modern energy forms. Not only do subsidies and entitlements not reach all those who are below the poverty line; others just above the poverty line, who are supposedly, but in reality anything but, 'rich', are excluded.

Reform measures for energy subsidies have been under consideration since early 2000 (RIS, 2010) but, as yet, have not been implemented. The discussion on subsidy reforms in India remains polarised. At present, there is no political consensus - neither between political parties whether in government or in opposition, nor between the central and state

${ }^{273}$ The argument for structuring the entitlements is also to revisit the norms set by the Advisory Board on Energy in 1985 for per capita useful energy (see Section 2.2.2), which are no longer relevant as aspirations of households have changed significantly.

${ }^{274}$ The argument builds on the Bastar experience, where the distribution utility fixed an entitlement of electricity load and free electricity up to consumption of 30 units per month for BPL households. If the household consumption was more than the entitlement, then they were charged the full tariff for the additional electricity consumption (see Section 5.3).

${ }^{275}$ Implementation of such policy measure is likely to have an adverse effect in short-term on use of LPG in rural households (see Section 2.2.3). Households will most likely restrict their use of LPG to number of subsidized cylinders per year due to price shock. This may result in backward shift to traditional energy carriers affecting women and increasing their drudgery. However, the conditional cash transfer recommend here might off-set this backward shift. It is also recognized that even when households make the transition to higher quality fuels such as LPG, they continue to use for specific tasks or as a back-up, lower quality fuels (this study, Case Story of Sojit Das in Gosaba, Box 5.5 and that of Bhawani Mishra and Sudhanshu Mund in Kalahandi, Box 5.19). The household might then adopt more complex energy management strategies with a hierarchy of preferences for LPG. 
governments. The political parties formally claim that partially phasing out or withdrawing subsidies would increase the burden on the poor. This statement on subsidy reforms to a large extent reflects opportunistic political behaviour (Bardhan, 2006) with politicians only too well aware that such policy reforms would reduce their leverage in using the 'instrument of subsidies' during election periods to attract votes.

This thesis has provided evidence of such opportunism in the case study of Gosaba, where an additional subsidy for solar PV was announced for BPL households before state elections and then immediately withdrawn after the political party was re-elected. Similarly, subsidies on kerosene oil have regularly been used to attract votes in the three case-study regions. Further, even if the central government were to take a key decision to reform energy subsidies, the parties involved would come under pressure from their political allies at the state level not to implement price increases (Section 5.4.4 and Section 5.5). Such pressure is hard to resist given that the central government has to rely on the political support of regional parties who are in power in the state governments.

Given these issues, there is an urgent need for decision-makers to recognise that subsidy reforms are not inherently anti-poor, and could be used to improve low-capacity end-users' access to modern energy carriers in rural India. Targeted subsidies, together with effective implementation, would enable low-capacity end-users to access modern energy carriers.

In conclusion, the integration of the above-mentioned recommendations, together with the bundling of contextual influences, could result in improved efficiency in energy supply and improved access by low-capacity end-users to modern energy carriers. The policy design achieved through this process would be both applicable and effective in implementation, and move low-capacity end-users out of the vicious circle of energy poverty. For this to occur, governmental intervention will be critical and essential. As such, policy reforms do not imply a reduced role for government, but rather a role in which government creates an enabling policy framework that enhances energy access by strengthening local organisations in terms of energy delivery, including enabling them to contribute to policy formulation, and ensures that policy instruments are better targeted.

\subsection{Contributions of this dissertation}

\subsubsection{Contribution to Academic Knowledge}

\section{A balanced understanding of the concepts of energy development and public policy reforms}

This dissertation selects and applies relevant concepts and empirical findings from existing literature and two periods of fieldwork on energy development and public policy reforms, and links these together to give an in-depth analysis that provides a new perspective for the study of access to modern energy carriers in the context of the political economy of energy sector reforms in India. Primarily based on the central premises of the arguments for public policy reforms, in particular on the 3-C model of Boorsma (1994) that is based on Characteristics (including phases and functions), Capabilities and Culture (Boorsma, 1994), this dissertation 
shows that energy sector policy reforms in India, and their implementation, for improving energy access are linked to the political economy. Specifically, the analysis on the privatisation of electricity distribution shows that if the capabilities and socioeconomic context are not kept in view (Boorsma, 1994) while undertaking a careful assessment of the characteristics of an energy carrier, and a detailed analysis of the phases and functions of each modern energy carriers, that the policy reforms become ineffective and inapplicable.

At the same time, the thesis shows that the role of the private sector in LPG distribution confirms the rationale advanced in the literature that competition results in improved availability of this particular energy carrier, but not necessarily of access to it. This thesis has shown that by taking a supply side approach, many of the contextual influences, such as gender relations, are missed. The study, by addressing the roles of government and of the market, provides an insight into their roles in a developing country context and shows that ownership is not necessarily critical since both forms of ownership have been shown, depending on other factors, to have succeeded and failed in improving energy delivery and energy access. As such, this research provides evidence against the arguments frequently seen in public policy reforms - that the private sector is more efficient at delivering energy carriers - and shows that public sector organisations can be equally effective in improving energy delivery as well as in improving access. In particular, the evidence from this research shows that the private sector tends to neglect the social, economic and local contextual factors that are crucial since these can either enhance or block access.

\section{An improved understanding of the vicious circle of energy poverty}

The research has provided insights into the macro-micro linkages in poverty alleviation (through energy and development, Section 2.2) and in access to modern energy (Barnett, 2000; Clancy et al., 2003) for low-capacity end-users. The political economy behind the public policy allowed one to examine the interplay of organisations and policies through two different delivery pathways - the government and the market. This has helped in formulating recommendations for strengthening the relationship between policy design and its implementation, by providing adequate responses for improving the organisations and the policy instruments.

The study contradicts the rationale used in the concept of the 'vicious circle' of energy poverty - that the only way to move low-capacity end-users out of energy poverty is through cash incomes generated through the productive use of energy (Barnett, 2000). The findings from the study contest this in that they show that an income surplus can be achieved through other forms of economic activity where energy does not have a direct role. Nevertheless, an income surplus is not a sufficient condition for modern energy access, as this is also influenced by a combination of contextual influences, and in particular gender (Section 2.2.2).

The study does however support the view that contextual influences, or complimentary inputs (IDS, 2003), play a critical role in enabling access to energy. This study also make a valuable contribution by attempting to understand energy poverty from a micro-perspective rather than 
from the more common macro-perspective (Barnett, 2000; Foster et al., 2000; Pachauri and Spreng, 2004), which will be discussed in the next section.

\subsubsection{Contribution to India's Energy Policy Discussion}

\section{An insight into inclusive policy reforms}

The analysis of the motives that shape India's energy policy shows an interesting combination of two different aspects working in tandem: the need to improve the overall energy sector through policy reforms, and the government's need to provide energy access to low-capacity end-users in rural India. India's energy policy can be seen as a combination of measures, some of which correct market failures and some that focus on improving imperfections in the role of government. This resulted in the emergence of the inclusive development agenda in 2004. The inclusive reform agenda is an emerging political-economic development paradigm that contributes to some extent, a new understanding of public policy reforms. This is particularly of relevance for developing countries that are undergoing the dual task of reforming energy sector and at the same time provide energy access to the poor.

The policy analysis in this study shows that, in improving the access of low-capacity endusers to modern energy, the role of the government, the role of the private sector and the use of public policies will be crucial. The study also shows that the requirement for the government to have a role does not mean that there is no role for the private sector and no need for policy reforms. This research argues that reforms do not imply the withdrawal of government, but that it should have a more proactive role in the delivery of modern energy carriers to ensure equitable access and move people out of energy poverty though creating an enabling policy environment and more effective policy instruments with appropriate checks and balances for private sector participation.

\section{'Breaking the Sound of Silence'}

The starting point of this research (as explained in the Prologue) was the 'sound of silence in the room', reflecting on the reality that there was little evidence, or even discussion, on the impact of policy sector reforms on energy access in rural India. Of the studies on India's development policy that relate to rural energy, this research is one of the few that analyse India's political economy from the micro-level perspective of the rural energy sector and access to modern energy carriers by low-capacity end-users. More specifically, this research has looked at energy access at the household level in relation to policy reforms. This study, with its focus on access to modern energy, provides new insights into the implementation of policies whereas other studies tended to have focused on the macro-impacts of economic reforms (for example, Dutt and Ravillion, 2002; Bardhan, 2007; and Singh, 2008). In the energy sector, other studies, for example those by Dubash and Rajan (2001), Mahalingam (2005), Modi (2005), Bhattacharya (2006) and Bhattacharya and Srivastava (2009), have looked at broader reforms in the power sector and focussed on regulatory aspects with little focus on household-level impacts.

This study has looked at the policy reforms from the perspective of low-capacity end-users' access to energy in rural India, and gone beyond a narrow focus on electricity by also 
considering access to modern energy forms for cooking. As such, the analysis as presented in this study is a contribution, albeit modest, to 'breaking the sound of silence' on policy reforms and their impacts on energy access by low-capacity end-users in rural India.

\section{A micro-perspective on understanding energy poverty}

An important contribution of this dissertation is towards the understanding of energy poverty from a micro-perspective. Studies on energy poverty, for example the one by Pachauri and Spreng (2004), have focused on defining indicators for energy poverty that are based on macro-economic data and quantitative classification. Such quantitative approaches to indicators often fail to understand the role of contextual influences in energy access. The quantitative indicators have also been frequently drawn from secondary data, and this fails to provide insight into the dynamics of intra-household factors that influence energy access. There are studies on access to LPG and kerosene oil that focus on describing the programmes and problems, for example by D'Sa and Murthy (2004) and Rehman et al. (2005), but these have not looked into factors that influence access at the household level including intrahousehold dynamics from a gender perspective.

This study, by making use of time-series data on energy access by low-capacity end-users, is also able to draw attention to the forward and backward shifts in modern energy use for cooking at the household level and to offer explanations as to why these occur. This type of transition is missed in studies, which take a 'snapshot in time'. In the literature, it is often implied that, once the economic capacity of a household improves, they will transit from a traditional energy carrier to a modern energy carrier $^{276}$.

The evidence collected here provides a contrasting finding - that such shifts are not always forward and that households, especially when it comes to cooking, frequently advance and retreat in their choice of energy carrier. Such transitions can be due to a number of factors that may be operable at any time, including the value attached to women's time, the availability of energy carriers, the price of energy carriers and intra-household dynamics, especially in terms of the roles of men and women and their negotiations, all of which have a bearing on access to modern energy carriers. By not taking a demand-side perspective, including the systematic collection of gender disaggregated data at the household level, the government misses these contextual influences and their affect.

\subsubsection{Suggested Areas for Future Research in India}

In respect to future research in the field of energy and development, a key recommendation would be to develop the modalities and establish a workable system to operationalise some of the recommendations made in this research. While the framework provides a lot of flexibility in dealing with multidisciplinary perspectives, it has not really identified concrete quantitative models or tools for use in the analysis. This was a consequence of the focus

\footnotetext{
${ }^{276}$ This is often described as climbing the Energy Ladder. However, experience has shown that households do not smoothly climb from traditional energy carriers to modern energy carriers, and several continue to use an energy mix for a variety of reasons (Hiemstra-van der Horst and Hovorka, 2008), some of which have been observed in the three case-study regions.
} 
being more on obtaining a broad range of perspectives and then integrating them to identify the effects of contextual influences on access to modern energy and analyse their linkages with enabling factors and delivery pathways for energy policies. Throughout, the emphasis has been on qualitative research into policies and policy implementation, and not on technical analyses such as those seen in economic and social cost-benefit approaches.

One area for further research could indeed be an in-depth analysis of the economic and social-cost benefits of the various possibilities in India. This study did not focus on the economics of technological options (centralised versus decentralised, grid versus off-grid, or versus grid-interactive off-grid, in electricity supply, or the potential for renewable energies) in the rural energy sector. Similarly, it did not focus on the social impacts (which would require a cost-benefit analysis of the impact of energy access on health and education, as well as a gender-disaggregated assessment of access to modern energy at the household level).

A second promising area for further research is to undertake a detailed socioeconomic and political impact assessment of energy pricing in the context of policy reforms. Such an analysis is essential if one is to provide rural low-capacity end-users with access to modern energy carriers within the overall policy context. It would identify more nuanced ways of pricing energy and policy instruments that could be used to provide subsidies and entitlements.

A third area for future research would be at the policy level in the context of emerging environmental concerns over climate change, and address how access to modern energy carriers in developing countries, for purposes of energy poverty alleviation, can emerge as an alternative to the prescriptive arguments for a low-carbon development advanced by industrialised countries.

\subsection{Concluding Remarks}

The overall outcome of this research has been confirmation that energy is a facilitator and not a solution in addressing all the development problems facing rural India. This is especially the case since some of the problems require political and socio-political solutions, and India is going through a change in the political perceptions of the problems, as reflected in the quote at the beginning of this chapter. Policy reforms do not have to mean that the responsibilities of the government are transferred to the private sector. This is a fallacy, and one that the political classes have used for short-term electoral gains. In reality, a policy reform should result in, whatever the government is doing, that its delivery and benefits reach those without access more efficiently and more effectively.

I conclude by borrowing the first line of the poem 'Ekla Chalo Re' by the Nobel laureate Rabindranath Tagore: 'If they answer not to thy call, walk alone', in which he exhorted people to continue their journey and fight for their rights, even in the face of abandonment or lack of support from others. The low-capacity end-users of rural India have walked this lonely path of limited or no access to modern energy carriers for a very long time - over six decades. What is now needed is for the government and the low-capacity end-users to walk in harmony. 
In Pursuit of a Light Bulb and a Smokeless Kitchen

It is time that India's energy policy took account of their long wait and implemented appropriate policies and programmes so that their aspirations become the reality: that they are no longer in pursuit, but can switch on a light bulb and cook food in a smokeless kitchen.

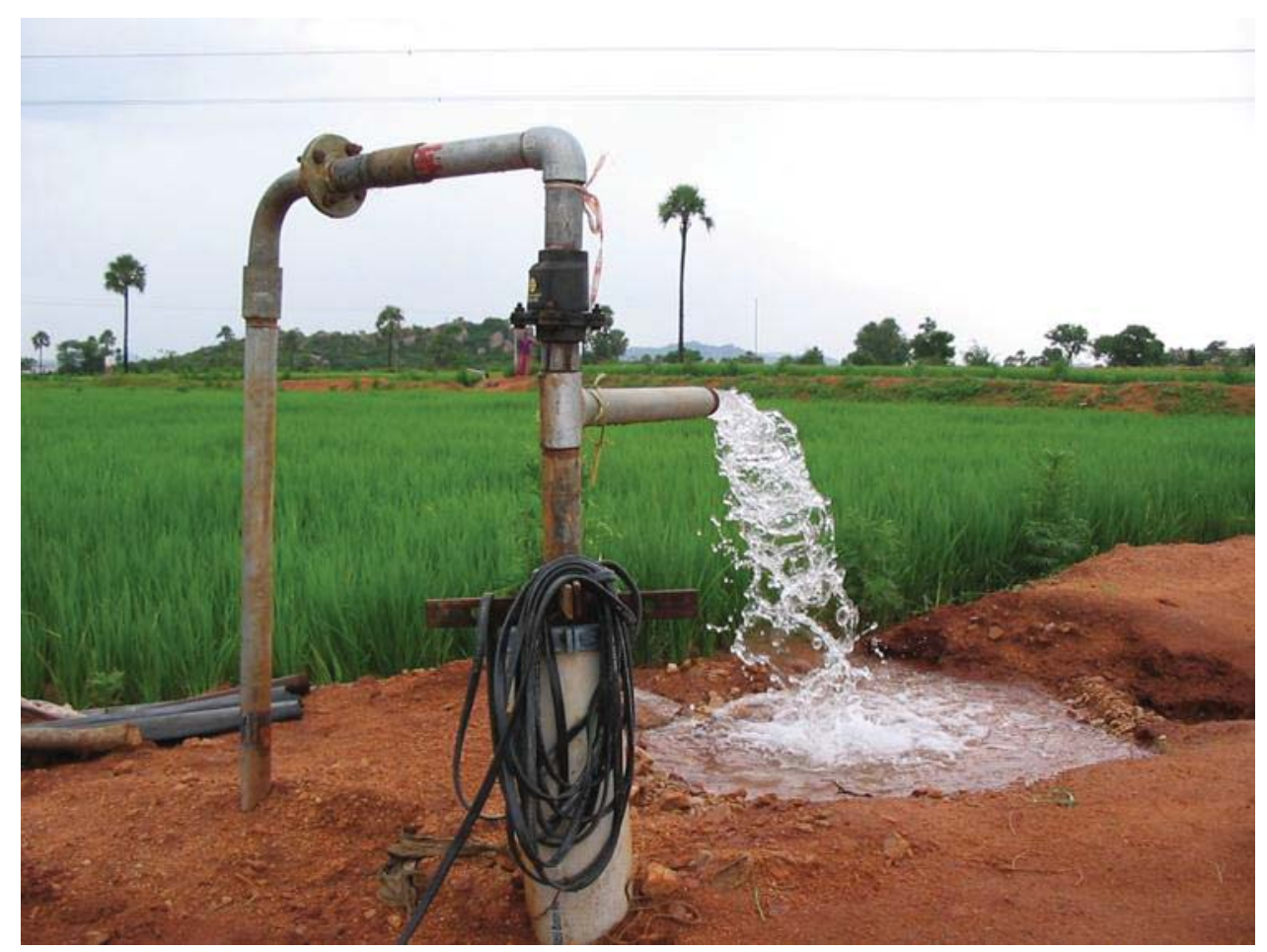




\section{References}

ABDUL KALAM, A. P. J. \& RAJAN, Y. S. 1998. India 2020: A Vision for the New Millennium, New Delhi, Viking Penguin Books.

ADAR, Z. \& GRIFFEN, J. M. 1976. Uncertainty and Choice of Pollution Control Instruments. Journal of Environmental Economics and Management, 3: 178-188.

AGARWAL, B. 1994. A Field of one's own: Gender and Land Rights in South Asia, Cambridge, Cambridge University Press.

AGARWAL, S. 2012. FM ushers in cash transfers of direct subsidies through UID. Mint.

AHKS 2002. Extension Process for Rural Energy - Field trials of PRA tools in Bastar. Chindgadh: Adivasi Harijan Kalyan Samiti.

AHLUWALIA, I. J. \& LITTLE, I. M. D. 1998. India's Economic Reforms and Development Essays for Manmohan Singh, Delhi, Oxford University Press.

AHLUWALIA, I. J. \& LITTLE, I. M. D. (eds.) 2012. India's Economic Reforms and Development: Essays for Manmohan Singh, New Delhi: Oxford University Press India.

AHLUWALIA, M. S. 1999. India's Economic Reforms: An appraisal. In: BAJPAI, N. (ed.) India in the Era of Economic Reforms. New Delhi: Oxford University Press.

AHLUWALIA, M. S. 2000. Economic Performance of States in Post-reform period. Economic and Political Weekly, XXXV (19): 1637-1648.

AKERLOF, G. 1970. The Market for Lemons: Quality Uncertainty and the Market Mechanism. Quarterly Journal of Economics, 84: 488-500.

ANNECKE, W. \& ENDELLI, M. 2006. Gender and prepayment electricity in Merlo, Argentina. ENERGIA News.

ANNECKE, W. J. 2003. One Man One Megawatt, One Women One Candle: Women, Gender and Energy in South Africa. Doctoral thesis, University of Natal.

BABBIE, E. 2003. The Practice of Social Research, Belmont, Wadsworth.

BACON, R. W. 1995. Privatization and Reform in the Global Electricity Supply Industry. Annual Review of Energy and Environment, 20: 119-143.

BACON, R. W. \& BESANT-JONES, J. 2001. Global Electric Power Reform, Privatization, and Liberalization of the Electric Power Industry in Developing Countries. Annual Review of Energy and Environment, 26: 331-359.

BAJPAI, N. 2002. A Decade of Economic Reforms in India: the Unfinished Agenda. CID Working Paper No. 89. Boston: Center for International Development, Harvard University.

BAJPAI, N. \& SACHS, J. D. 2000. India' Decade of Development. CID Working Paper No. 46. Boston: Center for International Development, Harvard University.

BANERJEE, A., BARDHAN, P., BASU, K., CHAUDHURI, M. D., GHATAK, M., GUHA, A. S., MAJUMDAR, M., MOOKERJEE, D. \& RAY, D. 2002. Strategy for Economic Reform in West Bengal. Economic and Political Weekly, XXXVII (41): 4203-4218.

BANIK, D. 2001. The Transfer of Raj: Indian Civil Servants on the Move. The European Journal of Development Research, 13 (1): 106-134.

BARDHAN, P. 1992. A Political Economy Perspective on Development. In: JALAN, B. (ed.) The Indian Economy - Problems and Prospects. New Delhi: Penguin Viking.

BARDHAN, P. 1998. The Political Economy of Development in India, Delhi, Oxford University Press. 
In Pursuit of a Light Bulb and a Smokeless Kitchen

BARDHAN, P. 2006. The Nature of Opposition to Economic Reforms in India. Yaleglobal Online [Online].

BARDHAN, P. \& MOOKERJEE, D. 2006. Land Reform, Decentrallized Governance and Rural Development in West Bengal. Medford: Tufts University.

BARNES, D. F. 2007. The Challenge of Rural Electrification. In: BARNES, D. F. (ed.) The Challenge of Rural Electrification: Strategies for Developing Countries. Washington D.C.: Resources for the Future.

BARNES, D. F. \& FLOOR, W. M. 1996. Rural Energy in Developing Countries: A Challenge for Economic Development. Annual Review of Energy and Environment, 21: 497-530.

BARNETT, A. 2000. Energy and the fight against Poverty. Economic Research Seminar Series. The Hague: Institute of Social Studies (ISS).

BASTAR DISTRICT PROFILE. 2002. Brief Statistical Data of Bastar [Online]. Raipur. [Accessed May 15 2004].

BAVISKAR, B. S. \& MATTHEW, G. 2009. Inclusion and Exclusion in Local Governance: Field Studies from Rural India New Delhi, Sage Publications.

BEALL, J. 1997. The Political Economy of Solid Waste Disposal. Ph D Thesis, Development Studies, London School of Economics.

BEN-DAVID, D. 1998. Convergence Clubs and Subsistence Economies. Journal of Development Economics, 55 (February 1998): 153-169.

BHATTACHARYA, D. \& RANA, K. 2008. Politics of PDS Anger in West Bengal. Economic and Political Weekly: 63-69.

BHOGAL, R. 2000. Nationalised Forest Produce: A study of Tendu Patta Policy of Madhya Pradesh, India - a devolution or a welfare policy?

BHOGAL, R. 2001. The Vandhan Initiative in Central Bastar. CIFOR Report. Bhopal.

BIRDSALL, N. \& NELLIS, J. 2003. Winners and Losers: Assessing the Distributional Impact of Privatization World Development, 31 (10): 1617-1633.

BLAUVELT, E. C. 2004. Deregulation: Magic or Mayhem? The Electricity Journal, 17 (7 (August/September)): 39-47.

BLOCK DEVELOPMENT OFFICE GOSABA 2001. Some Basic Information about Gosaba Block. Gosaba: Institution.

BOORSMA, P. B. 1994. Privatisation: Political and Economic Consideration. In: VAN DIJK, M. P. \& SCHULTENORDHOLT, N. G. (eds.) Privatisation Experience in African and Asian Countries. Amsterdam: SISWO.

BOORSMA, P. B. 1998. Privatizing the Muse "and all the jazz". In: BOORSMA, P. B., VAN HERNEL, A. \& VAN DER WIELEN, N. (eds.) Privatization and Culture: Experiences in the Art, Heritage and Cultural Industries in Europe. Dordrecht: Kluwer Academic Publishers.

BOUBAKRI, N., COSSET, J.-C. \& GUEDHAMI, O. 2008. Privatisation in Developing Countries: Performance and Ownership Effects. Development Policy Review, 26: 275308.

BOYCKO, A. S. \& VISHNY, R. 1996. A Theory of Privatization. Economic Journal, 106: 309-319.

BRENNEMAN, A. \& KERF, M. 2002. Infrastructure \& Poverty Linkages: A Literature Review. Washington D.C.: The World Bank.

BRESSERS, H. 2004. Understanding the implementation of instruments: How to know what works, where, when and how. In: LAFFERTY, W. M. (ed.) Governance for 
Sustainable Development: The Challenge of Adapting Form to Function. Cheltenham: Edward Elgar Publishing.

BRESSERS, H. \& O'TOOLE, L. J. 2005. Instrument selection and implementation in a networked context. In: ELIADES, P., HILL, M. M. \& HOWLETT, M. (eds.) Designing government: From instruments to governance. Montreal and Kingston: McGill-Queen's University Press.

BRINBERG, D. \& MCGRATH, J. E. 1985. Validity and the Research Process, California, Sage Publications.

BUCHANAN, J. M. 1988. Market Failure and Political Failure. Cato Journal, 8 (1): 1-14.

BYRNE, J. \& MUN, Y.-M. 2003. Rethinking reform in the Electricity sector: Power Liberalisation or Energy Transformation. In: WAMUKONYA, N. (ed.) Electricity Reform: Social and Environmental Challenges. Roskilde: UNEP.

CABRAAL, A., BARNES, D. F. \& AGARWAL, S. G. 2005. Productive Uses of Energy for Rural Development. Annual Review of Environment and Resources, 30: 117-128.

CASILLAS, C. E. \& KAMMEN, D. M. 2010. The Energy-Poverty-Climate Nexus. Science, 330 (6008): 1181-1182.

CECELSKI, E. 1995. From Rio to Beijing: Engendering the energy debate. Energy Policy, 23 (6): 561-575.

CECELSKI, E. 2004. Re-thinking gender and energy: Old and new directions. ENERGIA/EASE Discussion Paper. Leusden: ENERGIA.

CENSUS OF INDIA 2001a. Housing and Amenities, Census of India. Table H-9 and Table $H$-11. New Delhi: Office of the Registrar General, Census of India, Government of India.

CENSUS OF INDIA 2001b. Population Totals. Census of India 2001. New Delhi: Office of the Registrar General, Census of India, Government of India.

CHAMBERS, R. \& CONWAY, G. R. 1992. Sustainable Rural Livelihoods: Practical Concepts for the 21st Century. Discussion Paper No. 296. Brighton: Institute of Development Studies.

CHANDRASEKHAR, C. P. 2005. Will UPA Survive the Budget? Econscan [Online].

CHANDRASEKHAR, C. P. \& GHOSH, J. 2002. The Market that Failed. Leftword. New Delhi: Institution.

CHANDRASEKHAR, C. P. \& GHOSH, J. 2003. Employment Trends in West Bengal. The Hindu Business Line.

CHAUREY, A. 2001. The Growing Photovoltaic Market in India. Progress in Photovoltaics: research and applications, 9: 235-244.

CHAUREY, A., RANGANATHAN, M. \& MOHANTY, P. 2002. Enhancing Electricity Access in Rural Areas through Distributed Generation based on Renewable Energy. New Delhi: TERI.

CHAWLA, R., MISRA, N., PACHAURI, R. K. \& SRIVASTAVA, L. 2005. Petroleum Pricing in India: balancing efficiency and equity. New Delhi: The Energy and Resources Institute (TERI).

CHIBBER, P. 1995. Political Parties, Electoral Competition, Government Expenditures and Economic Reform in India. Journal of Development Studies, 32 (1).

CLANCY, J. S. 2011. Energy affordability and household energy security. Discussion Note 9 Electronic Forum on Energy Security in Asia and the Pacific, UNESCAP. Bangkok: Institution. 
CLANCY, J. S., MADUKA, O. \& LUMAMPO, F. 2007. Sustainable Energy Systems and Urban Poor Livelihoods. In: DROEGE, P. (ed.) Urban Energy Transition. Oxford and Amsterdam: Elsevier.

CLANCY, J. S., SKUTSCH, M. M. \& BATCHELOR, S. 2003. The Gender - Energy Poverty Nexus: Finding the Energy to address Gender concerns in Development. The Netherlands/U.K.: University of Twente/Gamos Ltd.

CLANCY, J. S., WINTHER, T., MATINGA, M. N. \& OPARAOCHA, S. 2011. Gender Equity in Access to and Benefits from Modern Energy and Improved Energy Technologies. World Development Report Background Paper. Leusden: ETC Nederland BV.

COASE, R. 1937. The nature of the firm. Economica, 4: 386-405.

COASE, R. 1960. The problem of social cost. Journal of Law and Economics, 3: 1-44.

CORBRIDGE, S. \& HARRIS, J. 2000. Reinventing India, Cambridge, Polity.

CSD-9 2002. Ninth Session, Agenda Item 4, Decisions. Energy for Sustainable Development, Section 6.22. Commission on Sustainable Development (CSD), United Nations.

CSEB 2002. Electricity Status in Chattisgarh. Raipur: Chattisgarh State Electricity Board, Government of Chattisgarh.

CURRIE, B. 2000. The Politics of Hunger in India: a study of democracy, governance and Kalahandi's poverty, New York, St. Martin Press.

D'SA, A. \& MURTHY, K. V. N. 2004. Report on the use of LPG as a domestic cooking fuel option in. Bangalore: International Energy Initiative.

D'SA, A., MURTHY, K. V. N. \& REDDY, A. K. N. 1999. India's Power Sector Liberalisation: An overview. Economic and Political Weekly, XXXIV (23): 14271434.

DAILY, G. 1997. Introduction: what are ecosystem services? In: DAILY, G. (ed.) Nature's Services: Societal Dependence on Natural Ecosystems. Washington D.C.: Island Press.

DANDA, A. A. 2007. Surviving in the Sundarbans: Threats and Responses. Ph D, University of Twente.

DANDEKAR, V. M. 1992. Forty Years after Independence. In: JALAN, B. (ed.) The Indian Economy - Problems and Prospects. New Delhi: Penguin Viking.

DANDEKAR, V. M. 1994. The Indian Economy, 1947-92: Agriculture, New Delhi, Sage Publications.

DATT, G. \& RAVALLION, M. 1998. Why Have Some Indian States Done Better Than Others at Reducing Rural Poverty? Economica, (21): 765-788.

DE MOOR, A. P. G. \& CALAMAI, P. 1997. Subsidizing unsustainable development: undermining the Earth with public funds. The Hague: Earth Council/Institute for Research on Public Expenditure.

DENZIN, N. K. \& LINCOLN, Y. S. (eds.) 1998. The Landscape of Qualitative Research: theories and issues, Thousand Oaks: Sage Publications.

DEVEREUX, S. 2001. Sen's Entitlement Approach: Critiques and Counter-critiques. Oxford Development Studies, 29 (3): 245-263.

DIXIT, S. \& SREEKUMAR, N. 2011. Challenges in Rural Electrification. Economic and Political Weekly, XLVI (43).

DIXIT, S., WAGLE, S. \& SANT, G. 2001. The real challenge in power sector restructuring: instilling public control through transparency, accountability and public participation (TAP). Energy for Sustainable Development, 5 (3): 95-102. 
DRAHOS, P. 2004. The Regulation of Public Goods. Journal of International Economic Law, 7 (2): 321-339.

DREZE, J. \& SEN, A. 2011. Putting Growth In Its Place. The Outlook.

DUBASH, N. K. 2005. Regulation as an Arena for Social Policy: Examples from Electricity in Asia. New Frontiers of Social Policy. Arusha.

DUBASH, N. K. \& CHELLA RAJAN, S. 2001. Power Politics: the process of power sector reform in India. Economic and Political Weekly, XXXVI (35): 3367-3391.

DUGGER, W. M. 1990. The New Institutionalism: New But Not Institutionalist. Journal of Economic Issues, 24: 423-431.

DUTTA, S. 2004. Mainstreaming Gender in Energy Planning and Policies. Bangkok: UNESCAP.

DUTTA, S. \& OPARAOCHA, S. 2010. Energy Services for Productive Uses: A Route to Women's Empowerment. Expert Group Meeting on 'Gender and Productive Resources: Women's Entitlements to Land, Livestock and Energy'. New Delhi, India

EBERHARD, A. 2005. From State to Market and Back Again: South Africa's Power Sector Reforms. Economic and Political Weekly, (December 10).

ESMAP 1999. Global energy sector reform in developing countries: a scorecard. Report No. 219/99. Washington D.C.: Energy Sector Management Assistance Programme (ESMAP), The World Bank.

FOSTER, V., TRE, J.-P. \& WODON, Q. 2000. Energy Prices, Energy Efficiency, and Fuel Poverty. Latin America and Caribbean Studies Programme. Washington D.C.: The World Bank.

FRANK, R. H. \& BERNANKE, B. S. 2004. Principles of Microeconomics, New York, McGraw- Hill/Irwin.

GABRIELLE, A. 2004. Policy Alternatives in reforming energy utilities in Developing Countries. Energy Policy, 32 (11): 1319-1337.

GALE, R. J. P. \& BARG, S. R. 1995. The Greening of Budgets: The Choice of Governing Instruments. In: GALE, R., BARG, S. \& GILLIES, A. (eds.) Green Budget Reform. London: Earthscan Publications.

GANGULY, B. K. \& CHAUDHARY, K. 2003. Forest Products of Bastar: A Story of Tribal Exploitation. Economic and Political Weekly, XXXVIII (28): 2985-2989.

GHOSH, S. 2002. Electricity Consumption and economic growth in India. Energy Policy, 30 (2): $125-129$.

GNESD 2007. Renewable Energy Technologies and Poverty Alleviation: Overcoming Barriers and Unlocking Potentials Roskilde: Global Network on Energy for Sustainable Development (GNESD).

GOC. 2002. Chattisgarh - profile [Online]. Raipur: Government of Chattisgarh. [Accessed July 15 2002].

GOI 1974. Report of the Fuel Policy Committee. New Delhi: Planning Commission, Government of India.

GOI 1985. Towards a perspective on energy demand and supply in India in 2004/05. Advisory Board on Energy. New Delhi: Planning Commission, Government of India.

GOI 1986. Report of the Energy Demand Screening Group (EDSG). New Delhi: Planning Commission, Government of India.

GOI 1993. Report of the Expert Group on Estimation of Proportion and Number of Poor. Perspective Planning Division. New Delhi: Planning Commission, Government of India.

GOI 1997. Fifth Pay Commission. New Delhi: Ministry of Finance, Government of India. 
GOI 2002. Union Budget 2002-03. New Delhi: Ministry of Finance, Government of India.

GOI 2003. Parallel Marketing in Petroleum Products Forty Fifth Report of the Standing Committee on Petroleum and Chemicals. New Delhi: Lok Sabha Secrtariat.

GOI 2008a. Economic Survey, 2007 - 2008, New Delhi, Ministry of Finance, Government of India.

GOI 2008b. National Action Plan on Climate Change, New Delhi, Government of India.

GOI 2010a. Economic Survey, 2009-2010, New Delhi, Ministry of Finance, Government of India.

GOI 2010b. Report of The Expert Group on A Viable and Sustainable System of Pricing of Petroleum Products. New Delhi: Government of India.

GOI 2012. Economic Survey, 2011 - 2012, New Delhi, Ministry of Finance, Government of India.

GOLDEMBERG, J., JOHANSSON, T. B., REDDY, A. K. N. \& WILLIAMS, R. 1987. Energy for a Sustainable World, Washington D.C., World Resources Institute.

GOLDEMBERG, J., JOHANSSON, T. B., REDDY, A. K. N. \& WILLIAMS, R. H. 1985. Basic Needs and Much More with One Kilowatt Per Capita. Ambio, 14 (4-5): 190200.

GOVERNMENT OF ORISSA 2002. Districts at a Glance 2002. Bhubaneshwar: Directorate of Economics and Statistics, Government of Orissa.

GOVINDA RAO, M., SHAND, R. T. \& KALIRAJAN, K. P. 1998-99. State Electricity Boards: A Performance Evaluation. The Indian Economic Journal, 46 (2): 33-59.

GRIDCO 2002. Status of Electricity in Orissa. Bhubaneshwar: GRIDCO.

GUHA, R. 2006. The Revolutions and its Children; Part II: Counter-Revolutionaries, The Battle for Bastar. The Indian Express, June 27, 2006.

HAINES, A., SMITH, K. R., ANDERSON, D., EPSTEIN, P. R., MCMICHAEL, A. J., ROBERTS, I., WILKINSON, P., WOODCOCK, J. \& WOODS, J. 2007. Policies for accelerating access to clean energy, improving health, advancing development, and mitigating climate change The Lancet, 370 (9594): 1264-1281.

HAMILTON, D. M. 1937. The Gosaba One Ruppee Note. Gosaba: Institution.

HANSEN, C. J. \& BOWER, J. 2003. Political Economy of Electricity Reform, A Case Study in Gujarat, India. Oxford: Oxford Institute for Energy Studies.

HARPER, M. 2000. Rural Electricity in Orissa. Public Services Through Private Enterprises: Micro-privatisation for improved delivery. New Delhi: Vistaar Publications.

HARRISS, J. 1993. What is Happening in Rural West Bengal? Agrarian Reform, Growth and Redistribution. Economic and Political Weekly, (28): 1237-1247.

HAVET, I., CHOWDHURY, S., TAKADA, M. \& CANTANO, A. 2009. Energy in National Decentralization Policies. A Review Focusing on Least Developed Countries and SubSaharan Africa. New Delhi: United Nations Development Programme.

HIEMSTRA-VAN DER HORST, G. \& HOVORKA, A. J. 2008. Reassessing the "energyladder": Householdenergy use in Maun, Botswana. Energy Policy, 36 (9): 3333-3344.

HUMAN RIGHTS WATCH 2008. "Being Neutral is Our Biggest Crime". Government, Vigilante, and Naxalite Abuses in India's Chhattisgarh State Washington D.C.: Human Rights Watch.

HUNT, S. 2002. Making Competition Work in Electricity, New York, Wiley.

IDS 2003. A Review of the Evidence and Case Studies in Rural China. ASTAE. Washington D.C.: The World Bank. 
IEA 2001. World Energy Outlook Insight: Looking at Energy Subsidies, Paris, International Energy Agency (IEA).

IEA 2009. World Energy Outlook. Paris: International Energy Agency.

IEA 2010. World Energy Outlook 2010, Paris, OECD/IEA.

IMRAN, M. \& BARNES, P. 1990. Energy Demand in the Developing Countries: Prospects for the future. World Bank Staff Paper \# 23. Washington D.C., The World Bank.

INDIA INFO LINE. 2000. Dismantling of APM: Review of the Petroleum Sector in India [Online]. [Accessed January 18, 2002].

IPCC 2011. IPCC Special Report on Renewable Energy Sources and Climate Change Mitigation. In: EDENHOFER, O., PICHS-MADRUGA, R., SOKONA, Y., SEYBOTH, K., MATSCHOSS, P., KADNER, S., ZWICKEL, T., EICKEMEIER, P., HANSEN, G., SCHLÖMER, S. \& VON STECHOW, C. (eds.) Prepared by Working Group III of the Intergovernmental Panel on Climate Change. Cambridge and New York: Cambridge University Press.

IRMA 2008. The State of Panchayats: 2007-2008. An independent Assessment. Volume 1, Thematic Report. New Delhi: Ministry of Panchayati Raj, Government of India.

JACCARD, M. \& MAO, Y. 2002. Making Markets work better. In: JOHANSSON, T. B. \& GOLDEMBERG, J. (eds.) Energy for Sustainable Development: A Policy Agenda. New York: UNDP.

JALAN, J. \& MURGAI, R. 2007. An Effective "Targeting Shortcut"? An Assessment of the 2002 Below-Poverty Line Census Method. Background Paper for India Safety Nets Review. New Delhi: Institution.

JENKINS, R. 1999. Democratic Politics and Economic Reforms in India, Cambridge, Cambridge University Press.

JOHANSSON, T. B. \& GOLDEMBERG, J. (eds.) 2002. Energy for Sustainable Development: a policy agenda, New York: UNDP.

JOSHI, S., ARORA, S., PAMLIN, D. \& SINHA, S. 2008. Indian Companies with the Solutions that the World Needs: Sustainability as a driver for innovation and profit, New Delhi, WWF India.

JOSHI, V. \& LITTLE, I. M. D. 1993. India: Macroeconomics and Political Economy, 19641991, New Delhi, Oxford University Press.

JOSKOW, P. L. 1989. Regulatory Failure, Regulatory Reform, and Structural Change in the Electrical Power Industry. Brookings Papers on Economic Activity.

KALAHANDI DISTRICT PROFILE. 2002. District at a Glance [Online]. Bhawanipatna: National Informatics Centre, Kalahandi District. [Accessed November 14, 2002 2002].

KANNUNGO COMMITTEE REPORT 2001. Report of the S Kannungo Committee on Power Sector Reforms in Orissa. Report submitted to the Government of Orissa. Bhubaneshwar.

KAPUR, D. 2011. The Shift to Cash Transfers: Running Better But on the Wrong Road? . Economic and Political Weekly, XLVI (21): 80-85.

KELKAR, G. \& NATHAN, D. 2005. Gender Relations and Energy Transition in Rural Asia. New Delhi: UNIFEM.

KELKAR, V. L. \& SARMA, E. A. S. 1996. Development of Energy Resources. In: KELKAR, V. L. \& RAO, V. V. B. (eds.) India Development Policy Imperatives. New Delhi: Tata McGraw-Hill Publishing Company Limited.

KEOHANE, N. O., REVESZ, R. L. \& STAVINS, R. N. 1999. The positive political economy of instrument choice in environmental policy. In: PANAGARIYA, A., 
In Pursuit of a Light Bulb and a Smokeless Kitchen

PORTNEY, P. R. \& SCHWAB, R. M. (eds.) Environmental and public economics: essays in honor of Wallance E Oats. Cheltenham.

KHANDEKER, S. R., BARNES, D. F. \& SAMAD, H. A. 2010. Energy Poverty in Rural and Urban India: Are the Energy Poor also Income Poor. Policy Reseacrh Working Paper. Washington D.C.: Institution.

KHEMKA, B. 2009. Misappropriation hits progress of RGGVY in Kalahandi. The Pioneer, November 7, 2009.

KOHLI, A. 1987. The State and Poverty in India: The Political Economy of Reform, Cambridge, Cambridge University Press.

KOHLI, A. 1989. Politics of Economic Liberalisation in India. World Development, 17 (3): 305-328.

KOOIJMAN-VAN DIJK, A. L. 2008. The Power to Produce. University of Twente.

KOOIJMAN-VAN DIJK, A. L. \& CLANCY, J. S. 2010. Enabling Access to Sustainable Energy: A Synthesis of Research Findings in Bolivia, Tanzania and Vietnam. Energy for Sustainable Development, 14: 14-21.

KOTWAL, A., MURUGKAR, M. \& RAMASWAMI, B. 2011. PDS Forever? Economic and Political Weekly, XLVI (21): 72-76.

KRISHNA, A. 2004. Escaping Poverty and Becoming Poor: Who Gains, Who Loses and Why? World Development, 32 (1): 121-136.

KRUGMAN, H. \& GOLDEMBERG, J. 1983. The Energy Cost of Satisfying Basic Human Needs. Technological Forecasting and Social Change, 24: 45-60.

KRUGMAN, P. \& WELLS, R. 2006. Economics, New York, Worth Publishers.

LITTLE, I. M. D. 1996. India's Economic Reform 1991-96. Journal of Asian Economics, 7 (2): 161-176.

LITTLECHILD, S. 2000. Privatisation, Competition and Regulation of the British electricity industry with implications for developing countries. ESMAP Report 226/00. Washington D.C.: The World Bank.

MAHENDRA DEV, S. 2004. Is Rural India Shining. CESS Working Paper No. 54. Hyderabad: Institution.

MANMOHAN SINGH. 2004. PM's address at the National Energy Conservation Awards [Online]. New Delhi: Prime Minister's Office, Government of India. [Accessed accessed on December 21, 2004 2004].

MATINGA, M. N. 2010. We Grow Up With It. University of Twente.

MAZUMDER, S. B. 1932. Gosaba Cooperative Commonwealth. A lecture by S B Mazumder. Gosaba: Institution.

MINISTRY OF FINANCE 1995. Economic Reforms: The First Two Years. In: KAPILA, R. \& KAPILA, U. (eds.) Understanding India's Economic Reforms: the past, the present and the future. Delhi: Academic Foundation.

MINISTRY OF FINANCE 2004. Central Government Subsidies in India. A Report [Prepared with assistance of the National Institute of Public Finance and Policy]. New Delhi: Department of Economic Affairs, Ministry of Finance, Government of India.

MINISTRY OF FINANCE 2011. Interim Report of the Task Force on Direct Transfer of Subsidies on Kerosene, LPG and Fertiliser. New Delhi: Ministry of Finance, Government of India.

MINISTRY OF FINANCE 2012. Union Budget: Speech of the Finance Minister. New Delhi: Ministry of Finance, Government of India. 
MISHRA, S. K. 2001. Poverty and Economic Change in Kalahandi, Orissa: The Unfinished Agenda and New Challenges. Journal of Social and Economic Development, III (2): 245-265.

MNES 2006. Annual Report 2005-06. New Delhi: Ministry of Non-Conventional Energy Sources, Government of India.

MODI, V., MCDADE, S., LALLEMENT, D. \& SAGHIR, J. 2005. Energy Services for the Millennium Development Goals. http://www.me.columbia.edu/facbios/modi/resources/MP_Energy.pdf. Washington D.C./New York: The World Bank and United Nations Development Programme.

MOHAN, D. \& SINHA, S. 2010. Vulnerability Assessment of People, Livelihoods and Ecosystems in the Ganga Basin, New Delhi, WWF India.

MOLTKE, A. V., MCKEE, C. \& MORGAN, T. (eds.) 2004. Energy Subsidies, Sheffield: United Nations Environment Programme and Greenleaf Publishing.

MOLYNEUX, M. 2009. Conditional Cash Transfers: A 'Pathway to Women's Empowerment'? Pathways of Women's Empowerment, Working Paper 5. Brighton: Institute for Development Studies.

MOPNG 2002. Annual Report 2001-02. New Delhi: Ministry of Petroleum and Natural Gas, Government of India.

MOPNG 2009. Annual Report 2008-09. New Delhi: Ministry of Petroleum and Natural Gas, Government of India.

MORGAN, T. 2004. Designing and implementing energy subsidy reforms. In: MOLTKE, A. V., MCKEE, C. \& MORGAN, T. (eds.) Energy Subsidies. Sheffield: United Nations Environment Programme and Greenleaf Publishing.

MUKHERJEE, A. \& SHAH, T. 2003. Groundwater Governance in South Asia. Water Policy Research. Anand: IWMI-Tata Water Policy Programme.

MUKHERJEE, K. P. \& JOSHI, R. 2009. Kalahandi Changes and Challenges. Hyderabad: National Institute for Rural Development (NIRD).

MUNASINGHE, M. 2001. Sustainable development and climate change: applying the sustainomics transdisciplinary meta-framework. International Journal of Global Environmental Issues, 1 (1): 13-55.

MUSGRAVE, R. A. 1959. The Theory of Public Finance, New York, McGraw- Hill.

MUSGRAVE, R. A. \& MUSGRAVE, P. B. 1973. Public Finance in Theory and Practice, New York, McGraw-Hill.

MYRDAL, G. 1965. Asian Drama: An Inquiry into the Poverty of Nations, Volume II, New York, Pantheon.

MYRDAL, G. 1969. Objectivity in Social Research, New York, Pantheon.

NABARD 2001a. Bastar District. Potential Link Credit Plan for the 10th Five Year Plan (2002-03 to 2006-07). Raipur: National Bank for Agriculture and Rural Development.

NABARD 2001b. Kalahandi District Report 2001. Mumbai: National Bank for Agriculture and Rural Development.

NARAYAN, D., CHAMBERS, R., SHAH, M. K. \& PETESCH, P. 1999. Voices of the Poor: Crying out for Change. Washington D.C.: The World Bank.

NAYAK, B. S. 2002. Public Distribution System and Food Security in Orissa: A Case Study of Kalahandi District. M Phil, University of Hyderabad.

NCAER 2005. Comprehensive Study to Assess the Demand and Requirement of SKO. New Delhi: National Council for Applied Economic Research.

NORTH, D. C. 1990. Institutions, Institutional Change and Economic Performance, Cambridge, Cambridge University Press. 
NORTH, D. C. 1993. Economic Performance through Time. American Economic Review, 84: 359-368.

NSSO 2007. Energy Sources for Indian Households for Cooking and Lighting, 2004-05. NSS 61st round. New Delhi: National Sample Survey Organisation, Ministry of Statistics and Programme Implementation, Government of India.

OECD 1994. Managing the Environment: The Role of Economic Instruments, Paris, OECD.

OECD 1996. Subsidies, Tax Disincentives and the Environment: Concepts, Paris, OECD.

OECD 1997. Water Subsidies and the Environment, Paris, OECD.

OLZ, S. \& BEEREPOOT, M. 2010. Deploying Renewables in Southeast Asia: Trends and Potentials Paris: Organisation for Economic Co-operation and Development (OECD) and International Energy Agency (IEA).

OOMMEN, M. A. 2004. Basic Services, Functional Assignments And Own Revenue of Panchayats - Some Issues in Fiscal Decentralization for the consideration of the Twelth Finance Commission. NIRD Presentation. Hyderabad: Institution.

OPARAOCHA, S. \& DUTTA, S. 2011. Gender and energy for sustainable development Current Opinion in Environmental Sustainability, 3 (4): 265-271.

OPSCHOOR, J. B. 1995. National and international economic instruments for climate change policy. In: ZWERVER, S., VAN ROMPAEY, R. S. A. R., KOK, M. T. J. \& BERK, M. M. (eds.) Climate Change research: evaluation and policy implications. Amsterdam: Elsevier.

OPSCHOOR, J. B. \& TURNER, R. K. (eds.) 1994. Economic Incentives and Environmental Policies: Principles and Practice, Dordrecht: Kluwer Academic Publications.

OREDA 2002. Status of Village Electrification. Bhubaneshwar: Orissa State Renewable Energy Development Agency (OREDA).

OWDM 2004. Western Orissa Rural Livelihoods Project. Orissa Watershed Development Mission (OWDM). Bhubaneshwar: Institution.

OWEN, A. D. 2006. Renewable energy: Externality costs as market barriers. Energy Policy, 34 (5): 632-642.

PACHAURI, S. 2004. An analysis of cross-sectional variations in total household energy requirements in India using micro survey data. Energy Policy, 32 (15): 1723-1735.

PACHAURI, S. \& JIANG, L. 2008. The household energy transition in India and China. Energy Policy, 36 (11): 4022-4035.

PACHAURI, S. \& SPRENG, D. 2004. Energy Use and Energy Access in Relation to Poverty. Economic and Political Weekly, XXXIX (3): 271-278.

PARIKH, J. \& LAXMI, V. 2000. Biofuels, Pollution and Health Linkages: A Survey of Rural Tamil Nadu. Economic and Political Weekly, XXXV (47): 4125-4137.

PARIKH, J. \& SANGEETA, K. 2008. Gender audit of India's national energy policy. ENERGIA NewS.

PATEL, V. \& RAJAGOPALAN, R. 2009. Fishing community issues in the Sundarban Tiger Reserve: a case study. Chennai: International Collective in Support of Fishworkers.

PATIL, B. 2010. The Status of Rural Energy Access in India: A Synthesis. Energy Technology Innovation Policy Discussion Paper No. 2010-09. Belfer Center for Science and International Affairs, Harvard Kennedy School, Harvard University.

PATNAIK, S. M. \& MEHROTRA, N. 2010. Micro-Level Development Practices Among Tribals: An exploration in Bastar. View on Social Action, 60: 385-399.

PATNAIK, U. 2006. Poverty and Neo-liberalism in India. Rao Bahadur Kale Memorial Lecture delivered at Gokhale Insitute of Politics and Economics, Pune, February 03, 2006. New Delhi: Institution. 
PATNAIK, U. 2011. How little can a person live on? The Hindu.

PEACOCK, A. 1992. Public Choice in Historical Perspective, Cambridge, Cambridge University Press.

PEDERSEN, J. D. 2000. Explaining Economic Liberalisation in India: State and Society Perspectives. World Development, 28 (2): 265-282.

PETERSEN, L. K. \& ANDERSEN, A. H. 2009. Socio-cultural Barriers to the Development of a Sustainable Energy System - The Case of Hydrogen. Aarhus: National Environmental Research Institute.

PETROLEUM PLANNING AND ANALYSIS CELL 2011. Fiscal Subsidies on PDS Kerosene and Domestic LPG. Under Subsidy Scheme 2002 New Delhi: Ministry of Petroleum and Natural Gas, Government of India.

PEZZEY, J. 1992. Sustainable Development Concepts: An Economic Analysis, Washington D.C., The World Bank.

PIGOU, A. C. 1920. The Economics of Welfare, London, McMillan \& Co.

PLANNING COMMISSION 1950. The First Five Year Plan (1950-55), New Delhi, Planning Commission, Government of India.

PLANNING COMMISSION 1980. The Sixth Five Year Plan, New Delhi, Planning Commission, Government of India.

PLANNING COMMISSION 2002a. Annual Report 2001-02 on The Working of State Electricity Boards and Electricity Department. New Delhi: Power and Energy Division, Planning Commission, Government of India.

PLANNING COMMISSION 2002b. India Vision 2020. Report of the Committee on India Vision 2020. New Delhi: Planning Commission, Government of India.

PLANNING COMMISSION 2002c. National Human Development Report 2001, New Delhi, Planning Commission, Government of India.

PLANNING COMMISSION 2002d. Tenth Five Year Plan: 2002-2007, New Delhi, Planning Commission, Government of India.

PLANNING COMMISSION 2006. Integrated Energy Policy: Report of the Expert Committee. New Delhi: Planning Commission, Government of India.

PLANNING COMMISSION 2007. Eleventh Five Year Plan: 2007-2012, New Delhi, Planning Commission, Government of India.

PLANNING COMMISSION 2008. Development Challenges in Extremist Affected Areas. Report of an Expert Group. New Delhi: Planning Commission, Government of India.

PLANNING COMMISSION 2011. Approach paper for the 12th Five Year Plan. New Delhi: Planning Commission, Government of India.

PRACTICAL ACTION 2012. Poor people's energy outlook 2012: Energy for earning a living. Rugby: Practical Action Publishing.

PRAYAS ENERGY GROUP 2012. Electricity for All: Challenges and Prospects.

Proceedings of the Roundtable on Electricity for All: Challenges and Prospects.

Pune: Prayas Energy Group.

PRICE, C. W. 2000. Better energy services, better energy sectors - and links with poor. Energy Services for the World's Poor. Washington D.C.: ESMAP, The World Bank.

PWC 2002. Infrastructure Development Action Plan for Chattisgarh - Final Report. PricewaterhouseCoopers Pvt Ltd.

RADHAKRISHNA, R. \& SUBBA RAO, K. 1997. India's Public Distribution System: A National and International Perspective. World Bank Discussion Paper No. 380. Washington D.C.: The World Bank. 
RAJAN, A. T. 2000. Power Sector Reform in Orissa: an ex-post analysis of causal factors. Energy Policy, 28: 657-699.

RAKHMANTO, P. A. 2009. The Political Economy of Market Liberalization Policies in India's Energy Sector. University of Twente.

RAMANI, K. V. \& HEIJNDERMANS, E. 2003. Energy, Poverty and Gender: A Synthesis. Washington D.C.: The World Bank.

RAMESH, J. 2004. Walk the Talk [Online]. New Delhi: The NDTV New Channel. [Accessed May 2004].

RAMESH, J. 2010. The Two Cultures Revisited: Some Reflections on the EnvironmentDevelopment Debate in India. 11th ISRO-JNCASR Satish Dhawan Memorial Lecture. Bangalore: Institution.

RAMNATH, M. 2003. Tropical Desiduous Forests and the Adivasi. Indigenous traditions as response to leaf fall in Bastar, India. Natural Resources Forum, 27 (4): 304-309.

RAO, D. N. \& GOVINDRAJAN, S. 2003. Community Intermediation in Rural Power Distribution. Water Policy Research - Highlight. Anand: Institution.

RAO, P. S. C., MILLER, J. B., WANG, Y. D. \& BYRNE, J. B. 2009. Energy-microfinance intervention for below poverty line households in India. Energy Policy, 37 (5): 16941712.

REDDY, A. K. N. 1999. Rural Energy: Goals, Strategies and Policies. Economic and Political Weekly, XXXIV (49): 3435-3445.

REDDY, A. K. N. 2000a. Energy and Social Issues. In: GOLDEMBERG, J. (ed.) World Energy Assessment: Energy and the Challenge of Sustainability. New York: UNDP.

REDDY, A. K. N. 2000b. Paying for Power. The Hindu.

REDDY, A. K. N. 2002. Towards a New Paradigm for Power Sector Reform in India. Energy for Sustainable Development, VI (4): 22-29.

REDDY, S. \& PAINULY, J. P. 2004. Diffusion of renewable energy technologies - barriers and stakeholders' perspectives Renewable Energy, 29 (9): 1431-1447.

RESERVE BANK OF INDIA 2010. Master Circular on Micro-Credit. In: INDIA, R. B. O. (ed.). Mumbai.

REVELLE, R. 1976. Energy Use in Rural India. Science, 192 (4): 969-975.

RIGG, J. 2006. Land, Farming, Livelihoods, and Poverty: Rethinking the Links in the Rural South. World Development, 34: 180-202.

RIS 2010. Fossil Fuel Subsidy Reform in India: Addressing the Challenges. RIS Policy Brief Series. New Delhi: Institution.

RUTHERFORD, M. 1992. What is Wrong with the New Institutional Economics (and What is Still Wrong with the Old)? Journal of Economic Issues, 24: 299-318.

RUTHERFORD, M. 1995. The Old and the New Institutionalism: Can Bridges Be Built? Journal of Economic Issues, 29: 443-451.

RUTHERFORD, M. 2001. Institutional Economics: Then and Now. Journal of Economic Perspectives, 15: 173-194.

SACHS, I. \& SILK, D. 1990. Food and Energy - Strategies for Sustainable Development, Tokyo, United Nations University Press.

SACHS, J. D. 2005. India's Market Reforms: The Triumph of Hope over Fear. The End of Poverty. London: Penguin Books.

SACHS, J. D., VARSHNEY, A. \& BAJPAI, N. (eds.) 1999. India in the Era of Economic Reforms, New Delhi: Oxford University Press.

SAGHIR, J. 2005. Energy and Poverty: Myths, Links and Policy Issues. No.4. Washington D.C.: The World Bank. 
SAINATH, P. 1998. Everybody Loves a Good Drought, New Delhi, Penguin.

SANKAR, T. L. 2002a. Power Reforms in India - the search for an indigenous model for promoting competition. Energy for Sustainable Development, VI (4): 5-16.

SANKAR, T. L. 2002b. Toward's A People's Plan for Power Sector Reform. Economic and Political Weekly, XXXVII (40): 4143-4151.

SARMA, E. A. S. \& SARMA, J. V. M. 2007. Financing Government Expenditure for Sustainable Development in India. Hyderabad: Institution.

SATHAYE, J. \& MEYERS, S. 1990. Urban Energy Use in Developing Countries. In: DESIA, A. V. (ed.) Patterns of Energy Use in Developing Countries. Ottawa: IDRC/UNDP.

SCHUMPETER, J. A. 1942. Capitalism, Socialism, and Democracy, New York, Harper.

SEN, A. 1981. Poverty and Famines: An Essay on Entitlement and Deprivation, Oxford, Oxford University Press.

SEN, A. 1990. Gender and Cooperative Conflicts. In: TINKER, I. (ed.) Persistent Inequalities: Women and World Development. New York: Oxford University Press.

SEN, A. 1999. Development as Freedom, New York, Alfred A Knopf.

SEN, A. 2003a. Continuing the Conversation: Amartya Sen talks with Bina Agarwal, Jane Humphries, and Ingrid Robeyns. Feminist Economics, 9 (2-3): 319-332.

SEN, A. (ed.) 2003b. Globalization, Growth and Inequality in South Asia: The Evidence from Rural India, New Delhi: Tulika.

SEN, A. K. 1993. Capability and Well-Being. In: NUSSBAUM, M. C. \& SEN, A. K. (eds.) The Quality of Life. Oxford: Clarendon Press.

SHAH, T. 2001. Wells and Welfare in the Ganga Basin: Public Policy and Private Initiative in Eastern Uttar Pradesh, India. Research Report 54. Colombo: International Water Management Institute.

SHAH, T., SCOTT, C., NARAYANA, P., KISHORE, A. \& SHARMA, A. 2003. The WaterEnergy Nexus in India: Approaches to Agrarian Prosperity with a Viable Power Industry. IWMI Research Report 70. Anand: International Water Management Institute.

SHIRLEY, M. M. 1999. Bureaucrats in Business: The Roles of Privatization versus Corporatization in State-Owned Enterprise Reform. World Development, 27 (1): 115136.

SINGH, N. 2008. India's Development Strategy: Accident, Design and Replicability. MPRA Paper No. 12453. Munich: Institution.

SINHA, N. 1996. The Political Economy of India's Telecommunication Reforms. Telecommunications Policy, 20 (1): 23-38.

SINHA, S. 1997. Financing Renewable Energy Technologies. TERI NEWSWIRE, III (23).

SINHA, S. 2001. The Rural Photovoltaic Market in India. In: GUPTA, J., VLASBLOM, J. \& KROEZE, C. (eds.) An Asian Dilemma. Amsterdam: Institute for Environmental Studies, Vrije University.

SINHA, S. 2003. Tare Tare Kiss: the story of a tribal women's self-help group's struggle to get electricity in their village. Energy for Sustainable Development, VII (3): 30-32.

SINHA, S. 2004. Solar Photovoltaic Development in India. In: HULTEN, S. (ed.) Global Experience in Solar Photovoltaic.

SINHA, S. 2010. Environmental Finance for Pro-Poor Development: Analysing the Role of Carbon Finance, New Delhi, WWF India/UNDP India.

SINHA, S., BHARAT R SHARMA \& CHRISTOPHER A SCOTT 2006. Understanding and Managing the Water - Energy Nexus: Moving Beyond the Energy Debate. In: 
SHARMA, B. R., VILLHOLTH, K. G. \& SHARMA, K. D. (eds.) Groundwater Research and Management: Integrating Science into Management Decisions. Colombo: International Water Management Institute.

SINHA, S. \& KHANNA, R. 2007. Rural Electricity Franchisee Experience in India: A compilation of different models and approaches. New Delhi: Institution.

SINHA, S., MAJHI, P., ROJAS, A. \& PARIKH, J. 2009. Making Carbon Markets Work for the Poor and Women. Energia.

SINHA, S., NARAYANA, P. \& AHMED, A. U. 2004. Water - Energy Nexus: Role of Community Institutions Models. SARI/Energy Research and Outreach Project 546103-08. Hyderabad/Dhaka: International Water Management Institute (IWMI) and Bangladesh Unnayan Parishad (BUP).

SINHA, S. \& RAMANA, P. V. 1997. Market Development of Solar Home Systems: Experience in the State of Gujarat. In: SINGH, D. (ed.) Renewable Energy for Village Electrification. New Delhi: Goldline Publishers.

SINHA, S., SHUKLA, A. \& MIRZA, A. 2000. Lighting in Sundarbans - from Dhibri to Solar Photovoltaic. In: BANERJEE, R., NAYAK, J. K. \& FERNANDES, B. G. (eds.) Renewable Energy Technology for the New Millennium. New Delhi: Allied Publishers.

SMITH, K. R. 2002. Indoor air pollution in developing countries: recommendations for research. Indoor Air, 12: 198-207.

SMITH, K. R. 2006. Health impacts of household fuelwood use in developing countries. Unasylva, 224 (57): 41-44.

SMITH, K. R., MEHTA, S. \& MAEUSEZAHL-FEUZ, M. 2004. Indoor smoke from household solid fuels. In: M. EZZATI, A. L., A. \& RODGERS, S. V. H. C. M. (eds.) Comparative quantification of health risks: global and regional burden of disease due to selected major risk factors. Geneva: WHO.

SO, A. Y. 1990. Social Change and Development: Modernisation, Dependency and Worldsystem Theories, California, Sage Publications.

SOLOGUREN, J. 2006. The role of micro-finance in the up-take of electricity: a case study of small and micro-finance enterprises in rural areas of Bolivia. University of Twente.

SONI, P. 2007. Global Solutions Meeting Local Needs. Vrije Universitiet.

SOUBBOTINA, T. P. 2004. Beyond Economic Growth: An Introduction to Sustainable Development, Washington D.C., The World Bank.

SREEKUMAR, N. Year. Lies, Damn Lies and Statistics: A Case study of Power reforms in Orissa. In: Asia Power Sector Reforms Workshop, 2002.

SRINIVASAN, T. N. 1994. Destitution: A discourse. Journal of Economic Literature, 32 (4): 1842-1855.

SRINIVASAN, T. N. \& BHAGWATI, J. 1995. India's Economic Reforms. In: KAPILA, R. \& KAPILA, U. (eds.) Understanding India's Economic Reforms. Delhi: Academic Foundation.

SRIRAM, M. S. \& FISHER, T. 2002. Beyond Micro-Credit: Putting Development Back into Microfinance, New Delhi, Vistaar Publications.

SRIVASTAVA, D. K. \& SEN, T. K. 1997. Government Subsidies in India, New Delhi, National Institute of Public Finance and Policy (NIPFP).

STIGLITZ, J. E. 1997. Economics, New York, W.W.Norton.

STIGLITZ, J. E. 2002a. Globalization and its Discontents, London, Penguin Books. 
STIGLITZ, J. E. 2002b. Transparency in Government. The Right to Tell: The Role of Mass Media in Economic Development. Washington D.C.: The World Bank.

STONE, J. L., TSUO, Y. S., ULLAL, H. S., WALLACE, W. L., SASTRY, E. V. R. \& BAOSHAN, L. 1998. PV Electrification in India and China: the NREL's experience in international cooperation. Progress in Photovoltaics: Research and Applications, 6 (5): 341-356.

STONEMAN, P. 1983. The Economic Analysis of Technological Change, New York, Oxford University Press.

STRANGE, S. 1988. States and Markets, London, Pinter Publishers.

SUNDAR, N. 1997. Subalterns and Soverigns: an anthropoligical history of Bastar 18541996, New Delhi, Oxford University Press.

SUNDAR, N. 2001. Divining Evil: The State and Witchcraft in Bastar. Gender, Technology and Development, 5 (3): 425-448.

SUNDAR, N. 2006. Bastar, Maoism and Salwa Judum. Economic and Political Weekly, XLI (29): 3187-3192.

SUNDARAJAN, U. 2000. Institutional Stakes in India's Oil and Gas Restructuring. In: AUDINET, P., SHUKLA, P. R. \& GRARE, F. (eds.) India's Energy: Essays on Sustainable Development. New Delhi: Manohar Publishers.

SWAMINATHAN, M. S. (ed.) 1993. Wheat Revolution - A dialogue, New Delhi: Macmillan India Ltd.

SWAMY, A. 1998. Parties, Political Identities and the Absence of Mass Political Violence in South India. In: BASU, A. K. \& KOHLI, A. (eds.) Community Conflicts and State in India. Delhi: Oxford University Press.

TELLAM, I. (ed.) 2000. Fuel for Change: World Bank Energy Policy - Rhetoric vs. Reality, London: Zed Books.

TERI 1998. Evaluation of Solar PV systems installed under the INDO-US Collaborative Programme. New Delhi: TERI.

THE INDIAN ECONOMY BLOG. 2008. Oil Pricing in India. [Accessed March 9, 2009].

TODARO, M. P. \& SMITH, S. C. 2003. Economic Development, Pearson Education Limited.

TOI 2005. Invest, Don't Subsidise. The Times of India (ToI), May 29, 2005.

TOMAN, M. A. \& JEMELKOVA, B. 2003. Energy and Economic Development: An Assessment of the State of Knowledge. The Energy Journal, 24 (4): 93-112.

TUCKER, M. 1999. Can Solar Cooking save Forests? Ecological Economics, 31: 77-89.

UNDP 2004a. Problems of Specific Regions (Chapter 10). West Bengal: Human Development Report 2004. New Delhi: UNDP.

UNDP 2004b. West Bengal: Human Development Report 2004, New Delhi, UNDP.

UNDP 2006. Expanding Access to Modern Energy Services. In: GITONGA, S. \& CLEMENS, E. (eds.) Replicating, Scaling Up and Mainstreaming at the local level Lessons from community-based initiatives. New York: United Nations Development Programme.

UNDP/WHO 2009. Energy Access in Developing Countries - A Review focussing on Least Developed Countries and Sub-Saharan Africa. New York: Institution.

UNEP 2008. Reforming Energy Subsidies. Paris: United Nations Environment Programme.

UNITED NATIONS 2010. Energy for a Sustainable Future. The Secretary-General's Advisory Group on Energy and Climate Change (AGECC). New York: United Nations. 
In Pursuit of a Light Bulb and a Smokeless Kitchen

UNITED NATIONS 2012. Sustainable Energy for All: A Framework for Action. Report of the Secretary-General's High-level Group on Sustainable Energy for All. New York: United Nations.

VAIDYANATHAN, A. 2006. Farmer's Suicides and the Agrarian Crisis. Economic and Political Weekly, XLI (38): 4009-4013.

VAN DIJK, M. P. \& SCHULTE NORDHOLT, N. G. 1994. Privatisation experiences in Developing Countries - how to assess? In: VAN DIJK, M. P. \& SCHULTE NORDHOLT, N. G. (eds.) Privatisation experiences in African and Asian Countries. Amsterdam: SISWO.

VELAYUDHAN, S. K. 2003. Dissemination of solar photovoltaics: a study on the government programme to promote solar lantern in India. Energy Policy, 31 (14): 1509-1518.

VENKATA RAMANA, P. 1998. As if Institutions Matter: An assessment of Renewable Energy Technologies in Rural India. University of Twente.

VICKERS, J. \& YARROW, G. 1991. Economic Perspectives on Privatization. Journal of Economic Perspectives, 5 (2): 111-132.

WBREDA 2001. Village Electrification Programme with Solar Photovoltaic Power Plants in Sunderbans area of West Bengal. Kolkatta: WBREDA.

WCED 1987. Our Common Future, Oxford, Oxford University Press.

WILLIAMS, J. H. \& GHANADAN, R. 2006. Electricity reform in developing and transition countries: A reappraisal. Energy, 31: 815-844.

WILLIAMSON, J. 1994. The Political Economy of Policy Reforms. Washington D.C.: Institute for International Economics.

WILLIAMSON, O. E. 1981. The Economics of Organization: The Transaction Cost Approach. American Journal of Sociology, (87): 548-577.

WILLIAMSON, O. E. 1996. The mechanisms of governance, New York, Oxford University Press.

WILLIAMSON, O. E. 1997. Transaction cost economics and public administration. In: BOORSMA, P., AARTS, K. \& STEENGE, A. (eds.) Public priority settings: rules and costs. London: Kluwer Academic Publishers.

WORLD BANK 1991. World Development Report: the Challenge of Development, Washington D.C., The World Bank.

WORLD BANK 1993. The World Bank's role in the electric power sector. A World Bank Policy Paper. Washington D.C.: The World Bank.

WORLD BANK 1995. Bureaucrats in Business: The Economics and Politics of Government Ownership, Washington D.C., The World Bank.

WORLD BANK 1996. Rural Energy and Development: Improving Energy Supplies to Two Billion People, Washington D.C., The World Bank.

WORLD BANK 1997. World Development Report: The State in a Changing World, New York, Oxford University Press.

WORLD BANK 1999. India: Household Energy Strategies for Urban India: the case of Hyderabad, Washington D.C., The World Bank.

WORLD BANK 2000. Energy Services for World's Poor, Washington D.C., The World Bank.

WORLD BANK 2002. Energy strategies for rural India: Evidence from six states. ESM258, Report 258/02. Washington D.C.: The World Bank.

WORLD BANK 2007. Agriculture for Development. Washington D.C.: The World Bank. 
XIM 2001. Socio-economic assessment of ORCES Project. Bhubaneshwar: Xavier Institute of Management (XIM).

YARROW, G. 1999. A Theory of Privatisation, or Why Bureaucrats are still in Business. World Development, 27 (1): 157-168.

YIN, R. K. 2003. Case Study Research, Designs and Methods, London, Sage Publications. 
In Pursuit of a Light Bulb and a Smokeless Kitchen 


\section{Summary}

After more than six decades of development planning, the majority of India's population, especially those living in villages, continue to wait for access to energy forms that enable them to switch on an electric light bulb and to cook food on a clean stove in a smokeless kitchen. India is a country of extreme economic and social contrasts, a situation that poses sustainability and development problems of varying magnitudes linked to its scale and geographical diversity. The rapidly growing economy, while bringing prosperity at the aggregate level, has also created social imbalances and inequities including in access to, and use of, resources. One of the outcomes of, and indeed a contributor to, economic growth has been an unprecedented increase in demand for energy. Embedded in meeting future energy demands is the challenge of providing access to modern energy carriers in rural India, an unfinished aspect of India's development vision since 1947. Nearly 77 million rural households (approximately half of the rural households in India) have no access to electricity and about 120 million households (about $80 \%$ of the rural total) use biomass energy for cooking. It is recognised that the level of energy access in rural India is similar to, and in some cases even lower than, that of some of the poorest countries of the world. India faces the challenge of lifting low-capacity end-users out of energy poverty while pursuing its energy policy reforms.

Therefore, the central focus of this dissertation is the impact on energy access by lowcapacity end-users of the shifts in the policy framework of India's energy sector. This saw an increasing reliance on the market and decreasing governmental intervention from 1991 to 2004, and then the return to a greater role for the government while pursuing policy reforms from 2004 onwards. As such, the objective of this study, as presented in Chapter 1 (Introduction), is to identify those circumstances under which the policy reforms in India's energy sector can lead to improved access to modern energy carriers and to sustainably meeting the energy needs of low-capacity end-users in rural India. This dissertation covers India's energy policy from 1950 to 2010, and in particular two critical phases of policy reforms - before and after 2004. It analyses the factors that influenced energy access in 200102, after a period in which the shift in energy policy had reduced the role of the state and put a strong emphasis on market forces. It further analyses the implementation of the policies initiated since 2004, and their effect on energy access in 2008-09, when the government's role was more active and that of the market limited. By examining energy access at two points in time, this dissertation provides a longitudinal analysis, a desirable feature that is often impossible in doctoral research, of the impact of policies on energy access by lowcapacity end-users in rural India. The hypothesis of this research is that, unless appropriate measures are applied, the energy policy reforms in India will not lead to improved access to modern energy carriers for the low-capacity end- users.

This dissertation is rooted in the growing global concerns that the lack of access to modern energy carriers in developing countries is constraining the ability of low-capacity end-users in rural areas to be part of mainstream economic and social development. Globally, nearly 1.5 billion people in developing countries do not have access to electricity and nearly three 
billion people use traditional energy carriers to meet their cooking energy needs. The value of energy in contributing to the economic and social development of humankind is well established and acknowledged. However, despite the apparent benefits of access to modern energy carriers (electricity, liquefied petroleum gas [LPG] and kerosene oil) in rural areas, especially for low-capacity end-users, the transition to modern energy carriers remains slow.

So far, the debate on energy and development has mainly focused on the macro-level (national aggregate) while neglecting the impacts of the energy - development linkage on the micro-level (village and household). On the micro-level, these linkages are far from clear because the links between limited access to modern energy carriers and the broader issue of development are diverse, both direct and indirect, and complex, and are not fully understood. At the household level, the linkages are complex in that improvements in energy access do not automatically translate to an increase in aggregate income or vice versa. The linkages become even more complex because of differing, and at times conflicting, priorities set by the various members of a household. Here, gender relationships have an impact since these influence decision-making including choices about energy carriers. Understanding the complex interplay requires empirical evidence and this dissertation is structured around the central research question: "How might future implementations of policy reforms in India's energy sector be adapted to achieve the dual objectives of improving the economic efficiency of energy supply and of improving low-capacity end-users' access to modern energy carriers?"

In Chapter 2 (Applied Concepts on Energy, Development and Policy Reforms), an analytical framework is derived based on the applied concepts of energy-development linkages at the micro-level and institutional aspects of public sector reforms. The linkages between energy sector policy and access to modern energy carriers are established through a combination of "delivery pathways", "enabling factors" and "contextual influences". Delivery pathways are the means of enabling access (availability and affordability) to modern energy carriers. Enabling factors are the combination of organisations and policy instruments that facilitate implementation of the policies, and these are specific to each pathway. Contextual influences are those demand-side issues that affect the degree of access to modern energy carriers, and whether these are strong or weak influences the degree of access to modern energy carriers. The dissertation, within the boundaries of the research objective, the hypothesis and the central research question, addresses three main research questions in order to understand the linkages between delivery pathways, enabling factors and contextual influences.

The linkages between energy and development show that access to modern energy carriers is a critical input for achieving social development and economic growth. Within the context of energy poverty, an important element in energy development and policy reforms is the complexity of the micro-level linkages. When people are living in energy poverty, they do not experience development. This dissertation defines energy poverty in terms of low-capacity end-users' lack of access, viewed as a function of availability and affordability, to energy services (energy used for consumptive end-uses such as lighting, cooking and the social benefits of education, health and drinking water; and productive end-uses such as irrigation and enterprise activities). This definition of energy poverty is reinforced by the inclusion of 
those links between energy access, gender and poverty that enhance the capability of lowcapacity end-users to improve their quality of life. A reasonable quality of life implies a life which is free from factors, such as indoor air pollution, that affect health; gaining adequate nourishment from cooked food and safe drinking water; being informed and knowledgeable about social and economic development including access to price information; and enjoying personal security through improved illumination. The dissertation shows that there are three causes of energy poverty: (i) a rural subsistence economy and the cost of modern energy carriers; (ii) the energy-gender linkage; and (iii) a weak delivery infrastructure and weak institutional mechanisms. The causes of energy poverty highlight those inequalities that need to be addressed in order to make energy policies effective and improve access to modern energy carriers.

Governments are well aware of the public benefits modern energy carriers help deliver. They also recognise that delivering this type of benefit is not of direct interest to markets, and consequently respond through intervening with public-sector policies (including instruments such as subsidies) to compensate for these market failures. Governmental intervention was the dominant paradigm in economic development from the Second World War until the early 1980s, when empirical evidence appeared to show that such interventions were not achieving their objectives, indeed might even be making the situation worse (government failures). The economic development paradigm shifted to one of rolling back the state and allowing the market to deliver growth. In order for this to happen, substantial reforms of public-sector policies were needed, with new objectives focussed on ensuring economic efficiency, primarily through institutional reforms and less political interference. The emphasis on policy reforms as a standard prescription for improving energy delivery occurred at a time when the 'social compact' (the connection between state and society) in most developing countries were unfulfilled. However, this dissertation argues that, in terms of improving economic performance, it is more than an issue of public versus private ownership. It is also important, given that the characteristics of each energy carrier (both traditional and modern) differ and that each enterprise involved in delivering an energy carrier has its own specific capabilities, plus the fact that the social and political factors (culture) also vary in each regional context, to recognise that energy policies have to be tailor-made. This insight stems from Boorsma's 3-C Model (1994), which is subsequently applied as part of the analytical framework of this study.

In Chapter 3 (Research Methodology), the arguments for the case-study regions selected are presented. The case-study regions - Gosaba Island (state of West Bengal), Bastar District (state of Chhattisgarh) and Kalahandi District (state of Orissa) - were identified using criteria related to energy access by low-capacity end-users and delivery pathways for modern energy carriers. These three case-study regions are representative of large parts of rural India that continue to suffer from limited access to modern energy. Given that the delivery pathways for each modern energy carrier differ, these three case-study regions can be compared to help to understand how, in the context of the policy frameworks for each energy carrier, social, economic, infrastructure and political factors (i.e. contextual influences) affect access to modern energy carriers by low-capacity end-users in rural India. Further, an ideological perspective, rooted in India's constitution and development paradigm of poverty alleviation, 
also influenced the selection of such case-study regions. India claims to be a welfare state and, as such, the objectives of policies and programmes should reach the poorest of the poor. By focusing on these three case-study regions, it is possible to assess the impact of policies in enabling energy access in some of the remotest regions of India.

The analysis of India's energy policy presented in Chapter 4 (Rural Energy Policy: The Meek Shall Inherit) answers the first main research question: How have energy sector reform policies been formulated to address the weaknesses apparent in the policies of the pre-reform phase in terms of improving access to modern energy carriers by low-capacity end-users in rural areas? The analysis shows that over the four development phases (centralised planning [1950-69], political populism [1969-91], reform [1991-2004] and inclusive reform [2004-10]) policies have addressed access to modern energy carriers by low-capacity end-users through programmes and budgets, but not sufficiently to create universal access. The assessment of the motives shaping India's energy policy shows a two-track approach: measures to reduce market failures, and reforms that focus on overcoming imperfections in the role of government in ensuring access to modern energy carriers. Between 1950, when India initiated its planned economy, and 1990, when India faced a major economic crisis, the focus within rural energy shifted from that of investing to enhance energy access to that of populist measures to appease voters. Nevertheless, the emphasis in the energy policy resonated with India's overall development strategy that focused on modernisation through self-reliance, while enhancing social and economic equity through trickle-down benefits.

Reforms in India's energy sector from 1991 on aimed to revive the sector, and address the policy failures and gaps, through sector reforms involving private sector participation in the energy sector. However, the regulatory frameworks were weak and questions were raised regarding the impact of these reform measures on the rural poor. Since 1991, the energy policy changes in the last two phases have been designed to improve access, to bring development and to deliver transitions in the organisations responsible for energy delivery. Following the political economy changes in 2004, principles of inclusive growth and development, together with reforms, have influenced energy sector policies. Specifically, since 2004, the policy reforms have been formulated with the political ideology of reforms having a 'human face' and addressing the agenda of inclusive development. Nevertheless, the policy still adopts a supply-side perspective on energy access. There is no systematic collection of gender-disaggregated data and, as a consequence, gender and energy linkages including intra-household dynamics due to 'cooperative conflict' (a point of cooperation and conflict at the same time within a household related to decision making) as argued by Amartya Sen (1990) are overlooked. The lack of a demand-side focus acts as a barrier to access even when the availability issues have been resolved. Energy policies also fail to take into account the development and presence of informal mechanisms for delivering modern energy carriers in the context of formal organisations failing to deliver on their responsibilities.

In Chapter 5 (Understanding Energy Access: Evidence from Gosaba, Bastar and Kalahandi), the second main research question is answered: Have the energy policies enabled lowcapacity end-users to gain access to modern energy carriers? The evidence from the three 
case-study regions shows that, despite there being policies and programmes for improving energy access in rural areas, their implementation has been oblivious to local conditions.

Although improvements in the policies and programmes can be seen, the evidence from the three case-study regions is that these policies and programmes lack the flexibility required to address the contextual influences. While the literature suggests that policymaking and policy implementation should be a mutual learning process, the analysis shows that current experiences with policy implementation in rural India are one-sided. In other words, the local contextual influences that affect implementation are not feeding into policymaking. As a result, while the availability has improved in many places, access to modern energy carriers by low-capacity end-users remains limited.

The analysis also shows that the limited access to modern energy carriers in rural areas is a function of multiple contextual influences and also linked with problems associated with delivery pathways. Energy is a facilitator, and access to modern energy carriers will not in itself alleviate the problems confronting India's rural areas. The evidence (based on a comparison of energy access scenarios between 2001-02 and 2008-09 and the policy changes since 2004) shows that the factors that influence access have not changed significantly in the case-study regions over this period, and that the implementation problems facing new energy policies have similarly remained unchanged. In practice, some of the changes needed in the villages are beyond the domain of the energy sector and, hence, bundling will be needed through public investments in other sectors to bring an overall change in the economic conditions in the villages. Further, some of the reforms in the energy sector have resulted in higher energy prices, as a consequence of which the unserved and underserved low-capacity end-users are changing their purchasing patterns and there is a backward shift to traditional energy carriers. For example, in all the three case-study regions, there is a significant shift in the purchasing pattern of kerosene oil, with households, and especially Below Poverty Line (BPL) households, now buying kerosene oil on the open market. This frequent purchase from the open market, at relatively high prices, has a significant bearing on household expenditure and, at the same time, raises questions on the effectiveness of the existing delivery pathways.

Policies formulated during the reforms phase for electricity distribution (i.e. privatisation) and for LPG (parallel marketing by the private sector) have yielded mixed results. For example, the 2008 fieldwork found that electricity access by BPL households in Gosaba had not changed since 2002, despite new policies and guidelines mandating compliance with the principle of universal energy access. As such, the electricity access situation in Gosaba conflicts with policies and contradicts the social and development objectives of inclusive growth. The experiences from Kalahandi with privatising electricity distribution raise a broader question regarding the applicability and effectiveness of such a reform policy for rural areas. The evidence gathered during the two fieldwork periods shows that while efforts were made to improve electricity access through social intermediation, these measures failed to improve access to electricity for low-capacity end-users in villages, and in Kalahandi a few BPL households (Kutir Jyoti consumers) were even disconnected.

The 1993 policy of parallel marketing LPG through private sector participation can be considered a positive measure in that it assisted in improving LPG availability in the rural 
areas through competition, an argument often linked to public sector reforms. In two of the research areas, Gosaba and Bastar, LPG availability improved due to the implementation of a parallel marketing scheme involving the private sector. Subsequent policy shifts, including greater flexibility for public sector companies to distribute LPG in rural areas, resulted in the diffusion and adoption of LPG in rural areas. However, despite its own policies on reforming fossil fuel subsidies, the central government continued to provide subsidies for LPG, and the price at public sector outlets was not increased. As a result, the private sector withdrew from the rural market. Further, drawing on the experiences in the three case-study regions over the two fieldwork periods, LPG being available may not be sufficient for low-capacity end-users to gain access. Some evidence was also found of households giving up their LPG connection. In 2002, a major concern for the households interviewed was the recurring costs involved, and this concern has grown since 2008 when the government did eventually start to reduce subsidies and, further, there are new proposals for subsidy reforms. Such a policy change will negatively affect LPG access by low-capacity end-users in rural areas.

The evidence from the case-study regions, together with the outcomes of the policy reforms, shows that, for energy access to be increased for low-capacity end-users, the government, despite its failings, has to continue to play a critical role. The findings suggest that access to modern energy carriers is generally better when the government is involved in their delivery than when it is left to the private sector (based on electricity distribution in Kalahandi). The study further shows that energy access is better where the government (at both national and local levels) has intervened. The policy designs that have created entitlements and subsidies for kerosene oil and that have targeted electricity at BPL households have ensured the availability of these energy carriers in rural areas, although there remain weaknesses in the implementation. Although the government programmes are intended to bring equity in energy access, this research shows that the policies and programmes are not always implemented effectively and sometimes not even applicable. As a consequence, large numbers of unserved and underserved low-capacity end-users (both those above and below the poverty line) remain.

Further, this research shows that the policy design (delivery pathways, organisations and policy instruments) remains top-down. The implementation of policies and programmes is only decentralised in the sense that a distributed network of organisations is involved. That is, the decentralisation is largely in terms of delivering energy carriers rather than as a contribution to policy formulation: the implementation of policies, schemes and measures is still decided at the top. The resulting failure of contextual factors to influence policy formulation also negates the basic premise of 'policy reforms with a human face'.

Chapter 6 (Conclusions: Will Rural India Shine?) summarises the principal arguments of the earlier chapters and analyses the linkages between contextual influences and enabling factors to answer the third main research question: What changes are required in the enabling factors to enhance access to modern energy carriers by low-capacity end-users? The dissertation makes it possible to reflect not only on the existing but also on possible future policies such that the latter can be effective in enhancing access to modern energy carriers. Similarly, identifying policy changes that have taken place over the two fieldwork periods 
covered by this dissertation provides an insight into how policies have been adapted. The evidence gathered also brings out examples of organisations and policy instruments that have been ineffective in improving energy access.

The findings discussed in this dissertation support the assertion that there is more to it than whether the ownership of an enterprise is in the public or the private sector. This research has found examples of both types of enterprise improving access to modern energy carriers as well as failing to deliver. The examples show that if policies and programmes ignore or underestimate the role of contextual influences, and do not allow flexibility to be introduced at the local level, then the implementation of energy policy reforms will be constrained in terms of enhancing access by low-capacity end-users to modern energy carriers. However, while there is a need for institutional flexibility, this dissertation recognises the need for appropriate systems of checks and balances in national/state policies and adjustments in policy instruments.

The dissertation builds its recommendation on the talisman given by Mahatma Gandhi in 1948, and intended to guide Indian leaders of the day and of the future in making decisions that would ultimately lead to the empowerment of the vulnerable (both economically and socially) and disadvantaged people of India. Now, more than six decades later, it is clear that the political classes, and the planners, bureaucrats and stakeholders involved in India's development, and in particular rural development, have failed to follow this talisman. Although, the policy recommendations in the dissertation are not intended as a talisman, it is believed that they could bring genuine changes, or at least trigger such changes, in relevant elements of energy policies that would move low-capacity end-users in rural India out of the vicious circle of energy poverty, and thus help fulfil the Mahatma Gandhi's vision of swaraj (freedom) from poverty.

The first recommendation is based on the recognition that the policy continuum requires an enabling regulatory framework (for both policy design and policy implementation) that reduces the uncertainties that make investors and end-users reluctant to invest in delivery pathways and in access to modern energy carriers. Further, the policies need to address demand-side issues such as equity, both inter- and intra- household, including understanding the interplay between those contextual influences that are critical in improving energy access. This will assist in strengthening organisations and policy instruments that connect the delivery pathways to the low-capacity users and make them more effective in delivering energy access while achieving inclusive development with a human face.

As a second recommendation, local organisations need to be further strengthened in their role as intermediaries (in energy delivery as well as in contributing to policy design). Within the Constitution of India, as well as in the Regulatory Acts governing the energy sector and in specific guidelines for national programmes, the existing regulations would allow decentralisation to be more effectively used. For example, the Constitution makes provision for decentralisation and for the involvement of Panchayati Raj Institutions (PRIs). Including PRIs in the energy delivery process should result in the more effective implementation of energy access programmes and reduce the current organisational complexities. They could be given responsibility for the aggregation, or bundling, of complimentary inputs and contextual 
influences, and work towards translating energy policies and programmes into effective and applicable implementation mechanisms. This dissertation argues that the cohesive dynamics of the PRIs could be utilised in ushering in improved energy access, especially for the poorest and the weakest emphasised in Gandhi's talisman.

The current system of subsidies has resulted in subsidising a section of the low-capacity endusers who could afford modern energy access even without subsidies. Conversely, it has excluded a section of the population, including both BPL and APL households, for whom subsidies could enable them to access modern energy carriers. The dissertation focuses on making subsidies and entitlements work better (highlighting the need for targeting), and hence the third recommendation is that while the targeted transfer of subsidies needs to be primarily initiated on the central-government level, it also requires the involvement of state governments and village-level organisations, such as PRIs, in order to properly identify those households that fall within the targeted groups. A related recommendation is to structure the entitlements by setting an upper limit for each modern energy carrier, but in a manner that targets those low-capacity end-users who do not have the capacity to pay and so does not perpetuate energy poverty.

An issue with reforming energy subsidies and implementing these recommendations is that this would need to be accompanied by more accurate identification of the intended beneficiaries if implementation is to be effective. To date, a single poverty line has been used in all the social welfare programmes that are subsidised by the government. The application of this single poverty line classification when providing entitlements and subsidies has been shown to be ineffective in enabling access to energy and reducing energy poverty in the casestudy regions. Hence, the fourth recommendation, and one that cuts across other sectors, is that the application of the APL/BPL division as a basis for providing entitlements and subsidies needs reconsideration if energy access is to be improved for low-capacity endusers.

To conclude, the integration of the above recommendations, together with the bundling of contextual influences, could result in increased efficiency in energy supply and improved access by low-capacity end-users to modern energy carriers. The policy design achieved through this process would be both applicable and effective in its implementation, and move low-capacity end-users out of the vicious circle of energy poverty. For this to occur, governmental intervention is both critical and essential. As such, the policy reforms do not imply a reduced role for government, but rather a role in which government creates an enabling policy framework that enhances energy access by strengthening local organisations in terms of energy delivery, including enabling them to contribute to policy formulation, and ensures that policy instruments are better targeted.

The dissertation exhorts the low-capacity end-users of rural India and the policymakers not to walk alone, but to walk in harmony with government programmes. It is time for India's energy policy to recognise the long wait of low-capacity end-users and to implement appropriate policies and programmes so that their aspirations can become a reality: that they are no longer dreaming of the day, but can switch on a light bulb and cook food in a smokeless kitchen. 


\section{Samenvatting}

Na meer dan zes decaden ontwikkeling moet de meerderheid van de bevolking van India, in het bijzonder de plattelandsbevolking, nog wachten op toegang tot vormen van energie die hen in staat stellen op elektrisch licht over te schakelen en tot het kunnen koken op schone fornuizen in een keuken zonder rook. India is een land van extreme economische en sociale tegenstellingen. Hierdoor ziet het zich gesteld voor problemen van duurzame ontwikkeling van diverse aard en grootte als gevolg van zijn omvang en geografische verscheidenheid. De snelle economische groei heeft, naast meer welvaart op nationaal niveau, ook gezorgd voor sociale onevenwichtigheden en voor ongelijke kansen in de toegang tot en het gebruik van hulpbronnen. Een van de gevolgen van, en tevens ook een oorzaak voor de economische groei is de ongeëvenaarde toename in de vraag naar energie. Inherent aan het beantwoorden van de vraag naar toekomstige energie behoeften is de uitdaging te voorzien in de toegang tot moderne energie dragers (zoals elektriciteit, LPG, en kerosine) op het platteland van India. Dit is, sinds 1947, nog steeds een onvoltooid aspect van de ontwikkelingsvisie van India. Bijna 77 miljoen rurale huishoudingen (ongeveer de helft van de plattelandsbevolking van India) hebben geen toegang tot elektriciteit en ongeveer 120 miljoen huishoudingen (zo'n 80 $\%$ van de gehele rurale bevolking) koken op traditionele energie dragers, zoals biomassa. Het is bekend dat het niveau van toegang tot vormen van energie op het platteland van India gelijk is aan, en in sommige gevallen zelfs lager dan, de situatie in sommige van de armste landen in de wereld. India staat dus voor de dubbele taak om enerzijds de laagvermogende eindgebruikers uit hun energie armoede op te tillen, terwijl tegelijkertijd energiebeleidshervormingen moeten worden doorgevoerd.

Vandaar dat de centrale blik van dit proefschrift ligt op de gevolgen van de beleidsveranderingen in de energiesector in India wat betreft de toegang tot energie voor de laagvermogende eindgebruikers. Deze veranderingen werden van 1991 tot 2004 gekenmerkt door een toenemende afhankelijkheid van de markt en een afnemende bemoeienis van de overheid, en, vanaf 2004, door een terugkeer naar een grotere rol van de overheid, terwijl is doorgegaan met beleidshervormingen. Hiermee is het doel van dit onderzoek, zoals in Hoofdstuk 1 (Introductie) uiteengezet, het identificeren van die omstandigheden waaronder beleidshervormingen in de energiesector van India kunnen leiden tot een verbeterde toegang tot moderne energie dragers en tot het voldoen aan een duurzame voorziening in de energie behoeften van de laagvermogende eindgebruikers op het platteland van India.

Dit proefschrift bestrijkt het energie beleid van India van 1950 tot 2010, en in het bijzonder de twee belangrijke perioden van beleidshervormingen: vóór en ná 2004. In 2001/02 werden de factoren die de toegang tot energie beïnvloedden, geanalyseerd toen, door een hervorming in het energiebeleid, de rol van de overheid was verminderd en waarin een grotere nadruk werd gelegd op de kracht van de markt. Vervolgens werden in 2008/09 de gevolgen geanalyseerd van de invoering, in 2004, van een beleidshervorming voor de toegang tot energie. Toen werd de rol van de overheid weer vergroot en die van de markt verminderd. Door op twee momenten in de tijd die toegang tot energie voor de laagvermogende eindgebruikers op het platteland van India te bestuderen, verkrijgt deze studie een wenselijke 
longitudinale analyse die dikwijls in een promotie onderzoek niet mogelijk is. De hypothese van dit onderzoek luidt als volgt: tenzij aangepaste maatregelen worden doorgevoerd, zullen energie hervormingen in India niet leiden tot een verbetering van de toegang tot moderne energie dragers voor de laagvermogende eindgebruikers.

Dit proefschrift sluit aan bij de toenemende, wereldwijde zorg, namelijk dat een gebrek aan toegang tot moderne energie dragers in ontwikkelingslanden de mogelijkheden voor laagvermogende eindgebruikers op het platteland belemmert in hun economische en sociale ontwikkeling. Wereldwijd heeft bijna 1,5 miljard van de bevolking in ontwikkelingslanden geen toegang tot elektriciteit en bijna drie miljard mensen maken gebruik van traditionele vormen van energie dragers om te kunnen koken. Het belang van energie voor de economische en sociale ontwikkeling van de mensheid wordt voldoende onderkend. Maar ondanks het feit dat de voordelen van toegang tot moderne energie dragers op het platteland, in het bijzonder voor laagvermogende eindgebruikers, overduidelijk aanwezig zijn verloopt de overgang daar naar toe traag. Tot dusver heeft de discussie over de relatie van energie en ontwikkeling zich voornamelijk beperkt tot het macro (nationaal) niveau, terwijl die voor het micro niveau (dorp en huishouding) verwaarloosd bleef. Op dit micro niveau zijn de verbanden tussen energie en ontwikkeling verre van duidelijk omdat die divers en complex zijn en nog niet volledig worden begrepen. Op het niveau van een huishouding zijn die verbanden complex omdat een verbetering van de toegang tot moderne energie dragers niet automatisch leidt tot een verhoging van inkomen, en dit geldt ook omgekeerd. Die verbanden worden nog complexer omdat leden van een huishouding verschillende, en soms zelfs onderling tegenstrijdige, belangen kunnen hebben. Hier zijn gender verhoudingen van invloed omdat deze beslissingen over de keuze van energie dragers beïnvloeden. Om deze complexe relaties te begrijpen, zijn empirische gegevens noodzakelijk vandaar dat in deze studie de centrale onderzoeksvraag luidt: "Hoe kunnen toekomstige toepassingen van beleidshervormingen binnen de energiesector van India zo worden aangepast dat de dubbele doelstelling van enerzijds een verbetering van een economische efficiëntie van het aanbod van energie, en anderzijds de verbetering van de toegang tot moderne energie dragers voor laagvermogende eindgebruikers kan worden bereikt?"

In Hoofdstuk 2 (Toegepaste Concepten betreffende Energie, Ontwikkeling, en Beleidshervormingen) is een analytisch raamwerk ontworpen dat gebaseerd is op concepten van verbanden tussen energie en ontwikkeling op micro niveau, en op institutionele aspecten van hervormingen in de publieke sector. De verbanden tussen het beleid in de energiesector en de toegang tot moderne energie dragers worden bepaald door een combinatie van "wegen van overdracht/ delivery pathways", "mogelijkheden scheppende factoren/ enabling factors", en "contextuele invloeden". Onder "wegen van overdracht" worden die middelen verstaan die leiden tot de beschikbaarheid en de betaalbaarheid van moderne energie dragers. "Mogelijkheden scheppende factoren" zijn een combinatie van organisaties en beleidsinstrumenten die behulpzaam zijn bij de invoering van beleid; en die zijn voor elke vorm van overdracht specifiek. "Contextuele invloeden" zijn kwesties van de vraagzijde die van invloed zijn op de mate van toegang tot moderne energie dragers; de sterkte of zwakte van die invloeden bepaald de mate van toegang. Binnen de kaders zoals gesteld door het doel, de hypothese, en de centrale onderzoeksvraag van dit onderzoek, worden drie hoofdvragen 
beantwoord om zodoende de verbanden te begrijpen tussen de "wegen van overdracht", de "mogelijkheden scheppende factoren", en de "contextuele invloeden".

De verbanden tussen energie en ontwikkeling laten zien dat toegang tot moderne energie dragers een kritisch gegeven is voor het bereiken van sociale ontwikkeling en economische groei. Binnen het kader van de zogenoemde energie armoede, is de complexiteit van verbanden op het micro niveau een belangrijk element voor ontwikkeling en beleidshervormingen. Wanneer mensen in een situatie van energie armoede leven, ervaren zij geen ontwikkeling. In deze studie wordt energie armoede omschreven in termen van: het ontbreken, gezien als een functie van beschikbaarheid en betaalbaarheid, van de toegang tot energie voorzieningen voor laagvermogende eindgebruikers. Onder energie voorzieningen wordt dan verstaan: de energie die benut wordt voor consumptief eindgebruik, zoals verlichting en kookfaciliteiten; voor sociale doeleinden zoals onderwijs, gezondheidszorg en drinkwater; en voor productieve doeleinden, zoals irrigatie en ondernemingen. Deze definitie van energie armoede wordt versterkt door insluiting van de verbanden tussen toegang tot energie, gender relaties, en armoede die het vermogen versterken van de laagvermogende eindgebruikers om de kwaliteit van hun leven te verbeteren. Een redelijke kwaliteit van leven betekent een leven dat gevrijwaard is van factoren, zoals luchtvervuiling binnenshuis, die de gezondheid schaden; het beschikken over gekookt voedsel en veilig drinkwater; de toegang tot informatie over sociale en economische ontwikkelingen, inclusief informatie over marktprijzen; en het gevoel van veiligheid door verbeterde verlichting. In dit onderzoek wordt aangetoond dat er drie oorzaken zijn voor energie armoede: (i) de rurale zelfvoorzienende economie en de kosten voor moderne energie dragers; (ii) de energie gender relaties; (iii) een slechte fysieke en dienstverlenende infrastructuur en zwakke institutionele mechanismen. De oorzaken van energie armoede tonen die ongelijkheden aan die geadresseerd dienen te worden zodat energie beleid effectief kan worden en daarmee de toegang tot moderne energie dragers kan worden verbeterd.

Overheden zijn zich bewust van de publieke voordelen die moderne energie dragers bieden. Zij realiseren zich ook dat het leveren van dit type van voordelen niet direct in het belang van de markt is, en reageren daarom met een aanbod van beleidsinstrumenten, zoals onder andere subsidies, om het falen van de markt te compenseren. Deze overheidsbemoeienis vormde het dominante paradigma voor economische ontwikkeling sinds de Tweede Wereldoorlog tot beginjaren tachtig, toen empirisch bewijs aantoonde dat zulke interventies hun doeleinden niet haalden. Soms werd zelfs daardoor de situatie verslechterd (falen van de overheid). Het economische ontwikkelingsparadigma verschoof daarom naar een paradigma waarin de staat zich terugtrok ten gunste van de markt. Om dit te bewerkstelligen moesten wezenlijke beleidshervormingen in de publieke sector worden doorgevoerd, met nieuwe doeleinden die gericht waren op het bereiken van economische efficiëntie. Dit gebeurde voornamelijk door institutionele hervormingen en met minder politieke ingrepen. Deze nadruk op beleidshervormingen als een standaard voorschrift voor het verbeteren van de energievoorziening gebeurde in een periode toen in de meeste ontwikkelingslanden het zogenoemde "maatschappelijk verdrag" (de verbinding tussen de staat en samenleving) nog onvoldoende aanwezig was. Echter, in deze studie wordt betoogd dat, wat betreft het verbeteren van economische prestaties, het om meer gaat dan alleen de kwestie van publiek 
versus particulier eigendom. Het gaat óók om de specifieke eigenschappen (Characteristics) van een bepaalde energie drager, de wijze waarop de onderneming die hierin voorziet, opereert (Capabilities), en deze wordt beïnvloed door specifieke sociale en politieke factoren (Culture): het zogenoemde Drie-C Model, (Boorsma, 1994), zoals dat in het analytisch raamwerk van deze studie is toegepast.

In Hoofdstuk 3 (Onderzoeksmethodologie) worden de argumenten gepresenteerd die geleid hebben tot de keuze van de onderzoeksgebieden. Deze regio's - Gosaba Island (West Bengalen), Bastar District (Chattisgarh), en Kalahandi District (Orissa) - zijn gekozen op basis van criteria die verband houden met de toegang tot energie door laagvermogende eindgebruikers en de aanwezigheid van "wegen van overdracht" voor moderne energie dragers. Deze drie regio's zijn representatief voor grote delen van ruraal India die nog steeds te lijden hebben van beperkte toegang tot moderne vormen van energie. Omdat voor elke moderne energie drager de "weg van overdracht" verschilt, biedt een vergelijking van deze drie regio's kennis over de wijze waarop "contextuele invloeden" doorwerken op de toegankelijkheid tot moderne energie dragers voor laagvermogende eindgebruikers, binnen het raamwerk van het specifieke beleid voor elke energie drager. Ook heeft een ideologisch perspectief, verankerd in de grondwet van India en in het ontwikkelingsparadigma ter bestrijding van de armoede, de keuze van de onderzoek regio's beïnvloed. India stelt dat het een welvaart staat wil zijn en als zodanig moeten de doeleinden van beleid en programma's de allerarmsten bereiken. Door onderzoek te doen in deze drie regio's is het mogelijk het effect te beoordelen van het beleid dat gericht is op het verbeteren van de toegang tot energie in enkele van de meest afgelegen gebieden van India.

In Hoofdstuk 4 (Ruraal Energie Beleid: De Zachtmoedige Zal Erven) wordt een analyse van het energiebeleid van India gepresenteerd en daarmee wordt een antwoord gegeven op de eerste hoofdvraag van dit onderzoek: Op welke wijze zijn binnen de energiesector de beleidshervormingen die een antwoord beogen te geven op de klaarblijkelijke zwakheden van het vorige beleid geformuleerd, zodat de toegang tot moderne energie dragers voor de laagvermogende eindgebruikers wordt verbeterd? Deze analyse toont aan dat in alle vier de ontwikkelingsfasen (centralistische planning [1950-1969]; politiek populisme [1969-91]; hervormingsperiode [1991-2004]; en de periode van inclusieve hervormingen [2004-10]) het beleid het probleem van toegang tot moderne energie dragers voor laagvermogende eindgebruikers heeft geadresseerd door middel van programma's en fondsen, maar op een onvoldoende wijze om algemene toegang te bewerkstelligen. De beoordeling van de motieven achter het energiebeleid van India laat een tweesporen benadering zien: enerzijds maatregelen die het falen van de markt beogen te temperen, en anderzijds hervormingen die gericht zijn op het voorkomen van onvolkomenheden in het beleid van de overheid om de toegang tot moderne energie dragers te verzekeren. Tussen 1950, toen India met zijn centralistische economie begon, en 1990, toen het land een enorme economische crisis had, verschoof de aandacht binnen de landelijke energie voorziening van een investeren in een vergroting van de toegang tot energie naar een meer populistisch beleid om de kiezers te paaien. Desondanks bleef in die periode de nadruk van het energiebeleid in lijn met de algemene ontwikkelingsstrategie van India die gericht was op een modernisering door binnenlandse productie. Terwijl tevens werd aangenomen dat een sociale en economische gelijkheid kon 280 
worden bewerkstelligd via het doorsijpelen van de winsten van de bovenlagen naar sociaal economische lagere bevolkingslagen.

Vanaf 1991 waren de hervormingen gericht op een herstel van de energiesector, en werd via participatie van private partijen een antwoord geboden op de gebreken en tekorten binnen deze sector. Echter, de regulerende raamwerken waren zwak en er werden vragen gesteld ten aanzien van het effect van deze hervormingsmaatregelen voor de armen op het platteland. Sinds 1991 werden de beleidsveranderingen in de derde en vierde periode ontworpen om de toegang te verbeteren en om ontwikkeling te bewerkstelligen en veranderingen door te voeren binnen de organisaties die verantwoordelijk zijn voor de toelevering van energie. Na de politiek economische veranderingen in 2004 hebben het principe van een inclusieve groei en ontwikkeling samen met de beleidshervormingen, de energiesector beïnvloed. Meer in het bijzonder kan gezegd worden dat sinds 2004 de beleidshervormingen gebaseerd zijn op een politieke ideologie van een "ontwikkeling met een menselijk gezicht" gericht op een inclusieve ontwikkeling. Toch werd het beleid nog steeds gekenmerkt door een aanbodgerichte visie op de toegang tot energie. Er bestaat geen systematische kennis die gestoeld is op empirische gegevens uitgesplitst naar gender kenmerken, en, als een gevolg daarvan, werden de verbanden tussen gender-energie, inclusief de dynamiek binnen de huishoudingen als gevolg van "coöperatieve conflicten" over het hoofd gezien. Amartya Sen (1990) verstaat hieronder: een kwestie van samenwerken en tegelijk van conflict binnen de besluitvorming in een huishouding. Het ontbreken van een blik op de vraagzijde vormde een belemmering voor de toegang, zelfs wanneer aan de beschikbaarheid van energie werd voldaan. Het energiebeleid gaf ook geen aandacht aan de ontwikkeling en aan de aanwezigheid van informele toeleveringsmechanismen voor moderne energie dragers wanneer de formele organisaties hun verantwoordelijkheden niet namen.

In Hoofdstuk 5 (Inzicht in de Toegang tot Energie: Gegevens uit Gosaba, Bastar, en Kalahandi) wordt een antwoord gegeven op de tweede hoofdvraag van dit onderzoek: Heeft het energiebeleid de laagvermogende eindgebruikers toegang verschaft tot moderne energie dragers? De gegevens uit de drie regio's laten zien dat ondanks een beleid en programma's gericht op een verbetering van de toegang tot energie op het platteland, er geen rekening is gehouden met de lokale condities in die gebieden. Er bestaat geen flexibiliteit in de maatregelen om een antwoord te bieden aan die "contextuele invloeden". Daar waar in de literatuur gesproken wordt van een wenselijkheid dat het beleid en de uitvoering daarvan een wederzijds leerproces behoren te zijn, laat een analyse van de onderzoeksgegevens zien dat de huidige uitvoering van het beleid op het platteland in India eenzijdig is. Dat wil zeggen dat de "contextuele invloeden" op de uitvoering niet worden meegenomen in het beleid. Dit heeft tot gevolg dat, hoewel de beschikbaarheid op vele plaatsen is toegenomen, de toegang tot moderne energie dragers voor laagvermogende eindgebruikers nog steeds beperkt blijft.

Ook toont de analyse aan dat die beperkte toegang niet alleen het gevolg is van een veelvoud van "contextuele invloeden" maar ook verband houdt met problemen die zich voordoen in de "wegen van overdracht". Energie vergemakkelijkt ontwikkeling, maar toegang tot moderne energie dragers heft op zich zelf de problemen op het platteland van India niet op. Een vergelijking van de gegevens van 2001/'02 met die van 2008/'09 en de beleidsveranderingen 
sinds 2004 toont aan dat de factoren die van invloed zijn op de toegang tot moderne energie dragers, niet significant zijn veranderd. Ook zijn de problemen in de uitvoering van het nieuwe energiebeleid onveranderd gebleven. In de praktijk blijkt dat sommige problemen buiten de bevoegdheden van de energiesector vallen, en daarom is het noodzakelijk dat er een bundeling van investeringen in andere beleidsterreinen plaatsvindt zodat er werkelijke veranderingen in de economische condities op het platteland kunnen ontstaan. Verder blijkt dat sommige beleidsveranderingen geleid hebben tot een verhoging van de energieprijzen met als gevolg dat de laagvermogende eindgebruikers die geen of onvoldoende toelevering van energie kregen, hun koop gedrag hebben veranderd en dat er zelfs sprake is van een terugkeer naar het gebruik van traditionele energie dragers. Zo vindt er een aanzienlijke verschuiving plaats in het koopgedrag van kerosine waarbij huishoudingen, in het bijzonder die tot de categorie Onder de Armoede Lijn (OAL) worden gerekend, nu hun kerosine op de vrije markt kopen. Dit regelmatig voorkomend gedrag van aankoop op de vrije markt, tegen een relatief hogere prijs, heeft grote gevolgen voor de uitgaven per huishouding, en doet de vraag rijzen naar de effectiviteit van de bestaande "wegen van overdracht".

Het beleid voor de distributie van elektriciteit dat tijdens de hervormingsperiode werd geformuleerd (nl. privatisering) en dat voor LPG (een parallelle markt voor de private sector) heeft een gemengd resultaat opgeleverd. Zo werd tijdens het veldwerk in 2008 geconstateerd dat de toegang tot elektriciteit voor de OAL huishoudingen in Gosaba sinds 2002 niet was veranderd, ondanks het nieuwe beleid en de richtlijnen die dwingend een algemene toegang tot energie voorschreven. Daarmee is de situatie in Gosaba in strijd met het beleid en weerspreekt het de sociale ontwikkelingsdoeleinden van de inclusieve groei. De ervaringen in Kalahandi met de privatisering van de distributie van elektriciteit leidt tot een bredere vraag betreffende de toepasbaarheid en de effectiviteit van een dergelijk hervormingsbeleid voor het platteland. Een vergelijking tussen de twee perioden van veldwerk toont aan dat ondanks inspanningen ter verbetering van de toegang tot elektriciteit door sociale bemiddeling deze maatregelen faalden om die toegang voor de laagvermogende eindgebruikers in de dorpen te verbeteren. In Kalahandi werden zelfs enkele OAL huishoudingen (de zgn. Kutir Jyoti gebruikers) van toegang tot elektriciteit afgesloten.

Het beleid uit 1993 van een parallelle markt voor LPG via participatie van de private sector, kan wel worden gezien als een positie maatregel, doordat het de beschikbaarheid van LPG op het platteland heeft verbeterd op basis van het concurrentie principe. Een argument dat dikwijls wordt gehanteerd bij de invoering van hervormingen in de publieke sector. Dit vond ook plaats in de twee onderzoeksgebieden, Gosaba en Bastar. Vervolg beleid, zoals een grotere flexibiliteit voor bedrijven in de publieke sector om LPG op het platteland te distribueren, leidde tot uitbreiding van het gebruik van LPG in die gebieden. Echter, ondanks de eigen overheidshervormingen ten aanzien van de subsidies op fossiele brandstoffen, bleef die zelfde overheid doorgaan met het verstrekken van subsidies voor LPG, terwijl de prijs bij de publieke verkooppunten niet werd verhoogd. Dit had tot gevolg dat de private sector zich uit de markt terugtrok. Verder blijkt uit een vergelijking tussen de gegevens van beide veldwerk perioden in de drie onderzoek regio's dat de beschikbaarheid van LPG op zich zelf niet voldoende was voor de toegang daartoe voor de laagvermogende eindgebruikers. Er bleek zelfs in sommige gevallen sprake te zijn van het opgeven van LPG gebruik. In 2002 
vormde de terugkerende onkosten voor de aanschaf van LPG een belangrijke zorg voor de gebruikers. En deze zorg was in 2008 alleen maar groter geworden toen de overheid tenslotte besloot de subsidies voor LPG te verminderen terwijl er ook sprake was van nieuwe voorstellen voor hervormingen op dit gebied. Zulke beleidsveranderingen zullen negatieve effecten hebben op de toegang tot LPG voor de laagvermogende eindgebruikers op het platteland.

De onderzoeksgegevens uit het veld en de uitkomsten van de analyse van de beleidshervormingen tonen aan dat de overheid, ondanks al haar tekortkomingen, blijvend een belangrijke rol moet spelen om de toegang tot energie voor de laagvermogende eindgebruikers te vergroten. De gegevens (gebaseerd op de elektriciteitsdistributie in Kalahandi) laten zien dat de toegang tot moderne energie dragers in het algemeen beter is gewaarborgd bij een deelname van de overheid in die distributie dan wanneer dit wordt overgelaten aan de private sector. Het beleid dat gezorgd heeft voor recht op en subsidies voor kerosine en dat speciaal gericht was op de voorziening van elektriciteit voor de OAL huishoudingen heeft de beschikbaarheid van de moderne energie dragers op het platteland verzekerd, hoewel er in de uitvoering zwakheden bleven. Al was het overheidsbeleid gericht op het aanbrengen van evenwichtigheid in de toegang tot energie, op grond van dit onderzoek kan worden gesteld dat dat beleid en de programma's daarvoor niet altijd effectief werden uitgevoerd en soms waren zij zelfs niet uitvoerbaar. Als gevolg daarvan blijft het aantal laagvermogende eindgebruikers die niet of onvoldoende van energie worden voorzien (zowel uit de categorie van Boven als die van Onder de Armoede Lijn) groot.

Dit onderzoek laat ook zien dat het beleid (zowel ten aanzien van de "wegen van overdracht", als ook wat betreft de organisaties en de instrumenten) top-down blijft. Er is in de uitvoering van beleid en van programma's slechts sprake van decentralisatie in zoverre het de distributie van netwerken van organisaties betreft. Dat houdt in dat de decentralisatie meer een kwestie is van een toelevering van energie dragers dan dat het een bijdrage vormt voor het formuleren van beleid: de beleidsuitvoering en de programma's en maatregelen worden nog steeds in de top bepaald. Het resultaat hiervan is dat contextuele factoren geen invloed hebben op de beleidsformuleringen en hierdoor wordt de basis vooronderstelling van "beleidshervormingen met een menselijk gezicht" ontkend.

Hoofdstuk 6 (Conclusies: Zal het Platteland van India Blinken?) vat de belangrijkste argumenten van de vorige hoofstukken samen en biedt een analyse van de verbanden tussen de "contextuele invloeden" en de "mogelijkheden scheppende factoren" waardoor een antwoord kan worden gegeven op de derde hoofdvraag: Welke veranderingen in de "mogelijkheden scheppende factoren" zijn noodzakelijk om de toegang tot moderne energie dragers voor de laagvermogende eindgebruikers te vergroten? Dit proefschrift biedt ruimte om niet alleen te reflecteren over het huidige beleid maar ook over mogelijk toekomstig beleid zodat dit effectief kan zijn in het vergroten van de toegang tot moderne energie dragers. Evenzo biedt een identificering van beleidsveranderingen die tussen beide onderzoeksperioden plaatsvonden inzicht in de wijze waarop het beleid is aangepast. Daarmee komen ook de voorbeelden van organisaties en van beleidsinstrumenten naar voren die ineffectief zijn gebleken. 
De resultaten laten zien dat er meer aan de orde is dan de vraag of een onderneming in staatshanden is of in particulier bezit. Dit onderzoek laat voorbeelden zien van beide typen bedrijven die de toegang hebben verbeterd en ook die hierin gefaald hebben. De voorbeelden tonen verder aan dat wanneer het beleid en de programma's geen rekening houden met de rol van de "contextuele factoren" of die onderschatten, en wanneer zij geen flexibiliteit op het lokale niveau toelaten, dat dan de uitvoering van de beleidshervormingen in de energiesector die de toegang tot moderne energie dragers voor de laagvermogende eindgebruikers beogen te vergroten, wordt belemmerd. Maar, hoewel er een behoefte is aan flexibiliteit wordt in dit proefschrift ook onderkend dat er een behoefte bestaat aan juiste systemen van controle op het beleid op federaal- en staatsniveau en aan aanpassingen in de beleidsinstrumenten.

De beleidsaanbevelingen in dit proefschrift beogen, in navolging van Mahatma Gandhi's Talisman uit 1948, de huidige en toekomstige leiders van India te leiden in hun proces van besluitvorming waarbij, uiteindelijk, de positie van de sociaal en economisch kwetsbaren wordt versterkt. Zestig jaar na hem is het nog steeds duidelijk dat de politieke klasse, de planmakers, bureaucraten en de overige belanghebbenden in de ontwikkeling van India, in het bijzonder die van de plattelandsbevolking, gefaald hebben zijn talisman te volgen. Hoewel de aanbevelingen op zich niet bedoeld zijn als talisman, zijn ze er wel op gericht wezenlijke veranderingen te bewerkstellingen, of op zijn minst de aanleiding daartoe te vormen, in relevante aspecten van het energiebeleid. Veranderingen waardoor laagvermogende eindgebruikers op het platteland van India uit hun vicieuze cirkel van energie armoede kunnen breken en daarmee Mahatma Gandhi's visioen van swaraj (vrijheid van armoede) in vervulling laten gaan.

De eerste aanbeveling is gebaseerd op de onderkenning dat voor de continuïteit van beleid een ondersteunend regulerend raamwerk (voor zowel het ontwerpen als voor de uitvoering) noodzakelijk is waardoor investeerders in de "wegen van overdracht" en de eindgebruikers van de moderne energie dragers minder onzeker worden. Verder moet het beleid gericht zijn op de vraagzijde, zoals kwesties als rechtvaardige verdeling, zowel tussen de huishoudingen als ook binnen de huishouding. Hierbij moet ook gelet worden op de samenhang tussen de "contextuele invloeden" die van groot belang zijn om de toegang tot energie te verbeteren. Dit zal bijdragen tot het versterken van de organisaties en beleidsinstrumenten die de "wegen van overdracht" verbinden met laagvermogende eindgebruikers. Een dergelijke versterking zal de toelevering van energie effectiever maken en daarmee een inclusieve ontwikkeling met een menselijk gezicht dichterbij brengen.

De tweede aanbeveling is gericht op de noodzaak lokale organisaties verder te versterken in hun rol als tussenschakels bij de toelevering van energie als ook bij een lokale inbreng in het ontwerpen van het beleid. Zowel binnen de grondwet van India als ook in de wettelijke bepalingen voor de energiesector en de specifieke richtlijnen voor nationale programma's biedt de bestaande regelgeving al de mogelijkheid voor een meer effectievere decentralisatie. Zo wordt er binnen de grondwet voorzien in decentralisatie en de betrokkenheid bij beleid voor de Panchayati Raj Instituties (PRI). Door deze PRI bij het proces van toelevering van energie te betrekken, wordt de effectiviteit van de uitvoeringsprogramma's, gericht op de toegang van energie, effectiever en wordt de huidige organisatorische complexiteit 
verminderd. Aan deze PRI kan de verantwoordelijkheid worden gegeven voor de samenbundeling van aanvullende maatregelen en voor de "contextuele invloeden". Daardoor kan een vertaling van het energiebeleid en de programma's op dat terrein naar effectieve en toepasbare uitvoeringsmechanismen beter worden bereikt. In dit proefschrift wordt betoogd dat de PRI ingeschakeld kunnen worden bij het aanleren van het gebruik van verbeterde energie dragers, speciaal voor de allerarmsten en zwakken zoals benadrukt wordt in Gandhi's talisman.

Het huidige systeem van subsidies heeft geleid tot de financiële ondersteuning van de laagvermogende eindgebruikers die zich de toegang tot moderne energie dragers al wel konden veroorloven ook zonder subsidies. Daartegenover heeft het delen van de samenleving buiten gesloten, zowel huishoudingen uit de categorie OAL als ook die van de BAL, aan wie subsidies juist die toegang tot moderne energie dragers zou verschaffen. Vandaar dat de derde aanbeveling waarbij gekeken dient te worden naar een efficiënter gebruik maken van subsidies en de rechten op toegang tot energie: de noodzaak van meer doelgerichtheid in het beleid. Gerichte subsidies, hoewel in de eerste plaats geformuleeerd op het centrale overheidsniveau, vergen zowel betrokkenheid van de overheid op staatsniveau als ook van lokale organisaties, zoals PRI, zodat een juistere keuze gemaakt kan worden voor de huishoudingen die binnen de doelstelling vallen. Een hieraan gekoppelde aanbeveling is het structureren van de rechten op energie dragers door het aanbrengen van bovengrenzen per moderne energie drager, waarbij die laagvermogende eindgebruikers in het vizier zijn die zelf niet in staat zijn hiervoor te betalen en die anders in de energie armoede blijven voort leven.

Een bijkomstige kwestie bij deze hervormingen van de energie subsidies en bij de invoering van deze aanbevelingen is, dat dit vergezeld dient te gaan van een scherpere identificatie van de beoogde belanghebbenden waardoor de uitvoering effectief wordt. Tot op heden wordt één enkele armoede grens gehanteerd voor alle sociale welzijnsprogramma's waarbij sprake is van overheidssubsidies. Maar de toepassing van deze enkelvoudige armoede grens voor het toekennen van rechten en subsidies is, in de drie onderzoek regio's, aantoonbaar niet effectief gebleken voor het verkrijgen van toegang tot energie en voor het verminderen van de energie armoede. Vandaar dat de vierde aanbeveling, één die ook voor andere sectoren opgaat, bedoeld is om de toepassing van de BAL/OAL indeling als basis voor het toekennen van rechten en subsidies te herzien ten einde een verbetering van de toegang van energie voor laagvermogende eindgebruikers te bereiken.

Tot slot, de samenvoeging van bovengenoemde aanbevelingen in combinatie met een bundeling van "contextuele invloeden" kan leiden tot een toegenomen efficiëntie in het gebruik van de energie voorraden en in een verbeterde toegang tot moderne energie dragers voor laagvermogende eindgebruikers. Het ontwerpen van een beleid dat hierop stoelt, is toepasbaar en effectief in zijn uitvoering, en voert de laagvermogende eindgebruikers uit hun vicieuze cirkel van energie armoede. Hiervoor is echter overheidsbemoeienis van wezenlijk belang. Vandaar dat de beleidsaanbevelingen niet een verminderde rol van de overheid beogen, maar zij zijn meer gericht op een overheid die een beleidsraamwerk bewerkstelligt waardoor de toegang tot energie wordt vergroot. Namelijk door het versterken van lokale organisaties gericht op de toelevering van energie en op het leveren van een bijdrage aan de 
In Pursuit of a Light Bulb and a Smokeless Kitchen

formulering van het beleid. Ook moet de overheid er voor zorgen dat de beleidsinstrumenten doelgerichter zijn.

In dit proefschrift worden de laagvermogende eindgebruikers op het platteland van India en de beleidsmakers aangespoord niet ieder apart hun weg te gaan, maar in harmonie met de overheidsprogramma's samen op te trekken. Het is de hoogste tijd dat de leiders van India die belast zijn met het energiebeleid, beseffen dat de laagvermogende eindgebruikers al zo lang hebben gewacht. Nu moeten zij overgaan tot de uitvoering van het juiste beleid en de juiste programma's zodat de hoop van de laagvermogenden werkelijkheid wordt: niet langer dromen van die dag, maar een gloeilamp kunnen aandoen en koken in een rookvrije keuken.

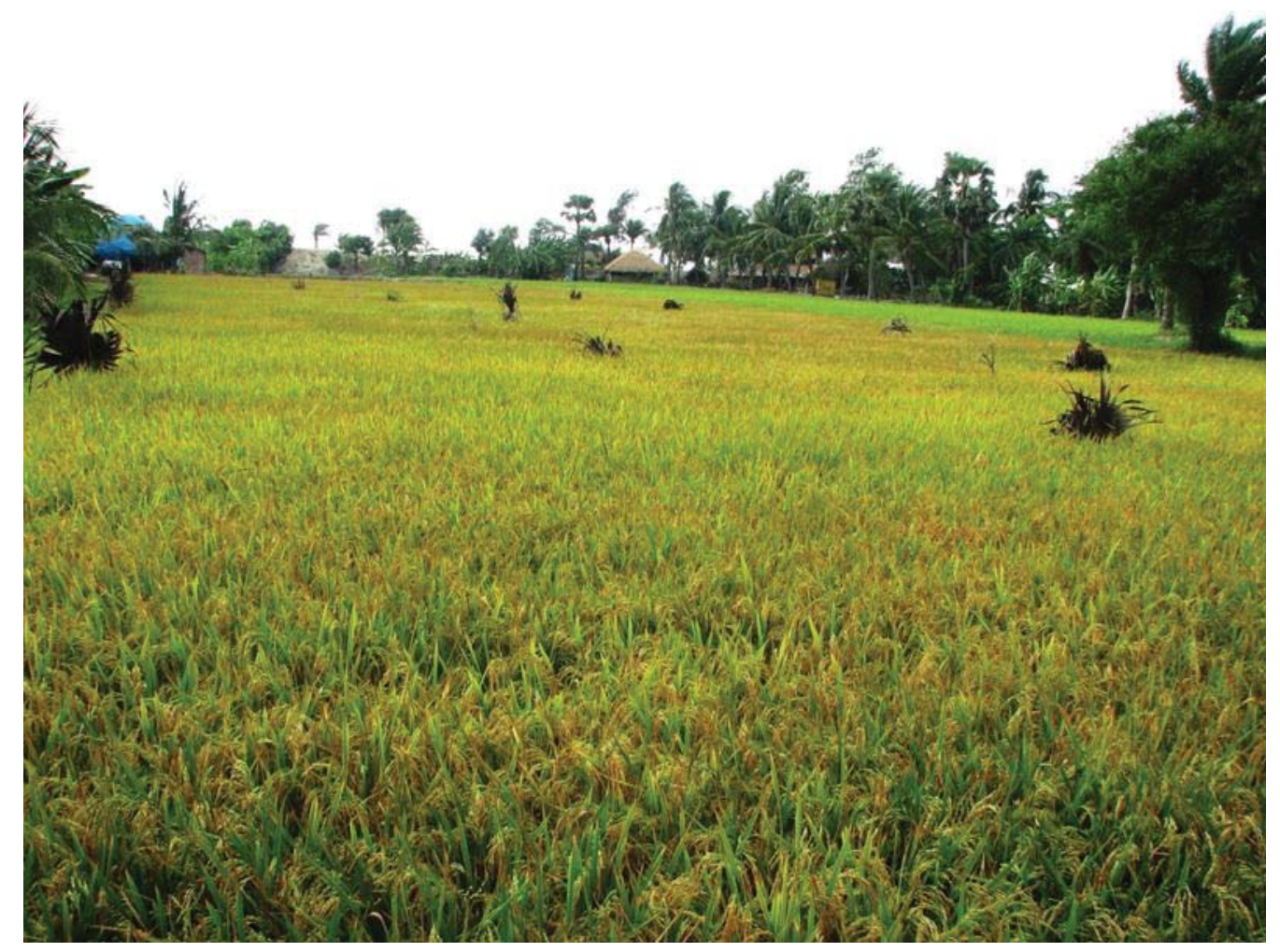




\section{Annex I: Profile of Case Study Regions}

\section{Gosaba Island}

Gosaba Island, set in a river, is part of the Gosaba Block and located in the Sundarbans delta region of the South 24 Parganas district in the State of West Bengal. This delta region is located in the estuary of the Ganga-Brahmaputra river system that flows into the Bay of Bengal. The Gosaba block consists of eleven islands of which ten are inhabited. Gosaba Island is the block headquarters and is located approximately 150 kilometres from the district headquarters, Alipore, part of the metropolitan city of Kolkata $^{277}$. Gosaba Island comprises two Gram Panchayats (GPs), Gosaba and Rangabelia, and includes eight villages.

According to the 2001 census, Gosaba Island's population is $27,000^{278}$. The population is heterogeneous, with a history of inward migration especially in the post-Independence period. Migrants from present-day Bangladesh and the Santhal regions of India were pushed into a relatively harsh natural environment, needing to clear forests for habitation and cultivation. The Island's population can be divided into three social categories: Schedule Caste (SC) making up 26.5\%, Schedule Tribe (ST) 4.5\%, and General Caste (Forward Caste, Muslims, and Other Backward Classes) 69\% (Census of India, 2001b).

Population growth on the Island, along with migration from other parts of the State and parts of Bangladesh, has reduced the per capita area of cultivable land. There is now overcrowding, high rates of disguised unemployment in agriculture, over-expansion of pisciculture and brackish water shrimp farming. The latter has created a range of ecological and socioeconomic problems in the region (UNDP, 2004b). Less than half of the rural workforce on Gosaba Island is able to find employment in agriculture (Block Development Office Gosaba 2001). The gender gap in the region's literacy rate is quite significant, with only $56.9 \%$ of the female population being literate compared with $78.7 \%$ of the male population (Census of India, 2001b). Nevertheless, the literacy rates are still higher than the national averages of $48 \%$ for women and $73 \%$ for men. The higher literacy rate among women reflects the social norms in this region that has traditionally valued education for both sexes.

As mentioned earlier, the economy of the region suffers from very substantial under-employment. The data from the National Sample Survey (2003) and the 2001 Census of India show a decline $(50.7 \%$ in 1991 to $47.3 \%$ in 2001) in the rate of male main workers ${ }^{279}$, which was countered by an increase ( $0.7 \%$ in 1991 to $6.9 \%$ in 2001) in the share of male marginal workers. This can be seen as an indication of there being fewer jobs being available throughout the year. These data have also been interpreted as showing that the more secure forms of employment have been replaced by less secure forms (Chandrasekhar and Ghosh, 2003). With the exception of landless households and those households which have assured irrigation sources, the rural population is dependent on subsistence rain-fed mono-cropping (dominated by boro rice) for their livelihoods. The limited possibilities for extending cultivation due to increasing groundwater salinity levels has led to an increasing dependence on fishing and the collection of baghda (tiger prawn) seeds ${ }^{280}$. All family members,

\footnotetext{
${ }^{277}$ Kolkata was earlier called Calcutta.

${ }^{278}$ Census 2001 data is the only published source of population information. The Census of India is presently working on the Census 2011 data but this is not yet available.

279 The Census, when classifying information on work uses the term 'main worker' to indicate someone's primary occupation.

${ }^{280}$ Collection of bagdha, or tiger prawn, seeds emerged as a main livelihood source in the 1980s for several reasons - the cyclones of 1981 and 1988 had washed away land belonging to the fishing community living along the banks of the river, and passes to enter the Sundarbans forests were being
} 


\section{In Pursuit of a Light Bulb and a Smokeless Kitchen}

including children, are involved. While this activity is essential for the landless households, the economic returns are today very low. The over-extraction and problems with the by-catch ${ }^{281}$ has increasingly made fishing and the collection of baghda prawn seeds unsustainable. There are also serious health hazards, especially for women and children, in wading for long hours in the saline water (Patel and Rajagopalan, 2009).

On the island, agriculture, fisheries, government services, business and trading are the main livelihood sources. Being located in an estuary, and given the high salinity of its river water, Gosaba Island is endowed with various species of fish (UNDP, 2004b). However, as already mentioned, the fish population is under threat due to unsustainable fishing practices. Further, the saline water has a negative effect on the Island's economy. The incursion of saline water has resulted in damage to ecological services such as land degradation and a deterioration in the groundwater quality, and this has had an impact on agriculture and fisheries. The Island lies on the periphery of the Sojnakhali forest reserve area but, since the forest has been classified as a protected and reserved area, access to minor forest products is limited. A positive aspect is the increase in tourism in the Sundarbans region; with the State government further identifying Gosaba Island as the main tourist location. However, tourism development is in its early stages and, at present, its contribution to the local economy is rather insignificant.

The geographical advantage of being a river island in terms of natural resources can easily become a disadvantage in terms of transport and communication infrastructure. There has been some infrastructural development on Gosaba Island, such as pucca (cemented and metalled) ferry ghats for the movement of people and goods by boat, the availability of a telephone network and the growth of a local market. However, four of the eight ferry ghats remain uncemented, which renders them inoperable for the landing and loading of goods at low tide. An inadequate infrastructure is seen as having a negative influence on the economic and social development of the Island (see Section 2.1.1). The economic activities on the Island have not increased significantly in comparison to economic developments observed in other rural areas of the State. However, Gosaba Island has emerged as the main market centre for other villages and islands in the Gosaba block.

Historical evidence shows that Gosaba Island, as an organized settlement, came into existence after the partitioning of Bengal in 1905 (Mazumder, 1932). In earlier days, Gosaba Island was called Hamiltonabad or Hamilton Estate ${ }^{282}$. According to Mazumder (1932), most of the early settlers were from the tribal population brought to the Island from the Santhal Parganas of the Chota Nagpur area (now in the State of Jharkhand). The tribal population were brought mainly to clear other humans from the forest area, which was the habitat of animals including the Royal Bengal Tiger. The tigers were considered under threat from hunters. Others who migrated to this island came from East Bengal (present-day Bangladesh) and the neighbouring district of Midnapore in West Bengal.

The peak period for the development of Gosaba's economy was between 1910 and 1955. Sir Daniel Hamilton, who developed the island, introduced the principle of cooperatives and helped in forming agriculture and credit cooperatives. On the Hamilton Estate, trading with intermediaries was abolished, and cooperatives became the prime buyer of paddy as well as the provider of agricultural inputs for the farmers. The Estate did not allow any kind of direct trading amongst the farmers.

enforced. Bagdha could be collected along the Island's banks and was highly lucrative in 1980, and a day's earnings could be higher than a day spent as a waged labourer. As such, this form of livelihood enabled the poorest, and especially women, to achieve economic stability.

${ }^{281}$ The term 'by-catch' refers to the collection of other fish species along with the main fish species. Bycatch is considered a problem when the other fish species are not released back into the water, nor eaten or sold by the fishermen. Such activity affects aquatic biodiversity.

${ }^{282}$ A British officer, Sir Daniel Hamilton, was granted permission from the then colonial administration to develop a new island colony. The few people who were then living on Gosaba were mainly outlaws. In 1910, the population was 910 (Mazumder, 1932). 
Farmers were not allowed to sell land to anyone except the Estate. In the 1940s, the Hamilton Estate also started primary healthcare services and established an educational institution. The school, known as the Rural Reconstruction Institution, was actually intended to provide training in alternative agricultural techniques to the local population. The power of the Estate over the island's economy was very strong and, during the Second World War, the Estate introduced its own currency, which was later abolished (Hamilton, 1937).

Post-independence, the Sundarbans region came under the political influence prevalent in other parts of the State of West Bengal; so challenging the laws and regulations of the Estate. A large number of farmers started to trade directly on the open market with merchants and traders from beyond the islands. This period also saw the demise of the cooperative institutions (dharmagolas) and the central bank, which slowly became dysfunctional and ceased to exist ${ }^{283}$. The pace of development on the island was rather slow between Independence and 1970. Most of the development work focused on the construction of baandh (dykes) around the island to prevent land erosion.

The pace of development was more rapid from the late-1970s. In 1977, a communist government came to power in West Bengal and initiated land reforms throughout the State, leading to the redistribution of land and the empowerment of socially and economically weaker sections of society (Harriss, 1993; UNDP, 2004b). Harriss (1993) attributed the social and economic development in Gosaba Island after 1980 to land reforms. In addition, the State government formulated programmes to strengthen the primary education system in rural areas and ensured the availability of safe drinking water through hand pumps, water tanks and the piped delivery of water (Banerjee, et al., 2002). In addition to building dykes, which continues today, the State government also made investments in other key infrastructure, such as building rural roads and pavements (including brick roads), constructing concrete ferry ghats and introducing bhatbhattis (mechanised boats).

In the 1990s, the Sundarbans region, including Gosaba Island, witnessed the emergence of new economic activity in the fisheries sector (UNDP, 2004a). The local population realized that, in the brackish river water, the baghda (tiger prawns) lings (seeds) were plentiful, and that there was a huge demand for them from the prawn culture farms (export-oriented units) located near Kolkata. Baghda seed collection became an economic activity for most of the fishing community and specifically among the poor and landless households. In 1999, an entire family would wade through the waters for five to six hours at low tide and would earn, on average, about Rs $30-R s 40^{284}$ per day. At the time of the first fieldwork period (2001), it was observed that a family could not earn more than Rs 25 a day by collecting baghda seeds ${ }^{285}$. In terms of purchasing power, this level of daily income would enable households to purchase about $4 \mathrm{~kg}$ (at Rs 6 per $\mathrm{kg}$ ) of rice from the PDS or about $2.5 \mathrm{~kg}$ (at Rs 10 per $\mathrm{kg}$ ) from the open market. Danda (2007) believes that there are two main reasons for the decline in income from baghda seed collection. First, the increase in the number of people engaged in this economic activity has driven prices down. Second, a drop in the availability of baghda due to the impact of seed collection methods on the marine ecosystem.

Another change that affected the local economy positively was the revision (in 1995-96) of the pay scales of government service employees. The Government of West Bengal implemented the recommendations of the Fifth Pay Commission ${ }^{286}$ (Banerjee, et al., 2002). On Gosaba Island, the households who had members working in the government services, such as in the health and

\footnotetext{
${ }^{283}$ Interview (on 25 May 2001) with Dr Burman, a medical practitioner and manager of the Gosaba Estate.

${ }^{284}$ Rs $45=1$ USD

${ }^{285}$ Based on field discussions as part of this study. The minimum monthly per capita consumption expenditure for a family below poverty line (BPL) in rural areas is Rs 365 (GoI 2002).

${ }^{286}$ Central government wage revisions are determined by the Pay Commission, a constitutional body established to make recommendations about every ten years (GoI 1997). Recommendations by the Fifth Pay Commission, which submitted its report in January 1997, included a three-fold increase in basic pay scales (Sarma and Sarma, 2007).
} 
education sectors, benefited from this revision. This increase in salary led to the emergence of a new group of households joining the middle-class income group with increased purchasing power and surplus disposable income. Consequently, there was an increase in demand for durable goods and services, which indirectly boosted the local economy, benefiting the island's business community.

\section{Bastar}

Bastar district is in the southern part of the State of Chhattisgarh ${ }^{287}$. The district is primarily rural, with the exception of the two urban settlements of Jagdalpur and Kondagaon. The district headquarters responsible for Bastar is located in Jagdalpur. More than $90 \%$ of the district's population of 1,302,253 live in rural areas. The rural areas of Bastar are endowed with rich natural and mineral resources. According to the district profile, Bastar alone accounts for $42 \%$ of the total forest area in the State. The district is criss-crossed by three main rivers: the Indravati, the Kolab (Sabri) and the Narangi that provide many opportunities for livelihood diversification, especially in terms of agriculture. In the rural areas of Bastar, agriculture and Non-Timber Forest Products (NTFP)/Minor Forest Products (MFP) are the main livelihood sources (Bastar District Profile, 2002).

Despite the ample natural resources, the tribal population of Bastar live in poverty, are generally illiterate and are staunch adherents to their cultural traditions. Sundar (2001) and Ramnath (2003) have argued that this strong attachment to their cultural traditions has led to a reluctance to participate in economic activities. Seventy per cent of the total population in the district are classified as tribal. The tribal groups, Halbis, Gonds, Marias, Mundias and Dhurwas, have diverse social norms and cultural values. The Gonds and Dhurwas are considered the most progressive due to a relatively high literacy rate and diverse economic activities including irrigated agriculture, government service and business. Nevertheless, there are significant variations in economic activities among the different subtribes of these tribal groups. The remaining $30 \%$ of the population comprises $5 \%$ general castes, $10 \%$ scheduled caste and 15\% other backward castes (Bastar District Profile, 2002). The tribes are protected under the Tribal Act. As a result, the district has seen very limited migration and settling of communities from outside Bastar, and that which has taken place is mostly concentrated in the urban areas and in the peri-urban villages. Since 1990, in some of the villages along the national highway and close to the urban town of Jagdalpur, around ten migrant farmers from other states, including Gujarat, have rented land from local tribal households. These migrant farmers have improved agricultural productivity through introducing land management and irrigation systems ${ }^{288}$.

The gender gap in the literacy rate in the district is quite significant, as only $34 \%$ of the female population are literate compared to 57\% of men (Bastar District Profile, 2002). The literacy among the tribal population is low. Despite the low literacy, the social norms and cultural patterns give tribal women similar social status to men. Although a patriarchal society, tribal women have rights to inherit property, and benefit from liberal social norms regarding marriage and participation in economic activities. The sex ratio (number of women per 1000 men) in the rural areas of the district is 943 and, in the overall district, 938. These figures are higher than the national average of 933 (Census of India, 2001b). The sex ratio is much higher than that in economically developed states such as Haryana (861), Punjab (876) and Delhi (821). However, the ratio is lower than that in states such as Kerala (1061) which have seen liberal changes in society and the emancipation of women.

${ }^{287}$ Chhattisgarh was created as a new State in 2000 after the division of the State of Madhya Pradesh. This came after years of struggle for a separate State by the local people, a demand based on their distinctive socio-cultural identity (GoC, 2002: 468).

${ }^{288}$ These farmers are located around Kolchur, on the national highway connecting it to Jagdalpur and the State capital, Raipur. 
The district's economy suffers from substantial under employment, with very limited employment opportunities in the district. In the rural areas, there are five main livelihood sources: government service, agriculture (including day labouring), collecting and selling of MFPs, business, and artisanship. Government service covers working in a range of government departments, such as health, education and rural development, and in Panchayati Raj institutions. In agriculture, rain-fed mono-cropping of paddy is the main product. In the survey district, only $3 \%$ of the cultivable agricultural land is irrigated, and productivity is low. The low productivity is due to several reasons: small land holdings ${ }^{289}$, poor land quality, single cropping, unimproved agricultural practices, poor access to extension services, low use of inputs (such as chemical fertilisers), limited use of irrigation facilities and a lack of proper marketing facilities. According to a PwC (2002) report, there are only four agricultural markets in the Bastar district, resulting in restricted opportunities for farmers to market their products. Chemical fertilisers are used mostly during the Rabi period ${ }^{290}$ when farmers cultivate paddy, wheat, sugarcane and vegetables. Market demand is increasing due to the growing urban populations of Jagdalpur and Kondagaon. Traditionally, the farmers used cattle dung as a fertilizer, and this continues to this day. The low productivity (7-8 quintals/acre) ${ }^{291}$ and the local variety of paddy result in a limited market outside the region. In the case of small farmers (landholdings up to five acres), most of the paddy is primarily for family consumption, and only about one-third at most is sold through the government procurement channel ${ }^{292}$.

The irrigated areas are either along the River Indravati or in catchment areas of the watersheds developed under government programmes. Although the district has the potential for multiple cropping, most of the tribal farmers cultivate land during only the kharif season. Changing the cropping pattern would require investments, for example in order to adopt improved agricultural practices, develop land and install irrigation facilities. The availability of electricity is an important input for irrigation as it can allow farmers to use electric pump sets. In Bastar district, only one household in every thirteen use electric irrigation pump sets. This is far below the national average of one in every four rural households (Mukherjee and Shah, 2003).

Most tribal farmers use traditional water lifting systems that involve human energy. Although these farmers said that they would like to follow the initiatives taken by the migrant farmers in Kolchur, most of them are unable to do so due to a lack of knowledge, skills and, more importantly, the resources to invest in irrigation, electricity and agricultural implements. However, access to finance is not a problem since credit institutions and credit facilities are available. The central government initiated a programme called 'Kisan Credit Card' in 1998 that allows farmers to borrow money based on their land holdings at the priority sector interest rate of $8 \%$ per annum. However, cultural norms play a significant role in tribal farmers' attitudes towards credit. For example, family elders play an influential role in dissuading younger farmers from taking credit because of their negative experiences in the past of indebtedness when banks mortgaged the land. Government interventions to promote

${ }^{289}$ Small land holdings result in lower productivity as mechanised methods for sowing and tilling become expensive per unit of crops produced. Even irrigating such small land holdings, especially during Kharif, becomes expensive because there is seepage of water into other fields (Dandekar, 1994). The farmers also incur other losses in the investments made in agricultural inputs (see next footnote).

${ }^{290}$ Rabi is the cropping period from December/January to May. Kharif cropping runs from June to September. The reason for this is that, during the monsoon when paddy is cultivated, there is no control on the quantity of water that will flow through the agricultural fields, whereas, during the Rabi period, the farmers release water based on requirements to avoid washing off the fertilisers and ensure they are effectively utilised.

${ }^{291}$ Based on discussions with the farmers in Kudalgaon, Ghatlohanga and Tikhralohanga between 10 April-25 May 2002. One quintal is equal to 100 kilogrammes.

292 The procurement price in 2002 for mota dhan (the local variety), as fixed by the government under the Minimum Support Price (MSP), was Rs 500/quintal. For the improved variety of rice, the MSP was fixed at Rs 575/quintal. 


\section{In Pursuit of a Light Bulb and a Smokeless Kitchen}

irrigated agriculture have not succeeded. In Kudalgaon, one of the case-study villages, a lift-irrigation project with water distribution tanks and channels was commissioned in 1998 with a State government investment of Rs 1.6 million. However, the project did not function beyond one cropping season. While the government agency argued that the people did not take sufficient interest in setting up a water user association to manage the project, the people claimed that the scheme was set up under duress as farmers were never interested, and it was only a showpiece for the State irrigation department ${ }^{293}$.

Collecting and selling MFPs provide households with a steady source of livelihood throughout the year. The forest areas of Bastar provide access to a variety of MFPs ${ }^{294}$ such as Mahua (a medicinal flower), Saal seeds (for soap making), Tamarind, Tendu leaves ${ }^{295}$ (used in beedi ${ }^{296}$ making) and Kosa (silk reeling from silkworms). In the villages, every member of a household will be directly or indirectly involved in the collection and sale of MFPs. A Van Dhan Samiti initiative was started in 1999-2000 by the State administration in the form of an Imli (tamarind) Andolan, aiming to liberate the tribal tamarind collectors from the clutches of the kochiyas (traders or middlemen). Bastar on average produces more than 35,000 tonnes of tamarind every year (CoG, 2002). The Van Dhan initiative involved a network of village Samitis (members of the village) who procured tamarind for marketing through TRIFED (Tribal Marketing Federation for forest products). Before the scheme was started, the tribal families were selling tamarind for Rs 2-3 per kg to traders. In 2000, the tribal families were paid about Rs 6 per $\mathrm{kg}$ under the Van Dhan initiative. In addition to this, they were encouraged to add value by making tamarind cakes (so obtaining an additional Rs 2-3 per kg) and selling these back to the cooperatives. While the scheme worked perfectly well in 2000 , it fell apart in 2001 due to collusion between the traders and the bureaucrats who created an artificial market (Bhogal, 2001). In those villages that are close to Jagdalpur, landless households are able to produce value-added products from some MFPs, in particular by making tamarind cakes. These activities involve both men and women. While men deal with the traders, women are involved at the household level in preparing tamarind cakes. The division of labour between men and women ensures that the control of the money stays with men, including decisions over regular household expenses, such as choice of energy carriers.

Apart from agriculture and the MFPs, the other main economic activity in the villages is rural artisanal work - pottery (terracotta), woodcarving, and wrought iron and other metal products. These local artisanal works have become very popular as Bastar Art or Tribal Art, with a market not only within the district but also beyond. The State government, as well as NGOs, has been active in promoting tribal art, and providing forward and backward linkages between the artisans and the market. However, the dependency of the rural population on agriculture and MFPs remains one of the district's significant problems. Industrial clusters are limited to a few agro-processing industries and a few service industries, such as repair shops in Jagdalpur. The landless labour force is unskilled and mostly finds employment as daily wage labourers in markets, agro-processing units and the service

\footnotetext{
${ }^{293}$ Based on the field survey in the village and discussions with the Gram Panchayat, 10 April $2002-25$ May 2002.

${ }^{294}$ These minor forest products (MFPs) are not uniformly available throughout the district as their availability is dependent upon the nature of the forest and forest cover.

${ }^{295}$ Revenue from the sale of tendu leaves accounts for nearly $50 \%$ of the State's income. The State transfers revenues from the profits to people in two ways: (i) $75 \%$ is allocated for rural development programmes; and (ii) 25\% is shared with individual households (Bhogal, 2000). Bhogal (2000) also adds that with the State using the largest share of the profits for rural development, most benefits do not directly reach the people who are involved in collecting the tendu leaves.

${ }^{296}$ Beedi is a local form of cigarette. Tobacco is placed in a tendu leaf and then rolled to form a beedi. 
industry in Jagdalpur. While the market provides such types of opportunity for regular work, most of the tribal workforce frequently abstain from work. The Panchayat Secretary of Tikhralohanga, another case-study village, said that the cultural habits among the tribal workforce hinder them earning a regular livelihood through selling their labour. Any money that is earned is often spent immediately on alcohol and other recreational activities, which often results in not returning to work the next day.

In Bastar district, the average amount of pucca (metalled) road is five kilometres per square kilometre, against the State average of nineteen kilometres (PwC, 2002). There are 2.4 kilometres per square kilometre of kutcha (non-metalled) roads in the district (PwC, 2002). With the exception of villages alongside the national and State highways, which are connected by metalled roads, the remaining villages in the district are connected through non-metalled roads. This lack of road infrastructure limits access to mechanical transportation and markets. Access to public transport is limited to those along the national and State highways that connect blocks and district headquarters. Villages, especially those in remote locations and in the forests, do not have access to transportation and villagers often have to walk to the nearest block headquarters or village to access public transport. The presence of Naxalite movements in the district has further affected the transport infrastructure, with no means of public transport in most parts after nightfall. The story is similar for the communication infrastructure, with no such facilities in the remote villages. The lack of adequate transport and communication infrastructures in the district severely affects the market infrastructure for the sale of agricultural crops and forest products. In 2004, the state government accorded political to Public Distribution System (PDS) by bringing it under the purview of community institutions and by doorstep delivery of food grains to the ration shop in the village and eliminating the rent-seeking in the distribution. Political will by the state government, increased transparency and community participation have led to PDS reforms in Chhattisgarh.

Since 2006, Bastar has been in the middle of a growing environment - development conflict resulting from increasing pressure to utilize its abundant resources by setting up industries ${ }^{297}$. Bastar is rich in mineral resources, and the State government has signed agreements with public and private sector bodies for setting up industrial units. These developments have received stiff resistance from the local communities owing to land acquisition and loss of livelihoods for the largely agrarian community with limited skills that would gain them employment in the proposed industries. According to Ramesh (2010), the concerns of the poor and the traditionally disadvantaged tribal sections of society, over access to the local resources, are often framed as q conflict between environment and development. However, what actually affects their daily lives, in a profoundly disturbing manner, concerns establishing fundamental rights over their livelihood security and determining the nature of what is generally termed as development (Ramesh, 2010).

Another development has been the Salwa Judum (peace initiative) movement that started in 2006 as a people's resistance movement against the left-wing Naxalites. Initially an uprising of local indigenous people, the Salwa Judum movement later received bipartisan support from both the opposition and ruling parties (Guha, 2006). The initial success of the movement soon resulted in escalating conflict between the Naxalites and the Salwa Judum (supported through training and ammunition from the

${ }^{297}$ Two steel plants are proposed for the district of Bastar close to Jagdalpur. Local NGOs and environmental activists are opposed to these projects and have mobilised local communities as they feel it will lead to the tribal population being excluded from their land, and not given employment as most of the skilled workforce will come from outside the district. However, a small number of activists recognise that such sustained opposition may harm the local economy in the long term since industrial development would lead to the establishment of ancillary activities that would provide employment for the local people. 


\section{In Pursuit of a Light Bulb and a Smokeless Kitchen}

police). The Salwa Judum was thus supported by the State government and political leaders as a countermeasure to the Naxalites and at the same time to create an enabling situation for new public and private sector industrial projects. As a result of the movement, tribal people have been displaced from their villages, and are forced to move into makeshift camps, leading to large-scale human rights violations. Between 2008 and $2009^{298}$, the region has witnessed escalated attacks and counter attacks on both sides, and the large-scale displacement of over 150,000 tribal people caught in the conflict between the Naxalites and Salwa Judum activists (Human Rights Watch, 2008).

The resistance to industrial development by local communities and conflicts in the district has slowed economic growth, investment and the development of new infrastructure in the district (Planning Commission, 2008).

\section{Kalahandi}

The district of Kalahandi occupies the South Western part of the State of Orissa. The total area of the district is 8,197 square kilometres and the district has a low population density of 168 people per square kilometre. Bhawanipatna houses the district headquarters and along with the town of Kesinga, where the main railway station of the district is located, forms the urban settlement. The district has thirteen administrative blocks. Kalahandi, at the time of India's independence, was a State run by a Prince and it merged with Orissa in 1948. In 1993, the district was divided into two separate districts: Kalahandi and Nuapada. Of the total population of 1,334,000, 92.5\% live in the rural areas.

Livelihoods in Kalahandi are characterised by a dependency on agriculture and waged labour (both on- and off-farm) (OWDM 2004). According to the 1997 Below Poverty Line survey, $62.71 \%$ of the rural population in Kalahandi live below the Government of India's official poverty line

(Government of Orissa 2002). The majority of the BPL population belong to marginalised groups such as the Scheduled Caste (17.67\%) and Scheduled Tribes (28.84\%). The basic quality of life indicators are amongst the worst in the country: the literacy rate in the district is $46 \%$, with female literacy at only 26.8\% (Census of India 2001b).

Kalahandi is part of the drought-prone KBK region - Kalahandi, Bolangir and Koraput. Over the last fifteen years there has been an improvement in the infrastructure and in agricultural production and food availability, but the district remains a backward area. The population of this area is highly heterogeneous, with a rich history of in- and out- migration. Poverty in the district is manifested by a lack of land distribution reforms and limited opportunities for economic activities apart from agriculture, which has resulted in out-migration of the rural population to work as labourers in cities and towns within and beyond the State. Eighty-seven per cent of the population depend upon agriculture (NABARD 2001). The data from 2001 national census indicated that, in Kalahandi district, 87.8\% of women are employed in agriculture (Census of India 2001b). The stakeholder consultations undertaken as part of this field study show that this high percentage is largely due to male migration from the villages.

The economy of the district suffers from a lack of economic and market linkages resulting in underemployment. The rural population is dependent on rain-fed mono cropping (paddy), shifting cultivation (paddy), and some subsidiary activities in the form of forest produce collection.

Agriculture and waged labour are the main sources of livelihood in the villages which are located on the plains. In the hill and forest villages, a combination of shifting agriculture, minor forest produce collection and selling, and on- and off- farm labour all contribute to livelihoods. The lack of economic activities is becoming more acute in forest villages as well as for small-scale land-holding farmers for whom there are few possibilities to extend the area of cultivation. Small and marginal farmers (with

\footnotetext{
${ }^{298}$ The second round of fieldwork in the village clusters was conducted during this period. 
less than three ha of land) account for $81 \%$ of the population, and only 3.5\% of the population count as large farmers (more than 10ha of land). In terms of cultivable area, the small and marginal farmers hold only $24 \%$ of the land, in comparison to $61 \%$ by the large farmers. Such disparity in access to cultivable land, plus limited access to irrigation, restricts small and marginal farmers to subsistence rain-fed cropping and, therefore, they are forced to migrate during the rabi season to work outside the district.

Besides access to land, the poor economic infrastructure in the agriculture sector, such as in terms of storage facilities for food grains and other agricultural and horticultural products, leads to distress sales, resulting in low prices for the farmers. The marketing channels are not adequately developed in the district, and farmers are dependent upon traders who are then able to procure food grains and other agriculture products at low prices (Sainath 1998; Mukherjee and Joshi 2009). As a woman of one Self-Help Group (SHG) noted in 2002: "In earlier days a trader would come and buy an entire tamarind tree from the household for Rs 50, whereas the trader would earn around Rs 3000 by selling the produce from that tree". The district has suffered bureaucratic inefficiencies reflected in the government's inability to break the collusion between the officials and traders. The exploitation of farmers by traders is common practice and any efforts to diminish this have met with little success. The traders formed a cartel and thwarted the efforts of the District Collector of Kalahandi. The traders were able to influence the politicians and this eventually resulted in the District Collector being transferred (Banik 2001).

Although the district enjoys food production sufficiency, a number of villages, especially those located in the remote hill areas, suffer from food insecurity and deaths linked to starvation. The livelihood problems of Kalahandi are at their most severe during the monsoon months of July to September. It is during these periods that inaccessible regions become cut-off and the public distribution system fails to deliver essential items (such as rice) to these areas. The erratic distribution of rainfall, both over space and time, results in droughts in the region. When the rains fail, drought conditions manifest themselves as early as July and food begins to be in short supply until the harvest period starts in November. Even if the government's assessment concludes that relief should be provided, this declaration is not made until November, and supplies are not issued until December. This can be six months after the problems began, and at a time when people can again provide food for themselves. It is in these intermediary periods when people are at their most vulnerable and suffer from the non-availability of food. Any collapse of the government's distribution infrastructure further aggravates their condition (Currie 2000).

There are hardly any other economic activities than agriculture in the district. Industry and the service sector are concentrated in Bhawanipatna and Kesinga. Further, there has been an industrial recession since 1990, and this continued throughout the two fieldwork periods. Agro-processing and other small-scale industries, which were opening in the district, have closed due to the lack of a market and high transaction costs. Since 2004, in the Lanjigarh block of the district, a private aluminium plant has been being set-up, and this started operation in 2007 by importing bauxite. The project has been trying to increase its production capacity by mining bauxite from the Niyamgiri Hills, but this is being strongly resisted by the local tribal community (Dongriya Kondhs) as they consider the hill to be sacred as well as being dependent on its resources for their livelihood. The limited industrial development in the district is also a reflection of the district's weak political representation in the State government. Political representation from the district has mostly been restricted to members of the former princely region and to gonthiyas (large landlords) who serve their own interests and those of the traders, rather than the interests of the wider electorate.

The communication and transport infrastructures are poorly developed in the district. While Bhawanipatna is connected to a State highway, the villages rely on a network of metalled, brick and mud roads. There is a railway line, but it only passes through a small corner of the district. The lack of a road infrastructure limits access to transportation and hence to the market. Access to public transport is limited to those plying the national and State highway connecting the block to district headquarters. 
Villages, especially those in remote locations and forests, do not have access to transport and often have to walk to the nearest block headquarters or village that does have access to public transport. The issue here is not that people are walking to block headquarters, but the fact that, even after four decades of rural development programmes, large parts of remote districts such as Kalahandi still do not have basic infrastructure.

In the absence of work opportunities within the district, both males and females migrate to the neighbouring district of Nuapada, to industrial centres in the neighbouring State of Chattisgarh, or to other areas beyond the State. According to the National Bank for Agriculture and Rural Development (NABARD), developments in the Kalahandi district are affected by industrial developments in the neighbouring districts in Chattisgarh State, which has better rail and road transport connectivity, as well as a good communication infrastructure and a reliable power supply for industrial development (NABARD 2001).

The Kalahandi district, like Bastar (the previous case study), is in the midst of an environment versus development debate. The State government signed an agreement with an aluminium company, Vedanta Aluminium Limited, to establish a plant in Lanjigarh block. While the plant is not that opposed as such, resistance comes from the nature-worshipping 8,000-strong Dongria Kondhs tribe who are opposed to mining bauxite in their scared Niyamgiri hills, home to tribe's god Niyam Raja. The hills provide food for the tribal people. The fruit that grows there is sold in village markets, and the rivers originating in the Niyamgiri hills provide water for irrigation on the plains below. The project has received criticism from environmentalists despite bringing significant changes to the socioeconomic scenario of the region. The Ministry of Environment and Forests (MoEF) of the Government of India, in August 2010, rejected earlier clearances granted for mining bauxite from the Niyamgiri hills. 


\section{Annex II: Rural Energy Scenario in India}

Access to modern energy carriers in the rural areas of India remains low (Table AII.1). This is despite the fact that there have been several government-funded programmes since 1950 . While nearly $90 \%$ of villages are electrified using a former definition ${ }^{299}$, only $44 \%$ of the rural households have access to electricity. LPG is used for cooking by a very small percentage (5.7\%) of rural households although the decade 1991-2001 saw a near fivefold increase in the use of LPG in the rural areas. However, the dependency on biomass fuels, such as wood, cow dung cake and crop residues, remains very high (Table AII.1). Biomass fuels are used by nearly $90 \%$ of rural households as their primary fuel for cooking. Kerosene oil is mostly used for lighting in rural households, with only a very small per cent (1.6 \%) of rural households using kerosene oil for cooking (Table AII.1). In the absence of these two modern energy carriers (LPG and electricity), the majority of rural households depend upon biomass fuels for cooking and kerosene oil for lighting (Table AII.1).

Table AII.1: Distribution of rural households (percentage) by energy carriers used for cooking and lighting

\begin{tabular}{|c|c|c|c|c|c|c|c|c|}
\hline Energy carriers & \multicolumn{4}{|c|}{ Cooking } & \multicolumn{4}{|c|}{ Lighting } \\
\hline & $1991^{\mathrm{a}}$ & $\begin{array}{l}1993- \\
94^{\mathrm{b}}\end{array}$ & $\begin{array}{l}1999- \\
2000^{c}\end{array}$ & $2001^{d}$ & $1991^{\mathrm{a}}$ & $\begin{array}{l}1993- \\
94^{\mathrm{b}}\end{array}$ & $\begin{array}{l}1999- \\
2000^{c}\end{array}$ & $2001^{d}$ \\
\hline Fuelwood & 71.7 & 78.2 & 75.5 & 64.1 & & & & \\
\hline Cow dung cake & 19.6 & 11.5 & 10.6 & 12.8 & & & & \\
\hline Crop residue & & & & 13.1 & & & & \\
\hline Coal/soft coke & 1.5 & & & 1.1 & & & & \\
\hline LPG & 1.2 & 1.9 & 5.4 & 5.7 & & & & \\
\hline Biogas & 0.4 & & & 0.5 & & & & \\
\hline Kerosene & 1.3 & & & 1.6 & & 62.1 & 50.6 & 55.6 \\
\hline Electricity & 0.2 & & & 0.1 & 30.5 & 37.4 & 48.4 & 43.5 \\
\hline Solar energy & & & & & & & & 0.3 \\
\hline Other & & $7.7^{\mathrm{f}}$ & $7.4^{f}$ & 0.8 & & 0.8 & 1.0 & 0.3 \\
\hline $\begin{array}{l}\text { No } \\
\text { cooking/lighting }\end{array}$ & & 0.7 & 1.1 & 0.2 & & & & 0.3 \\
\hline \multicolumn{9}{|c|}{$\begin{array}{l}\text { Note: a. Census of India 1995; b NSSO 1997; c. NSSO 2000; d. Census of India 2001a; } \\
\text { e. the Census } 1991 \text { did not give the percentage of rural households using kerosene oil, but since } \\
\text { electrification was low, the Census data was interpreted as more than } 65 \% \text { of the rural households } \\
\text { were using kerosene oil for lighting; f. NSSO survey included biogas, coke/soft coke and electricity as } \\
\text { other fuels }\end{array}$} \\
\hline
\end{tabular}

${ }^{299}$ The former definition of village electrification was "A village will be deemed to be electrified if electricity is used in the inhabited locality, within the revenue boundary of the village, for any purpose whatsoever". In 2004-05, the definition was revised such that "A village would be declared as electrified, if:

(i) A basic infrastructure such as a Distribution Transformer and Distribution lines are provided in the inhabited locality as well as the Dalit Basti/ hamlet where it exists (For electrification through Non-Conventional Energy Sources a distribution transformer may not be necessary);

(ii) electricity is provided to public places like Schools, the Panchayat Office, Health Centre, Dispensaries, Community centres etc., and;

(iii) the number of households electrified is at least $10 \%$ of the total number of households in the village". 
Figure AII.1 shows the electrification status of rural households in India across the various states. Even in those states where all villages are "electrified", many households remain unconnected ${ }^{300}$. Several reasons can be given for unconnected rural households. Primarily this is due to either new households being established post-electrification, or the inability of households to pay for the last stretch of grid extension.

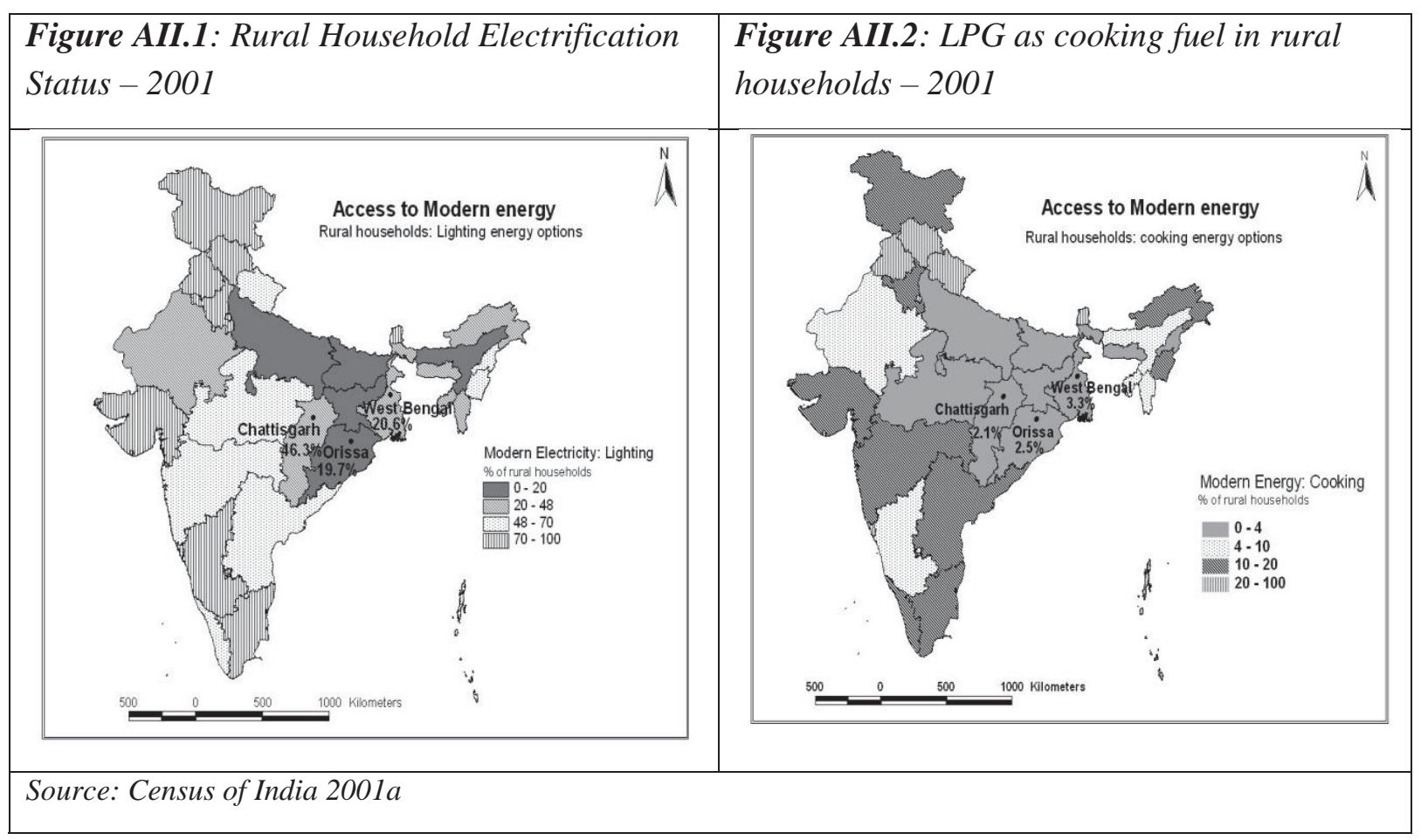

Figure AII.2 provides an overview of the access to LPG by rural households across India. Access to LPG in rural areas, irrespective of the relative economy of the State, remains extremely low. The lack of governmental intervention, as with electricity, has similarly restricted the diffusion of LPG in rural areas. When there has been a government initiative, LPG access by rural households has increased. For example, in the states of Uttarakhand and Himachal Pradesh, the State governments have promoted LPG diffusion to rural households as a measure to slow the depletion of forest resources. States with higher per capita incomes (for example, Karnataka, Gujarat and Maharashtra) may still have low diffusion rated for LPG to rural households because their GDPs do not reflect intrahousehold dynamics.

${ }^{300}$ According to the 1991 Census, $30.5 \%$ of the rural households in India had access to electricity, $1.2 \%$ of rural households used LPG for cooking, and 1.3\% of rural households used kerosene oil for cooking. Kerosene oil for lighting was not reported separately in the Census. As mentioned in Table AII.1, the Census results were interpreted as more than $65 \%$ of the rural households were using kerosene oil for lighting. Biomass fuels (crop residues were not reported separately) were used in $91.3 \%$ of rural households. 


\section{Annex III: Survey Instruments}

\section{A: Household Information Sheet (First Fieldwork 2001-02)}

\begin{tabular}{|c|c|c|}
\hline 2. Village: & 3. District: & 4. Family size: \\
\hline 5. Primary Occupation: & Secondary Occupation: & $\begin{array}{ll}6 . & \text { Type of House (Kutchha/ } \\
& \text { Pucca/Mixed): }\end{array}$ \\
\hline \multicolumn{3}{|c|}{ 7.1 Electricity connection: 1 Yes 2 No [If No skip 11.1 and 12.1] } \\
\hline \multicolumn{3}{|c|}{ 7.2 LPG connection: 1 Yes $\quad$ 2 No [If No skip 11.2 and 12.2] } \\
\hline \multicolumn{3}{|c|}{$\begin{array}{ll}\text { 7.3 Solar PV system: } 1 \text { Yes } & \text { 2 No }\end{array}$ [If No skip 11.3 and 12] } \\
\hline \multicolumn{3}{|c|}{ 7.4 Telephone: 1 Yes 2 No } \\
\hline
\end{tabular}

\section{ASSET OWNERSHIP}

8.1 Which of the following assets you own:

\begin{tabular}{|l|l|l|}
\hline \multicolumn{1}{|c|}{ Asset } & Yes-1; No-0 & \\
\hline Cooker & & \\
\hline Colour TV/Black and White TV & & \\
\hline Radio/Transistor/ Two-in-one & & \\
\hline Video CD player & & \\
\hline Ceiling fans/Table Fans & & \\
\hline Bicycle/ Motorcycle & & \\
\hline Others (list) & & \\
\hline
\end{tabular}

8.2 Land holding

\begin{tabular}{|l|l|l|}
\hline Landless & Marginal ( $<1$ ha or $<2.5$ acres) & Small (1 - 2 ha or 2.5 -5 acres) \\
\hline $\begin{array}{l}\text { Semi-medium (2 - 4 ha or 5 - } \\
10 \text { acres) }\end{array}$ & $\begin{array}{l}\text { Medium (4 - 10 ha or } 10-25 \\
\text { acres) }\end{array}$ & Large ( $>10$ ha or $>25$ acres $)$ \\
\hline
\end{tabular}

\section{EXPENDITURE}

\begin{tabular}{|l|l|l|l|}
\hline 9.1. What is your average monthly household expenditure? Rs \\
\hline 9.2 Domestic (Rs/month) \\
\hline 9.2.1 Food and milk & 9.2.2 Electricity-domestic & 9.2.3 Kerosene Oil & 9.2.4. LPG \\
\hline 9.2.5 Education & 9.2.6 Transport & 9.2.7 Battery & 9.2.8 Solar PV system \\
\hline 9.2.9 Clothing & 9.2.11 Health/ Medicine & 9.2.12 Festivals/religious ceremonies \\
\hline 9.3 Agriculture (Rs/annum) \\
\hline 9.3.1 Electricity & 9.3.2 Diesel & 9.3.3 Water - irrigation: \\
\hline 9.3.4 Transport & 9.3.5 Expenditure on agricultural inputs (seeds, fertilisers and pesticides) \\
\hline
\end{tabular}


In Pursuit of a Light Bulb and a Smokeless Kitchen

\section{DOMESTIC ENERGY USE - FOR ALL THE HOUSEHOLD 10.1 Lighting}

10.1.1 What are the lighting devices do you use?

\begin{tabular}{|l|l|l|l|l|l|}
\hline 10.1.1 What are the lighting devices do you use? \\
\begin{tabular}{|l|l|l|l|l|} 
Lighting Device/Use \\
in the household
\end{tabular} & $\begin{array}{l}\text { Position in the } \\
\text { house where used }\end{array}$ & Number & Used/day & $\begin{array}{l}\text { Hours } \\
\text { used/day }\end{array}$ & $\begin{array}{l}\text { Fuel use/ } \\
\text { month }\end{array}$ \\
\hline Kerosene lamp/lantern & & & & & \\
\hline Oil lamp (dhibri) & & & & & \\
\hline Battery & & & & & \\
\hline Solar lantern & & & & \\
\hline PV system & & & & \\
\hline 10.1.2 How much time (hours) do you spend per day cleaning/preparing kerosene lighting devices? \\
\hline
\end{tabular}

\subsection{Cooking}

10.2.1 Where do you do the cooking? Inside/ Outside 10.2.2 How many hours per day do you spend on cooking?

10.2.3 What cooking devices do you use?

\begin{tabular}{|l|l|l|l|}
\hline Cooking device & Nos. & $\begin{array}{l}\text { Number of times you cook } \\
\text { on the device every day }\end{array}$ & $\begin{array}{l}\text { Average quantity of } \\
\text { fuel used per month }\end{array}$ \\
\hline Biomass stove (chimney) & & & \\
\hline Biomass stove & & & \\
\hline Kerosene stove Pressure/Wick & & & \\
\hline LPG stove: Single/double burner & & & \\
\hline No of cylinders replaced per month & & & \\
\hline
\end{tabular}

10.3 Energy fuels - traditional

\begin{tabular}{|c|c|c|c|c|c|c|c|c|c|c|c|}
\hline \multirow[t]{2}{*}{ Fuel } & \multicolumn{2}{|c|}{ Source } & \multicolumn{2}{|c|}{ Quantity } & \multicolumn{2}{|c|}{ Frequency } & \multicolumn{2}{|c|}{ Price } & \multirow[t]{2}{*}{ Distance } & \multirow{2}{*}{$\begin{array}{l}\text { Who } \\
\text { brings fuel }\end{array}$} & \multirow{2}{*}{$\begin{array}{l}\text { Time } \\
\text { spent }\end{array}$} \\
\hline & A & $\mathrm{B}$ & A & $\mathrm{B}$ & A & B & A & B & & & \\
\hline Wood & & & & & & & & & & & \\
\hline Cattle dung & & & & & & & & & & & \\
\hline $\begin{array}{l}\text { Cattle dung+ } \\
\text { wood }\end{array}$ & & & & & & & & & & & \\
\hline Crop residues & & & & & & & & & & & \\
\hline
\end{tabular}

\subsection{Modern Energy Carriers}

\begin{tabular}{|l|l|l|l|l|l|l|}
\hline Fuel & Source & $\begin{array}{l}\text { Quantity per } \\
\text { purchase }\end{array}$ & Frequency & $\begin{array}{l}\text { Price } \\
\text { (Rs) }\end{array}$ & $\begin{array}{l}\text { Who brings } \\
\text { the fuel }\end{array}$ & $\begin{array}{l}\text { Time spent } \\
\text { (in hours) }\end{array}$ \\
\hline Electricity - grid & & & & & & \\
\hline Electricity - diesel & & & & & & \\
\hline Kerosene oil & & & & & & \\
\hline LPG & & & & & & \\
\hline Torch battery & & & & & \\
\hline Car battery & & & & & \\
\hline $\begin{array}{l}\text { Frequency code - 1: at least once a week; 2: about every 15 days; 3: about every 3 weeks; 4: once a } \\
\text { month; 5: every 1-1.5 months }\end{array}$
\end{tabular}




\subsection{FOR HOUSEHOLDS WITH ELECTRICITY (GRID AND PV) AND LPG CONNECTION}

\subsection{Electricity}

11.1.1 When did you get the electricity connection (Year):

11.1.2 Have you added any electrical appliances since then? Yes/No

11.1.3 If Yes, then please list them

11.1.4 What did you use for lighting/fan before getting electricity connection? Kerosene devices/ PV System/DG supply/Battery

11.1.5 What did you use for operating the TV before getting an electricity connection? PV system/DG supply/Battery

11.1.6 How do you pay for electricity? Flat tariff/Un-metered/Meter

11.1.7 Electrical appliances used in the household

\begin{tabular}{|c|c|c|c|c|}
\hline & Number & Wattage & Average number used/day & Average Hours used/day \\
\hline \multicolumn{5}{|l|}{ Bulb } \\
\hline \multicolumn{5}{|l|}{ Tube Lights } \\
\hline Ceiling/Table Fan & & \multirow{5}{*}{$\begin{array}{l}\text { DO NOT } \\
\text { ASK }\end{array}$} & & \\
\hline Table fans & & & & \\
\hline \multicolumn{4}{|l|}{ Radio } & \\
\hline \multicolumn{4}{|l|}{ TV } & \\
\hline \multicolumn{4}{|l|}{ Refrigerator } & \\
\hline \multicolumn{5}{|c|}{ 11.1.8 Do you use electricity for irrigation? Yes/No } \\
\hline \multicolumn{3}{|c|}{ 11.1.8.1Do you own a pump-set? Yes/No } & \multicolumn{2}{|c|}{$\begin{array}{l}\text { 11.1.8.2 Do you share a pump-set with another farmer? } \\
\text { Yes/No }\end{array}$} \\
\hline \multicolumn{3}{|c|}{$\begin{array}{l}\text { 11.1.8.3 What is the type of pump-set? } \\
\text { Centrifugal/ Submersible }\end{array}$} & \multicolumn{2}{|c|}{$\begin{array}{l}\text { 11.1.8.4 What type of pump-set do you use? } \\
\text { Electric/Diesel/Kerosene }\end{array}$} \\
\hline \multicolumn{5}{|c|}{ 11.1.9. Do you have any problems with the supply of electricity you receive? Yes/No } \\
\hline \multicolumn{5}{|c|}{ 11.1.10. What problems do you experience with the electricity supply? } \\
\hline
\end{tabular}

\begin{tabular}{|c|c|c|}
\hline \multicolumn{3}{|c|}{ 11.2 Solar PV System } \\
\hline \multicolumn{3}{|c|}{ 11.2.1 When did you buy the PV system (Year): } \\
\hline \multicolumn{3}{|c|}{ 11.2.2 Do you own: Solar lantern/Solar Home System (SHS) } \\
\hline \multicolumn{3}{|c|}{ 11.2.3 What was the cost of the system (Rs): } \\
\hline \multicolumn{3}{|c|}{ 11.2.4 Please tell us about the light points and number of hours that you use them } \\
\hline & Position : Room-R; Verandah-V; Kitchen - K & Hours used per day \\
\hline \multicolumn{3}{|l|}{ Light point $-1(9 \mathrm{~W} / 11 \mathrm{~W})$} \\
\hline \multicolumn{3}{|l|}{ Light point $-2(9 \mathrm{~W} / 11 \mathrm{~W})$} \\
\hline \multicolumn{3}{|l|}{ Light point $-3(9 \mathrm{~W} / 11 \mathrm{~W})$} \\
\hline TV & & \\
\hline \multirow{2}{*}{\multicolumn{3}{|c|}{$\begin{array}{l}\text { Are you satisfied with the number of hours of light you get and number of hours you can watch TV? } \\
\text { Are you satisfied with the overall performance of the PV system? }\end{array}$}} \\
\hline & & \\
\hline \multicolumn{3}{|c|}{ If Yes, then what are the benefits you find? } \\
\hline If No, then what problems & you face? & \\
\hline
\end{tabular}

\subsection{LPG}

11.3.1. When did you get the LPG connection?

11.3.2. When did you apply for the connection?

11.3.3. Why did you not buy LPG earlier? not available (no dealer/retailer)/ very expensive/waiting time/ had no knowledge

11.3.4 From where do you get the LPG supply? Public sector dealer/Private sector dealer

11.3.5. What was the initial cost (Rs) of getting the connection?

11.3.6. What refuelling charge do you pay (Rs)?

11.3.7. How did you come to start using LPG as a fuel?

11.3.8. Did you know about LPG as a cooking fuel before you got the connection?

11.3.9. Do you have a? Single cylinder/Double cylinder 


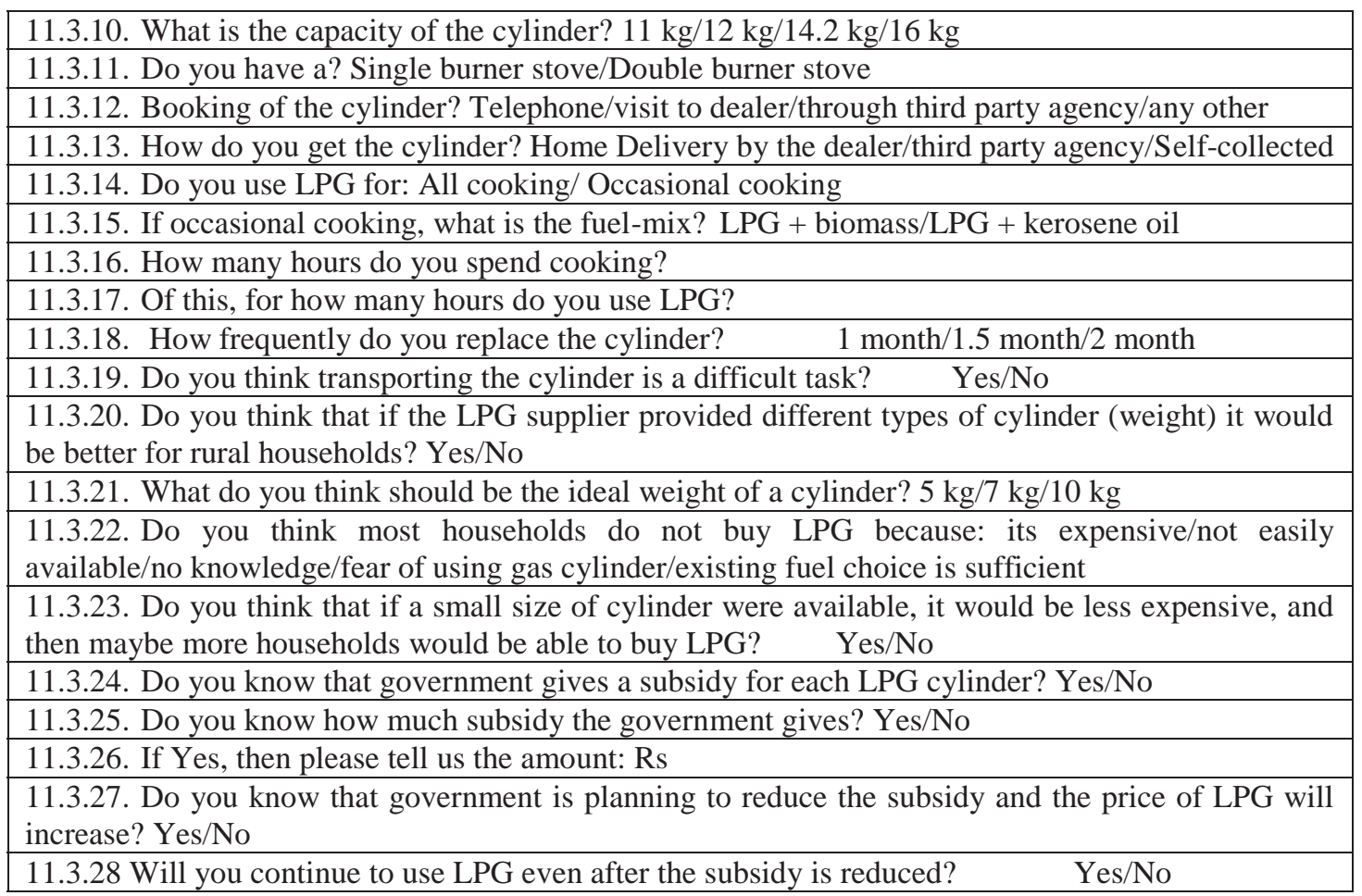

\subsection{For all Households which uses Electricity (Grid or PV) or LPG}

11.4.1 What changes (both positive and negative) do you see that has taken place in your household after you started using either electricity, LPG or a PV system?

\begin{tabular}{|l|l|}
\hline Changes & Positive (+)/Negative (-) \\
\hline & \\
\hline
\end{tabular}

\subsection{For all Households not using Electricity and LPG}

You are not using electricity or LPG in the household at present. Why are you not willing to get an electricity connection or pay for an improved electricity supply or get an LPG connection?

12.1 Electricity [Tick multiple]

\begin{tabular}{|c|l|l|}
\hline Code & Mark a tick & Reason \\
\hline 01 & & Cannot afford to pay (threat of bankruptcy) \\
\hline 02 & & Do not believe we would get improved supply \\
\hline 03 & & Demand is already met from self-generation \\
\hline 04 & & Can meet additional demand from self generation at lower cost \\
\hline 05 & & Believes the current tariff is already high \\
\hline 07 & & Other (please specify) \\
\hline
\end{tabular}

12.2 LPG [Tick multiple]

\begin{tabular}{|c|l|l|}
\hline Code & Mark a tick & Reason \\
\hline 01 & & Cannot afford to pay (threat of bankruptcy) \\
\hline 02 & & Do not believe that the increased price will improve supply \\
\hline 03 & & Can meet additional demand from other sources \\
\hline 04 & & Believes the current price is already above the cost \\
\hline 05 & & Other (please specify) \\
\hline
\end{tabular}




\section{B: Village Information Sheet}

GENERAL INFORMATION

1. Village respondent's name:

2.1 Village:

2.2 Block:

2.3 District:

3. Distance from the nearest town $(\mathrm{km}): 4$. Name of the town:

5. Number of households in the village:

6. Total population:

7. $\quad$ Distance from main road $(\mathrm{km})$ :

8. Percentage of the total households electrified?

9. Household Distribution

\begin{tabular}{|l|l|l|l|l|}
\hline No. & Type & Land area owned & \multicolumn{2}{|c|}{ Number of households } \\
\cline { 4 - 5 } & & & Patwari & Sarpanch \\
\hline 9.1 & Large farmers & $>10$ ha or $>25$ acres & & \\
\hline 9.2 & Medium farmers & $4-10$ ha or $10-25$ acres & & \\
\hline 9.3 & Semi-medium farmers & $2-4$ ha or $5-10$ acres & & \\
\hline 9.4 & Small farmers & $1-2$ ha or $2.5-5$ acres & & \\
\hline 9.5 & Marginal farmers & $<1$ ha or $<2.5$ acres & & \\
\hline 9.6 & Landless households & & & \\
\hline
\end{tabular}

LAND DISTRIBUTION

10. AREA (ha/acres)

\begin{tabular}{|l|l|l|}
\hline Village: & Cultivated: & Irrigated: \\
\hline
\end{tabular}

MARKET INFRASTRUCTURE

\begin{tabular}{|l|l|l|}
\hline Bank: & Other Institutions: & Local industries: \\
\hline
\end{tabular}

ENERGY INFRASTRUCTURE

\begin{tabular}{|c|c|c|c|}
\hline \multicolumn{2}{|c|}{ Shops/dealers/traders } & Location & Number \\
\hline \multicolumn{4}{|c|}{ LPG } \\
\hline \multirow[t]{2}{*}{ Kerosene oil } & PDS & & \\
\hline & Open shops & & \\
\hline \multicolumn{4}{|c|}{ Battery charging stations } \\
\hline \multicolumn{4}{|c|}{ Electrical products shops (selling bulbs, tubelights, etc.) } \\
\hline \multicolumn{4}{|c|}{ Energy stores - I (selling torch batteries) } \\
\hline Energy stores & I (stoves, LPG lamps, kerosene oil devices, etc.) & & \\
\hline
\end{tabular}

RAINFALL AND IRRIGATION

12.1 Monsoon period (months)

12.2Source of Irrigation: Canal/Bore well/Open well/Ponds

12.3Is there any buying of water for irrigation? Yes / No

LOCAL GOVERNANCE STRUCTURE

13.1 Role of political bodies/Panchayats/Cooperatives/NGOs

13.2 Role of Educational and Health Institutions

13.3 Role of Markets and Traders 


\section{C: Information Sheet for Second Fieldwork Period (2008-09)}

\section{Case Stories -}

Name of the household:

1. What is current primary occupation? Has there been any change in number of family members earning and contributing to household income?

2. Are women in the household also involved in income-earning activities? If yes, then what is the nature of the employment (Service/Business or Trade/Fishing/Labour)?

3. Which energy carriers do they use for this activity?

a. What are the energy carriers used for: Lighting (Grid Electricity/PV/Battery/Kerosene oil/or combination)

b. Cooking (LPG/Biomass/Kerosene oil/or Combination)

4. When did they get Electricity/LPG, if any? Have they changed use (type and patterns) since you were last there? What influenced their decision?

What are the benefits of having access to Electricity or LPG?

5. What are the main constraints in not being able to have Electricity or LPG (for households without access)

6. What is the quality of services provided by the retailers/dealers : (a) Electricity; (b) LPG ; (c) Kerosene oil

Mapping of Local Organisations involved in Delivery of Modern Energy Carriers and Specific Change in Policy (Entitlement, Subsidy)

\section{Grid Electricity}

1. What have been the changes in the roles of the cooperative/distribution utility and the governance structure, why, and when did these changes occur? Who were the main actors involved- does it require independent decisions on grid extension, tariff and providing connections to BPL households?

2. Have there been any implementations under the RGGVY programme since 2005? How many villages/households have been electrified under the new programme? Where has this been done (crosscheck if the BPL households at the time of the first fieldwork period and may have come under APL households category have an electricity connection)? What criteria were used to make these decisions?

3. Total number of consumers - domestic and commercial (commercial consumers category) in villages studied

4. Tariff in 2008-09, when was it last revised? By how much, in fixed prices, and in percentages; if possible identify the percentage of energy prices relative to the purchase power of the households (at least for case study households)

5. How many hours of power supply? Quality of supply? Year of introduction of new supply hours and why? Has this required new investment - if yes how funded? Moreover, by what amount of money/funding was involved?

6. Tariff collection efficiency and how having a local organisation ensures collection with large and dispersed consumer base. How many disconnections, and who if any: were these disconnected consumers, for what reasons?

7. Does it now have a scheme/programme for BPL households?

8. What are the plans for adding new consumers/households in accordance with national rural electrification goals? Investment funds - by which department - and criteria for grid extension?

\section{Solar PV}

1. Is there an ongoing government programme? What subsidy is provided, and if so by which department? Has there been any change (governance and criteria) in the implementation of the programme? Alternatively, any private organization involved?

2. Have there been any changes (+/-) in number of systems since you were last there? Those who have acquired a system - how - purchase or scheme?

3. What is the system for after-sales services and retailers?

\section{LPG}

1. Who are the suppliers of LPG? Public or Private, or both?

2. How many public sector dealers? Any change in numbers? What are the reasons? Where do they operate? How LPG cylinders are transported and made available in the villages? What additional 
charges are paid by the consumers? Have the number of consumers increased? What is the cost of a new LPG connection and LPG cylinder refill?

3. How many Private Sector LPG suppliers? Have the number of consumers increased? Where and who? What is the current cost of an LPG cylinder refill from the private sector?

4. What has been the impact of the price revision of LPG in recent months in terms of consumers purchasing refills? Impact of price increase on new connections.

\section{Kerosene oil}

1. What is the per capita allocation in 2007-08? If any change, in which year was this introduced? Why?

2. What is the price of kerosene oil under the PDS?

3. Any change in the delivery mechanism - say from fortnightly delivery to constant availability under the PDS? Why?

4. What type of kerosene oil is available in the open market - blue (PDS) or white (Parallel marketing)?

5. If PDS, what is the price (2008) per litre? How do consumers buy? Has there been any change or increase in number of consumers buying more frequently in small quantities/monetary terms? Is there more fraud reported? By whom, through what kinds of mechanisms?

\section{Biomass}

1. What types of biomass fuels are sold? What is the price of the various fuels? Has use changed? Why?

2. What kinds (APL/BPL) of households are buying these fuels? Any information on frequency of such purchases? 


\title{
Annex IV: Rural Electrification Programmes in India (1950-2010)
}

\author{
Rural Electrification Programmes (1950-1990) \\ Village and Household electrification
}

Village and household electrification programmes were initiated as part of the First Five-Year Plan (1951-56) in 1952. Starting with the modest target of 3000 villages, the programme's emphasis was on household electrification until the advent of the Seventh Five-Year Plan, where the emphasis shifted from intensive (i.e., households) to extensive (i.e., village) electrification.

\section{Pump-set Energisation programme}

The response to the droughts of 1966, and the consequent food shortages, was the promotion of using groundwater for irrigation to increase agricultural productivity and output in order to ensure food security. A national pump-set energisation programme was initiated after the formation of the Rural Electricity Corporation in 1969.

\section{Minimum Needs Programme (MNP)}

The MNP exclusively targeted states with rural electrification levels below $65 \%$ and it provides $100 \%$ loans for ensuring connectivity. The MNP was initiated in 1974 with resources drawn from the Central Plan Assistance.

\section{Kutir Jyoti Programme (KJP)}

The KJP was initiated in 1988-89 to provide a single point light connection (60 W) to all Below Poverty Line (BPL) households in the country. KJP provides a 100\% grant for the cost of internal wiring and service connection charges.

\section{Rural Electrification Programmes (1990 - 2004)}

\section{Pradhan Mantri Gramodaya Yojna (PMGY)}

The PMGY, launched in 2000-2001, provided additional financial assistance from the central government to all states on a $90 \%$ loan and $10 \%$ grant basis for the provision of minimum services. These included services related to rural health, education, drinking water and rural electrification. The PMGY, with a budget of about Rs 16 billion during the tenth planning period, was coordinated and monitored by the Rural Development Division of the Planning Commission. Under the PMGY, the states had the flexibility to decide where to allocate funds among the six basic services. Thus, the states could use their allocation to expedite the pace of rural electrification. The PMGY scheme was renamed Bharat Nirman in 2005 and the rural electrification scheme was merged with the RGGVY (see below) in the same year.

\section{Accelerated Rural Electrification Programme (AREP)}

The AREP, operational since 2002, provides a subsidised loan of $4 \%$ to states for RE programmes. The AREP covers electrification of un-electrified villages and households and has an approved budget of Rs 5.6 billion under the Tenth Plan. The interest subsidy is available to State governments and electricity utilities on loans from approved financial institutions such as the REC (Rural Electrification Corporation), the PFC (Power Finance Corporation) and from the NABARD under 
the Rural Infrastructure Development Fund (RIDF).

\section{Rural Electricity Supply Technology Mission (REST)}

The REST Mission was set up by MoP as an expert group of ministerial and sector representatives in September 2002. The mission's objective was to the progressively electrify all villages and households by 2012 through local renewable energy sources and decentralized technologies, together with conventional grid connection. The REST Mission ceased to be active in 2003 as its objectives were being fulfilled through MNRE programmes. However, today, there are ongoing efforts to revive the REST Mission.

\section{Minimum Needs Programme (MNP)}

The MNP was continued into the post-reform period with Rs 7.75 billion released during 2001-03 for rural electrification. The scheme was discontinued in 2004-05 because of difficulties in implementation and its funding was redirected to the RGGVY.

\section{Kutir Jyoti Programme (KJP)}

The scheme was merged into the "Accelerated Electrification of One Lakh Villages and One Crore Households' in May 2004 and subsequently into the RGGVY. The total budget of KJP in the Tenth Plan was Rs 8.27 billion.

\section{Rural Electrification Programmes (2004 - 2010)}

\section{Rajiv Gandhi Grameen Vidyutikaran Yojana (RGGVY)}

As indicated above, the Accelerated Electrification of One Lakh Villages and One Crore Households, the MNP and the KJP have now been merged to form the RGGVY.

The RGGVY was the final national RE scheme launched by MoP during the period covered by this study. The programme aims to execute the vision of rural electrification laid out in the NCMP and recommended by the Chief Ministers' Conference in 2001. The plan was initiated in April 2005 with the following objectives:

- provision of electricity access to all households (including rural households) by 2009 (including the 23.4 million households living below the poverty line);

- Quality and reliable power supply at reasonable rates; and

- Minimum lifeline consumption of one kWh per household per day, as a merit good, by 2012.

The electrification programme envisaged under RGGVY did not achieve its target during the Tenth Plan period, and the programme was further extended into the Eleventh Plan period (2007-12) and new conditions were introduced to encourage better implementation:

- States were to ensure a minimum of six to eight hours of power supply per day;

- States were to ensure the quality and a reliable power supply at reasonable rates; 
- The use of franchisees became mandatory in the management of rural distribution;

- Introduction of the three-tier 'Quality Monitoring Mechanism' to ensure the quality of materials and implementation; and

- States are obliged to notify the REC of their rural electrification plans within six months.

To achieve these objectives, the RGGVY envisages creating:

- A Rural Electricity Distribution Backbone (REDB) with at least one 33/11 KV (or 66/11 $\mathrm{KV}$ ) substation in each block;

- A Village Electrification Infrastructure (VEI) with at least one distribution transformer in each village/habitation;

- Decentralized Distributed Generation (DDG) systems grid connection is not cost-effective or feasible.

The establishment of the RGGVY positions rural electricity as a necessary component of broadbased economic and human development. Its approach to access to electricity looks beyond the original RE framework of increasing agricultural production through irrigation. The programme, in addition to meeting household electricity needs, aims to provide a continuous supply of quality grid power to rural areas for spreading industrial activity, providing modern healthcare facilities, and enabling the use of information technology.

The RGGVY recognizes the need for revenue sustainability for RE projects and boldly states that electricity supplied must be paid for. The scheme proposes managing rural distribution through franchisees that could be user associations, cooperatives, NGOs or even individual entrepreneurs. Further, the distribution utilities under the new RE framework are required to enter into Bulk Supply Tariff agreements (BST) with the proposed franchisees to ensure commercial viability. The State governments are also required to make adequate provisions for revenue subsidies to the utility. In 2009, the Government of India passed an order providing guidelines for village electrification through RGGVY-based decentralised distributed generation.

\section{Remote Village Electrification Programme (RVEP)}

The RVEP is a programme of the MNRE. The scope of the RVEP is the provision of electricity for:

- All non-electrified remote census villages by 2007;

- All households of non-electrified remote census villages by 2012; and

- All non-electrified remote hamlets of electrified census villages by 2012

The RVE programme is implemented in the states by State nodal agencies that receive a 90\% capital subsidy from the MNRE. A remote village or remote hamlet is considered electrified if at least $10 \%$ of the households are provided with a lighting facility. Under the RVEP, the electrification process entails choosing the most appropriate energy technologies through the identification of locally available energy resources. However, if such solutions are unfeasible, and if the only means for electrification is through use of isolated lighting systems (such as solar PV), then these should be adopted. However, in this situation, the remote villages receiving them should not be declared as electrified. 


\section{About the Author}

Shirish Sinha was born in 1973 in Guwahati, India. He obtained a Bachelor's degree in Science from Osmania University, Hyderabad in 1993 and a Master's degree in Rural Development Management from the Institute of Rural Management, Anand (IRMA) in 1995. Shirish started working on rural energy during his final year at IRMA. In 1995, he joined Tata Energy Research Institute (now called The Energy and Resources Institute, or TERI) and worked on rural energy planning and policy for improving access to energy and to renewable energy technologies. He started his PhD with the Technology and Development Group of the University of Twente, with a focus on energy poverty in the context of energy policy reforms in India. Between 2003 and 2005, Shirish worked with the International Water Management Institute (IWMI), first as a Visiting Research Scholar and then as Principal Researcher and Deputy Chief of Party on the ground water - electricity nexus in India's agriculture sector. In 2005, he joined PricewaterhouseCoopers (PwC) as Principal Consultant, focusing on decentralised institutional systems for electricity distribution management in rural areas and renewable energy and energy/power policy at the State level. In 2007, Shirish moved back to the development sector with the World Wide Fund for Nature (WWF) India as Head - Climate and Energy, where he developed WWF India's Climate Programme on ecosystem-based Climate Adaptation, Energy, Business \& Industry, a national and international Climate Policy, and public campaigns and advocacy. He played an instrumental role in including the theme of energy access and poverty in WWF's network-wide Global Climate and Energy Initiative. In 2008, Shirish restarted his PhD research, with the title 'In Pursuit of a Light Bulb and a Smokeless Kitchen', as a longitudinal analysis of the role of energy sector policies in alleviating rural energy poverty in India. Shirish has published over twenty papers and articles in journals, book chapters and proceedings. He has authored and co-authored six books and has six edited publications in the field of energy and climate change. He has held a fellowship from the World Bank Institute under the Joint Japan World Bank Graduate Scholarship, and a Developing Country Fellowship from NWO-WOTRO.

Since October 2010, Shirish has been working with the Swiss Agency for Development and Cooperation (SDC) in their India programme as Senior Thematic Advisor - Climate Change, where he is responsible for programmes in the field of climate change adaptation, rural and renewable energy, and climate and energy policy. 
In Pursuit of a Light Bulb and a Smokeless Kitchen focuses on access to modern energy carriers by low-capacity end-users in rural India. The longitudinal analysis examines the role of energy sector policies in alleviating rural energy poverty in India. Energy poverty remains a key impediment to development for India, and especially for its rural population, despite over six decades of development programmes, policies and measures. Although India's energy sector has undergone significant policy reforms, the three case-study regions where fieldwork has been conducted show that the effectiveness and applicability of energy policy design and implementation in improving energy access for low-capacity end-users leaves much to be desired.

Comparative analyses of the case studies reveal that increased household income can act as a trigger for a shift to modern energy carriers. However, changes in energy prices and intra-household dynamics create 'energy shocks' that can result in repeated switching 'forward' and then 'backward' between modern and traditional energy carriers. This research, based on longitudinal analysis with data gathered in two separated periods, shows that access to modern energy is a means to development, but not an end in itself, in addressing all the development deficits faced by rural India. The thesis concludes that in order to move low-capacity end-users in rural India out of energy poverty, public policies involving government intervention will be both critical and essential. It calls for the strengthening of local institutions through an enabling framework and targeted subsidies and entitlements to improve their working and better address current inclusion and exclusion errors.

ISBN: 9789036534826 